\begin{tabular}{|c|c|c|c|c|c|}
\hline \multirow{2}{*}{$\begin{array}{l}\text { To } \\
\text { Distribution }\end{array}$} & \multirow{2}{*}{\multicolumn{3}{|c|}{$\begin{array}{l}\text { From } \\
\text { TWRS Engineering/Facility \& } \\
\text { Equipment Engineering }\end{array}$}} & \multicolumn{2}{|l|}{ Page 1 of 1} \\
\hline & & & & \multicolumn{2}{|c|}{ Date $9-27-94$} \\
\hline \multirow{2}{*}{\multicolumn{4}{|c|}{$\begin{array}{l}\text { Loject Title/Work Order } \\
\text { Lovel Tank Waste Disposal Study }\end{array}$}} & \multicolumn{2}{|c|}{ EDT No. 605629} \\
\hline & & & & \multicolumn{2}{|l|}{ ECN No. } \\
\hline Name & MSIN & $\begin{array}{l}\text { Text } \\
\text { With All } \\
\text { Attach. }\end{array}$ & Text Only & $\begin{array}{l}\text { Attach./ } \\
\text { Appendix } \\
\text { Only }\end{array}$ & $\begin{array}{c}\text { EDT/ECN } \\
\text { Only }\end{array}$ \\
\hline
\end{tabular}

U.S. Department of Energy. Richland Operations office
C. V. Banks
R. Carreon
$57-53$
L. A. Huffman
$57-53$
J. E. Navarro
$57-53$
$57-53$
J. C. Peschong
$57-53$

$x$
$x$
$x$
$x$
$x$

Westinghouse Hanford Company

H. Babad ( 3 copies)

K. C. Burgard

S. A. Burris

L. P. Diediker

D. W. Duncan

P. Felise

J. S. Garfield

R. Kit

M. Mann

C. Miller

D. E. Mitchell

J. A. Mullally

R. J. Murkowski

J. G. Propson

R. C. Roal

G. H. Weissberg

G. F. Williamson

G. D. Wright

Central Files (orig. + 2)

DPC-2 (2 copies)

OSTI (2 copies)

PIMS

57-30

R4-01

H6-25

$\mathrm{T} 1-30$

G6-07

G6-06

H5- 49

G6-06

HO-36

S4-55

H5- 49

G6-06

R4-01

S4-58

H5-27

G6-04

R4-01

G6-04

L8-04

G6-51

L8-07

$54-53$

Pacific Northwest Laboratory

J. H. Holbrook

J. H. Westsik

B1-40

P7-19

$x$
$x$
$x$
$x$
$x$
$x$
$x$
$x$
$x$
$x$
$x$
$x$
$x$
$x$
$x$
$x$
$x$
$x$
$x$
$x$
$x$
$x$

WA Department of Ecology

R. E. Cordts

P.0. Box 47600

01ympia, WA 98504-7600 


\section{DISCLAIMER}

Portions of this document may be illegible in electronic image products. Images are produced from the best available original document. 


\section{ENGINEERING DATA TRANSMITTAL}

ALtix
2. To: (Receiving Organization)

a. F. Williamson

LLW Program Office

5. Proj./Prog./Dept./Div.:

TWRS Engineering

8. Originator Remarks:

TWRS initial release of LATA, Inc. Low Level Tank Waste Disposal Study, WHC-SD-W378-ES-001

11. Receiver Remarks:
3. From: (Originating Organization)

Facility and Equipment Engineering

J. A. Mullally
Page 1 of 1

1. EDT 605629
6. Cog. Engr.:

4. Related EDT No.:

N/A

7. Purchase Order No.:

N/A

9. Equip./Component No.:

$\mathrm{N} / \mathrm{A}$

10. System/Bldg./Facility:

$N / A$

12. Major Assm. Dwg. No.:

$N / A$

13. Permit/Permit Application Mo.: $N / A$

14. Required Response Date: $9 / 27 / 94$

15

\begin{tabular}{|c|c|c|c|c}
\hline (A) & & (C) & (D) & (E) Title or Description of Data \\
Item & (B) Document/Drawing No. & $\begin{array}{c}\text { Sheet } \\
\text { No. }\end{array}$ & $\begin{array}{c}\text { Rov. } \\
\text { No. }\end{array}$ & $\begin{array}{c}\text { Transmitted } \\
\text { No. }\end{array}$
\end{tabular}

No.

No. Transmitted

Low Level Tank Waste Disposal Study

\section{(G)}

\begin{tabular}{|c|c|c|c|}
\hline (F) & $(G)$ & $(H)$ & $(I)$ \\
\hline $\begin{array}{c}\text { Approval } \\
\text { Desig- } \\
\text { nator }\end{array}$ & $\begin{array}{c}\text { Reason } \\
\text { for } \\
\text { Trans- } \\
\text { mittal }\end{array}$ & $\begin{array}{c}\text { Origi- } \\
\text { nator } \\
\text { Dispo- } \\
\text { sition }\end{array}$ & $\begin{array}{c}\text { Receiv- } \\
\text { er } \\
\text { Dispo- } \\
\text { sition }\end{array}$ \\
\hline
\end{tabular}

1

1

1

\begin{tabular}{|c|l|}
\hline 1 & $\begin{array}{l}\text { WHC-SD-W378-ES- } \\
001\end{array}$ \\
\hline & \\
\hline & \\
\hline & \\
\hline & \\
\hline 16
\end{tabular}

\begin{tabular}{|l|l|l|}
\hline & 0 \\
\hline & & \\
\hline & & \\
\hline & & \\
\hline & & \\
\hline
\end{tabular}

16.

Approval Designator (F)

\begin{tabular}{|l|}
\hline 1. Approval \\
2. Relesse \\
3. Information
\end{tabular}

Reason for Transmittal (G)

KEY

4. Reviow

5. Post-Review

(see WHC-CM-3-5,

Sec.12.7)

3. Information

6. Dist. (Receipt Acknow. Required)

SIGNATURE/DISTRIBUTION

(See Approval Designator for required signatures)

\begin{tabular}{|c|c|c|}
\hline $\begin{array}{l}\text { Rea- } \\
\text { son }\end{array}$ & Disp. & (J) Name \\
\hline 1 & 1 & Cog.Eng. J.A. \\
\hline 1 & 1 & Cog. Mgr. J.G. \\
\hline & & QA \\
\hline & & Safety \\
\hline & & Env. \\
\hline 1 & 1 & LLW Program of \\
\hline $\begin{array}{l}18 . \\
\text { J.A. } \\
\text { tigne }\end{array}$ & ally & $\frac{1 / 28 / 94}{6 a t e}$ \\
\hline
\end{tabular}

(K) Signature

(L) Date (M) MSIN

$M S I N$
120194
$206-06$

(J) Name

(K) Signature
1. Approved

2. Approved w/comment

3. Disapproved w/comment

N/A 


\section{RELEASE AUTHORIZATION}

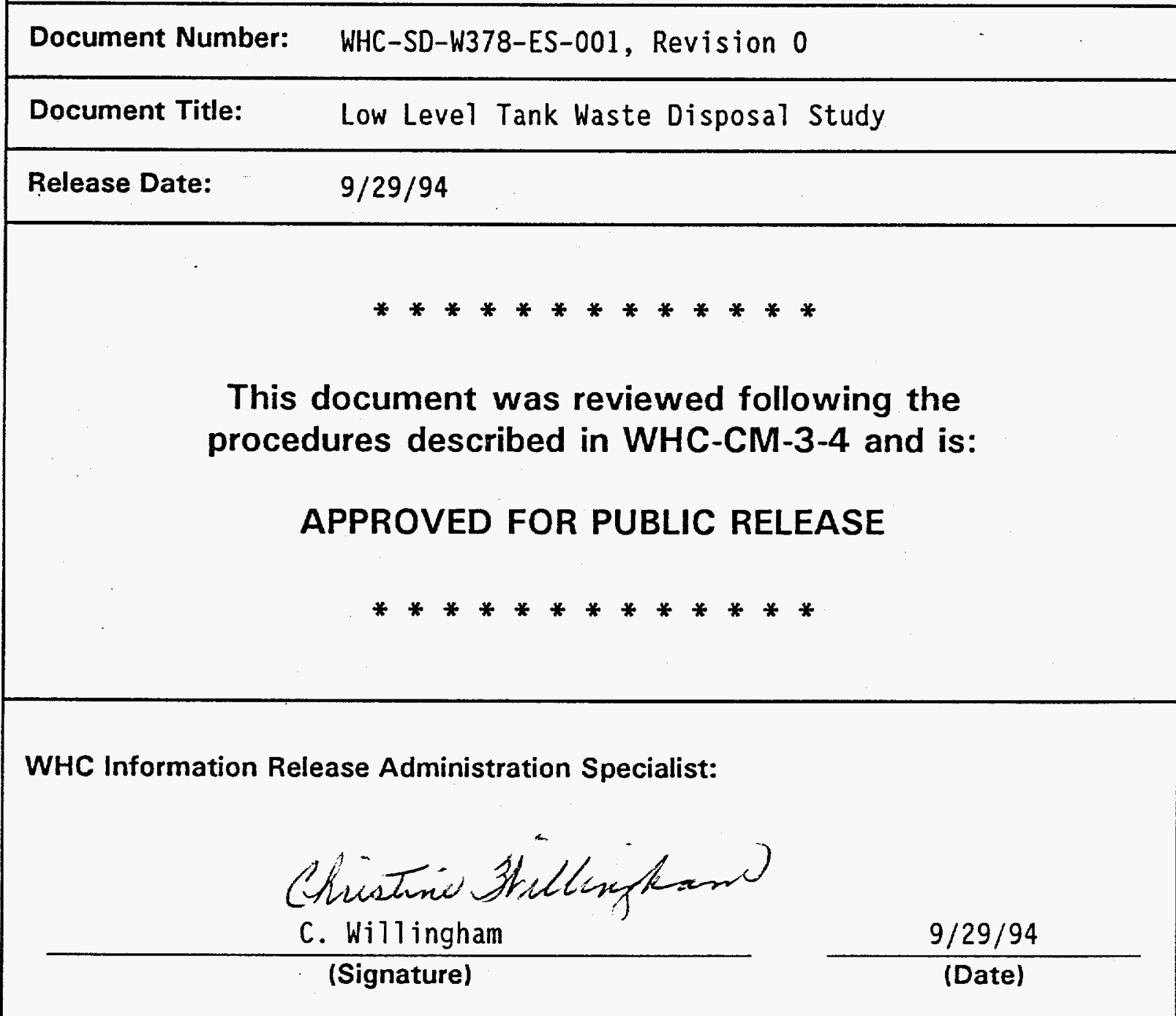


2. Title

Low Level Tank Waste Disposal Study

3. Number

WHC-SD-W378-ES-001

4. Rev No.

5. Key Words

Radioactive Waste Disposal, Low Level Waste

Disposal, Low Level Radioactive Waste, Radioactive Waste Vitrification, Vitrified Radioactive Waste Disposal
6. Author

Name: J. A. Mullally

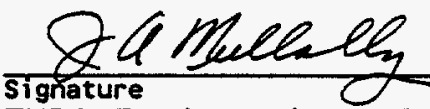

TWRS Engineering, Facilities and Equipment Engineering organization/Charge code 7E850/D47F7

\section{Abstract}

The study develops and evaluates technical options for the below grade disposal of Hanford Site vitrified low level radioactive tank wastes. Options considered are glass form geometry as determined by long-term durability, waste product packaging, matrix materials for water exclusion, bounding of released radioisotopes, engineered barriers, waste site and package monitoring, waste package retrieval, package transport to disposal site, disposal site configuration, and disposal site closure.

8. Prose AND USE OF DOCUMENT - This document was prepared for uSa within the the Department of Energy and its contractors. It be use 10 to perform, direct, or integrate under U.S. D forditi of Energy contracts. This documents not approved 19. public rete int il reviewed.

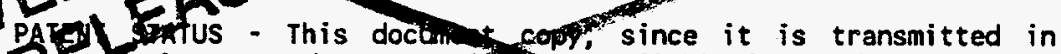

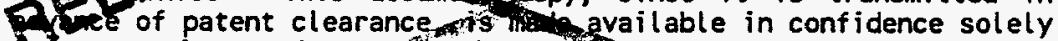
- Tor use in performane of work U.S. Department of Energy. This document is to be published nor its contents otwetwise disseminated or used for pimoses other than specified alsve before patent approval for such releaseor use has been sovifted, upon request, from the Patent Counsel, U.S. butertment of nergy field office, Richland, WA.

DISCLAIMER - This report was prepared as an account of work sponsored by an agency of the United States Government. Neither the United States Goverment nor any agency thereof, nor any of their employees, nor any of their contractors, subcontractors or their employees, makes any warranty, express or implied, or assumes any legal liability or responsibility for the accuracy, completeness, or any third party's use or the results of such use of any information, apparatus, product, or process disclosed, or represents that its use would not infringe privately owned rights. Reference herein to any specific commercial product, process, or service by trade name, trademark, manufacturer, or otherwise, does not necessarily constitute or imply its endorsement, recommendation, or favoring by the United States Government or any agency thereof or its contractors or subcontractors. The views and opinions of authors expressed herein do not necessarily state or reflect those of the United States Government or any agency thereof.

9. Impact Level NA
10.

RELEASE STAMP

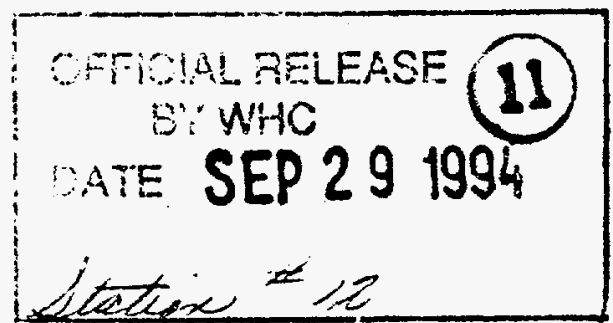




\title{
LOW LEVEL TANK WASTE DISPOSAL STUDY
}

September 28, 1994

\author{
Prepared for: \\ Westinghouse Hanford Company \\ P.O. Box 1970 \\ Richland, WA 99352
}

\author{
Prepared by: \\ Los Alamos Technical Associates, Inc. \\ British Nuclear Fuels Limited, Inc. \& Plc. \\ Southwest Research Institute \\ TRW, Inc.
}




\section{EXECUTIVE SUMMARY}

Purpose Westinghouse Hanford Company (WHC) contracted a team consisting of Los Alamos Technical Associates (LATA), British Nuclear Fuel Laboratories (BNFL), Southwest Research Institute (SwRI), and TRW through the Tank Waste Remediation System (TWRS) Technical Support Contract to conduct a study on several areas concerning vitrification and disposal of low-level-waste (LLW). The purpose of the study was to investigate how several parameters could be specified to achieve full compliance with regulations. The most restrictive regulation governing this disposal activity is the National Primary Drinking Water Act which sets the limits of exposure to 4 mrem per year for a person drinking two liters of ground water daily. To fully comply, this constraint would be met independently of the passage of time. In addition, another key factor in the investigation was the capability to retrieve the disposed waste during the first 50 years as specified in Department of Energy (DOE) Order 5820.2A. The objective of the project was to develop a strategy for effective long-term disposal of the low-level waste at the Hanford site.

Approach During the kick-off meeting, the team was told to begin with a clean slate and develop an overall approach for reaching the objectives of the project. The approach was to (1) address each key area using a systems engineering approach and then (2) integrate the results of studying these key areas into a strategy for meeting the objectives. The key areas included glass formulation and geometry, matrix material, transportation, engineered barriers, disposal site concept, and monitoring to verify waste containment. Glass corrosion only occurs when the glass comes into contact with water, therefore, a major consideration besides achieving a durable glass composition and shape, was how to keep water from migrating into contact with the waste.

Issues. The following paragraphs summarize the issues studied.

\section{Glass Formulation}

Due to the very high sodium content of Hanford LLW, either soda lime silicate or alkali borosilicate glasses are suitable. Alkali borosilicate glass was selected due to its thermal expansion properties and durability. No radiation stability or selective leaching of uranium, neptunium or technetium is expected. Alternative glass formulations; silicon titanates and lead iron phosphates, are promising but would require significant development.

Matrix

Of the various matrix materials used throughout the nuclear industry; organics (bitumen, resins, plastics), hydraulic cements, sulfur polymer cement, glass and low melting point metals, only sulfur cement appears to enhance the very long term performance of the overall disposal system.

\section{Glass Geometry}

Three glass geometries; cullet/marbles, sheet glass and various size monoliths were investigated. The causes and effects of both bulk and surface cracking and crystallization on larger forms were identified. A ranking exercise; with glass quality, surface area to volume ratio, transportation ease, retrievability, secondary waste generation and total waste volume, was performed. A glass monolith in a container or sheet glass in a container received top rankings. 


\section{Packaging}

Regulatory, system and detailed requirements were established and used to develop evaluation criteria. These criteria were input into a Kepner Tregoe decision ranking system to assess a total of 11 different packaging options. The important criteria were determined to be radiological containment, robustness, minimal close uptake, efficient use of disposal site area, retrievability and cost. The monolithic glass block in a container (hot pour) scored highest, but containerized cullet/marbles, sheet glass and monolithic glass block (cold fit) scored nearly as well.

\section{Engineered Barriers}

The fundamental issues of 1 ) containment of radionuclides focuses on inhibiting corrosion of the glass and 2) isolation of leached radionuclides focuses on enhancement of sorption and inhibiting colloidal mass transport. Glass corrosion is affected by solution, $\mathrm{pH}$, silica concentration, incompatible materials, and glass surface area to leachate volume ratio. A critical issue is inhibiting long-term accelerative corrosion mechanism. The use of a sulfur type matrix, the Hanford cap type infiltration barrier, added sulfides to immobilize technicium and three absorbent materials are promising.

\section{Transportation}

The equivalent safety transportation system is the recommended option for transporting the low-level vitrified waste the one mile distance from the vitrification facility to the disposal facility. The recommended method of transportation (i.e., via truck on dedicated road, via truck on public access road, via railcar on dedicated tracks, or via railcar or rail spur) is a topic for a trade study. Both the disposal and lag storage facilities should accommodate remotely handled, non-shielded containers.

\section{Disposal System}

Available geology, performance and cost factors evaluation determined that the disposal facility should be located on the 200 plateau, features which exclude water during facility operations, remote placement of glass containers into lifts, double barrier flooring to satisfy RCRA and a minimum double barrier for closure are recommended design elements of a single trench facility.

\section{Monitoring}

Process control sensors should be used to monitor the critical steps in the vitrification process to ensure that the glass is in the most stable condition. Inspection of the vitrified waste and any matrix should be inspected to verify uniformity, minimal porosity, and no cracks. This inspection should occur just prior to placing the vitrified waste into the disposal facility. The facility that will serve for the final disposal site must be inspected to ensure that it is free of major defects, also contain fiber-optic and/or other embedded sensors that will monitor the potential migration of water through the facility and vitrified waste. Finally, the closure of the disposal site needs to be inspected and have fiber-optic monitors placed in the various layers to monitor the migration of water into and through the vault. 
International

The disposal of radioactive waste is of international concern to many groups of people. Political, conservation, national and international regulatory groups are all actively involved in disposal proposals. International treatment disposal policies do differ but broadly have the same goal, safe immobilization of radioactive waste for thousands of years.

The main observations from international policies for waste disposal in relationship to the Hanford LLW tank waste are:

- No information could be found to show that any other country is vitrifying Hanford equivalent waste. Most countries are encapsulating this type of waste in cement or bitumen.

- Waste volumes to be treated are very much larger than most other countries although information on China and Russia is limited.

- The LLW tank waste at Hanford would be classified as Intermediate Level Waste (ILW) in many countries, because of the long-lived nuclides.

- The international consensus is deep disposal of ILW, providing the geology and the hydrogeology can be shown to be adequate.

- There are many long-term studies to determine the stability of geological rock formations and the movement of underground water. These studies will obtain practical scientific evidence of how the repository should perform over a long time period.

- Some countries are making the best use of available geological formations to isolate the waste. Belgium, for instance, has decided that Boom clay is very suitable for long-term disposal of nuclear waste.

\section{Overall}

The use of the following system for the manufacture and disposal of low level vitrified waste is recommended. A silica-based glass monolith would be placed into a Sulfur Polymer Cement (SPC) container, and transported in an equivalent safety transport package to the disposal site where it will be disposed of using a multiple barrier system. Remote handling should be used in order to minimize dose uptake. Monitoring technologies should be applied for process control in making glass, inspection of the glass form, container, vault structures, matrix material, and monitoring migration of water through the vault and corrosion of the glass. 


\section{CONTENTS}

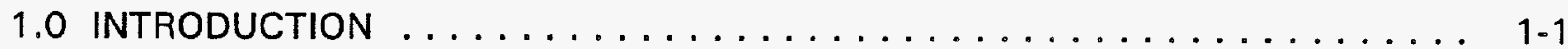

1.1 BACKGROUND ...................... 1-1

1.2 INITIAL LLW GLASS PRODUCT AND DISPOSAL SPECIFIC CRITERIA . . 1 -

1.3 TASK ELEMENTS $\ldots \ldots \ldots \ldots \ldots \ldots \ldots \ldots \ldots \ldots \ldots \ldots \ldots$

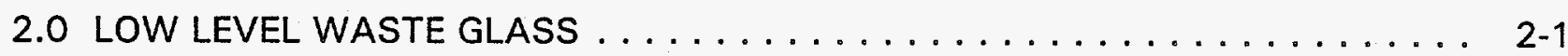

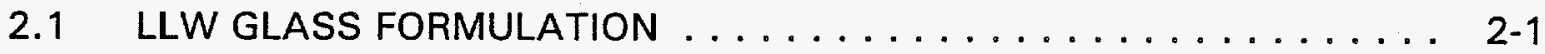

2.1 .1 Requirements ................... 2-1

2.1.2 Design Options ................... 2-2

2.1.3 Methodology to Evaluate Options ............. 2-11

2.1.4 Observations, Conclusions and Recommendations ....... 2-12

2.2 MATRIX MATERIAL $\ldots \ldots \ldots \ldots \ldots \ldots \ldots \ldots \ldots \ldots . \ldots \ldots$

2.2.1 Requirements . . . . . . . . . . . . . . . 2. 244

2.2.2 Design Options ................... 2-44

2.2.3 Methodology to Evaluate Options ............ 2-47

2.2.4 Observations, Conclusions and Recommendations ....... 2-52

2.3 LOW-LEVEL WASTE GEOMETRY $\ldots \ldots \ldots \ldots \ldots \ldots \ldots \ldots \ldots$

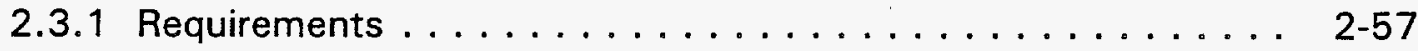

2.3.2 Design Options ................... 2-58

2.3.3 Methodology to Evaluate Options . . . . . . . . . 2-64

2.3.4 Observations, Conclusions, and Recommendations ... . . . . . 2-71

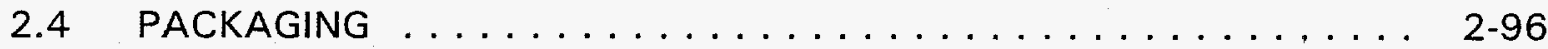

2.4.1 Requirements ................... 2-96

2.4.2 Design Options .................... 2-99

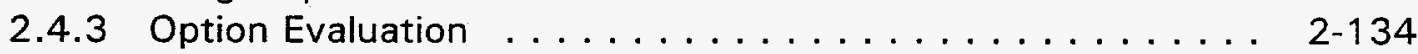

2.4.4 Observations and Conclusions ............. 2-136

3.0 ENGINEERED BARRIERS $\ldots \ldots \ldots \ldots \ldots \ldots \ldots \ldots \ldots \ldots \ldots \ldots$ 3-1

3.1 NEAR-SURFACE LAND DISPOSAL ISSUES (BACKGROUND) $\ldots \ldots \ldots 3-2$

3.2 UNDERGROUND DISPOSAL REQUIREMENTS $\ldots \ldots \ldots \ldots \ldots \ldots . . \ldots$

3.3 HANFORD'S DISTINGUISHING DISPOSAL FACTORS .......... $3-5$

3.4 DIRECT BURIAL OF GLASS - SCOPING CALCULATIONS . . . . . . . . 3-6

3.5 TECHNICAL ISSUES ASSOCIATED WITH GLASS CORROSION . . . . . 3-9

3.6 TECHNICAL ISSUES ASSOCIATED WITH RADIONUCLIDE

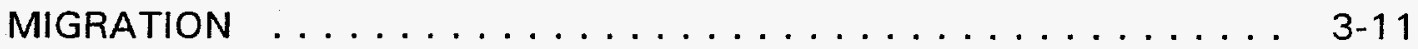

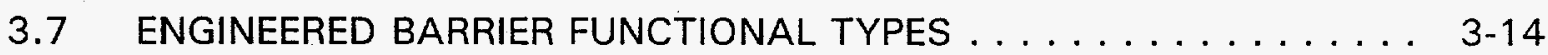

3.8 ENGINEERED BARRIER MATERIAL OPTIONS $\ldots \ldots \ldots \ldots \ldots \ldots, 3-16$

3.9 DESIGNING THE ENGINEERED BARRIER SYSTEM $\ldots \ldots \ldots \ldots \ldots 3-17$

3.10 SUMMARY AND RECOMMENDATIONS $\ldots \ldots \ldots \ldots \ldots \ldots \ldots, 3-22$

4.0 TRANSPORTATION $\ldots \ldots \ldots \ldots \ldots \ldots \ldots \ldots \ldots \ldots \ldots \ldots \ldots$ 4-1

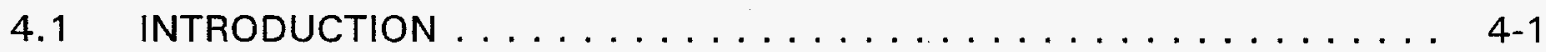

4.2 REQUIREMENTS $\ldots \ldots \ldots \ldots \ldots \ldots \ldots \ldots \ldots \ldots \ldots$ 4-1

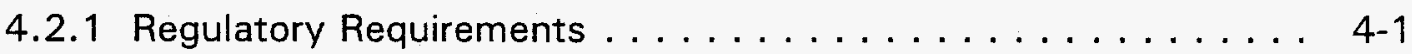

4.2.2 Hanford Site Requirements $\ldots \ldots \ldots \ldots \ldots \ldots \ldots \ldots$ 4-2

4.2 .3 System-Wide Requirements $\ldots \ldots \ldots \ldots \ldots \ldots \ldots$ 4-2 
CONTENTS (continued)

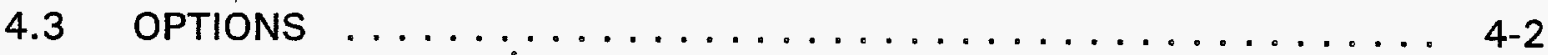

4.3.1 Transportation ...................... 4-2

4.3 .2 Lag Storage . . . . . . . . . . . . . . . . . 4-3

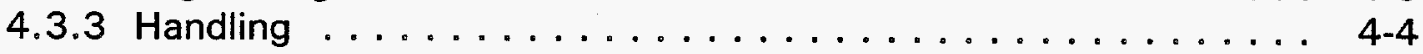

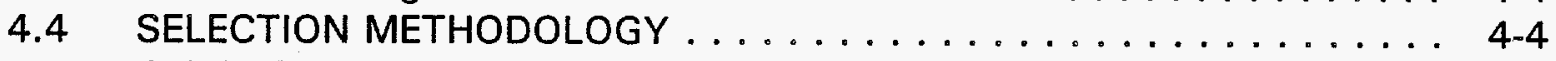

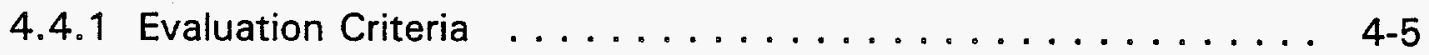

4.4 .2 Weight Factors . . . . . . . . . . . . . . . . 4-6

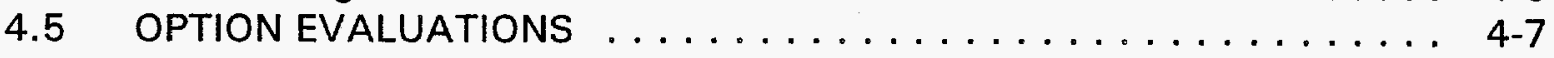

4.5 .1 Transportation . . . . . . . . . . . . . . . 4-7

4.5 .2 Lag Storage . . . . . . . . . . . . . . . . 4-10

4.5 .3 Handling . . . . . . . . . . . . . . . . . 4-12

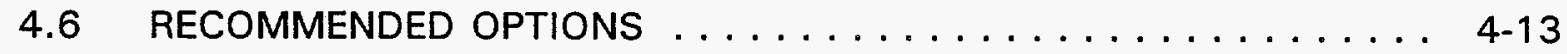

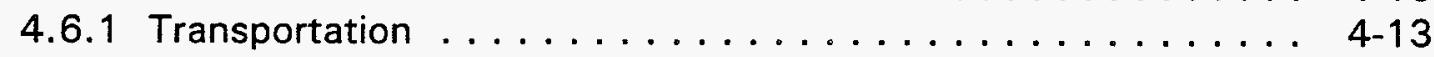

4.6 .2 Lag Storage ...................... 4.14

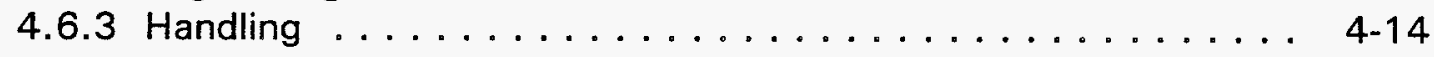

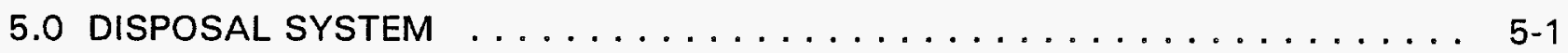

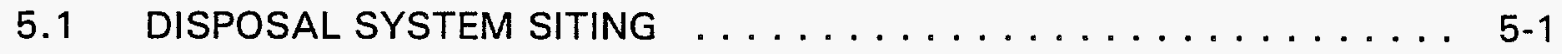

5.1 .1 Constraints and Requirements ............... . . 5-1

5.1 .2 Methodology to Evaluate Options . . . . . . . . . . . . 5-1

5.1.3 Characteristics Related to Disposal Site Selection ......... . 5-1

5.1 .4 Disposal Options ...................... 5-3

5.1 .5 Evaluation of Alternative Disposal Options . . . . . . . . . . . 5-4

5.1 .6 Identification of Preferred Alternative . . . . . . . . . . . 5-6

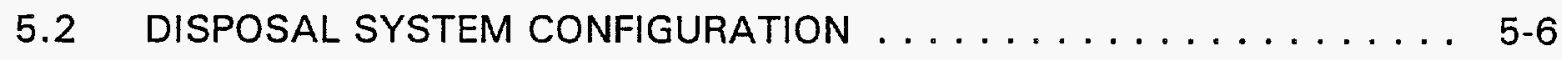

5.2 .1 Project Requirements . . . . . . . . . . . . . . . 5-7

5.2 .2 Land Disposal Options . . . . . . . . . . . . . . . . 5-11

5.2.3 Methodology to Evaluate Options . . . . . . . . . . . . 5-14

5.2 .4 Liner System . . . . . . . . . . . . . . . . . . 5 5-14

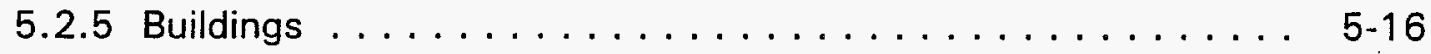

5.2.6 Cover Technology .................. 5-17

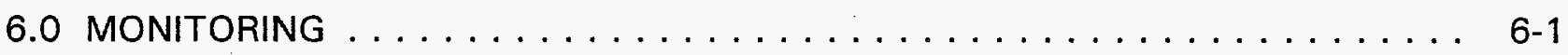

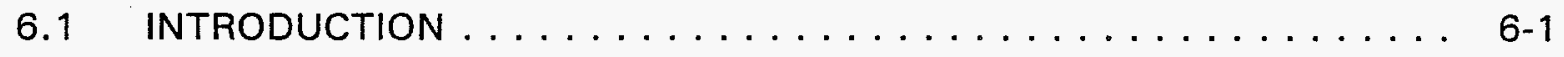

6.1 .1 Background ........................ 6-1

6.1 .2 Literature Review . . . . . . . . . . . . . . . . 6-1

6.1.3 General Discussion of Waste Vitrification and Disposal

6.1.4 General Discussion of Application of Monitoring Technology . . 6-2

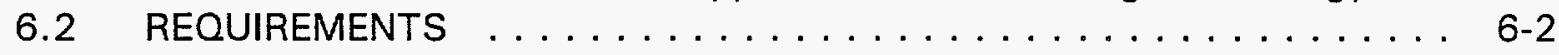

6.3 OPTIONS .......................... 6.3

6.3.1 Inspection and Evaluation Technology for Glass and Disposal

Site Structures . . . . . . . . . . . . . . . . . 6-4

6.3.2 Retrievable Monitors for Water and Other Defects in Vault ... 6-11

6.3.3 Nonretrievable Monitors Placed in the Glass Forms and Vault . 6-13

6.3.4 Nonretrievable Monitors for Presence of Radionuclides and Moisture in Sorption Barrier . . . . . . . . . . . . . . . 6- 6 . . . . . .

6.3.5 Conventional Monitoring Technologies ............ . 6-15 
CONTENTS (continued)

6.4 SELECTION METHODOLOGY FOR EVALUATION AND MONITORING . 6-15 6.4.1 Sensor Technologies Used for Process Control and Inspection . 6-15

6.4.2 Retrievable Coupons and Sensors . . . . . . . . . . . . . . 6-16

6.4 .3 Nonretrievable Sensors . . . . . . . . . . . . . . . . 6-16

6.4.4 Fiber Optics and Raman Spectroscopy .............. 6. 6-16

6.5 OPTIMIZATION OF EVALUATION AND MONITORING

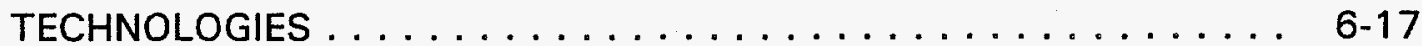

6.6 RECOMMENDATIONS $\ldots \ldots \ldots \ldots \ldots \ldots \ldots \ldots \ldots \ldots \ldots$

7.0 INTERNATIONAL WASTE FORMS FOR HANFORD EQUIVALENT WASTES $\ldots \ldots$ 7-1

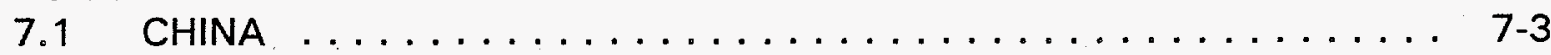

7.1 .1 Overview ........................... $7-3$

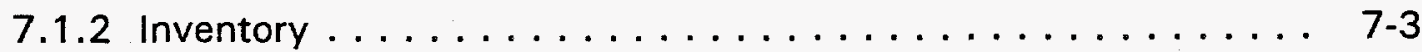

7.1 .3 Waste Form . . . . . . . . . . . . . . 7 7-3

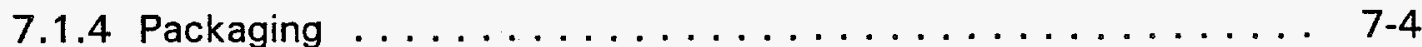

7.1 .5 Transport ...................... 7.4

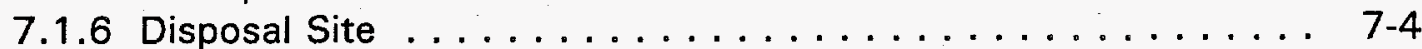

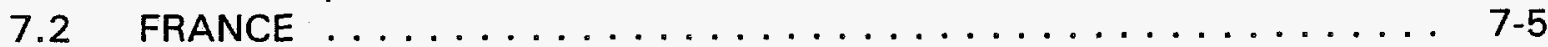

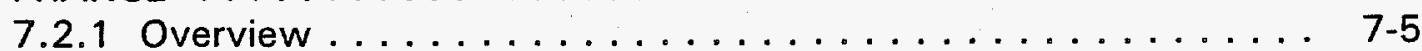

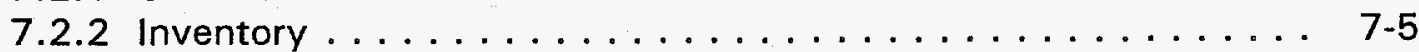

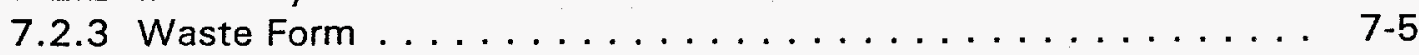

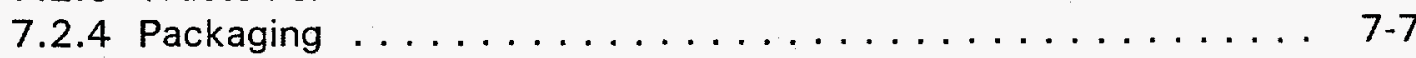

7.2 .5 Transport $\ldots \ldots \ldots \ldots \ldots \ldots \ldots \ldots \ldots \ldots \ldots \ldots \ldots$

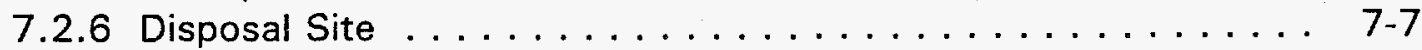

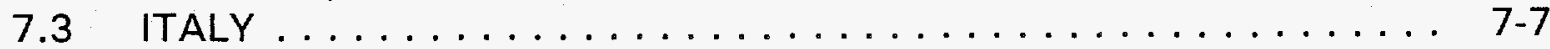

7.3.1 Overview ...................... $7-7$

7.3 .2 Inventory .................... 7 .8

7.3 .3 Waste Form ..................... $7-8$

7.3 .4 Packaging ...................... $7-11$

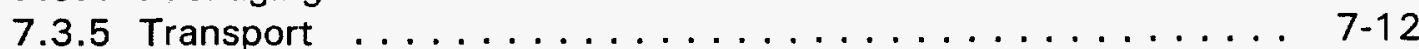

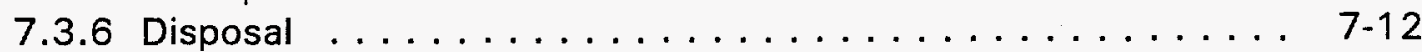

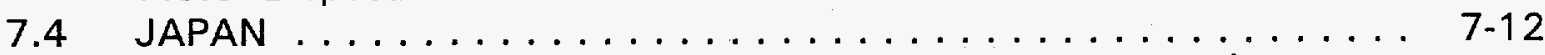

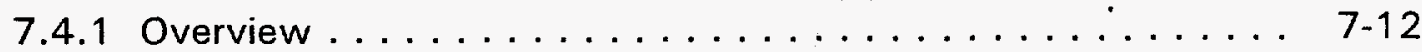

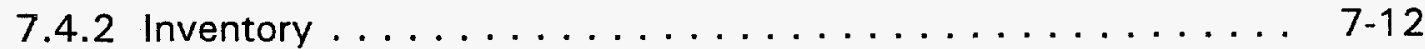

7.4 .3 Waste Form . . . . . . . . . . . . . . $7-13$

7.4 .4 Packaging .................... $7-14$

7.4 .5 Transport ....................... $7-14$

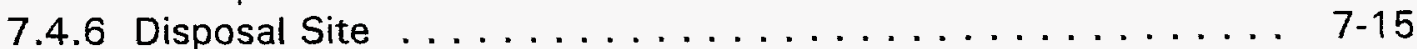

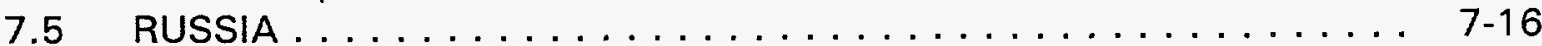

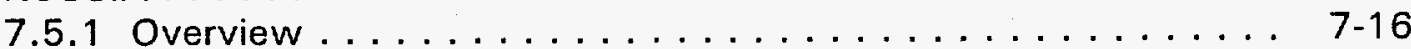

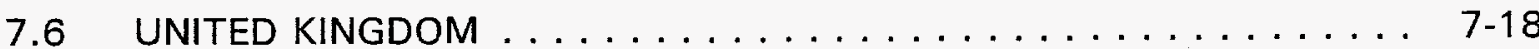

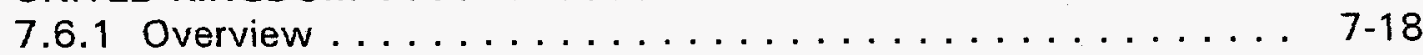

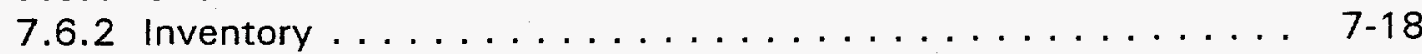

7.6 .3 Waste Type ........................ $7-19$

7.6 .4 Packaging ......................... $7-20$

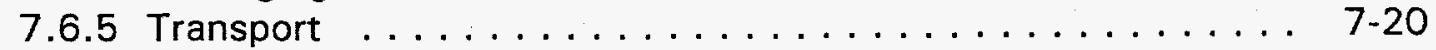

7.6 .6 Disposal Site . . . . . . . . . . . . . . . . . 7-20 
CONTENTS (continued)

7.7 UNITED STATES OF AMERICA $\ldots \ldots \ldots \ldots \ldots \ldots \ldots \ldots \ldots .7-21$

7.7.1 Overview .................... 7-21

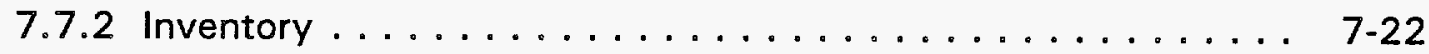

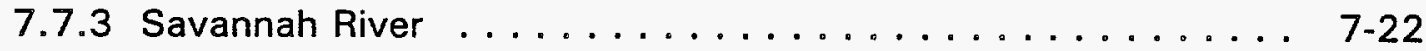

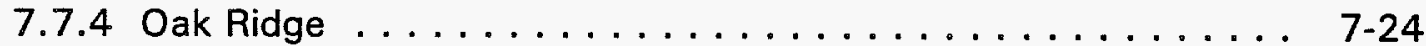

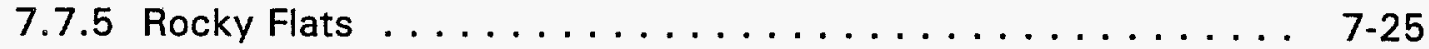

7.7.6 West Valley and Los Alamos Disposal Facilities ........ . 7-26

7.8 BELGIUM, GERMANY, AND SWITZERLAND DISPOSAL SYSTEMS . . 7 7-26

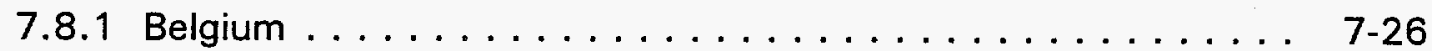

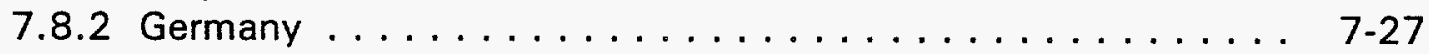

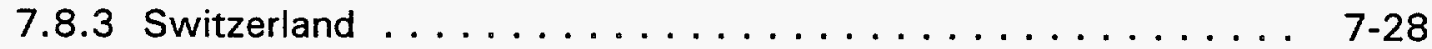

8.0 OVERALL SYSTEM INTEGRATION $\ldots \ldots \ldots \ldots \ldots \ldots \ldots \ldots \ldots \ldots$ 8-1

8.1 ASSUMPTIONS $\ldots \ldots \ldots \ldots \ldots \ldots \ldots \ldots \ldots \ldots \ldots \ldots \ldots . \ldots \ldots \ldots$

8.2 SYSTEM REQUIREMENTS $\ldots \ldots \ldots \ldots \ldots \ldots \ldots \ldots \ldots$ 8-1

8.2.1 Performance Assessment Requirements . . . . . . . . 8-1

8.2.2 Other Requirements $\ldots \ldots \ldots \ldots \ldots \ldots \ldots \ldots \ldots$ 8-1

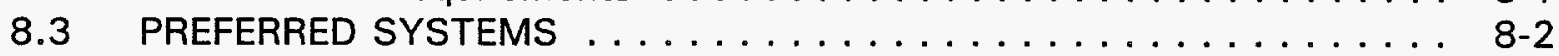

8.4 OBSERVATIONS, CONCLUSIONS, AND RECOMMENDATIONS $\ldots \ldots 8$ 8-2 


\subsection{INTRODUCTION}

Westinghouse Hanford Company (WHC), by use of the Tank Waste Storage Technical Support Contract, P.O. No. MTS-SWV-312057, has issued Task 010 to the team of Los Alamos Technical Associates (LATA); British Nuclear Fuels Limited (BNFL), both Inc. (based in USA) and Plc. (based in U.K.); Southwest Research Institute (SwRI); and TRW Inc. The team is to provide an independent team of experts to assist WHC in development and evaluation of conceptual alternatives for the glass waste form geometry, matrix material, packaging, transport, and on-site disposal system for the low level tank waste (LLW) at Hanford.

\subsection{BACKGROUND}

Since 1943 various radioactive wastes from defense operations have accumulated in underground waste tanks at the Hanford site. There are 149 single shell tanks (SST) and 28 double shell tanks (DST) for a total of 177 tanks on the Hanford site. One hundred and sixtyone of these tanks are $75 \mathrm{ft}$ in diameter and 29.75 to $54 \mathrm{ft}$ high with nominal capacities of 500,000 to $1,000,000$ gallons. The remaining 16 tanks are smaller units of similar design having a diameter of $20 \mathrm{ft}$, height of $25.5 \mathrm{ft}$, and capacity of 55,000 gallons. Over the years, radioactive waste from several processing facilities has been distributed among the tanks forming three general physical waste types: sludge, saltcake, and liquid. Sludge consists of solid hydrous metal oxides which precipitated during the neutralization of acid wastes before their transfer to the storage tanks. Saltcake consists of the various salts formed from the evaporation of water from the alkaline wastes. Liquids exists as supernatant and interstitial liquid in the tanks. The known major constituents in the Hanford site waste tanks are sodium nitrate, sodium nitrite, silicates, aluminiates, hydroxides, phosphates, sulfates, carbonates, organics, ferrocyanides, uranium, and calcium, in addition to fission products created by the processing of irradiated fuel.

Currently, activities are underway to retrieve wastes from all tanks. The retrieved waste will be pretreated to separate it into two waste streams; a high level waste (HLW) stream which contains the majority of all radionuclides and a minimum of chemical constituents (and therefore volume), and a low level waste (LLW) stream which contains the majority of the chemical constituents.

The Tri-Party Agreement (latest revision) required vitrification of LLW instead of the previous technology, which was to incorporate the waste in a grout matrix and then place it into vaults. The LLW vitrification process will produce approximately 0.21 million cubic meters (7.5 million cubic feet) of a vitrified waste form which will be capable of being safely disposed of on the Hanford site. An additional requirement placed on the waste form and the waste disposal (storage) system is that the waste form be retrievable for at least 50 years, starting at year 2028.

The disposal of LLW on the Hanford site must be accomplished safely and cost effectively. In order to accomplish this it has been determined that, in parallel with the LLW project development activities, an independent outside team of experts should assist in developing and evaluating alternatives for the glass waste form geometry, waste glass composition, matrix material (if any), packaging, transport, and on-site disposal system. 
It is noted that the LLW vitrification project is at an early stage and the melter selection, glass formulation, waste form geometry, and disposal system design have yet to be established.

\subsection{INITIAL LLW GLASS PRODUCT AND DISPOSAL SPECIFIC CRITERIA}

The following criteria were provided by WHC and serve as the initial functions and requirements that various options are to attain.

- The LLW shall be placed in an on-site, near-surface disposal system.

- The LLW shall be retrievable for 50 years, starting from year 2028 . The retrievability simply has to be achievable, not necessarily easy.

- The top of the disposal system shall be a minimum of 5 meters (16.4 feet) below grade.

- The LLW radionuclide concentrations do not exceed the limits for commercial LLW (10 CFR 61 Class C Waste).

- Approximately 0.21 million cubic meters (7.5 million cubic feet) of waste glass will be produced. The volume specified is based on a cullet form.

- The LLW cesium chain source term is assumed to be $4.7 \mathrm{Ci} /$ cubic meter 10.13 $\mathrm{Ci} /$ cubic foot) and the thermal load is assumed to be $0.0117 \mathrm{Watt} / \mathrm{cubic}$ meter (0.00032 Watt/cubic foot).

- The LLW strontium chain source term is assumed to be $28 \mathrm{Ci} /$ cubic meter 10.80 $\mathrm{Ci} /$ cubic foot) and the thermal load is assumed to be $0.0938 \mathrm{Watt} / \mathrm{cubic}$ meter (0.00268 Watt/cubic foot).

- Soda-lime silica and alumino-borosilicate compositions are candidate glass compositions for Hanford site LLW feeds. Typical composition ranges are 15 25 wt $\% \mathrm{Na}_{2} \mathrm{O}, 0-12$ wt $\% \mathrm{CaO}, 5-12$ wt $\% \mathrm{AL}_{2} \mathrm{O}_{3}$ 0-21 wt $\% \mathrm{~B}_{2} \mathrm{O}_{3}, 1-5$ wt $\%$ other LLW components, and the balance (50-70 wt\%) $\mathrm{SiO}_{2}$. Other composition variations and components may be proposed to optimize glass formulation for the specific vitrification system.

- The disposal and site, as a minimum, must be compliant with WAC-173-303655 RCRA Landfill, DOE Order 5820.2A Part III, 10 CFR 61 Subpart C \& D, 40 CFR 265 Subpart N, and Draft 40 CFR 193. [Note: DOE Order 5820.2B is now a draft document, however, it uses a 10,000 year compliance time frame. Order 5820.2A requires compliance for 1,000 years.]

\subsection{TASK ELEMENTS}

The LATA, BNFL, SwRI, and TRW team accomplished the following items based on the Initial LLW Glass Product and Disposal Specific Criteria and additional criteria developed during task implementation. (Note: The primary team member's responsibility is listed in parenthesis 
after each item as is the section number where the task element is found. The order of the task elements is the same as given in the WHC Task Order.)

- Determine the optimum glass form geometry concepts supportive of cost effectively meeting the disposal criteria. The glass form geometry has not been determined and therefore, any form such as marbles, rods, cubes, monolithic cast into containers, etc., may be considered for evaluation. In this portion of the study, durability of the glass is the driving function rather than, for example, volume reduction. (BNFL, 2.2)

- Review, develop, and evaluate packaging technology concepts for the waste glass and any matrix material that will allow cost effective handling and retrievability of the waste glass. Retrieval has to be achievable but not necessarily easy. (BNFL, TRW, 2.3)

- Develop and evaluate engineered barrier concept options for disposal. This would include both physical and chemical barriers and/or retardation concepts into the disposal system design that would cost effectively improve system performance. (SwRI, 3.0)

- Develop and evaluate conceptual methods for monitoring the integrity of packaged glass waste, the disposal system performance, and the disposal site. Concepts to be considered might include remote retrieval and inspection of corrosion coupon samples of barrier materials and the glass product to verify predicted behaviors. (SwRI, 6.0)

- Develop and evaluate site closure concepts and requirements for the disposal method and disposal system concepts. (LATA, 5.1)

- Develop and evaluate disposal concepts for structures and configurations of the disposal system. (LATA, 5.2)

- Evaluate glass and matrix chemical formulation concepts leading to compositions that may chemically retard the release of ${ }^{99} \mathrm{Tc},{ }^{129} \mathrm{l}, \mathrm{U}$, and $\mathrm{Np}$ from the waste glass/matrix. (BNFL/SwRI, 2.1)

- Interact with the on-going LLW disposal performance assessment process by WHC during the development of packaging and disposal options. The various disposal system options and concepts developed through this study will be ranked by WHC based on their anticipated performance, using performance assessment methodology and anticipated costs. (All, throughout report when applicable)

- Attend meetings with the public and other stakeholders to review the selection of packaging/disposal alternatives as requested by WHC. Some of these requests may occur after completion of the disposal options study. (All, no meetings to date) 
- Perform a review of the waste forms used by other countries for wastes equivalent to the Hanford tank wastes, including a review of how these materials are pretreated, packaged, and disposed of, and what is the performance criteria for the waste form, disposal system, and disposal site. Similarities between Hanford wastes and those in other countries will be identified along with any possible routes for technology infusion or transfer. (BNFL, 7.0)

- Develop and evaluate transport concepts for the LLW package from the LLW facility to the disposal site and placement of the package in the disposal system. As an example, the study should include a tradeoff of handling lightly shielded containers with a manned transporter versus non-shielded containers handled by a remotely operated, or manual shielded, transporter. (BNFL, 4.0)

- Conduct ALARA reviews throughout all aspects of the study to consider personnel exposure and dose. (All, throughout report)

While all of the original task order elements were given above, this report is organized as follows:

1.0 INTRODUCTION

2.0 LLW GLASS

2.1 Glass Formulation

2.2 Matrix

2.3 Glass Geometry

2.4 Packaging

3.0 ENGINEERING BARRIERS

4.0 TRANSPORTATION

5.0 DISPOSAL SYSTEM

5.1 Disposal Site

5.2 Disposal Facility

\subsection{MONITORING}

7.0 INTERNATIONAL WASTE FORM REVIEW

\subsection{OVERALL SYSTEM INTEGRATION}

Section 8.0 uses the preferred option from each section, the overall system requirements, and the performance assessment requirements for vitrified low level waste disposal to recommend an overall system of concepts which appears to be effective; based on this level of analysis. 


\subsection{LOW LEVEL WASTE GLASS}

\subsection{LLW GLASS FORMULATION}

The purpose of this section of the study is to evaluate glass formulations that may be suitable to produce a vitrified product of high durability from the low level waste (LLW) currently stored at Hanford. Details of the anticipated waste stream composition of the Hanford Tank (LLW) for vitrification are contained in tables 2.1-1 (WHC-SD-WM-EE-004 Rev.0) and 2.1-2 (SDI Bolt to Karnesky 13 Jan 1994).

This report comprises a review of the published literature on radioactive waste glass formulations and published studies on the retention of radionuclides in vitrified products. The study also contains experience gained by British Nuclear Fuels plc (BNFL) in support of its high level waste vitrification program.

A number of glass formulations have been considered and the optimum determined. Particular attention has been paid to the behavior of ${ }^{99} \mathrm{TC},{ }^{129} \mathrm{I}, \mathrm{U}$ and ${ }^{237} \mathrm{~Np}$ in glass as their retention was indicated as particularly desirable in the task specification.

\subsubsection{Requirements}

2.1.1.1 Regulatory Requirements. DOE Order 5820.2A - Radioactive Waste Management. Relevant Sections;

1) General public protection. Disposal systems shall be designed to ensure that exposure to any member of the public that results from disposal of solid LLW shall not exceed $25 \mathrm{mrem} / \mathrm{yr}$ Effective Dose Equivalent (EDE) through all exposure pathways for at least 1,000 years after disposal (This will probably be changed to 10,000 years after disposal.)

(2) Groundwater Protection. Disposal systems shall be designed to meet the Clean Water Act and the Safe Drinking Water Act as well as ensure that disposal of LLW after $09 / 26 / 88$ does not result in concentrations of radionuclides in groundwater exceeding those corresponding to an EDE of $4 \mathrm{mrem} / \mathrm{yr}$ to any person who might drink 2 liters per day of water from a well drilled into the aquifer, for at least 1,000 years after disposal. (Probably change to 10,000 years after disposal.) The point of compliance shall be no further than 100 meters from the edge of the waste.

2.1.1.2 System Wide Requirements. Retain as much of the waste as possible for as long as possible within project cost and timescales while satisfying all regulatory performance criteria.

Durability and waste retention characteristics of the glass will be assessed. Glass formulations will be evaluated for their ability to retain Uranium, Neptunium, Technetium, lodine, and other elements.

2.1.1.3 Task Specific Requirements. The reference waste composition indicates a high proportion of sodium. The optimum glass formulation is required to incorporate this waste. 
Leach Rate - The formulation of the glass must minimize the potential glass leach rate due to water solubility. The radionuclide concentrations must not exceed the drinking water concentrations as stated in DOE Order 5820.2A.

Glass Quality - The formulation of the glass is to facilitate the production of acceptable quality glass by having insensitive processing parameters; eg. variable cooling rates acceptable, no annealing, etc.

\subsubsection{Design Options}

2.1.2.1 General Comments. Effect of radiation dose on product durability. Blocks of highly radioactive glass were produced by a pilot plant at Harwell in the UK in 1966 . In 1977 a simple accelerated leach test was performed on the 1966 glasses by placing $150 \mathrm{~g}$ samples in water at $90^{\circ} \mathrm{C}$ for seven days and measuring the weight loss, a similar test being carried out simultaneously on a freshly manufactured nonradioactive reference glass prepared from simulated waste. The respective bulk leach rates for the 1966 glass and its 1977 inactive counterpart were $3.3 \times 10^{-4}$ and $3.5 \times 10^{-4} \mathrm{~g} \mathrm{~cm}^{-2}$ day $^{-1}$. These were of the expected values and showed that after eleven years there was no evidence of any aging phenomenon. The leach resistance of the 1966 radioactive glass at this stage being equivalent to that of freshly prepared glass.

More recent work on simulated waste glasses doped with ${ }^{238} \mathrm{Pu}$ has shown that alpha radiation doses equivalent to hundreds of years exposure have a negligible effect on their leach resistance, adding to the confidence that glass is highly resistant to radiation damage (Burns et al 1981). As the specific activity of the Hanford site tank LLW is expected to be low (see table 2.1-2), radiation should have a negligible effect on the integrity of the glass over 10,000 years or more.

\section{Diffusion of Radionuclides}

The number of publications on mass transfer of long-lived actinides in glasses is limited. Soviet researchers have studied ion migration in glasses in order to understand possible delocalization mechanisms of radionuclides in vitrified radioactive wastes during longterm storage (Ivanov et al., 1988 and Ivanov et al., 1990). The diffusion coefficients of 237. $\mathrm{Np},{ }^{239} \mathrm{Pu}$ and ${ }^{241} \mathrm{Am}$ were determined for two candidate alumino-phosphate and aluminoborosilicate glasses at temperatures slightly lower than their transformation temperatures. The compositions of the glasses, candidates for Soviet radioactive waste incorporation, are given in the table 2.1-3 (Ivanov et al.,1990).

The results are presented in Table 2.1-4 ((Ivanov et al 1990) and it can be seen that the actinide diffusion coefficients in the alumino-phosphate glasses at $673 \mathrm{~K}(400 \mathrm{C})$ are of the order of $10^{-18} \mathrm{~m}^{2} \mathrm{~s}^{-1}$ and in the aluminoborosilicate glasses at $773 \mathrm{~K}(500 \mathrm{C})$ are of the order of $10^{-19} \mathrm{~m}^{2} \mathrm{~s}^{-1}$. Comparing these results with migration data for other radionuclides, it can be concluded that actinides are some of the least mobile elements in glasses. In particular, the actinide diffusion coefficients are 10-100 times less than the corresponding values for $\mathrm{Sr}$ and $C s$ and 5-6 orders of magnitude less than that for sodium. It was also found that crystallization of the glasses increased the diffusional mobility of ${ }^{237} \mathrm{~Np}$. However, it should be noted that the crystallization was induced by heat treatments which were designed to simulate the radiogenic heat produced in HLW. Hence, this is not likely to be a significant 
problem for vitrified LLW. Also, a very small amount of water when absorbed by the crystallized alumino-phosphate glass increased the low-temperature migration of ${ }^{237} \mathrm{~Np}$. It was thought that this increase in diffusion was caused by the crystallized glasses being heterophasic amorphous crystalline materials with interfaces between crystals and residual glass, micro- and macrocracks, and pores. These all facilitate migration of ions, including $\mathrm{Np}$, compared to bulk diffusion.

2.1.2.2 Retention of Radionuclides. Retention of Uranium. Summary. The Virginia Military Institute showed that borosilicate glass is effective for uranium retention as long as the uranium is in the desired redox state (redox is a way of measuring the state of oxidation or reduction, oxidation is the loss of electrons and reduction is the gain of electrons). Other major constituents (iron, manganese, nickel and titanium (all of which are present in the Hanford wastell can effect the uranium redox state. The presence of significant iron in the glasses should stabilize the uranium redox state so that it is unaffected by the other components.

An Italian study showed that the addition of zinc oxide increases the durability of borosilicate glass by its ability to exist in several coordination sites. However at high $\mathrm{pH}$ the SiO network is destroyed and some species such as Fe(III), Zn(II), Al(III) and Ti(IV) form a surface protective layer and hence depress the leach rate. However, the uranium ions pass into solution and do not contribute towards layer formation.

Work at BNFL Sellafield showed that an increase in uranium content had no significant effect on the quality of the glass product.

\section{Technical Discussion.}

Studies have been carried out on the incorporation of uranium in borosilicate glasses for the purpose of immobilizing nuclear waste. Extensive investigations were carried out at the Virginia Military Institute on the redox chemistry of uranium in borosilicate glasses (Balazs 1982, Schreiber et al 1983, Schreiber et al 1984 and Schreiber et al 1985). Uranium, when dissolved in simple borosilicate glass, establishes redox equilibrium amongst the U (VI), U (V) and $U$ (IV) states. By controlling the melt temperature, the imposed oxygen activity and the base composition, uranium can be incorporated into borosilicate glass in its desired redox state.

The coordination chemistry of the uranium redox states in borosilicate glasses effectively duplicates that previously determined in aluminosilicate glasses (Schreiber and Andrews et al 1981 and Schreiber et al 1981). $U$ (VI) exists as $U_{2}{ }^{2+}$ ions, $U$ (V) is octahedral coordination with some tetragonal distortion and $U$ (IV) has eightfold coordination to the solvent anions. $U(V I)$ and $U(V)$ are much more soluble than $U$ (IV) in most glassforming systems. For example, over $40 \mathrm{wt} \% \cup(\mathrm{VI})$ can be readily incorporated in borosilicate glasses. However, real systems are complicated by the presence of other multivalent elements in much greater concentrations in the processed glass. For example iron, manganese, nickel, and titanium can be major redox constituents in the glass frit or nuclear waste which affect the stable uranium redox state through mutual interactions and/or complex formations in the melt. Thus, it is desirable to obtain uranium in a state that can be readily incorporated into glass and that will resist leaching from the glass. 
It has been found that iron acts as a buffer to both the reduction as well as the oxidation of $U(V)$ by other redox species in glass-forming melts, and since iron is in excess over most reducing and oxidizing agents in glasses to be used for the immobilization of nuclear wastes, the distribution of uranium redox states in these glasses should remain unaffected by the presence of other redox components. Even though $U(V)$ is not considered a stable entity in most aqueous solutions, it has been demonstrated to be a stable redox ion in glasses processed for the immobilization of nuclear waste. $U$ (VI) and $U$ (IV) are not the only uranium redox states to be considered in 'real' glasses.

An Italian study to determine the influence of some oxides on the durability of borosilicate glass showed that strontium and uranium oxides have little effect on the chemical properties of the glass matrix (Calestani 1986). Zinc oxide increased the glass durability by several orders of magnitude by its ability to exist in several coordination sites, either bridging two oxygens or sharing in a three- or four-coordinate network formation with such elements as boron or aluminum. This could make the glass durable either by decreasing the number of non-bridging oxygens or by making more difficult the ion exchange with $\mathrm{H}_{3} \mathrm{O}^{+}$owing to its stronger bonding with oxygen. However, alkali and alkaline - earth cations contained in the glass, when immersed in water, moved into the solvent, raised the $\mathrm{pH}$, and accelerated the dissolution of the SiO network. Some divalent or polyvalent species such as Fe (III), Zn (III), $\mathrm{Al}$ (III) and $\mathrm{Ti}$ (IV) produced a surface-protective layer which depressed the leaching rate. The study of this layer and its correlation to durability is one of the requirements to be considered when preparing a suitable glass for containing nuclear waste. Table 2.1-5 shows the compositions of the glasses studied and Figures 2.1-1 to 2.1-6 show the results obtained. The behavior of the uranium ion in the U2 glass (Figure 2.1-5) appears to show that uranium ions pass into solution after network breakdown and that they do not participate in layer formation.

Studies have also been carried out at Sellafield in the UK on the limits of incorporation of uranium in "Magnox" and "Thermal Oxide Reprocessing Plant (THORP)" type highly active (HA) waste residues. Typically for Magnox waste, it was found that an increase in the uranium content from $15 \mathrm{grams} /$ tonne $(\mathrm{g} / \mathrm{te}) \mathrm{U}$ up to $1600 \mathrm{~g} / \mathrm{te} \mathrm{U}$ (for a melt temperature of $1100^{\circ} \mathrm{C}$ ) had no observable effect on the quality of the glass product.

\section{Retention of Technetium and lodine Summary}

BNFL at Sellafield investigated the effects of the presence of technetium in highly radioactive waste during vitrification and in the final glass product. It was concluded that the addition of technetium to the glass did not effect the density of the glass or the leach rate of other elements and that the leach rate of technetium was comparable to $\mathrm{Cs}$, Mo and $\mathrm{Sr}$.

Vitrified radioactive waste glasses do not usually contain more than $1 \%$ of iodine as this element has a high vapor pressure and volatilizes from the melt. Most of the iodine present in the waste is usually volatilized during vitrification and is treated by the off-gas system.

\section{Technical Discussion}

Studies were carried out at Sellafield to investigate the effect of the presence of technetium in Magnox highly radioactive waste during vitrification and in the glass product. Good agreement was obtained between the ${ }^{99} \mathrm{Tc}$-doped glasses and the non-active reference 
glasses in terms of general appearance. No extra phases were identified that could be linked to the presence of technetium. Scanning Electron Microscopy (SEM) examinations showed that the technetium was present within the glass matrix and concentrated with ceria around $\mathrm{Ce}, \mathrm{Zr}$-rich particulates. The technetium was thought to be present in the glass as $\mathrm{TcO}_{2}$ because its unit cell parameters (monoclinic, $a=5.53, b=4.79, c=5.53 \mathrm{~A}$ ) are similar to those of the cubic $\mathrm{CeO}_{2} / \mathrm{ZrO}_{2}$ system (5.32 A). $\mathrm{Tc}_{2} \mathrm{O}_{7}$ was unlikely to be present in the glass because it melts at $119.5^{\circ} \mathrm{C}$, boils at $310.6^{\circ} \mathrm{C}$ and would have vaporized during the vitrification process. The addition of technetium to the Magnox glass did not affect the density of the glass product.

The chemical durability of the Tc-doped glasses was assessed over a period of about 480 days. It was found that the addition of Tc to the glass did not affect the leach rate of the other elements present. A comparison with similar nonradioactive leach tests confirmed that the leach rates of base glass components, fission products, and corrosion elements were in good agreement with those of the Tc-doped glasses. After 486 days at $70^{\circ} \mathrm{C}$, the amount of Tc lost through leaching was of the order of $1.0 \%$, whereas the amount of Tc leached in the $25^{\circ} \mathrm{C}$ experiment after 486 days was approximately $0.2 \%$. Comparison of the Tc cumulative elemental leach rates with those of the other fission products showed that their values were very similar, suggesting that Tc does not behave differently from $\mathrm{Cs}$, Mo and $\mathrm{Sr}$.

It is not anticipated that the vitrified LLW will contain more than $1 \%$ of the iodine originally present in the waste stream as this element has a high vapor pressure and will volatilize in the melter. The iodine volatilized during vitrification will need to be treated by the off-gas system.

Although not directly applicable to Hanford vitrified waste the following comment is added for information from grouted HLW experiments by NIREX in the UK. Experimental measurements of the solubility of technetium under near-field conditions were carried out as part of the safety studies for the NIREX grouted waste disposal project (Pilkington et al, 1988). Experimental measurements of the solution concentration of Tc in contact with hydrated $\mathrm{TCO}_{2}$ under conditions similar to those expected to be found in the near-field of an intermediate level waste repository were obtained. The solution concentration of Tc under high $\mathrm{pH}$ and reducing conditions was found to be about $10^{-7} \mathrm{~mol}^{-1}$ and was independent of the type of cement leachate used and $\mathrm{pH}$ in the range 8-13. However, the presence of organic degradation products increased the solution concentration of Tc slightly. There is no reason to assume that the reducing conditions will persist within the near field environment of a shallow Burial LLW disposal facility for an extended period of time unless reducing agents were specifically added to the disposal site.

\section{Retention of Neptunium Summary}

Japan Atomic Energy Research Institute studied the release of $\mathrm{Np}$ from Np-doped borosilicate waste glass. The results showed that most borosilicate glasses are comparable in their ability to immobilize $\mathrm{Np}$.

Radioactive tracer studies have been carried out at Sellafield in the UK on Windscale Vitrification Plant (WVP) product glasses doped with $\mathrm{Np}$. The results showed that the presence of $\mathrm{Np}$ in the waste glass did not significantly alter its general properties. 


\section{Technical Discussion}

Research was carried out at the Japan Atomic Energy Research Institute to study the release of neptunium from neptunium-doped borosilicate waste glass (Nakayana et al 1989). Some release data for neptunium have been obtained for relatively limited types of glass and they are summarized in table 2.1-6 (Nakayana et al 1989). The composition of the ${ }^{237} \mathrm{~Np}-$ doped waste glass studied in the Japanese investigation is given in Table 2.1-7 (Nakayana et al 1989). The standard MCC-1 static leach test method was applied to the ${ }^{237} \mathrm{~Np}$-doped borosilicate waste glass at $90^{\circ} \mathrm{C}$ for durations up to 91 days and the results are shown in Figures 2.1-7 to 2.1-10 (Nakayana et al 1989) and Table 2.1-8 (Nakayana et al 1989). The normalized elemental mass loss for $\mathrm{Np}$ was found to be about $5 \mathrm{gm}^{-2}$ for both deionized water and silicate water leachates. The value is similar to those for other borosilicate waste glasses, $1 \sim 10 \mathrm{gm}^{-2}$, indicating that most borosilicate waste glasses are comparable in their ability to immobilize Np. The time dependence of the neptunium release from the glass was different than those of the soluble glass components such as sodium, boron and cesium, but similar to that of strontium. It appeared that some of the $\mathrm{Np}$ probably remained in the surface layer formed on the leached glass and it was predicted to be in the form of $\mathrm{NpO}_{2} \cdot \mathrm{xH}_{2} \mathrm{O}$ (based on available solubility data). The chemical behavior of $\mathrm{Np}$ species in glass surface layers deserves further investigation.

Radioactive tracer studies have been performed at Sellafield in the UK on Windscale Vitrification Plant (WVP) product glasses (borosilicates) doped with neptunium-237 and it was found that the inclusion of $\mathrm{Np}$ in the waste glass did not significantly alter its general properties. Scanning Electron Microscopy examinations revealed that $\mathrm{Np}$ can be found as both a dissolved species distributed homogeneously throughout the glass matrix and also enriched in association with $\mathrm{Ce}$ and $\mathrm{Ce}, \mathrm{Zr}$-rich particulates. This probably occurs because $\mathrm{NpO}_{2}$ and $\mathrm{CeO}_{2} / \mathrm{ZrO}_{2}$ have similar sized lattice unit cells, (cubic $5.434 \mathrm{~A}^{\circ}$ and cubic about 5.32 $A^{0}$, respectively). The chemical durability of ${ }^{237} \mathrm{~Np}$-doped Sellafield glasses were assessed over a 486-day period using a series of static leach tests. The cumulative elemental leach rates for $\mathrm{Np}$ at 25 and $70^{\circ} \mathrm{C}$ were found to be $0.8 \times 10^{-6}$ and $7.4 \times 10^{-6} \mathrm{~g} \mathrm{~cm}^{-2} \mathrm{~d}^{-1}$ respectively which are low and are very similar to those obtained for $\mathrm{Cs}$, Mo and $\mathrm{Sr}$.

2.1.2.3 Glass formulations. The following glass formulations were identified as potentially suitable for the vitrification of LLW similar to Hanford.

- Silica-based networks

- Silicon Titanate glasses

- Lead Iron Phosphate glass

- Novel Methods

These formulations have been discussed in detail below.

Silica Based Networks.

It is possible to make a large variety of glass with different chemical and physical properties by adjusting chemical compositions, and glasses with specific properties may be devised to meet almost any imaginable requirement. The current requirement is to vitrify an alkaline aqueous low-level waste with a sodium nitrate concentration of approximately $80 \%$. The other major components in the waste are aluminum $-8 \%$ and potassium $5 \%$ (see Tables 2.1-1 and 2.1-2) A patent search has revealed that a substantial amount of work has been 
carried out by the Japanese on the vitrification of aqueous low level sodium nitrate containing waste. Unfortunately, in the short time available it has not been possible to have the patents translated into English. However, it has been possible to glean that compositions in the range:

$\begin{array}{ll} & \text { wt \% } \\ \mathrm{SiO}_{2} & 25-65 \\ \mathrm{~B}(\mathrm{OH})_{3} & 1-20 \\ \mathrm{Al}(\mathrm{OH})_{3} & 1-5 \\ \mathrm{CaCO}_{3} & 1-15 \\ \mathrm{Na}_{2} \mathrm{O} & 15 \text { (in the final waste form) }\end{array}$

will form highly stable vitreous solids which have excellent resistance to heat and water, and are mechanically and chemically strong (Patent 1987). Another Japanese patent gives a more precise glass formulation for encapsulating sodium nitrate wastes (Patent 1987). (Hanford waste has a high concentration of sodium which could form some sodium compounds in the glass. Therefore sodium nitrate waste encapsulation is included in this study).

$\begin{array}{lc} & \text { wt } \% \\ \mathrm{SiO}_{2} & 60 \\ \mathrm{Na}_{2} \mathrm{O} & 19 \\ \mathrm{~B}_{2} \mathrm{O}_{3} & 10 \\ \mathrm{Al}_{2} \mathrm{O}_{3} & 3 \\ \mathrm{CaO} & 8\end{array}$

The very nature of multicomponent silicate glass compositions, (i.e., in excess of six components), complicates the investigation of their corrosion behavior. The basic principles governing the corrosion processes of glasses are not well understood. For example, $\mathrm{K}_{2} \mathrm{O}$ silicate glasses corrode at a much faster rate than $\mathrm{Na}_{2} \mathrm{O}$ silicate glasses. This is commonly referred to as the mixed alkali effect. The presence of small percentages of $\mathrm{Al}_{2} \mathrm{O}_{3}$ in glass decreases the corrosion rate significantly and reduces the effect of $\mathrm{pH}$ on glass durability for silicate glasses. This is thought to occur because of the formation of an alumina-silicate rich surface film that is resistant to corrosion solution of high pH (Dilmore 1977).

\section{Chemical Durability of Silicate Glasses}

It has been postulated that the thermodynamic stability of a glass depends on the stability of its component oxides, which in turn depends on the activity of those oxides in the glass and the equilibrium constants for hydration, ionization and complex formation. However, the free energy changes associated with these reactions may not be strictly applicable to predicting chemical durability, probably because the configuration of the oxide in the network structure (i.e., the linkage of the oxide to silicon) has not been taken into account. The activation energy, which takes into account the dependence of reaction initiation on temperature and the oxide linkage, is probably more significant.

The kinetics of reactions between sodium silicate glasses containing $\mathrm{Al}_{2} \mathrm{O}_{3}$ and $\mathrm{ZrO}_{2}$ and water in aqueous solutions of $\mathrm{pH} 1.4$ to 12.7 were studied (Das 1981). The compositions of the glasses and solutions used in the experiments are given in Tables 2.1-9 and 2.1-10. It was found that the diffusion of alkali ions and the leaching of alkali and $\mathrm{SiO}_{2}$ from the glasses were influenced by the occupancy of surface sites by alkali ions above a critical $\mathrm{pH}$. However, the activation energies of the processes varied linearly with the 
logarithm of mole fraction of surface sites occupied by $\mathrm{H}^{+}$. Identical slopes were obtained for all glasses for a given process (see Figure 2.1-11). The results were explained on the basis that transport of alkali ions is retarded as a result of increased boundary concentration and that suitable sites for reaction were lacking.

Some American workers have also studied the dissolution rates of silicate glasses in water at $\mathrm{pH} 7$ (Perera et al 1991). The glass compositions are given in Table 2.1-11 and the results are given in Tables 2.1-12 and 2.1-13 and Figure 2.1-12. It was discovered that natural obsidian glass dissolved most slowly, at a rate comparable with those of quartz and crystalline aluminosilicate minerals. Commercial soda-lime glass containing alumina dissolved slowly, at about the same rate as vitreous silica, and soda-lime silicate glasses without alumina dissolved much more rapidly. Pyrex borosilicate glass dissolved at a rate intermediate between those of soda-lime silicate glasses with and without alumina. At room temperature Pyrex borosilicate glass dissolved about 100 times faster than a commercial soda-lime glass containing alumina. However it should be noted that the durability of a pyrex borosilicate glass can be significantly improved by the addition of elements such as alumina. It was suggested that surface structure is the main factor determining the relative dissolution rates of silicate glasses. Glasses with transformed surface layers caused by hydration dissolve most rapidly, while phase separation and openness of the glass structure are also important factors. The dissolution rates of silicate glasses measured by other investigators at $\mathrm{pH} 7$ are given in Table 2.1-14.

Perera and Donemus (1991) continued their durability studies by looking at the influence of solution $\mathrm{pH}$ on the dissolution rates of commercial soda-lime and Pyrex borosilicate glasses. The compositions of the glasses studied are given in Table 2.1-15 and the results are in Table 2.1-16 and Figures 2.1-13 and 2.1-14. The dissolution rate was constant with time and increased with an increase in $\mathrm{pH}$ from 4 to 9 . This result contrasts with the nearly constant solubility of amorphous silica in this $\mathrm{pH}$ range, suggesting that factors other than silica solubility influence the rate of dissolution of a silicate glass at a particular temperature. The activation energy for dissolution was nearly constant with $\mathrm{pH}$ for the Pyrex borosilicate glass, and decreased somewhat as $\mathrm{pH}$ increased for the soda-lime glasses. The openness of the glass surface influenced strongly the rate of dissolution. The solubility of silica as a function of $\mathrm{pH}$ increased at $\mathrm{pH}$ above 8 but did not seem to be quantitatively related to dissolution rate. Other possible influences on the rate were thought to be surface structure, surface charge, silica solubility and chemical reaction rates.

In the mid 1970's some researchers in Austria examined some ancient glasses by microscopic inspection to determine their degree of corrosion and by neutron activation analysis to determine the presence of trace elements to look for correlations and possible influences on the long-term behavior of glasses (Nauer et al 1977). The glasses that were studied were second century Roman pieces, fragments of medieval painted window panes and baroque glasses of Viennese origin; in general, the sodium glasses contained fewer trace elements and proved to be more resistant against corrosion and devitrification than the potassium glasses. As an example, one of the sodium glasses, a piece from a Roman beaker, had the following chemical composition:

$\begin{array}{ll} & \% \\ \mathrm{SiO}_{2} & 64 \\ \mathrm{Na}_{2} \mathrm{O} & 15.5 \\ \mathrm{~K}_{2} \mathrm{O} & 3.5\end{array}$




$\begin{array}{ll}\mathrm{CaO} & 6.5 \\ \mathrm{MgO} & 4.5 \\ \mathrm{Sb}_{2} \mathrm{O}_{5} & 2.6 \\ \mathrm{Fe}_{2} \mathrm{O}_{3}, & <1.5 \\ \mathrm{Eu}, \mathrm{Sr}, \mathrm{Cs}, \mathrm{Sc}, \mathrm{Co} & <0.5\end{array}$

and had proved to be relatively resistant to corrosion. Only a very thin upper layer could be lifted which had apparently protected the glass matrix underneath. The geological literature contains numerous studies on the stability of natural silicate glasses under a variety of environmental conditions. The processes of glass hydration, devitrification and dissolution can be described and their rates have been estimated from field and laboratory observations.

These processes are also likely to affect any glass proposed as a waste solidification medium, so observations of natural silicate glasses may be very informative if waste disposal glasses are similarly reactive. A review of the data for natural silicate glasses suggests that (Zielinski 1980);

1. The breakdown of glass in the total absence of water is too slow to be of concern for the periods of time required $(10,000$ years) for safe waste disposal.

2. Contact between glass and a hot aqueous phase greatly accelerates all processes of glass destruction. Glass hydration and dissolution rates become fast enough that significant alteration of glass can occur in the period required for hazardous radionuclides to decay. For example, experimental studies and observations of devitrification rinds in dated hydrated glasses indicate that devitrification is greatly catalyzed by water but is still on the order of 2-3 $\mu$ per 100 million years at $20^{\circ} \mathrm{C}$.

3. Other environmental parameters that can influence the rate of glass/water interaction, but to a lesser extent than temperature, include solution $\mathrm{pH}$ (highly acid or alkalinel, solid surface area and composition, solution Eh, salinity and the presence of complexing agents.

\section{Novel Methods}

A Japanese patent describes a process for vitrifying radioactive wastes containing sodium compounds $\left(\mathrm{NaOH}, \mathrm{Na}_{2} \mathrm{O}, \mathrm{Na}_{2} \mathrm{CO}_{3}\right.$ and/or $\left.\mathrm{NaNO}_{3}\right)$. In the process, radioactive zircaloy waste (e.g., spent cladding) is oxidized to form $\mathrm{ZrO}_{2}$. A glass forming material is then mixed with $5-20$ wt $\%$ of the $\mathrm{ZrO}_{2}$ and up to $30 \mathrm{wt} \%$ of the waste sodium compounds. The mixture is heated to $1100-1500{ }^{\circ} \mathrm{C}$ and cooled to solidity. The product is reported to be a highly stable vitreous solid from which the sodium compounds do not leach (Patent 1986).

\section{Silicon Titanate glas}

An Italian patent has been published which describes a process for encapsulating radioactive waste in silicon titanate glass. The silicon titanate glass was developed specifically for encapsulating radioactive wastes which contain high percentages of alkaline metal oxides ( $20-40 \%$ by weight) while maintaining high durability and being in a form suitable for final disposal. 
The silicon titanate glass is prepared by adding silicon anhydride and titanium dioxide to melted salts or solutions containing active fission products. Any water present is evaporated, the mixture is then calcined at $800-850^{\circ} \mathrm{C}$, and melting takes place between 900 and $1200^{\circ} \mathrm{C}$. The molten mass is rapidly cooled to obtain an insoluble and tough vitreous solid.

For example, a glass of the following composition by weight:

\begin{tabular}{ll} 
& \multicolumn{2}{c}{$\%$} \\
$\mathrm{Fe}_{2} \mathrm{O}_{3}$ & 8.95 \\
$\mathrm{Cr}_{2} \mathrm{O}_{3}$ & 0.46 \\
$\mathrm{NiO}$ & 0.19 \\
$\mathrm{Cs}{ }_{2} \mathrm{O}$ & 1.48 \\
$\mathrm{SrO}$ & 0.41 \\
$\mathrm{BaO}$ & 0.76 \\
$\mathrm{RuO}_{2}$ & 1.07 \\
$\mathrm{Re}_{2} \mathrm{O}_{3}$ & 4.91 Where $\mathrm{Re}=$ rare earth group elements. \\
$\mathrm{MOO}_{3}$ & 2.36 \\
$\mathrm{ZrO}_{2}$ & 2.02 \\
$\mathrm{Na}_{2} \mathrm{O}$ & 23.85 \\
$\mathrm{SiO}_{2}$ & 21.50 \\
$\mathrm{TiO}_{2}$ & 32.01
\end{tabular}

was found to have undergone a weight loss of $0.41 \%$ over 24 hours at $95^{\circ} \mathrm{C}$, and a leaching factor of $4.17 \times 10^{-8} \mathrm{~g} / \mathrm{cm}^{2} /$ day for 10 days at $250^{\circ} \mathrm{C}$. The volume reduction factor (i.e, the ratio between the initial volume of the solution and the final volume of the resulting glass) was about 7 (Brambilla Patent).

The silicon titanate glass was found to be more durable than borosilicates for encapsulating radioactive solutions rich in alkaline metals.

\section{Lead Iron Phosphate Glasses}

An excellent summary of lead iron phosphate (LIP) glasses has been published which discusses both their physical and chemical properties (Lutze et al 1988). To date their use has only been considered for the encapsulation of HLW and their ability to incorporate high levels of sodium is not known; this would have to be explored experimentally.

The lead iron phosphate nuclear waste glasses were discovered in 1984 . These glasses, like many of the phosphate glasses, are corrosion resistant in aqueous solution at temperatures below $100^{\circ} \mathrm{C}$ and they can be melted and poured at temperatures that are relatively lower than those of silicate glass compositions. They do not, however, suffer from devitrification during cooling, and are much less corrosive than sodium phosphate melts and can thus be processed in crucibles made from a variety of materials.

A number of LIP glasses have been investigated and evaluated. Compositions of the glasses are given in Tables 2.1-17 to 2.1-19. Waste loadings were typically $6.5-16 \mathrm{wt} \%$. Because of the high density of these glasses however, these concentrations give essentially the same waste per volume loading as found in most borosilicate waste glasses. 
Durability tests undertaken on both defense and commercial waste loaded glasses have indicated that the net release of elements from the LIP glass was at least 100 to 1000 times smaller (See. Figures 2.1-15 and 2.1-16) than the corresponding release from a borosilicate glass. Thus, they appear to be very resistant to water corrosion when the solution temperature is below about $150^{\circ} \mathrm{C}$. Above $150^{\circ} \mathrm{C}$ the corrosion rate increases rapidly due to phosphoric acid formation.

One of the biggest advantages of the LIP glass is its low pouring temperature. (High processing temperatures will increase the volatilization rate of the low melting point elements such as iodine, cesium and lead. Handling these elements in an off-gas system could be difficult). Experiments have shown that pouring is easily achievable with temperatures as low as $800^{\circ} \mathrm{C}$. However, processing temperatures quoted as being 100 to $250^{\circ} \mathrm{C}$ lower than the temperature required for a borosilicate glass $\left(1150^{\circ} \mathrm{C}\right.$ stated), could be misleading. Internal melter temperatures on the Full Scale Inactive Facility (FSIF) and at Windscale Vitrification Plant (WVP) of the order of $1030-1050^{\circ} \mathrm{C}$ have been shown to be satisfactory in the processing of HLW glass at flowsheet composition while using a borosilicate base glass. A disadvantage of this process for vitrifying HLW is the lack of pilot scale data. All experiments to date appear to have been conducted under laboratory conditions. Melter crucible construction materials are also limited at this stage of development - stabilized zirconium, platinum or alumina.

\subsubsection{Methodology to Evaluate Options}

The two prefered glasses for vitrifying Hanford LLW are soda lime silicate and alkali borosilicate after evaluation against performance criteria. The performance criteria that were chosen for the assessment were:

- Waste incorporation level

- Thermal expansion of glass

- Durability of glass

- Radiation stability of glass

- Crystalization

Both glass systems exhibit reasonably good durability which may be further improved by the addition of key elements such as alumina, magnesium, etc. Durability will improve with lower levels of sodium. However, as the Hanford LLW contains a high proportion of sodium, a compromise must be reached between durability (the key parameter) and waste incorporation levels. It would be possible to make a very durable soda lime silicate glass with very low levels of sodium but the volumes of glass produced would be excessive and would not be consistant with the policy of volume reduction. The durability of a borosilicate glass is likely to be better than that of soda lime silicate glass but its sodium content may be limited to $\sim 5 \%$.

The thermal expansion properties of the glass will be important, especially if the glass is cast into large blocks. The thermal expantion of borosilicate glass is less than that of soda lime silicate and so a borosilicate glass would be favoured for the casting of glass monoliths. 
It is worth noting that the presence of $\mathrm{B}_{2} \mathrm{O}_{3}$ in the borosilicate system is not an essential requirement for the Hanford waste because the waste is not heat-generating and because it is not required for aiding the incorporation of molybdenum (which is only present in minute quantities). The presence of $\mathrm{B}_{2} \mathrm{O}_{3}$ allows processing at lower temperatures. Also, with alkali borosilicates, treatment below the liquidus temperature (i.e, during cooling) may lead to some phase separation. In this case the high alkali phase formed could be more easily leached. However, crystalization in a glass may not necessarily impair the glass's overall performance. Results from the Sellafield (UK) HLW vitrification development programe carried out by BNFL PIc have shown that crystalization induced by heat treatments in a "MAGNOX" waste glass does not significantly alter durability. Crystallization is very unlikly to occur in a glass whose temperature is below its glass transition temperature because the glass is too viscous for molecular rearrangments to occure.

Radiation stability is of limited importance for LLW but borosilicates have been shown to be stable to radiation and are currently used to vitrify HLW.

For soda lime silica and borosilicate glasses the performance criteria have been ranked, as an aid to selecting the most suitable glass for vitrifying Hanford LLW. The results are given below for glasses which do not contain aluminum or other elements which could be added to improve durability.

An option ranking table was made with the options scored from 1 to 5 . A high score is best.

\begin{tabular}{||l|c|c|c|c||}
\hline & Information & Score & Information & Score \\
\hline Incorporation (Na \%) & $15 \%$ & 5 & $5 \%$ & 1 \\
\hline Thermal Expansion & $\sim 95 \times 10^{-7}$ & 2 & $-33 \times 10^{-7}$ & 5 \\
\hline Durability & LESS & 2 & MORE & 4 \\
\hline Radiation Stability & & 3 & & 4 \\
\hline Crystallization & & 3 & & 4 \\
\hline Total & & 15 & & 18 \\
\hline
\end{tabular}

As given in the table, a borosilicate glass is the prefered option.

\subsubsection{Observations, Conclusions and Recommendations}

2.1.4.1 Observations and Conclusions. The glass formulations which appear most suitable for use with the Hanford LLW, which has a very high sodium content ( $83 \%$ ), are soda lime silicates with a small percentage of alumina to improve durability and alkali borosilicates. Both systems have been well characterized and exhibit good durability.

However in terms of durability and thermal expansion properties, an alkali borosilicate glass would be the favored option for vitrifying the Hanford LLW. It is also the glass type that has been internationally accepted for the incorporation of radioactive waste. 
There does not appear to be a problem with the stability of these glasses in terms of radiation dose and they are capable of retaining uranium, neptunium and technetium within their matrices. There is no evidence to suggest that these elements would be leached from the glass preferentially. Glasses do not usually contain more than $1 \%$ of iodine as this element has a high vapor pressure and volatilizes from the melt. Most of the iodine present in a waste is usually volatilized following vitrification and will need to be trapped in the off-gas system.

Some alternative glass formulations are available (e.g., silicon titanates and lead iron phosphates), but neither process has been fully developed to plant scale. Their suitability is questionable. It is not known if lead iron phosphates are suitable for vitrifying high sodium wastes because no work has been carried out in this area.

Finally, it is very difficult to compare leaching/durability results for different waste forms which have been obtained using different test methods.

2.1.4.2 Recommendations. The following recommendations are made:

- The literature search should be expanded. This review was limited due to time constraints.

- Experimental work should be carried out with simulated Hanford LLW to verify the predicted durability of the selected glass formulations.

- $\quad$ Studies on the glass composition and product geometry should be linked with the requirements/flowsheet for an actual glass-making process. 
Fig. 2.1-1

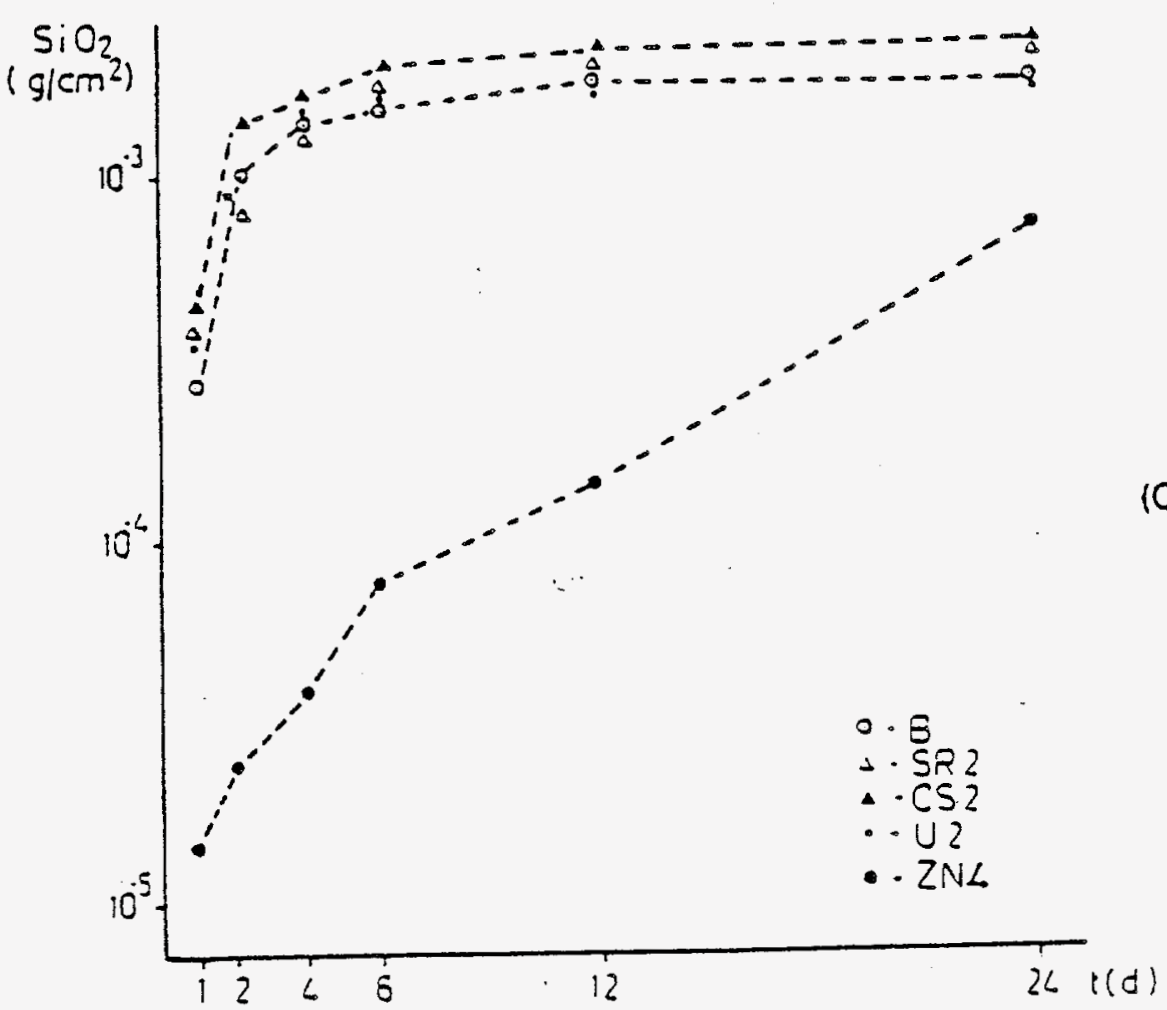

Amount of $\mathrm{SiO}_{2}$ leached out during the experiments by the five glasses.

Fig. 2.1-2

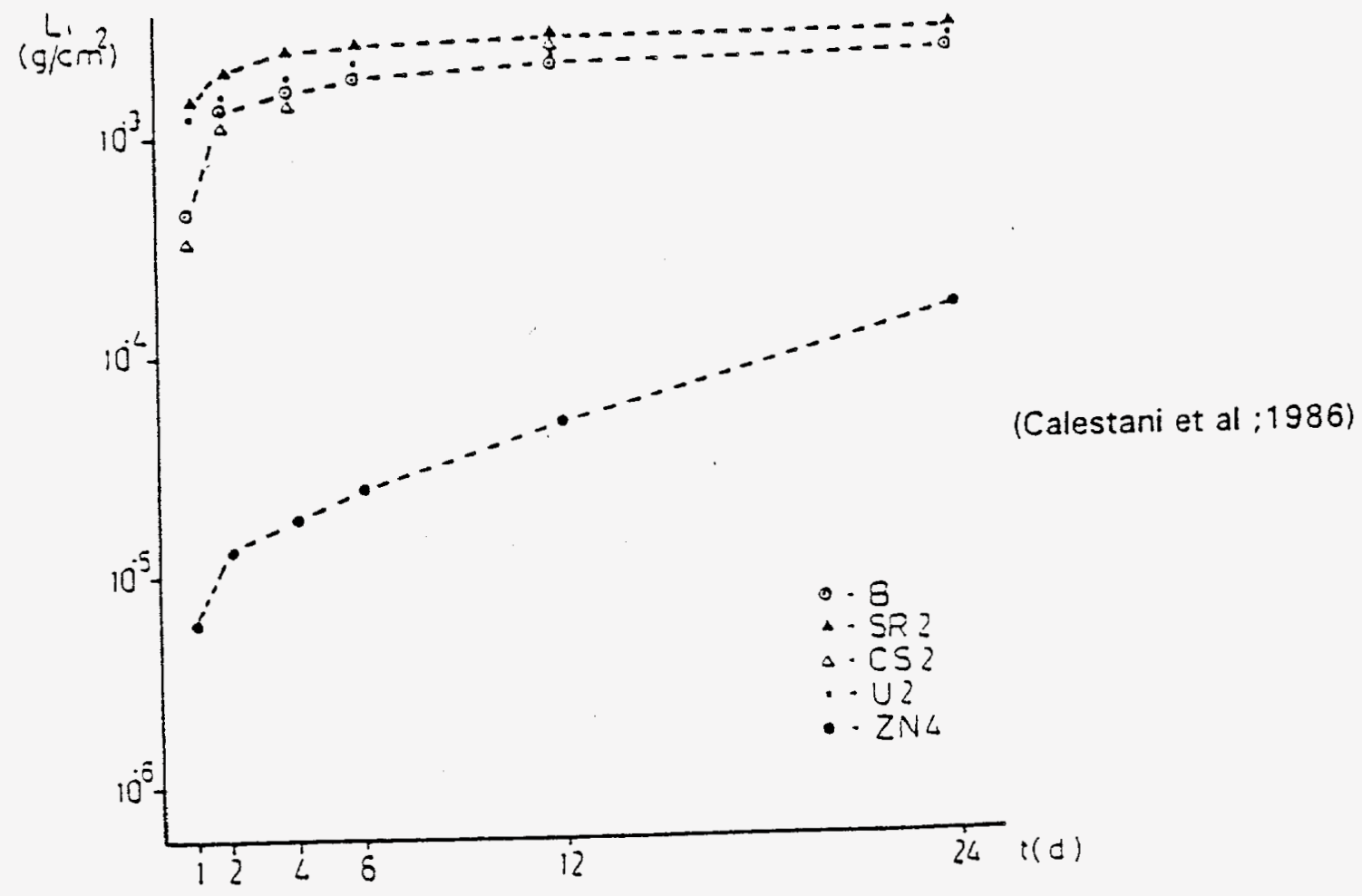

Amount of $\mathrm{Li}$ leached out. 
Fig. 2.1-3

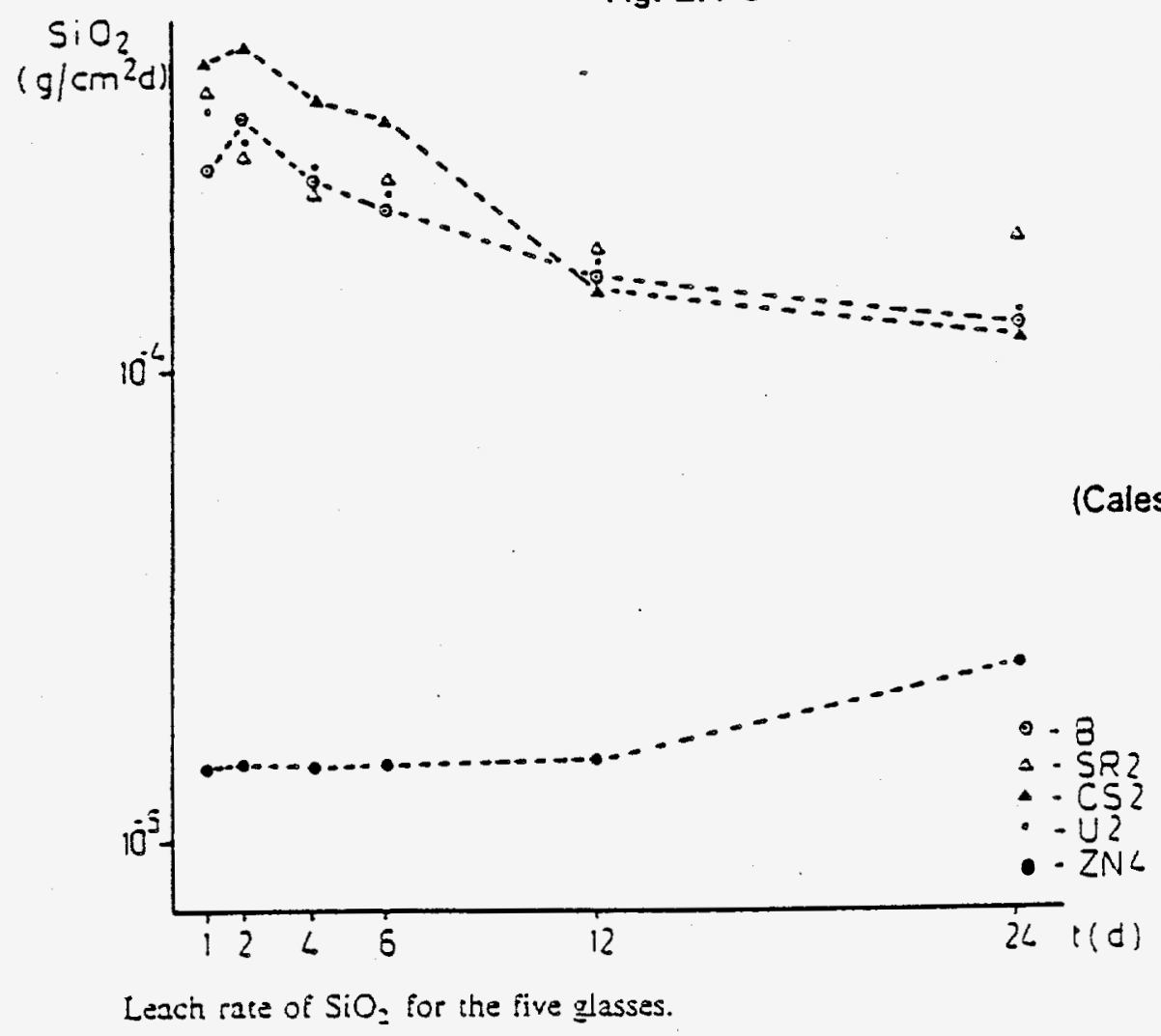

Fig. 2.1-4

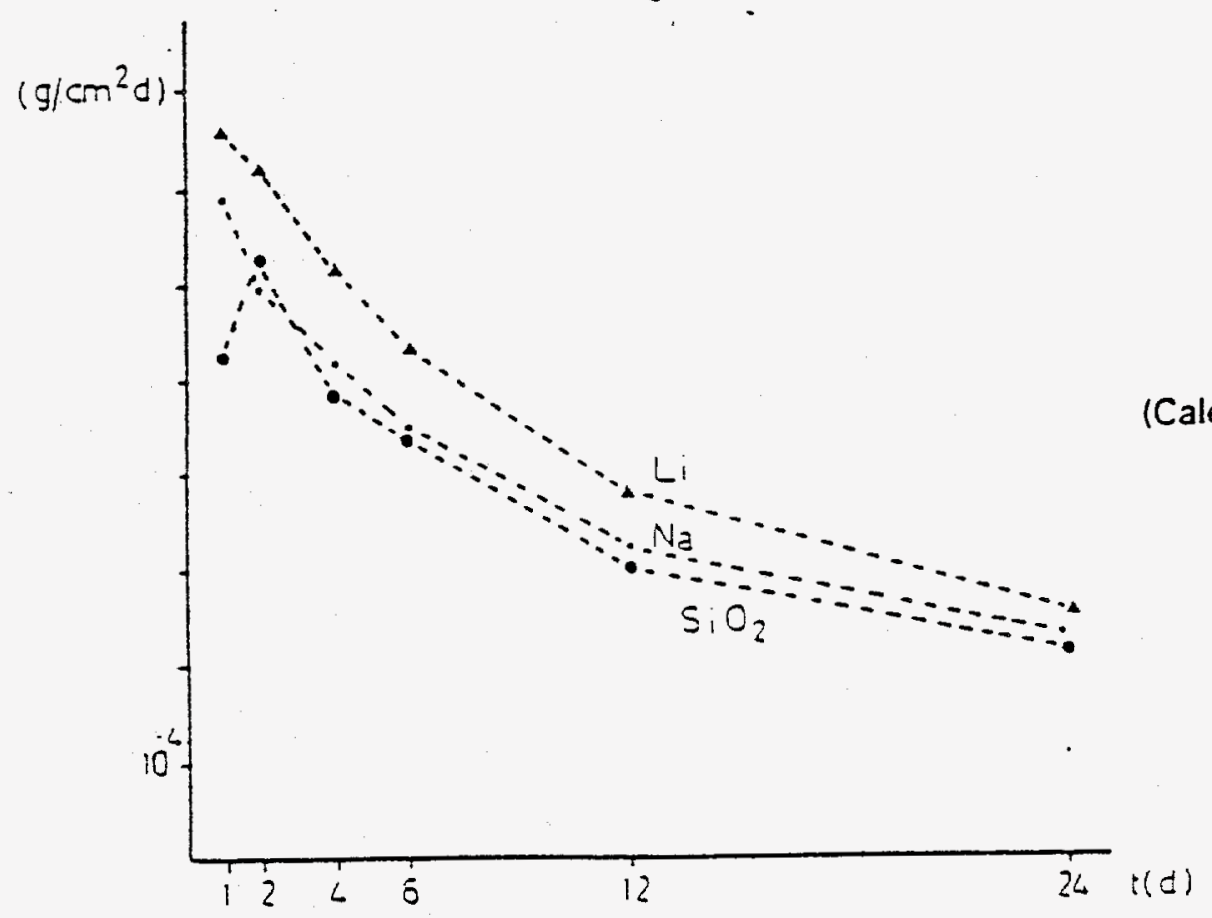

Leach rate of various ions for base glass $\mathrm{B}$. 
Fig. 2.1-5

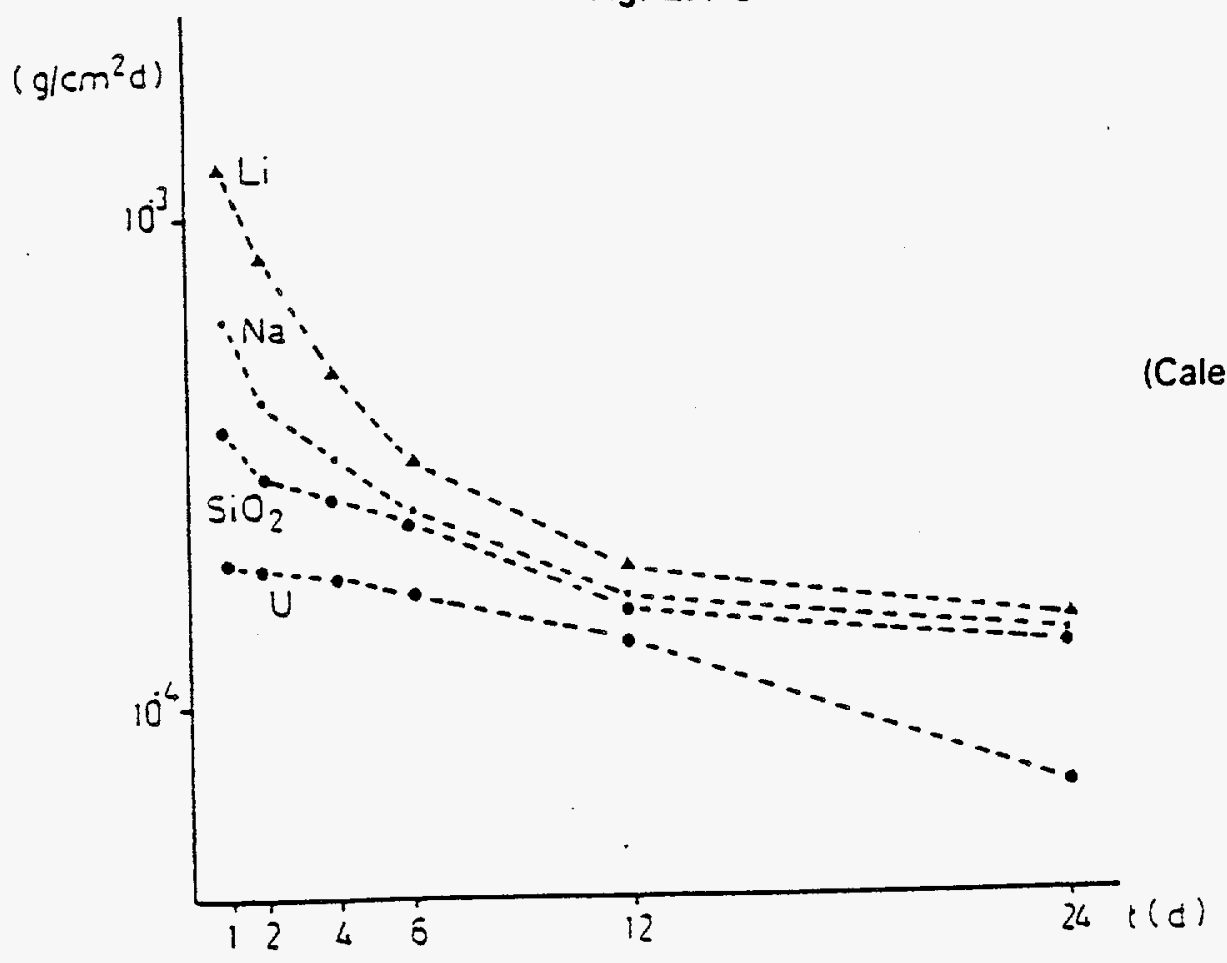

Leach rate of various ions for U2 glass.

Fig. 2.1-6

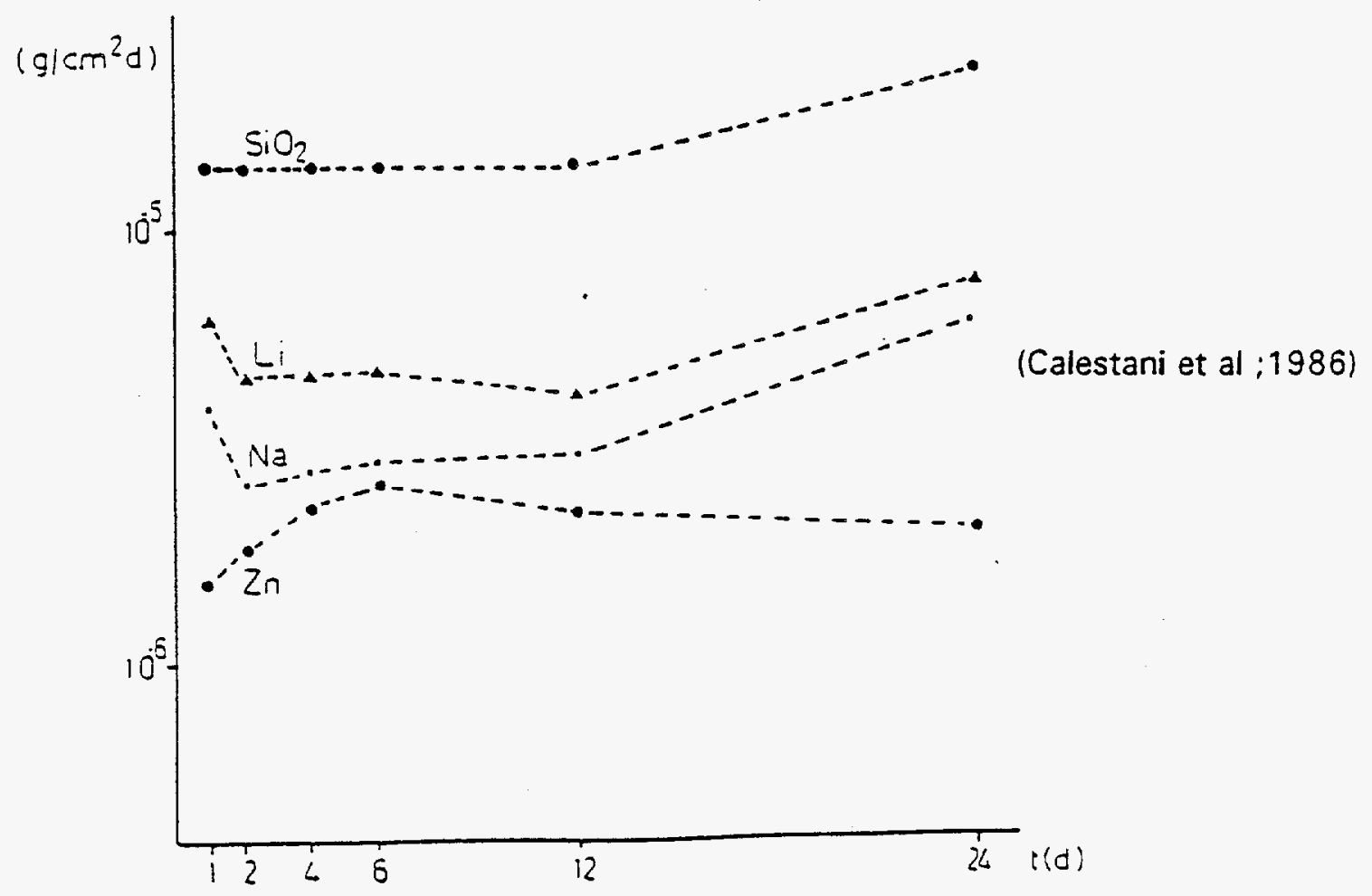

Leach race of various ions for ZN4 glass. 

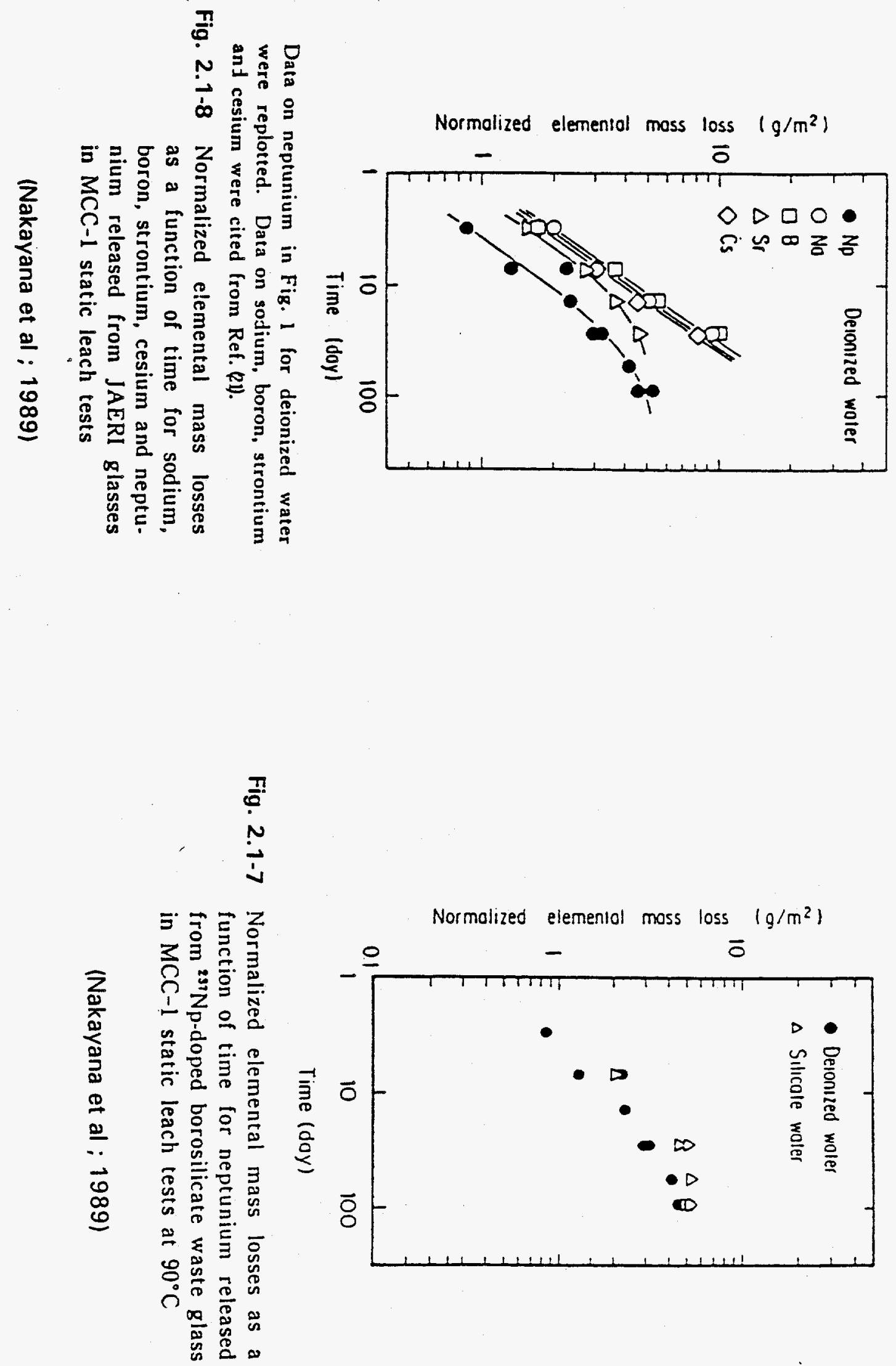


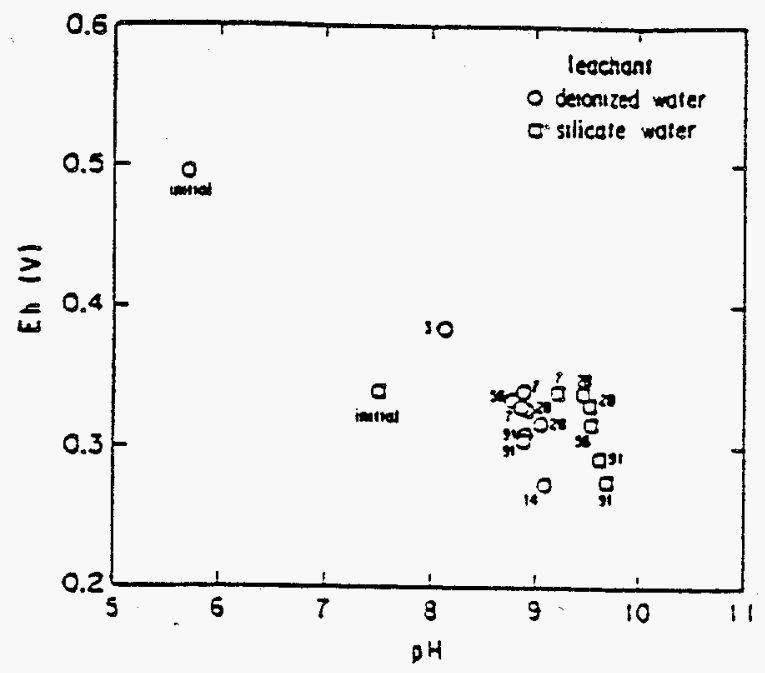

Numbers next to the points denote the leach durations. The "initial"s denote the values for leachants.

Fig. 2.1-9 Measured $\mathrm{pH}$ and En values of glass leachates

(Nakayana et al ; 1989)

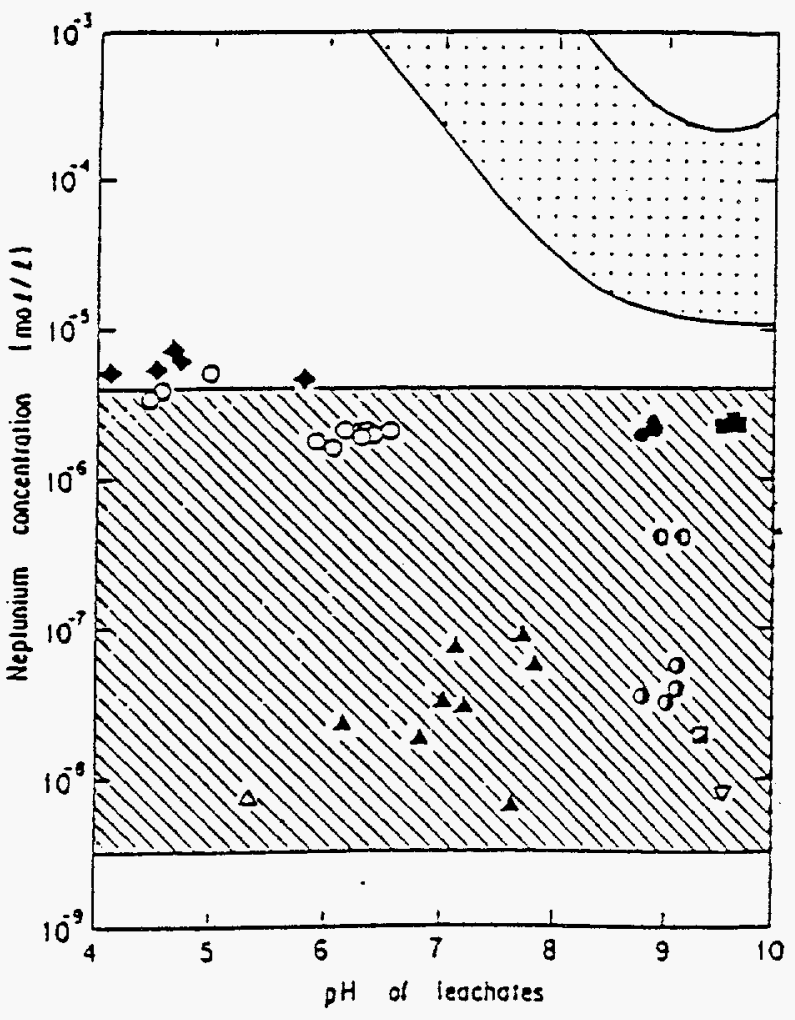

\begin{tabular}{|c|c|c|c|}
\hline leorunium & dissolution frem & glasses & \\
\hline symooi & lecetiont & $\begin{array}{l}\text { leocion } \\
\text { oxation } \\
\text { (coy) }\end{array}$ & Ret \\
\hline 0 & $\begin{array}{l}0.0015 \mathrm{M} \mathrm{CaCl} \\
+-0001 \mathrm{M} \text { ximpdrese }\end{array}$ & $298-302$ & 111 \\
\hline 0 & 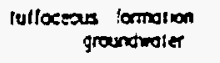 & $90-183$ & (4) \\
\hline 0 & $\begin{array}{c}\text { iulfoceas lamation } \\
\text { qramptriter }\end{array}$ & $36-91$ & (5) \\
\hline$a$ & deionited water & 96 & $(7)$ \\
\hline$\nabla$ & $\begin{array}{l}\text { smithesic rosolf } \\
\text { sraundwaier }\end{array}$ & sô & 171 \\
\hline$\Delta$ & $\begin{array}{l}\text { sminetic Permon } \\
\text { Zasin brine }\end{array}$ & 56 & $\{i \mid$ \\
\hline$\Delta$ & $\begin{array}{l}\text { Junthetic Perminan } \\
\text { Bosin xise }\end{array}$ & $56-37 i$ & 181 \\
\hline$\bullet$ & $\begin{array}{l}\text { deionized woter } \\
\text { stlicate water }\end{array}$ & $\begin{array}{l}56-91 \\
56-91\end{array}$ & $\begin{array}{l}\text { Thers: } \\
\text { Thus: }\end{array}$ \\
\hline
\end{tabular}

Solubilities of neglunium solid choses

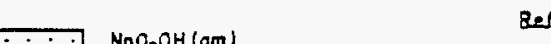
$\therefore$

a): The concentrations of $\mathrm{Np}(\mathrm{OH}),(3 q)$ were calculated based on available data on the solubility produce $K_{s p}\left(\log K_{s p}=-j 4.3\right.$ for ionic strength $I(\mathrm{~mol} / l)=0.0(50)=-53.3$ for $l=0.025-0.04 i^{(5)}$. and $=-51 .+$ for $l=0.3^{(3: 3)}$ and the hydrolysis constant $K(\log K=46)$ for $N_{p}+4 O H^{*}=N p(O E)$ iss.

Fig. 2.1-10 Neptunium concentrations in glass leachates obtained from MCC-1-type static leach tests for durations of 50 d or longer, and expecred solubilities of $\mathrm{NpO}_{2} \cdot x \mathrm{H}_{3} \mathrm{O}(\mathrm{am})$ and $\mathrm{NpO}_{3} \mathrm{OH}(\mathrm{am})$ based on : hermodynamic daca 

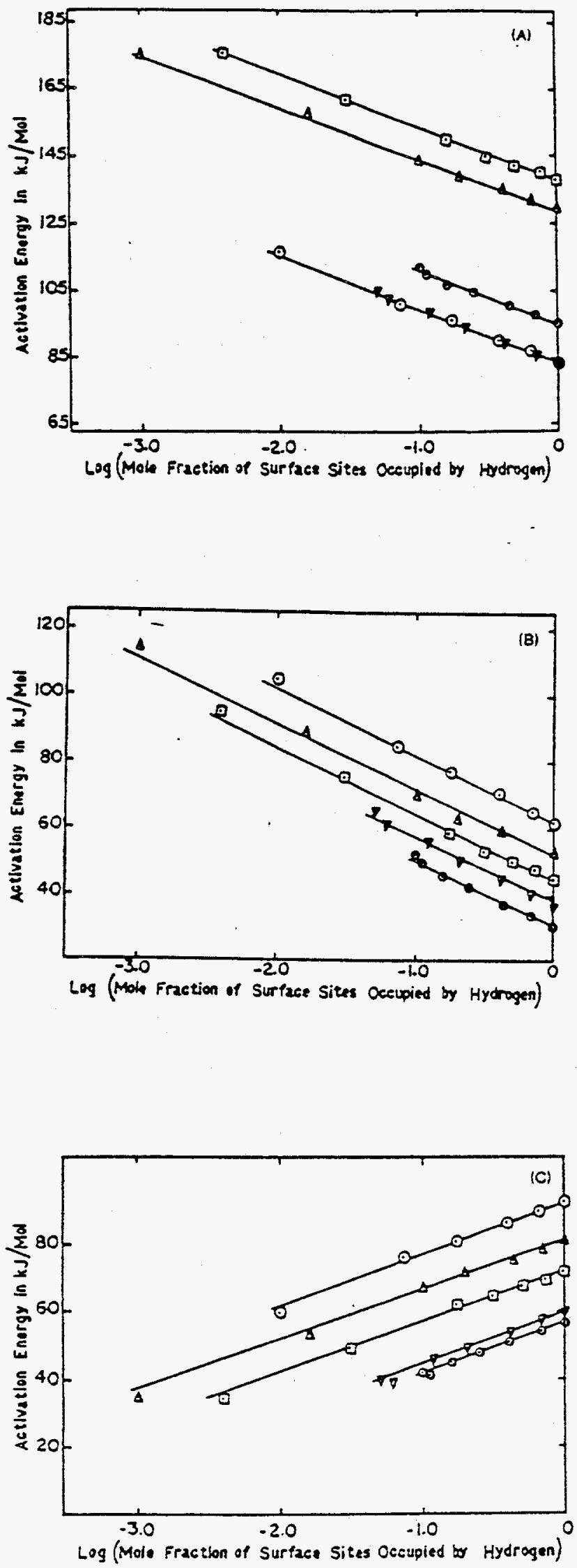

Fig. 2.1-11 Activation energies for $(A)$ diffusion. (B) alkali extraction. and $(O$ SiO: extraction vs log (mole fraction of surface sites occupied bv hudrogen) for glasses $(\odot) S_{1},(\Delta) A l_{1},(E) A l_{1}(\nabla) Z_{r_{1}}$ and (ब) $\mathrm{Zr}_{r}$ 


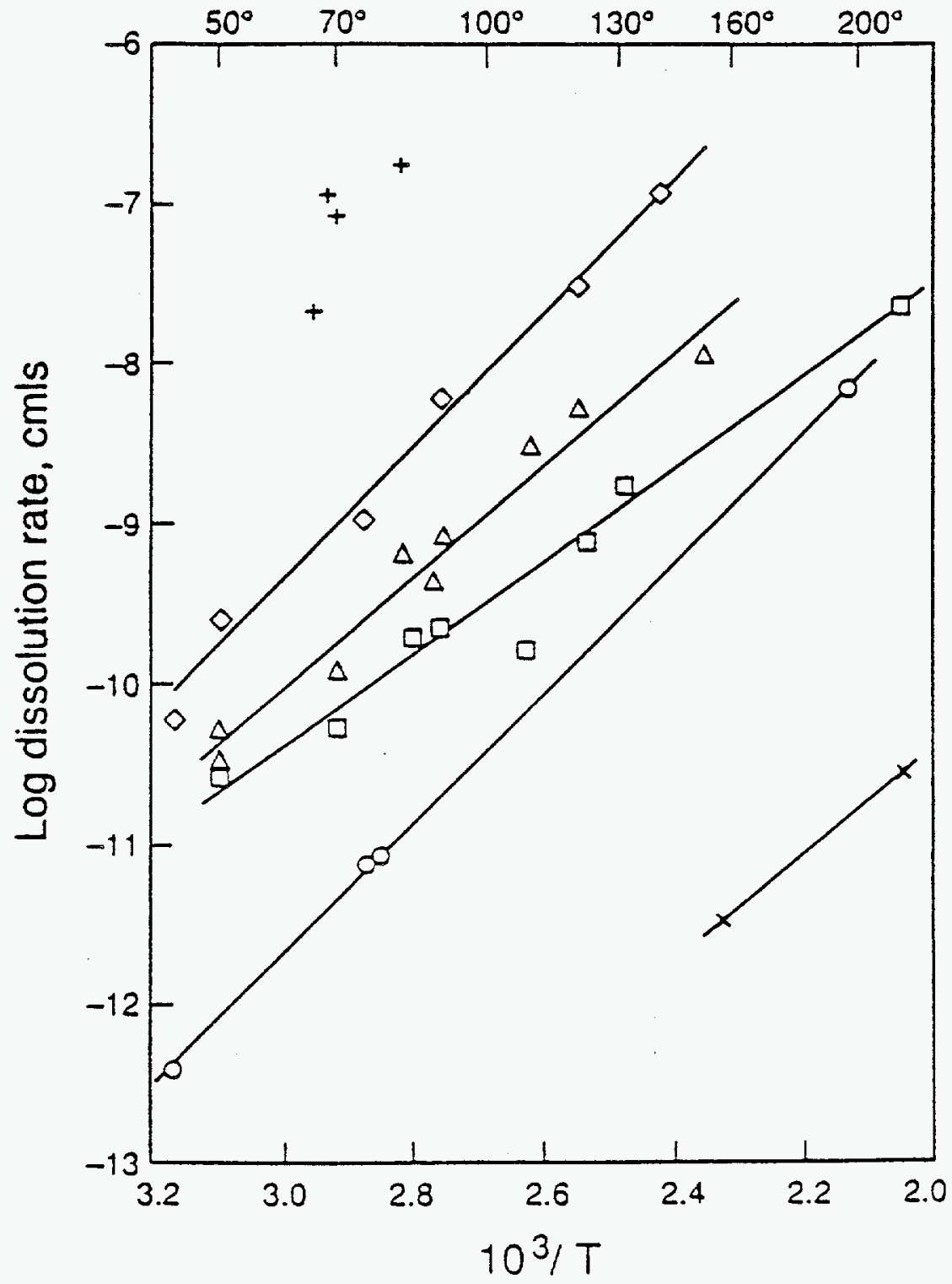

Fig. 2.1-12 Logarithm of dissolution rates as a function of reciprocal temperature for different silicate glasses (Table I) at $\mathrm{pH} 7$ :

$(+)$ sodium trisilicate; $(\diamond) 015$ soda-lime; $(\Delta)$ PPG soda-lime;

$(\square)$ Pyrex borosilicate; (O) R6 soda-lime, and ( $x$ ) obsidian.

(Perrara et al ; 1991) 


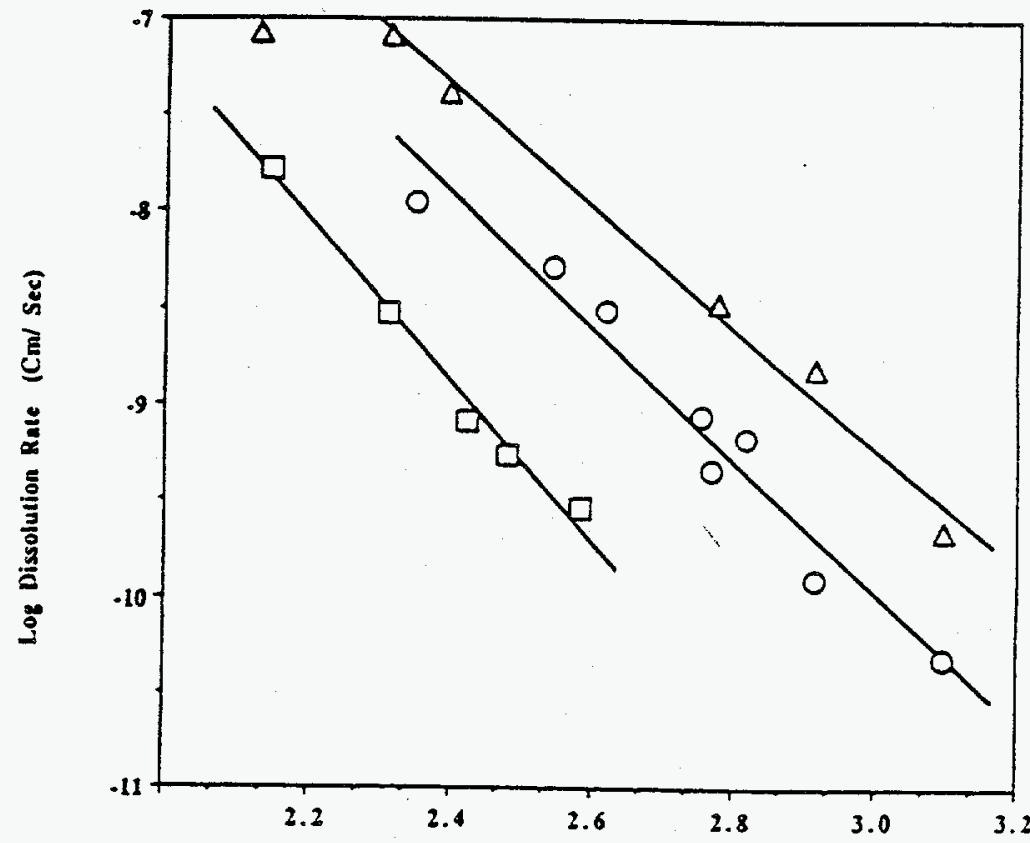

Fig. 2.1-13

$1000 / T(K)$

$\mathrm{pH}: 04,07,0 \mathrm{garithms}$ of dissolution rates $y$ of commercial soda-lime glass $F$ as a function of reciprocal temperature in solutions of different

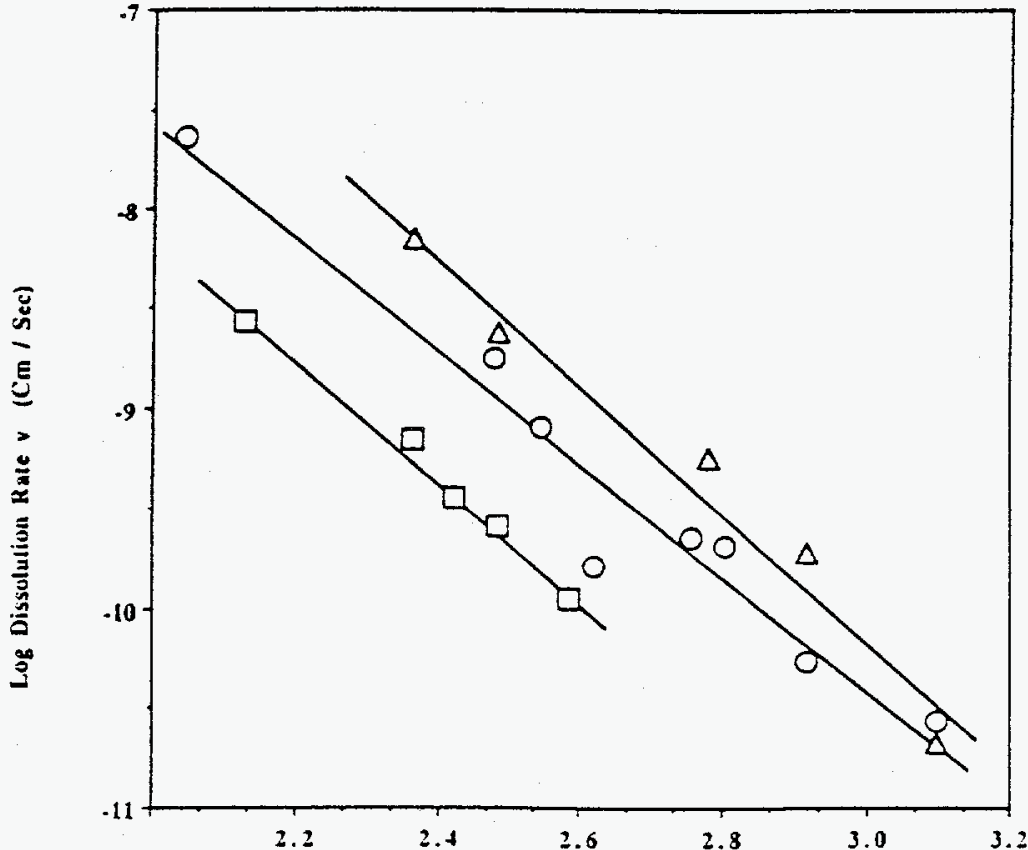

Fig. 2.1-14

$1000 / \mathrm{T}(\mathrm{K})$

Logarithm of dissolution rates $v$ of Pyrex borosilicate glass $P$ as a function of reciprocal temperature in solutions of different pH: $\square$ 4, $07 . \Delta 9$. 


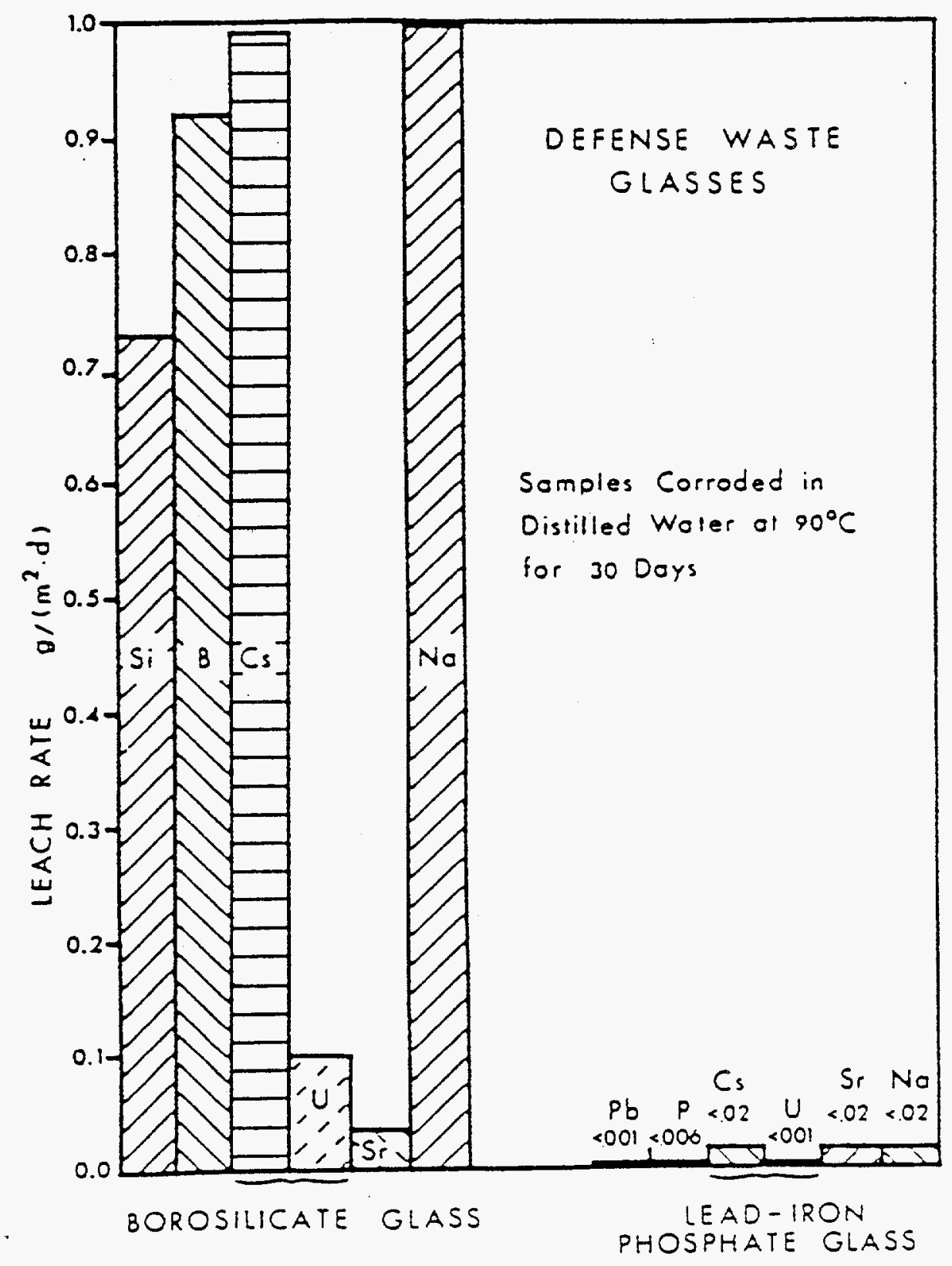

Fig. 2.1-15a

The 30 d corrosion rates at $90^{\circ} \mathrm{C}$ in distilled water for a lead-iron phosphate (glass $\$ 1 . D$ ) and a horosilicute (Frit $131 \div 29$ wt", of waste composition DI) nuclear waste glass louded with simulated defensc waste. The concentrations of all elements present in the lead-iron phosphate leachate were helow the detectability limits of standurd analytical chemical rechniques. Lead-iron phosphale and horosilicate nuclear wasie glasses had the same waste-per-rolume loading.

(Lutze et al ; 1988) 
Final

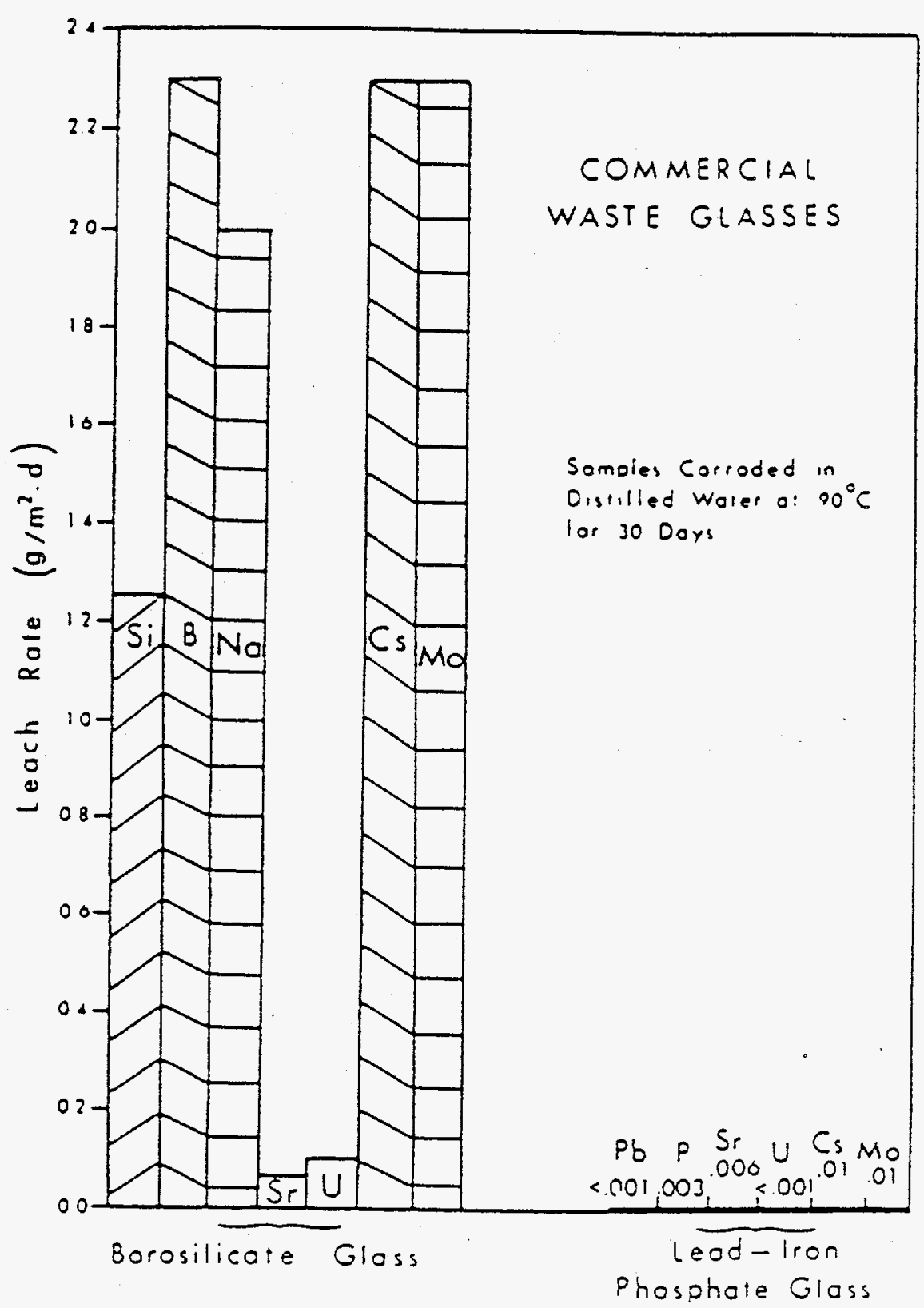

Fig. 2.1-15b

The $30 \mathrm{~d}$ corrosion rates at $90^{\circ} \mathrm{C}$ in distilled water for a lead-iron phosphate glass ( $\neq 1-\mathrm{C}$ ) (Schiewer el al. 1986) and a borosilicate glass (PNL 76-78) (Strachan et al. 1981) loaded with simulated commercial waste.

(Lutze et al ; 1988) 


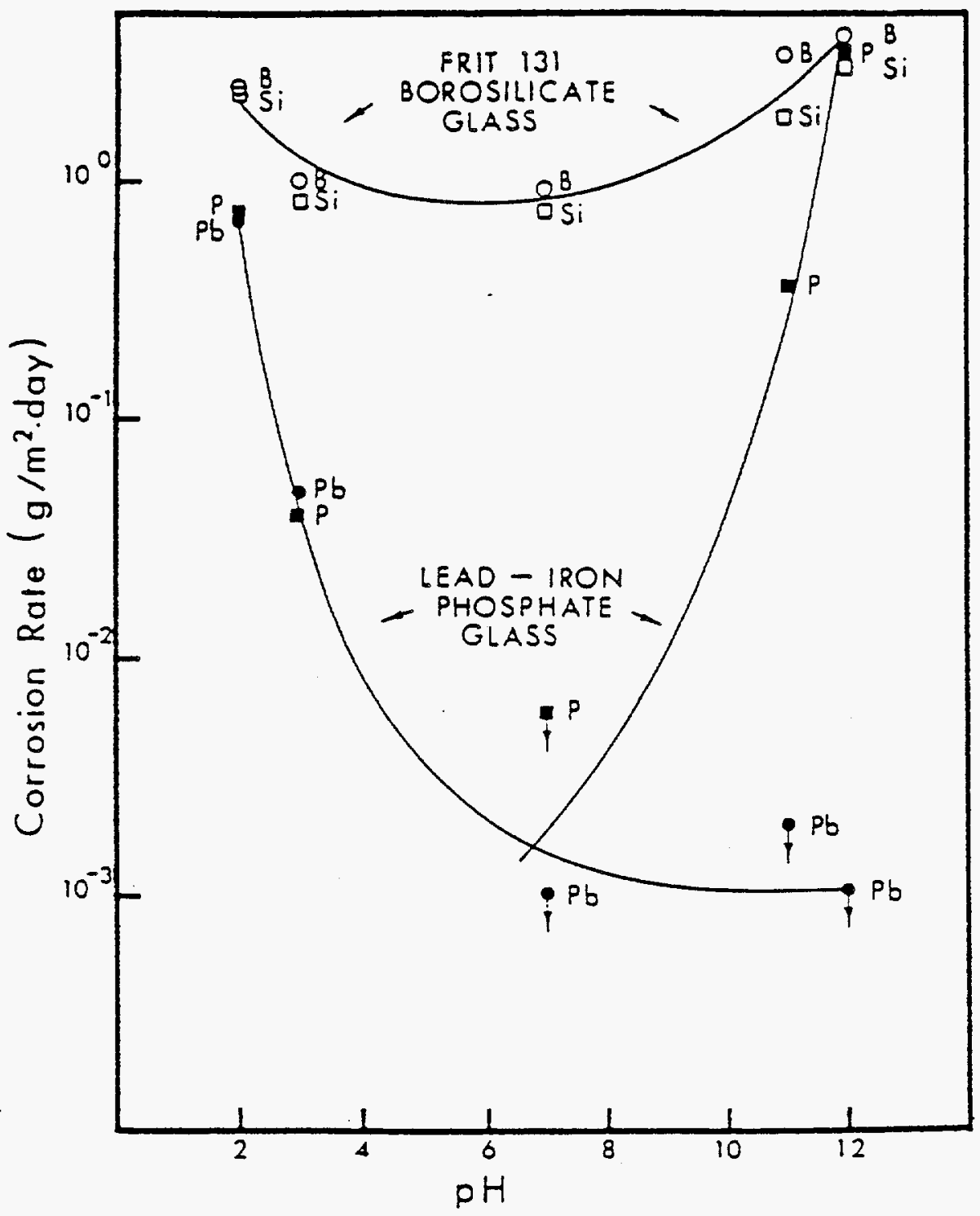

Fig. 2.1-16

The 30 ) corrosion rates of lead-iron phosphate (\$-D) and borosilicate (Frit $131+29$ wi"is of waste composition DI) nuclear waste glasses at $90^{\circ} \mathrm{C}$ as a function of the solution $\mathrm{pH}$. The solution $\mathrm{pH}$ was varied hy adding the appropriate amounts of either hydrochloric acid (HCl) or sodium hydroxide ( $\mathrm{NaOH}$ lo distilled water. No buliering agent was used, and the $\mathrm{pH}$ value quoled refers to the initial $\mathrm{pH}$ of the corroding solution. For clarity, the corrosion rates of only the major constituents of each glass are shown.

(Lutze et al ; 1988) 


\section{Anticipated composition of the Hanford Waste \\ (From WHC-SD-WM-EE-004 Rev 0. page 2.52)}

(See table 2 for Radionuclide inventory)

Table 2.1-1

Waste

Component:

Chemicals

Ag

A]

As

B

$\mathrm{Ba}$

$\mathrm{Be}$

$\mathrm{Bi}$

$\mathrm{Ca}$

$\mathrm{Cd}$

$\mathrm{Ce}$

$\mathrm{Cr}$

$\mathrm{Cu}$

$\mathrm{Fe}$

$\mathrm{Hg}$

K

La

$\mathrm{Li}$

$\mathrm{Mg}$

Mn

Mo

$\mathrm{Na}$

Nd

$\mathrm{Ni}$

$P$

$\mathrm{Pb}$

$\mathrm{Sb}$

$\mathrm{Se}$

Si
Total Feed:

Concentration $\left(\mathrm{MD}^{(\mathbf{a})}\right.$

$6.48 \times 10^{-5}$

$4.48 \times 10^{-1}$

$1.99 \times 10^{-4}$

$3.37 \times 10^{-3}$

$8.22 \times 10^{-5}$

$1.78 \times 10^{-3}$

$3.13 \times 10^{4}$

$3.87 \times 10^{-3}$

$1.12 \times 10^{-4}$

$1.44 \times 10^{-4}$

$1.18 \times 10^{-2}$

$2.79 \times 10^{-4}$

$1.01 \times 10^{-2}$

$5.49 \times 10^{-6}$

$2.00 \times 10^{-1}$

$1.15 \times 10^{-4}$

$6.81 \times 10^{-5}$

$2.83 \times 10^{-3}$

$3.66 \times 10^{-3}$

$6.40 \times 10^{-4}$

5.50

$1.20 \times 10^{-4}$

$1.26 \times 10^{-3}$

$4.98 \times 10^{-2}$

$3.27 \times 10^{-4}$

$6.86 \times 10^{-4}$

$3.95 \times 10^{-4}$

$6.08 \times 10^{-3}$
Total

Inventory:

$(\mathrm{kg})^{(b)}$

$8.53 \times 10^{2}$

$1.47 \times 10^{6}$

$1.82 \times 10^{3}$

$4.44 \times 10^{3}$

$1.38 \times 10^{3}$

$1.96 \times 10^{3}$

$7.98 \times 10^{3}$

$1.89 \times 10^{4}$

$1.54 \times 10^{3}$

$2.46 \times 10^{3}$

$7.49 \times 10^{4}$

$2.16 \times 10^{3}$

$6.88 \times 10^{4}$

$1.34 \times 10^{2}$

$9.54 \times 10^{5}$

$1.95 \times 10^{3}$

$5.77 \times 10^{1}$

$8.39 \times 10^{3}$

$2.45 \times 10^{4}$

$7.49 \times 10^{3}$

$1.54 \times 10^{7}$

$2.11 \times 10^{3}$

$9.02 \times 10^{3}$

$1.88 \times 10^{5}$

$8.27 \times 10^{3}$

$1.02 \times 10^{4}$

$3.81 \times 10^{3}$

$2.08 \times 10^{4}$
Molecular Weight

(g/mol)

107.868

26.9815

74.9216

10.81

137.33

9.0122

208.98

40.08

112.41

140.12

51.996

63.546

55.847

200.59

39.0983

138.906

6.941

24.305

54.938

95.94

22.9898

144.24

58.70

30.9738

207.2

121.75

78.96

28.0855

continued 


\section{Anticipated composition of the Hanford Waste (From WHC-SD-WM-EE-004 Rev 0. page 2.52) \\ (See table 2 for Radionuclide inventory)}

Table 2.1-1 Continued

Waste

Component:

Chemicals

$\mathrm{Ta}$

Ti

V

W

$\mathrm{Zn}$

$\mathrm{Zr}$

$\mathrm{CN}^{-}$

$\mathrm{NH}_{3}$

$\mathrm{CO}_{3}^{-2}$

$\mathrm{Cl}$

$\mathrm{F}$

$\mathrm{SO}_{4}^{-2}$

$\mathrm{NO}_{3}$ -

$\mathrm{NO}_{2}$

$\mathrm{PO}_{4}{ }^{-3}$

$\mathrm{OH}^{-}$
Total Feed:

Concentration $\left(\mathrm{M}^{(2)}\right.$

$1.36 \times 10^{-5}$

$9.55 \times 10^{-5}$

$3.14 \times 10^{-4}$

$1.13 \times 10^{-3}$

$1.03 \times 10^{-3}$

$2.56 \times 10^{-2}$

$4.01 \times 10^{-4}$

$1.21 \times 10^{-2}$

$1.11 \times 10^{-1}$

$8.48 \times 10^{-2}$

$7.14 \times 10^{-1}$

$7.16 \times 10^{-2}$

2.74

$5.04 \times 10^{-1}$

$3.07 \times 10^{-2}$

1.15
Total Inventory:

$(\mathrm{kg})^{(\mathfrak{b})}$

$3.00 \times 10^{2}$

$5.58 \times 10^{2}$

$1.95 \times 10^{3}$

$2.53 \times 10^{4}$

$8.22 \times 10^{3}$

$2.85 \times 10^{5}$

$1.27 \times 10^{3}$

$2.51 \times 10^{-4}$

$8.13 \times 10^{5}$

$3.67 \times 10^{5}$

$1.65 \times 10^{6}$

$8.39 \times 10^{5}$

$2.07 \times 10^{7}$

$2.83 \times 10^{6}$

$3.56 \times 10^{5}$

$2.39 \times 10^{6}$
Molecular Weight ( $\mathrm{g} / \mathrm{mol})$

180.948

47.90

50.9415

183.85

65.38

91.22

26.0177

17.0304

60.0092

35.453

18.9984

96.0576

62.0049

46.0055

94.9714

17.0073 


\section{Anticipated Radionuclide Composition of the Hanford Waste for Disposal Via Low Level Waste Vitrification}

(source DSI Bolt to Karnesky 01/13/94)

Table 2.1-2

The following table lists the current assumed radionuclide amounts going to LLW treatment and the LLW disposal inventory.

The basis used to for these estimates is the Tank Waste Technical Ootions Report, WHC-EP-0616. The uranium isotopic distribution is based on the values determined in Technical Aspects of Lona-Term Management Alternatives for HighLevel Defense Waste at the Hanford Site, RHO-LD-141. Since these bases are currently under review, the data prosented here may change in the future.

\begin{tabular}{|c|c|c|c|}
\hline Radionuclide & $\begin{array}{c}\text { Curies to LLW } \\
\text { Treatment }\end{array}$ & $\begin{array}{c}\text { Percent Retention } \\
\text { in Glass }\end{array}$ & $\begin{array}{c}\text { Curies in LLW } \\
\text { Glass }\end{array}$ \\
\hline${ }^{14} \mathrm{C}$ & $5.0 E \div 03$ & 1 & $5.0 E \div 01$ \\
\hline${ }^{90} \mathrm{Sr}, \mathrm{Y}$ & $6.0 E \div 06$ & 100 & $6.0 E \div 06$ \\
\hline${ }^{99} \mathrm{TC}$ & $2.4 E \div 04$ & 100 & $2.4 E+04$ \\
\hline${ }^{129} \mathrm{I}$ & $5.1 E+01$ & 10 & $5.1 E+00$ \\
\hline${ }^{137} \mathrm{Cs}, \mathrm{Ba}$ & 1.0E+06 & 100 & $1.0 E \div 06$ \\
\hline $236 \mathrm{U}$ & $3.9 E+01$ & 100 & $3.9 E \div 01$ \\
\hline $235 \mathrm{U}$ & 1. $2 E \div 00$ & 100 & $1.2 E \div 00$ \\
\hline $238 \mathrm{U}$ & $2.8 E \div 01$ & 100 & $2.8 \varepsilon \div 01$ \\
\hline${ }^{237} \mathrm{~Np}$ & $6.2 E+\infty 0$ & 100 & $6.2 E \div 00$ \\
\hline${ }^{239} \mathrm{Pu}$ & $1.6 E+03$ & 100 & $1.6 E+03$ \\
\hline${ }^{260} \mathrm{Pu}$ & 4. $0 E+02$ & 100 & $4.0 E \div 02$ \\
\hline${ }^{261} \mathrm{Am}$ & $8.0 E \div 03$ & 100 & $8.0 E+03$ \\
\hline
\end{tabular}


Table 2.1-3

Candidate Glass compositions

\begin{tabular}{|c|c|c|c|c|}
\hline 3 & Alumino - & Phosphates & Alumino - & borosilicates \\
\hline Composition & Glass 1 & Glass 2 & Glass 3 & Glass 4 \\
\hline $\mathrm{Na}_{2} \mathrm{O}$ & 26.0 & 26.0 & 16.1 & 16.1 \\
\hline $\mathrm{Al}_{2} \mathrm{O}_{3}$ & 24.6 & 15.3 & 16.6 & 16.6 \\
\hline $\mathrm{P}_{2} \mathrm{O}_{5}$ & 49.4 & 49.4 & & \\
\hline $\mathrm{UO}_{2}$ & & 0.3 & & \\
\hline $\mathrm{ZrO}_{2}$ & & 14 & & 0.5 \\
\hline $\mathrm{Cr}_{2} \mathrm{O}_{3}$ & & 1.8 & & \\
\hline $\mathrm{MoO}_{3}$ & & 1.1 & & \\
\hline $\mathrm{Fe}_{2} \mathrm{O}_{3}$ & & 3.6 & & 2.4 \\
\hline $\mathrm{NiO}$ & & 1.1 & & \\
\hline $\mathrm{CaO}$ & & & 17.5 & 1.0 \\
\hline $\mathrm{B}_{2} \mathrm{O}_{3}$ & & & 20.0 & 20.0 \\
\hline $\mathrm{SiO}_{2}$ & & & 29.8 & 29.8 \\
\hline $\mathrm{Cs}_{2} \mathrm{O}$ & & & & 2.1 \\
\hline $\mathrm{MgO}$ & & & & 0.9 \\
\hline Sro & & & & 1.6 \\
\hline $\mathrm{La}_{2} \mathrm{O}_{3}$ & & & & 9.0 \\
\hline
\end{tabular}

( Ivanov et al., 1990) 
Final

Table 2.1-4. Diffusion Coefficients of Actinides and Other Radionuclides in Glasses (Ivanov et al., 1990)

\begin{tabular}{|c|c|c|c|}
\hline $\begin{array}{c}\text { Glass } \\
\text { Number }\end{array}$ & Temperature, $\mathrm{K}$ & Diffusant & $\begin{array}{c}\text { Diffusion } \\
\text { coefficient, m }\end{array}$ \\
\hline \multirow[t]{6}{*}{1} & 673 & ${ }^{22} \mathrm{Na}$ & $1 . \mathrm{OE} 10^{-12}$ \\
\hline & & ${ }^{137} \mathrm{Cs}$ & $2.2 \mathrm{E} 10^{-16}$ \\
\hline & & ${ }^{90} \mathrm{Sr}$ & $7.2 \mathrm{E} 10^{-17}$ \\
\hline & & ${ }^{237} \mathrm{~Np}$ & $2 \mathrm{E} 10^{-18}$ \\
\hline & & ${ }^{239} \mathrm{Pu}$ & $1 \mathrm{E} 10^{-18}$ \\
\hline & & ${ }^{241} \mathrm{Am}$ & $1 \mathrm{E} 10^{-18}$ \\
\hline \multirow[t]{6}{*}{2} & 673 & ${ }^{22} \mathrm{Na}$ & $6.3 \mathrm{E} 10^{-13}$ \\
\hline & & ${ }^{137} \mathrm{Cs}$ & $2 . \mathrm{OE} 10^{-17}$ \\
\hline & & ${ }^{90} \mathrm{Sr}$ & $5.0 \mathrm{E} 10^{-17}$ \\
\hline & & ${ }^{237} \mathrm{~Np}$ & $2 \mathrm{E} 1 \mathrm{O}^{-18}$ \\
\hline & & ${ }^{239} \mathrm{Pu}$ & $2 \mathrm{E} 10^{-18}$ \\
\hline & & ${ }^{241} \mathrm{Am}$ & $1 \mathrm{E} 10^{-18}$ \\
\hline \multirow[t]{6}{*}{3} & 773 & ${ }^{22} \mathrm{Na}$ & $3.8 \mathrm{E} 10^{-11}$ \\
\hline & & ${ }^{137} \mathrm{Cs}$ & $6 \mathrm{E} 10^{-18}$ \\
\hline & & ${ }^{90} \mathrm{Sr}$ & $5 \mathrm{E} 10^{-18}$ \\
\hline & & ${ }^{237} \mathrm{~Np}$ & $-10^{-19}$ \\
\hline & & ${ }^{239} \mathrm{Pu}$ & $-10^{-19}$ \\
\hline & & ${ }^{241} \mathrm{Am}$ & $-10^{-19}$ \\
\hline \multirow[t]{6}{*}{4} & 773 & ${ }^{22} \mathrm{Na}$ & $4.5 \mathrm{E} 10^{-13}$ \\
\hline & & ${ }^{137} \mathrm{Cs}$ & $2 \mathrm{E} 10^{-18}$ \\
\hline & & ${ }^{90} \mathrm{Sr}$ & $3 \mathrm{E} 10^{-18}$ \\
\hline & & ${ }^{237} \mathrm{~Np}$ & $-10^{-19}$ \\
\hline & & ${ }^{239} \mathrm{Pu}$ & $-10^{-19}$ \\
\hline & & ${ }^{241} \mathrm{Am}$ & $-10^{-19}$ \\
\hline
\end{tabular}




\section{Table 2.1-5}

Compositions (wt. $\%$ ) of the glasses studied

\begin{tabular}{lllllllll}
\hline & $\mathrm{SiO}_{2}$ & $\mathrm{~B}_{2} \mathrm{O}_{3}$ & $\mathrm{Li}_{2} \mathrm{O}$ & $\mathrm{Nia}_{2} \mathrm{O}$ & $\mathrm{SrO}$ & $\mathrm{Cs}_{2} \mathrm{O}$ & $\mathrm{U}_{3} \mathrm{O}_{3}$ & $\mathrm{ZnO}$ \\
\hline $\mathrm{B}$ & 55.5 & 29.2 & 5.0 & 10.3 & - & - & - & - \\
$\mathrm{SR} 1$ & 50.4 & 26.6 & 4.5 & 9.4 & 9.1 & - & - & - \\
$\mathrm{SR} 2$ & 46.2 & 24.3 & 4.2 & 3.6 & 16.7 & - & - & - \\
$\mathrm{CS} 1$ & 50.4 & 26.5 & 4.6 & 9.4 & - & 9.1 & - & - \\
$\mathrm{CS} 2$ & 46.2 & 24.3 & 4.2 & 5.6 & - & 16.7 & - & - \\
$\mathrm{U} 1$ & 50.4 & 26.6 & 4.5 & 9.4 & - & - & 9.1 & - \\
$\mathrm{L} 2$ & 46.2 & 24.3 & 4.2 & 8.6 & - & - & 16.7 & - \\
$\mathrm{ZN4}$ & 53.3 & 28.0 & 4.3 & 9.9 & - & - & - & 4.0 \\
\hline
\end{tabular}

(Calestani et al ;1986) 
RETENTION OF NEPTUNIUM

(Nakayana et al ; 1989)

Table 2.1-6 Literature data on release of neptunium from waste glasses

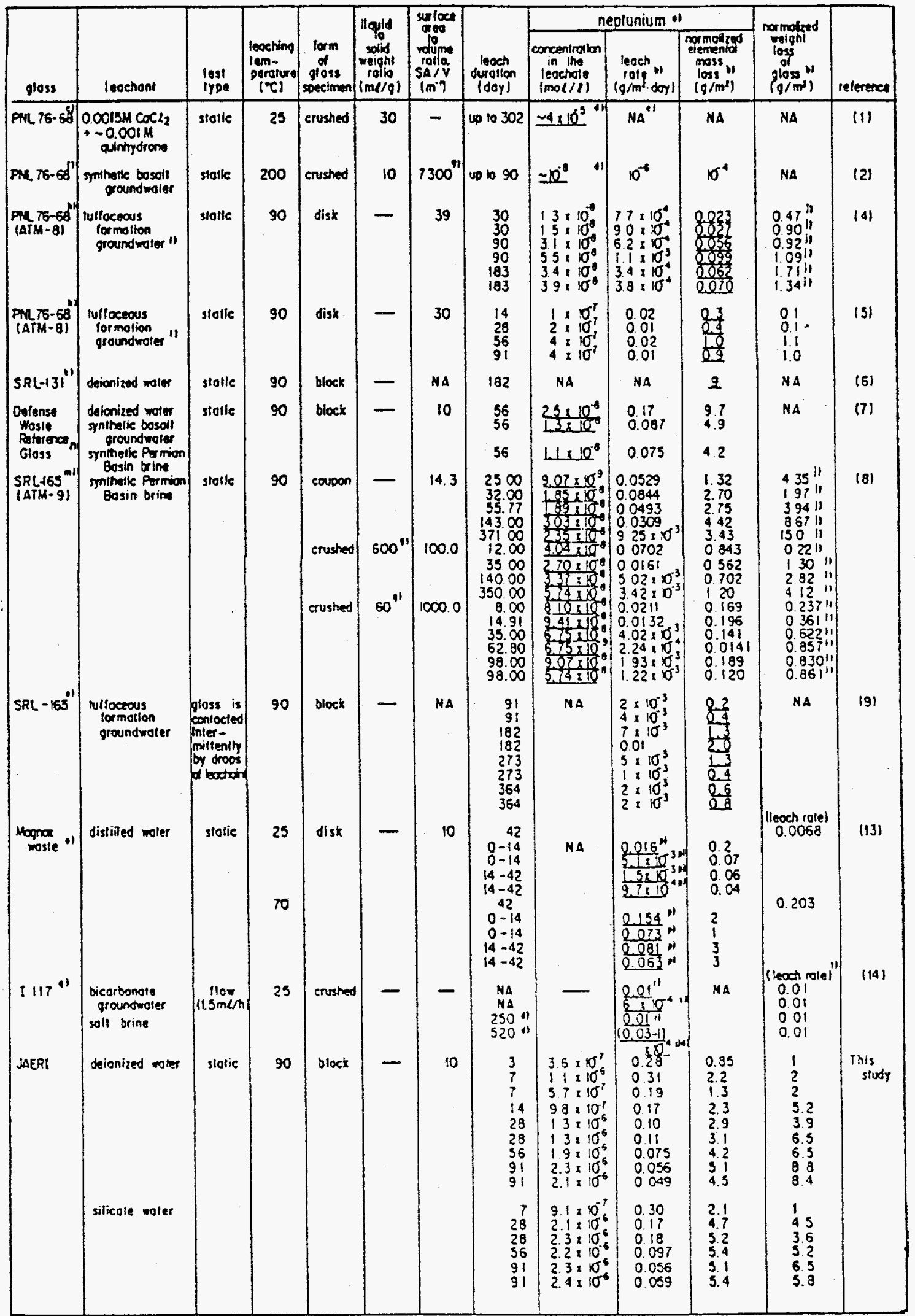




\section{RETENTION OF NEPTUNIUM}

Table 2.1-6 continued

(Nakayana et al ; 1989)

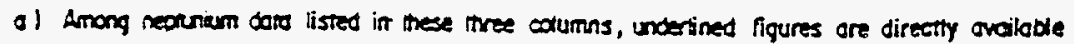

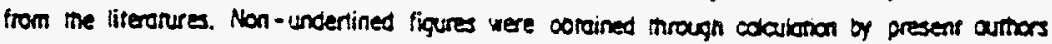
with the uncerlined tor axd expenmental gorcmeter values given in the lireronures.

D) colculared wim the initiel surfece areas

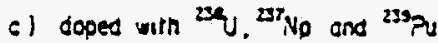

d) reed our from a figure snown in the literarure

e) $N A=$ Nor ovainole

1) dooed inth $237 \mathrm{~Np}$ and ${ }^{23} \mathrm{P}$ s

9) exleulcsed oy gresent ournors by using poromener values given in the literorure

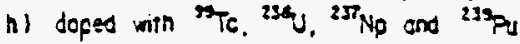

i) j-13 wejl-wates pre-equalitroted of $90^{\circ} \mathrm{t}$ with nutf

i) values for boren. indicating the amounts of glass dissolved

k) modified by the oddition of several minor woste slements, U. ${ }^{237} \mathrm{No},{ }^{239} \mathrm{Pu}$ and ${ }^{211} \mathrm{Am}$.

(1) doped wisn $U .{ }^{25} \mathrm{~Np}$ and $219 \mathrm{PS}$

m) doped with "TC. ${ }^{234}$, ${ }^{23}{ }^{120}{ }^{253} P_{y}$ and ${ }^{243} \mathrm{Am}$

n) coped with ${ }^{237} \mathrm{No}$. "3PPs and $241 \mathrm{~mm}$

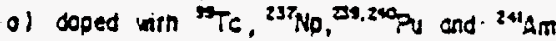

o) given as the overog̣e volue during the lecen durotion

a) a sodium borosilicare gioss coped with ${ }^{27} \mathrm{NP}$

f) oxic condition lair-sonuroted condition !

s) anoxic condition ( $\mathrm{n} \leq-200 \mathrm{mV}$ )

P) values for sodium

Table 2.1-7 Composition of ${ }^{25} \mathrm{~Np}$-doped waste glass

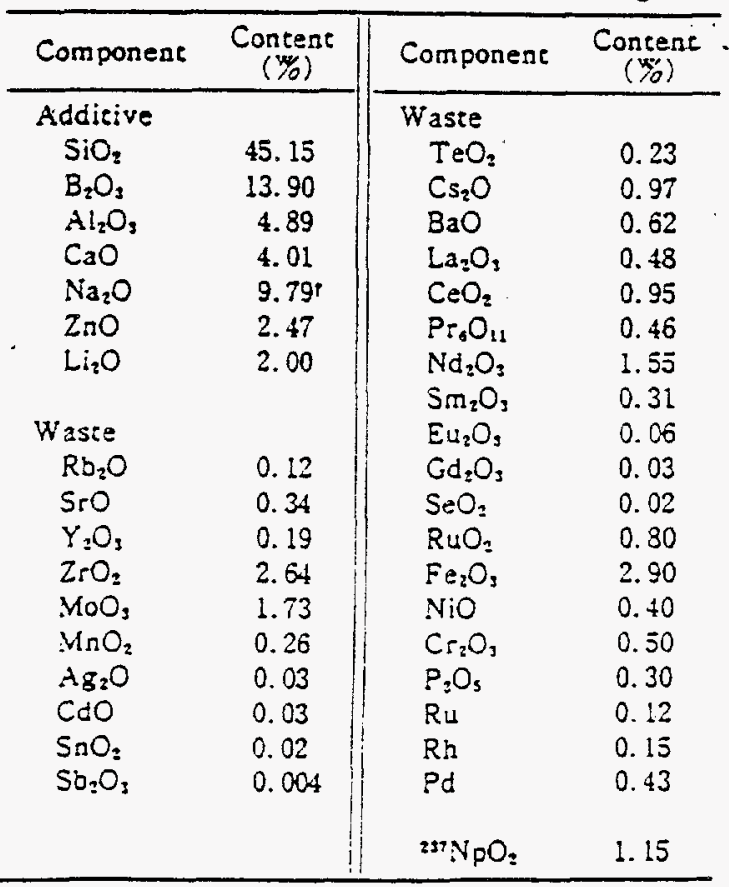

- Component contains both additive and waste. 
Table 2.1-8

\begin{tabular}{|c|c|c|c|c|}
\hline \multirow{3}{*}{ Leachant } & \multicolumn{4}{|c|}{$\begin{array}{l}\text { Veptunium concentrations in filtered } \\
\text { and unfiltered leachates }\end{array}$} \\
\hline & \multirow{2}{*}{$\begin{array}{l}\text { Leach } \\
\text { duration } \\
\text { (d) }\end{array}$} & \multicolumn{3}{|c|}{$\begin{array}{l}\text { Neptunium concentracion } \\
\qquad(\mu \mathrm{mol} / l)\end{array}$} \\
\hline & & Leachate & $\begin{array}{l}\text { First } \\
\text { filtrace }\end{array}$ & $\begin{array}{l}\text { Second } \\
\text { filtrate }\end{array}$ \\
\hline \multirow{3}{*}{$\begin{array}{l}\text { Deionized } \\
\text { water }\end{array}$} & 56 & 1.9 & 1.5 & 1.5 \\
\hline & 91 & 2.3 & 2.2 & 2.1 \\
\hline & 91 & 2.1 & 2.1 & 2.2 \\
\hline \multirow{5}{*}{$\begin{array}{l}\text { Silicate } \\
\text { water }\end{array}$} & 28 & 2.1 & 1.9 & 1.9 \\
\hline & 28 & 2.3 & 1.6 & 1.7 \\
\hline & 56 & 2.2 & 2.0 & 2.1 \\
\hline & 91 & 2.3 & 2.2 & 1.9 \\
\hline & 91 & 2.4 & 2.5 & 2.4 \\
\hline
\end{tabular}

(Nakayana et al ; 1989) 
Table 2.1-9

Compositions of Solutions Used for Leaching

\begin{tabular}{ll}
\hline pH range & \multicolumn{1}{c}{ Solution } \\
\hline $1.4-5.0$ & $\mathrm{HCl} /$ glycine \\
5.0 & Acetic acid/tris* \\
7.0 & Water \\
$7.0-9.0$ & $\mathrm{HCl} /$ tris \\
$9.5-11.0$ & $\mathrm{NH}, \mathrm{OH} / \mathrm{NH}, \mathrm{Cl}, \mathrm{Cs}_{2} \mathrm{CO}_{3}, \mathrm{NaOH} / \mathrm{H}_{3} \mathrm{BO}$ \\
$12.0-13.0$ & $\left(\mathrm{CH}_{3}\right)_{4} \mathrm{NOH}, \mathrm{KOH}$ \\
\hline
\end{tabular}

- Tris = tris (hyroxymethyl) aminomethane.

Ref 4

Table 2.1-10

Chemical Analysis of Glasses Studied

\begin{tabular}{lcccc}
\hline & & \multicolumn{3}{c}{ Consticuent $\left(\mathrm{mol}^{\circ}\right)$} \\
\cline { 3 - 5 } Glass & $\mathrm{Na}_{2} \mathrm{O}$ & & $\mathrm{ZrO}_{3 / 2}$ & $\mathrm{SiO}_{2}$ \\
\hline $\mathrm{S}_{1}$ & 15 & 5 & & 85 \\
$\mathrm{Al}_{1}$ & 15 & 20 & & 80 \\
$\mathrm{Al}_{2}$ & 15 & & 5 & 65 \\
$\mathrm{Zr}_{1}$ & 15 & & 10 & 80 \\
$\mathrm{Zr}_{2}$ & 15 & & & 75 \\
\hline
\end{tabular}

Ref 4 
Table 2.1-11

(Perrara et al ; 1991)

Composition of Glasses

\begin{tabular}{|c|c|c|c|c|c|c|c|}
\hline \multirow[b]{2}{*}{ Giass } & \multirow{2}{*}{$\begin{array}{l}\text { Density } \\
\text { (g/cm })\end{array}$} & \multicolumn{6}{|c|}{ Composition (wt\%) } \\
\hline & & $\overline{\mathrm{SiO}_{2}}$ & $\mathrm{Na}: \mathrm{O}$ & $\mathrm{CaO}$ & $\mathrm{Al}_{2} \mathrm{O}$ & $\mathrm{MgO}$ & $\mathrm{B}_{2} \mathrm{O}_{3}$ \\
\hline $\begin{array}{l}\text { Sodium trisilicate } \\
\text { Coming } 015 \text { soda-lime } \\
\text { PPG soda-lime } \\
\text { Kimble R6 soda-lime } \\
\text { Pyrex borosilicate } \\
\text { Obsidian }\end{array}$ & $\begin{array}{l}2.44 \\
2.49 \\
2.49 \\
2.45 \\
2.23 \\
2.36\end{array}$ & $\begin{array}{l}75 \\
72 \\
74 \\
74 \\
82 \\
76\end{array}$ & $\begin{array}{l}25 \\
22 \\
13.3 \\
12.9 \\
4 \\
3.6\end{array}$ & $\begin{array}{l}6 \\
8.3 \\
6.8 \\
0.5\end{array}$ & $\begin{array}{l}0.06 \\
1.8 \\
2 \\
13\end{array}$ & $\begin{array}{l}3.7 \\
4.5\end{array}$ & 14 \\
\hline
\end{tabular}

Table 2.1-12

Logarithm of Dissolution Rate of Glasses in

(Perrara et al ; 1991) Buffered Water at pB 7 at Different Temperatures

\begin{tabular}{|c|c|c|c|c|c|c|}
\hline \multirow[b]{2}{*}{ Temperature $\left({ }^{\circ} \mathrm{C}\right)$} & \multicolumn{6}{|c|}{$-\log v(v \text { in } c m / s)^{\circ}$} \\
\hline & $\overline{\mathrm{Na}_{2} \mathrm{O} \cdot 3 \mathrm{SiO}_{2}}$ & 015 & PPG & Pyrex & $R 6$ & Obsidian \\
\hline $\begin{array}{r}43 \\
50 \\
50 \\
66 \\
69 \\
70 \\
75 \\
78 \\
82 \\
84 \\
88 \\
90 \\
108 \\
109 \\
120 \\
121 \\
131 \\
140 \\
153 \\
157 \\
197 \\
216\end{array}$ & $\begin{array}{l}8.68 \\
6.92 \\
7.07(P) \\
6.77\end{array}$ & $\begin{array}{r}10.19(\mathrm{P}) \\
9.57(\mathrm{R})\end{array}$ & $\begin{array}{l}9.92 \\
9.17 \\
9.34 \\
9.05 \\
8.51 \\
8.28\end{array}$ & $\begin{array}{l}10.57 \\
10.27\end{array}$ & $\begin{array}{l}11.12(\mathrm{R}) \\
11.08(\mathrm{P})\end{array}$ & $\begin{array}{l}11.46 \\
10.55\end{array}$ \\
\hline
\end{tabular}

-Measurement techaique: $P$ is profilometer, $R$ is Rutberford backscattering, otbers are weight change.

Table 2.1-13 Rates of Dissolution of Different Glasses at.

(Perrara et al : 1991) $90^{\circ} \mathrm{C}$ and Activation Energies for Dissolution

\begin{tabular}{lcc}
\multicolumn{1}{c}{ Glass } & $\begin{array}{c}-\log v \\
(v \text { in } \cos / \mathrm{s})\end{array}$ & $\begin{array}{c}\text { Activation energy, } \\
Q(\mathrm{~kJ} / \text { mon })\end{array}$ \\
\hline Sodium trisilicate & $6.4^{\dagger}$ & \\
Corning 015 soda-lime & 8.18 & 84 \\
PPG soda-lime & 9.05 & 68 \\
Pyrex borosilicate & 9.64 & 54 \\
Kimble R6 soda-lime & 10.70 & 79 \\
Obsidian & $12.7^{+}$ & 62 \\
\hline
\end{tabular}

-Fron Fig. 1. 'Extrapolated. 
Table 2.1-14

DISSOLUTION̈ RATES OF SILICATE GLASSES MEASURED BY OTHER INVESTIGATORS AT PH 7

\begin{tabular}{|l|l|c|c|}
\hline Glass & $\begin{array}{l}\text {-logv } \\
(\mathrm{V} \text { in } \\
\mathrm{cm} / \mathrm{s})\end{array}$ & $\begin{array}{l}\text { Temperature } \\
\left({ }^{\circ} \mathrm{C}\right)\end{array}$ & Ref \\
\hline $0.75 \mathrm{SiO}_{2}-15 \mathrm{Na}_{2} 0-0.1 \mathrm{CaO}$ & 8.72 & 100 & 27 \\
\hline Commercial soda-lime with 2\% alumina & 10.5 & 90 & 28 \\
\hline Vycor.96\% silica & 10.1 & 100 & 29 \\
\hline Fused silica & 13 & 25 & 30 \\
\hline Ouartz (crystalline) & 12.7 & 100 & 31 \\
\hline
\end{tabular}

(Perrara et al ; 1991) 
Final

Table 2.1-15

Compositions of Glasses

\begin{tabular}{|c|c|c|c|c|c|c|c|c|}
\hline \multirow[b]{2}{*}{ Name } & \multirow[b]{2}{*}{ Notation } & \multirow{2}{*}{$\begin{array}{l}\text { Density } \\
\left(\mathrm{g} / \mathrm{cm}^{3}\right)\end{array}$} & \multicolumn{6}{|c|}{ Composition (we\%) } \\
\hline & & & $\mathrm{SiO}:$ & $\mathrm{Na}: \mathrm{O}$ & $\mathrm{CaO}$ & $\mathrm{Al}: \mathrm{O}_{3}$ & $\mathrm{MgO}$ & $\mathrm{B}: \mathrm{O}_{3}$ \\
\hline $\begin{array}{l}\text { Pittsburgh Plate Glass } \\
\text { Kimble R6 soda-7ime } \\
\text { Pyrex borosilicate (Corning 7740) }\end{array}$ & $\begin{array}{l}F \\
\text { B } \\
P\end{array}$ & $\begin{array}{l}2.49 \\
2.45 \\
2.23\end{array}$ & $\begin{array}{l}74 \\
74 \\
80\end{array}$ & $\begin{array}{c}13.3 \\
12.9 \\
4\end{array}$ & $\begin{array}{l}8.3 \\
6.8\end{array}$ & $\begin{array}{l}0.06 \\
1.8 \\
2\end{array}$ & $\begin{array}{l}3.7 \\
4.5\end{array}$ & 14 \\
\hline
\end{tabular}

(Perrara et al 1991)

Table 2.1-16

Dissolution Rates* v of Glasses in Solutions of Different pH

\begin{tabular}{|c|c|c|c|c|c|c|c|}
\hline \multirow[b]{2}{*}{$T(C)$} & \multicolumn{3}{|c|}{ F-PPG } & \multicolumn{3}{|c|}{ P-Pyrex borosilicate } & \multirow{2}{*}{$\frac{\text { B-soda-lime }}{\mathrm{pH} 7}$} \\
\hline & $\mathrm{pH} 4$ & $\mathrm{pH} 7$ & pH 9 & $\mathrm{pH} 4$ & $\mathrm{pH} 7$ & $\mathrm{pH} 9$ & \\
\hline $\begin{array}{l}43 \\
50\end{array}$ & & $3.7(-11)$ & $2.2(-10)$ & & $2.7(-11)$ & $2.1(-11)$ & $3.9(-13)^{7}$ \\
\hline 50 & & $5.1(-11)$ & & & & & \\
\hline $\begin{array}{l}70 \\
75\end{array}$ & & $1.2(-10)$ & $1.6(-9)$ & & $5.4(-11)$ & $2.0(-10)$ & $7.6(-12)^{\ddagger}$ \\
\hline $\begin{array}{l}78 \\
82\end{array}$ & & $6.8(-10)$ & & & & & $8.4(-12)^{t}$ \\
\hline 84 & & & $35(-0)$ & & $2.0(-10)$ & & \\
\hline $\begin{array}{l}81 \\
88\end{array}$ & & $4.6(-10)$ & $3.2(-9)$ & & & $5.6(-10)$ & . \\
\hline 90 & & $8.9(-10)$ & & & $2.3(-10)$ & & \\
\hline $\begin{array}{l}100 \\
109\end{array}$ & & $3.1(-9)$ & & & $1.0(-10)$ & & \\
\hline $\begin{array}{l}114 \\
120\end{array}$ & $2.9(-10)$ & $5.3(-9)$ & & $1.1(-10)$ & & & \\
\hline $\begin{array}{l}121 \\
130\end{array}$ & $5.4(-10)$ & & & $2.6(-10)$ & $8.0(-10)$ & $2.4(-9)$ & \\
\hline $\begin{array}{l}131 \\
140\end{array}$ & $8.2(-10)$ & & & $3.5(-10)$ & $1.8(-9)$ & & \\
\hline $\begin{array}{l}145 \\
150\end{array}$ & & & $4.2(-8)$ & $7.0(-10)$ & & $7.1(-9)$ & \\
\hline $\begin{array}{l}153 \\
160\end{array}$ & . $3.0(-9)$ & $1.1(-8)$ & $8.3(-8)$ & & & & \\
\hline $\begin{array}{l}193 \\
197 \\
216\end{array}$ & $1.7(-8)$ & & $8.5(-8)$ & $2.7(-9)$ & $2.3(-8)$ & & $7.2(-8)$ \\
\hline
\end{tabular}

(Perrara et al 1991) 
Table 2.1-17 Compositions of simulated nuclear waste (wt\%) (Lutze et al , 1988)

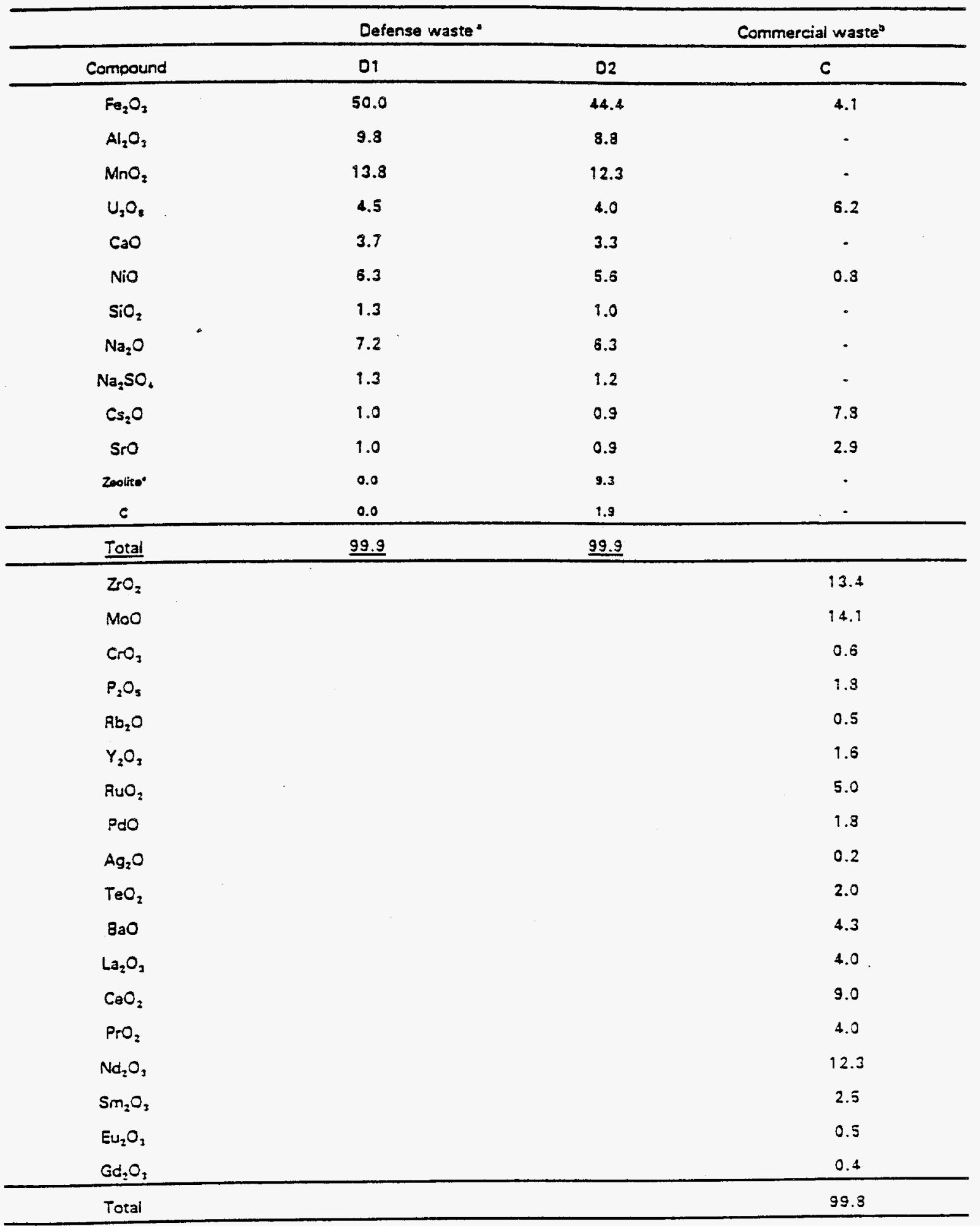

a. The "composite" composition of US defense waste currently in interim storage at the Savannah River Facility (Baxter 1983).

b. The "PW-46" commercial waste composition (Oversby 1982), which is typical of the nuclear waste from the reprocessing of spent fuel rods from commercial light water power reactors.

c. The zeolite used was a $50 / 50$ mix by weight of calcium-aluminum silicate (Linde $5 \mathrm{~A})$ and sodium-aiuminum silicate (Linde 4-A). 
Table 2.1-18 Compositions of lead-Iron phosphate commercial waste glasses |wt \%|

(Lutze et al , 1988)

\begin{tabular}{|c|c|c|c|c|c|c|c|c|c|c|}
\hline compound & $1 . C$ & $2-C$ & $2.5 \cdot \mathrm{C}$ & $3-c$ & 4.C & 5.C & 6-C & $7-c$ & 8.C & 9.C \\
\hline $\mathrm{P}_{2} \mathrm{O}_{3}$ & 32.2 & 33.1 & 33.6 & 33.9 & 39.2 & 40.1 & 41.2 & 42.3 & 40.44 & 41.4 \\
\hline $\mathrm{PbO}$ & 50.6 & 51.9 & 62.9 & 53.3 & 41.1 & 42.0 & 43.1 & 44.3 & 38.6 & 32.2 \\
\hline $\mathrm{Fe}_{2} \mathrm{O}_{3}$ & 10.8 & 8.4 & 6.85 & 6.1 & 13.1 & 11.2 & 8.8 & 6.3 & 14.5 & 19.7 \\
\hline $\begin{array}{l}\text { simulated } \\
\text { commercial } \\
\text { waste }\end{array}$ & 6.4 & 6.6 & 6.6 & 6.8 & 6.5 & 6.7 & 6.9 & 7.0 & 6.5 & 6.6 \\
\hline Total & 100.0 & 100.0 & 99.95 & 100.1 & 99.9 & 100.0 & 100.0 & 99.9 & 100.04 & 99.9 \\
\hline $\begin{array}{l}\text { Glass } \\
\text { density } \\
\left(\mathrm{g} / \mathrm{cm}^{3}\right)\end{array}$ & 5.0 & 4.0 & 4.9 & 4.9 & 4.6 & 4.4 & 4.3 & 4.3 & 4.5 & 4.25 \\
\hline $\begin{array}{l}\text { wastel } \\
\text { volume } \\
\text { loading } \\
\left(\mathrm{g} / \mathrm{cm}^{3}\right)\end{array}$ & 0.32 & 0.32 & 0.32 & 0.33 & 0.30 & 0.29 & 0.30 & 0.30 & 0.29 & 0.28 \\
\hline
\end{tabular}

$\mathrm{P}_{2} \mathrm{O}_{5}$ added as $\mathrm{NH}_{4} \mathrm{H}_{2} \mathrm{PO}_{4}$ 
Table 2.1-19 Compositions of lead - iron phosphate defense waste glasses (wt\%) (Lutze et al, 1988)

\begin{tabular}{|c|c|c|c|c|c|c|c|}
\hline Compound & $1-D$ & 2-D & $3-0$ & 4-D & 5-D & $6-D$ & 7-Da \\
\hline $\mathrm{P}_{2} \mathrm{O}_{5}$ & 32.9 & 32.9 & 39.5 & 35.6 & 43.5 & 29.3 & 25.5 \\
\hline $\mathrm{PbO}$ & 51.6 & 51.6 & 41.4 & 45.8 & 36.9 & 56.3 & 60.1 \\
\hline $\mathrm{Fe}_{2} \mathrm{O}_{3}$ & 7.75 & 6.88 & 9.55 & 9.3 & 9.8 & 7.2 & 7.2 \\
\hline $\mathrm{Al}_{2} \mathrm{O}_{3}$ & 1.55 & 1.36 & 1.87 & 1.82 & 1.92 & 1.41 & 1.41 \\
\hline $\mathrm{MnO}_{2}$ & 2.14 & 1.91 & 2.63 & 2.57 & 2.70 & 1.99 & 1.99 \\
\hline $\mathrm{CaO}$ & 0.57 & 0.51 & 0.71 & 0.69 & 0.72 & 0.53 & 0.53 \\
\hline $\mathrm{NiO}$ & 0.97 & 0.86 & 1.20 & 1.17 & 1.23 & 0.91 & 0.91 \\
\hline $\mathrm{SiO}_{2}$ & 0.20 & 0.16 & 0.25 & 0.24 & 0.25 & 0.19 & 0.19 \\
\hline $\mathrm{Na}_{2} \mathrm{O}$ & 1.12 & 0.98 & 1.37 & 1.34 & 1.41 & 1.04 & 1.04 \\
\hline $\mathrm{Na}_{2} \mathrm{SO}_{4}$ & 0.20 & 0.18 & 0.25 & 0.24 & 0.25 & 0.19 & 0.19 \\
\hline $\mathrm{U}_{3} \mathrm{O}_{3}$ & 0.70 & 0.62 & 0.86 & 0.84 & 0.88 & 0.65 & 0.65 \\
\hline $\mathrm{Cs}_{2} \mathrm{O}$ & 0.155 & 0.15 & 0.19 & 0.19 & 0.20 & 0.14 & 0.14 \\
\hline Sro & 0.155 & 0.15 & 0.19 & 0.19 & 0.20 & 0.14 & 0.14 \\
\hline zeolite $^{b}$ & 0.0 & 1.44 & 0.0 & 0.0 & 0.0 & 0.0 & 0.0 \\
\hline C & 0.0 & 0.29 & 0.0 & 0.0 & 0.0 & 0.0 & 0.0 \\
\hline Total & 100.01 & 99.99 & 99.97 & 99.99 & 99.96 & 99.96 & 99.99 \\
\hline $\begin{array}{l}\text { waste } \\
\text { loading( } \\
\text { wt\%) }\end{array}$ & 15.5 & 15.5 & 19.1 & 18.6 & 19.6 & 14.4 & 14.4 \\
\hline $\begin{array}{l}\text { Glass } \\
\text { density } \\
\left(\mathrm{g} / \mathrm{cm}^{3}\right)\end{array}$ & 4.7 & 4.7 & 4.0 & 4.5 & 4.0 & 5.1 & 5.4 \\
\hline $\begin{array}{l}\text { Waste/ } \\
\text { volume } \\
\left(\mathrm{g} / \mathrm{cm}^{3}\right)\end{array}$ & 0.73 & 0.73 & 0.76 & 0.83 & 0.78 & 0.73 & 0.78 \\
\hline
\end{tabular}

a Not a homogeneous glass-a large amount of crystalline material

b The zeolite used was a 50/50 mix by weight of calcium aluminum silicate (Linde $5 \mathrm{~A}$ ) and sodium-aluminum silicate (Linde $4 \mathrm{~A}$ ).

$\mathrm{P}_{2} \mathrm{O}_{5}$ added as $\mathrm{NH}_{4} \mathrm{H}_{2} \mathrm{PO}_{4}$

$\mathrm{Na}_{2} \mathrm{O}$ added as $\mathrm{Na}_{2} \mathrm{CO}_{3}$ 


\section{References}

Brambilla G, Quercioli E, Avagadro A, Patent No IT1077009 Vitrification of Radioactive Waste

Calestani G, Montenero A, Ferraguti E, Ingletto G \& Bettinelli M., J Non-Cryst, Solids, Vol. 84, pp 452 - 462 (1986).

Influence of some oxides on the durability of a borosilicate glass.

Das C R, J Am Ceram. Soc., Vol. 64 (4), pp 188-193 (1981).

Chemical Durability of Sodium Silicate Glasses Containing $\mathrm{Al}_{2} \mathrm{O}_{3}$ and $\mathrm{ZrO}_{2}$.

Dilmore M F, Diss. Abst. Int. B., Vol. 38 (6), p 2806-B (1977)

Chemical Durability of Multicomponent Silicate Glasses

El-Shamy $T M$, Lewins $J$, and Douglas $R \mathrm{~W}$, "The Dependence on the $\mathrm{pH}$ of the Decomposition of Glasses by Aqueous Solutions," Glass Technol., 13, 81-87 (1972).

Harvey K B, Litke C D, and Boase C A, "The Dissolution of Simple Glass. Part 1: Initial Model and Application to an Open Glass/Water System." Phys. Chem. Glasses, 27, 15021 (1986).

Ito K \& Kanno T, J Nucl. Sci. Technol., Vol 25 (6), pp 534-539 (1988)

Sorption Behavior of Carrier-Free Technetium-95m on Minerals, Rocks and Backfill Materials under both Oxidizing and Reducing Conditions

Ivanov I A, Gulin A N, Shatkov V M \& Shashukov E A; Translated from Zhurnal Strukturnoi Khimii, Vol 30, No 6, pp 817-820 (Nov-Dec 1988)

Migration of Neptunium-237 in Glasses and Ceramics

Ivanov I A, Sedov V M, Gulin A N, Shatkov V M \& Shashukov $E$ A, Translated from Radiokhimiya, Vol. 32, No 5, pp 139-142 (Sept - Oct 1990)

Diffusion of Actinides in Glasses Containing Model Radioactive Wastes.

Kumata M, Vandergraaf T T, Radioactive Waste Management and the Nuclear Fuel Cycle, Vol. $17(2)$, pp 107-11 (1993)

Technetium behavior under deep geological conditions

Lanford W A, Davis K, Lamarche P, Laursen T, Groleau R, and Doremus R H, Hydration of Soda-Lime Glass,' J Noncryst. Solids, 33, 249-66 (1979).

Lutze W \& Ewing R C, Elsevier Science Publishers BV (1988)

Radioactive Waste Forms for the Future

Nakayana S \& Banba T, J Nucl, Sci, Tech, Vol 26 (6), pp 607-615 (June 1989)

Release of Neptunium from Neptunium - Doped Borosilicate Waste Glass

Nauer G, Sorantin H \& Krejsa P, J Radioanal. Chem., Vol 39, pp 127-136 (1977)

Determination of Trace Elements in Ancient Glass Pieces and Correlation with Corrosion and Devitrification 
Patent No J61013196 (1986)

Vitrification of Radioactive Sodium Compounds

Patent No J61132898 (1987)

Solidification of Radioactive Waste

Patent No J61082200

Vitrification of Sodium Nitrate Solutions

Perera G \& Doremus R H ,J Am Ceram. Soc., Vol. 74 (6), pp 1269-1274 (1991). Dissolution Rates of Silicate Glasses in Water at $\mathrm{pH} 7$

Perera G \& Doremus R H , J Am Ceram. Soc., Vol 74 (7), pp 1554-1558 (1991). Dissolution Rates of Commercial Soda-lime and PYREX Borosilicate Glasses: Influence of Solution $\mathrm{pH}$

Pilkington N J \& Wilkins J D, NSS/R120 Safety Studies Nirex Radioactive Waste Disposal (1988)

Experimental Measurements of the Solubility of Technetium under Near-Field Conditions

Rana M A and Douglas R W, The Reaction between Glass and Water. Part 1: Experimental Methods and Observations, Phys. Chem. Glasses, 2, 196-205 (191).

Rimstidt J D and Barnes H L, "The Kinetics of Silica-Water Reaction," Geochim, Cosmochim, Acta, 44, 1683-99 (1980).

Schreiber H D, Balazs G B, Williams B J \& Andrews S M.

Scient. Basis Nucl. Waste Mgmt., Vol. 3, pp 109 - (1981).

Schreiber H D, Balazs G B \& Williams B J.

Lunar Planet Sci., Vol. 12, pp 943 - (1981)

Schreiber HD, Balazs G B. Physics and Chemistry of Glasses, Vol 23, No 5, pp $139-146$. (Oct 1982).

The Chemistry of Uranium in Borosilicate Glasses. Part 1. Simple Base Compositions Relevant to the Immobilization of Nuclear Waste.

Schreiber HD, Balazs G B, Jamison P L \& Shaffer A P, Physics and Chemistry of Glasses, Vol 23, No 5, pp 147 - 153. (Oct 1982).

The Chemistry of Uranium in Borosilicate Glasses. Part 2. Base Compositions Containing Titanium Relevant to the Immobilization of Nuclear Waste.

Schreiber H D, Minnix L M, Carpenter B E \& Solberg T N, Physics Chem. Glasses, Vol 24, No $6, \mathrm{pp} 155-(1983)$.

The Chemistry of Uranium in Borosilicate Glasses. Part 3.

Schreiber H D, Minnix LM, Balazs G B \& Carpenter B E, Physics Chem. Glasses, Vol. 25, No 1 , pp 1 - (1984).

The Chemistry of Uranium in Borosilicate Glasses. Part 4. 
Schreiber H D, Carpenter B E, Eckenrode J P \& Balazs G B, Physics Chem. Glasses, Vol. 26, No 1 , pp 24 - 30 (1985).

The Chemistry of Uranium in Borosilicate Glasses. Part 5. The Ferric-Ferrous Couple as a REDOX Buffer for the Uranium REDOX State Distribution Against Reducing Agents in a Borosilicate Melt.

Strickert R, Friedman A M \& Fried S ,Nucl. Technol., Vol. 49 (2), pp 253-26 (1980).

The sorption of technetium and iodine radioisotopes by various minerals

Zielinski R A, Nuclear Technology, Vol. 51, pp 197-200 (1980)

Stability of Glass in the Geologic Environment: Some Evidence from Studies of Natural Silicate Glasses 


\subsection{MATRIX MATERIAL}

An investigation for the selection of a matrix material to protect and augment the performance of vitrified LLW has been undertaken in this section.

\subsubsection{Requirements}

2.2.1.1 Regulatory Requirements. DOE Order 5820.2A - Radioactive Waste Management.

1) General Public Protection. Disposal systems shall be designed to ensure that exposure of any member of the public that results from disposal of solid LLW shall not exceed $25 \mathrm{mrem} / \mathrm{yr}$ Effective Dose Equivalent (EDE) through all exposure pathways for at least 1,000 years after disposal 110,000 years in 5820.2B).

2) Groundwater Protection. Disposal systems shall be designed to meet the Clean Water Act and the Safe Drinking Water Act as well as ensure that disposal of LLW after 09/26/88 does not result in concentrations of radionuclides in groundwater exceeding those corresponding to an EDE of $4 \mathrm{mrem} / \mathrm{yr}$ to any person who might drink 2 liters per day of water from a well drilled into the aquifer, for at least 1,000 years after disposal $(10,000$ years in $5820.2 \mathrm{~B})$. The point of compliance shall be no further than 100 meters from the edge of the waste.

2.2.1.2 System Wide Requirements. Retain as much of the waste as possible for as long as possible within project cost and timescale constraints satisfying all regulatory performance criteria.

2.2.1.3 Task Specific Requirements. The matrix material is to:

- minimize ground water contact with the glass;

- reduce the leachability of radionuclides from the glass;

- minimize corrosion of the glass; and

- have long-term durability $(10,000$ years plus).

\subsubsection{Design Options}

The following matrix materials have been investigated in an attempt to identify an acceptable material for use in concert with the expected glass formulations and possible glass form geometries.

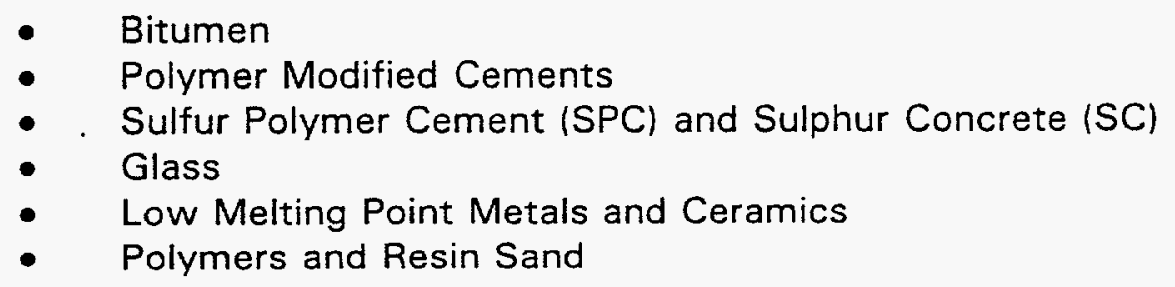

A summary of the evaluation of the above matrix options is shown in table 2.2.1, with further discussion below: 
2.2.2.1 Bitumen. Bitumen has been used throughout the world at a temperature of $180^{\circ} \mathrm{C}$ (Mayberry et al, 1993; Landes et al, 1982) for the encapsulation of low and intermediate level waste, though its use is not as problematic as SPC, as its working envelope is greater than that associated with SPC (Van Dalen, 1989, Mayberry 1993). The matrix requires the use of essentially dry wastes otherwise processing problems such as steaming and consequently poor product quality such as foaming will arise. In comparison to freshly hydrated cement, the permeability of the bitumen will hinder the escape of gases formed by radiation of the waste form creating possible instability. Processing costs would be high compared with cementitious materials because the use of bitumen requires high temperatures and off gas treatment facilities. The process would also involve plant cleaning using toxic and flammable solvents giving rise to potential fire hazards. The material has a high creeprate which, in the long term, could result in a non-homogeneous distribution of waste within the bitumen. Hence, it is essential that it is always contained. In the early 1980's, because of serious technical problems and safety implications posed by potential fires, the UK regulators strongly advised against the use of bitumen as an encapsulation material.

This material is not considered suitable for this application as containment in the disposal site cannot be guaranteed for 10,000 years or more, and it is not considered further.

2.2.2.2 Polymer Modified Cements. These are similar in application to Sulphur Polymer Cement giving improved performance in relation to polymers at considerably more cost than the plain Portland Cement systems. The addition of polymer to cement used in the construction of thick monoliths can affect the hydration characteristics of the cement and possibly lead to a retardation of set (Lee 84). The presence of organic additives in cements can also cause degradation of the matrix material and subsequent gas generation creating possible product instability on irradiation.

These types of cements are not suitable for use with vitrified waste due to their alkaline nature and are not considered further; however, a cementation derivative may be worth investigating (see 2.2.3.1).

2.2.2.3 Sulphur Polymer Cement (SPC) and Sulphur Concrete (SC). Sulphur polymer cement consists of 95 wt. \% sulphur with 2 wt. \% dicyclopentadiene and $2.5 \mathrm{wt}$. \% oligomers of cyclopentadiene (Mayberry et al, 1993; Kalb et al, 1991; Kalb et al, 1990). This material has been investigated as a potential encapsulant for a series of low level wastes including wastes (e.g. boric acid) which have been found to cause problems when encapsulated with ordinary Portland cement. The SPC is mixed with the waste at an optimum temperature of $135^{\circ} \mathrm{C}$ and allowed to cool to form a solid waste product. The SPC is in a usable state only within a narrow temperature range between approximately $130-150^{\circ} \mathrm{C}$. Temperatures above $149 / 150^{\circ} \mathrm{C}$ result in a sharp rise in viscosity because of additional polymerization within the SPC and the evolution of hydrogen sulphide gas (Van Dalen et al, 1989; Mayberry et al, 1993). Below $128^{\circ} \mathrm{C}$ hard solidified blocks of material are formed in the melt, rendering the encapsulant ineffective.

The wasteforms created using SPC (and SC) to develop strength at a greater rate than those produced with Portland Cement Concrete (PCC) (Mayberry et al, 1993). SPC has been shown to possess increased strengths in construction when compared to PCC (Mayberry et al, 1993; Kalb et al, 1991; Kalb et al, 1990). Full strength was reached in a matter of hours rather than weeks (Mayberry, et al, '93). Soon after solidification, the compressive strength of the wasteforms produced using SPC (and SC) were in the order of $60-80 \%$ of the final product strength reached in after a year (Van Dalen et al, 1989). 
Sulphur exists in different allotropic forms and has different densities that are sensitive to cooling rates. Therefore, it is likely that microcracking will occur on the surfaces of large monoliths during cooling. Such stress cracks are potential areas for oxidation and the formulation of expansive sulphate in the cement (Mattus, et al, '94). Any cracking would degrade the performance of the matrix and may provide areas for biological and chemical attack.

SPC has the ability to immobilize heavy metals and a wide range of other materials. Heavy metal oxides present in mixed waste incinerator ash are bound chemically to SPC and those metals which have a higher affinity for sulphur than oxygen are considered to form sulphides (such as lead, copper and brass) (Mattus et al, 1994; Van Dalen et al, 1989; Darnell et al, 1992).

The SPC matrix has a low permeability and porosity; however, the porosity of this material is controlled by the nature of the waste incorporated (Mattus et al, 1994). For example, studies carried out on the encapsulation of Incinerator Ash (Van Dalen et al, 1989) in SPC indicated the porosity of the wasteforms was decreased by the presence of aluminum trioxide in the ash which helped to de-aerate the molten sulphur cement on encapsulation. SPC and PCC have a similar resistance to freeze/thaw damage (Mattus et al, 1994; Mayberry et al, 1993). Further work showed that SPC wasteforms liberated no radiolytic gas following irradiation to $20 \mathrm{Mgy}$ ( $y$ or B) and that the mechanical strength of the SPC increased over the period of irradiation (Mattus et al, 1994; Van Dalen et al, 1989; Mayberry et al, 1993).

Short term testing of sulphur cements containing no waste have shown no evidence of microbial growth over a period of 21 days (Mattus et al, 1994); however, little is known about the possibility of long term bacterial attack, especially under conditions which could be anticipated in the disposal site. Several publications (Van Dalen et al, 1989) discuss the action of bacillus ferroxidious, a chemolithotrophic bacterium capable of using sulphur and sulphur compounds as its source of energy. These bacteria are able to oxidize elemental sulphur over a broad $\mathrm{Ph}$ range.

It is noted that sulphur has a limited thermodynamic stability field (Mattus et al, 1994). It is also unstable above pH8 and electropotential measurements suggest it's most stable form where oxygen and moisture is present would be as sulphate anion. Stability deep in the earth as a natural form is aided by its occurrence adjacent to protective rock types such as gypsum and limestone (Miller, 1994). This fact is considered critical in a long-term assessment of its stability for 10,000 years or more near the earth's surface where moisture and oxygen are obviously present to a significant degree (Miller, 1994).

2.2.2.4 Glass. Glass is acknowledged as a primary encapsulant for High Level Waste, and its properties are well understood as indicated in other sections of this report. Its use as an encapsulating matrix for cullet or to encapsulate vitrified monoliths has been addressed in Section 2.4. A major problem would be direct fusion with the active product which may disperse the waste into the matrix.

The problem of radioactive waste disposal into the matrix, combined with the brittle nature and cracking potential of encapsulant glass, makes its selection as a candidate material low.

The utilization of glass has many limitations and is not selected. 
2.2.2.5 Low Melting Point Metals and Ceramics. This material requires higher operational temperatures than other options (except glass). The anticipated high capital and running costs compared with Portland cement and SPC systems regarding vitrified waste incorporation offers limited incentive to pursue these technologies in the light of more economic and technologically proven methods. The main problems associated with the use of these materials include:

(i) high material costs

(ii) difficulty in producing a homogeneous wasteform due to waste segregation with different density materials

(iii) off-gas system required to treat heavy metals

(iv) toxicity problems related to wasteform and disposal

(v) scale up of mixing process has not been achieved to date

These are presently considered inappropriate for large scale use.

Synroc is an alternative crystalline wasteform to borosilicate glass for the encapsulation of high level waste. The leach resistance of Synroc is generally found to be superior to that of borosilicate glass. Synroc is, however, vulnerable to damage from selfirradiation (Maddrel, 1993).

2.2.2.6 Polymers and Resin Sand. Examples are epoxy resins, polyesters, polyurethanes. Some epoxy and polyester resins have reasonably long-term stability in radiation fields, depending on the nature of the catalyst systems. However, they are technically not recommended for thick sections (which would be required for a durable encapsulating matrix), due to the considerable exothermic nature of the chemical reaction during polymerization. This reaction can be readily controlled with small laboratory specimens, but not for bulk items. Cold cured Urethane or other polymer systems are untried particularly at a large scale. Polyethylene is the exception to this but its long term durability within a radiation field is likely to be unfavorable and data is limited.

Fire hazards are a potential problem, and in general, the life expectancy of the material is low due to the degradation of organic materials and such systems have limited tolerance to radioactive wastes.

The life expectancy of this type of material is not considered suitable for this application (organic degradation) and it is not considered further.

\subsubsection{Methodology to Evaluate Options}

BNFL has undertaken an extensive program of work to identify a method of disposing of nuclear wastes either stored on the Sellafield site or arising as a consequence of plant operations. The wastes concerned include metallic fuel cladding, aqueous sludges and flocs. The preferred disposal route for these wastestreams involves their immobilization in a suitable encapsulation matrix prior to engineered storage and ultimate disposal. A systematic approach has been adopted by BNFL (Fairhall, 1994), to accurately characterize the physical and chemical nature of each wastestream requiring disposal and to compare the performance of the wasteforms produced using a range of different matrix encapsulation options against specific regulatory criteria (Fairhall, 1994) concerning the wasteform processing and properties. The matrix options evaluated have included cement, polymer modified cement bitumen, polymers, resin sand, glass, low melting point metals and ceramics. 
The BNFL product evaluation work has identified cement formulations consisting of ordinary Portland cement blended with blastfurnace slag or pulverized fuel ash as the most suitable encapsulation matrices for encapsulating all 23 different Sellafield wastestreams produced to date (Fairhall, 1993). The use of cement to encapsulate the wastes combined the beriefits of a comparatively simple, cost effective and versatile processing technology with the production of monolithic wasteforms with good actinide retention properties. BNFL has generated a database on the physical, chemical and thermal stability of the cemented waste products which demonstrates they are of sufficient quality to satisfy regulatory requirements for LLW (Fairhall, 1989; Fairhall et al, 1985; Fairhall et al, 1989).

Other matrix options were also found to produce waste products which showed adequate strength and radiation stability as previously discussed above commensurate with the cement products. However, in order to match the quality of the cement products, these options were found to require a very complicated and costly processing technology and plant design involving the use of hazardous chemicals and/or conditions. This was especially the case when considering glass,ceramics and high melting point metals as encapsulants.

The polymers were also found to have a lower resistance to high temperatures. For example, pyrolysis of the more volatile waste components (Ridley et al, 1988) began at approximately $300^{\circ} \mathrm{C}$ and continued until the onset of surface burning at approximately $600^{\circ} \mathrm{C}$. The release of pyrolysis gases was considered to present and/or provide a means of propagating a fire (Ridley et al, 1988). In comparison, cement waste monoliths have been demonstrated to remain stable following exposure to fire temperatures of $1000^{\circ} \mathrm{C}$ for a period of 2 hours (Fairhall et al, 1985).

The other matrix options studied were, therefore, not considered to exceed the benefits associated with the use of cement as an encapsulant under the applications apparent at Sellafield. As a consequence of the product evaluation studies, BNFL has designed and built a number of encapsulation plants on the Sellafield site to treat the most significant wastestreams arising.

The advantages and disadvantages of the use of various matrix options are summarized in Table 2.2.1.

The only materials considered potentially suitable for use as a matrix with vitrified LLW are a Cementatious derivative or SPC. Further detail on these materials is discussed below.

2.2.3.1 Cementitious Materials. It is recognized that encapsulation of a vitrified product in a cementitious matrix is not feasible due to potential alkali attack of the silica. Consideration should be given to the development of a very high slag based cement grout as a matrix material which may afford significant resistance to alkali attach when used as a glass encapsulant.

It is also noted that it may be possible to develop similar high content slag grouts as encapsulants, with selective additives which will have liquid permeabilities in the order of $10^{-13}$ $\mathrm{m} / \mathrm{s}$ significantly higher than more conventional cement grouts with Pulverized Fly Ash (PFA) or Blast Furnace Slag (BFS) additives. Such grouts, which would also be formulated to chemically react with active species such as Tc, may offer an alternative to vitrification or sulphur matrix encapsulation. They would be expected to have a similar long-term performance to SPC and could offer significant benefits regarding processing and overall costs. 
2.2.3.2 Sulphur Polymer Cement (SPC) and Sulphur Concrete (SC) SPC is a durable high strength concrete that is resilient to attack by most acids and salts and has been proved to be suitable for encapsulating heavy metals. However it is not recommended for use with strong alkali ( $>10 \%$ ) oxidizing agents or organic solvents. Also chemical reactions may occur when SPC is used as an encapsulant for nitrate salts. This must be carefully assessed as the Hanford waste contains significant quantities of nitrate. lon exchange resins may rupture the waste products following their encapsulation in SPC due to the resins absorbing moisture from the environment and then swelling. Organic materials are unsuitable wastes for encapsulation because they don't adhere to the matrix.

The use of SPC as a matrix binder is limited to materials which contain little or no water or bound water of crystallization which is unstable below $150-155^{\circ} \mathrm{C}$ otherwise fissures can be formed due to the generation of steam.

Work by McBee et al indicates that aggregates (or wastes) must possess a moisture content $\leq 1 \%$ to obtain a satisfactory waste product. This may require heating the waste to as much as $200^{\circ} \mathrm{C}$ to evaporate any associated water.

Specimens containing sand and fly ash have demonstrated a decrease in compressive strength on their immersion in water. The level of reduced strength was considered to relate to the amount of penetration of water into pores and microcracks in the specimens. A similar effect has been recorded on freeze-thaw cycling (McBee).

It has a good performance in leach test but this assumes that total monolithicity can be maintained over a long time period and the presence of cracks will potentially increase leaching.

There is limited published durability information available on waste forms encapsulated over a long time period.

Consideration if used as a matrix for vitrified wastes:

Cullet when used as an aggregate, would require preheating; and it would be preferable to use single size material. Reasons for single sized aggregate are:

a) when heated the rate of cooling would be more uniform and hence better controlled than for a graded material;

b) whereas "graded" aggregate is preferable in structural concrete and has some advantages regarding pumpability, the use of a single size could enable slightly less sulphur matrix to be used. A slight reduction in some mechanical properties may result but this is not considered to be detrimental;

c) the uniform cooling of single size "aggregate" will minimize shrinkage and cracking problems.

Compared with SPC, sulphur polymer concrete (SC) with conventional aggregates will reduce stress and the reduction will be dependant on the amount of aggregate used. Some reinforcement would still be required. The use of glass fibers will certainly help to control the cracking to a significant effect as conventional concrete but the effect of any fibers in pumping would need to be addressed. 
If larger glass blocks were to be encapsulated these will require to be supported during pouring and setting of the SPC to ensure complete encapsulation. In addition it will be necessary to control the stress patterns in SC generated during the cooling of the glass monolith. The use of glass (or other) fibers for reinforcement will certainly be advantageous and the use of low alkaline glass fibers as used in the Construction Industry could be considered.

A crack free matrix would have the maximum leach resistance. Any form of cracking should be prevented over the required time period. The influx of aqueous media via cracks could result in a high $\mathrm{Ph}$ at the glass-matrix interface which may accelerate the glass corrosion. Any volume increase due to corrosion product formulation would propagate cracking. This point is considered to require significant research input, the leaching properties of the glass obviously playing a dominant role in such a mechanism.

Creep of SC as a concrete matrix with conventional aggregates has been demonstrated to be low. This must be confirmed using only glass as a small aggregate.

Modeling of the very low radiogenic heat output of the glass and the low thermal conductivity of the $\mathrm{SC}$ is needed to predict the maximum temperature of various size matrix blocks.

It is not known if there is any chemical bonding between the SPC and glass and this would need investigating in light of the alkaline nature of the glass and the low chemical resistance of SPC to alkaline conditions. Lack of bonding could result in increased waste penetration and hence glass leach rate.

Potential use of $\mathrm{SC}$ as a mass matrix or as a retrievable product. Retrievability infers the need for removal of either individual blocks or a reasonably practical engineered methodology for cutting a large mass of waste material into handleable size and safety extracting this for further treatment.

Individual blocks of matrix and glass could be:

- Glass cullet as a concreted material with SC contained within a structural element.

- A single large monolith placed in a container and surrounded by SC or SPC.

- A number of medium size monoliths/glass sheets placed in a container and surrounded by SC or SPC.

The latter case requires processing conditions to prevent potential leak paths between glass and the matrix. Also, containers, no matter how carefully stacked, have obvious leaks paths between them.

Containers could be metal (stainless steel is usual or perhaps even mild steel) but the choice would need to be considered carefully, dependant on glass size, container, durability for 80 years or more, and the impact of its corrosion products on the matrix and glass. 
Another option is using a container made from SC; however, it would need to contain reinforcement and suitable lifting arrangements for handling purposes. The use of conventional steel reinforcement is considered unsuitable, but the use of a carbon-fibre and glass fibre type material is possible, as is a type of vapor-deposited flexible metallic fibre (used in some conventional concrete nuclear waste containers in Europe). Even though mechanical properties of SC are similar to more conventional concretes, the use in this scenario would require a prolonged period of research and full scale evaluation.

One possible method of retrieving single "cast in the vault" monolith could be by the use of drilling (or installing at casting stage) an array of accessible vertical and horizontal voids, about 1.5" diameter; these could be filled when required by an expanding Portland-type cement which would create controlled cracks in the monolith to give finite sections for removal. The design of this to ensure the cullet/matrix monolith performance was not affected would be very complex; as would be removal of the individual sections.

Scale up factors for consideration when using SC (11). A principal problem in using SPC and SC is the narrow temperature range in which the material is sufficiently mobile to be processed. There have been trials using boxes approximately $3^{\prime} \times 3^{\prime} \times 3^{\prime}$ with a cullet and SPC mix and these have demonstrated that precise temperature control is necessary for the melting, mixing, pouring and for the final container. On the assumption that SPC and cullet can be transported, it is envisaged that problems may well arise if attempting to produce a large built volume of this material as a uniform block using successive batches of material. This is due to satisfactory bonding between batches and uniform cooling to prevent or minimize cracking.

The physical form of the SPC may control the time taken for initial melting. If the SPC is in flake or other forms, it may be agitated for more uniform and quicker heating. Solid blocks may overheat on their outside surfaces if a high temperature is used. It is anticipated that material would be melted slowly, requiring perhaps 24 hour continuous processing.

Processing SPC and SC would require the use of enclosed facilities with suitable offgas equipment to cope with the $\mathrm{H}_{2} \mathrm{~S}$ and $\mathrm{SO}_{2}$, both of which are corrosive and toxic. This factor will also need to be considered if it is decided to pump and pour a cullet/matrix mix into a disposal vault.

The pumping of SPC, with or without cullet and aggregate (as SC) and particularly over long distances, is seen to present serious problems of temperature control; also pumping pressures with a thick viscous medium are envisaged to be much increased from those used for standard concrete.

Pump blockages and recovery could create major problems and processing down time due to solidification, settling of the cullet, radioactive contamination control and access through secondary and/or tertiary confinement.

All vitrified products would need to be in a well controlled and critically defined thermal environment immediately prior to encapsulation to ensure the SPC and SC would not suddenly cool and form voids. These processing conditions would be different for cullet which would quickly lose heat if exposed to ambient temperature. For glass monolith blocks, differential temperature between interior and exterior of the glass may require a long cooling period causing slumping or creeping of the SC after the initial encapsulation. 
A significant practical problem to be addressed is end-product cooling of SPC and SC and the effect of this on overall product quality. Differences in thermal and shrinkage properties of glass and sulphur may cause matrix cracking. Such cracking will obviously increase the permeability of the matrix and make the waste form susceptible to long-term leaching. It is anticipated that this problem would need to be resolved not just by modeling but by full-scale experimentation.

The requirements for slow and carefully controlled heating, not just of the SPC or SC and glass form but of the waste container together with the need for controlled cooling of encapsulated products suggests extensive processing facilities will be necessary.

Summary of SPC as a matrix material. SPC has been used as a specialty concrete (SC) in limited areas within the construction industry in the USA (McBee et al, 1985). The material has exceptional durability in resisting chemical attack over standard cement systems and has reasonably similar mechanical properties.

Its use as an inert immobilizing matrix for use with toxic, nuclear and mixed wastes has been investigated by various bodies on a laboratory and limited full-scale basis (Mattus et al, 1994; Van Dalen et al, 1989; Mayberry et al, 1993; Darnell et al, 1992; Kalb et al, 1991; Kalb et al, 1990; Fairhall, 1989; Fairhall et al, 1985).

The overall conclusions are that there are four principal areas of potential concern. These are as follows:

a) The capacity of the plant and its functioning within a very close temperature range; including handling and distribution of the hot SPC, would be challenging.

b) Problems associated with differential thermal properties when the end product is cooled must be researched. These will depend on the method of matrix application and glass geometry. Any significant cracks in the matrix in the order of about $0.3 \mathrm{~mm}$ and reaching the outer matrix could negate the advantages of using SPC or SC as an extremely durable and water impermeable material.

c) Matrix-glass interface reactions, if any, are not known but need to be examined in terms of the known problem of poor resistance of SPC to alkalis $(>10 \%)$. This could be relevant since leaching from the glass would be caustic.

d) SPC and SC are relatively new materials compared with conventional concretes and while some accelerated long term testing has been carried out, it is considered further work on this topic is required. Microbiological degradation and SPC's stability to oxidation or reduction in an environment near the earth's surface require modeling and research.

\subsubsection{Observations, Conclusions and Recommendations}

The general conclusion is that while SPC is a potentially acceptable material for immobilization and there are few, if any, current alternative matrices available for very long term performance and use with encapsulated, vitrified, wasteforms, there are still many practical problems to be overcome. Insufficient work has been carried out to demonstrate long term integrity and the solution to these problems will be technically difficult to resolve. 
The review of the alternative encapsulants/matrices indicates that further work with novel cementitious systems should be considered with a view of developing these materials as encapsulants which exhibit a combination of very low permeabilities and hence leach rates together with the enhanced ability to retain active species which are currently known to be difficult to process. 


\begin{tabular}{|c|c|c|c|c|}
\hline \multirow{2}{*}{ ENCAPSULANT } & \multicolumn{2}{|c|}{ PROCESS } & \multicolumn{2}{|c|}{ IMMOBILIZEED WASTE } \\
\hline & ADVANTAGES & DISADVANTAGES & ADVANTAGES & DISADVANTAGES \\
\hline Bitumen & Incorporates Dewatering & $\begin{array}{l}\text { Potential fire hazard. } \\
\text { High temperature process. } \\
\text { Difficult for solid wastes. }\end{array}$ & $\begin{array}{l}\text { High leach resistance. } \\
\text { Low volume. }\end{array}$ & $\begin{array}{l}\text { Potential fire hazard. } \\
\text { Low radiation stability. } \\
\text { Deforms on heating. Low } \\
\text { self-shielding. Not self- } \\
\text { supporting. High creep. }\end{array}$ \\
\hline Cement & $\begin{array}{l}\text { Simple process. } \\
\text { Proven Technology. } \\
\text { Low Process Temperatures. } \\
\text { Removes residual water. } \\
\text { Inexpensive. } \\
\text { Non-combustible. } \\
\text { Versatile - can deal with a wide } \\
\text { range of wastes. }\end{array}$ & $\begin{array}{l}\text { Low initial strength. } \\
\text { Potential for pre-setting in } \\
\text { pipework. }\end{array}$ & $\begin{array}{l}\text { High strength product. } \\
\text { High radiation stability. } \\
\text { Good self-shielding. } \\
\text { Non-combustible product. } \\
\text { Self-supporting matrix. } \\
\text { High pH matrix. } \\
\text { Durable and physically } \\
\text { stable. }\end{array}$ & $\begin{array}{l}\text { Produces gasses by } \\
\text { radiolysis. }\end{array}$ \\
\hline $\begin{array}{l}\text { Polymer Modified } \\
\text { Cements }\end{array}$ & $\begin{array}{l}\text { Relatively simple process. } \\
\text { Proven technology. } \\
\text { Low process temperature. } \\
\text { Removes residual water. }\end{array}$ & $\begin{array}{l}\text { Potential fire hazard. } \\
\text { Expense increases with polymer } \\
\text { content. } \\
\text { Organic solvents required for } \\
\text { washdown. } \\
\text { Short setting times. }\end{array}$ & $\begin{array}{l}\text { Improved strain resistance. } \\
\text { Good self-shielding. } \\
\text { Self-supporting matrix. } \\
\text { High pH matrix. }\end{array}$ & $\begin{array}{l}\text { Reduced radiation } \\
\text { stability. } \\
\text { Organic components. }\end{array}$ \\
\hline $\begin{array}{l}\text { Sulfur Polymer } \\
\text { Cement }\end{array}$ & $\begin{array}{l}\text { Full mechanical strength } \\
\text { achieved on setting. }\end{array}$ & $\begin{array}{l}\text { Limited long term data available. } \\
\text { Poor resistance to alkalis. } \\
\text { Close temperature control required. } \\
\text { Toxic gas produced. } \\
\text { Viscous outside control temperature. }\end{array}$ & $\begin{array}{l}\text { Has potential for very low } \\
\text { permeability. } \\
\text { Satisfactory radiation } \\
\text { stability. } \\
\text { Able to immobilize heavy } \\
\text { metals. }\end{array}$ & $\begin{array}{l}\text { Controlled cooling } \\
\text { required. } \\
\text { Variable porosity. } \\
\text { Long term sulfur stability } \\
\text { suspect. }\end{array}$ \\
\hline Ceramics & None & $\begin{array}{l}\text { Requires high temperatures and } \\
\text { pressure. } \\
\text { Very expensive. } \\
\text { Highly complex process. }\end{array}$ & $\begin{array}{l}\text { Good self-shielding. } \\
\text { Non-combustible. } \\
\text { Self-supporting matrix. } \\
\text { High radiation stability. } \\
\text { Low leaching. } \\
\text { Low volume. } \\
\end{array}$ & $\begin{array}{l}\text { Uncertain performance in } \\
\text { drop tests. } \\
\text { May sustain thermal } \\
\text { stress damage. }\end{array}$ \\
\hline Glass & Limited. & $\begin{array}{l}\text { High temperature process. } \\
\text { Waste requires pre-drying. } \\
\text { Highly complex process. } \\
\text { Complex off-gas treatment. } \\
\text { Expensive. }\end{array}$ & $\begin{array}{l}\text { Good self-shielding. } \\
\text { Non-combustible. } \\
\text { High radiation stability. } \\
\text { Low leaching. } \\
\text { Low volume. }\end{array}$ & $\begin{array}{l}\text { High potential for } \\
\text { fracturing. } \\
\text { Low thermal stress } \\
\text { capability. }\end{array}$ \\
\hline
\end{tabular}




\begin{tabular}{|l|l|l|l|l|}
\hline \multirow{2}{*}{ ENCAPSULANT } & \multicolumn{2}{|c|}{ PROCESS } & \multicolumn{1}{c|}{ IMMOBILIZED WASTE } \\
\cline { 2 - 5 } & \multicolumn{1}{|c|}{ ADVANTAGES } & \multicolumn{1}{|c|}{ DISADVANTAGES } & \multicolumn{1}{|c|}{ ADVANTAGES } \\
\hline $\begin{array}{l}\text { Low Melting Point } \\
\text { Metals }\end{array}$ & Proven casting technology. & $\begin{array}{l}\text { High temperature process. } \\
\text { Waste requires pre-drying. } \\
\text { Very expensive. } \\
\text { Probably toxic. }\end{array}$ & $\begin{array}{l}\text { Good self-shielding. } \\
\text { Non-combustible. } \\
\text { Self-supporting matrix. } \\
\text { Low leaching. } \\
\text { High radiation stability. } \\
\text { Good thermal conductivity. }\end{array}$ & $\begin{array}{l}\text { Probably toxic following } \\
\text { disposal. } \\
\text { Meits under fire } \\
\text { conditions. } \\
\text { High density could } \\
\text { increase transport cost. }\end{array}$ \\
\hline Polymer & $\begin{array}{l}\text { Relatively simple process. } \\
\text { Proven technology. } \\
\text { Low temperature process. } \\
\text { Fast setting. }\end{array}$ & $\begin{array}{l}\text { Potential fire hazard. } \\
\text { Experience increases with polymer } \\
\text { addition. } \\
\text { Organic solvents required for } \\
\text { washdown. } \\
\text { Less tolerant to residual water. } \\
\text { Difficult to encapsulate wet wastes. } \\
\text { High Exotherms. }\end{array}$ & $\begin{array}{l}\text { High strain resistance. } \\
\text { Low permeability. } \\
\text { Self-supporting matrix. }\end{array}$ & $\begin{array}{l}\text { Potential fire hazard. } \\
\text { Reduced radiation } \\
\text { stability. } \\
\text { Organic components or } \\
\text { filler may enhance } \\
\text { equilibrium leaching. }\end{array}$ \\
\hline Resin Sand & $\begin{array}{l}\text { Difficult to encapsulate wet waste. } \\
\text { Requires high temperature for curing. } \\
\text { Requires drying. }\end{array}$ & $\begin{array}{l}\text { High strength product. } \\
\text { Self-supporting matrix. } \\
\text { Good self-shielding. }\end{array}$ \\
\hline $\begin{array}{l}\text { Potentially simple process. } \\
\text { Curring and dewatering }\end{array}$ & $\begin{array}{l}\text { Potential fire hazard. } \\
\text { High porosity product. } \\
\text { Poor leaching } \\
\text { characteristics. } \\
\text { Reduced radiation } \\
\text { stability. }\end{array}$ \\
\hline
\end{tabular}




\section{REFERENCES}

Curwen, S., G. Fairhall, and F. Ridley, 1989. Phase 3a Report for Magnox Swarf.

Darnell, Aldrich, and Logan, 1992. Full Scale Tests of Sulfur Polymer Cement and Non Radioactive Waste in Heater and Unheated Prototypical Containers, INEL Report EGG-WM10109, February, 1992.

Fairhall, G., 1989. DOE/RW/89-050, Objectives and Scope of the Joint Funded BNFL/DoE Product Evaluation Development Programme.

Fairhall, G. A. and F. J. Ridley, 1985. ILWRP(85)P30; Phases 2 and 3 Summary Report for Magnox Swarf.

Kalb, Heiser, and Columbo, 1990. Comparison of Modified Sulfur Cement and Hydraulic Cement for Encapsulation of Radioactive Mixed Wastes, Brookhaven National Laboratory.

Kalb, Heiser, and Columbo, 1991. Modified Sulfur Cement Encapsulation of Mixed Waste Contaminated Incinerator Fly Ash, Waste Management Volume 2, pp 147-153.

Landes, A. J., et al., 1982. PCMITF/P1 Immobilization of Plutonium Residues and Shredded Soft PCM in Bitumen.

Lee, D., 1984. PETF(84)P81 500L Process Trial Using Latex Polymer Modified Cement for Infilling Magnox Swarf.

Maddrel, 1993. TD Memo 534, SYNROC: A Review of Its Development and Performance.

Mattus and Mattus, 1994. ORNL - Evaluation of Sulfur Polymer Cements as a wasteform for immobilization of $L L$ radioactive and mixed waste, ORNL/TM12657, March 1994.

Mayberry, Dewitt, and Darnell, 1993. MWIP Low Level Mixed Final Wasteforms, Volume 1 Technical Area Status Report for US DOE, August, 1993.

McBee, Sullivan, and Fike, 1985. Sulfur Construction Materials, U.D. Department of Interior, Bureau of Mines Bulletin.

Miller, E. W., 1994. R\&D Report No. 106 Vitrified Low Level Waste Disposal Study Task 7 Matrix Wasteprim Study, WHC Task 7 MJB-SWV-312057/010 LATA Task WT100.

Ridley, F. and S. Curwen, 1988. ILWRP(88)P15; Phase 2 Report 2-21 for Plutonium Contaminated Material Incinerator Ash.

Van Dalen and Rijpkema, 1989. Modified Sulfur Cement, A low porosity encapsulation material for low, medium, and alpha waste, Commission of European Communities, Nuclear Science and Technology. 


\subsection{LOW-LEVEL WASTE GEOMETRY}

The decision has been made to vitrify Hanford low level waste prior to disposal. This section of the study aims to assess the advantages and disadvantages of the glass form geometry options available, leading to selection of one (or more) appropriate geometries.

The discussion of the pros and cons relating to each option are followed by a ranking evaluation using a weighted scoring system which considered the most desirable attributes of each. Factors thought likely to influence the performance of the highest ranked option have then been considered in greater detail. The glass manufacturing process itself has not been considered except where appropriate to identify interface issues.

\subsubsection{Requirements}

2.3.1.1 Regulatory Requirements. DOE Order 5820.2A - Radioactive Waste Management Relevant Sections;

1) General public protection. Disposal systems shall be designed to ensure that exposure to any member of the public that results from disposal of solid LLW shall not exceed $25 \mathrm{mrem} / \mathrm{yr}$ Effective Dose Equivalent (EDE) through all exposure pathways for at least 1,000 years after disposal $(10,000$ years in $5820.2 \mathrm{~B})$.

(2) Groundwater Protection. Disposal systems shall be designed to meet the Clean Water Act and the Safe Drinking Water Act as well as ensure that disposal of LLW after $09 / 26 / 88$ does not result in concentrations of radionuclides in groundwater exceeding those corresponding to an EDE of $4 \mathrm{mrem} / \mathrm{yr}$ to any person who might drink 2 liters per day of water from a well drilled into the aquifer, for at least 1,000 years after disposal 110,000 years in $5820.2 \mathrm{~B}$ ). The point of compliance shall be no further than 100 meters from the edge of the waste.

2.3.1.2 System Wide Requirements. Retain as much of the waste as possible for as long as possible within project cost and timeframe constraints satisfying all regulatory performance criteria.

For a given glass formulation, enhance the waste-retention capabilities of the glass product by producing a glass form that maximizes durability, minimizes surface area and water intrusion.

2.3.1.3 Task Specific Requirements. Minimize the total volume of waste. The size and shape of the glass form will impact the total volume of waste in the disposal site.

Provide for Retrievability. The size and shape of glass form must not preclude retrieval of the waste.

Enable transportation and handling of waste. Transportation requirements of the disposal system must be considered. 


\subsubsection{Design Options}

There are three typical sizes that were considered; smail as represented by cullet or marbles, medium as represented by sheet and large as represented by monoliths. These sizes/shapes are not an exhaustive listing, since small cubes or long rods could have also been considered. These three sizes/shapes are all readily manufactured, have highly variable surface area to volume ratios, span the range of possible handling options from bulk handling to individually transported units, and are produced by very different processes. Since these three categories effectively span many parameters of interest, they have been selected for further analysis. Consideration of another size/shape category could be the focus of a future study.

\section{General comments}

The following section discusses several issues which may be detrimental to glass quality and durability and may be applicable to more than one geometry. Cracking, its effect on surface area, and devitrification by crystallization are addressed.

\section{Cracking}

One of the prime reasons for casting large monoliths of product glass is to minimize the surface area which may become exposed to groundwater and thereby become a source of mobile radionuclides arising from the process of leaching. Cracking within large blocks of glass is known to occur if cooling is not controlled and, although difficult, it is important to attempt to assess the increase in surface area which is likely to occur through cracking and the impact this will have on the overall durability of the product.

It is widely accepted that there are two distinct mechanisms that result in cracking in containerized glass monoliths. The first results from internal thermal stresses due to thermal gradients set up when the glass cools too quickly. The cracking which results is observable in the bulk of the glass as radial cracks. The second mechanism results from shear fracturing at the surface of the glass due to the differential thermal expansion of glass and container. Smith et al (1981) have investigated these mechanisms and identified the temperature of their occurrence. Methods of eliminating or reducing their effects on the integrity of the product glass blocks containing highly active (HA) waste simulants were also identified.

\section{Bulk Fracturing}

Above $\mathrm{Tg}$ (the glass transformation temperature), no cracking occurs as the network is mobile. Between $\mathrm{Tg}$ and $400^{\circ} \mathrm{C}$ fracture stresses are large because of the large volume changes and plastic behavior that occur with the temperature differences that exist between the center line of the block and the outer surface.

The cooling rate at this time is very important and bulk cracking can be eliminated if sufficient annealing is allowed. If the cooling rate cannot be sufficiently slow then the outer glass solidifies while the central core is still fluid. Then as the center cools, it contracts and stresses are set up as the outer glass is rigid. Tensile failure occurs. If there are no compressive forces exerted on the external surface of the block, i.e., the container has a lower thermal expansion than the glass or there is no container, then the outer surface of the glass may crack as it shrinks onto the hot, less dense core. 
Slate et al. (1981) concur that the extent of bulk cracking is strongly dependent on the cooling rate. They suggest that thermal fracturing can be controlled using a limited amount of insulation during filling and cooling of containers due to the slower cooling rate and hence lower induced stresses. Like Smith et al, these studies involved Savannah River Laboratory HA waste containers using simulants. The container dimensions were 10 feet long cylinders of 2 feet diameter. A multistage cooling regime was proposed with slow cooling occurring around $\mathrm{Tg}$ and faster cooling before and after this point. They estimated that crack-free ingots would require 18 to 20 days of controlled cooling which could be undertaken in an annealing facility to allow uninterrupted production. Cooling rates of 0.5 to $1.0^{\circ} \mathrm{C} / \mathrm{h}$ have been proposed (Smith, et al., 1981 and Slade, et al., 1981) around Tg to minimize cracking. Such long controlled cooling times would impede production. However containers could be fast cooled to maintain production rate, then reheated and slowly cooled later when more convenient, in an annealing facility. Refusion can be undertaken by raising the block temperature to $\sim 600^{\circ} \mathrm{C}$. One hour was found to be adequate for SNL containers (Smith, et al., 1981). Recovery at such low temperature and short time is expected to minimize crystal formulation. Crystallization occurs faster and more extensively at higher temperatures and longer hold times.

\section{Surface Fracturing}

It is accepted that the majority of the increase in the surface area of a block, due to cracking, takes place near to the outer glass surface due to container interactions. The greater thermal expansion of common container materials, mild steel and stainless steel, causes stress as the outer surface of the glass cools. The container shrinks radially, compressing the glass but also simultaneously drags the glass axially, imparting frictional shear loading on the block surface. This causes circumferential cracking. The fragments resulting from this type of cracking are much smaller than from bulk fracturing, the smallest occurring between 0.5 and 1 inch from the container wall. Suggestions that $1 \%$ of the volume of the glass is responsible for more than $50 \%$ of the total surface area have been made (Slate et al 1981).

Annealing of the product has no effect on surface cracking because the stress arising from differential thermal expansion occurs at all temperatures below the strain point.

Surface fracturing tends to occur below $350^{\circ} \mathrm{C}$ (Slate et al 1981 ). Figure 2.3-1 shows the results of the work of Smith et al, (1981), and the impact of slower cooling on bulk fracturing but its relative ineffectiveness on surface fracturing. The degree of cracking was measured by counting acoustic emissions which were plotted against temperature for containers having different cooling rates.

Amelioration of the situation is possible by mechanical means. Smith et al (1981) and Slate et al (1981) propose a number of solutions such as the use of alumina or graphite containers or liners which have a lower thermal expansion than the glass. Alumina-silica or graphite pastes or papers could, if carefully chosen and applied to the inside of the container, improve the product durability as they could bond to the outer glass surface and decrease the surface fracturing.

\section{Measurement of the Degree of Cracking}

Both Smith et al (1981) and Slate et al (1981) have attempted to quantify the increase in surface area due to cracking in differently cooled SNL containers of glass. Their results for 
calculation of the internal fracture area for fast cool containers ( 25 hours) were in relative agreement at 27 and 35 times the external area. The factor reduced to 17 or 18 for containers cooled over 50 hours and 7 at 100 hours (Slate et al 1981). Slate et al (1981) also noted that if the fines were ignored the factor for very fast cooled containers fell from 27 to 14 (see Figure 2.3-2). This is a reasonable presumption as fractures constitute only a small fraction of the mass, and if made this reduces but does not eliminate the case for controlled cooling, as carefully controlled cooling (i.e, $0.5^{\circ} \mathrm{C} / \mathrm{h}$ ) can reduce the ratio to 2 .

Work carried out in support of British Nuclear Fuels (BNFL) Windscale Vitrification Plant (WVPI and the French AVH facility measured the increase in surface area due to cracking as between 12 and 17 for their products $1400 \mathrm{~kg}$ of non-active simulant glass in cylindrical stainless steel containers $430 \mathrm{~mm}$ in diameter). The WVP container design was based on ensuring that the maximum center line temperature does not exceed $500^{\circ} \mathrm{C}$ in the product store due to the effect of radiogenic heat. The heat output of the waste limited the volume of the container for cask and transport operations.

Cooling curves for three $2 \times 200 \mathrm{~kg}$ pours produced in the UK and two $2 \times 200 \mathrm{~kg}$ pours produced in France are provided as Figures 2.3-3 to 2.3-17. Figures 2.3-4 to 2.3-7 relate to glass poured into a cold container, whereas the containers used for the other four experiments were preheated to $450^{\circ} \mathrm{C}$, (figures $2.3-8$ to $2.3-15$ ), and $650^{\circ} \mathrm{C}$, (figures $2.3-16$ and 2.3-17). The preheat furnace is used to reduce the thermal shock to the container which could result in the formation of stress fields, and also to reduce the degree of cracking which occurs at the surface of the glass ingot due to the high thermal gradient present.

The cooling curves show a cooling rate between 500 and $300^{\circ} \mathrm{C}$ of around $30^{\circ} \mathrm{C} / \mathrm{hr}$ for all containers, with the outer layers of glass leading the center line temperature by about 8 hours. The relatively low bulk fracture found in this type of product may result from this fairly low cooling rate.

BNFLs experience of pouring large glass blocks indicates that cracking, although present, does not necessarily result in a weak unstable product. Around 70 tonnes of nonactive glass as either 100 or $200 \mathrm{~kg}$ blocks was produced by the Full Scale Inactive Facility (FSIF) at Sellafield during the R\&D program. Several mild steel demountable containers were cast and subsequently sampled at different levels and radii. When freed from their molds the blocks did not fall to pieces, as can be seen in figures 2.3-18 and 2.3-19, although some shards did come away from the bulk, possibly due to adherence to the container wall. Some of these blocks were stored for more than a year and others were transported several hundred miles without a container in order to undertake non-destructive tests, with little noticeable damage.

Sampling the glass required breaking it up. This required significant force by sledgehammer and crowbar to break up the blocks. This mechanical stability was further confirmed during commissioning of WVP when stainless steel product containers, holding 400 $\mathrm{kg}$ of non-active glass, were sampled as part of the product quality assurance confirmatory work (see figs 2.3-20 and 2.3-21). This also confirmed that adherence of glass to stainless steel is greater than for mild steel. The containers were sliced open using a grinding wheel and the halves wrenched from the product. Cracking due to thermal stress and container/glass interaction, typical of that found by others (Smith et al (1981) and Slate et al (1981)) can be seen if the top end is examined, but the products remained essentially monolithic. 
Real time radiography and tomography were used by BNFL to provide visualization of the internal details of glass products cast in demountable mild steel containers, $430 \mathrm{~mm}$ in diameter. A total of seven $200 \mathrm{~kg}$ ingots were examined. Each ingot was radiographed at between 1 and 3 degree intervals over $180^{\circ}$. Resolution was 30 to 50 thousandths of an inch. It was expected that cracks greater than $0.1 \mathrm{~mm}$ wide would be observed. Fine cracks were determined by measurement of the mean attenuation coefficient of each tomograph. The amount of cracking observed was low, reflecting the similar level of cracking found in other ingots (Burch et al (1987).

The radiographs and tomographic projections also examined the voids created in the blocks due to shrinkage as the glass core hardens. Voidage in the pours was generally between 0.5 and 1.8 liters with surface areas ranging from 400 to $1100 \mathrm{~cm}^{2}$. Such voids should be expected in large blocks. Their presence slightly increases the surface area available for leaching and would not be conducive to transportation and stacking of uncontainerized products due to the potential weakening of the upper area of the block.

\section{Implications of Cracks on Durability}

The effective leach rate is dependent on the separation between the fracture surfaces. If the enclosing container is assumed to have dissolved/corroded away then there is the potential for the entire glass surface to become exposed to groundwater. However, this will be very dependent on the storage conditions within the repository, i.e., whether there can be significant movement of blocks resulting in mechanical shear to open the fractures. For many of the fractures the shard separations would be very small and penetration by ground water, ever by capillary action is unlikely. Even if it does, the flowrate in the crack is likely to be so slow that the leachate becomes quickly saturated and leach rates would be lower than at the external surface.

Westsik et al (1981) plotted the normalized release (material leached) i.e., release based on the total surface area, at specific points in time versus the ratio of crack surface area (SAC) to total surface area (SAt) (Figure 2.3-22). Loose, well-spaced pellets were used to represent an infinite crack width. The plot shows that there is no appreciable leaching from cracks of nominally zero crack width and also that the normalized release for the sample with $0: 038 \mathrm{~cm}$ crack width is less than that of the external surface by as much as 2 to 5 times.

Large containers having a lower surface-to-volume ratio should have a lower cooling rate, and therefore may exhibit less cracking in the bulk glass due to the process of selfannealing. Although cracking resulting from higher thermal gradients existing within the glass may degrade this benefit, the reduced surface layer, where the majority of cracking occurs from container interactions, will probably result in less cracking overall and, therefore, a more durable product.

\section{Crystallization/Devitrification}

When glass is held for extended periods of time at or around its Tg there is a potential for crystalline phases to appear. Crystallization is most marked on the surface of the glass, along cracks and around bubbles. In general crystallization is an unwanted process, although a small amount is tolerable in the glass. 
Slow cooling associated with large product blocks has the potential to increase crystallization. However, the experience of Westsik et al (1981) and BNFL has been that crystallization is limited even over prolonged periods, and that the leach rates of devitrified glasses are similar to normal glasses.

The cooling curves for BNFL containers (fig 2.3-4 to 2.3-17) show the center line cooling time from pour initiation to $500^{\circ} \mathrm{C}$ is up to 16 hours. Experiments designed to determine the temperature which maximizes crystallization in BNFL glass over the short-term (16.5 hours) produced the result of $650^{\circ} \mathrm{C}$ (Rowley et al 1984). It was estimated that with the radiogenic heat present in highly active waste the center line temperature on WVP would be around $650^{\circ} \mathrm{C}$ for 16 hours under normal conditions and in the worst case 2 weeks. Laboratory examination and assessment of heat treated samples showed that for a residence time of 16.5 hours at $650^{\circ} \mathrm{C}$ the total volume fraction of precipitated solids was less than $5 \%$, typically 2 to $3 \%$. Increasing the waste incorporation rate above normal $125 \mathrm{wt} \%$ waste oxides) also increased crystallization. Samples held for 2 weeks at $650^{\circ} \mathrm{C}$ resulted in a crystallized volume fraction of about $10 \%$, with normal waste loading. Analysis of the products from the Full Scale Inactive Facility and from commissioning trials at WVP supported these findings, in that very little crystallization was found.

Density changes for the BNFL heat-treated glasses were also very small, as would be expected from the limited degree of crystallization which occurred. Density increases of less than $0.2 \%$ were observed with normal waste loaded glasses exposed to short-term heat treatment and less than $1 \%$ for samples treated at $650^{\circ} \mathrm{C}$ for 2 weeks. Density increases were again dependent upon waste incorporation rate.

Analysis of the products from the FSIF and from commissioning trials at WVP supported these findings, in that very little crystallization was found. Experiments using laboratory prepared glasses have demonstrated that a volume fraction of $10 \%$ crystallization does not affect the durability of the products. Long-term studies, heat treatment for 1 year at between 450 and $550^{\circ} \mathrm{C}$, showed only $2 \%$ by volume crystallization and even at $550^{\circ} \mathrm{C}$ the figure was only $6 \%$. All values for bulk and elemental leach rates were within the range expected for as cast glass of this composition. Hence it was concluded that there was no measurable change in the chemical stability of the glasses studied even after this extended heat treatment (Rowley et al. (1984), Johnson et al. (1985), Charteris et al. (1989), Magrabi et al. (1987), Foster et al (1989)). This has positive implications for large castings of low level waste glass and the extended cooling times associated with such blocks. With little or no radiogenic heat present crystallization is unlikely to be a major problem and any impact on durability should be minimal.

2.3.2.1 Monoliths. Monoliths are manufactured in one of two ways; either by hot pour into a mold with extraction from the mold to allow cooling and annealing, or by hot pour into a metal container followed by cooling and annealing of the containerized glass.

Monolithic Glass Block (Without Container). General System description. Glass from the melter is poured into a series of prepared molds via a feed carrousel and allowed to cool until solid. The glass is then extracted from the mold and moved into a storage area where it is left to cool and anneal for several weeks. Following cooling the glass is decontaminated lif possible), placed in a sealed transport package and moved to the disposal site in a shielded transport container. At the disposal site the monolith is removed from the transport package and placed in a disposal vault where it would be surrounded by a barrier system. 
Monolithic Glass Block in a Container. General system description. In this option a preheated metal container is filled directly with liquid vitrified waste in a single pour. A carrousel or similar device will be used to feed the containers to the melter to maintain throughput. The carrousel will be sized so as to allow the container to remain on the carrousel until the glass temperature cools to a point where it can be moved. The filled containers would be allowed to cool in a storage area until a temporary waterproofing cap can be added and the outside of the container decontaminated to an acceptable level. The containers would then be moved out of the initial storage area to a welding cell where a lid would be permanently welded in place.

Cooling. The cooling rate of any block (presently uncertain) will play a significant role in determining the cost effectiveness of the chosen glass volume. The effect on the process throughput of slow-cooling glass blocks would be a requirement to build a radioactively contained storage facility of sufficient size to hold the total output of the vitrification plant until the glass block has cooled sufficiently to allow further handling. This handling could include decontamination and sealing. Sealing could be accomplished by fitting a 'shrink fit' plug in the neck of the container as per existing WHC design followed by decontamination and the welding in place of the permanent container lid. This would be completed as soon as possible allowing the filled containers to be moved to a second storage area for any remaining cooling (likely to be weeks but the actual duration is not known). The second storage area would need to provide shielding but would not require contamination control facilities.

Container liners - A liner material can be added within the container to reduce surface cracking caused by glass bonding to the stainless steel and the differential expansion rates of the glass and container. For further information see section 2.4.2.1 and 2.4.2.2.

2.3.2.2 Cullet/Marbles. Cullet is manufactured by pouring molten glass into a water quenched flume. As the glass enters the flume, the resultant thermal shock shatters the glass into small irregular fragments. The glass is further size reduced by mechanical means and then dried using hot air or ovens before it is loaded into a hopper or container.

Marbles are produced either by molds (possibly water cooled) or by chopping and rolling poured streams of glass into spherical shapes. Following manufacture, the marbles are transported to storage hoppers or fed directly into containers. In this report the term marble also includes other small regular shapes such as gems, etc.

For the purpose of this report cullet and marbles are considered together.

Once manufactured, cullet/marbles can become the basis of a number of final product forms, namely;

i) Pouring the cullet/marbles directly into a container for transport/storage

ii) Pumping/blowing cullet directly to a disposal vault

iii) Mixing the cullet/marbles with a matrix material and pouring it into a container for transport/storage

iv) Producing a cullet/marbles/matrix block using a mold 
v) Pumping a cullet/marbles/matrix mix directly to a disposal vault

The use of a matrix material is discussed in detail in sections 2.2 and 2.4 and so will not be considered further in this section. Only Items i) and ii) will be evaluated. For further information see section 2.4.2.5. and 2.4.2.7.

2.3.2.3 Sheet Glass. Sheet glass can be produced up to $25 \mathrm{~mm}$ thick on glass industry standard production equipment in the quantities required at Hanford (135 tonnes/day). The process can be fully automated including glass handling and stacking. The glass can be annealed and cooled on the same continuous production line and can be automatically cut into rectangular sheets and stacked into containers.

As part of this continuous process, it may be possible to decontaminate the glass sheets using a high pressure water spray and pass the contamination free sheets to a 'clean' containerization area.

Breaking the glass sheets during transportation or stacking is a potential problem as this would increase the surface area available for leaching. For further information see section 2.4.2.4.

\subsubsection{Methodology to Evaluate Options}

A number of options were assessed using a simple ranking system. The qualities most required of the product were weighted in order of their perceived importance. Each option was then assigned a score against each of the qualities based on an appreciation of product geometries and their properties. Six qualities were chosen for this exercise.

(i) Surface area exposed to groundwater in the long-term, and hence the potential durability of the product

(ii) Glass Quality

(iii) An assessment of the ease of transportation and handling of the products

(iv) The retrievability of the products in terms of exhuming the material from the vault and including the ease of recovery in case of a requirement to remelt or repackage the product

(v) The production of secondary wastes, both liquid and solid/mechanical

(vi) The waste volume occupied following vitrification of the total inventory

The scoring ranges selected for each of these qualities was as follows:

Glass Quality

Surface Area

Transport and Handling

Retrievability

$\begin{array}{lll}5 & \Rightarrow & 100 \\ 5 & \Rightarrow & 100 \\ 5 & \Rightarrow & 80 \\ 5 & \Rightarrow & 50\end{array}$




$\begin{array}{llll}\text { Secondary Waste } & 5 & \Rightarrow & 50 \\ \text { Waste Volume } & 5 & \Rightarrow & 50\end{array}$
preferable.

The weighting reflects the relative importance of the attributes, high scores being

2.3.3.1 Glass Quality. Monolith in Container/Free Standing Monolith. For this study durability was highlighted as the most important consideration and large monoliths in containers score highly in this regard, especially in the short-term when the integrity of the container is still maintained. However, for performance assessments, the container is assumed to have corroded or been breached, thus leaving the glass exposed to attack by ground water.

The mechanical stability of the monolith is then important and studies have shown that surface cracking due to container/glass interactions and bulk cracking resulting from thermal stresses, which arise as the block cools, could result in a significantly larger potential surface area, and hence leach rate, than the monolith, although this would still be much lower than cullet. This subject is considered in detail in section 2.3.2. Options are available to minimize cracking such as controlled cooling and the use of container liners which would not impart stresses on the glass, as their thermal expansions are similar. Crystallization also becomes more likely with large monoliths although there is evidence that this has little or no impact on the durability of the product (see Section 2.3.2.).

Production of a free-standing monolith would require the use of a mold and probably necessitate the use of a release agent. This would ensure that the glass did not adhere to the mold as it cooled for a reasonable period of time before demoulding. Bulk cracking would occur without annealing and surface cracking would occur unless liners or pastes were used to avoid the differential thermal expansions of the glass and mold. Molds would also have to be preheated to avoid thermal shock of the outer glass layer.

Production of glass monoliths would result in reasonably good quality glass but with a number of surface cracks which would increase the surface area and therefore affect the leach rate. A score of 85 is given to the monolith option for glass quality.

\section{Cullet/Marbles}

As cullet is manufactured by a quenching process, the cracking and crystallization caused by cooling/annealing are not encountered. Consequently the quality of the glass product is good. It is noted that fine particles are produced during cullet manufacture. However these are typically removed during washing and are returned to the melter for rework. The marble manufacturing process can also be regulated to produce good quality glass. A score of 95 is given to cullet/marbles for glass quality.

\section{Sheet Glass}

The sheet glass process produces a very high quality product as the cooling/annealing of $25 \mathrm{~mm}$ thick glass sheets can be accurately controlled producing a product free from fractures and cracks. A score of 100 is given for produced glass quality. 
2.3.3.2 Surface Area Exposed to Groundwater. The following formulas were used to determine the surface area (A) to volume (V) ratio of the glass forms under consideration;

(1) Sphere (of radius $R$ )

(2) Cylinder (of radius $\mathrm{R}$ and height $\mathrm{H}$ )

(3) Rectangular (of height $H$, width $W$, Length L)
$A / \mathrm{V}=3 / \mathrm{R}$

$A / V=2 \pi R(R+H) / m R^{2} H$

$A / N=2(H W+H L+W L) / W L H$

Cullet was considered to be a cube with sides of 0.125 " (although in practice cullet is of irregular shape with a varying surface area to volume ratiol

A cylinder with $\mathrm{H}=2 \mathrm{R}$ gave the best surface area to volume ratio for cylinders. Cubes gave the best surface area to volume ratio for rectangular blocks.

Sheet glass was considered to be of a rectangular form $12.7 \mathrm{~mm}$ high by $1.5 \mathrm{~m}$ wide.

Using the above equations, the following results were obtained:

1) Cullet - Using the definition of cullet given above, its surface to volume ratio was determined to be $2000 \mathrm{~m}^{-1}$.

2) Spheres - The table below shows the surface to volume ratio of a number of spheres ranging from $1 \mathrm{~mm}$ and $4 \mathrm{~mm}$ marbles to large spheres ranging between 1 and $5 \mathrm{~m}^{3}$.

\begin{tabular}{|c|c|c|}
\hline Sphere Dia. & Sphere Vol. & Surface Area to Volume Ratio \\
\hline $1 \mathrm{~mm}$ & $5.23 \times 10^{-10}$ & 5998 \\
\hline $4 \mathrm{~mm}$ & $3.35 \times 10^{-8}$ & 1500 \\
\hline $1.24 \mathrm{~m}$ & $1 \mathrm{~m}^{3}$ & 4.84 \\
\hline $1.56 \mathrm{~m}$ & $2 \mathrm{~m}^{3}$ & 3.83 \\
\hline $1.80 \mathrm{~m}$ & $3 \mathrm{~m}^{3}$ & 3.35 \\
\hline $1.92 \mathrm{~m}$ & $4 \mathrm{~m}^{3}$ & 3.05 \\
\hline $2.12 \mathrm{~m}$ & $5 \mathrm{~m}^{3}$ & 2.82 \\
\hline
\end{tabular}

3) Plate Glass - A series of plate glass lengths ranging from 1 to $5 \mathrm{~m}$ were considered. The surface volume to area ratios are presented in the table below.

\begin{tabular}{|c|c|c|c|}
\hline Length $(\mathbf{m})$ & Volume $\left(\mathbf{m}^{\mathbf{3}}\right)$ & Surface Area $\left(\mathbf{m}^{\mathbf{2}}\right)$ & Ratio $\left(\mathbf{m}^{-1}\right)$ \\
\hline 1 & 0.02 & 3.06 & 160.8 \\
\hline 2 & 0.04 & 6.09 & 159.8 \\
\hline 3 & 0.06 & 9.11 & 159.4 \\
\hline 4 & 0.08 & 12.10 & 159.3 \\
\hline 5 & 0.10 & 15.20 & 159.2 \\
\hline
\end{tabular}


As can be seen from the above table, there is no benefit from increasing the length of the sheet glass with regards to surface area.

4) Cylindrical Monolith - Again, a series of glass volumes were considered ranging from 1 to $5 \mathrm{~m}^{3}$. The surface volume to area ratios are presented in the table below.

\begin{tabular}{|c|c|c|c|}
\hline Volume $\left(\mathbf{m}^{\mathbf{3}}\right)$ & Diameter/Height $(\mathbf{m})$ & Surface Area $\left(\mathbf{m}^{\mathbf{2}}\right)$ & Ratio $\left(\mathbf{m}^{-1}\right)$ \\
\hline 1 & 1.08 & 5.54 & 5.54 \\
\hline 2 & 1.37 & 8.78 & 4.39 \\
\hline 3 & 1.56 & 11.52 & 3.84 \\
\hline 4 & 1.72 & 13.96 & 3.49 \\
\hline 5 & 1.85 & 16.20 & 3.24 \\
\hline
\end{tabular}

5) Rectangular Monolith - Results are presented in the table below.

\begin{tabular}{|c|c|c|c|}
\hline Length of side & Volume $\left(\mathbf{m}^{3}\right)$ & Surface Area $(\mathbf{m})$ & Ratio $\left(\mathbf{m}^{\mathbf{2}}\right)$ \\
\hline $1 \mathrm{~m}$ & 1 & 6 & 6.0 \\
\hline $1.26 \mathrm{~m}$ & 2 & 9.52 & 4.76 \\
\hline $1.44 \mathrm{~m}$ & 3 & 12.48 & 4.16 \\
\hline $1.59 \mathrm{~m}$ & 4 & 15.12 & 3.78 \\
\hline $1.71 \mathrm{~m}$ & 5 & 17.54 & 3.51 \\
\hline
\end{tabular}

Of these, the sphere has the best surface area to volume ratio followed by the cylinder and then the cube, e.g., for a $5 \mathrm{~m}^{3}$ product the ratio of surface area to volume are $2.82,3.24$, and 3.51 respectively. Large sphere manufacture, though possible, would require a container or mold which was stable and not prone to rolling, thus either flat bottomed or otherwise stabilized. The efficient use of vault space would be compromised by using such a container geometry. The cylinder, with diameter equal to height, approximates a spherical container with a flat base. The vertical sides improve space utilization in the vault and the flat upper surface is conducive to stacking containers one upon another. The fabrication of cylindrical containers is also fairly simple.

The cubic waste form may appear to be the best in terms of vault space utilization but has a higher surface area to volume ratio than the cylinder and thus higher leaching area in total. Also the fabrication of a cubic container is more complicated than a cylinder.

The optimum size for a cylindrical monolith depends on more than just the ratio of surface area to volume. As the volume increases the gains made in terms of the ratio of surface area to volume diminish.

Cylindrical containers have been used in the past for storage of vitrified high-level waste. The ratio of height to diameter for these has been significantly greater than one to one due to the need to dissipate radiogenic heat. With low level waste this consideration is not 
important but the time taken to lose process heat and the risk of devitrification are higher with low surface area to volume container shapes, although studies have shown that durability is not reduced significantly for simulated highly active wastes due to limited devitrification. Studies involving simulated Hanford low-level waste are necessary to confirm this observation.

Changing the ratio of the height to diameter for a cylinder to $2: 1$ does not significantly affect the surface area to volume ratio. For a $5 \mathrm{~m}^{3}$ monolith the ratio rises from 3.24 to 3.44 and for $10 \mathrm{~m}^{3}$ from 2.57 to 2.72 . The ratios are still less than that for comparable volume cubes.

Assuming the following data, it is possible to compare the time that it would take the various glass forms to corrode away completely, and to estimate the rate of release of inventory. The assumptions are:

1) Constant glass corrosion rate of $5 \times 10^{-7} \mathrm{~g} / \mathrm{cm}^{2} /$ day (neglecting the effect of any vault, container or matrix material). (This data has been obtained from BNFL PIC and is the corrosion rate for Sellafield vitrified HLW borosilicate glass obtained by Static test at $25^{\circ} \mathrm{C}$.

2) All the glass is available for corrosion immediately after the disposal site is closed.

3) The glass is of good quality i.e., no effect of cracking/devitrification has been taken into account.

4) The total volume of glass in the disposal site is $210,000 \mathrm{~m}^{3}$.

5) The density of the glass is $2.7 \mathrm{~g} / \mathrm{cm}^{3}$.

The following results are obtained:

\begin{tabular}{|l|c|c|}
\hline & Time to Dissolve (yrs) & Loss of Inventory / year \\
\hline Cullet & 789 & $1.3 \times 10^{-3}$ \\
\hline $3 \mathrm{~m}$ long plate glass & 9739 & $1.0 \times 10^{-4}$ \\
\hline $3 \mathrm{~m}^{3}$ Rectangular Block & 355,637 & $2.2 \times 10^{-6}$ \\
\hline $3 \mathrm{~m}^{3}$ Cylindrical Block & 385,944 & $2.6 \times 10^{-6}$ \\
\hline $3 \mathrm{~m}^{3}$ Sphere & 445,746 & $2.2 \times 10^{-6}$ \\
\hline
\end{tabular}

It is apparent from the table above that glass cullet has the highest dissolution rate of all the glass geometries reviewed.

One possible option to alleviate this problem would be to encapsulate the glass in an impermeable matrix barrier. Reducing or eliminating water ingress to the glass would reduce the glass corrosion/leach rate. The use of an encapsulating matrix material would equally reduce the corrosion/leach rate for all glass geometries. The use of matrix materials was discussed in section 2.2. 
It is also initially apparent that plate glass is not particularly durable; however, the exposed surface area for leaching is probably much better than it appears. Flat glass sheets can be produced, which when stacked upon each other, reduce the area available for leaching significantly, such that the stack of sheets approximates a monolith of the same stack dimensions.

The scoring of the alternatives for surface area exposed to groundwater is as follows:

$\begin{array}{ll}\text { Monolith } & \text { (score 90) } \\ \text { Cullet } & \text { (score 5) } \\ \text { Sheet Glass } & \text { (score 80) }\end{array}$

2.3.3.3 Transport and Handling. Use of Containers. The transport of cullet/marbles, monoliths or sheet glass within a suitable container presents few problems. Containers can be sealed with a welded lid and decontaminated to acceptable levels. Transport can proceed using existing technologies of cranes and road/rail transportation.

Handling of cullet/marbles and monoliths within the vitrification facility is simple, however plate glass would require more sophisticated handling techniques to prevent breakage while stacking in containers is being carried out.

Monoliths or Cullet/marbles in containers are given a score of 80 , while sheet glass in a container is given a score of 60 .

\section{No Containers}

The transportation of monoliths or cullet/marbles without containers would have many difficulties and safety considerations. If free standing monoliths could be produced and safely transferred to the vault, it should be noted that the primary containment is now the vault itself unless the monoliths are entombed by a matrix of some sort. The containerless option is only given a score of 10 .

\section{Pumping}

The difficulties of pumping cullet/marbles (and cullet/marble/matrix) are discussed in section 4 (Transportation) of this report. This option is also only given a score of 10 .

2.3.3.4 Retrievability (and possible rework). Containerized waste forms are easily retrievable from the vault if required, however only the cullet is in a form that could be easily reworked if required. The monolith and the sheet glass would need to be removed from their containers and sized reduced to allow rework. Removing the monolith from its container would be a difficult task, giving the uncontainerized monolith an advantage here.

Cullet/marbles that have been pumped into a vault can be retrieved using various types of mechanical systems. Contamination control, due to the fines produced during the initial pumping operation and retrieval, would be onerous. Contamination control would also be required of the monolith without a container. 
Scores of the alternatives for retrievability are as follows:

monolith + container (score 50)

cullet + container (score 50)

sheet glass + container (score 50)

monolith without container (score 30)

cullet pumped to vault (score 30 )

2.3.3.5 Secondary Waste. Monolith With or Without Containers. Secondary wastes are minimized, although there would be decontamination liquid from container or block washing prior to transport. There would be as little mechanical waste generated by this process as any other possible option. This alternative is given a score of 50 for secondary waste generation.

\section{Cullet/marbles}

Cullet is usually made by pouring molten glass into water. This produces a secondary waste stream of contaminated water which must be recycled. The cullet must be dried using hot air or ovens before it can be loaded into the container. The humid, contaminated air stream must be treated. Marbles are produced either by molds or by chopping and rolling poured glass streams, which require specialized mechanized plants. Any pipework or equipment used to transfer cullet to the vault would also become a secondary waste. A score of 25 was given for these alternatives.

\section{Sheet Glass}

The disadvantage of sheet glass production is that the process involves the use of several process stages which come into direct contact with the glass product. The mechanical items involved would become contaminated, making maintenance difficult and following failure would eventually become secondary waste. If the glass is made by the float glass process, the molten tin used to float the glass during production would also become a secondary waste. This alternative is given a score of 30 .

2.3.3.6 Waste Volume. Containers. An advantage of a containerized system is the efficient use of repository volume. If containers are carefully designed they could be stacked several high in close formation possibly achieving a density packing of around $85 \%$ with remote operations.

A disadvantage of cullet/marbles compared with a monolith in a container is that the packing density of cullet or marbles is approximatly $20 \%$ less and more storage space is required.

Scores are as follows:

monolith + container (score 40)

cullet/marbles + container (score 25)

sheet glass + container (score 40) 


\section{Pumped System}

Pumping cullet/marbles directly to the vault eliminates space that would be taken up by containers and is given a score of 35 .

\section{Option ranking table}

The ranking exercise produced the following result:

\begin{tabular}{|l|c|c|c|c|c|c|c|}
\hline & $\begin{array}{c}\text { Glass } \\
\text { Quality }\end{array}$ & $\begin{array}{c}\text { Surface } \\
\text { Area }\end{array}$ & $\begin{array}{c}\text { Transport } \\
\text { and } \\
\text { Handling }\end{array}$ & Retrievable & $\begin{array}{c}\text { Secondary } \\
\text { Waste }\end{array}$ & $\begin{array}{c}\text { Waste } \\
\text { Volume }\end{array}$ & $\begin{array}{c}\text { Total } \\
\text { Monolith + Container }\end{array}$ \\
\hline Cullet + Container & 95 & 90 & 80 & 50 & 50 & 40 & 395 \\
\hline Free Standing Monolith & 85 & 90 & 10 & 30 & 50 & 40 & 305 \\
\hline Cullet pumped to vault & 95 & 5 & 50 & 50 & 25 & 35 & 260 \\
\hline Sheet Glass + Container & 100 & 80 & 60 & 50 & 30 & 40 & 360 \\
\hline
\end{tabular}

The results of the ranking exercise suggest that two options stand out as being the preferred glass forms, namely the monolith in container and the sheet glass in container.

\subsubsection{Observations, Conclusions, and Recommendations}

The results of the assessment performed in this study are that there are two options which are scored highest. These are the glass monolith in a container, and glass sheets packaged in a container.

The primary requirement is minimal loss of glass and this can be met by both of the above options. Both options limit the surface area available for leaching; but in the long term, once the container (anticipated life 80 years) has corroded, the glass will be exposed directly to the ground water. An initial performance assessment produced by WHC, (Rawlins et al. 1994), stated that a fractional release of 1 part per million from the engineered system is needed to meet the drinking water dose objective of 4 millirem per year. They further stated that because of modeling uncertainties a lower fractional release limit should be used in design requirements. It is not believed that vitrified waste can achieve this level of leach resistance without additional protection. Back-filling or overpacking with a suitable barrier material would possibly protect the glass. (See 2.4 Matrix materials, 2.3 Packaging and 3.0 Engineering Barriers).

The sheet glass process can be of very high throughput, up to 5000 te/wk. Glass of up to one inch in thickness is readily produced in sheets twelve feet square. Each sheet is annealed prior to cutting using computerized machines. Warehouse and stacking facilities can also be fully automated. The quality of the product can therefore be closely controlled and as mentioned earlier the surface area available for leaching would be less than the actual surface area because of the reduced leach rate from fine cracks, which in effect is what the separation between glass sheets would approximate. The main disadvantages with this process are the secondary equipment waste generation and maintenance of the conveying rollers and other equipment on the production line. 
Production of a glass monolith is the simplest option. Cylindrical containers of a large volume could be produced with few problems. Graphite or alumina liners or graphite or silicaalumina pastes on the inner wall of the container could be utilized to eliminate cracking near the surface of the glass due to the differential expansion of the glass and container material. Also, annealing in a separate facility may be required to avoid bulk cracking due to the thermal stresses caused by a more rapid cooling. The monolithic product would have an excellent surface area to volume ratio and as stated earlier, overpacking with a matrix/barrier material should improve inventory retainment in the long-term. (Overpacking is an option available to sheet glass containers and cullet/marble containers alike).

The shape chosen and the size of the monolith, will depend partially on the handling requirements, transport methods and requirements, casking arrangement and storage implications. Also of major importance are the filling, cooling and annealing processes which must fit in with the required plant throughput. By taking all these factors into consideration, the maximum advisable package size is $10 \mathrm{~m}^{3}$. It would weigh about 26 .tonnes with possible dimensions of height $3.72 \mathrm{~m}$ and diameter $1.86 \mathrm{~m}$. However, cooling a block of this size could take from 4 to 10 weeks depending on the amount of cracking acceptable. Large cooling and storage areas would also be required. (See section 2.4.) At this time a preferred size of monolith cannot be stated as there are many uncertainties requiring clarification. Few large monolithic glass blocks have ever been cast. Experimental knowledge of the extent of cracking, durability of the chosen formulation (with waste encapsulation), crystallization effects and the length of time required to cool/anneal to prevent cracking will be required.

Knowledge of the relative cooling times of various sizes of monolithic block and the anticipated sizes and costs of the various cooling storage areas will also be required as this will further influence the economic choice of monolithic block size.

Both sheet glass and monoliths would be easily retrievable. The containers would be cut open, the sheet glass removed and crushed for remelting if required, or the monolith crushed and separated from the container.

This initial assessment of the waste form geometry options indicates that the preferred choice should be either glass monolith in a container, or a sheet glass production process with sheets stacked in a container. Each one has advantages and disadvantages associated with it and at this time a definite choice between them cannot be made. Further work is required to study these options taking into consideration the actual glass manufacturing processes in detail and the effect of waste composition variations on the glass properties before a final choice is made. 
Figure. 2.3-1 Fracture in waste glass during cooling

(Smith et al. 1981)

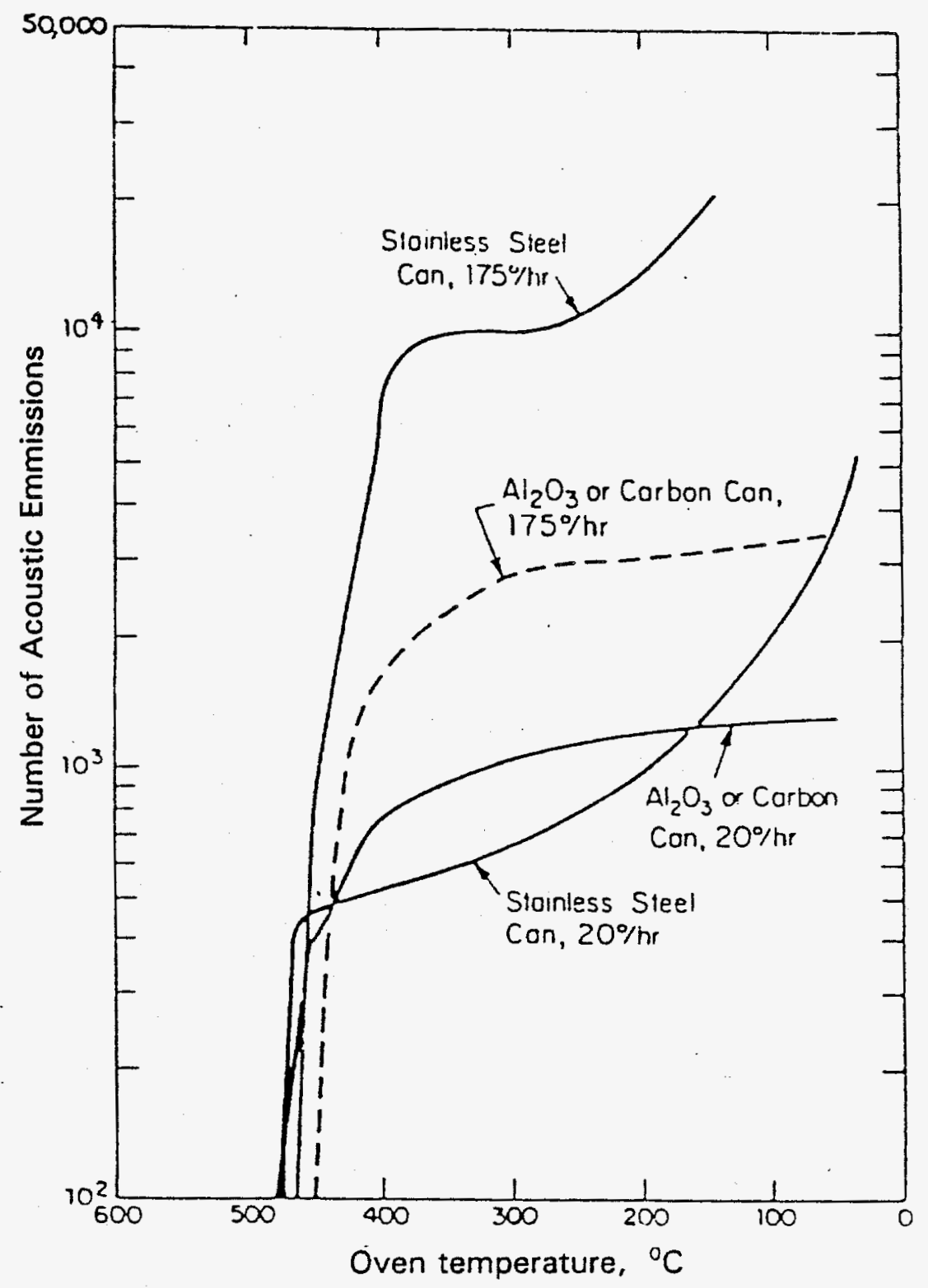


Figure 2.3-2 Effect of cooling time on relative surface area of thermal cracks in glass cast in $60 \mathrm{~cm}$ dia. carbon steel canisters

(Slate ot al. 1981)

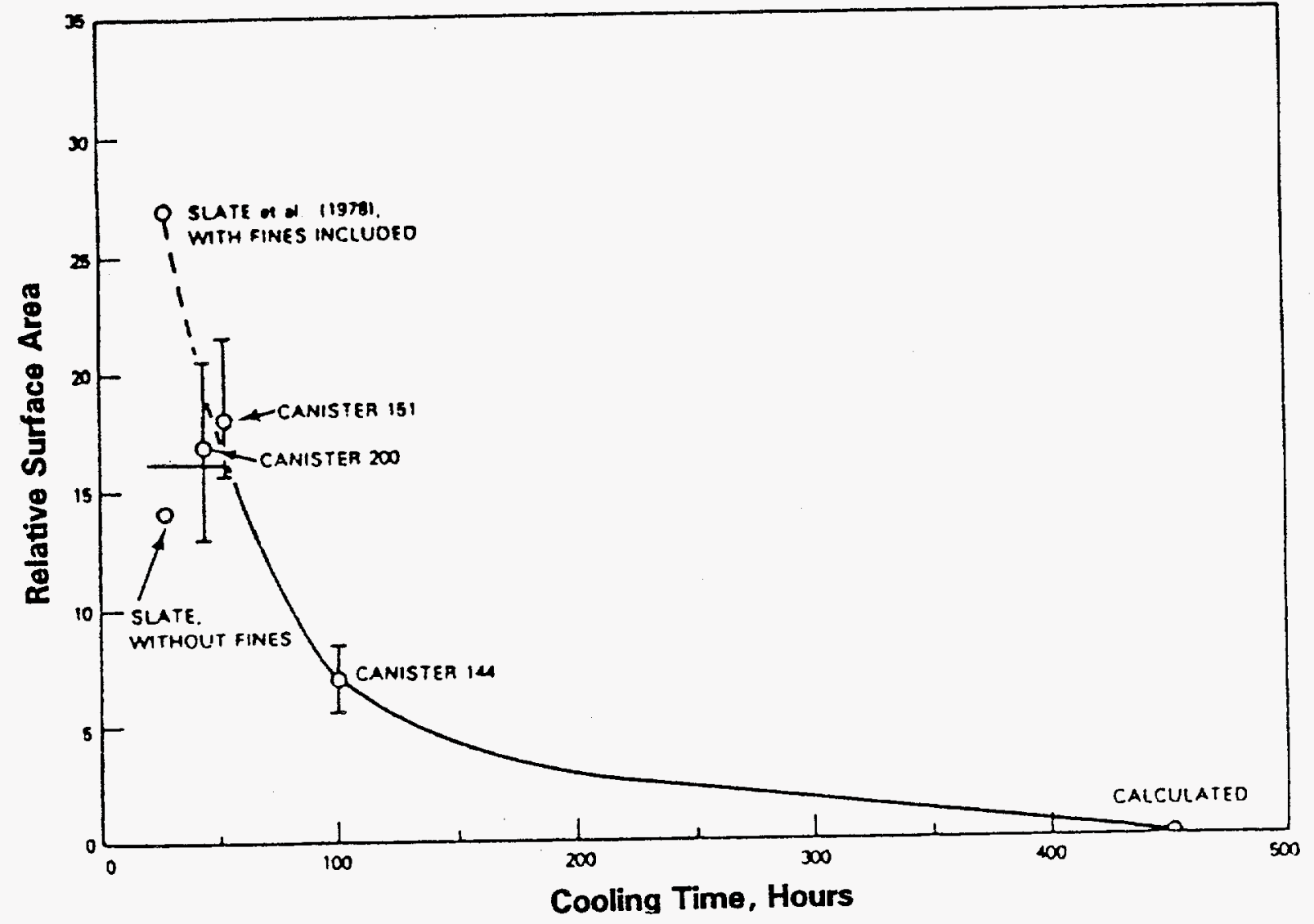


Figure. 2.3-3 THERMOCOUPLE POSITIONS AND NUMBERS IN BNFL VITRIFIED WASTE CONTAINERS USED TO PRODUCE COOLING DATA

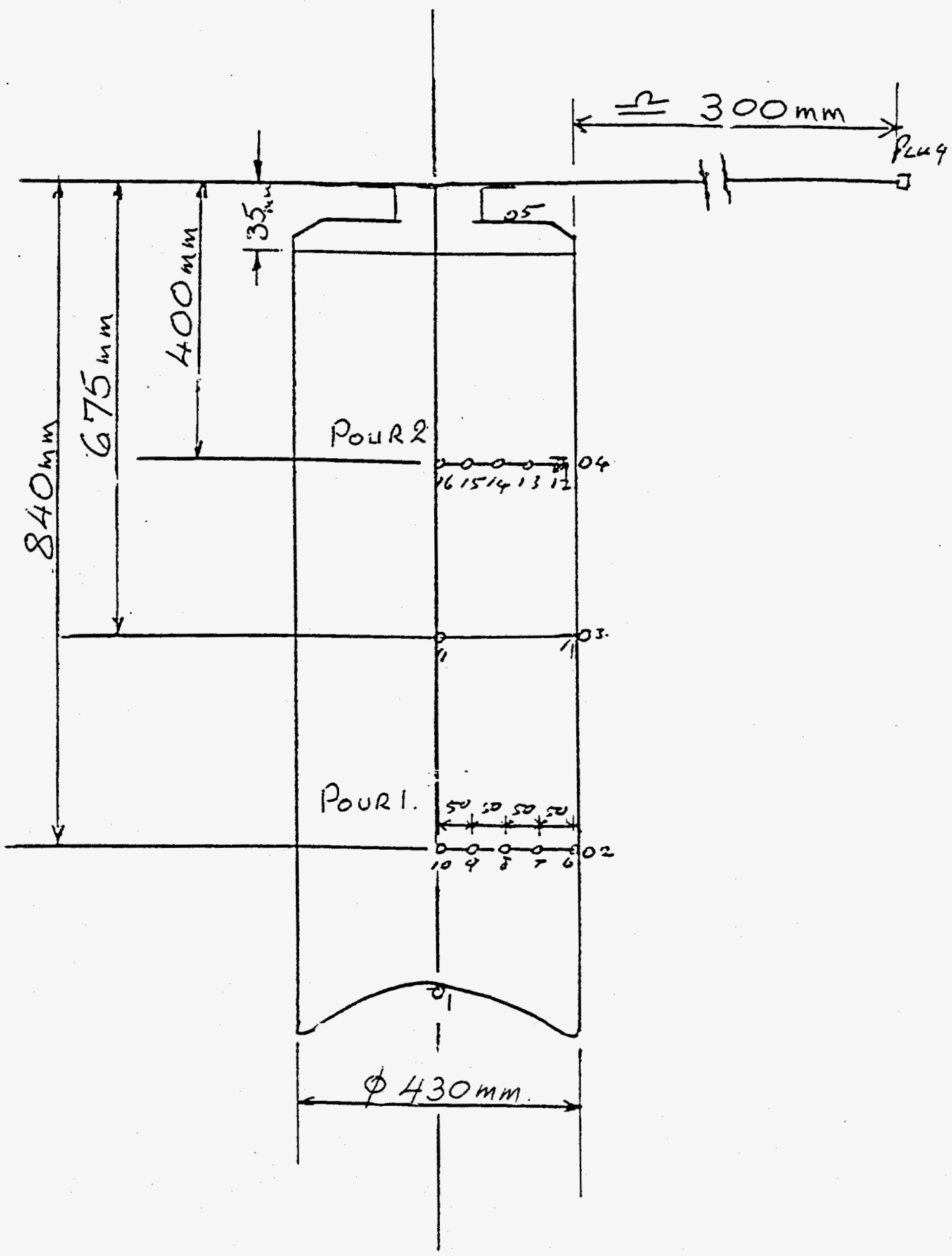




\section{AVH CONTAINER 309/5-GLASS POUR-Oct.1986}

\section{External Thermocouples}

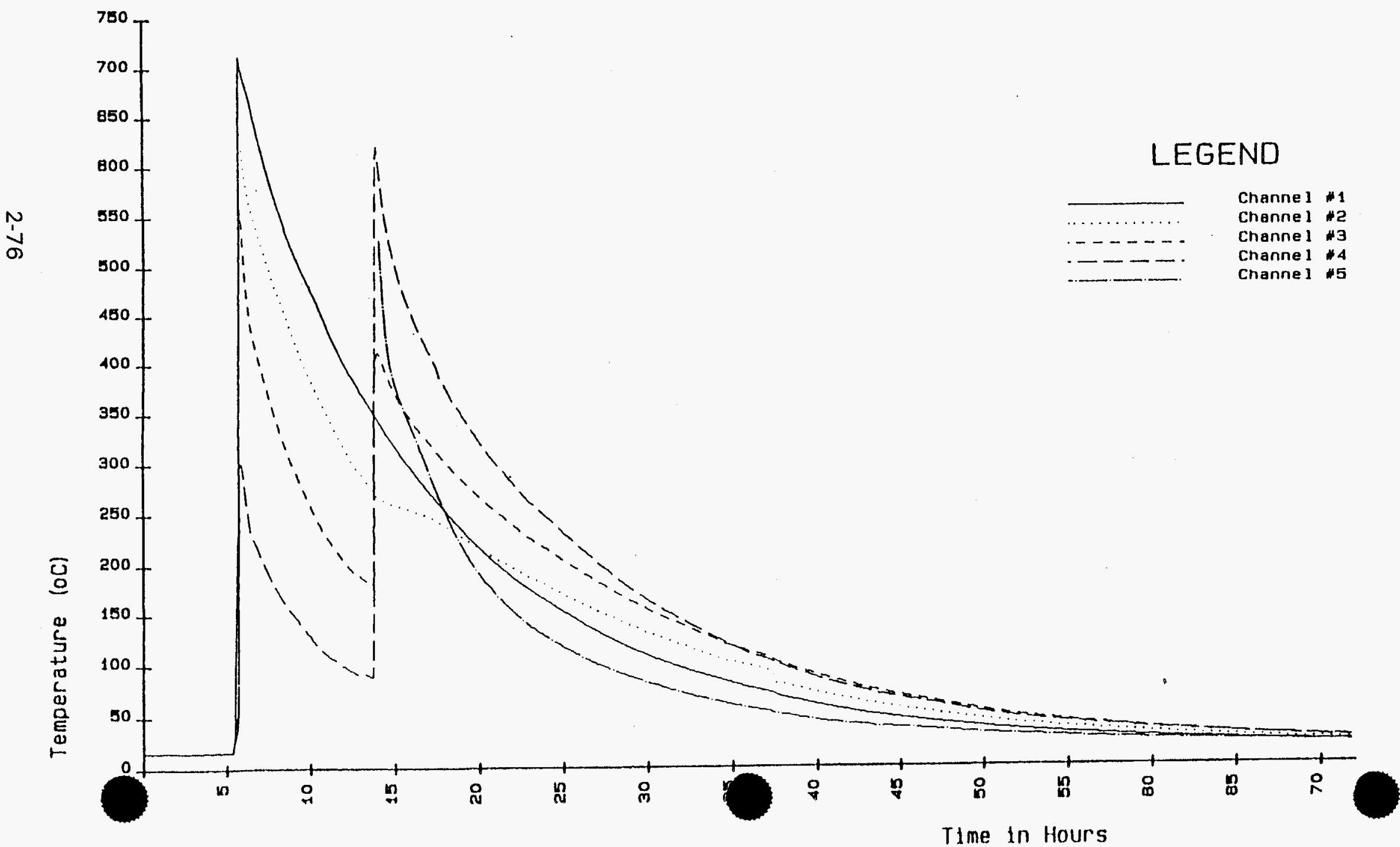


Final

Figure. 2.3-5
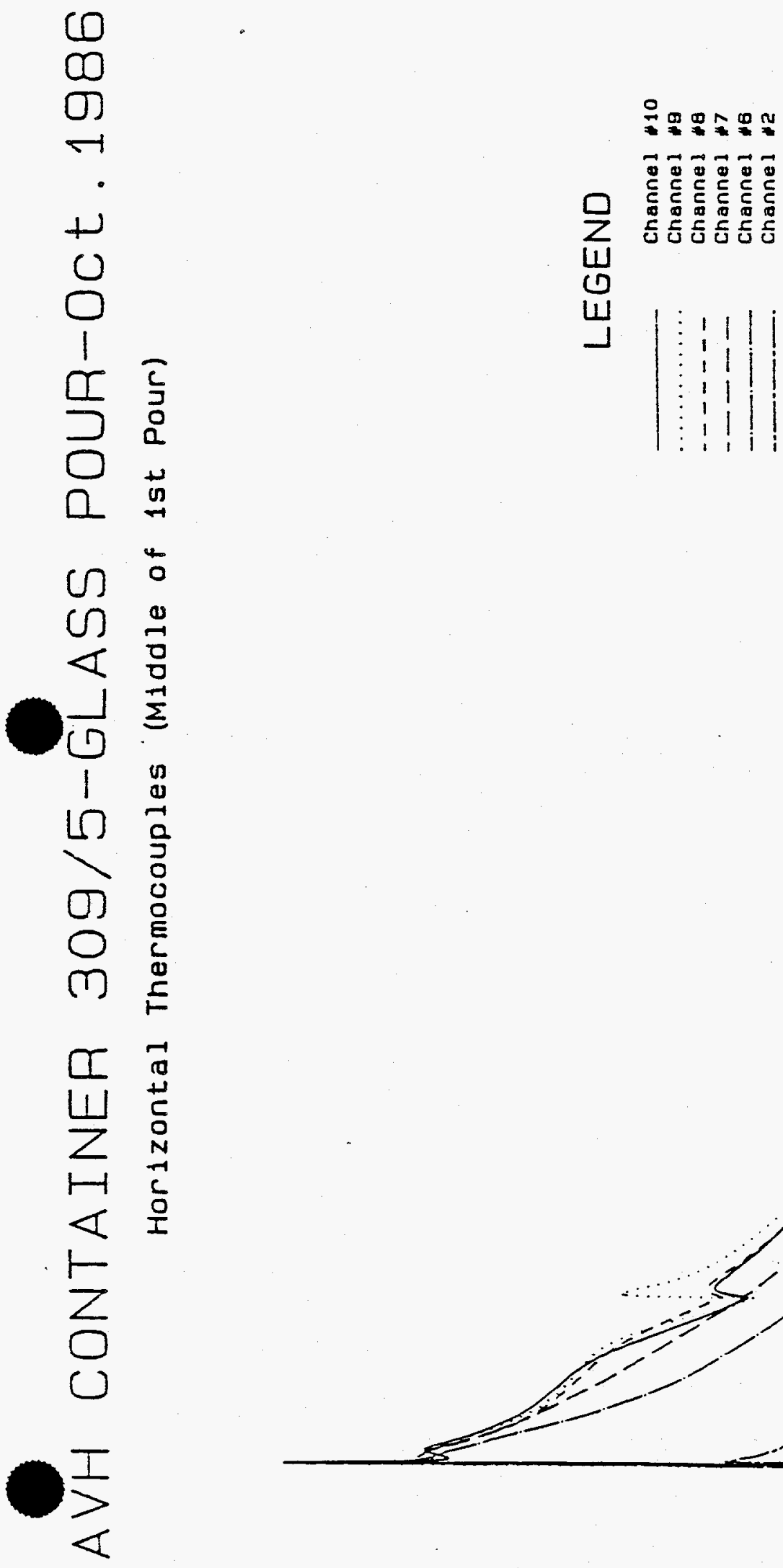
Final

0
0
0
+
0
0

$\frac{1}{0}$

o $\stackrel{4}{\circ}$

$0 \%$

$<$ 品

(1) 2

1

10 孚

(1) O

0

(1) $\stackrel{0}{F}$

T

$\left\lfloor\frac{1}{2}\right.$

$H \frac{N}{c}$

$<$ 오

1

2

$(3$

$\stackrel{I}{\geq}$

WHC-SD-W378-ES-001 Revision 0

Figure. 2.3-6

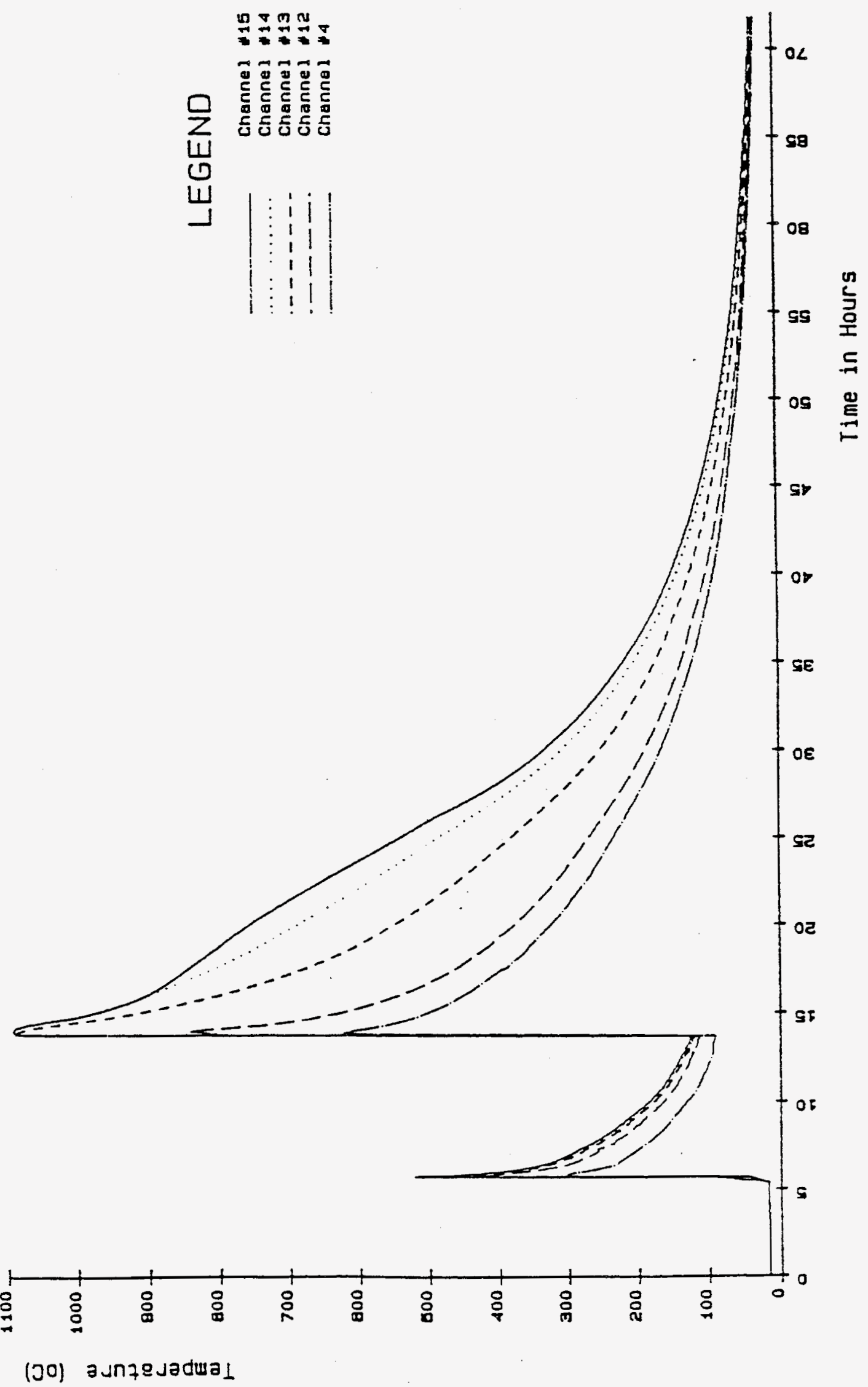


AVH CONTAINER 309/5-GLASS POUR-Oct.1986 Vertical Thermocouples (External \& Internal)

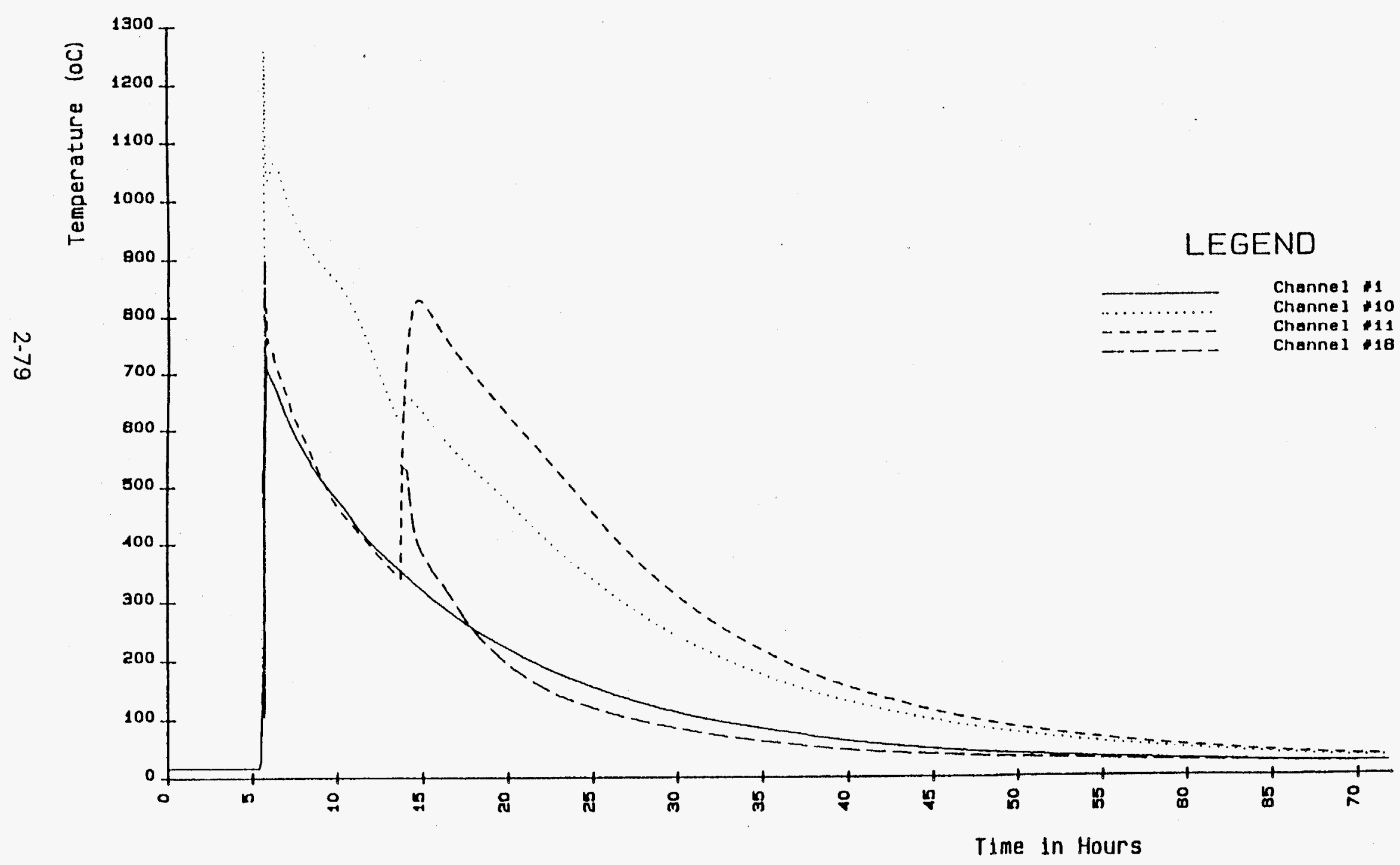

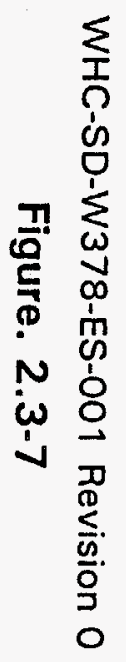

\begin{tabular}{l}
8 \\
8 \\
$N$ \\
$\infty$ \\
0 \\
0 \\
$\varnothing$ \\
\hline
\end{tabular} 


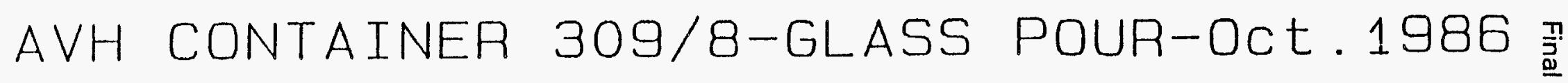

External Thermocouples

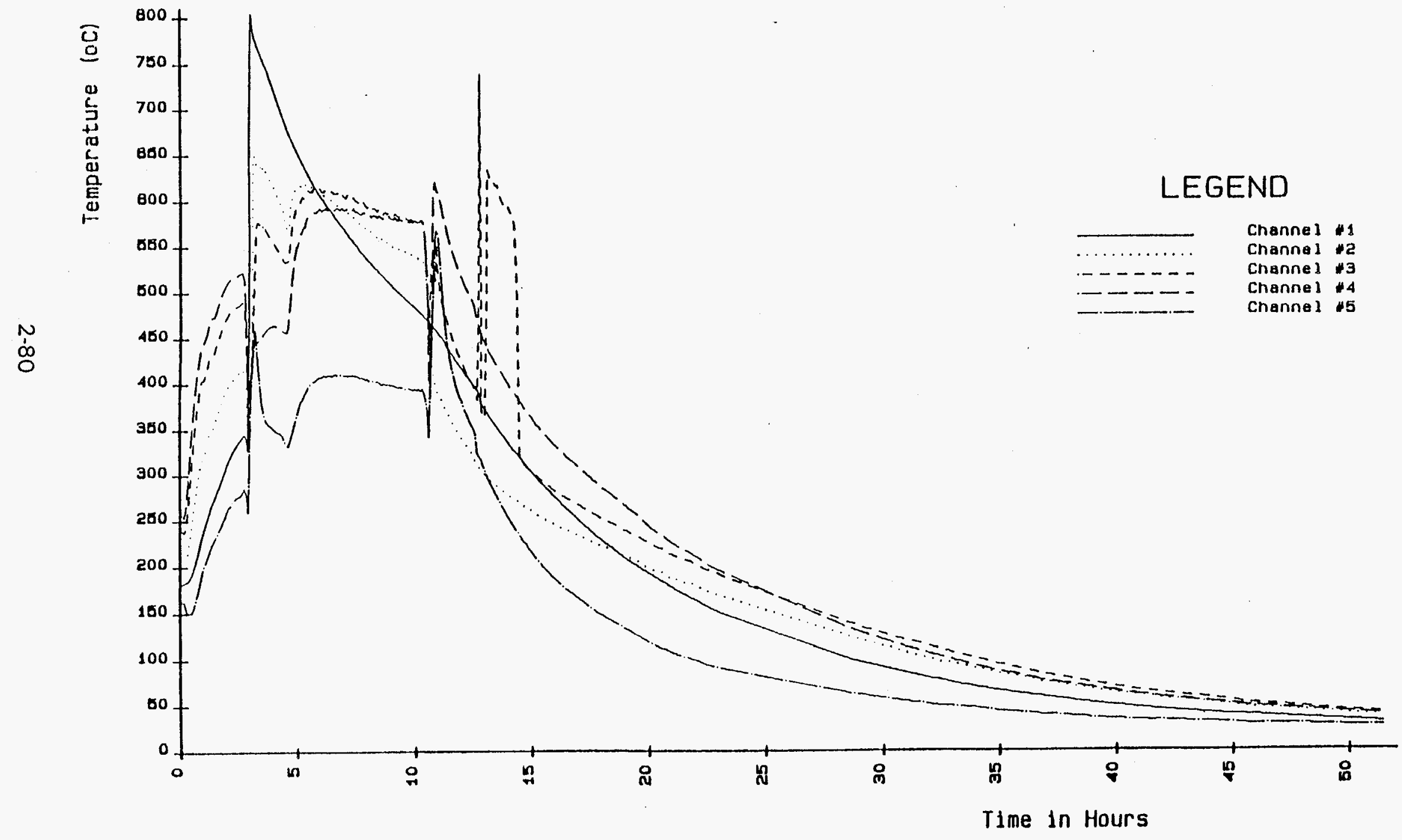


Final

(1)

O

o

H

$+$

0

$\frac{1}{0}{ }_{0}^{0}$

0 ० 0

$0 \Omega$

$<\underset{0}{0}$

(1) $\Sigma$

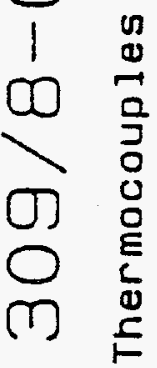

a

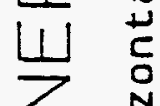

$\sum \frac{1}{2}$

< $\frac{\text { I }}{1}$

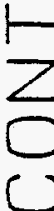

$\frac{I}{4}$
WHC-SD-W378-ES-001 Revision 0

Figure. 2.3-9

$\div g$

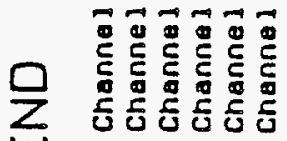

W

山

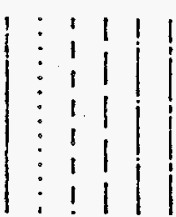

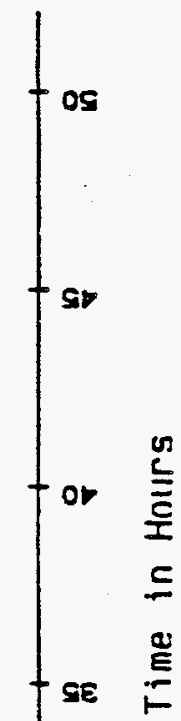
$\because 111$ $\because 11$ $\because 11$ $\therefore 111$ o

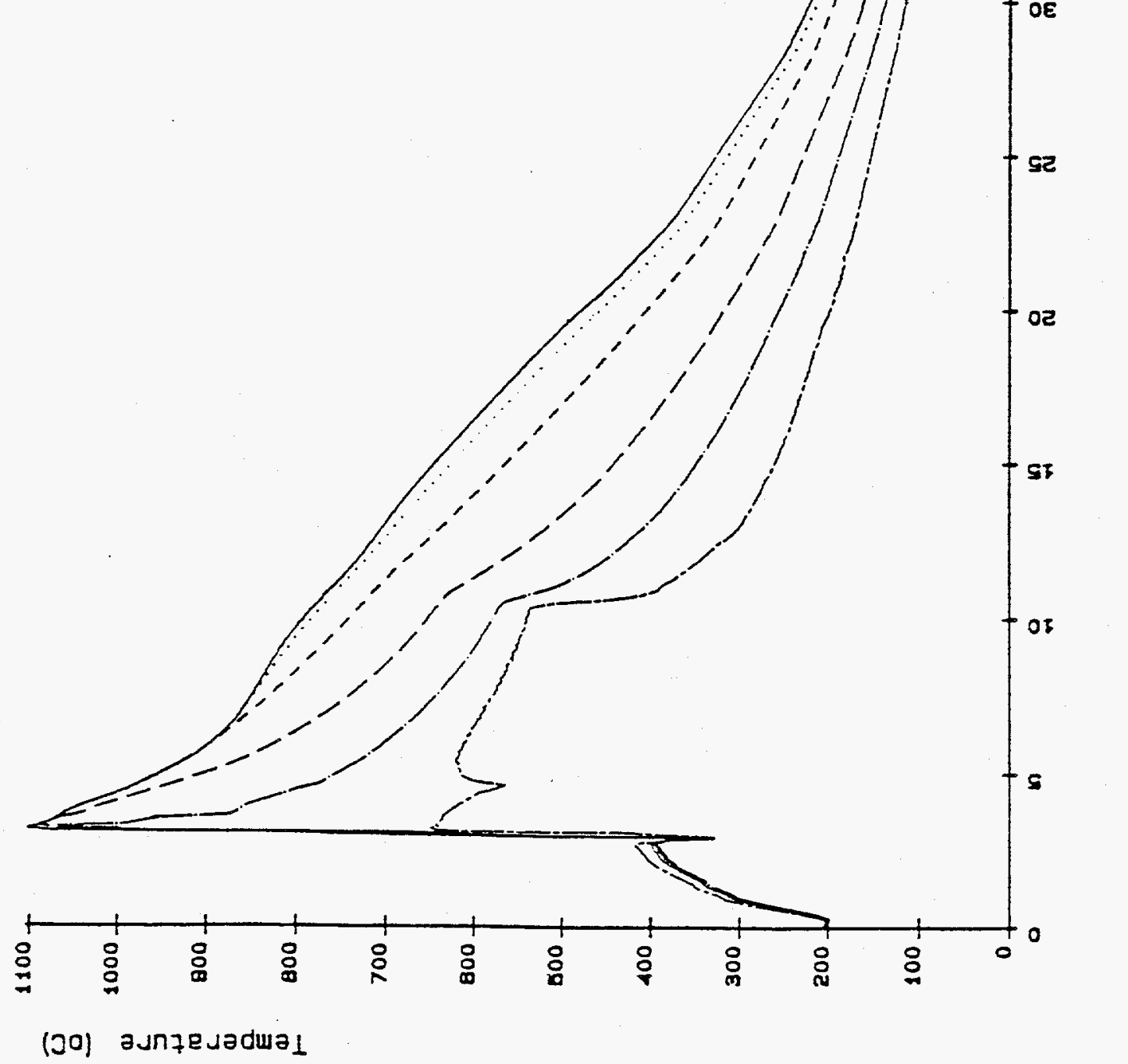


Final

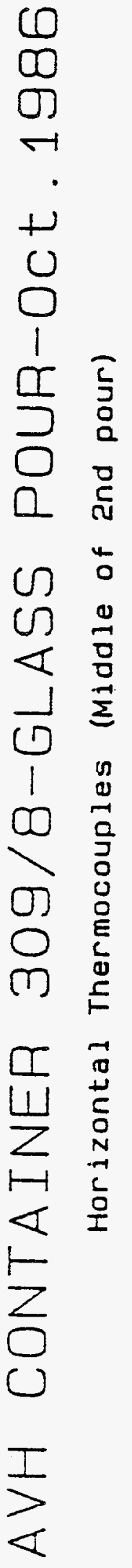

Figure. 2.3-10

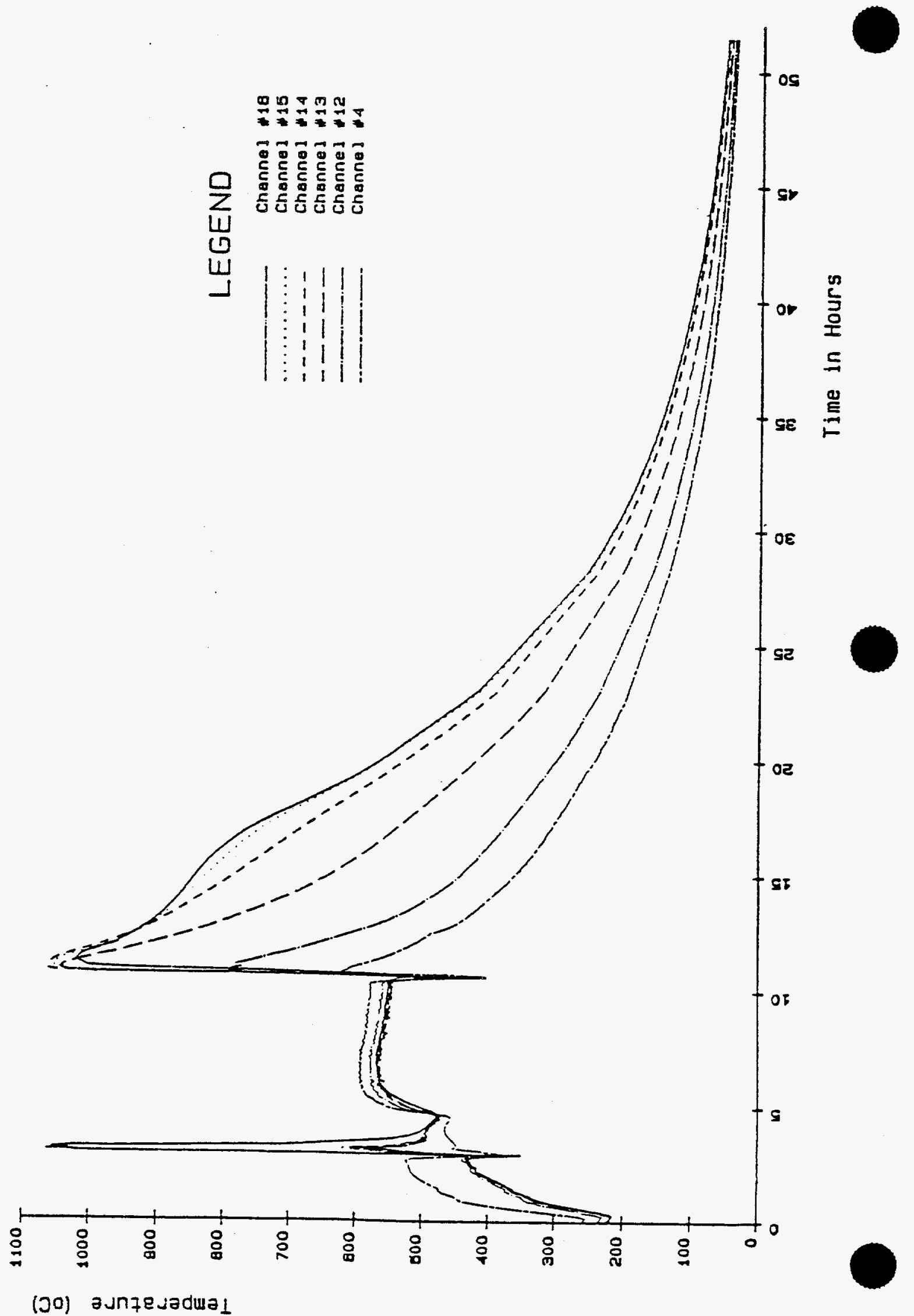


AVH CONTAINER 309/8-GLASS POUR-Oct. 1986

Vertical Thermocouples (Vessel Centre Line)

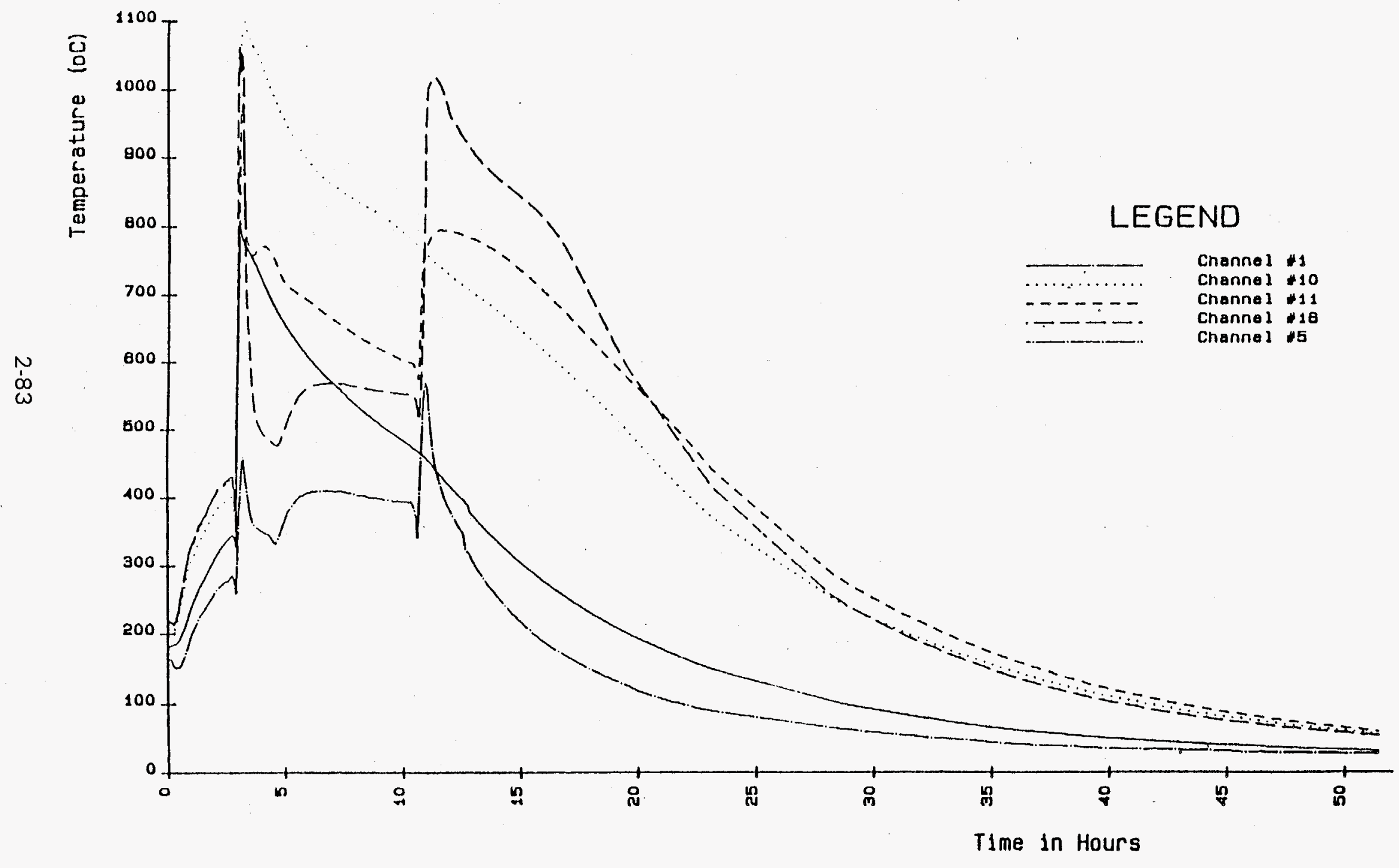

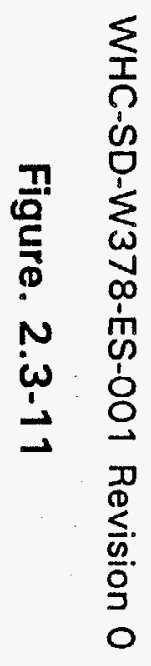

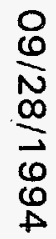


AVH CONTAINER 309/12-GLASS POUR-Oct.1986 External Thermocouples

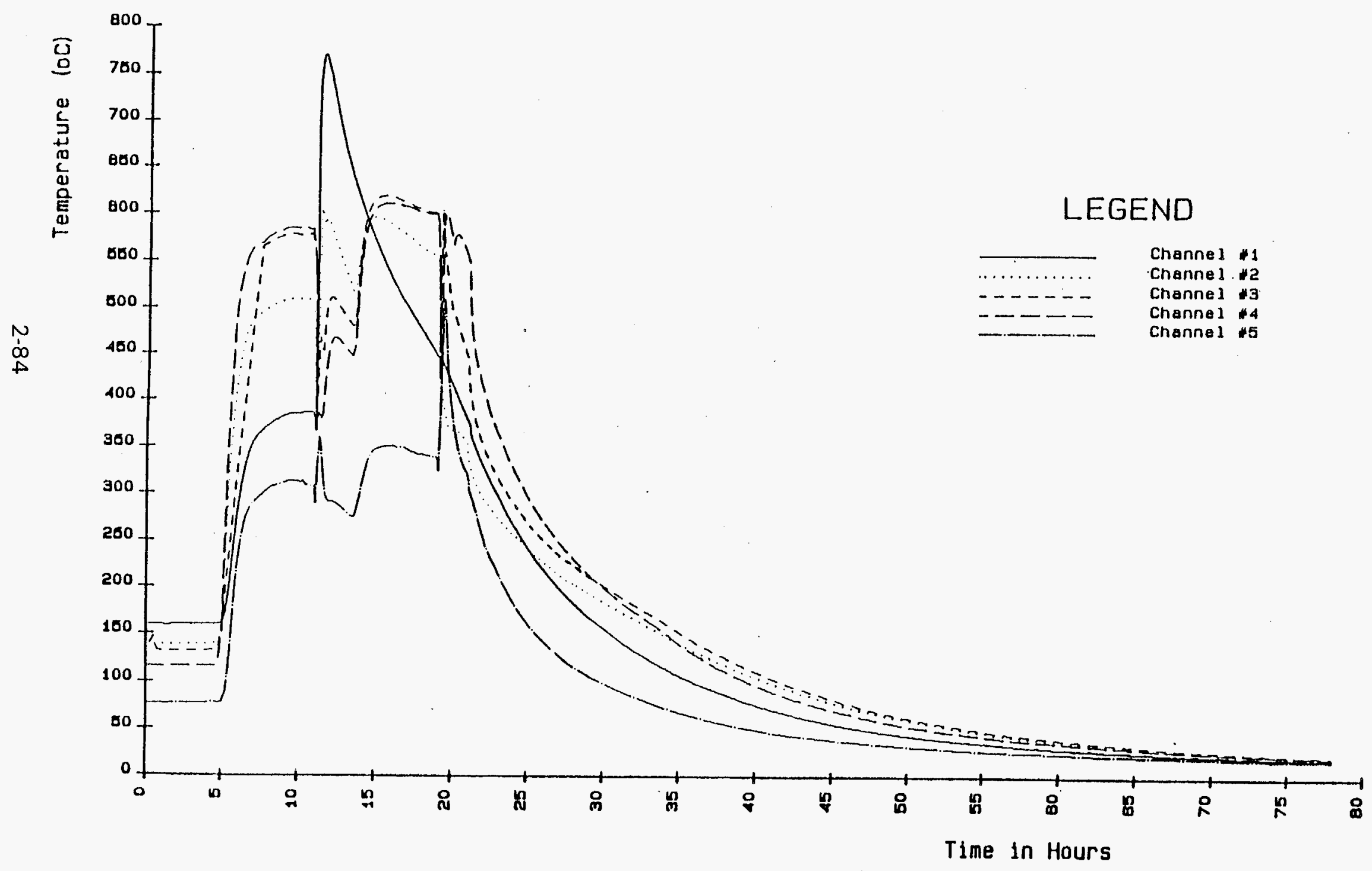


Final

CO

$\infty$

O)

$\frac{1}{0}$

C

0

$<\frac{0}{0}$

(1) $\Sigma$

$1 \stackrel{0}{0}$

윽

$>\quad 0$

D)

$0 \stackrel{\frac{c}{E}}{E}$

(1) $E$

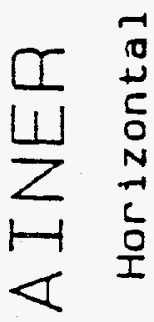

$\underset{\square}{\square}$

$\frac{1}{5}$
WHC-SD-W378-ES-001 Revision 0

$09 / 28 / 1994$

Figure. 2.3-13

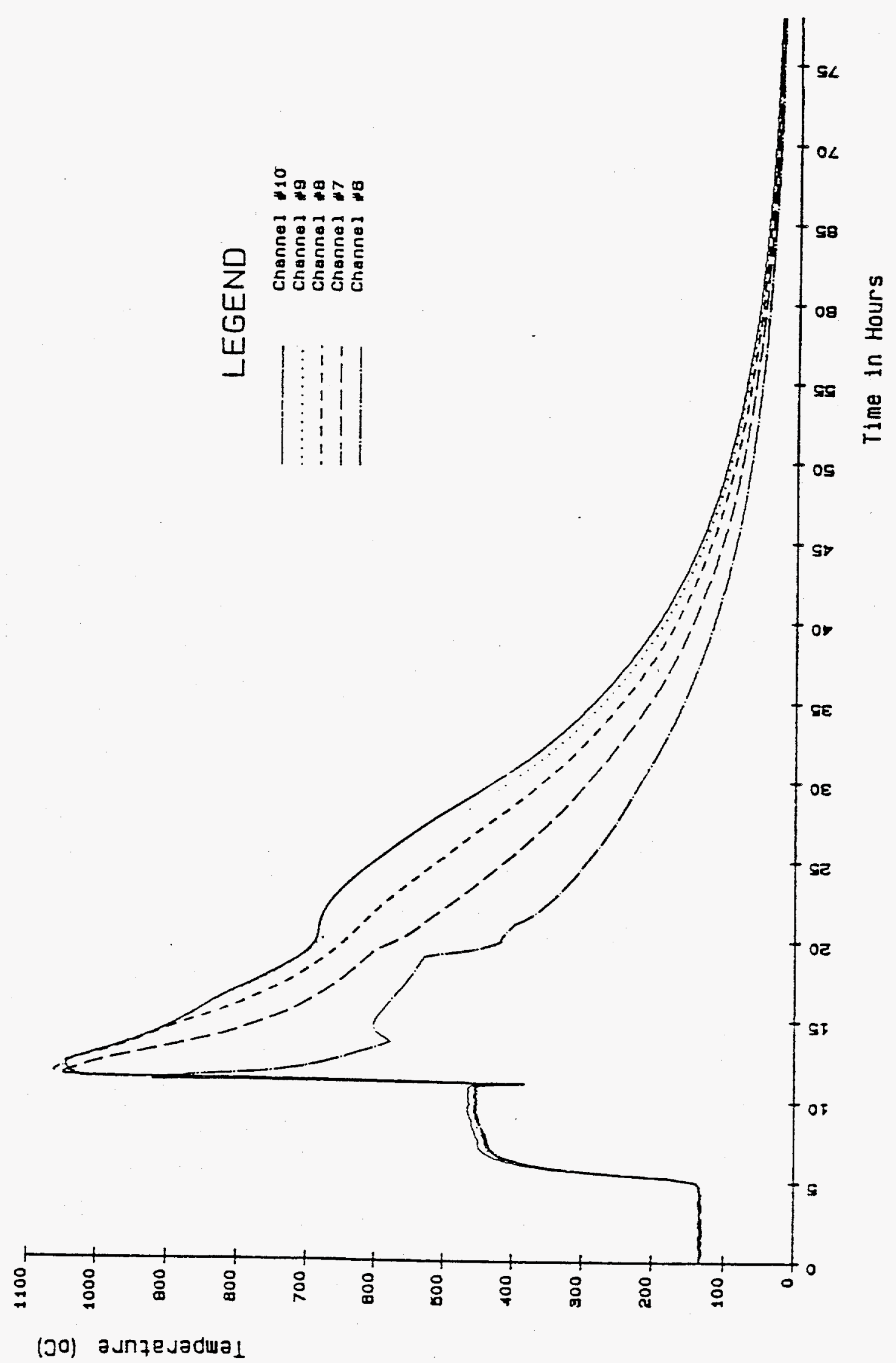


Final

6

$\infty$

(1)

$\rightarrow$

$+$

0

1

$\frac{1}{0}$ 官

(1) 도

0 \%

U

1
0

ก

$\rightarrow \frac{0}{0}$

$>8$

0)

m $\stackrel{\Xi}{F}$

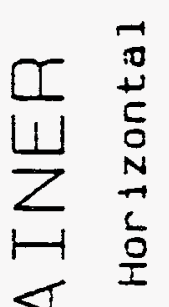

Z

$\frac{1}{i}$
WHC-SD-W378-ES-001 Revision 0

Figure. 2.3-14

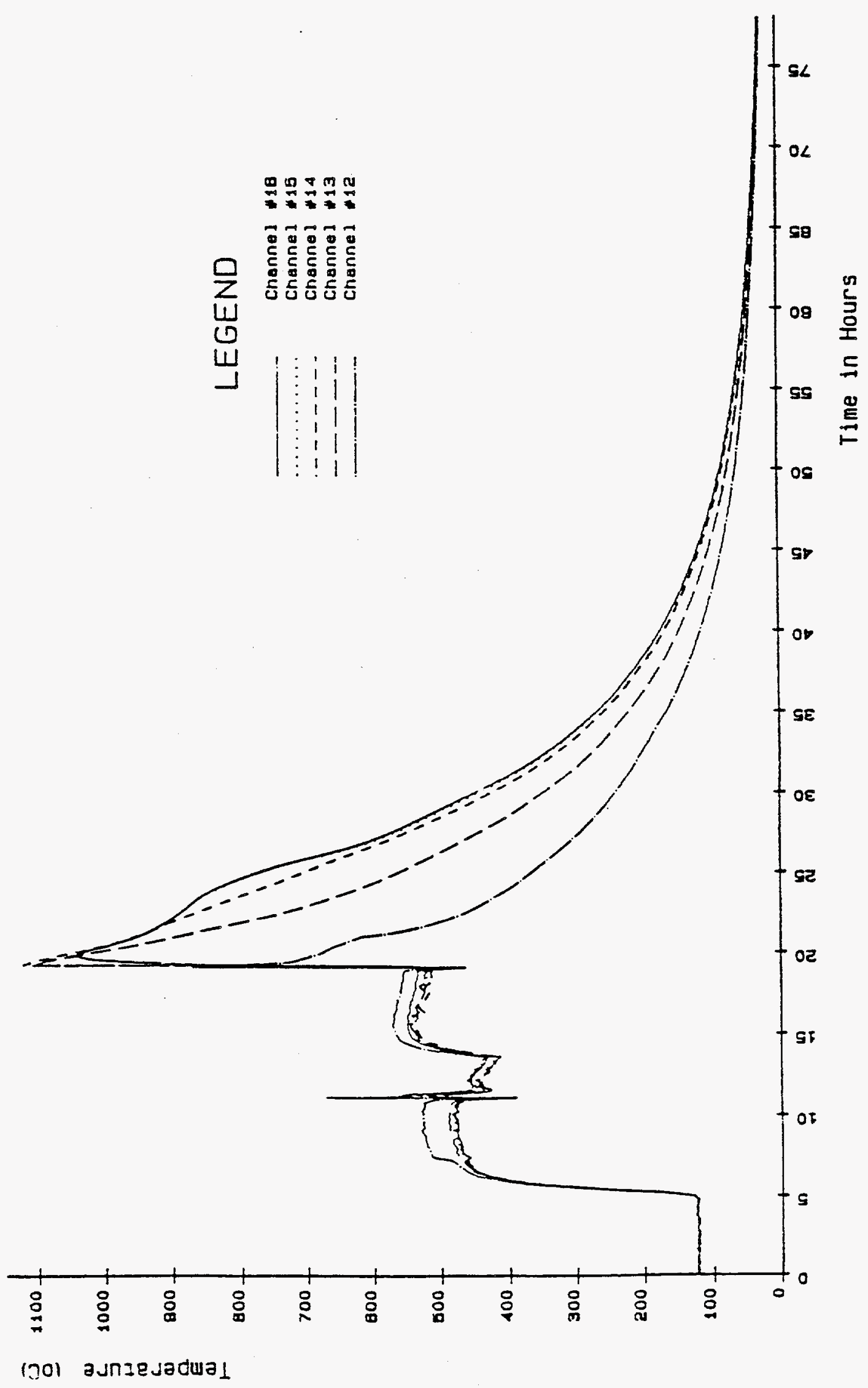


Final

co

$\infty$

(0)

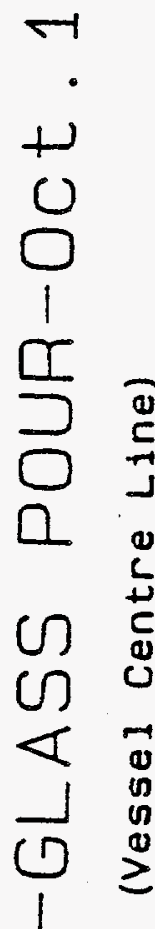

U *

$\begin{array}{ll}\rightarrow & 0 \\ 0 & 0 \\ 0 & 0 \\ 0 & \frac{0}{8} \\ 0 & \stackrel{0}{5}\end{array}$

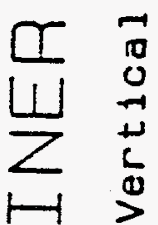

$\varangle$

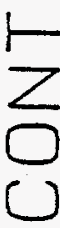

$\stackrel{T}{2}$

Figure. 2.3-15

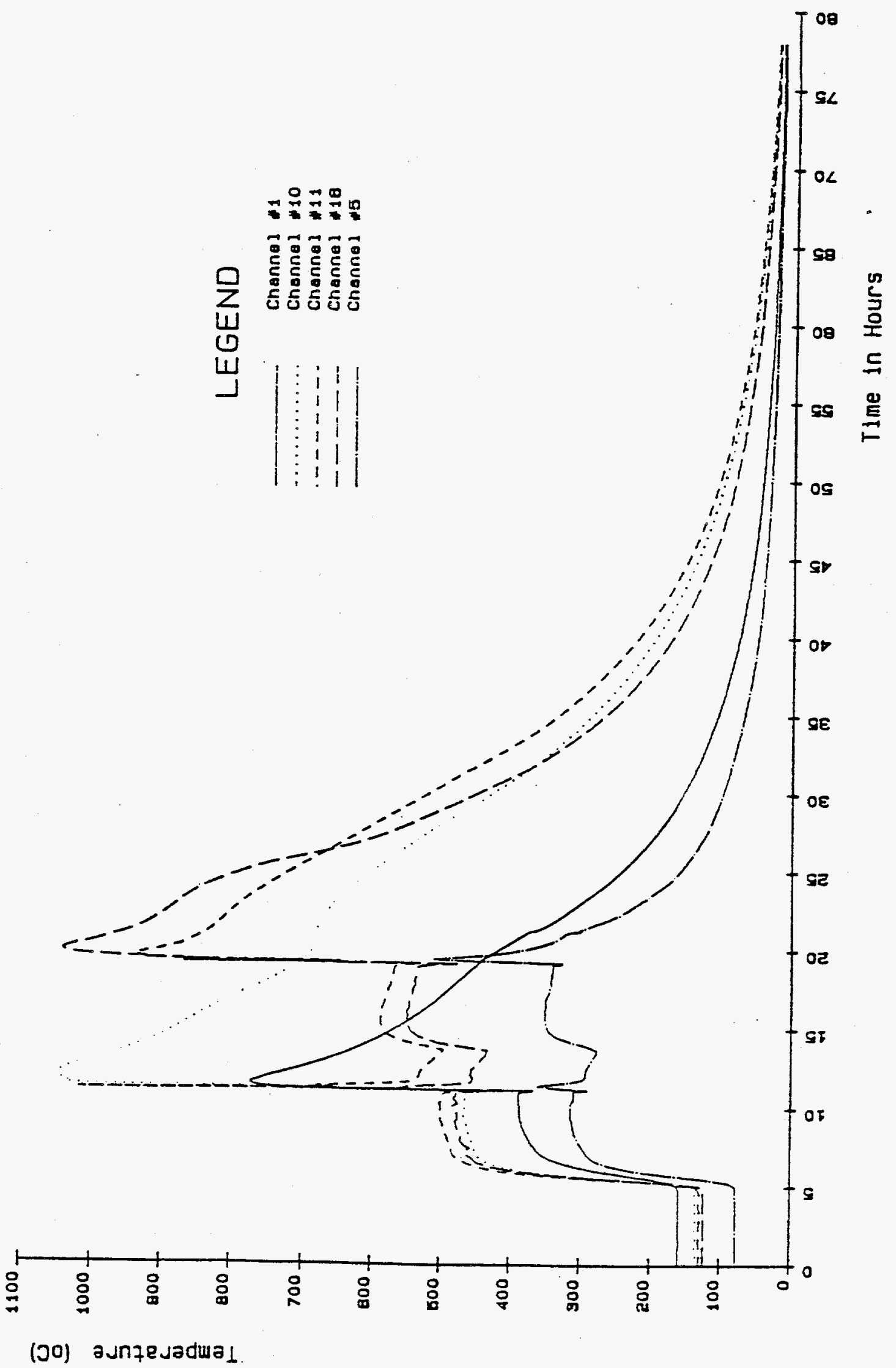


Final

Figure. 2.3-16 COOLING CURVE FOR A $400 \mathrm{KG}$ CONTAINER FROM THE 3RD MARCOULE TRIAL FOR BNFL

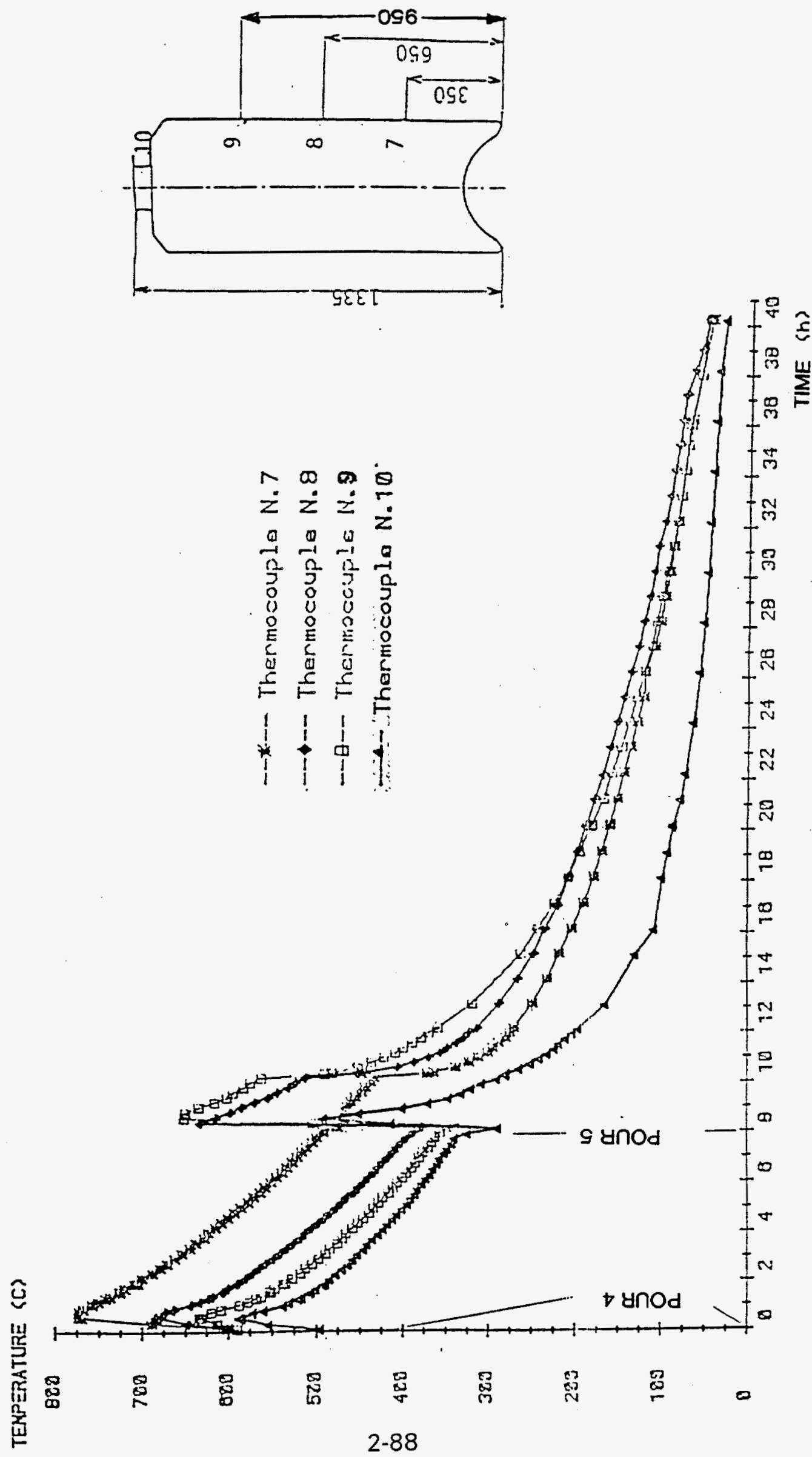




\section{TEMPERATURE (C)}

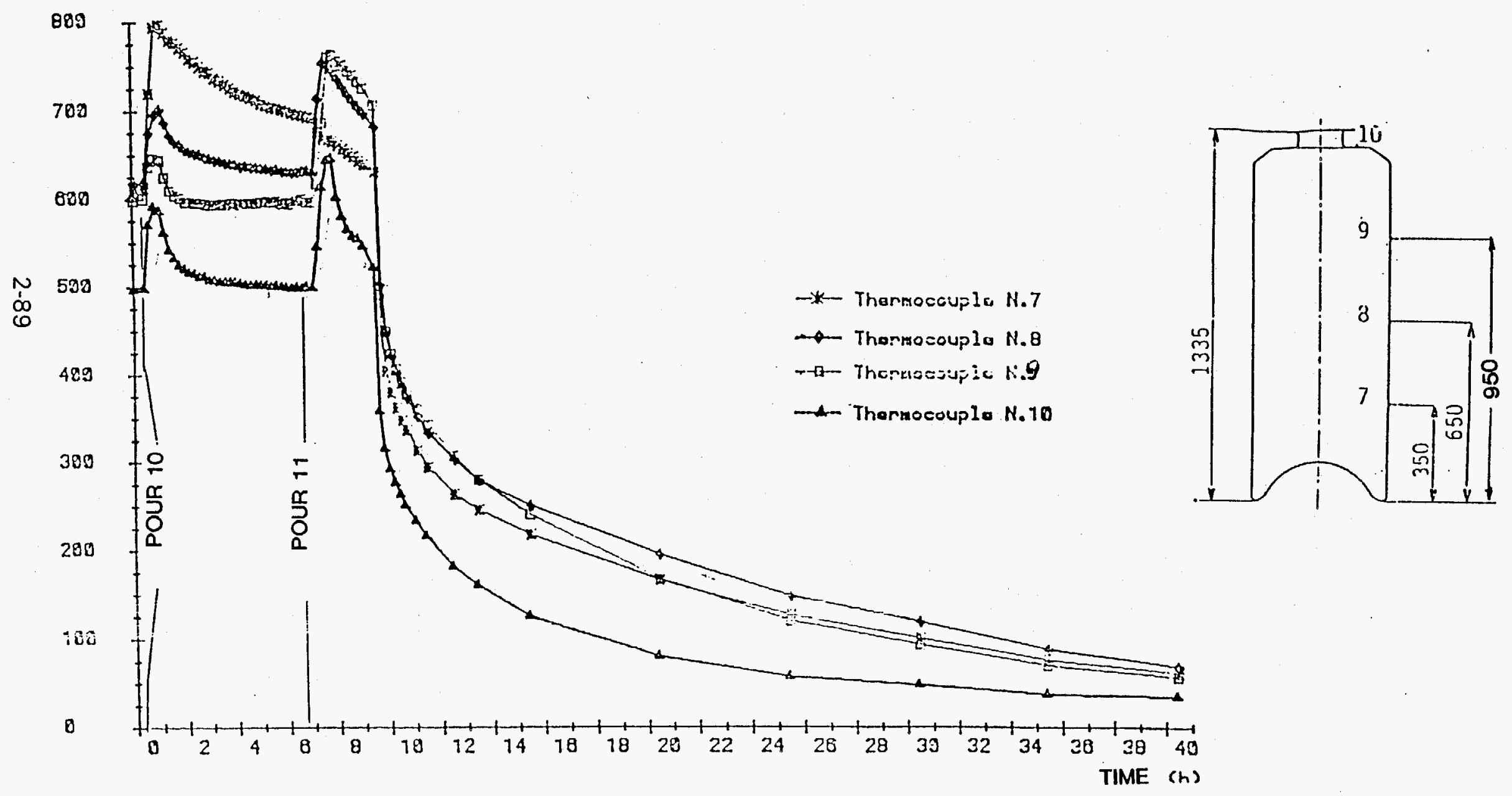




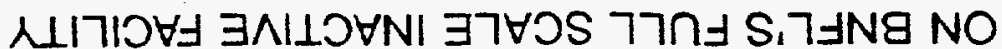

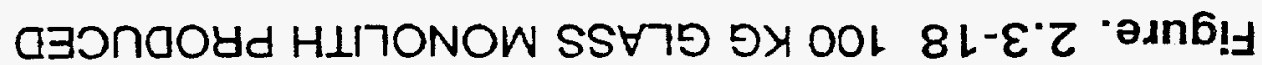

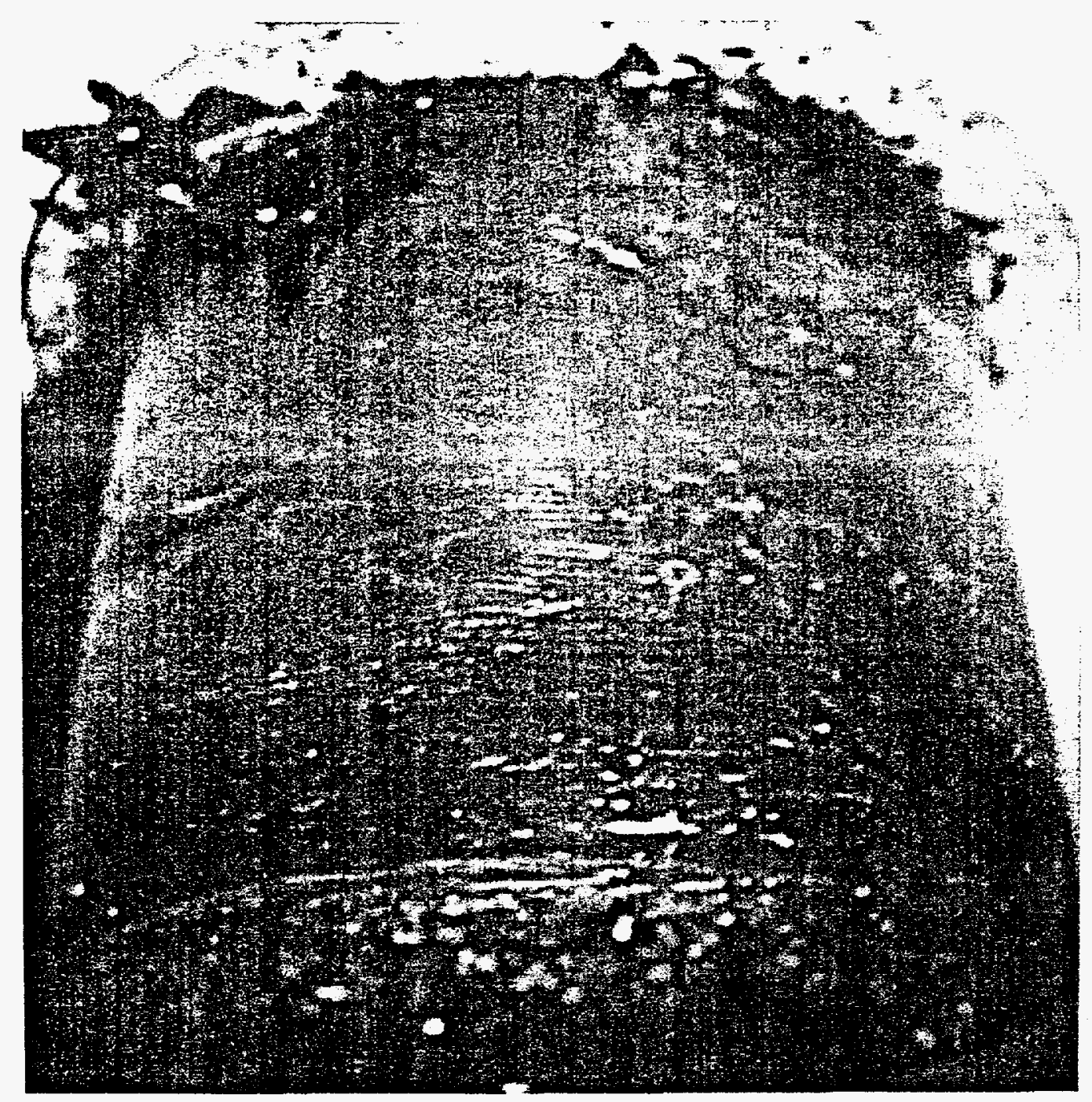


Final

WHC-SD-W378-ES-001 Revision 0

$09 / 28 / 1994$

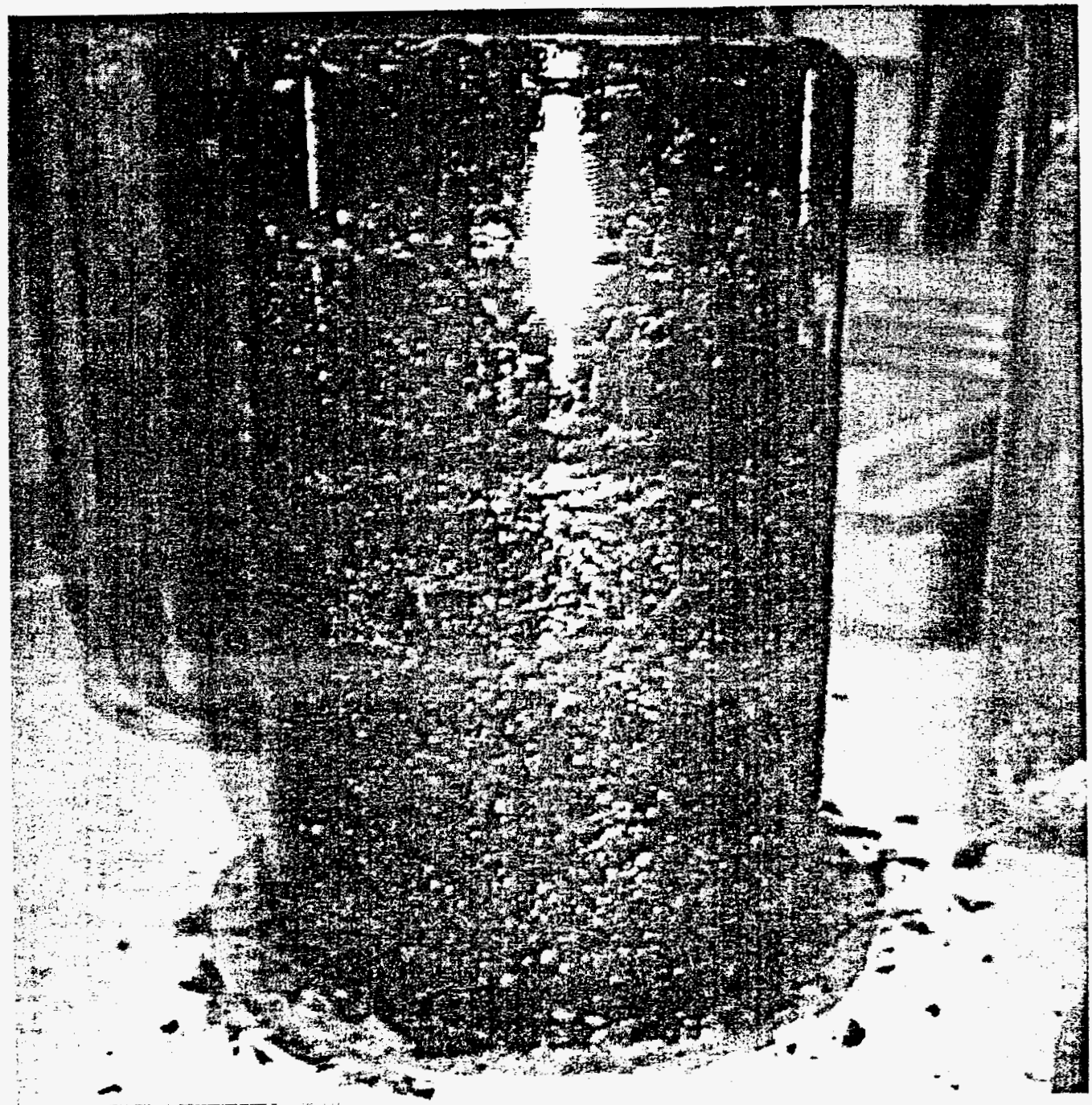

Figure. 2.3-19 $200 \mathrm{KG}$ GLASS MONOLITH PRODUCED ON BNFL'S FULL SCALE INACTIVE FACILITY 


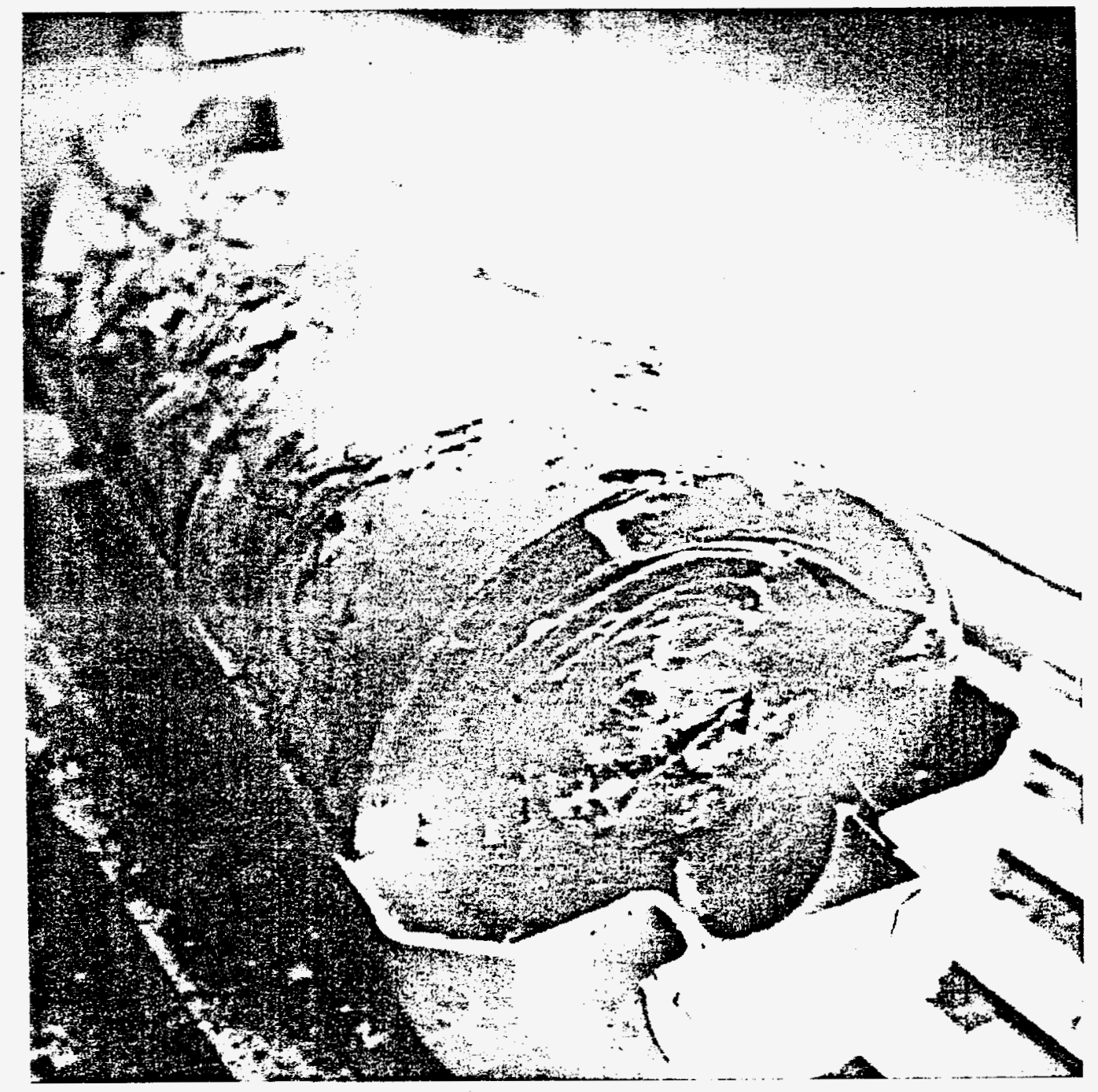

Figure. 2.3-20 400 KG GLASS MONOLITH PRODUCED ON BNFL'S WVP DURING INACTIVE COMMISSIONING 


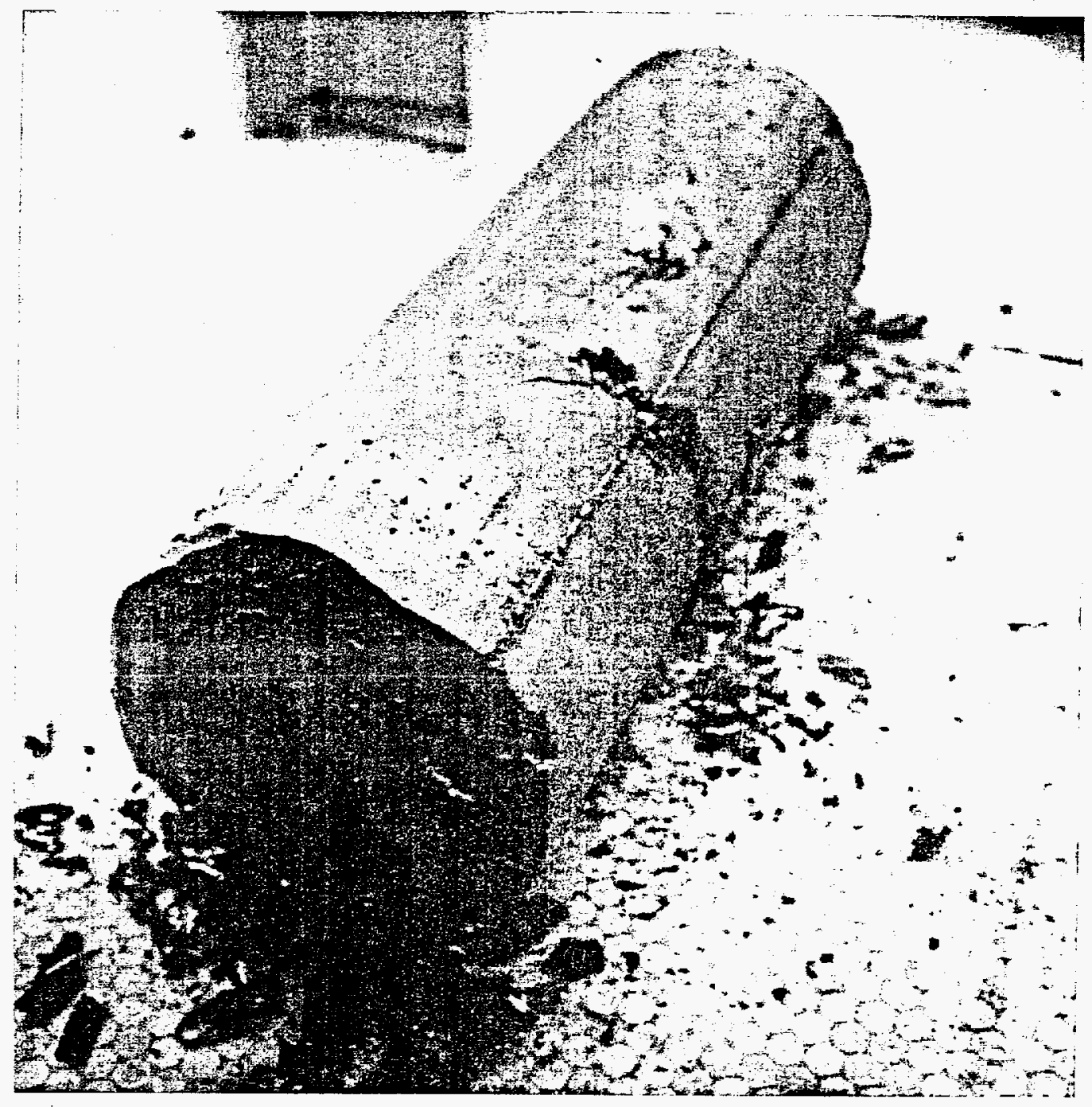

Figure. 2.3-21 $400 \mathrm{KG}$ GLASS MONOLITH PRODUCED ON BNFL'S WVP DURING INACTIVE COMMISSIONING 
Figure 2.3-22 Normalized release at 78 days versus ratio of crack surface area to total surface area. Normalized release is based on total surface area.

(Westsik et al. 1981)

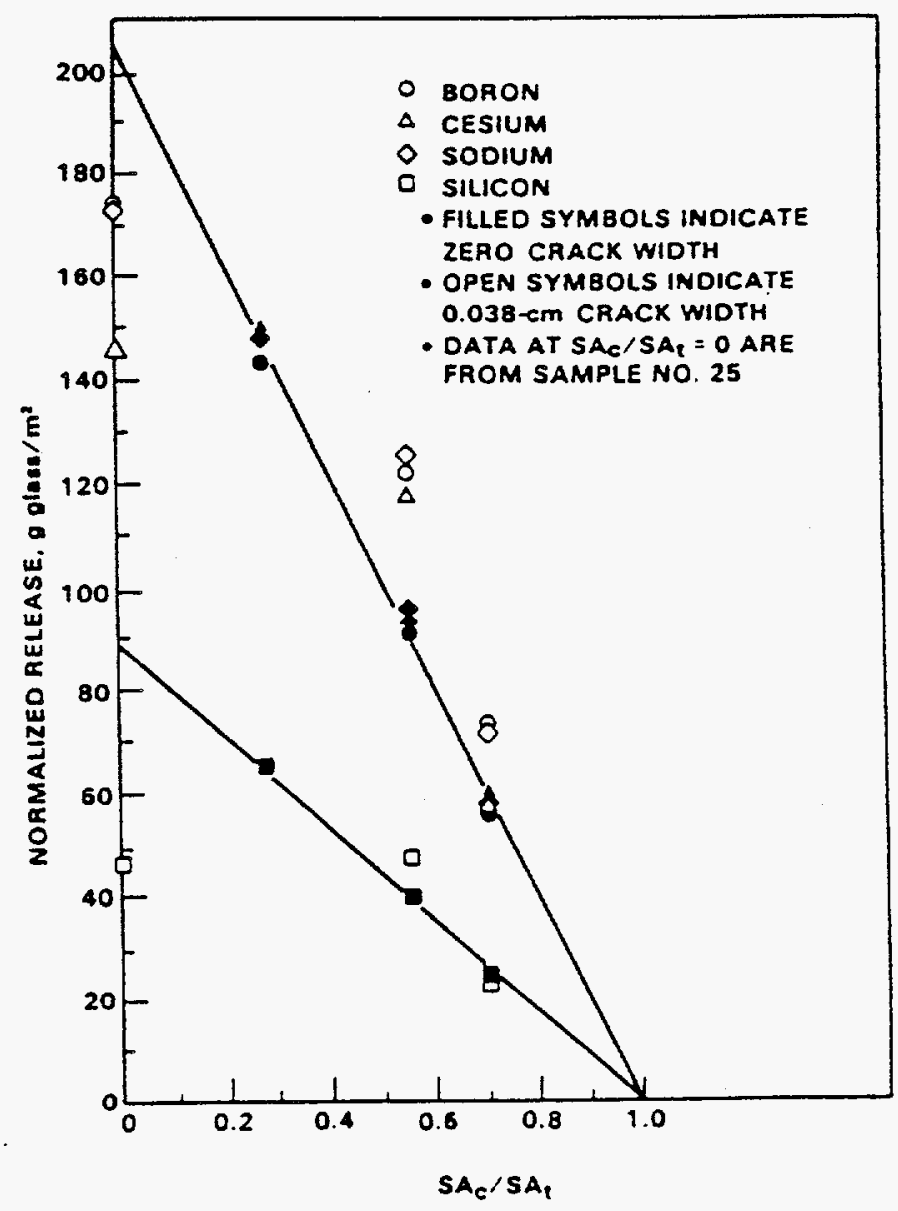




\section{References}

Burch S F et al. "Tomographic and image intensification assessment of FSIF I glass samples" Harwell AERE-G 4634 (1987).

Charteris $\mathrm{S}$ and Jenkinson J. "Investigation of the thermal stability of $\mathrm{MW}$ glass incorporating WRWII Magnox Waste" BNFL Vitrification Group Note Number 89/12 (1989).

Foster R A and Evans R. "An Investigation of the Thermal Stability of MW Magnox Glasses at the nominal WVP flowsheet composition under possible storage conditions". BNFL Research Memorandum RM 751 (1989).

Johnson P S and McCluskey K. "Assessment of the Thermal Stability of an MW Glass Incorporating Future Magnox Waste" BNFL Vitrification Report Number 4.7/1 (1985).

Magrabi C and Bradley R. "Interim Progress Report on the Thermal Stability of Flowsheet Magnox Glasses between 450 and $550^{\circ} \mathrm{C}$ ". BNFL Vitrification Group Note number $87 / 36$ (1987)

Rowley $\mathrm{PN}$ and Johnson $\mathrm{P}$ S. "Effects of a nucleation and growth heat treatment program on MW Magnox 4.8 Waste Glass". BNFL Vitrification Report Number $4.8 / 1$ (1984).

Slate S C and Peters R D. "Fracturing of simulated high-level waste glass in canisters" Nuclear Engineering and Design 67 (1981) P425-445.

Smith $\mathrm{P} \mathrm{K}$ and Baxter $\mathrm{C} \mathrm{A}$. "Fracture during cooling of cast borosilicate glass containing nuclear waste" prepared for the US Department of Energy under contract DE.AC09.76SR00001, September 1981.

Westsik $\mathrm{J} \mathrm{H}$ and Perez $\mathrm{J} \mathrm{M}$. "Effects of cracks on glass leaching" Nuclear and Chemical Waste Management, Vol ô pp 165-168, 1981. 


\subsection{PACKAGING}

\section{Introduction}

In this section of the study, packaging technology concepts for the waste glass and Waste glass/matrix combinations have been developed and reviewed. The options identified have been evaluated using the Kepner/Tregoe options evaluation technique to identify packaging systems that will allow the cost effective handling, transportation and retrievability of the glass waste.

It is noted that the initial criteria (section 1.2) state that retrieval is to be achievable but not necessarily easily.

A vitrified glass package will be considered as an individual waste glass monolith, some waste glass forms packaged in a container (multiple units can be stacked in a larger disposal vault), or a lined disposal vault filled directly with vitrified low level waste. All three options are considered in this study.

\subsubsection{Requirements}

2.4.1.1 Regulatory Requirements. DOE Order 5820.2A - Radioactive Waste Management

1) General public protection. Disposal systems shall be designed to ensure that exposure to any member of the public that results from disposal of solid LLW shall not exceed $25 \mathrm{mrem} / \mathrm{yr}$ Effective Dose Equivalent (EDE) through all exposure pathways for at least 1,000 years after disposal 110,000 years in 5820.2B).

(2) Groundwater Protection. Disposal systems shall be designed to meet the Clean Water Act and the Safe Drinking Water Act as well as ensure that disposal of LLW after 09/26/88 does not result in concentrations of radionuclides in groundwater exceeding those corresponding to an EDE of $4 \mathrm{mrem} / \mathrm{yr}$ to any person who might drink 2 liters per day of water from a well drilled into the aquifer, for at least 1,000 years after disposal $(10,000$ years in $5820.2 \mathrm{~B})$. The point of compliance shall be no further than 100 meters from the edge of the waste.

2.4.1.2 System Wide Requirements. Retain as much of the waste as possible for as long as possible within project cost and timescale constraints satisfying all regulatory performance criteria.

2.4.1.3 Task - Specific Requirements. Minimize the total volume of the waste deposited in the disposal system. The packaging is to be designed so as to maximize the economic use of available space within the vault.

Provide for retrievability. The packaged waste is to be designed so as to be retrievable from the disposal facility for 50 years from 2028 .

Provide for transportation and handling. The packaging, reusable transport container (if required) and handling equipment are to be shielded as required to minimize radiation exposure within ALARA principles. 
The packaging design is to facilitate ease of transportation. The design of the packaging/transport system is to meet all transport and safety regulations required by site regulations and regulatory bodies.

Provide for monitoring. Consideration is to be given to monitoring glass quality when designing the waste packaging.

2.4.1.4 Detailed Requirements. In sections 2.4.1.4 to 2.4.4 the packaging of the waste will be assumed to be a container unless otherwise stated.

The following detailed list of container requirements were derived from both the system wide and task specific requirements above and a detailed review of low level waste disposal requirements. If a container is not used and a transport cask is used, the transport cask must meet the majority of these requirements.

\section{Handling:}

1) The container must be sufficiently robust so as to withstand transportation of approximately one mile to the disposal site.

2) The container is to be suitable for either remote handling or manual handling dependant upon the package radiation dose rate.

3) The design of the container should enable ease of handling.

4) Dependant on size, the container should be stackable within the disposal vault.

5) The container is to be designed so as to be retrievable from the disposal system for a minimum of 50 years from 2028 .

6) The container is to be sized so as to maximize the use of available space within the disposal vault.

7) The container is to act as structural and radiological containment for the LLW for a minimum of 50 years following vault closure (circa 2028).

Transportation:

1) The container, transport equipment and handling equipment are to be shielded as required to minimize dose uptake to operators.

2) The container design is to facilitate ease of transportation and maximize the use of available space on the transporter.

3) The design of the container transport system is to meet all transport and safety regulations required by site regulations and regulatory bodies.

4) The container/transport system is to provide all necessary containment and radiation protection required by site regulations and regulatory bodies. 


\section{Glass/Matrix composition}

1) Container material is to be compatible with glass/matrix formulation and not result in accelerated corrosion.

2) The container must accommodate glass geometry with minimum voidage, and minimize damage during transportation.

\section{Temperature}

If it is found advantageous to pour hot molten glass/matrix material into package then:

1) Container material must be able to withstand either:

a) a sudden temperature rise without physical damage, weakening or metallurgical change.

b) preheating to a suitable fill temperature without physical damage, weakening or metallurgical change.

2) If required (to slow down glass cooling) the container is to accept additional heating without damage.

3) If possible the thermal expansion coefficient of the glass and packaging material should be similar to reduce cracking in the glass; or container liners should be used.

\section{Sampling}

Provision is to be made in the design of the container for glass sampling (sampling capability is required from 2028 for 50 years).

Life of container

The container is to act as structural and radiological containment for the LLW for a minimum of 50 years after vault closure (circa 2078).

\section{Size of packaging}

The size of the packaging is to be determined by the optimum glass size/matrix formulation (i.e. monolithic block, cullet/sulphur polymer cement).

\section{Contamination Containment}

The package is to provide as a minimum. contamination containment during handling, transportation and the first 50 years of vault storage following vault closure.

\section{Decontamination}

The external surface of the package is to be capable of being decontaminated after filling with vitrified LLW, if required. 


\section{Shielding}

An assessment of dose uptake from the vitrified waste is to be undertaken to determine if the packaging should be designed as a shielded container. Alternatively the packaged LLW can be transported in a shielded container and loaded/unloaded using suitably shielded or remote equipment.

\section{Watertight packaging}

The packaging is to be designed as a watertight container and is to remain watertight until the disposal site is permanently closed and monitoring ceased (circa 2078).

\subsubsection{Design Options}

2.4.2.1 General Comments. Assumptions. The following assumptions are used as a basis for this study.

1) It is assumed that the vitrification/ disposal process will operate 24 hours per day, 7 days per week, 52 weeks per year. Throughput calculations will be based on this figure.

2) Estimated quantity of vitrified glass to be produced is 210,000 cubic meters (WHC scope of work document $03 / 8 / 94$ ).

3) Vitrified waste is to be retrievable for 50 years starting 2028 (WHC scope of work document 03/8/94).

4) LLW is to be disposed of on-site in a near surface disposal system. The top of the vault is to be 5 meter minimum below grade.

5) LLW radionuclides and quantities given in 'Don't Say It' dated 01/13/94 from Boldt to Karnesky are to be used as the reference radionuclide inventories in the low level vitrified waste. The anticipated dose rate will be based on these figures.

6) LLW radionuclides concentrations will not exceed the limits for commercial LLW (10 CFR 61 Class C Waste).

7) Chemical composition of the LLW is assumed to be that stated in the 'Performance Assessment Of Grouted Double Tank Waste Disposal At Hanford'. However, radionuclide content is assumed to be that stated at 5 above and not as stated in the Grout Performance Assessment.

8) The LLW Cesium chain source is assumed to be $4.7 \mathrm{Ci} / \mathrm{cubic}$ meter and the thermal load is assumed to be $0.0117 \mathrm{Watts} / \mathrm{cubic}$ meter.

9) The LLW Strontium chain source is assumed to be $28 \mathrm{Ci} /$ cubic meter and the thermal load is assumed to be 0.0938 Watts/cubic meter. 
10) The container must comply with DOE Order 5820.2A - Radioactive Waste Management.

\section{Matrix Material}

The use of matrix materials is discussed in section 2.2. However for this portion of the study where the term matrix or matrix material is used it refers to the use of Sulfur Polymer Cement (SPC). It is noted that in section 2.2 the use of SPC in this application has uncertainties associated with its use but in the absence of any suitable alternatives it is used for the reference matrix material.

\section{Throughput of Vitrification plant}

The following calculation of the potential plant throughput of the vitrification plant is based on a total vitrified LLW production of 0.21 million cubic meters ( 7.5 million cubic feet). This is a WHC given figure for anticipated glass cullet production. It will be used in this study as the base production rate for all types of glass form.

Vitrification is scheduled to take place during 16 years from 2005 to 2021 ('LLW Program Status' G. Williamson LLW program office dated April 11 1994) will be:

Assuming the vitrification plant operates 24 hours per day, 365 days per year, output

$$
\begin{aligned}
& 210,000 \div 16=13125 \mathrm{~m}^{3} / \text { year } \\
& 13125 \div 365=35.96 \mathrm{~m}^{3} / \text { day } \\
& 35.96 \div 24=1.498 \mathrm{~m}^{3} / \text { hour }
\end{aligned}
$$

Assuming a glass density of $2.67 \mathrm{~kg} / \mathrm{liter}$ then the output will be:

$1.498 \times 1000 \times 2.67=4000 \mathrm{~kg} /$ hour

$4000 \times 24=96000 \mathrm{~kg} /$ day.

or approx 100 tonnes per day.

Plant availability factor:

There are considerable uncertainties when operating a radioactive waste vitrification plant:

- The melter life and maintenance down time (not known in detail).

- The maintenance down time of the glass forming equipment (not known in detail).

- Off-gas system (efficiency and operability presently unknown).

- Glass rework (amount if any presently unknown).

Taking these factors into consideration the plant availability figure is assessed at approximately $60 \%$. The anticipated designed throughput of the plant is therefore required to be a minimum of 140 tonnes per day. 


\section{Quality control of production plant output:}

A decision has not yet been made on whether the vitrification plant will operate on a 'feed forward' or 'feed back' basis.

In 'feed forward' the quality of the glass produced is expected to be acceptable and no reworking of out-of-specification product glass is anticipated. If this is the case, containers and the glass form do not need to be designed or selected for return and rework of the glass.

'Feed Back' design anticipates that some of the glass produced is out-of-specification and would necessitate the feed back of the out-of-specification glass to the melter. Glass return for rework would need to be built in to the design of the container (particularly large monolith containers) and be considered in the selection of the glass form.

In this study it is assumed that the vitrification plant will operate on a 'feed forward' basis and that recovery for rework is not a critical factor in container or glass geometry selection.

2.4.2.2 Size of Container. In this section of the study the maximum size of a monolithic block is assumed to be $10 \mathrm{~m}^{3}$ as stated in the glass geometry section (2.3), and will be the reference size for this section. If following further evaluation and experimental work the optimum monolithic block size is reduced to $5 \mathrm{~m}^{3}$ or $3 \mathrm{~m}^{3}$, the recommendations of this section will remain valid.

If glass cullet/marbles/ in a matrix material is the chosen form, a $10 \mathrm{~m}^{3}$ container is a realistic size for handling, transportation and vault disposal.

Factors that are to be considered to determine the optimum size of monolithic block are:

Durability.

As stated in glass geometry (2.3.3.2), the durability of the vitrified glass is in direct proportion to the surface/volume ratio of the glass form. Therefore the larger the monolith the lower the radionuclide release caused by glass corrosion.

\section{Cracking/crystallization.}

It is presently thought theoretically possible to cast a 'good' block of glass up to 10 $\mathrm{m}^{3}$ volume but experimental confirmation is required to determine the quality of the glass. with respect to cracking, crystallization, leach rate and radiological loading at these sizes.

\section{Cooling.}

The cooling rate of the block (presently uncertain) will play a significant role in determining the cost effectiveness of the chosen glass volume. The existing European containerized high level vitrified waste $(0.4 \mathrm{~m}$ diameter $\times 1.1 \mathrm{~m}$ long) is naturally cooled for 36 hours before the container end cap is welded in place. 
Monolithic lead glass blocks $\left(1.25 \mathrm{~m}^{3}\right)$ have previously been cast for radiological shield windows, and to eliminate potential cracking, the blocks were cooled in a controlled environment for approximately 10 weeks. (It is presently anticipated that the Savannah river containerized HLW vitrified from will take 30 days to cool to a disposable level, however heat of radiolysis is significant when dealing with HLW).

As stated in 2.3.2 it is believed that slow cooling will prevent a glass block from becoming partially crystallized with a possible resultant reduction in durability. Experimental data will be needed to support this assumption.

The effect on the process throughput of slow-cooling large glass blocks up to $10 \mathrm{~m}^{3}$ would be a requirement to build a contamination controlled 'active' storage facility of sufficient size to hold the total output of the vitrification plant until the waste glass (and container) has cooled sufficiently to allow the containers to be sealed. Sealing could be accomplished by fitting a 'shrink fit' plug in the neck of the container as per existing WHC design followed by decontamination and the welding in place of the permanent container lid. This would be completed as soon as possible, allowing the filled containers to be moved to a second storage area for the remaining cooling period. This is likely to be weeks, but the actual duration is not yet known. Experimental data is required. The second storage area would need to provide shielding but would not require contamination control facilities.

It is presently assumed that glass blocks would be cooled slowly under ambient conditions i.e. no cooling or heating. If it proves necessary an insulated cover could be fitted over a cooling block to reduce the rate of cooling. The total heat load from the glass into a facility will need to be calculated and provision for control of the facility's temperature made.

Typical size of the first storage area.

Assuming a containerized output of 100 tonnes of glass per day lapproximately 36 $\mathrm{m}^{3} /$ day) from the melter plant and that a 5 day cooling period is required before the containers can be temporarily sealed. An active containment building holding at least twenty $10 \mathrm{~m}^{3}$ filled containers would be required to meet the cooling time delay imposed on the system.

This containment building would have to be shielded, monitored and ventilated with HEPA filters and air lock doors to prevent the spread of contamination. Remotely operated handling and transport equipment for container movements would also be required.

Typical size of second stage storage area.

The second stage area assuming a five week cooling/annealing period, would have to contain a minimum of 140 containers, $10 \mathrm{~m}^{3}$ each. This area would have provision for radiation shielding and environmental monitoring but contamination control will not be required. Remotely operated handling and transport equipment or shielded contact handling equipment will be required for glass/container movements. Prior to moving to this second storage building the external surfaces of the container would be decontaminated; possibly by high pressure water jet.

Plant throughput. The reference glass block is $10 \mathrm{~m}^{3}$ in size with a weight of 27 tonnes. At a plant throughput of 100 tones per day this equates to the production of 4 monoliths each day. To assist handling, the containers will be designed with attachments to facilitate remote handling or shielded contact handling equipment. 
Container liners - A liner material can be added within the container to reduce surface cracking caused by glass bonding to the container and the differential expansion rates of the glass and container. Potential liner materials include alumina or graphite but further evaluation and testing is required to determine compatibility with both the glass and container and the effect of any long-term corrosion products.

2.4.2.3 Shape of container. The shape of the LLW glass/container recommended in glass geometry is a cylinder as this is thought to be the most economic production shape for a large monolith. For this section of the study the shape of the LLW glass/container will be assumed to be rectangular as this is regarded as the most efficient shape for vault disposal.

A trade study is required however to determine:

a) The relative costs of rectangular and cylindrical containers (typically 10,5 and $3 \mathrm{~m}^{3}$ ).

b) The additional disposal site costs for storing cylindrical containers as against the more volume-efficient rectangular containers.

c) The difference in costs of handling and transportation equipment to move various sizes and weights of containers. (typically 26 tonne $\left(10 \mathrm{~m}^{3}\right), 13$ tonne $\left(5 \mathrm{~m}^{3}\right)$ and 10 tonne $\left(3 \mathrm{~m}^{3}\right)$ containers $)$.

Knowledge of the relative cooling times of various sizes of monolithic block and the anticipated sizes and costs of the various cooling storage areas will also be required as this will further influence the economic choice of monolithic block size.

An additional consideration when determining the shape of the containers (discussed in section 2.4.2.4) is the option of having the container the same size and shape as the prospective HLW containers.

Following receipt of this cost and cooling analysis an informed decision can be made on the economics of container geometry.

\subsubsection{Advantages of commonality of size/shape of LLW and HLW Vitrified waste} containers. The design of the high level vitrified waste container has yet to be finalized but two options have been referenced, a $10 \mathrm{~m}^{3}$ cylinder and a $1.44 \mathrm{~m}^{3}$ cylinder (WHC-SD-WM-ES295 rev O) Either container would have loading and handling devices on one end with two lifting lugs provided for the attachment of remote handling equipment.

There are potential advantages in designing both the HLW and LLW vitrification containers with the same external dimensions and shape and the same lifting attachments. (It is not proposed that they are the same container as the HLW containers construction will almost certainly be over engineered for LLW requirements).

These advantages are:

- Should out of specification LL vitrified waste be produced it may be more economic to dispose of it as HLW rather than providing the facilities to open a container and size reduce the glass to feed back into the LLW melter. 
- Should it be necessary for any reason to remove the containerized vitrified waste from the Hanford site, the container geometry would be acceptable at the Yucca mountain repository.

2.4.2.5 Container Material. Stainless steel is the only material in use throughout the world as the container material for the receipt of hot poured vitrified glass. There is concern however that the products of corrosion of a stainless steel container will accelerate the corrosion of Hanford vitrified waste. This concern requires further evaluation.

2.4.2.6 Radiation dose rate. The typical dose rate for a $10 \mathrm{~m}^{3}$ rectangular glass monolith and a $0.15 \mathrm{~m}^{3}$ cylindrical glass monolith packaged in a $5 \mathrm{~mm}$ thick steel shell are detailed below.

Note - this is an approximate calculation only, using Microshield software

Assumptions:

Glass Rectangle

Glass cylinder

Composition:

Contaminants:
$10 \mathrm{~m}^{3}=2.15 \mathrm{~m} \times 2.15 \mathrm{~m} \times 2.15 \mathrm{~m}$

$0.15 \mathrm{~m}^{3}=0.45 \mathrm{~m}$ dia $\times 1.22 \mathrm{~m}$ high

$75 \% \mathrm{SiO}_{2}$ ( Silica oxide), $25 \% \mathrm{Na}_{2} \mathrm{O}$ (sodium oxide)

(Strontium) Sr $9027.3 \mu \mathrm{Ci} / \mathrm{cm}^{3}$

(Technetium) Tc $990.109 \mu \mathrm{Ci} / \mathrm{cm}^{3}$

(Barium) Ba $1374.545 \mu \mathrm{Ci} / \mathrm{cm}^{3}$

(This is a daughter of (Cesium) Cs 137 which is a pure $\beta$ emitter)

Dose Rate:

The gamma dose rates at $5 \mathrm{~mm}$ from the side surface of the cylinders are:

$$
10 \mathrm{~m}^{3}=5 \mathrm{mSv} / \mathrm{hour} \text { (0.5 Rems/hour) }
$$

$0.15 \mathrm{~m}^{3}=3 \mathrm{mSv} /$ hour $(0.3$ Rems/hour)

The control limit for site operations is 0.25 Rems/year.

It is noted that the dose rate is very similar for both blocks even though one block is 66 times bigger than the other. This is believed to be due to self shielding within the glass blocks.

2.4.2.7 Methodology to Evaluate Options. Design options have been identified in section 2.4.2.8 below. These options have been assessed and scored using the Kepner Tregoe opinion ranking system to determine the preferred options. Evaluation criteria have been established identifying the key attributes of performance and a numerical bias loading identified for each of the attributes. The bias loading is a maximum of 5 and the larger number indicating the most desirable attribute. The design options 1 to 11 have been scored and the results are tabulated in section 2.4.3.

\section{Evaluation Criteria.}

Bias score

- Provide radiological contamination containment

- Robustness/Durability of containment (to year 2078)

- Minimize dose uptake to personnel

- Maximize use of disposal area

- Retrievability ( to year 2078)

- Minimize Cost

- Ease of handling and transportation

- Simplicity of packaging operations 


\section{Selection of evaluation criteria.}

The following are comments on the choice of evaluation criteria.

\section{Provide radiological contamination containment.}

This evaluation criteria is to measure the packages ability to provide radiological contamination containment throughout handling, transportation, vault placement and closure of the disposal system including the post closure monitoring period of 50 years (ending circa 2078).

Radiation protection will be provided by external shield walls and the use of remote handling/shielded contact handling equipment.

\section{Robustness/Durability of containment}

The container is to be designed as a sacrificial package but with a minimum life expectancy to year 2078 . The container is expected to remain in a robust, sealed, handlable, retrievable condition for this timescale. This criteria is a measure of the container/vault anticipated ability to remain in a sound condition for this period of time.

\section{Minimize dose uptake by personnel}

All operations should be designed to minimize dose uptake to personnel. This evaluation is a measure of the anticipated personnel dose rate efficiency of the packaging operation.

\section{Maximize use of disposal area.}

To minimize the cost of the disposal system the waste glass and packaging shape/size should be designed to fill as much of the vault as possible and minimize voidage. This also includes the ability of the package to be stacked up to five high in the disposal vault. The evaluation score is a measure of the waste glass/package effectiveness in filling the vault volume and minimizing voidage.

\section{Retrievability.}

This is a measure of the ease of retrievability of the waste glass/package from the disposal site.

\section{Minimize cost.}

Part of the scope of this study is to minimize the cost of waste disposal. The score for this criteria represents a judgement on the overall cost of packaging using the methods stated.

\section{Ease of handling and transportation.}

The scoring of this evaluation criteria represents the relative ease of handling and transportability of the package. 


\section{Simplicity of Packaging operations.}

This reflects the ease and simplicity of packaging operations and includes the minimization of high maintenance operational plant.

2.4.2.8 Container and Disposal Options. The following have been identified as potential packaging options. A brief process description of each option is followed by a scored review of the option using the evaluation criteria identified in section 2.4.2.7.

A comment on uncertainties and unknowns completes each section.

Option

1) Monolithic glass block without container.

2) Monolithic glass block with matrix coating, without container.

3) Monolithic glass block in container. (Hot pour)

4) Monolithic glass block in container (cold fit)

5) Monolithic glass block and matrix in container.

6) Sheet glass in container

7) Sheet glass and matrix in container

8) Cullet/marbles in container

9) Cullet/marbles/matrix in container

10) Disposal Vault filled with cullet/marbles

11) Disposal Vault filled with cullet/marbles/matrix

Vault packing fractions

The following have been used when calculating the approximate vault packing fractions in the option evaluations below:

1) Monolith without container.

Vitrified waste monoliths (without containers) are assumed to be rectangular and 10 $\mathrm{m}^{3}$. The space required around the monoliths for remote handling lifting attachments and stacking/vault placement is assumed (an approximation) to require $15 \%$ of the vault volume. (If cylindrical containers are used (not considered here) the voidage increases by approximately $20 \%)$.

\section{2) Containerized vitrified waste.}

Containerized vitrified waste (monoliths, sheet or cullet/marbles) is assumed to be in $10 \mathrm{~m}^{3}$ containers. The container body and the space required around the container for remote handling lifting attachments and stacking/vault placement is assumed to require $15 \%$ of the vault volume. (If cylindrical containers are used [not considered herel the voidage increases by approximately $20 \%$ ).

3) Monolith or sheet glass in SPC container.

A Sulfur Polymer Cement (SPC) container, or matrix encapsulation (SPC), is assumed to be $200 \mathrm{~mm}$ thick around a $10 \mathrm{~m}^{3}$ glass monolith or glass sheet stack. The volume occupied by the SPC of the total block is therefore: 
i) Volume of glass block $=2.15 \mathrm{~m} \times 2.15 \mathrm{~m} \times 2.15 \mathrm{~m}=10 \mathrm{~m}^{3}$

ii) Overall volume of a glass block with an SPC matrix coating or SPC container $=2.55 \mathrm{~m} \times 2.55 \mathrm{~m} \times 2.55 \mathrm{~m}=16.58 \mathrm{~m}^{3}$

iii) Therefore the volume of total the block occupied by SPC $=6.85 / 16.85=$ $40 \%$

iv) The total volume of the vault available for vitrified glass when using monoliths or glass sheets in SPC containers or with an SPC coating is: $100 \%$ $15 \%$ (handling) $-(85 \% \times 0.4$ SPC container $/$ coating $)=51 \%$

4) Monolith or sheet glass in SPC container with SPC encapsulation.

It is assumed that a glass monolith (or stack of sheet glass) in a Sulfur Polymer Cement (SPC) container $(200 \mathrm{~mm}$ thick) with matrix (SPC) encapsulation (50 mm thick) has a total SPC coating of $250 \mathrm{~mm}$ thick around the $10 \mathrm{~m}^{3}$ glass block or glass sheet stack. The volume occupied by the SPC of the total block area is therefore:

i) Volume of Glass block $=2.15 \mathrm{~m} \times 2.15 \mathrm{~m} \times 2.15 \mathrm{~m}=10 \mathrm{~m}^{3}$

ii) Overall volume of a glass block with SPC matrix encapsulation within an SPC container $=2.65 \mathrm{~m} \times 2.65 \mathrm{~m} \times 2.65 \mathrm{~m}=18.61 \mathrm{~m}^{3}$.

iii) Therefore the volume of total block size occupied by SPC $=8.61 / 18.61=$ $46 \%$

iv) The total volume of the vault available for vitrified glass when using monoliths or glass sheets in a $200 \mathrm{~mm}$ SPC container with a $50 \mathrm{~mm}$ SPC matrix encapsulation is: $100 \%-15 \%$ (handling) $-185 \% \times 0.46$ SPC container and matrix) $=46 \%$

5) Glass cullet/marbles.

Glass cullet or marbles for the requirements of this section of the study are assumed to have a packing density of $70 \%$. i.e, a $10 \mathrm{~m}^{3}$ container will actually contain $7 \mathrm{~m}^{3}$ of glass.

6) Glass cullet/marbles in an SPC container.

Therefore the total volume of the vault available for vitrified glass when using cullet/marbles in SPC containers is: $100 \%-15 \%$ (handling) $-(85 \% \times 0.4$ (SPC container/coating)] $\times 0.7$ (cullet/marbles packing fraction) $=36 \%$

7) Glass cullet/marbles in an SPC container with matrix encapsulation.

The total volume of the vault available for vitrified glass when using cullet/marbles/matrix in an SPC container (assuming $40 \%$ matrix material) is:

$100 \%-15 \%$ (handling) - $[(85 \% \times 0.4$ (SPC container/coating) $] \times 0.6$ packing fraction (matrix occupies $40 \%$ ) $=31 \%$

(High Level Waste containers are only filled to approximately $80 \%$ of capacity with 
glass to ensure the containers are not overfilled and to allow for swelling of the glass due to radiolysis. The swelling effects of LLW are not known and therefore containers have been assumed to be full for the purposes of this study).

\section{Option 1) Monolithic Glass Block Without Container.}

General System description. Glass from a melter is poured into a series of prepared molds via a feed carrousel and allowed to cool until solid. The glass is then extracted from the mold and moved to a storage area where it is left to cool and anneal for several weeks. Following cooling the glass is decontaminated, placed and sealed into a reusable transport package and then moved to the disposal site in a shielded transport vehicle.

At the disposal site the monolith is removed from the transport vehicle, extracted from the transport package and is placed in a disposal vault where it would be surrounded by a barrier system as discussed in section 3.0. The shielded transport vehicle and sealable transport package are both reusable.

The building for cooling and loading the glass blocks in the vitrification plant would be a controlled contamination area in addition to the controlled contamination area containing the production and decontamination plants. Facilities will also be required for the loading of the monoliths into the reusable sealed transport packages.

A further controlled active area building would be required covering the disposal vault and receipt area where the blocks would be unload and placed in a vault. This controlled area building would remain in position over the vault until the vault is sealed.

\section{Option evaluation}

Provide radiological contamination containment (5)

Following casting, a monolithic block without a container is likely to have loose (smearable) contamination on its outer surface. Decontamination by a high pressure water wash, could possibly remove the surface contamination but any further handling /collision or surface cracking of the brittle block is likely to generate additional lose contamination. It is therefore unlikely that the block will be sufficiently robust so as to be handled, transported and placed into the vault without suitable contamination control packages, buildings and facilities in all areas including the disposal site.

If retrieval is required, opening the disposal system and recovering the blocks would require the reinstallation of the contamination control building over the vault area.

Score 2 out of 5

\section{Robustness/durability of package (5)}

A brittle glass block is susceptible to damage during handling, transportation, vault placement and vault closure. Score 2 out of 5 


\section{Minimize dose uptake by personnel (5)}

It is assumed that all equipment and operations will be designed to minimize dose uptake by personnel. Radiation protection will be provided by external shield walls and the use of remote handling or shielded contact handling equipment. Dose received during maintenance operations is not considered here.

Score 5 out of 5

\section{Maximize use of disposal area (5)}

The glass blocks can be cast to any shape to maximize the volume of glass in a disposal vault. Package and matrix materials are not used further increasing the maximum use of the disposal area. The space required for handling requirements within the vault will reduce glass content in the disposal site to approximately $85 \%$ if rectangular glass blocks are used. It may be desirable to pack a barrier material (e.g., Sulfur) between the containers. If so the glass volume in the disposal site could be reduced even further. The maximum score is given. Score 5 out of 5

\section{Retrievability(5)}

If retrieval is required, opening the disposal system and recovering the blocks will require the installation of a contamination control building over the vault area. Building and operating such a containment system is onerous. Score 3 out of 5

\section{Minimize cost of packaging (5)}

This option has no container and therefore scores maximum points.

(The plant costs for the additional containment facilities required for loading, storing and vault placement, and the requirement for reusable transport containers will add considerably to the overall project costs but are not considered here). Score 5 out of 5 .

\section{Ease of handling and transportation (3)}

Handling a large monolith (without a container with incorporated lifting lugs) would not be easy when using contact handling or remote handling equipment. Grabs holding the blocks on the lifting equipment would tend to spall the outer surface of the glass particularly if the block has existing surface cracking.

Transportation would require the manufacture and use of reusable transport containers in addition to the shielded transport container required by all the other options (except 10 and 11). Score 1 out of 3

\section{Simplicity of packaging operations (3)}

Transportation of the bare monolith requires the use of a reusable sealed container for transportation to the disposal site, where it is unloaded and placed in the vault, and the emptied container returned to the vitrification plant. All loading and unloading operations are completed in radiation areas using remote or shielded equipment. These are not simple operations. Score 1 out of 3 


\section{Unknowns/Uncertainties}

It is not known if large monoliths can be cast economically with minimal cracking and of sufficient quality to allow handling and transportation without a container.

\section{Option 2) Monolithic glass block with matrix (SPC) coating, without container.}

General System description. Glass from a melter is poured into a series of prepared molds via a feed carrousel and allowed to cool until solid. The glass is then extracted from the mold and moved into a storage area where it is left to cool and anneal for several weeks. Following cooling the glass is decontaminated and moved into a radiologically clean area where it is placed in a second larger mould. The interspace between the mould and the block is then filled with molten matrix material (presently assumed to be Sulfur Polymer Cement) covering the block completely. (The block is rested on pre-formed matrix spacers in the mould to ensure complete encapsulation).

The assumed thickness of the matrix coating for this study is $200 \mathrm{~mm}$. This is an estimate for optioneering purposes, detailed modeling work is required to determine an accurate figure.

It is anticipated that the SPC will bond with the glass forming a barrier envelope around the glass block. It is possible the SPC may need reinforcement (eg Carbon fibre) to be effective as the difference in expansion rates between the glass and SPC material may cause SPC without reinforcement to crack (experimental data is needed).

Following encapsulation, the glass/SPC block is placed into a shielded transport container and moved to the disposal site. If cracking in the SPC coating cannot be eliminated then a reusable sealed transport container may be required in addition to the shielded transport vehicle as in option 1 above. At the disposal site the block is removed from the transport container and placed in a disposal vault where it would be surrounded by a barrier system as discussed in section 3.0.

\section{Option evaluation}

\section{Provide radiological contamination containment (5)}

It is anticipated that the SPC coating applied to the block will act as a contamination containment barrier during handling, transportation and vault placement.

Radiation protection will be provided by external shield walls and the use of remote handling/shielded contact handling equipment. Radiation protection during transportation will be provided by the use of a shielded transport container.

The difference in thermal expansion rates between glass and SPC may result in some cracking of the matrix material. The addition of reinforcement material may eliminate this problem. However uncertainties exist about the effectiveness of the containment provided by SPC. Score 3 out of 5 
Robustness/durability of package (5)

The SPC/glass block is susceptible to damage during handling, transportation, vault placement and vault closure which could reduce its durability. Score 3 out of 5

Minimize dose uptake by personnel (5)

It is assumed that all equipment and operations will be designed to minimize dose uptake by personnel. Radiation protection will be provided by external shield walls and the use of remote handling or shielded contact handling equipment. Dose received during maintenance operations is not considered here. Score 5 out of 5

\section{Maximize use of disposal area (5)}

The glass/SPC blocks can be cast to maximize the use of the disposal area. The space required for handling requirements and the SPC coating $1200 \mathrm{~mm}$ thick and assuming a rectangular block) will reduce the glass content of disposal site to approximately $50 \%$ if rectangular glass blocks are used. It may also be desirable to pack between the containers with a barrier material (eg Sulfur). If so, the glass volume in the disposal site is reduced further. Score 2 out of 5

\section{Retrievability (5)}

If retrieval is required, opening the disposal system and recovering the blocks will possibly require the installation of a contamination control building over the vault area as it could not be guaranteed that the matrix coating had not cracked and separated from the block. Building and operating such a containment system is onerous. Score 3 out of 5

\section{Minimize cost of packaging (5)}

This option uses the SPC coating as packaging and an approximation of coating process costs will be used as the relative packaging costs in this comparative review of packaging costs.

The plant costs for the additional containment facilities required for storing the cooling glass blocks and the requirement for reusable transport containers, if required, will add considerably to the overall project costs but are not considered here.

Score 3 out of 5 .

\section{Ease of handling and transportation (3)}

Handling a large glass block with an SPC coating (without a container which incorporates lifting lugs) would not be easy when using either contact handling or remote handling equipment. Contact points of the lifting equipment would tend to spall the outer surface of the glass and matrix materials particularly if the block has existing surface cracking.

Transportation may require the manufacture and use of reusable transport containers in addition to the shielded transport container required by all the containerized options. Score 1 out of 3 
Simplicity of packaging operations (3)

The SPC coating operation using remote handling or shielded contact handled equipment is expected to be time consuming and difficult.

Transportation of the SPC/glass block may require the use of a reusable sealed container for transportation to the disposal site. If a sealed transport container is required all loading and unloading operations will be undertaken in radiation areas using remote or shielded equipment. These are not simple operations and are scored accordingly.

Score 1 out of 3

\section{Unknowns/Uncertainties}

It is not known if large monoliths can be cast economically with minimal cracking and of sufficient quality to allow handling and transportation without a container. Similarly, details of SPC reinforcement requirements and crack propagation properties when used as a glass coating are unknown.

It is possible that the glass will expand or slump due to radiological action. If such an action occurs it is not presently known if this will cause cracking in the encasing matrix material and if this will cause the matrix material to become unsuitable for its purpose.

\section{Option 3) Monolithic Glass Block in a Container (hot pour) .}

General system description. In this option a preheated metal container is filled directly with vitrified glass in a single pour. A carrousel or similar device will be used to feed the containers to the melter to maintain throughput. The carrousel will be sized so as to allow the container to remain on the carrousel until the glass temperature cools to a point where it can be transported.

In this study it is assumed that a metal container, of sufficient strength and to act as the glass mold without serious deformation, is used. If, to minimize costs, the container is not designed for an unsupported glass fill, then a temporary support frame would be used to hold the container until the glass solidifies.

The filled containers would be allowed to cool in a storage area until a temporary waterproofing cap can be added. The outside of the container would than be decontaminated to an acceptable level. The containers would next be moved out of the initial storage area to a welding cell where a lid would be permanently welded in place. Following welding the container would be transported to a storage building for cooling/annealing for a number of weeks; possibly 4-6 weeks (experimental data is required). The container is then transported to the disposal site in a shielded transport vehicle for vault disposal.

At the disposal site the containerized monolith is removed from the transport vehicle and placed in the disposal vault where it will be surrounded by a barrier system as discussed in section 3.0. 


\section{Option evaluation}

\section{Provide radiological contamination containment (5)}

It is anticipated that the glass container will act as the contamination containment barrier during handling, transportation and vault placement. Radiation protection will be provided by external shield walls and the use of remote handling/shielded contact handling equipment. Radiation protection during transportation will be provided by the use of a shielded transport container or vehicle. Score 5 out of 5

\section{Robustness/durability of package (5)}

The container protects the glass block from serious damage during handling, transportation, vault placement and vault closure. Durability of the glass is good. Score 5 out of 5

\section{Minimize dose uptake by personnel (5)}

It is anticipated that all equipment and operations will be designed to minimize dose uptake by personnel. Radiation protection will be provided by external shield walls and the use of remote handling or shielded contact handling equipment. Dose received during maintenance operations is not considered here.

Score 5 out of 5

Maximize use of disposal area (5)

The glass containers can be made to any shape and filled with glass to maximize the use of the disposal area. Matrix materials are not used in this option, thereby increasing the volume of the disposal area available for vitrified waste. Container body, lifting attachments, and space required for handling requirements will reduce glass content of disposal site to approximately $85 \%$ (if a rectangular waste glass block is used). It may be desirable to pack between the containers with a barrier material (eg Sulfur). If so, the glass content of the disposal site would be reduced further. Score 5 out of 5

\section{Retrievability (5)}

If retrieval is required, opening the disposal system and recovering the containerized blocks before 2728 (the design life of the container) will probably not require the installation of a contamination control building over the vault area. Score 5 out of 5

\section{Minimize cost of packaging (5)}

Relative packaging costs have been compared with each of the other options. The time required to package an item has also been factored into the cost. The plant costs for the additional containment facilities required for storing the cooling glass blocks will add considerably to the overall project costs and are not considered here.

Score 3 out of 5 . 
Ease of handling and transportation (3)

Handling a large glass block in a container with incorporated lifting lugs would be relatively easy when using either contact handling or remote handling equipment. Handling/lifting equipment would not damage the glass even if the block has existing surface cracking. Score 3 out of 3

Simplicity of packaging operations (3) 3 out of 3

This is the simplest of the containerized options and has few difficult operations. Score

\section{Uncertainties/Unknowns}

It is not known if large monoliths can be cast economically, with minimal cracking and of sufficient glass quality for long term disposal.

\section{Option 4) Monolithic Glass Block in Container (cold fit).}

Genera/ System description. In this option a preheated metal mold is filled directly with vitrified glass in a single pour. A carousel or similar device will be used to feed the molds to the melter to maintain throughput. The carrousel will be sized so as to allow the cast monolith to remain on the carrousel until the glass temperature cools to a point where it can be transported. The glass is then extracted from the mold and moved into a storage area to cool and anneal for a number of weeks; possibly 4-6 weeks. (Experimental data is required). Cooling of the glass blocks prior to containerization would require the construction of a large 'controlled' contamination area at the vitrification plant.

Following cooling, the glass may be decontaminated (possibly by high pressure water wash), placed into a container and the container sealed. The filled container is then moved to the disposal site in a shielded transport vehicle. At the disposal site the containerized monolith is removed from the shielded transport vehicle and placed in the disposal vault where it will be surrounded by a barrier system as discussed in section 3.0 .

As the glass is placed in the containers 'cold' there are no temperature limitations on the choice of container material and the choice of materials is therefore extended to;

- Reinforced concrete (possibly SPC)

- Metal (Stainless steel, mild steel, cast iron, copper, lead etc.)

- Other materials, plastics etc

The performance assessment of the disposal system will consider containers to be of long term benefit only if they will last 10,000 years or more, or have a chemical property, such as causing precipitation of leached radionuclides. The metal container identified in option 3 above is designed to last for only 50 years after vault closure to facilitate retrieval should this be required during the closure monitoring period. It is considered sacrificial after this date. It is not thought possible to design an economic metal or plastic container for this application to last more than 10,000 years. 
Therefore this option will consider:

1) A container made from SPC which is seen as the only potentially long life container system, (See section 2.2 Matrix materials).

2) A stainless steel container which will provide initial contamination containment and glass protection. It will also improve the handleability of the glass from the vitrification plant to the disposal vault and will simplify retrieval should it be necessary. But the container will be designed to last only until the end of the monitoring period after vault closure, program date 2078.

$S P C$ container Process - As above a decontaminated glass monolith would be placed within an SPC container, assumed wall thickness $200 \mathrm{~mm}$, and an SPC lid would be cemented in place. It is anticipated that the container would need to be reinforced. Due to its limited life, steel reinforcement would not be suitable for this purpose but other non-reactive materials such as carbon fiber or glass fiber may be suitable alternatives. The assumed $200 \mathrm{~mm}$ thickness of the SPC container is only an estimate, Detailed modeling will be required to determine an accurate figure.

Stainless steel container Process - As above, a decontaminated glass monolith would be placed within the container and a top cover welded in place.

\section{Option evaluation}

\section{Provide radiological contamination containment (5)}

It is anticipated that the glass container will act as the contamination containment barrier during handling, transportation and vault placement. Radiation protection will be provided by external shield walls and the use of remote handling/shielded contact handling equipment. Radiation protection during transportation will be provided by the use of a shielded transport container or vehicle. Score 5 out of 5 .

\section{Robustness/durability of package (5)}

The container would protect the glass block from serious damage during handling, transportation, vault placement and vault closure. Durability of the container is good.

Score 5 out of 5

\section{Minimize dose uptake by personnel (5)}

It is assumed that all equipment and operations will be designed to minimize dose uptake by personnel. Radiation protection will be provided by external shield walls and the use of remote handling or shielded contact handling equipment. Dose received during maintenance operations is not considered here.

Score 5 out of 5

\section{Maximize use of disposal area (5)}

The containers and glass blocks can be made in a form that maximize the use of the disposal area. It is assumed that the use of an SPC container will require a container wall 
thickness of approximately $200 \mathrm{~mm}$, subsequently decreasing the volume of the disposal vault available for the vitrified waste. The container body, lifting attachments, and space required for handling requirements will possibly reduce glass content of disposal site to approximately $50 \%$ (assuming a rectangular block is used). Score 2 out of 5

Metal container - The containers and glass blocks can be made in a form that maximize the use of the disposal area. The use of a metal container will require a container with a wall thickness of $5 \mathrm{~mm}$. The container body, lifting attachments, and space required for handling requirements will reduce glass content of disposal site to approximately $85 \%$ (assuming a rectangular block is used). It may be desirable to pack with a barrier material (eg Sulfur) between the containers. If so the glass content of the disposal site would be reduced further. Score 5 out of 5

\section{Retrievability (5)}

If retrieval is required, opening the disposal system and recovering the containerized blocks before 2078 will probably not require the installation of a contamination control building over the vault area. Lifting attachments on the container will simplify remote handling or shielded contact handling operations. Score 5 out of 5

\section{Minimize cost of packaging (5)}

Relative packaging costs and the time element to complete packaging have been compared with each of the other options. It has been assumed for purpose of this study that the cost of a stainless steel container and an SPC container are the same. (The plant costs for the additional containment facilities required for storing the cooling glass blocks will add considerably to the overall project costs but are not considered here). Score 3 out of 5 .

\section{Ease of handling and transportation (3)}

Handling a large glass block in a container with incorporated lifting lugs would be relatively easy when using contact handling or remote handling equipment.

Score 3 out of 3

\section{Simplicity of packaging operations (3)}

This option requires a glass block to be cast and cooled, decontaminated, and fitted into a container. The container, sealed by cementing a pre-cast lid in place or welding a fabricated lid, is then transported to the disposal site. This is a time consuming and potentially difficult operation with significant facilities requirements.

Score 1 out of 3

\section{Uncertainties/Unknowns}

SPC reinforcement requirements/details and crack propagation properties when used as a container material are not known in sufficient detail. Experimental data required. 


\section{Option 5) Monolithic glass block and matrix in a container.}

General System Description. In this option a preheated metal mold is filled directly with vitrified glass in a single pour. A carousel or similar device will be used to feed the molds to the melter to maintain throughput. The carrousel will be sized so as to allow the cast monolith to remain on the carrousel until the glass temperature cools to a point where it can be transported. The glass is then extracted from the mold and moved into a storage area to cool and anneal for a number of weeks; possibly 4-6 weeks. (Experimental data is required). Cooling the glass blocks prior to containerization would require the construction of a large 'controlled' contamination area at the vitrification plant.

Following cooling, the glass is decontaminated (possibly by high pressure water wash) and placed into a metal container leaving an interspace (presently assumed to be $200 \mathrm{~mm}$ ) on 5 sides between the glass block and container. The interspace between the container and the glass block is then filled with matrix material covering the block completely. (The glass block is placed on pre-formed matrix spacers in the container to ensure complete and even encapsulation). The container is filled with matrix material, the pour forming a $200 \mathrm{~mm}$ thick lid for the container.

The filled container is then moved to the disposal site in a shielded transport vehicle. At the disposal site the containerized monolith is removed from the shielded transport vehicle and placed in the disposal vault where it will be surrounded by a barrier system as discussed in section 3.0 .

The thickness of the matrix material, presently assumed to be $200 \mathrm{~mm}$, is a estimate. Detailed modeling work is required to determine an accurate figure.

As the glass is placed in the containers 'cold' but covered by matrix material, probably, $\mathrm{SPC}$, there are temperature limitations on the choice of container material. The choice of materials is therefore extended to;

- Reinforced concrete (possibly SPC)

- Metal (Stainless steel, mild steel, cast iron, copper, lead etc.)

The performance assessment of the disposal system will consider containers to be of long term benefit only if they will last 10,000 years or more, or have a chemical property such as causing precipitation of leached radionuclides. The metal container identified in option 3 above is designed to last for only 50 years after vault closure to facilitate retrieval should this be required during the closure monitoring period. It is considered sacrificial after this date. It is not thought possible to design an economic metal container for this application to last more than 10,000 years.

Therefore this option will consider:

1) A container made from SPC which is seen as the only potentially long life container system, (See section 2.2 Matrix materials). 
2) A stainless steel container which will provide initial contamination containment and glass protection. It will also improve the handleability of the glass from the. vitrification plant to the disposal vault and will simplify retrieval should it be necessary. But the container will be designed to last only until the end of the monitoring period after vault closure, program date 2078 . Following this date the stainless steel container is assumed to have failed and the matrix fill becomes the glass containment/protection.

SPC container with SPC matrix material. As above, a decontaminated glass monolith would be placed within an SPC container (assumed to have a wall thickness of $200 \mathrm{~mm}$ ) and the interspace ( reduced to $50 \mathrm{~mm}$ for SPC containers) filled with molten SPC. The container is then sealed by cementing a pre-cast cover in position.

It is anticipated that the Interspace layer of SPC can be reduced to $50 \mathrm{~mm}$ from the $200 \mathrm{~mm}$ assumed for the metal container below, as the SPC container becomes part of the matrix barrier. It is anticipated that the molten SPC will bond with the glass and with the SPC container forming a $250 \mathrm{~mm}$ thick cohesive matrix barrier around the glass block.

It is anticipated that the container would need to be reinforced. Due to its limited life, steel reinforcement would not be suitable for this purpose but other non-reactive materials such as carbon fiber or glass fiber may be suitable alternatives. Data on reinforced SPC containers is limited and the permanence of any bonding between the reinforcement/matrix/glass is unknown.

Stainless steel container with SPC matrix material. Process - As above a decontaminated glass monolith would be placed within the container and the interspace (approximately $200 \mathrm{~mm}$ ) filled with molten SPC. A stainless cover will then be fitted and welded in place.

It is anticipated that the molten SPC will bond with the glass forming a cohesive barrier around the glass block.

\section{Option evaluation}

\section{Provide radiological contamination containment (5)}

It is anticipated that the container will act as the contamination containment barrier during handling, transportation and vault placement. Radiation protection will be provided by external shield walls and the use of remote handling/shielded contact handling equipment. Radiation protection during transportation will be provided by the use of a shielded transport container or vehicle. Score 5 out of 5

\section{Robustness/durability of package (5)}

Either type of container material protects the glass block from serious damage during handling, transportation, vault placement and vault closure. Durability is good. Score 5 out of 5 
Minimize dose uptake by personnel (5)

It is assumed that all equipment and operations will be designed to minimize dose uptake by personnel. Radiation protection will be provided by external shield walls and the use of remote handling or shielded contact handling equipment. Dose received during maintenance operations is not considered here. Score 5 out of 5

Maximize use of disposal area (5)

The containers and glass blocks can be made in a form that maximize the use of the disposal area. The use of an SPC container with matrix infill will result in a total wall thickness of approximately $200 \mathrm{~mm}$ plus $50 \mathrm{~mm}$ of matrix which decreases the volume of the disposal area available for the vitrified waste. It is anticipated that the container body, matrix, lifting attachments, and space required for handling requirements will reduce glass content of a disposal vault to approximately $45 \%$ (It is assumed a rectangular block is used) .

The use of a stainless steel container $(5 \mathrm{~mm}$ thick) and a $200 \mathrm{~mm}$ thick layer of SPC will also decrease the volume of the disposal area available for the vitrified waste. The container body, lifting attachments, and space required for handling requirements within the vault will decrease the glass content of a disposal vault to approximately $50 \%$ (It is assumed a rectangular block is used).

Score of both options 2 out of 5

\section{Retrievability (5)}

If retrieval is required, opening the disposal system and recovering the containerized blocks before 2728 (the design life of the metal container and minimum design life of the SPC container) will probably not require the installation of a contamination control building over the vault area. Lifting attachments on the container will simplify remote handling or shielded contact handling operations. Score 5 out of 5

\section{Minimize cost of packaging (5)}

Relative packaging costs and the time element for packaging have been compared with each of the other options. It has been assumed for purpose of this study that the cost of a stainless steel container and an SPC container are the same. (The plant costs for the additional containment facilities required for storing the cooling glass blocks will add considerably to the overall project costs but are not considered here). Score 3 out of 5 .

\section{Ease of handling and transportation (3)}

Handling a large glass block in a container with incorporated lifting lugs would be relatively easy when using either contact handling or remote handling equipment. Score 3 out of 3

\section{Simplicity of packaging operations (3)}

This option requires a glass block to be cast and cooled, decontaminated, and lifted into a container. The container is filled with SPC, sealed and transported to the disposal site. These are time consuming and relatively difficult operations. Score 1 out of 3 


\section{Uncertainties/Unknowns.}

SPC reinforcement requirements/details and crack propagation properties when used as a container material are not known in sufficient detail. Experimental data is required.

It is possible that the glass will expand or slump due to radiological action. If such an action occurs it is not presently known if this will cause cracking in the encasing matrix material and if this will cause the matrix material to become unsuitable for its purpose.

\section{Option 6) Sheet Glass in Container.}

General System description. The sheet glass is produced ( $25 \mathrm{~mm}$ thick) on standard glass industry production equipment using either sheet glass or float glass production systems. The glass is cooled, annealed and cut into rectangular sheets on the same automated/continuous production line. The glass sheets are then decontaminated and stacked horizontally in containers. The tops are welded onto containers and the containers transported to the disposal site in shielded transport vehicles for vault disposal.

Decontamination of the glass sheets (using a high pressure water wash) as part of the manufacturing process if possible would enable the cut sheets to be passed from a contaminated area into a contamination free zone. Radiation shielding would still be required, but the design and maintenance of the remote or shielded contact handled equipment to load the containers, fit and weld the container lids, and to monitor and dispatch the filled containers to the disposal site would be simplified.

The size of the sheet glass container can be optimized to suit transport and vault requirements and vault space utilization would be high. The shape of the sheet glass and hence containers will always be rectangular but this is not seen as a problem.

Breaking the sheet glass during transportation or stacking is a potential problem. Further evaluation in cooperation with a sheets glass manufacturer is required to quantify the mechanical strength of $25 \mathrm{~mm}$ thick sheet glass and the protection required during transportation and storage.

As the glass is placed in the containers 'cold' there are no temperature limitations on the choice of container material and the choice of materials is therefore the same as option 4 (fitting a cold monolithic block in a container).

Therefore this option will consider:

1) A container made from SPC which is seen as the only potentially long life container system, (See section 2.2 Matrix materials).

2) A stainless steel container which will provide initial contamination containment and glass protection. It will also improve the handleability of the glass from the vitrification plant to the disposal vault and will simplify retrieval should it be necessary. But the container will be designed to last only until the end of the monitoring period after vault closure, program date 2078. 
SPC container Process - As above a decontaminated glass monolith would be placed within an SPC container, assumed wall thickness $200 \mathrm{~mm}$ and a pre-cast SPC lid cemented in place. It is anticipated that the container would need to be reinforced. Due to its limited life, steel reinforcement would not be suitable for this purpose but other non-reactive materials such as carbon fiber or glass fiber may be suitable alternatives. (The assumed thickness of the container for this study is $200 \mathrm{~mm}$. This is only an estimate, detailed modeling work is required to determine an accurate figure).

Stainless steel container Process - As above, the decontaminated glass sheets would be placed within a container and a top cover welded in place.

\section{Option evaluation}

\section{Provide radiological contamination containment (5)}

It is anticipated that the container will act as the contamination containment barrier during handling, transportation and vault placement. Radiation protection will be provided by external shield walls and the use of remote handling/shielded contact handling equipment. Radiation protection during transportation will be provided by the use of a shielded transport container. Score 5 out of 5

\section{Robustness/durability of package (5)}

The container protects the glass block from serious damage during handling, transportation, vault placement and vault closure. Durability is good.

Score 5 out of 5

\section{Minimize dose uptake by personnel (5)}

It is anticipated that all equipment and operations will be designed to minimize dose uptake by personnel. Radiation protection will be provided by external shield walls and the use of remote handling or shielded contact handling equipment. Dose received during maintenance operations is not considered here. Score 5 out of 5

\section{Maximize use of disposal area (5)}

The containers and glass blocks can be made in a form that maximize the use of the disposal area. The use of an SPC container will require a container wall thickness of approximately $200 \mathrm{~mm}$ decreasing the volume of the disposal area available for the vitrified waste. Therefore the container body, lifting attachments, and space required for handling requirements will reduce glass content of disposal site to approximately $50 \%$.

Score 2 out of 5

Stainless Steel container - The containers and glass sheets can be made/cut in a form that maximize the use of the disposal area. The use of metal container construction will require a container wall thickness of $5 \mathrm{~mm}$ thick. The container body, lifting attachments, and space required for handling requirements will reduce glass content of disposal site to approximately $85 \%$. It may be desirable to pack between the containers with a barrier material (eg Sulfur). If so, the glass content in the disposal site would be reduced further.

Score 5 out of 5 


\section{Retrievability (5)}

If retrieval is required, opening the disposal system and recovering the containerized blocks before 2728 will probably not require the installation of a contamination control building over the vault area. Lifting attachments on the container will simplify remote handling or shielded contact handling operations. Score 5 out of 5

\section{Minimize cost of packaging (5)}

Relative packaging costs and the time element for packaging have been compared with each of the other options. It has been assumed for purpose of this study that the cost of a stainless steel container and an SPC container are the same. (The plant and maintenance costs for the additional production equipment will add considerably to the overall project costs but are not considered here).

Score 3 out of 5 .

\section{Ease of handling and transportation (3)}

Handling sheet glass in a container with incorporated lifting lugs would be relatively easy when using either contact handling or remote handling equipment. Score 3 out of 3

\section{Simplicity of packaging operations (3)}

This option requires the glass sheets to be rolled, cooled, cut, decontaminated, and stacked into containers. The containers are sealed by a separate operation; welding. Score 1 out of 3

\section{Option 7) Sheet Glass and matrix in Container.}

General System description. The sheet glass is produced (25 $\mathrm{mm}$ thick) on standard glass industry production equipment using either the sheet glass or the float glass production system. The glass is cooled, annealed and cut into rectangular sheets on the same automatic/continuous production line. The glass sheets may then be decontaminated and stacked horizontally in containers.

SPC spacers, $200 \mathrm{~mm}$ thick, are placed in the base of the (metal) container and the first (bottom) sheet of glass is placed on the top of the spacers. Subsequent sheets of glass are stacked directly on top of each other. The glass is sized to fit in the container with a 200 $\mathrm{mm}$ gap between the glass and the container on all 6 sides of the glass stack. The interspace between the container and the stack of glass sheets is then filled with matrix material covering the sheets completely and filling the container. (The assumed thickness of the matrix coating for this study is $200 \mathrm{~mm}$. This is an estimate detailed modeling work is required to determine an accurate figure).

A sealing cover is placed in position and welded onto the container. After filling and sealing the container is transported to the disposal site in a shielded transport vehicle for vault disposal. 
Decontamination of the glass sheets (using a high pressure water wash) as part of the manufacturing process, if possible, would enable the cut sheets to be passed from a contaminated area into a contamination free zone. Radiation shielding would still be required, but the design and maintenance of the remote or shielded contact handled equipment to load the containers and add the matrix material and the matrix plant equipment would be in a clean area. The fitting and welding of the container lids (if required) would also be undertaken in a contamination free area but radiation levels would be relatively high (see 2.4 .2 .6 ) requiring the use of remote control welding equipment or shielded contact handled welding equipment.

The size of the sheet glass container can be optimized to suit transport and vault requirements but vault space utilization is low due to the addition of the matrix material. The shape of the sheet glass and hence containers will always be rectangular but this is not seen as a problem.

Breaking the sheet glass during transportation or stacking is a potential problem. Further evaluation in cooperation with a sheets glass manufacturer is required to quantify the mechanical strength of $25 \mathrm{~mm}$ thick sheet glass and the protection required during transportation and storage.

As the glass is placed in the containers at the temperature of molten SPC choice of materials is therefore the same as option 5

Therefore this option will consider:

1) A container made from SPC which is seen as the only potentially long life container system, (See section 2.2 Matrix materials). The assumed thickness of the container for this study is $200 \mathrm{~mm}$. This is an estimate, detailed modeling work is required to determine an accurate figure.

2) A stainless steel container which will provide initial contamination containment and glass protection. It will also improve the handleability of the glass from the vitrification plant to the disposal vault and will simplify retrieval should it be necessary. But the container will be designed to last only until the end of the monitoring period after vault closure, program date 2078. Following this date the stainless steel container is assumed to have failed and the matrix fill becomes the glass containment/protection.

SPC container with SPC matrix material. Process - As above, glass sheets would be placed within a SPC container (assumed to have a wall thickness of $200 \mathrm{~mm}$ ) and the interspace (reduced to $50 \mathrm{~mm}$ for SPC containers) filled with molten SPC. The container is then sealed by cementing a pre-cast cover in position.

It is anticipated that the Interspace layer of SPC can be reduced to $50 \mathrm{~mm}$ from the $200 \mathrm{~mm}$ assumed for the metal container below, as the SPC container becomes part of the matrix barrier. It is anticipated that the molten SPC will bond with the glass and with the SPC container forming a $250 \mathrm{~mm}$ thick cohesive matrix barrier around the glass block. 
It is anticipated that the container would need to be reinforced. Due to its limited life, steel reinforcement would not be suitable for this purpose but other non-reactive materials such as carbon fiber or glass fiber may be suitable alternatives. Data on reinforced SPC containers is limited and the permanence of any bonding between the reinforcing/matrix/glass is unknown.

Stainless steel container with SPC matrix material. Process - As stated in the general system description a decontaminated glass monolith would be placed within the container and the interspace (approximately $200 \mathrm{~mm}$ ) filled with molten SPC. A stainless cover will then be fitted and welded in place. It is anticipated that the molten SPC will bond with the glass forming a cohesive barrier around the glass block.

\section{Option evaluation}

\section{Provide radiological contamination containment (5)}

It is anticipated that the container will act as the contamination containment barrier during handling, transportation and vault placement. Radiation protection will be provided by external shield walls and the use of remote handling/shielded contact handling equipment. Radiation protection during transportation will be provided by the use of a shielded transport container. Score 5 out of 5

\section{Robustness/durability of package (5)}

The container protects the glass from serious damage during handling, transportation, vault placement and vault closure. Durability is good.

Score 5 out of 5

\section{Minimize dose uptake by personnel (5)}

It is anticipated that all equipment and operations will be designed to minimize dose uptake by personnel. Radiation protection will be provided by external shield walls and the use of remote handling or shielded contact handling equipment. Dose received during maintenance operations is not considered here. Score 5 out of 5

\section{Maximize use of disposal area (5)}

The containers and glass sheets can be made/cut in a form that maximize the use of the disposal area. The use of an SPC container plus matrix material will result in a wall thickness of approximately $200 \mathrm{~mm}$ plus $50 \mathrm{~mm}$. Decreasing the volume of the disposal area available for the vitrified waste. It is anticipated that the container body, lifting attachments, and space required for handling requirements will reduce glass content of a disposal vault to approximately $45 \%$.

The use of a stainless steel container $(5 \mathrm{~mm}$ thick) and a $200 \mathrm{~mm}$ thick layer of SPC will also decrease the volume of the disposal area available for the vitrified waste. The container body, lifting attachments, and space required for handling requirements within the vault will decrease the glass content of a disposal vault to approximately $50 \%$.

Score of both options 2 out of 5 


\section{Retrievability (5)}

If retrieval is required, opening the disposal system and recovering the containerized blocks before 2728 will probably not require the installation of a contamination control building over the vault area. Lifting attachments on the container will simplify remote handling or shielded contact handling operations. Score 5 out of 5

\section{Minimize cost of packaging (5)}

Relative packaging costs have been compared with each of the other options. (It also includes an element for the time taken to package an item). It has been assumed for purpose of this study that the cost of a stainless steel container and an SPC container are the same. (The plant and maintenance costs for the additional production equipment will add considerably to the overall project costs but are not considered here).

Score 3 out of 5 .

\section{Ease of handling and transportation (3)}

Handling glass sheets in a container with incorporated lifting lugs would be relatively easy when using either contact handling or remote handling equipment. Score 3 out of 3

Simplicity of packaging operations (3)

This option requires the glass sheets to be rolled, cooled, cut, decontaminated, and stacked into containers. The container is sealed by a separate operation. Score 1 out of 3

\section{Unknowns and Uncertainties}

It is possible that the glass will expand and slump due to radiological action. If such an action occurs it is not presently known if this will cause cracking in the encasing matrix material and if this will cause the matrix material to become unsuitable for its purpose.

\section{Option 8) Cullet/Marbles - In Container.}

General System Description. Cullet is manufactured by pouring molten glass into a water quenched flume. As the glass enters the flume, the resultant thermal shock shatters the glass into small irregular fragments. The glass is further size reduced by roller crushers and screened to remove process fines. The cullet is dried (by hot air) and loaded into storage hoppers.

Marbles are produced either by molds (possibly water cooled) or by chopping and rolling poured glass streams into spherical shapes. Following manufacture the marbles are transported to storage hoppers. In this report the term marble also includes other small regular shapes such as gems, etc.

Glass cullet or marbles are conveyed from storage bins and placed/poured into a container. The container lid is welded in place and the container body is decontaminated (possibly by high pressure water jet). The filled container is then moved to the disposal site in a shielded transport vehicle and placed into the disposal vault where it will be surrounded by a barrier system. 
For the purpose of this report, cullet and marbles are considered together.

As the glass is placed in the containers 'cold' there are no temperature limitations on the choice of container material and the choice of materials is therefore the same as option 4 (fitting a cold monolithic block in a container).

Therefore this option will consider:

1) A container made from SPC which is seen as the only potentially long life container system, (See section 2.2 Matrix materials).

2) A stainless steel container which will provide initial contamination containment and glass protection. It will also improve the handleability of the glass from the vitrification plant to the disposal vault and will simplify retrieval should it be necessary. But the container will be designed to last only until the end of the monitoring period after vault closure, program date 2078.

SPC container Process - As above, the cullet/marbles would be poured into a SPC container ( $200 \mathrm{~mm}$ wall thickness) and a pre-cast SPC lid cemented in place. It is anticipated that the container would need to be reinforced. Due to its limited life, steel reinforcement would not be suitable for this purpose but other non-reactive materials such as carbon fiber or glass fiber may be suitable alternatives. The assumed thickness of the container for this study is $200 \mathrm{~mm}$. This is an estimate, detailed modeling work is required to determine an accurate figure).

Stainless steel container Process - Cullet/marbles would be poured into a stainless steel container and a top cover welded in place.

\section{Option evaluation}

\section{Provide radiological contamination containment (5)}

It is anticipated that the container will act as the contamination containment barrier during handling, transportation and vault placement. Radiation protection will be provided by external shield walls and the use of remote handling/shielded contact handling equipment. Radiation protection during transportation will be provided by the use of a shielded transport container. Score 5 out of 5

\section{Robustness/durability of package (5)}

The container protects the glass from spillage during handling, transportation, vault placement and vault closure. Durability is good.

Score 5 out of 5

\section{Minimize dose uptake by personnel (5)}

It is assumed that all equipment and operations will be designed to minimize dose uptake by personnel. Radiation protection will be provided by external shield walls and the use of remote handling or shielded contact handling equipment. Dose received during maintenance operations is not considered here. Score 5 out of 5 


\section{Maximize use of disposal area (5)}

SPC container - The container can be made in a form that maximize the use of the disposal area. The use of an SPC container will result in a container wall thickness of approximately $200 \mathrm{~mm}$ thick, decreasing the volume of the disposal area available for the vitrified waste. Therefore the container body, cullet/marble packing fraction, lifting attachments, and space required for handling requirements will reduce glass cullet/marbles content in the disposal site to approximately $35 \%$.

Score 2 out of 5

Metal container - The containers can be made in a form that maximize the use of the disposal area. The use of metal container construction will require a container wall thickness of $5 \mathrm{~mm}$ thick. The container body, cullet/marble packing fraction, lifting attachments, and space required for handling requirements will reduce glass cullet/marbles content of the disposal site to approximately $60 \%$. It may be desirable to pack between the containers with a barrier material (eg Sulfur). If so the glass content in the disposal site would be reduced further.

Score 3 out of 5

\section{Retrievability (5)}

If retrieval is required, opening the disposal system and recovering the containerized blocks before 2728 will probably not require the installation of a contamination control building over the vault area. Lifting attachments on the container will simplify remote handling or shielded contact handling operations. Score 5 out of 5

\section{Minimize cost of packaging (5)}

Relative packaging costs and the time element for packaging have been compared with each of the other options. It has been assumed for purpose of this study that the cost of a stainless steel container and an SPC container are the same. (The plant and maintenance costs for the additional cullet/marble production equipment will add to the overall project costs but are not considered here).

Score 3 out of 5 .

Ease of handling and transportation (3)

Handling cullet/marbles in a container with incorporated lifting lugs would be relatively easy when using either contact handling or remote handling equipment.

Score 3 out of 3

\section{Simplicity of packaging operations (3)}

This option requires the glass cullet/marbles to be size reduced/rolled and then fed via storage hoppers into containers. The containers are sealed by cementing or welding the lid in position. Score 2 out of 3 


\section{Option 9) Cullet/Marbles/Matrix in Container.}

General System description. Cullet is manufactured by pouring molten glass into a water quenched flume. As the glass enters the flume, the resultant thermal shock shatters the glass into small irregular fragments. The glass is further size reduced by roller crushers and screened to remove process fines. The cullet is dried (by hot air) and loaded into storage hoppers.

Marbles are produced either by molds (possibly water cooled) or by chopping and rolling poured glass streams into spherical shapes. Following manufacture the marbles are transported to storage hoppers. In this report the term marble also includes other small regular shapes such as gems, etc.

Glass cullet or marbles are conveyed from storage bins and mixed with a matrix material (SPC). The resulting mixture is poured into a container. The container lid is welded in place and the container body is decontaminated (possibly by high pressure water wash). The filled container is then moved to the disposal site in a shielded transport vehicle and placed into the disposal vault where it will be surrounded by a barrier system as discussed in section 3.0.

For the purpose of this report, cullet and marbles are considered together.

As the glass is placed in the containers at the temperature of molten SPC, the choice of materials is therefore the same as option 5 .

Therefore this option will consider:

1) A container made from SPC which is seen as the only potentially long life container system, (See section 2.2 Matrix materials). The assumed thickness of the container for this study is $200 \mathrm{~mm}$. This is an estimate, detailed modeling work is required to determine an accurate figure.

2) A stainless steel container which will provide initial contamination containment and glass protection. It will also improve the handleability of the glass from the vitrification plant to the disposal vault and will simplify retrieval should it be necessary. But the container will be designed to last only until the end of the monitoring period after vault closure, program date 2078. Following this date the stainless steel container is assumed to have failed and the matrix fill becomes the glass containment/protection.

\section{Option evaluation}

Provide radiological contamination containment (5)

It is anticipated that the container will act as the contamination containment barrier during handling, transportation and vault placement. Radiation protection will be provided by external shield walls and the use of remote handling/shielded contact handling equipment. Radiation protection during transportation will be provided by the use of a shielded transport container.

Score 5 out of 5 
Robustness/durability of package (5)

The container protects the glass block from serious damage during handling, transportation, vault placement and vault closure. Durability is good. Score 5 out of 5

\section{Minimize dose uptake by personnel (5)}

It is anticipated that all equipment and operations will be designed to minimize dose uptake by personnel. Radiation protection will be provided by external shield walls and the use of remote handling or shielded contact handling equipment. Dose received during maintenance operations is not considered here. Score 5 out of 5

Maximize use of disposal area (5)

The containers can be made in a form that maximize the use of the disposal area. The use of an SPC container with cullet/marble/matrix mix will reduce the glass content of the disposal vault to approximately $30 \%$. (Assuming $40 \%$ matrix content)

The use of a stainless container with a cullet/marble/matrix mix will reduce the glass content of a disposal vault to approximately $50 \%$. (Assuming $40 \%$ matrix content) Score of both options 2 out of 5

Retrievability (5)

If retrieval is required, opening the disposal system and recovering the containerized blocks before 2728 will probably not require the installation of a contamination control building over the vault area. Lifting attachments on the container will simplify remote handling or shielded contact handling operations. Score 5 out of 5

\section{Minimize cost of packaging (5)}

Relative packaging costs and the time element for packaging have been compared with each of the other options. It has been assumed for purpose of this study that the cost of a stainless steel container and an SPC container are the same. The plant and maintenance costs for the additional cullet/marble production equipment will add to the overall project costs but are not considered here.

Score 3 out of 5 .

\section{Ease of handling and transportation (3)}

Handling cullet/marbles in a container with incorporated lifting lugs would be relatively easy when using either contact handling or remote handling equipment.

Score 3 out of 3

\section{Simplicity of packaging operations (3)}

This option requires the glass cullet/marbles to be size reduced/rolled and then fed via storage hoppers into a mixing chamber where matrix material is added. The resultant mixture is then containerized and a lid cemented or welded in position. Score 2 out of 3 


\section{Unknowns and Uncertainties}

It is possible that the glass will expand and slump due to radiological action. If such an action occurs it is not presently known if this will cause cracking in the matrix material and if this will cause the matrix material to become unsuitable for its purpose.

\section{Option 10) Disposal Vault Filled with Cullet/Marbles.}

General System description. Cullet is manufactured by pouring molten glass to a quench flume. As the glass enters the flume, the resultant thermal shock from water contact shatters the glass into small irregular fragments. The glass is further size reduced by roller crushers and screened to remove process fines. The cullet is dried (by hot air) and loaded into storage hoppers.

Marbles are produced either by molds (possibly water cooled) or by chopping and rolling poured glass streams into spherical shapes. Following manufacture the marbles are transported to storage hoppers. In this report the term marble also includes other small regular shapes such as gems, etc. In this section cullet and marbles are assessed together.

The glass cullet or marbles are conveyed from the storage bins and pneumatically transferred via shielded pipeline from the vitrification plant to the disposal site vaults. It is anticipated that several pneumatic transfer booster stations will be required in the transfer pipeline (up to a mile long) to maintain the glass flow. At the disposal site the glass is directed to each individual vault as required.

\section{Option evaluation}

\section{Provide radiological contamination containment (5)}

The cullet/marbles are manufactured in a shielded and controlled contamination area within the vitrification plant and all contaminants (small particles of radioactive glass and dust etc) will be held within the containment system.

The cullet/marble pneumatic transfer system which feeds the cullet/marbles from the vitrification plant to the disposal site will require several booster stations to maintain flow. Maintaining containment and shielding of the pipeline transfer system and booster stations during breakdowns and maintenance will require temporary or permanent containment/shielding buildings.

Pneumatic transfer of abrasive cullet or marbles will erode the transfer pipework and may lead to loss of containment of the system. It is anticipated that transferring cullet or marbles along pipelines will generate glass fines. A loss of containment would likely result in a major release of airborne contamination particularly when using compressed air as a transport medium.

The fines generated during transportation and the compressed air transport medium would combine to generate airborne contamination at the pipe discharge point to the vault. Therefore a second controlled, area building covering the disposal vault would be required to treat the contaminated air. A method of reducing the airborne contamination could be developed. It is not anticipated that this method would eliminate the need for a vault containment building; which would be required until the vault is filled and sealed. 
If retrieval is required, opening the disposal system and recovering the cullet/marbles would require the re-installation of a contamination control building over the vault area. Radiation protection will be provided by external shield walls in all areas.

Score 2 out of 5

\section{Robustness/durability of package (5)}

The vault is considered as the containment package in this option. It is assumed that a concrete vault will be constructed, with suitable barriers and linings, to prevent water ingress and vault degradation over the time period considered; til the year 2078 .

Score 5 out of 5

\section{Minimize dose uptake by personnel (5)}

It is anticipated that all equipment and operations will be designed to minimize dose uptake by personnel. Radiation protection will be provided by external shield walls and the use of remote handling or shielded contact handling equipment. Dose received during maintenance operations is not considered here. Score 5 out of 5 ,

Maximize use of disposal area (5)

The use of glass cullet/marbles without containers and without matrix coatings would effectively use the disposal area. The glass content of the disposal vault would be approximately $70 \%$. It may be desirable to pack cullet/marbles with a barrier material (eg Sulfur). If so the glass content of the disposal site would be reduced.

Score 4 out of 5

\section{Retrievability (5)}

If retrieval is required, opening the disposal system and recovering the glass will require the re-installation of a contamination control building over the vault area. This would be burdensome. Retrieval of the glass by a suction process or mechanical means could be relatively simple.

Score 2 out of 5

\section{Minimize cost of packaging (5)}

This option has no container and therefore scores maximum points. (The plant costs for the additional containment facilities required for loading, storing and vault placement, will add considerably to the overall project costs but are not considered here).

Score 5 out of 5 .

\section{Ease of handling and transportation (3)}

Designing, operating and maintaining a pneumatic transport facility to move abrasive glass cullet or marbles down a long pipe system (up to 1 mile) is not considered a simple operation. Maintenance would be onerous and breakdowns could be frequent due to erosion caused pipe failure, glass blockages and/or technical failure of the pneumatic transport system.

Score 1 out of 3 


\section{Simplicity of packaging operations (3)}

Manufacture of the cullet/marbles, transportation to the disposal site in the pneumatic transport system and the filling of the vaults is difficult. All loading, transportation, and unloading operations are undertaken in 'Active' areas using remote or shielded equipment. Score 1 out of 3

\section{Uncertainties/Unknowns}

The reliability of the pneumatic transport system for cullet/marble movements (approximately one mile) from the vitrification plant to the disposal site is uncertain.

\section{Option 11) Disposal Vault Filled with Cullet/Marbles/Matrix.}

General System description. Cullet is manufactured by pouring molten glass in to a quench flume. As the glass enters the flume, the resultant thermal shock from water contact shatters the glass into small irregular fragments. The glass is further size reduced by roller crushers and screened to remove process fines. The cullet is dried (by hot air) and loaded into storage hoppers.

Marbles are produced either by molds (possibly water cooled) or by chopping and rolling poured glass streams into spherical shapes. Following manufacture the marbles are transported to storage hoppers. In this report the term marble also includes other small regular shapes such as gems, etc.

The glass cullet or marbles are conveyed from the storage bins and transferred to a mixing tank where a metered amount of matrix material is added. Sulfur cement is the probably matrix and is used for this option. The resultant mix is pumped via shielded, trace heated, pipeline from the vitrification plant to the disposal site vault. It is anticipated that several booster pumping stations (and effective trace heating) will be required in the transfer pipeline (up to a mile long) to maintain the glass/matrix mixture and flow rate. At the disposal site the glass is directed to each individual vault as required.

In this section cullet and marbles are assessed together.

\section{Option evaluation}

Provide radiological contamination containment (5)

The cullet/marbles are manufactured in a shielded and controlled contamination area within the vitrification plant and all contaminants (small particles of radioactive glass and dust etc) will be held within the containment system.

The cullet/marble/matrix pumping system which feeds the cullet/marbles/matrix from the vitrification plant to the disposal site will require several booster stations to maintain the correct mixture and flow. Maintaining containment and shielding of the pipeline transfer system during breakdowns and maintenance will require temporary or permanent containment/shielding buildings. 
Pumping abrasive cullet or marbles in a matrix material will erode the transfer pipework and may lead to loss of containment of the system. The erosion will be less than that anticipated from the pneumatic transfer of dry cullet. It is anticipated that transferring cullet or marbles in a matrix material through pipelines will generate glass fines and that a loss of containment (pipe failure) is likely to result in a release of contamination to the environment.

The fines generated during transportation may generate airborne contamination at the pipe discharge point in the vault filling area. Therefore a second radiation/controlled contamination area building covering the disposal vault receipt area would be required to prevent emissions. The vault radiation/contamination control building will be required until the vault is filled and sealed.

If retrieval is required, opening the disposal system and recovering the cullet/marbles/matrix would require the re-installation of the radiation/contamination control building over the vault area.

Radiation protection will be provided by external shield walls in all areas.

Score 2 out of 5

Robustness/durability of package (5)

The vault is considered as the containment package in this option. It is assumed that a concrete vault will be constructed, with suitable barriers and linings, to prevent water ingress and vault degradation over the time period considered; til the year 2078 .

Score 5 out of 5

Minimize dose uptake by personnel (5)

It is assumed that all equipment and operations will be designed to minimize dose uptake by personnel. Radiation protection will be provided by external shield walls and the use of remote handling or shielded contact handling equipment where possible. Dose received during maintenance operations is not considered here. Score 5 out of 5

Maximize use of disposal area (5)

The use of a matrix material in conjunction with the glass cullet/marbles would reduce the glass content of each disposal vault to approximately $50 \%$. (Assuming a $50 \%$ matrix content required for pumpable mixture)

Score 2 out of 5

Retrievability (5)

If retrieval is required, opening the disposal system and recovering the solidified concrete will require the re-installation of a contamination control building over the vault area. Building and operating such a containment system is burdensome. Retrieval of the glass is complicated by the addition of the matrix material to the cullet/marbles. One option would be to apply localized heating to the matrix material and use a suction process to remove the melted glass/matrix mix. A further option would be to mechanically break the matrix and remove it in sections. Neither option is easy.

Score 1 out of 5 


\section{Minimize cost of packaging (5)}

This option has no container and therefore scores maximum points.

(The plant costs for the additional containment facilities required for loading, storing and vault placement; and the facilities for mixing the cullet/marbles with the matrix will add considerably to the overall project costs but are not considered here).

Score 5 out of 5 .

\section{Ease of handling and transportation (3)}

Designing, operating and maintaining a pumped transport facility to move glass cullet/marbles and matrix mix down a long pipe system (up to 1 mile) is not considered a simple operation. Maintenance would be onerous and breakdowns could be frequent (erosion caused pipe failure, blockages, pump failure, failure of the trace heating etc).

Score 1 out of 3

\section{Simplicity of packaging operations (3)}

Manufacture of the cullet/marbles, addition of the matrix, pumping the mixture to the disposal site and the filling of the vaults is difficult. All loading, pumping, and discharge operations are undertaken in 'Active' areas using remote or shielded equipment.

Score 1 out of 3

\subsubsection{Option Evaluation}

The options outlined in section 2.4.2. have been assessed using the Kepner Tregoe decision ranking system. Evaluation criteria were established identifying key attributes and a bias loading was identified for each criteria. The options 1 to 11 were then assessed and a score noted against each of the criteria. The results are tabulated below.

Evaluation Criteria.

- Provide radiological contamination containment

- Robustness/Durability of containment (to year 2078)

- Minimize dose uptake to personnel

- Maximize use of disposal area

- Retrievability (80 years minimum)

- Minimize Cost

- Ease of handling and transportation

- Simplicity of packaging operations

\section{Bias score}

5

5

5

5

5

5

3

3

List of options

Option 1

Option 2

Option 3

Option 4

Option 5

Option 6

Option 7

Option 8

Option 9

Option 10

Monolithic glass block without container.

Monolithic glass block with matrix/glass coating, without container.

Monolithic glass block in container. (hot pour).

Monolithic glass block in container (cold fit).

Monolithic glass block and matrix in container.

Sheet glass in container.

Sheet glass and matrix in container.

Cullet/marbles in container.

Cullet/marbles/matrix in container.

Disposal vault filled with cullet/marbles.

Option 11

Disposal vault filled with cullet/marbles/matrix. 


\begin{tabular}{|c|c|c|c|c|c|c|c|c|c|c|c|c|}
\hline \multicolumn{13}{|c|}{$\begin{array}{c}\text { Opinion Ranking Table } \\
\text { (High score is best) }\end{array}$} \\
\hline Evaluation & Bias & & & & & Optio & & & & & & \\
\hline Criteria & & 1 & 2 & 3 & 4 & 5 & 6 & 7 & 8 & 9 & 10 & 11 \\
\hline $\begin{array}{l}\text { Provide contamination } \\
\text { protection }\end{array}$ & 5 & 2 & 3 & 5 & 5 & 5 & 5 & 5 & 5 & 5 & 2 & 2 \\
\hline $\begin{array}{l}\text { Robustness/Durability of } \\
\text { packaging }\end{array}$ & 5 & 2 & 3 & 5 & 5 & 5 & 5 & 5 & 5 & 5 & 5 & 5 \\
\hline Minimize dose uptake & 5 & 5 & 5 & 5 & 5 & 5 & 5 & 5 & 5 & 5 & 5 & 5 \\
\hline Maximize use of vault & 5 & 5 & 2 & 5 & $5 *$ & 2 & $5 *$ & 2 & $3^{*}$ & $2^{*}$ & 4 & 2 \\
\hline Ease of Retrievability & 5 & 3 & 3 & 5 & 5 & 5 & 5 & 5 & 5 & 5 & 2 & 1 \\
\hline $\begin{array}{l}\text { Minimize costs of } \\
\text { packaging }\end{array}$ & 5 & 5 & 3 & 3 & 3 & 3 & 3 & 3 & 3 & 3 & 5 & 5 \\
\hline $\begin{array}{l}\text { Ease of handling / } \\
\text { transportation }\end{array}$ & 3 & 1 & 1 & 3 & 3 & 3 & 3 & 3 & 3 & 3 & 1 & 1 \\
\hline $\begin{array}{l}\text { Simplicity of packaging } \\
\text { operations }\end{array}$ & 3 & 1 & 1 & 3 & 1 & 1 & 1 & 1 & 2 & 2 & 1 & 1 \\
\hline Total & 36 & 24 & 21 & 34 & 32 & 29 & 32 & 29 & 31 & 30 & 25 & 22 \\
\hline
\end{tabular}

* The result stated here is for a Stainless steel container. If an SPC container is used deduct 3 points from this score and the final score. (See individual text for qualification).

These results represent the advantages and disadvantages of packaging the vitrified LLW and not an assessment of which is the best glass geometry, matrix and container option. For an overview of the system integration, see section 8.0

Results in scored order are:

Score
position
1
2 Tie
2 Tie
4
5
6 Tie
6 Tie
8
9
10
11

Option 3 Monolithic glass block in container (hot pour)

Option 6 Sheet glass in container

Option 4 Monolithic glass block in container (cold fit)

Option 8

Option 9

Cullet/marbles in container

Option 7

Cullet/marbles/matrix in container

Option 5

Option 10

Option 1

- Option 11

Option 2
Sheet glass and matrix in container

Monolithic glass block and matrix in container

Disposal vault filled with cullet/marbles

Monolithic glass block without container

Disposal vault filled with cullet/marbles/matrix

Monolithic glass block with matrix/glass coating, without container 


\subsubsection{Observations and Conclusions}

As a result of the evaluation, options 1 to 11 fall into 5 distinct categories:

\section{Category 1)}

Option 3 Monolithic glass block in container. (hot pour)--score 34 points

This option scored the highest marks of all the options and therefore best satisfies the selected evaluation criteria. It scored maximum points in all section except minimize cost of packaging. From a packaging perspective it is the simplest of the options.

\section{Category 2)}

Option $6 \quad$ Sheet glass in container--score 32

Option $4 \quad$ Monolithic glass block in container (cold fit)--score 32

Option $8 \quad$ Cullet/marbles in container--score 31

These options all use containers and are without a matrix material. The use of a container improves contamination control and handling, transportation is simplified and retrieval if required is straight forward. Not using a matrix material improved the vault glass packing factor considerably and was the single factor that lifted the scores of these options above those of category 3.

It is to be noted that if an SPC container is used on these options in place of the stainless steel container scored in the table then the scores of category 2 options are similar to those of category 3. The use of the SPC container resulting in a similar reduction in vault glass packing factor as the use of a matrix material.

\section{Category 3)}

Option 9 Cullet/marbles/matrix in container--score 30

Option 7 Sheet glass and matrix in container--score 29

Option 5 Monolithic glass block and matrix in container--score 29

These options also use containers which lift these scores above the other remaining options but the incorporation of a matrix material results in a $40 \%$ reduction in vault glass packing fraction.

Category 4)

Option 10 Disposal vault filled with cullet/marbles--score 25

Option 1 Monolithic glass block without container--score 24

The fourth category do not have containers and lost scoring points because of the consequential reduction in contamination containment, ease of handling and transportability and retrievability. 
Category 51

Option 11 Disposal vault filled with cullet/marbles/matrix--score 22

Option 2

Monolithic glass block with matrix/glass coating, without container-score 21

These last two options lost scoring points as they do not have containers and consequently have reduced contamination containment, ease of handling, transportability and retrievability. They also include a matrix material resulting in a reduction in the vault glass packing fraction.

\section{Container Materials}

Stainless steel is the only material in use throughout the world as the container material for the receipt of hot poured vitrified glass. There is concern however that the products of corrosion of a stainless steel container will accelerate the corrosion of Hanford vitrified waste.

Sulfur polymer cement (SPC) is a potential construction material for long life container and also a matrixing material that could contribute to disposal performance and be acceptable in a performance assessment. The use of Sulfur polymer cement (SPC) as a matrix material is discussed in sections 2.2 and 3.0 .

\subsubsection{Recommendations}

\section{Use of container:}

The highest scoring options (options 3 to 9) all use containers. Therefore, it is recommended that containers are used to transport the glass from the vitrification plant to the disposal site. This will minimize contamination release, provide ease of handling (remote handling may be required), and provide ease of waste recovery for 50 years from 2028 . It is to be noted that a metal container is considered sacrificial by the end of the 50 years monitoring period following the vault closure programmed for 2028 . It will cease to be considered as effective for the performance assessment.

\section{Size/Shape of container:}

Glass can be poured into any size and shape of container up to an assumed maximum of $10 \mathrm{~m}^{3}$. However, the durability of the glass (in direct proportion to the surface / volume ratio) and glass quality (cracking, crystallization, etc) depends on the size and shape of the monolithic glass cast and hence the size and shape of the container. Efficient use of the vault also depends on the size/ shape of the container.

A trade study is recommended to determine:

a) The relative costs of rectangular and cylindrical containers (typically 10,5 and $3 \mathrm{~m}^{3}$

b) Disposal site costs (including the additional disposal site costs for storing cylindrical containers as against the more volume-efficient rectangular containers). 
c) The difference in costs of handling and transportation equipment to move various sizes and weights of containers. (typically 26 tonne $\left(10 \mathrm{~m}^{3}\right), 13$ tone $\left(5 \mathrm{~m}^{3}\right)$ and 10 tone $\left(3 \mathrm{~m}^{3}\right)$ containers $)$.

d) Determine the cooling times of various sizes of monolithic block.

e) The anticipated sizes and costs of the various cooling storage areas.

Following receipt of this cost and cooling analysis an informed decision can be made on the economics of container geometry.

(An additional consideration when determining the shape of the containers (discussed in size consideration) is the option of having the container the same size and shape as the prospective HLW containers).

\section{Container Materials}

There is concern that the products of corrosion of a stainless steel container will accelerate the corrosion of Hanford vitrified waste. This concern requires further evaluation.

The use of Sulfur polymer cement (SPC) as a container material regarding reinforcement options/requirements, bonding abilities with glass, anticipated life in shallow burial, etc. requires further evaluation. 


\subsection{ENGINEERED BARRIERS}

Engineered barriers are cognizantly placed human-made design features integrated into disposal repositories. Their function is to improve the repositories' long-term performance to attain specified performance objectives. The conceptual barrier options contained in this section are oriented toward the issues associated with near-surface disposal of mixed lowlevel waste at the Hanford facility. A specific repository design is not proposed, for this is possible only in conjunction with a performance assessment that is outside the scope-of-effort of this exercise and detailed knowledge concerning site-specific properties, glass formulation, and configuration of the engineered barrier system.

Please note that the term mixed waste refers to a waste form containing both radioactive materials and hazardous waste materials, as defined by the Environmental Protection Agency (EPA) in Title 40 of the Code of Federal Regulations (CFR) Part 261 [40 CFR 2611. The terms low-level and high-level denote the origination of the waste and do not describe the level of radiation associated with the waste form. For instance, high-level waste refers to waste associated with spent nuclear reactor fuel rods and products of initial waste processing for nuclear weapons production. Low-level waste, by definition, includes everything that is not high-level waste. Therefore, the term mixed low-level waste refers to waste containing both EPA defined hazardous materials and low-level radionuclide constituents.

Hanford is a former Department of Energy (DOE) plutonium production facility. Its mission was recently redirected to waste management and environmental restoration. The. Hanford facility is designated a CERCLA site, (Comprehensive Environmental Response, Compensation, and Liability Act of 1980, also known as Superfund, and Superfund Amendments and Reauthorization Act (SARA) of 1986), with congressional mandates for environmental restoration. The legally binding Tri-Party Agreement, originally negotiated in 1989 and recently amended in 1994 (Wadde, 1994), sets forth milestones over a 30-year period to bring the Hanford facility into compliance with CERCLA, RCRA (Resource Conservation and Recovery Act of 1976, including the Hazardous and Solid Waste Amendments of 1984 (HSWA), NEPA (National Environmental Policy Act of 1969), and all applicable state environmental and health standards as mandated by the Federal Facilities Compliance Act of 1992.

The Tri-Party Agreement is a negotiated compliance agreement between the DOE, EPA, and the Washington State Department of Ecology. It specifies that the nearly 65 million gallons of mixed waste currently stored in 177 underground tanks be separated into high-level and low-level mixed waste streams and mandates the waste be converted to an immobilized form by solid solution incorporation into glass (a process called vitrification). Disposal of the high-level vitrified waste will be at the Federal High-Level Waste Repository, with its proposed location at Yucca Mountain currently undergoing analysis. The low-level vitrified waste is to be disposed of in a near-surface disposal repository to be constructed at the Hanford Reservation, as mandated by the Tri-Party Agreement.

This section identifies options and key technical issues associated with engineered barriers for the near-surface low-level mixed waste repository to be built at Hanford. The two main design objectives are to inhibit the corrosion of the vitrified waste and mitigate contaminate migration. This section is organized to first review the fundamental issues 
associated with near-surface disposal; followed by describing the mechanisms involved. Finally, engineered barrier concepts are presented and issues requiring resolution are delineated.

\subsection{NEAR-SURFACE LAND DISPOSAL ISSUES (BACKGROUND)}

The overall disposal goals are to keep or contain the hazardous and/or radioactive constituents to a small geographic region and maintain long-term isolation of these constituents from the undisturbed environment. As such, the fundamental thrusts associated with near-surface disposal are containment and isolation. This section will focus on identifying the main mechanisms associated with containment and isolation. Containment, as used in this section, means keeping the mixed low-level constituents from being released from solid solution in the vitrified waste. Isolation, as used in this section, means restricting migration of released mixed low-level constituents by both the engineered and natural barriers, thus inhibiting contamination of the groundwater used for drinking and irrigation.

Consider a simple disposal scenario for the direct burial of vitrified waste in a nearsurface repository. Figure 3-1 contains a simple drawing of the essential elements for this discussion. These elements include the glass waste form, the soil surrounding the vitrified waste, the groundwater commonly used for drinking, and surface precipitation. Initially, the vitrified waste form both contains and immobilizes the hazardous constituents from the environment, accomplished through incorporating the hazardous waste in solid solution with glass, shown conceptually in Figure 3-2 (Hench, 1986). There are two mechanisms that can release the hazardous constituents from the glass: diffusion and corrosion, with corrosion being the dominant mechanism. Details concerning glass corrosion are discussed in the 3.5 Technical Issues Associated with Glass Corrosion. Glass corrodes when it encounters water, which results in the release of mixed, low-level constituents. The rate of corrosion is very small relative to a human lifetime, but it is significant relative to the half-lives associated with some of the radionuclides and the requirement to maintain their long-term control in the disposal site.

The main source of water to a near-surface disposal repository is precipitation. For the Hanford conditions, water migration occurs by unsaturated drainage of the soil, with average subsurface moisture content on the order of 10-30\% saturation (Glee, 1994). The migration of moisture is mainly through advective flow induced through gravitation at a rate thought to be on the order of $0.1 \mathrm{~cm} /$ year (Karnesky, 1994). Thus, some of the surface precipitation migrates through the soil to eventually come in contact with the glass, resulting in its corrosion and subsequent release of mixed low-level constituents.

Once the mixed, low-level constituents are released, they may be free to migrate with the flow of the unsaturated groundwater as it flows toward the saturated zone, also known as the aquifier. From a macroscopic viewpoint, the mixed, low-level constituents travel quickly through the environment once they enter the aquifer (Freeze, 1979). In addition, the aquifer is a major source of water for both drinking and irrigation. There are two mass transport mechanisms active in both the saturated and unsaturated zones: soluble and colloidal mass transport. The soluble species transport mechanism enables dissolved species to travel freely with the hydrologic flow. Colloidal mass transport involves the formation of microscopic solids that behave as though they are in solution by mechanisms such as electrostatic repulsion and Brownian motion and can also migrate freely with the flow. Mass 
transport mechanisms are further discussed in 3.6 Technical Issues Associated with Radionuclide Migration. Mixed, low-level constituents released from the glass may migrate through the environment at rates comparable to the groundwater flow, and the amount of mass migration is not necessarily limited by species solubility.

By enclosing the vitrified waste in an engineered barrier system as depicted by Figure 3-3, enhanced containment and isolation may be achieved. In reality, the problems associated with an engineered barrier system are identical to the simple scenario. The problem is the inability of the engineered barrier system to keep moisture from the vitrified waste in the geologic time frame of interest, on the order of ten thousand years. The reason for this is that engineering methods and knowledge of long-term material degradation have not evolved to the point where long-term behavior can be predicted with reasonable accuracy $110 \mathrm{CFR}$ 60.102). Since their performance is extremely hard to predict and prove for time durations in excess of hundreds of years, engineered barriers are traditionally assumed to structurally degrade with time.

There are several mechanisms that allow moisture to migrate through degraded engineered barriers. Examples include cracks, interconnected porosity, or the long-term engineered barrier degradation into granular form. For instance, water vapor may diffuse through cracks or porosity in the engineered barrier with subsequent condensation by various mechanisms. Moisture can be absorbed at the surfaces of cracks and particles and migrate into and out of the disposal facility by capillarity action in the cracks or simple gravitational induced advective flow (Marshall, 1988). It is not important to debate the exact mechanisms enabling water to enter and exit a repository. It is only important to understand that moisture is assumed to migrate into and out of an engineered barrier system in the time frame of ten thousand years. Thus the fundamental problems associated with a near-surface engineered barrier disposal system are the same as those associated with direct burial of the vitrified waste. The major difference will be the amount of moisture that will flow near or contact the vitrified waste form in the first few hundred years.

In summary, the water naturally present in the environment will eventually come in contact with the vitrified waste containing mixed low-level waste materials in a near-surface disposal facility. This moisture will cause the glass to corrode and release mixed low-level contaminates. These contaminants will migrate with the unsaturated groundwater flow until reaching the water table, where they enter the aquifer used for drinking and irrigation. The aquifer also enables enhanced migration of the contaminates throughout the environment.

\subsection{UNDERGROUND DISPOSAL REQUIREMENTS}

There are three entities governing the mixed low-level waste disposal effort at Hanford:

- The Federal Environmental Protection Agency (EPA)

- The Department of Energy (DOE)

- The Washington State Department of Ecology

With respect to underground disposal of mixed low-level waste, the EPA regulations are found in Title 40 in the Code of Federal Regulations, traditionally cited as 40 CFR (U.S. EPA, 1992), in the following parts: 
- $\quad 40$ CFR 141 for National Primary Drinking Water Regulations

- $\quad 40$ CFR 261 for Identification and Listing of Hazardous Waste

- $\quad 40$ CFR 268 for Land Disposal Restrictions

The DOE regulations relative to near-surface engineered barrier systems are found in DOE Order 5820.2A, "Radioactive Waste Management" Chapter 3 Section 3, "Management of Low-Level Waste - Requirements" (U.S. DOE, 1988). An interpretation of DOE Order 5820.2A specific to Hanford is found in RLID 5820.2A, "Radioactive Waste Management" Chapter 3 Section 3, "Management of Low-Level Waste - Requirements" (U.S. DOE Richland, 1993).

The Washington State Department of Ecology regulations relative to engineered barrier systems are found in The Washington State Administrative Code (WAC) (WA DOE 1990) in the following parts:

- WAC 173-200 for Water Quality Standards for Groundwaters

- WAC 173-303 for Dangerous Waste Regulation

- WAC 246-221 for Radiation Protection Standards

- WAC 246-250 for Radioactive Waste - Licensing Land Disposal

For this mixed low-level disposal study the NRC regulations are included because they are applicable and relevant in terms of guidance. The NRC regulation relative to low-level waste disposal is 10 CFR 61 - Licensing Requirements for Land Disposal of Radioactive Waste.

Hanford's Performance Assessment team has undertaken a detailed study of the applicable regulations and is close to issuing a report (Karnesky, 1994). This report and a previous performance assessment on grouted waste provide regulatory understanding (Kincaid, 1993). A decision, due to the conceptual nature of this report, was made not to consider the gaseous release of ${ }^{14} \mathrm{C}$ by the $\mathrm{CO}_{2}$ mass transport mechanism or radon gas in this study. Restrictive regulations exist for both radioisotopes and should be considered in the future. Of primary concern is the most restrictive RCRA regulation found in the National Primary Drinking Water Regulations 40 CFR 141 (U.S. EPA, 1992), which states that the total exposure to radionuclides by drinking four liters of contaminated groundwater a day be limited to $4 \mathrm{mrem} /$ year.

Since the most restrictive requirement for near-surface disposal of Hanford's low-level mixed waste is the drinking water standard, the requirement for engineered barriers will be toward attaining compliance. To understand how engineered barriers can be integrated into a system to meet this requirement, the issues associated with containment and isolation must be identified and options proposed to enhance the repository performance. As previously stated, the specific design and relative effectiveness of these options can only be established through a performance analysis, as specified in the DOE regulations (U.S. DOE 1988).

In summary, the most restrictive performance requirement of a near-surface disposal site is compliance with the National Primary Drinking Water Regulation 40 CFR 141 . The accepted performance of the underground disposal site can only be judged after a performance assessment has been completed. 
The next section focuses on the factors which increase the difficulty in complying with the drinking water regulation.

\subsection{HANFORD'S DISTINGUISHING DISPOSAL FACTORS}

There are at least three factors that distinguish the Hanford disposal effort from most other low-level waste disposal efforts:

1. Significant quantities of long lived radionuclides

2. Large quantity of waste for disposal, and

3. Small groundwater volumes to dilute the leached radionuclides' concentration.

These three factors effectively direct the disposal effort and associated engineered barrier designs. Most commercial and defense low-level waste contains only short-lived radionuclides which require containment for only a few hundred years before decaying to innocuous levels of activity. Thus, the engineered barriers need to retain structural integrity for only that time domain. Designing containment structures which can remain intact with a high degree of reliability for only a few hundred years can be accomplished with a good degree of certainty.

However, the low-level waste to be disposed of at Hanford contains significant quantities of uranium, transuranics, and technetium which have long half-lives. The challenge is for the disposal system to remain functional for thousands of years in order to comply with the Drinking Water Regulation 40CFR141. For example, 24,000 curies of technetium-99 $\left({ }^{99} \mathrm{Tc}\right)$ (Bolt, 1994) with a half-life of 213,000 years (Weast, 1974) will be disposed of in the low-level waste. Millions of years must pass before the technetium will decay to activity levels acceptable for disposal by direct burial.

The type and quantity or volume of waste being disposed of will greatly influence the types of engineered barriers used to obtain compliance with National Primary Drinking Water Regulations (U.S. EPA, 1988). This governing regulation is not concerned with the rate af which radionuclides leach from the surface of the vitrified waste but is concerned with the total concentration of radionuclides found in the aquifer. At issue is the large volume of waste, estimated to be $210,000 \mathrm{~m}^{3}$, the associated surface area available for corrosion and subsequent release of large quantities of radionuclides into the aquifer. The engineered barriers associated with the disposal system need to exhibit a higher degree of integrity when large volumes of waste are involved compared with smaller disposal volumes.

The demand for engineered barrier integrity is further increased by the semi-arid weather conditions at Hanford. Because only a small amount of rain is received annually, the volume of groundwater and associated exchange rate is limited. Geologic modeling (Kincaid, 1993) indicates that a well drilled in the vicinity of the disposal site will cause all the ground water leaching from the disposal site to migrate towards that one active well. The net result is that most leached products from the disposal site are available to be consumed by a single person drinking from that well, in addition to irrigating crops and watering livestock with that water. The significance is that the design of the disposal system must have adequate performance to enable a single person to consume 4 liters of water per day from this well without exceeding drinking water standards. For the proposed volume of waste, limited volumes of migrating groundwater, and time period needed for isolation, the design of an effective engineered barrier system is not easy. 


\subsection{DIRECT BURIAL OF GLASS - SCOPING CALCULATIONS}

The relative importance of engineered barriers to the long-term disposal of Hanford's mixed low-level waste can be established with a few elementary calculations. Consider the simple case where no engineered barriers are used, i.e., the vitrified waste is buried directly in the ground. Release of the radionuclides into the environment would occur by corrosion of the glass as ground moisture comes in contact with it. A bounding condition is at what annualized volume can the radionuclides be released into the surrounding environment by glass corrosion and still be able to maintain compliance with the National Primary Drinking Water Regulations.

An acceptable annualized volume of radionuclides released from the disposal site can only be established through a performance assessment. The Hanford Performance Assessment Team has recently undertaken such an analysis to understand the implications of the direct burial scenario. They have established a release rate, in terms of the permissible annual fractional release of the repository inventory of radionuclides, of one millionth of the inventory per year in order to meet drinking water standards (Mann, 1994). A caveat to this analysis is that all radionuclides released from the glass are free to migrate through the unsaturated groundwater. In other words, species solubility is not accounted for in the fractional release cited above. This assumption may not be as conservative as it first seems, as discussed in 3.6 Technical Issues Associated with Radionuclide Migration. However, equilibrium distribution coefficients, $\mathrm{Kd}$ 's, were used in the calculations which effectively reduces the specific radionuclide inventory as the unsaturated contaminated groundwater migrates towards the water table.

The annualized fractional release value of one millionth of the inventory per year will be used in the following analysis to obtain an appreciation for the inherent degree of stabilization afforded by the glass, the influence of exposed glass surface area, and more importantly how effective the engineered barriers must be to meet the established performance objectives. Elementary calculations will be performed in this section to illustrate the relative importance of the surface-area-to-volume ratio of the vitrified waste form placed into the repository setting. Justification of the corrosion rates used in this analysis is set forth in Section 3.5 Technical Issues Associated with Glass Corrosion.

Consider the direct burial of glass and the ground moisture that will inevitably come in contact with the glass. The Hanford moisture level and associated migration rate have been previously studied and documented in detail (Kincaid, 1993). The moisture causes the glass to corrode, and this process releases contained radionuclides and other hazardous constituents into the surrounding environment. Only the corrosion of the glass is considered in these calculations.

Although corrosion rates are dependent upon many factors including specific glass compositions, the literature can be used to establish the bounding values for use in this analysis. A detailed DOE review of the leach resistance of nuclear waste forms concluded that the corrosion rates of glass are bounded between $1 \mathrm{~g} \mathrm{~m}^{-2} \mathrm{~d}^{-1}$ for poor quality glass and $1.0 \times 10^{-3} \mathrm{~g} \mathrm{~m}^{-2} \mathrm{~d}^{-1}$ for very high quality corrosion resistant glass (U.S. DOE, 1981). These bounding corrosion rates are for accelerated testing at elevated temperature. Justification of the validity for this analysis will be made in Section 3.5 Technical Issues Associated with Glass Corrosion. These rates can be temperature adjusted by use of the Arrhenius-type rate equation, where Knauss found an appropriate activation energy for nuclear waste glass to be 
$20 \mathrm{kcal} / \mathrm{mol}$ (Knauss, 1990). Thus a change in temperature from 90 to $20^{\circ} \mathrm{C}$ represents slightly less than a three orders of magnitude reduction in corrosion rates. For this elementary analysis, the bounding corrosion rates between $1.0 \times 10^{-3}$ and $1.0 \times 10^{-6} \mathrm{~g} \mathrm{~m}^{-2} \mathrm{~d}^{-1}$ will be used.

Since glass corrosion occurs at its surface, the total amount of corrosion will be directly proportional to the total surface area exposed to moisture. Other issues such as changes in $\mathrm{pH}$, aqueous flow rates, and silica concentrations in aqueous solutions which influence corrosion rates will be addressed in Section 3.5, for which it will be shown that the above assumptions are valid for an order-of-magnitude analysis. These elementary calculations will demonstrate the relative influence of glass geometry and the relative protection requirements of an engineered barrier system.

For the fixed volume of vitrified waste anticipated at Hanford, $210,000 \mathrm{~m}^{3}$, the glass surface area will be primarily a function of the size of glass produced, and a second order effect will be its exact shape. For this elementary order of magnitude study, only the size of the glass will be of concern. For mathematical simplicity, the shape under consideration will be a cube. The surface area of a cube is known to be six times the area of one side of the cube, or:

Surface Area $=6 \mathrm{~b}^{2}$,

where $b$ is the length of the cube's side. Note that the volume of a cube is:

$V_{c}=b^{3}$

where $V_{c}$ is the volume of the cube. The surface-area-to-volume ratio is found by dividing equation (1) by equation (2) yielding:

(Surface Area / Cube Volume) $=6 \mathrm{~b}^{-1}$.

The total vitrified waste surface area $g$ is found by multiplying the surface-area-to-volume ratio of the cube by the total vitrified waste inventory $V_{t}$ yielding:

$g=6 b^{-1} V_{t}$

Because the corrosion rate of glass has been shown capable of sustaining accelerated corrosion rates in simulated repository conditions, comparable in magnitude to the forward corrosion rate, the glass corrosion kinetics used in this analysis will be linear. The total annual corrosion volume can be obtained by multiplying equation (4) by the annualized corrosion rate, a, yielding the expression:

Total Annual Corrosion Volume $=6 \mathrm{~b}^{-1} \mathrm{~V}_{\mathrm{t}} \mathrm{a}$,

Where the corrosion rates $1 \times 10^{-3}$ and $1 \times 10^{-6} \mathrm{gm} \mathrm{m}^{-2 \mathrm{~d}-1}$ are converted to annualized corrosion rates $1.4 \times 10^{-5}$ and $1.4 \times 10^{-8} \mathrm{~cm} \mathrm{yr}^{-1}$ respectively using a reference glass density of $2.6 \mathrm{~g} / \mathrm{cc}$. The annualized fractional release is obtained by dividing the total annual corrosion volume by the total vitrified waste inventory $V_{t}$ yielding:

Annualized Fractional Release $=6 \mathrm{~b}^{-1} \mathrm{a}$

eq. (6) 
Since bounding orders of magnitude for glass corrosion rates have been previously established, eq. (6) can be plotted in terms of the length of a side of the vitrified waste cube. Such a plot is contained in Figure 3-4. The ordinate axis represents the fraction of glass inventory which corrodes annually under these assumptions, with the heavy solid line at the value $1 \times 10^{-6}$ representing the permissible fractional release established by Hanford's Performance Assessment Team that would meet the drinking water standards. The abscissa represents the length of one side of this theoretical glass cube. The upper and lower bound corrosion rates obtained from the literature are plotted on the upper and lower portions of the graph respectively. This analysis does not take into consideration annual changes in inventory or changes in surface area.

The permissible annualized fractional release of $1 \times 10^{-6}$ lies between the fractional release lines representing the bounding corrosion rates. This indicates that near-surface disposal of Hanford's mixed low-level waste looks feasible but will most likely require an engineered barrier system to ensure that the performance objectives will be met. It is unlikely that long term glass corrosion rates will be known with any precision, and the exact permissible annualized fractional release will increase with time.

A striking characteristic of this plot is the order-of-magnitude influence which the size of the waste glass has on the fractional release. An order-of-magnitude change in the surface area available for corrosion corresponds directly with an order-of-magnitude change in fractional release. There is a distinct disadvantage in using a glass waste form with a high surface-area-to-volume ratio. Conversely, there is a motivation to obtain the lowest surfacearea-to-volume ratio possible. However, there is a limit to the size of glass that one can use in a subsurface disposal repository. In the time frame of thousands of years the engineered barrier system and waste glass contents are expected to be highly stressed by mechanisms such as ground subsidence, earthquakes, etc. The net result would be the fracturing of very large glass pieces into smaller pieces with irregular surfaces. The optimal size of glass is not exactly known, but it seems likely that data exists concerning geologic materials and associated size distribution that naturally occur.

With respect to shape, a sphere has the lowest surface-area-to-volume ratio, but its surface area to volume ratio is only half that of a cube with the same characteristic dimension. This is only true when the surfaces are smooth. For example, consider an object that is spherical but has a very rough surface. The surface-area-to-volume ratio can increase by an order of magnitude due to surface roughness. The use of small glass pieces with rough and irregular surfaces greatly compounds the problem.

Another point is the quality of the glass formulation, used to vitrify the waste. Indepth understanding of corrosion mechanisms and how they are influenced by the feed waste stream is an important requirement both in the glass formulation and identifying an effective engineered barriers design.

Although this exercise is very simplistic, it does capture the essence. The vitrified waste form does not possess the inherent ability to fully stabilize the radionuclides by itself. The uncertainty associated with obtaining the performance objectives by direct burial of the vitrified waste form necessitates the use of engineered barriers. The size of the solidified waste form affects its ability to contain the radionuclides in the time frame of thousands of years. There is a benefit in using large smooth surfaced waste geometries, but a limit exists with respect to the size that can be maintained in a geological setting. The corrosion rate of 
the glass is obviously important. The glass is the first primary barrier impeding the mixed, low-level constituents from migrating into the environment. By increasing the vitrified waste form's inherent ability to contain and immobilize the wastes' constituents, the required functionality and associated cost of the engineered barriers diminishes.

\subsection{TECHNICAL ISSUES ASSOCIATED WITH GLASS CORROSION}

Hanford's mixed low-level waste will be incorporated into a solid solution of glass to immobilize or contain these constituents from migrating into the environment. The glass matrix is therefore the primary barrier to contain the contaminates to a small geographical region in the environment. Vitrification is considered to be the best available technology for immobilization. Therefore, it is prudent to develop an engineered barrier system that, in part, focuses on long-term preservation of the vitrified waste form. This section will be used to present some of the fundamental technical issues associated with glass corrosion. The purpose is to enable understanding of glass corrosion mechanisms to the point that the knowledge will help identify engineered barrier options. Only the specific information that is relevant to Hanford's anticipated repository environment will be presented. An extensive review of glass corrosion has been conducted and can be refered to for detailed knowledge (Manaktala, 1992).

Consider the long-term repository environment that the vitrified waste is expected to encounter. The unsaturated hydrologic conditions suggest that the glass will experience mainly water vapor and relatively small amounts of liquid resulting from the unsaturated drainage of precipitation migrating towards the water table. For the large anticipated volume of glass, its associated surface area, and arid climate at Hanford, it is reasonable to expect that the glass surface area to water volume ratio will be a very high value.

Considerable effort has been expended to obtain an overview of glass performance issues in repository environments. The glass composition has a major effect. Consider the various glasses and associated release rates (or corrosion rates) shown in Figure 3-5 (Jantzen, 1984). It is important to be aware that the release rate of glass is a function of its composition, and that release rates can vary by a couple orders of magnitude.

The release rate is also a function of the leachate water chemistry and is particularly sensitive to the amount of dissolved silica content in the leachate. Figure 3-6 contains a plot from Peterson et al. (1983) that illustrates how the glass release rate decreases as the silica concentration in the leachate increases. This is an important concept that will be used to understand material incompatibilities associated with engineered barriers.

Another aspect of water chemistry that influences the corrosion of glass is $\mathrm{pH}$. Figure 3-7 contains a plot of release rate as a function of $\mathrm{pH}$ (McElvoy, 1986). Note that the corrosion rate increases as the leachate either increases or decreases in $\mathrm{pH}$ relative to the neutral value. This concept is fundamental in understanding why accelerative corrosion can take place in a repository environment. Note that basalt naturally has an associated $\mathrm{pH}$ value of 8 . Basalt is a primary geologic constituent at Hanford.

These concepts are required to understand potential material incompatibilities between the vitrified waste and engineered barrier components. Figure 3-8 contains a plot of the effect of iron in the leachate with respect to the glass corrosion rate versus time (McVay, 1981). 
Notice that the highest corrosion rate is associated with the cross-hatched region indicating that the leachate contains iron. In addition the corrosion rate associated with the de-ionized (DI) water is lower than the leachate containing iron. The explanation is that iron forms iron silicates, which reșults in reducing the silica content of the leachate. As illustrated in Figure 3-6, as the silica content of the water decreases, the corrosion rate increases. The corrosion rate associated with the leachate concentration in equilibrium with basalt is shown in Figure 3-8. Basalt is a mineral which contains silica. The increase in silica content in the leachate decreases the corrosion rate of the glass. Materials used in the engineered barrier system can be both beneficial and detrimental due to their chemical nature. Care must be used in selecting these materials.

Glass corrosion rate is also a function of temperature. Figure 3-9 contains a plot of glass dissolution rate as a function of both temperature and $\mathrm{pH}$. Of interest is the decrease in the corrosion rate as a function of temperature. Since the glass corrosion rate at room temperature is extremely slow relative to generating any data from an experiment, high temperature testing of glass is used in the laboratory to simulate glass corrosion behavior over long time periods at low temperature. Most accelerated corrosion testing of glass is performed at $90^{\circ} \mathrm{C}$. Glass' well-behaved corrosion rate dependence on temperature follows the Arrhenius-type rate equation, with an associated activation constant of approximately 20 $\mathrm{kcal} / \mathrm{mole}$ as determined by Knauss (1990).

When the glass and leachate are contained in a closed system, as anticipated in a repository, the dissolution of the glass increases the silica content of the leachate causing the corrosion rate to decrease. Figure 3-10 contains a plot of concentrations of silica and other elements as a function of time (Bourcier, 1994) and Figure 3-11 contains data illustrating that the dissolution rate is decreasing as a function of time. However, these trends are not maintained over long periods of time for high glass-surface-to-leachate-volume ratios as would be expected in a Hanford disposal repository.

Closed system glass dissolution experiments were performed at two different glass surface-area-to-leachate-volume ratios $\left(2,000 \mathrm{~m}^{-1}\right.$ and $\left.20,000 \mathrm{~m}^{-1}\right)$ (Ebert, 1993). The experimentally measured time dependence of each experiment's $\mathrm{pH}$ values are contained in Figure 3-12's plot. Two very important features can be observed. With regard to time, the $\mathrm{pH}$ rises dramatically till reaching a near limiting value. The second important feature is that the higher surface-to-volume ratio experiment has a substantially higher limiting $\mathrm{pH}$ value associated with it. Also note that both limiting values are at very high values of $\mathrm{pH}$. The problem is that high $\mathrm{pH}$ values increase the glass dissolution rate (see Figures 3-7 and 3-9). The effect of the higher $\mathrm{pH}$ associated with high surface to volume ratios is to induce an accelerated corrosion mechanism.

Figure 3-13 contains plots of elemental release as a function of time for these two conditions (Elbert, 1993). There are two striking features observed when plot (a) is compared with plot (b). The first is the order-of-magnitude difference in the ordinate scales. The second is the inversion of the predominant plotted feature. With the surface-area-to-volume ratio of $2,000 \mathrm{~m}^{-1}$, the released constituent concentration trends towards constant values, indicating the dissolution rate is approaching zero with respect to its initial value. Conversely, the $20,000 \mathrm{~m}^{-1}$ experiment exhibits constituent concentration values that increase linearly with time, which indicate that dissolution is proceeding at a near constant value. 
Feng (to be published) has demonstrated that this accelerated corrosion mechanism is active in a variety of glass compositions. Figure 3-14 contains the results for six different glass compositions for surface-area-to-volume ratios ranging from $20 \mathrm{~m}^{-1}$ to $40,000 \mathrm{~m}^{-1}$. The experiment was designed to determine if the limiting $\mathrm{pH}$ value could be correlated with surface-area-to-volume ratio. Feng (to be published) holds that such a relationship exists and offers the plot of $\mathrm{pH}$ vs. the log of the surface to volume ratio contained in Figure 3-15 as proof.

The issue with this accelerated corrosion mechanism is that glass dissolution can be sustained until all the amorphous glass is consumed. The mechanism and driving force are as follows. According to Bourcier (1991), glasses are unstable at room temperature and react with water to partially dissolve and form crystalline and non-crystalline secondary solids. Figure 3-16 contains the typical features observed in the alteration layers of a reacted waste glass (Mendel, 1984). Extending outward from the fresh glass layer are: (1) a diffusion layer of hydrated and alkali-depleted glass in which diffusion gradients of alkalis and hydrogen are observed; (2) an amorphous and often layered region composed of depleted glass in which patches of material are crystallizing into secondary phases such as clays and serpentine minerals; and (3) a non-continuous secondary phase layer of crystalline secondary phases, commonly including clays, zeolites, and transition metal oxides. These types of precipitates are found in association with long-term accelerative corrosion of glasses with high surface to leachate volume ratios (Ebert, 1993; Feng, 1993). The reduction in the Gibbs free energy between the amorphous phase and crystalline phase drives the reaction in favor of producing crystalline precipitates. Since the silica concentration in the leachate is not increasing, there is no inhibition of this cycle. The reactions are catalyzed by high values of $\mathrm{pH}$.

The critical problem with respect to vitrified mixed low-level waste is that there is no evidence to suggest that the dissolution rate associated with the long-term accelerative corrosion mechanism will ever decrease. In addition, in the above-cited experiments, the longterm dissolution rate is similar to the forward reaction rate. According to Bourcier (1991), commonly seen $90^{\circ} \mathrm{C}$ long-term accelerative corrosion rates for nuclear waste glasses vary between 0.1 to $1.0 \mathrm{gm}^{-2} \mathrm{~d}^{-1}$. Adjusting the rate for $20^{\circ} \mathrm{C}$ vields values for the corrosion rate on the order of $1 \times 10^{-3}$ to $1 \times 10^{-4} \mathrm{~g} \mathrm{~m}^{-2} \mathrm{~d}^{-1}$, which are on the high side of the corrosion rates used in the scoping calculations of Section 3.4. The technical issue is how to prove, with reasonable certainty, that long-term accelerative corrosion can be inhibited for the subsurface disposal of vitrified waste at Hanford.

\subsection{TECHNICAL ISSUES ASSOCIATED WITH RADIONUCLIDE MIGRATION}

Two main radionuclide migration mechanisms are discussed in this section: sorption and colloidal mass transport. Knowledge of these mechanisms is needed to either insure operation if the mechanism would be beneficial or inhibit undesireable effects.

Extensive reviews have been conducted on sorption and its potential importance with respect to radionuclide migration (Turner, 1991; Turner, 1991a). Sorption involves the desired selective exchange of mass as it transitions from dissolved species (adsorbate) to the solid form associated with the surface of some media (adsorbent). Desorption is this process in reverse. It can take place through ion exchange, where solution species are substituted with readily exchangeable ions, or chemisorption where a chemical reaction takes place. Sorption is influenced by many factors, requiring the obtainment of a considerable amount of 
site specific information before a determination can be made concerning what sorption process, if any, will take place. Sorption/desorption cycles are responsible for the formation of many mineral deposits.

Sorption of different elements is influenced in different ways by physical and chemical properties of the geologic environment. Physical geologic properties influencing sorption include specific surface area, density of ion exchange sites in the surface, cation exchange capacity, surface charge and potential, and crystallographic orientation. Chemical factors influencing sorption include concentrations of the species of interest, presence of complexing ligands, solution $\mathrm{pH}$, redox potential, competitively sorbing species, temperature and ionic strength. Those items of particular importance to engineered barriers are solution $\mathrm{pH}$ and complexing ligands.

Sorption is a surface phenomenon influenced by the number of localized charge regions residing on the adsorbent's surface. Both positively and negatively charged regions exist on solids, but sorption capability is related to the total number of sites and associated charge available for sorption (Kent, 1988). Solution pH influences the number of sites available with a given charge on the surface through protonation/deprotonation reactions. Simply stated, at low $\mathrm{pH}$ a large number of $\mathrm{H}^{+}$ions are in aqueous solution and tend to tie up the negatively charged regions on the adsorbent's surface. At high $\mathrm{pH}$ the opposite is true. Alkaline solutions contain large numbers of $\mathrm{OH}^{-}$ions which tend to tie up positively charged regions on the adsorbent's surface. As the solution $\mathrm{pH}$ is increased from acid to alkaline, a material's sorption capability changes from adsorbing anions to adsorbing cations. The $\mathrm{pH}$ at which an equal number of both positive and negative sites are available for adsorption is called the $\mathrm{pH}$ of Zero Point Charge $\left(\mathrm{pH}_{\mathrm{zpc}}\right)$. Its relevance to Hanford's mixed low-level waste disposal effort is in the choice of sorption materials for engineered barriers.

The radionuclides leached from the vitrified waste are expected in both the anion and cation forms and are dependent upon chemical species and other factors such as complexing. In addition, alkali conditions are anticipated since the natural soil conditions produce aqueous solution pH of about 8.5, and leachate from the glass is anticipated to be somewhere between 8.5 and 12 . The problem is not with adsorption of the cationic species to retard migration of the radionuclides, for most geologic materials selectively adsorb positive ions due to their inherent negative charge. The problem is adsorption of anionic species such as $\mathrm{Tc}^{4+}$. The focus for selecting sorption barriers is identification of those materials with high $\mathrm{pH}_{z p c}$ so that anionic adsorption capability will be maintained for the long term.

Complexing ligands, both organic and inorganic, can negatively influence the performance of a disposal facility and can be introduced through inappropriate engineered barriers. Mobile complexing ligands, such as $\mathrm{CO}_{3}{ }^{2-}$ and $\mathrm{SO}_{4}{ }^{2-}$, change the sorption characteristics by competing with sorption materials for the ionic species of interest. The problem is the resulting complexes are either neutral or anionic molecules with weak or reduced electrostatic attraction (Serne, 1990), which results in high mobility in the environment (Siegel, 1990).

Colloidal mass transport is a mechanism by which substantial amounts of radionuclides can migrate both quickly and efficiently throughout the environment without regard to aqueous solubility, and in some cases colloids show little to no ability to be adsorbed. A significant review of the literature have been undertaken as the first step in assessing longterm implications of colloidal mass transport with regard to the high-level waste repository at 
Yucca Mountain (Manaktala, to be issued). Colloids are very small particles somewhere in size between 0.01 to $10 \mu \mathrm{m}$. There are two colloid classes of interest: 1$)$ groundwater colloids and 2) real or true colloids. A comparison of colloids with other known water particles is contained in Figure 3-17 (McCarthy, 1989), and a more detailed comparison with organic materials is contained in Figure 3-18 (Thurman, 1985).

Groundwater colloids are naturally present in all groundwater and may have been formed by physical or chemical processes. These are of interest for two reasons. The first reason is that colloids can be collected, analyzed, and correlated with geographical area to determine their migration characteristics. The second reason is that groundwater colloids are chemically surface-active and thus possess the ability to adsorb radionuclides. This is especially true for radionuclides with valence greater than $2^{+}$(Kim, 1993), enabling easy migration of the radionuclides throughout the environment.

Real or true colloids may be chemically formed from previously dissolved species including radionuclides. They can be formed by hydrolysis (Kim, 1993), polymerization, condensation, and precipitation processes (Maiti, 1989; Choppin, 1991). Of special interest is the tetravalent actinide ions which readily form colloids even at low values of solution $\mathrm{pH}$ (Olofsson, 1982; Olofsson, 1982a).

Colloids are important in understanding potential radionuclide transport due to their mobility through the geologic environment. For example, Kingston and Whitbeck (1991) performed a study on groundwater colloids for their characterization with respect to size and concentration. The summary table from this study is contained in Figure 3-19. The most significant conclusion from this study is that no correlation was found between colloid concentration and sample environment. A correlation was expected due to differences in water chemistry and local geologic compositions. In addition, significant differences in colloid composition was not observed. In general, Kim (1991) reports the number of colloids present in groundwater range from $10^{8}$ to $10^{17}$ per liter of water. The number of colloids, capability of adsorbing radionuclides, and general mobility in the geologic environment raise serious questions concerning radionuclide mass transport.

The colloid's ability to migrate, even in unsaturated flow, is related to its electrostatic charge. In general, geologic materials exhibit a negative surface charge. A negatively charged colloid is repelled from the surface causing it to remain in the hydrologic flow. There is a velocity profile associated with hydrologic flow caused by boundary layer drag on the geologic materials, shown conceptually by Figure 3-20 (van der Lee, 1993). Colloids tend to move with the maximum hydrologic velocity, and not the mean velocity, enabling fast migration through the geologic environment.

The formation of colloids by the corrosion of vitrified waste glass is significant. Bates (1992) has studied the corrosion of simulated high-level waste glass and found that radioactive colloids had formed. In accelerated corrosion tests with surface-area-to-volume of $20,000 \mathrm{~m}^{-1}$, Bates concluded that about $30 \%$ of the $\mathrm{Np}$ released from the glass formed colloids, and $99 \%$ of the released $\mathrm{Am}$ and $\mathrm{Pu}$ were in colloidal particles. Test results are contained in Figure 3-21.

The formation of colloids at a near-surface disposal repository has the potential for anomalous transport of radionuclides and other contaminants through the environment. Such occurrences are documented in the literature. Los Alamos National Laboratory (Penrose et al., 
$1990)$ documents the anomalous migration of ${ }^{239,}{ }^{240} \mathrm{Pu}$ and ${ }^{241} \mathrm{Am}$ through the Mortandad Canyon at Bandelier in New Mexico. The ensuing investigation concludes that colloidal mass transport is responsible for the anomalous migration. Both plutonium and americium are preferentially associated with a certain size-fraction of colloids with $85 \%$ of the Pu associated with colloids greater than $25 \mathrm{~nm}$ in size, and $43 \%$ of Am associated with particles below $2 \mathrm{~nm}$ in size. The $\mathrm{Pu}$ colloids are not exchangeable in the $25-450 \mathrm{~nm}$ size-fraction, and one-half of the Am is found to be in a nonexchangeable anionic species form.

Another example of anomalous radionuclide migration in the environment is at the Maxey Flats Low-Level Waste Repository in Kentucky (Toste et al., 1984). The anomalous migration of ${ }^{238} \mathrm{Pu}$ and ${ }^{60} \mathrm{Co}$ is caused by anionic colloid formation. Under anoxic conditions ${ }^{60} \mathrm{Co}$ is found as an anionic specie and migrates extensively. Under anoxic conditions the ionic state of ${ }^{238} \mathrm{Pu}$ changes to $50 \%$ cationic, $25 \%$ anionic, and $25 \%$ non-ionic. The anionic species is cited as the reason for enhanced radionuclide migration.

Colloidal mass transport of radionuclides at the Nevada Test Site is another example (Buddemeier, 1988). Anomalous migration of usually strongly sorbing and/or insoluble species is attributed to colloidal mass transport. Negatively charged, naturally occurring groundwater colloids compete with the host rock for the strongly sorbing radionuclides. The colloids cause hydrological transport through the fracture-flow system. Both the groundwater colloids and colloids formed by insoluble species are found to be very small in size. Experimental results indicate that a substantial proportion of the radionuclides associated with suspended colloids pass through conventional 0.1-0.45 $\mu \mathrm{m}$ filters; traditionally used to distinguish between "particulate" and "dissolved" species.

Many other numerous examples exist in the literature. For some additional examples, the reader is referred to a good survey article (McCarthy and Zachara, 1989) on the effect of colloidal mass transport of contaminants.

The importance of colloidal mass transport is that it needs to be seriously considered in the design and subsequent analysis of a near-surface disposal facility. The mobility of the radionuclides, once released from the vitrified waste form, is not just a function of the radionuclide solubility and associated $\mathrm{Kd}$ factors, but is also a function of the colloids which can be formed or are present. Colloidal mass transport is not well known concerning the governing parameters associated with formation of colloids and associated transport mechanisms. As such, it is difficult to identify what aspects of a proposed design need to be altered to avoid this mass transport mechanism. The inability to control colloidal mass transport with a high degree of confidence increase the relative importance of designing the engineered barrier system to inhibit the long-term accelerated glass corrosion mechanism.

\subsection{ENGINEERED BARRIER FUNCTIONAL TYPES}

Based on this research, six engineered barrier functional types should be considered. These types, in their relative configuration, are pictorially contained in Figure 3-22. The functionality and logic behind each of the barrier types will be discussed in the order that the surface precipitation migrating toward the water table would encounter each barrier type. The effectiveness of and need for these types can only be determined through a performance analysis. 
The function of the first barrier type is to divert the surface precipitation around the subsurface disposal facility. The primary thrust is to reduce the potential for radionuclide migration in the vicinity of the vault. Since transport of both soluble and colloidal species is directly related to the hydrologic flow, a reduction in groundwater flux will positively correlate with the reduction in the migration rate of released radionuclides. The principles upon which such a barrier, such at the Hanford Cap, are designed are well established (Marshall, 1988; Freeze, 1979) and will not be discussed herein. A benefit to the use of this type of barrier is that it can be designed for a 10,000 year or greater design lifetime.

The function of the second engineered barrier type is to chemically condition the water in terms of solution $\mathrm{pH}$ and dissolved constituents. There are two advantages to maintaining a neutral to slightly acidic solution $\mathrm{pH}$. As previously discussed, increasing alkali solution concentrations adversely affect the corrosion rate of glass, as does increasing acidic levels. The Hanford soils are expected to naturally produce a solution $\mathrm{pH}$ of about 8.5. Reducing this level to 7 or slightly lower would assist in helping reduce the corrosion of the vitrified waste waste form. Also, increasing the silica concentration of the water passing through this barrier would reduce the tendency for glass corrosion. One possibility is the use of crushed basalt to both buffer $\mathrm{pH}$ and add silica to penetrating precipitation. The uncertainty associated with this barrier concept is its relative effectiveness in association with the accelerated glass corrosion mechanism.

The subsurface disposal vault structure may or may not act as an engineered barrier. The tendency is to construct these structures using concrete and steel reinforcing bars. The problem is that water easily passes through concrete while increasing the solution $\mathrm{pH}$ to values around 12 in the near-term, and around 9 in the long term. The iron contained in the reinforcing bars combines with silica to form iron silicates resulting in reduced silica concentration. Therefore, the use of concrete with steel reinforcing bars in construction of the vault could nullify any potential benefits placed into the migrating groundwater by the water chemistry conditioning barrier.

The use of a matrix material to surround the vitrified waste form could potentially serve four separate functions. The first function could be to limit the amount of moisture that would come in contact with the surface of the glass by use of a matrix material with low water permeability. Although this matrix would eventually develop cracks through it and generally degrade in performance, it is possible that some matrix to glass interfaces would remain intact in the long term, which would serve to effectively reduce the amount of glass surface area available for corrosion. The second function that the matrix could serve is to further alter the water chemistry migrating through it. Since the corrosion of glass is expected to increase the solution $\mathrm{pH}$, the use of a matrix capable of buffering the solution $\mathrm{pH}$ toward neutrality would be beneficial. It could be extremely beneficial if this buffering action inhibits the accelerative glass corrosion mechanism, for this would change the corrosion kinetics by orders of magnitude. The third function the matrix could perform is immobilization of leached radionuclides. The most likely possibility would be a chemical reaction resulting in the precipitation of an insoluble species. The fourth possible function the matrix material could perform is to cause agglomeration or growth of colloids such that their size restricts or inhibits their migration.

A second water chemistry modification barrier type below the vault could be useful and possibly serve up to three functions. The first two functions overlap those proposed for the matrix material: precipitation of soluble species and agglomeration of colloids for 
immobilization. The third function proposed for this barrier is alteration of solution $\mathrm{pH}$ to obtain the $\mathrm{pH}_{\mathrm{zpc}}$ (pH for Zero Point Charge) associated with the sorption barrier. This change in $\mathrm{pH}$ results in an equal number of positively and negatively charged sorption sites in the adsorbent's surface. This enables the sorption barrier to be effective for anionic and cationic species, both soluble and colloidal.

To summarize, six engineered barrier types have been proposed. The objective of the first engineered barrier is to divert water around the subsurface disposal facility. The second engineered barrier conditions infiltrating water in an attempt to inhibit glass corrosion. The third engineered barrier is the structural vault, with the focus on not introducting detrimental materials into the facility. The fourth engineered barrier is a matrixing material surrounding the glass to serve any or all of the following functions: minimizing moisture in contact with the vitrified waste form, reducing the glass surface area available for corrosion, further altering the solution chemistry to inhibit corrosion, and immobilizing the leached radionuclides through chemical precipitation or agglomeration of colloids. The fifth engineered barrier could also immobilize leached radionuclides through precipitation and agglomeration, and would also alter the solution $\mathrm{pH}$ to the $\mathrm{pH}_{2 \mathrm{pc}}$ enabling the sixth engineered barrier to possibly adsorb all charged species.

\subsection{ENGINEERED BARRIER MATERIAL OPTIONS}

The bulk of this study was oriented towards identifying the issues and developing engineered barrier functions. Material options were not probed in depth and should be focused on in a future study. However, the following options are offered.

With respect to the engineered barriers contained in Figure 3-22, the hydrologic engineered barrier would likely be made from indigenous materials. Options for the water chemistry engineered barrier material have not been identified other than the need to include materials with high silica concentrations.

A possible material for the vault is sulfur polymer cement or sulfur polymer concrete (U.S. DOE, 1993). Although there are many unknowns associated with the use of this material that would require further exploration before such a material could be recommended, its attributes motivate serious consideration.

In addition to the vault, there may be some advantage in using sulfur polymer cement or some sulfur compound for the glass matrix material. Consider the immobilization of leachable Technetium, thought to be the most difficult radionuclide to immobilize due to its high solubility and anionic form; $\mathrm{TCO}_{4}$ : Technetium sorption by natural sulfide materials has been studied (Bock, 1989) and found to be effective due to formation of relatively insoluble $\mathrm{Tc}_{2} \mathrm{~S}_{7}$. The technical question is whether sulfur polymer cement responds in a similar manner.

Materials for use in the water chemistry engineered barrier have not yet been identified, but a possible material for use in the following sorption barrier has. The objective was to find a stable geologic type material with as high of $\mathrm{pH}_{\mathrm{zpc}}$ as possible. Three candidate materials have been found. Alumina has a $\mathrm{pH}_{\mathrm{zpc}}$ of around 8.7. Goethite and ferrihydrite each have a $\mathrm{pH}_{\mathrm{zpc}}$ of around 8. The advantage in using these materials is that the natural geologic soil solution $\mathrm{pH}$ at Hanford is between 8 and 9. Thus, these materials should be able to adsorb both anionic and cationic species while using indigenous basaltic material to buffer the $\mathrm{pH}$. 
The above material options have not been studied to understand the ramifications of their effectiveness or compatibility with other components in an engineered barrier system. They are offered as a starting point for future study.

\subsection{DESIGNING THE ENGINEERED BARRIER SYSTEM}

The purpose of the engineered barrier system is to enhance the performance of the near-surface disposal facility toward meeting the stated performance objectives. There are two main functions that the engineered barrier system would serve at Hanford: preserving the containment of radionuclides in the vitrified waste form and isolating the leached contaminates from migrating into the environment at large. The purpose of this section is to discuss the relevant issues associated with designing each of the engineered barrier options set forth in section 3.8 .

The key technical uncertainty that prevents the design of a near-surface disposal facility for Hanford's mixed low-level vitrified waste is the uncertainty in knowing if long-term accelerated glass corrosion will be experienced in the disposal facility in the geologic time scale of 10,000 years. If accelerated corrosion does not take place, the design of the nearsurface disposal facility is relatively easy. When laboratory glass corrosion experiments more closely simulate disposal facility conditions, accelerated glass corrosion becomes even more prominent. For this reason it is unlikely that in depth defense will ever be developed for dismissing accelerated glass corrosion without the use of an engineered barrier system specifically designed to inhibit accelerated corrosion.

The main issue in designing an engineered barrier system to inhibit accelerated corrosion is the lack of knowledge concerning the parameter controlling accelerated glass corrosion. Accelerated glass corrosion was only discovered three to four years ago as the glass-surface-area-to-leachate-volume ratio was increased in an attempt to simulate long-tern unsaturated disposal conditions. The recent discovery of this mechanism coupled with the long duration needed to conduct each experiment means that little knowledge concerning methods for its control is currently available. Of particular concern is the implementation of obvious solutions, because most obvious solutions have unobvious problems associated with them. For example, consider the hydrologic control barrier who's function is to reduce the volume of water migrating through the disposal facility. The obvious solution is to construct this engineered barrier such that the maximum amount of groundwater is diverted away from the disposal facility. The unobvious problem associated with this solution is that the reduced groundwater flowing through the disposal site effectively increases the glass surface-area-toleachate-volume ration, thus increasing the likelihood that accelerated glass corrosion could occur; assuming other factors being favorable. The problem with not using a hydrologic control barrier is if accelerated glass corrosion occurs in the disposal facility for either known or unknown reasons, the migration of leached radionuclides through the environment, in soluble or colloidal form, proceeds at the maximum rate possible. The best possible solution is the use of a hydrologic control barrier with subsequent barrier systems to insure that the vitrified glass corrodes at the lowest possible rate.

The water chemistry conditioning barrier is another example of where an obvious solution has unobvious problems associated with it. It is obvious from the previous discussion that crushed glass is not a good candidate material for this barrier, because use of a crushed glass barrier effectively increases the glass surface-area-to-leachate-volume ratio of the entire 
repository. A crushed glass layer could then precondition any infiltrating groundwater and cause accelerated corrosion of the vitrified waste form. However, an obvious solution for the water chemistry conditioning barrier is to incorporate indigenous geologic materials such as crushed basalt. The reason is because it contains high concentrations of $\mathrm{SiO}_{2}$ and other buffering agents. The $\mathrm{SiO}_{2}$ is expected to increase the silica content of groundwater migrating through it which is known to retard glass corrosion. In addition, other constituents in the basalt act as buffering agents to maintain the $\mathrm{pH}$ around 8.5 . The combination of high concentrations of silica and near neutral solution $\mathrm{pH}$ inhibits glass corrosion. A possible unobvious associated with this solution occurs if solution concentration equilibrium is not achieved. Groundwater buffering by basalt occurs because a combination of acid and base forming constituents coexist in the mineral. However, the most soluble constituents such as $\mathrm{Na}, \mathrm{P}$, and $\mathrm{Ca}$ from basic solutions, would tend to leach first, and to a greater extent that the acid forming constituents. If the barrier is too thin, the migration time through the barrier would not sufficiently long enough for the solution to obtain equilibrium conditions. For this scenario, the infiltrating groundwater would initially possess a higher $\mathrm{pH}$. Migrations of this groundwater to the vitrified glass could contribute to accelerated glass corrosion. Although the increase in groundwater $\mathrm{pH}$ as it migrates through this barrier would be a transient phenomena; once accelerated glass corrosion of the vitrified waste form is established, it is not clear that a reduction in migrating groundwater to near neutral levels will retard the accelerated corrosion rate. Another unobvious problem associated with the use of basalt is the potential for some of its constituents to adversely react with the glass and/or form colloids. For example, basalt also contains iron, which can form iron silicates and iron oxide colloids. The presence of iron in solution can aggravate glass corrosion and colloids accelerating the transport of radionuclides into the environment. A detailed performance assessment is the only means available to determine which materials are useful options for the water chemistry conditioning barrier.

Designing a vault is also difficult due to the limited number of structural materials available and the issue of material incompatibility. Traditionally, vaults are made from concrete. Unfortunately, glass and concrete are incompatible materials in the time domain of 10,000 years. Concrete possesses a porous structure that enables water to migrate through it.

The problem is the $\mathrm{pH}$ of the migrating water increases to valued approaching 12 in the short-term due to leaching of soluble constituents in the concrete such as $\mathrm{Ca}(\mathrm{OH})_{2}, \mathrm{NaOH}$, and $\mathrm{KOH}$. In the long-term, water migrating through the concrete will come into equilibrium with calcium aluminates and calcium silicates which increase the solution $\mathrm{pH}$ to around 9 . The increased groundwater $\mathrm{pH}$ would increase the corrosion rate of the vitrified waste form contained inside the vault as the groundwater comes in contact with it. This may also initiate accelerated glass corrosion. An alternative material developed for civil structural applications by the U.S. Department of the Interior is sulfur concrete (McBee et al., 1983, and Malthotra, V.M., 1975). From a structural standpoint, sulfur concrete is several time stronger than conventional hydraulic concrete and as such should be suitable material for use in vault fabrication. In addition, construction practices have been established for sulfur concrete (McBee et al., 1983). A second benefit to using sulfur concrete is its high resistance to moisture penetration and extremely low water solubility (McBee et al., 1975) which inhibits the long-term loss of material through leaching. This increases the performance of the vault. Impeding moisture migration into the vault by use of a moisture impermeable wall such as sulfur concrete cannot be defended for long periods of time since subsidence, seismic forces, or intrusion can result in penetrations of the wall. The third benefit is the lack of 
incompatibility issues identified between sulfur and glass. A potential concern of the use of sulfur concrete is the lack of knowledge concerning how it will degrade in the long-term. Other material options for vault construction have not been identified.

A requirement exists that the waste form be retrievable from the disposal facility for some period of time. Containment of the waste form in some type of portable container is probable. The container material should be selected to maintain material compatibility with all other materials used in the engineered barrier system, including the vitrified waste form. Common structural material such as iron and steel could facilitate glass corrosion through lowering the silica leachate concentration by precipitation of iron silicides. It may be possible to use these types of materials in constructing the portable containers if the degree of protection afforded by other elements of the engineered barrier system is sufficient to compensate for iron's detrimental effects. However, this can only be established through a performance analysis. If the performance analysis indicates that the introduction of iron into the system is unacceptable, the recommendation would be to fabricate the portable containers from sulfur concrete or sulfur polymer cement (Mayberry et al., 1993). These materials could also be used as a matrix to encapsulate the vitrified waste form. This option is re-addressed later on in this section.

A problem associated with placing the vitrified waste form into portable containers in the near-surface disposal facility is the very high humid conditions that the glass will experience. The relative humidity in a near-surface disposal facility is nearly $100 \%$ (Marshall and Holmes, 1998). Containers can not be used to isolate the humidity from the vitrified waste form, because acceptable reasoning can not be made that the containers will not fail within hundreds of years. Container failure means that gaseous transport of water to the vitrified waste form is assured with subsequent corrosion. A matrix material could be used to limit the amount of moisture that comes in contain with the surface of the glass if bonding between the matrix and glass can be maintained. Although some type of matrix degradation such as cracking will be required to be considered in the performance analysis, the result is a more torturous migration path, which is beneficial. Other possible attribute that a matrix material may provide include chemical alteration of infiltrating water to reduce the corrosion rate, and possible immobilize contaminates that leach from the glass through precipitation. With these potential benefits, the use of a matrix material is high recommended. The following are material categories examined for the purpose of identifying suitable matrixing materials.

- Organics

- Polymers

- Polyethylene

- Polyvinyl Chloride

- Polymethyl Methacrylate

- Epoxy

- Urea Formaldehyde

- Polyurethanes

- Petrochemicals

- Asphalt

- Bitumen

- Wax 
- Biological

- Gelatins

- Caseins

- Alginates

- Cellulosics

- Poly Sacchrides

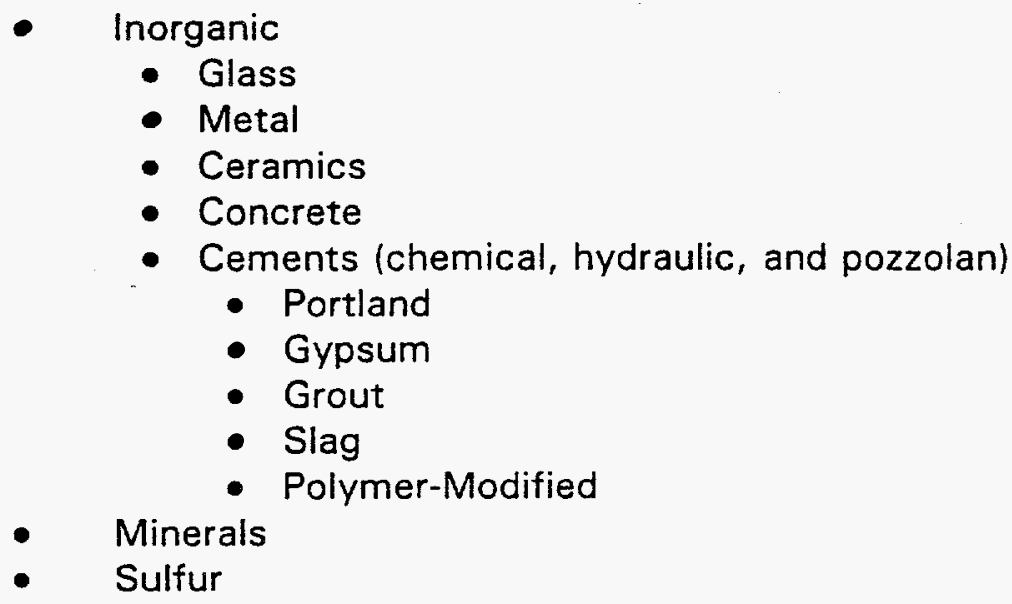

This does not represent an exhaustive search for suitable matrixing materials. In general, long-term stability issues surrounds most organic materials. Of particular interest is the degradation process which usually leads to formation of small organic colloids. Since these types of colloids are cited as contributing to anomalous radionuclide transport observed for disposal conditions (Toste et al., 1984), their intentional introduction into the disposal facility is not recommended. With respect to inorganic materials, the use of the material systems such as glass, ceramics, most minerals, and specialty metals is questioned from the standpoint of fabrication. The use of material from the categories of concrete, cements, and common metals is questioned on the basis of chemical compatibility with the vitrified waste form. The leading candidate material emerging from this simple review is sulfur.

Sulfur has many potential attributes for use as a matrix material. Because it is highly impermeable to moisture (McBee et al., 1983) and is considered practically insoluble in water (Windholz et al., 1976), it could potentially reduce the amount of moisture contacting the glass surface for long periods of time. Sulfur polymer cement has been studied by the DOE (Mayberry et al., 1994) as an encapsulated material for low-level mixed waste streams stored at DOE facilities. Advantages listed in this report for sulfur polymer cement include: immobilization of toxic metals, high compressive strength, resistant to thermal cycling, radiation stability, biological stability, and leach resistant. However, the long-term stability for shallow land burial is in question (Mattus and Mattus, 1994). Elemental sulfur is found at the earth's surface around volcanoes. At Mt. Lassen in California, sulfur was obtained from open-pit mines in 1800's. It is also mined using the Frasch process (Landes, K. K., 1981) from the tope of salt domes. It is possible that elemental sulfur will be stable in Hanford's disposal facility.

Sulfur matrixing material may also provide chemical immobilization of leached metals from the vitrified waste. Most heavy metals are found in nature in the form of sulfides that are usually insoluble (Weast, R. C., 1974). For example, when lithium, sodium, potassium, copper, mercury, or silver come in contact with sulfur at room temperature they react to form 
sulfides (Windholz et al., 1976). Chemical immobilization may be enhanced by incorporating natural sulfide materials into the sulfur matrix. For example, the mobility of technetium is decrease by the presence of natural sulfides such as pyrrhotite due to the formation of insoluble $\mathrm{Tc}_{2} \mathrm{~S}_{7}$, which is removed from solution through precipitation and immobilized through entrapment (Bock et al., 1988 and Lieser and Bauscher, 1988). It has also been noted that the hydrolysis of pyrrhotite forms $\mathrm{H}_{2} \mathrm{~S}$, which tends to decrease the solution $\mathrm{pH}$ when oxidation takes place to form $\mathrm{H}_{2} \mathrm{SO}_{4}$ (Lieser and Bauscher, 1988). This reduction in solution $\mathrm{pH}$, in the Hanford disposal facility environment, could be useful in inhibiting the accelerated glass corrosion mechanism (Feng and Pegg, to be published).

The design of water chemistry modification barrier below the vault has not been contemplated, because the requirements are dependent upon the chemical attributes of the groundwater migrating out of the vault which has not been identified. A performance assessment is needed to make this determination.

Three materials have been potentially identified for incorporation into the design of the sorption barrier below the vault. The objective is to find a stable geologic type material with a high $\mathrm{pH}_{2 \mathrm{pc}}$ enabling adsorption of both anionic and cathodic species. Different forms of alumina possess a high $\mathrm{pH}_{\mathrm{zpc}}$ of about 8.5 (Huang and Stumm, 1972 and Sprycha, 1989) to about 9 (Hayes et al., 1990). Ferrihydrite has a slightly lower $\mathrm{pH}_{\mathrm{zpc}}$ of 8 (Dzombak and Morel, 1990), as does geothite (Hsi and Langmuir, 1985, and Hayes et al., 1990). The specific design of this barrier will be highly dependent upon the results of a performance assessment.

In summary, their are two fundamental mechanisms that control the long-term performance of a near-surface disposal facility: corrosion of the vitrified waste form which mobilizes radionuclides and mass transport mechanisms such as soluble and colloidal mass transport which enables radionuclides migration through the environment. Based on a preliminary performance analysis conducted by Hanford personnel, disposal of vitrified mixed low-level waste in a near surface disposal facility seems feasible and easily accomplished provided the rate of glass corrosion is not governed by long-term accelerated corrosion. A primary focus of future work should developing a means to inhibit accelerative glass corrosion. Primary factors influencing the amount of released radionuclides into the environment include the exposed surface area of the glass and associated rates for glass corrosion and radionuclide migration. Techniques identified to minimize radionuclide migration include limiting the amount of groundwater migrating through the disposal facility, minimizing the formation of colloids through minimizing detrimental materials introduced into the disposal facility, and chemically precipitating or agglomerating insoluble species to a size not transportable by unsaturated flow. Design features should be incorporated to mitigate colloidal mass transport, since sizable amount of both normally insoluble and soluble species can be unexpectedly transported. Sorption barriers should be capable of adsorbing both anionic and cathodic species, which is possible when using a sorbing material at its $\mathrm{pH}_{\mathrm{zpc}}$. Prevention of accelerative glass corrosion methods have not been identified. The unsaturated hydrologic conditions typical of shallow land disposal increase the likelihood that accelerated glass corrosion will take place. Investigating the use of a matrixing material such as sulfur polymer cement with additives such as sulfides may prove useful in mitigating accelerative glass corrosion mechanism. 


\subsection{SUMMARY AND RECOMMENDATIONS}

The goal of engineered barriers is to enhance the disposal facility's performance, enabling the stated performance objectives to be obtained. The fundamental issues are containment of the radionuclides in the vitrified waste-form and isolation of leached radionuclides from the localized geographic regions. The issue of containment focuses on inhibiting corrosion of the vitrified waste form. The issue of isolation focuses on enhancement of sorption and inhibiting colloidal mass transport.

Factors influencing the corrosion of glass include solution $\mathrm{pH}$, silica concentration in the leachate, incompatible materials, and glass surface-area-to-leachate-volume ratio. The critical problem is inhibiting the long-term accelerative corrosion mechanism, which is fundamentally motivated by thermodynamics.

With respect to migration of leached radionuclides, the critical issue is whether the colloidal mass transport is of real concern, and if so, how can it be inhibited.

The following recommendations are made for future study.

- Identifying the largest stable glass size for use in the disposal facility by studying the size distribution that naturally occurs for similar substances naturally buried in the earth.

- Conduct long-term accelerated glass corrosion tests (high surface-area-toleachate volume ration) with basalt mixed into the specimen to determine the influence of other groundwater constituents expected to infiltrate into the disposal facility.

- Conduct a study specifically for identifying other matrix materials that were missed by this and other studies.

- Identify the long-term stability of sulfur polymer cement in terms of mechanical and biological degradation. Information could be obtained by the retrieval, examination, and testing of samples buried up to 20 years ago.

- Determine if a sulfur type matrix is capable of inhibiting accelerated glass corrosion.

- Determine if and to what extent a sulfur type matrix can precipitate radionuclides from leachate and/or agglomerate colloids to increase their size above which they can not migrate via unsaturated flow.

- Determine if the addition of sulfides to a sulfur matrix enhances precipitation or agglomeration.

- Evaluate the potential effectiveness of absorbent materials like alumina, geothite, and ferihydrite to retard the migration of positive and negatively charged ions and colloids. 
Final

Figure 3-1. Fundamental Elements at a Near Surface Disposal Site

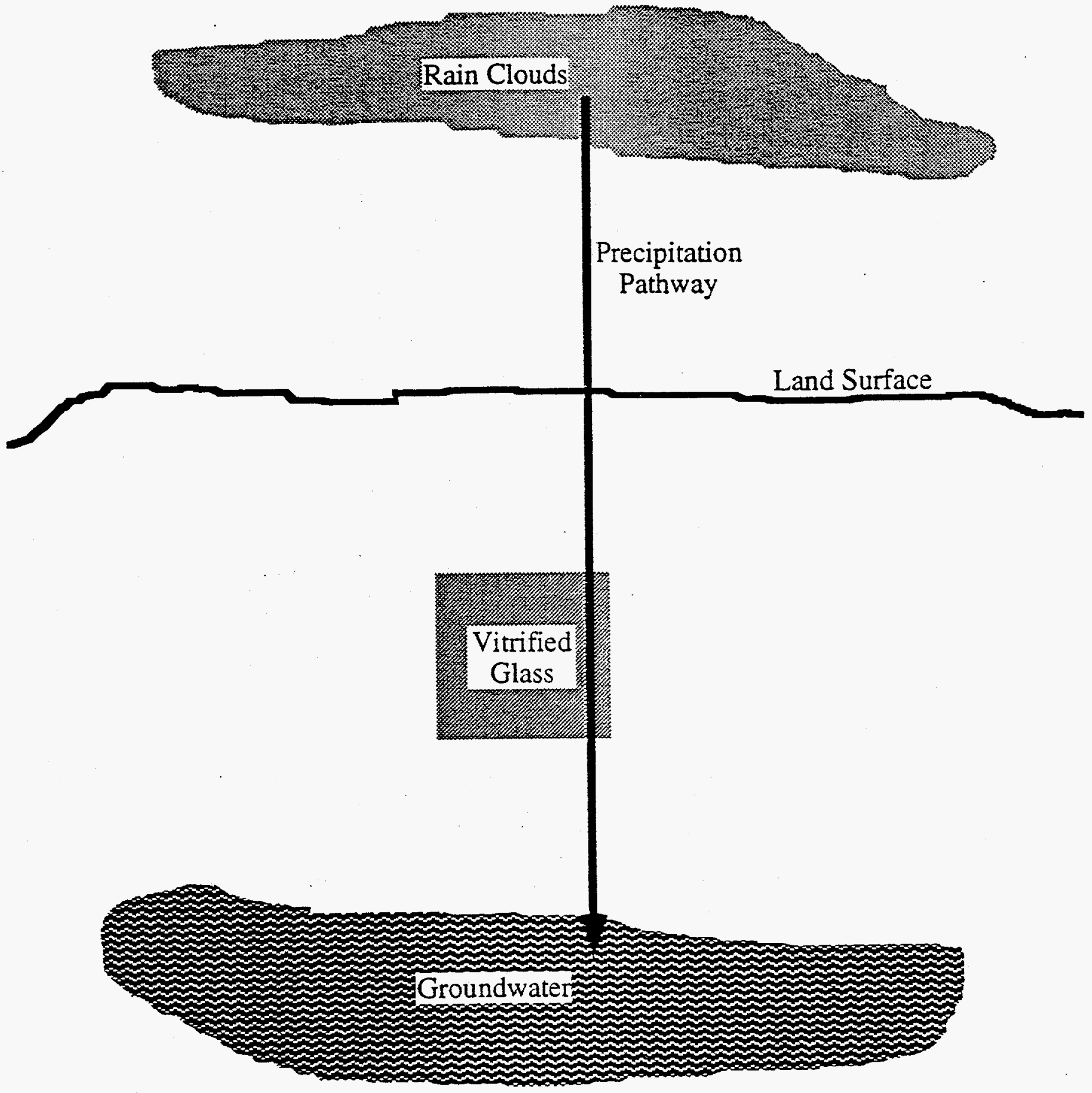


Figure 3-2. Schematic of Alkali Borosilicate Glass Structure Containing Dissolved Nuclear Wastes [2]

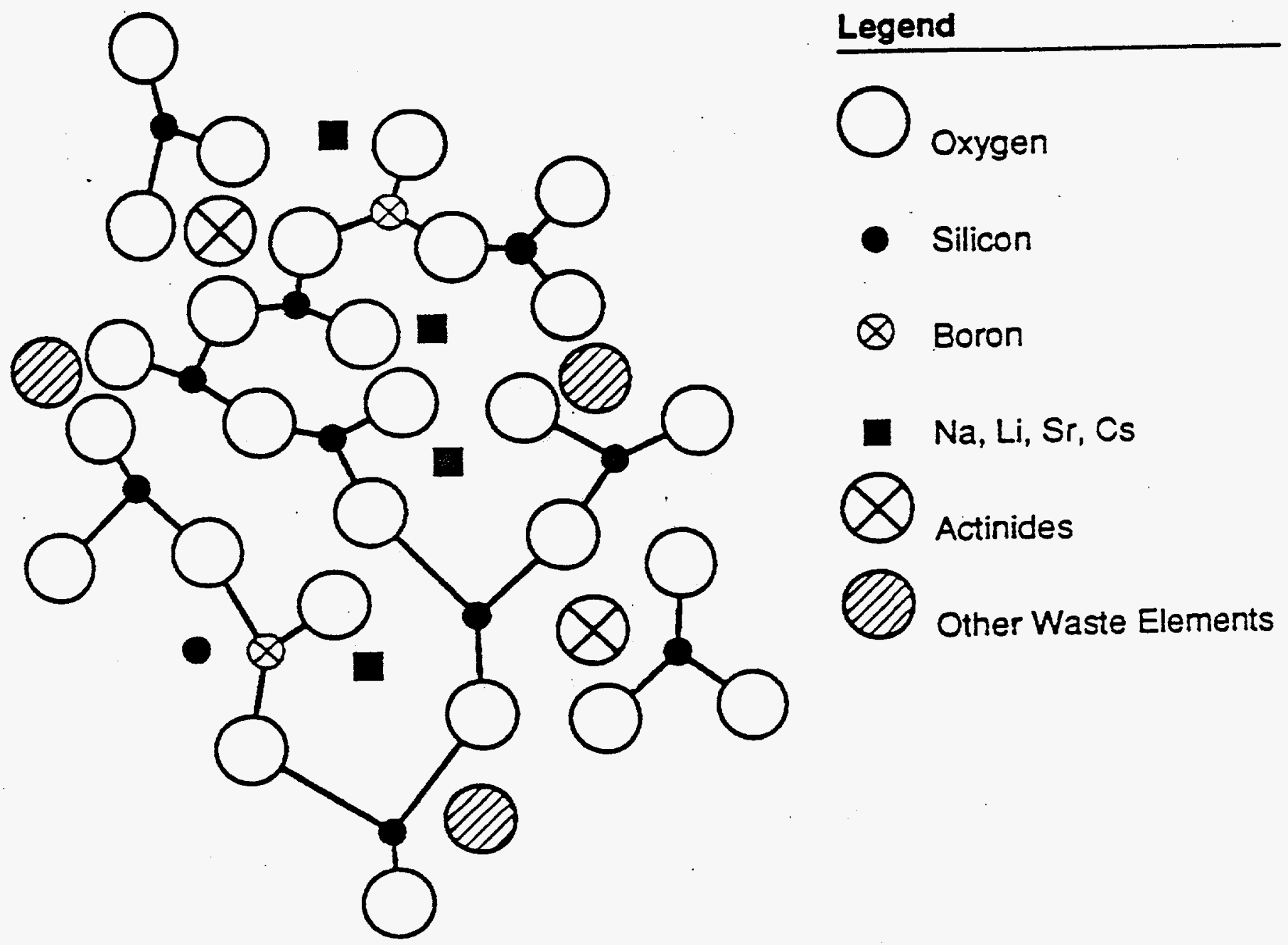


Final

Figure 3-3. Primitive Engineered Barrier System for Near Surface Disposal

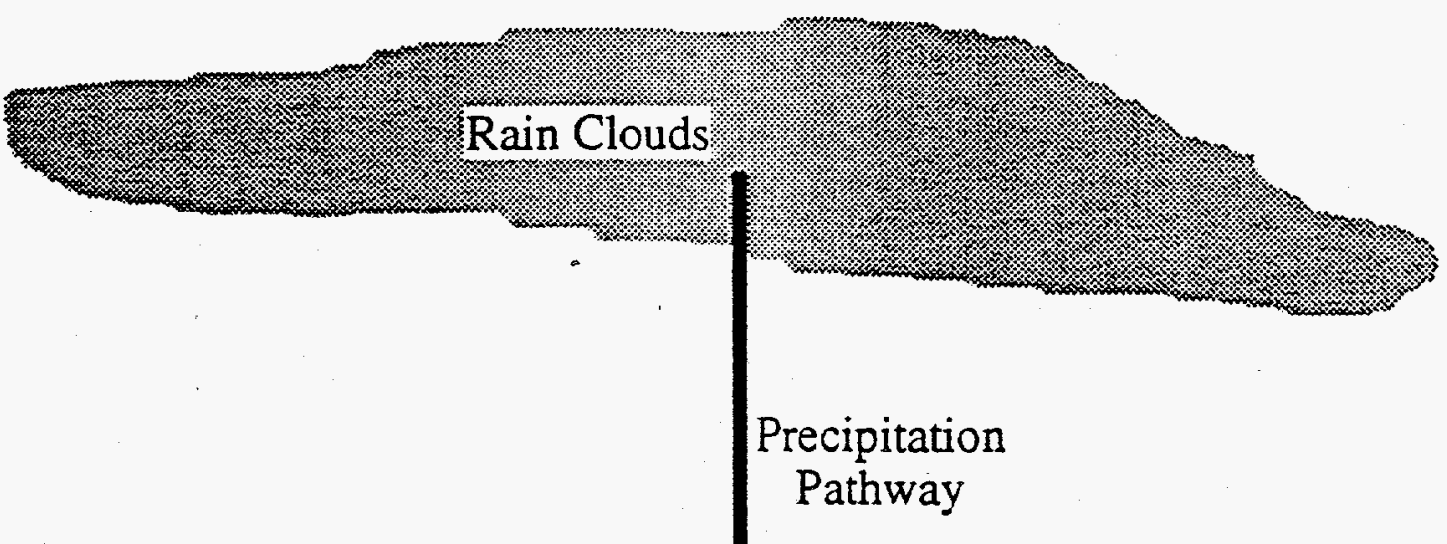

Land Surface

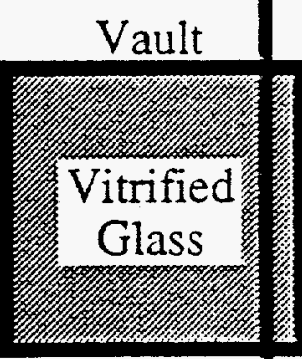

Groundwater 
Figure 3-4. Annual Fractional Release Plot

\section{Annual Fractional Release of Radionuclides}

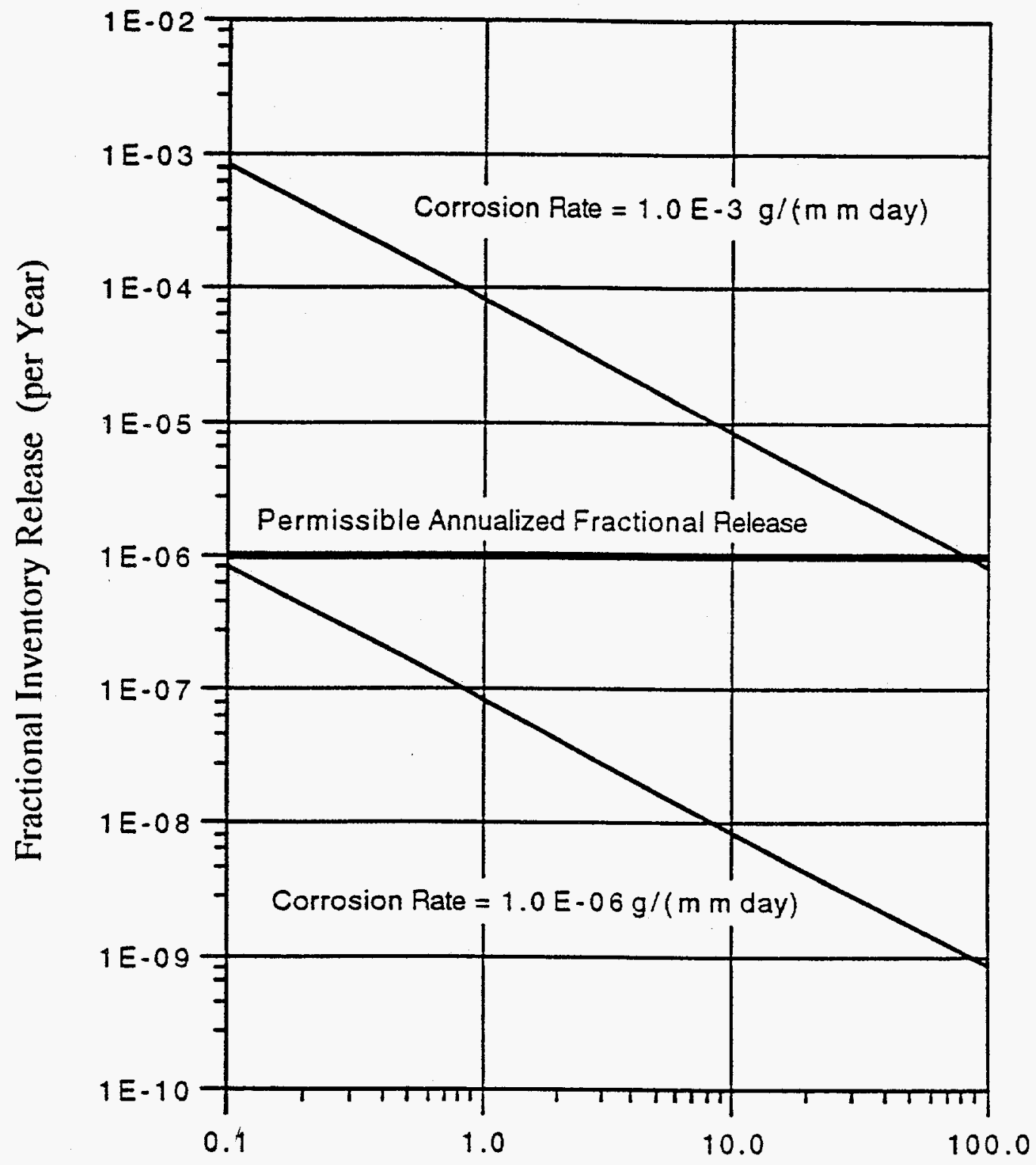

Dimension of Waste Glass Cube (cm) 
Figure 3-5. Release of Structural Silica as a Function of Glass Hydration Energy [21]

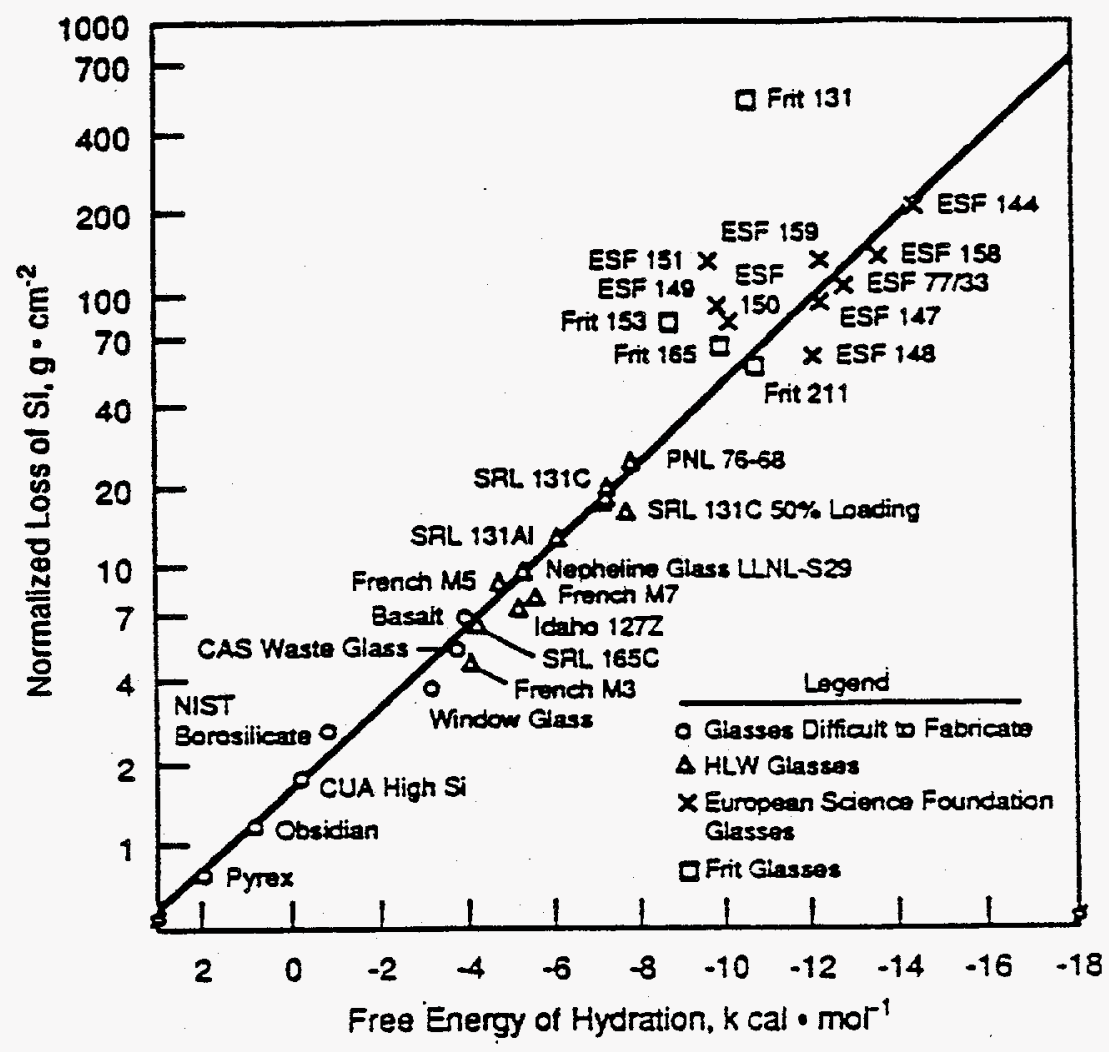

Figure 3-6. Boron Release as a Function of Silicon Content of the Leachate [22]

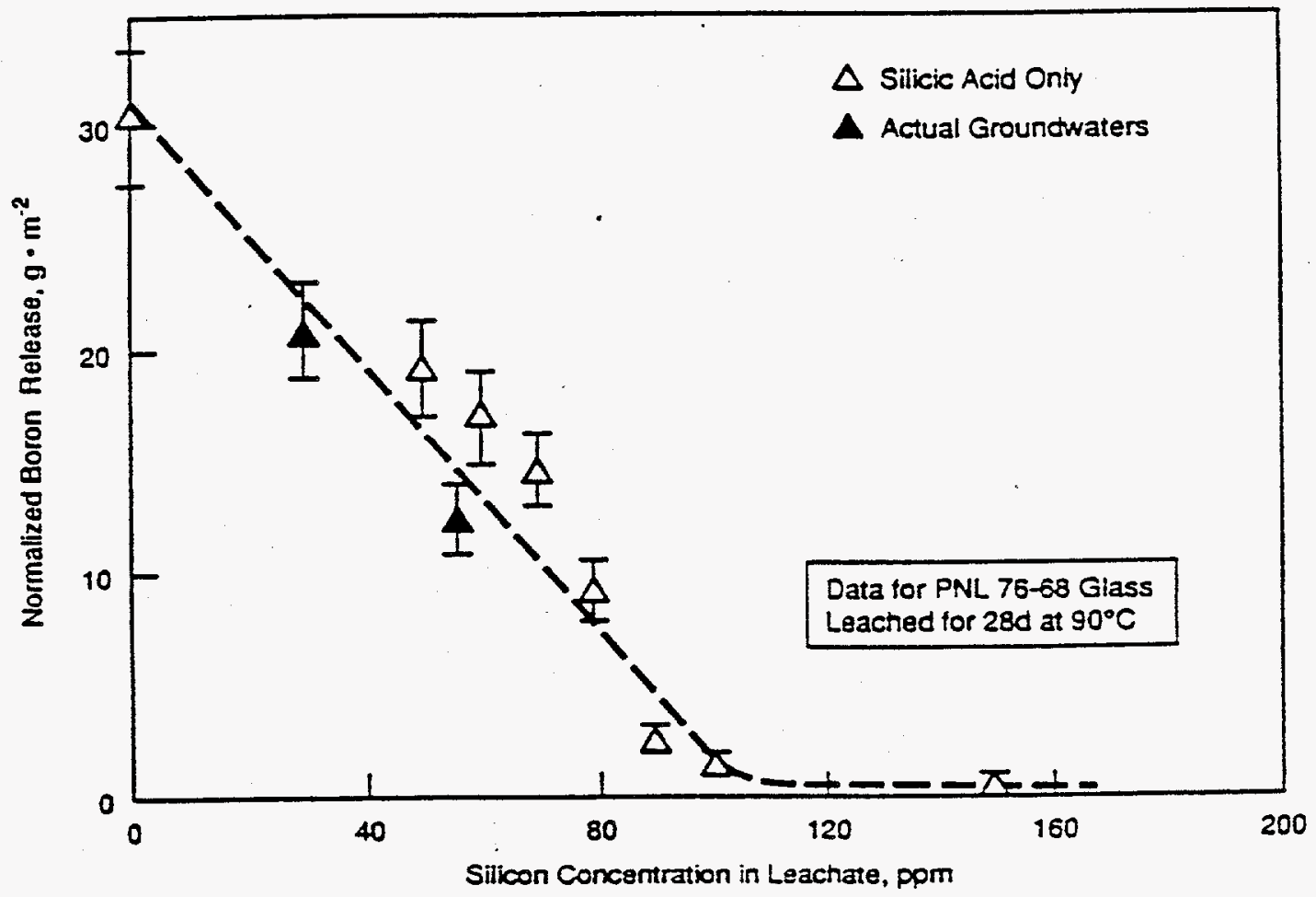


Figure 3-7. Mass Loss of Borosilicate Glass as a Function of Leachate pH [23]

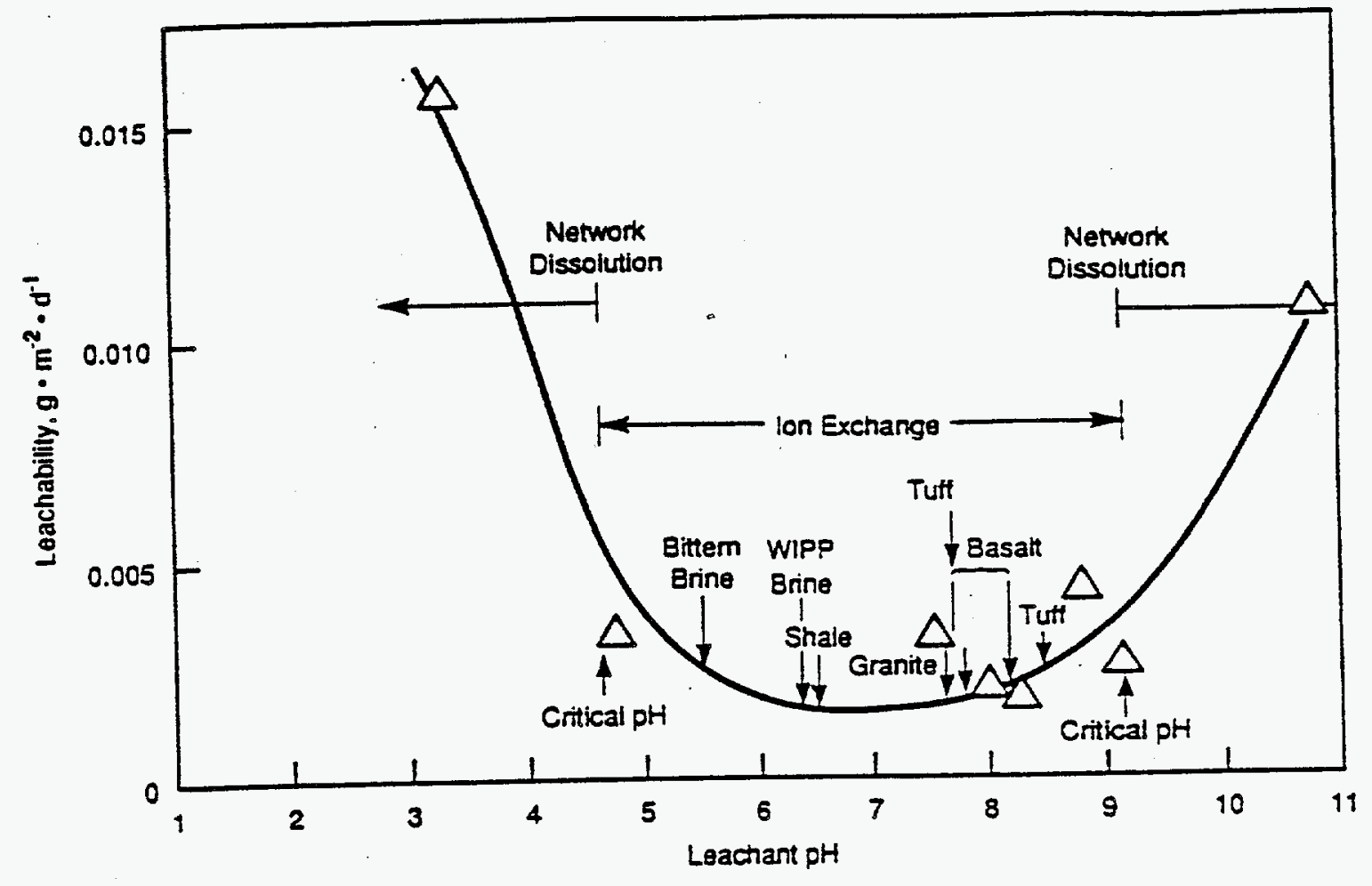

Figure 3-8. Illustration of the Effect of Iron in the Leachate on Corrosion of PNL-76-68 Borosilicate Glass [24]

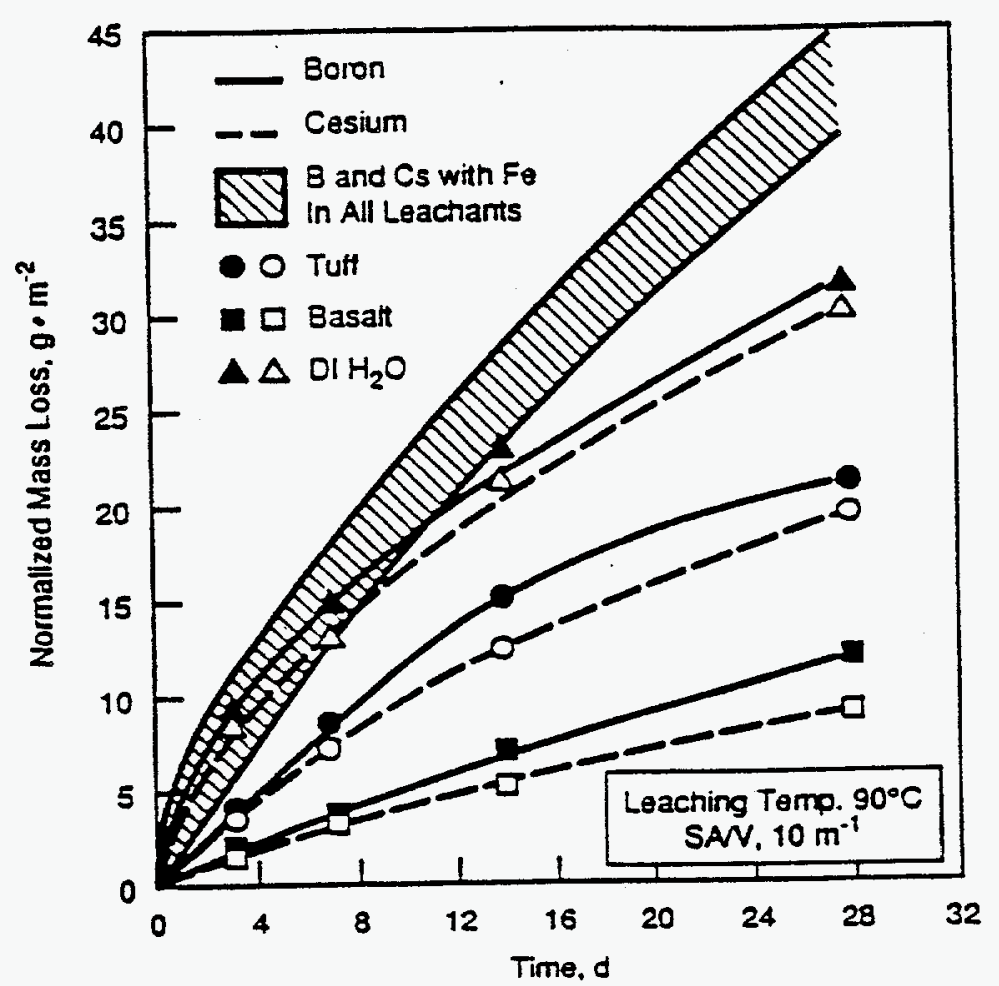


Figure 3-9. Temperature Dependence on Glass Dissolution Rate [18]

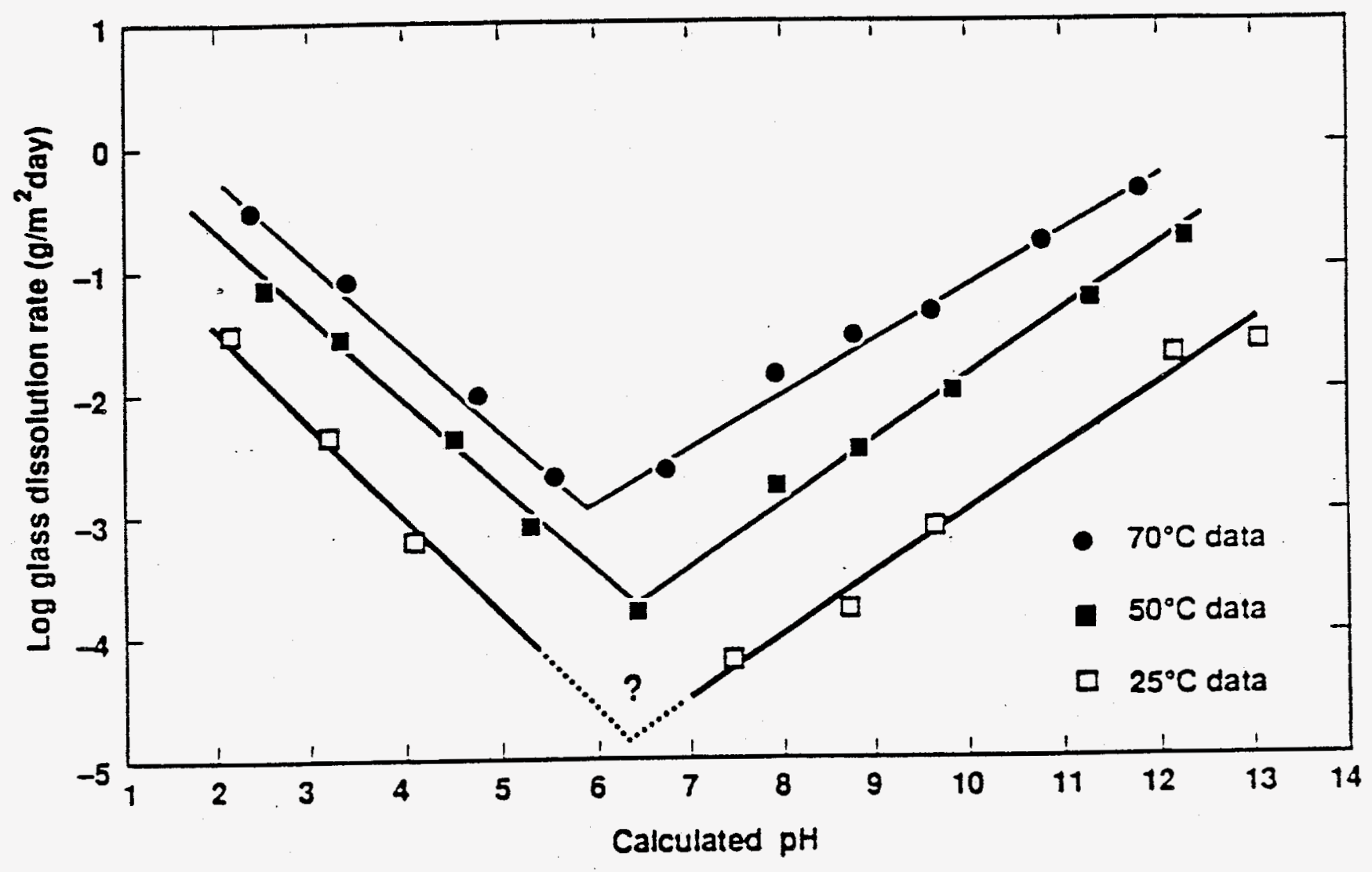


Figure 3-10. Normalized Elemental Concentrations vs. Time For CSG Glass Dissolving at $100^{\circ} \mathrm{C}[12]$

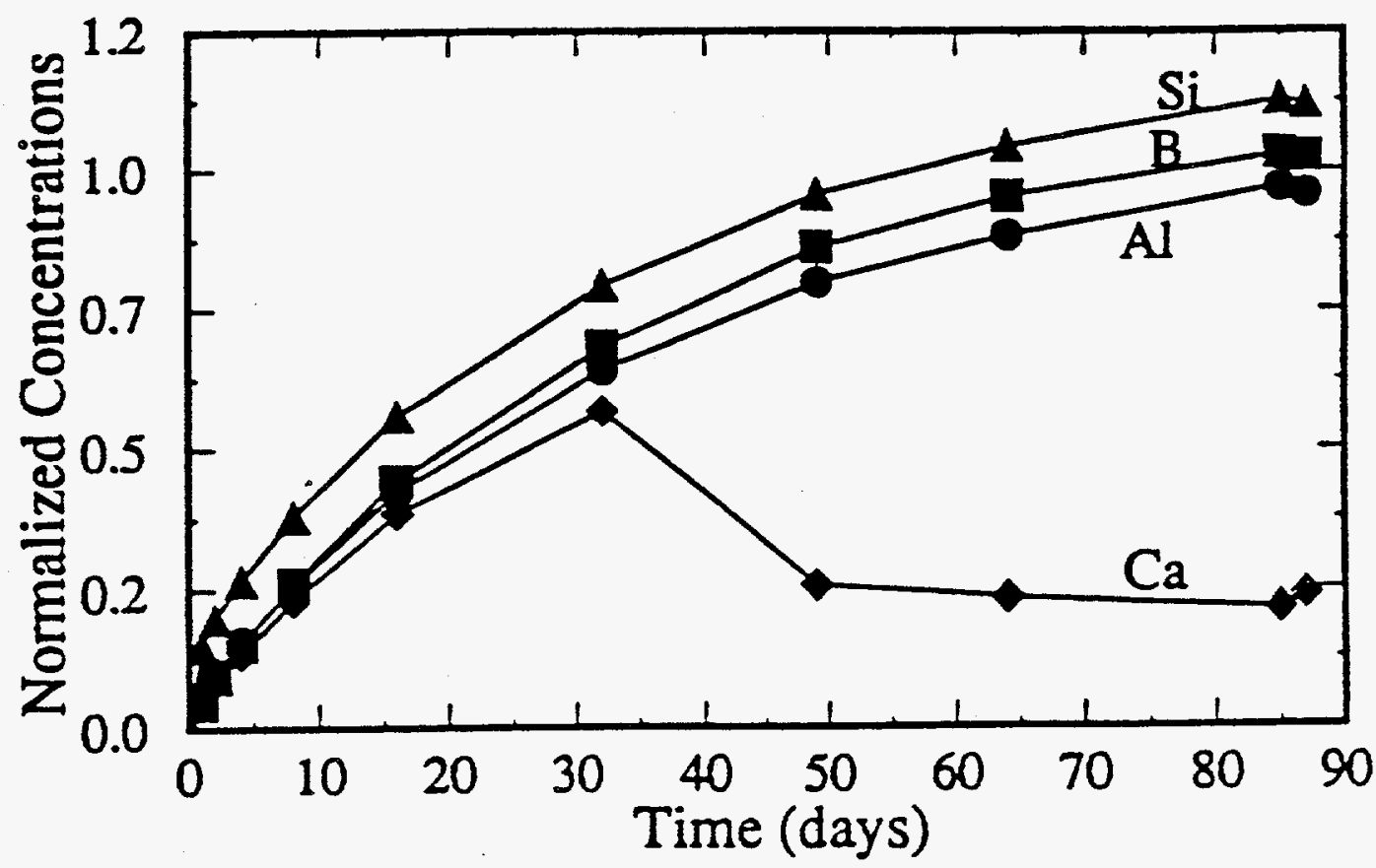

Figure 3-11. Cumulative and Derivative Si Release from CSG Glass at $100^{\circ}[12]$

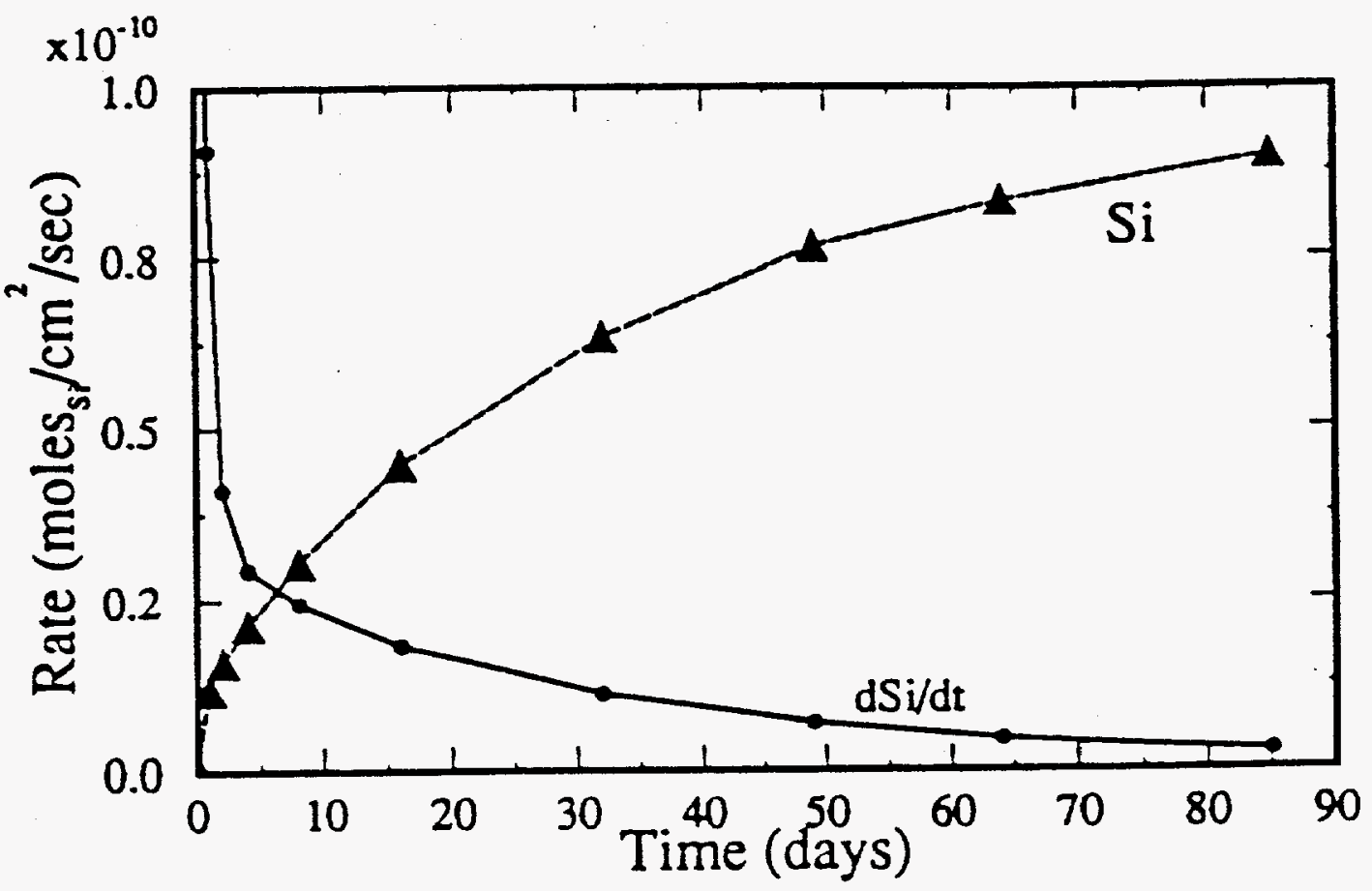


Figure 3-12. Leachate pH Values vs. Reaction Time [25]

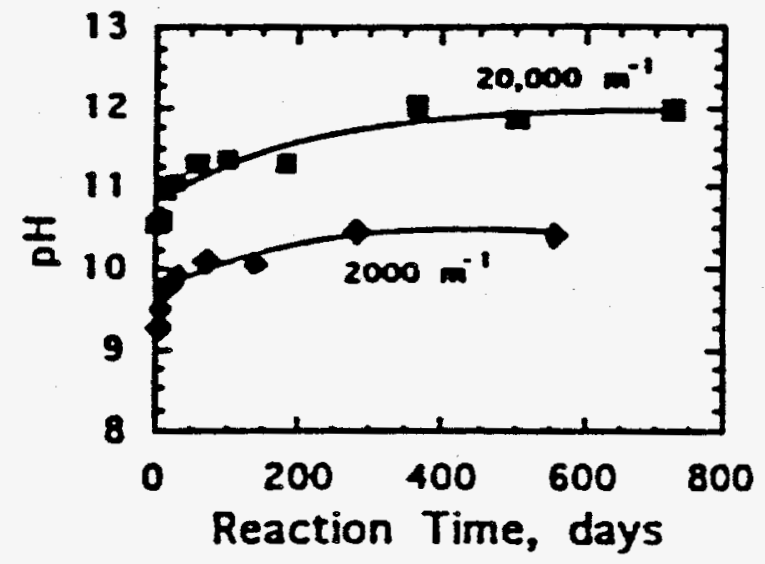

Leachate $\mathrm{pH}$ Values $\left(25^{\circ} \mathrm{C}\right)$ vs. Reaction Time for Tests With SRL 202 Glass at ( 1$) 2000 \mathrm{~m}^{-1}$ and $(\boldsymbol{D}) 20,000 \mathrm{~m}^{-1}$.

Figure 3-13. Normalized Elemental Mass Loss vs. Reaction Time [25]
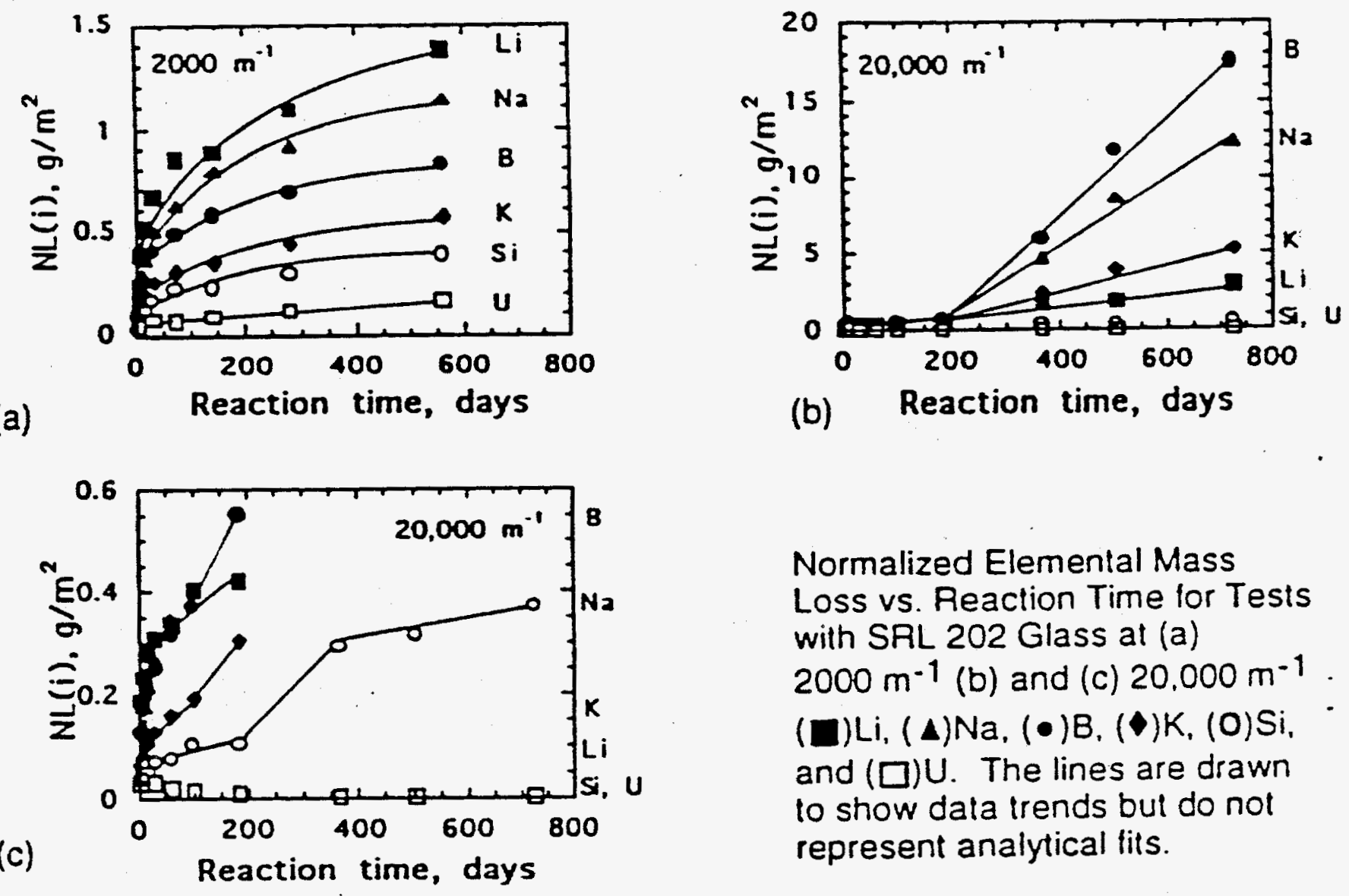

Normalized Elemental Mass Loss vs. Reaclion Time for Tests with SRL 202 Glass at (a) $2000 \mathrm{~m}^{-1}$ (b) and (c) $20.000 \mathrm{~m}^{-1}$. (D) Li, ( 4$) \mathrm{Na},(\bullet) \mathrm{B},(\bullet) \mathrm{K},(\mathrm{O}) \mathrm{Si}$. and $(\square) \cup$. The lines are drawn to show data irends but do not represent analytical fits. 
Figure 3-14. Steady-State $\mathrm{pH}$ Values vs. S/V Ratio [13]
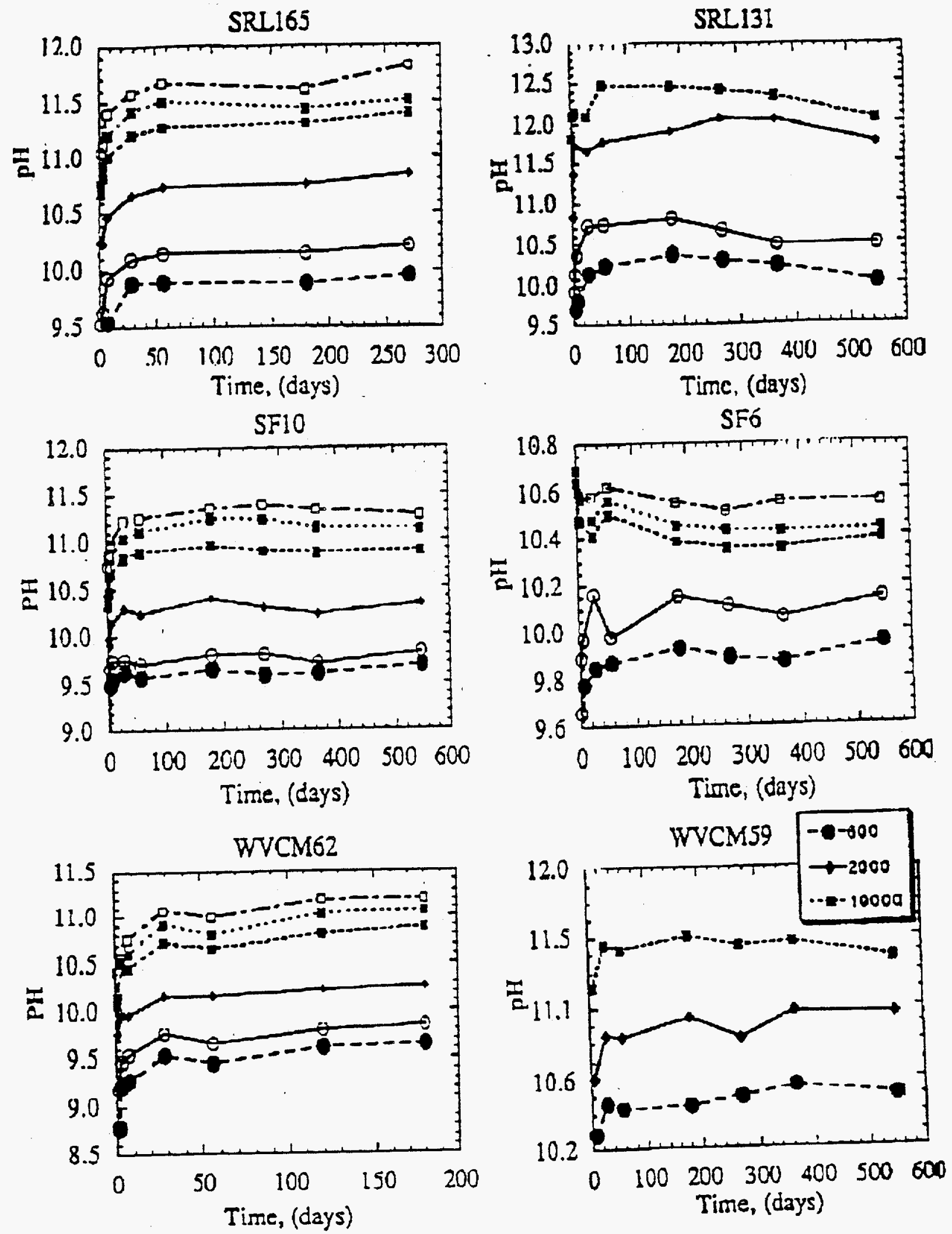

$$
\begin{array}{lll|}
-0-20 & \rightarrow-2000 & \cdots-20000 \\
-200 & \cdots-10000 & \rightarrow-40000
\end{array}
$$


Figure 3-15. Correlation of pH with Log S/V Ratio [13]

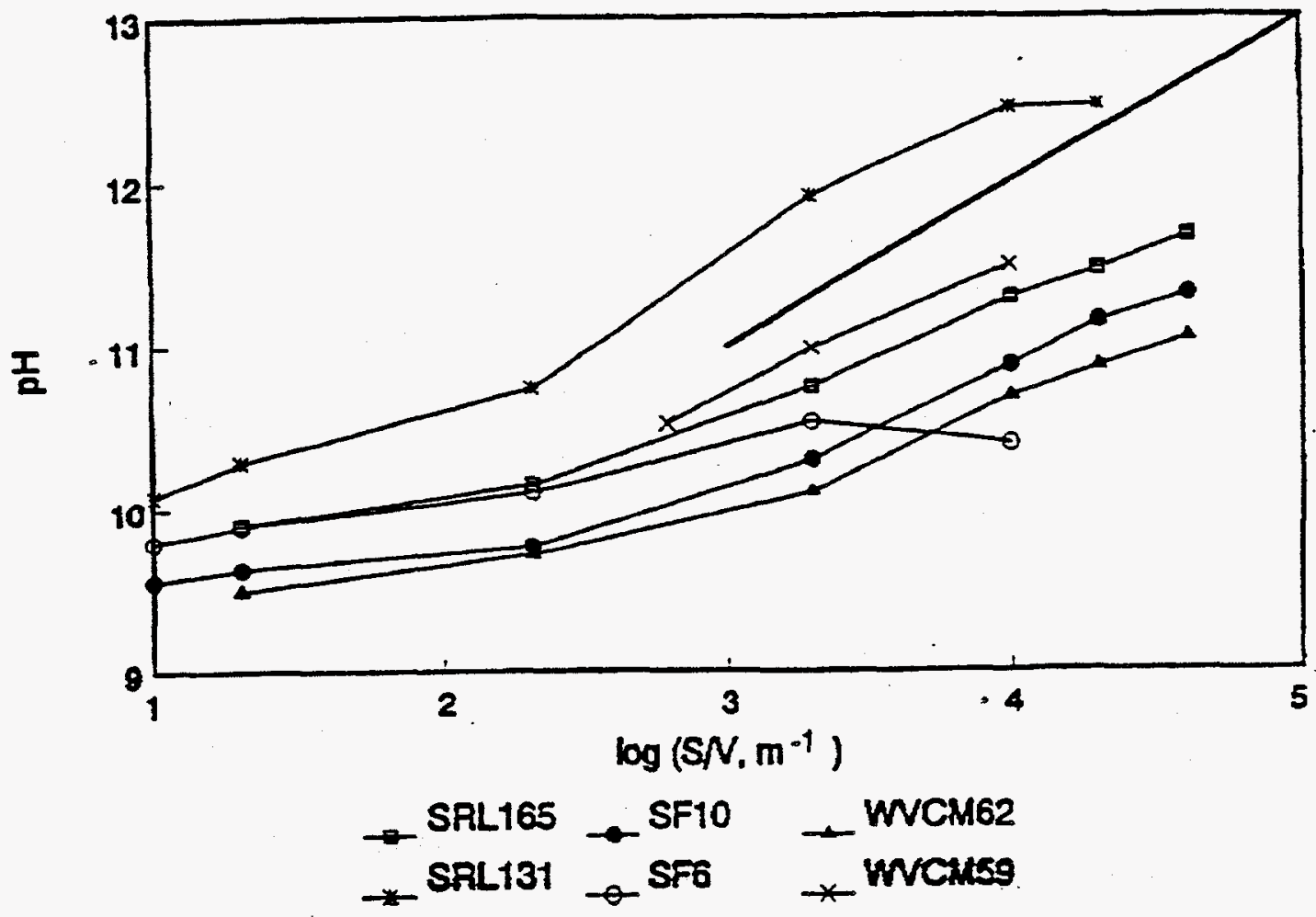

Figure 3-16. Features Observed in Surface Layers of Corroded Glass [27]

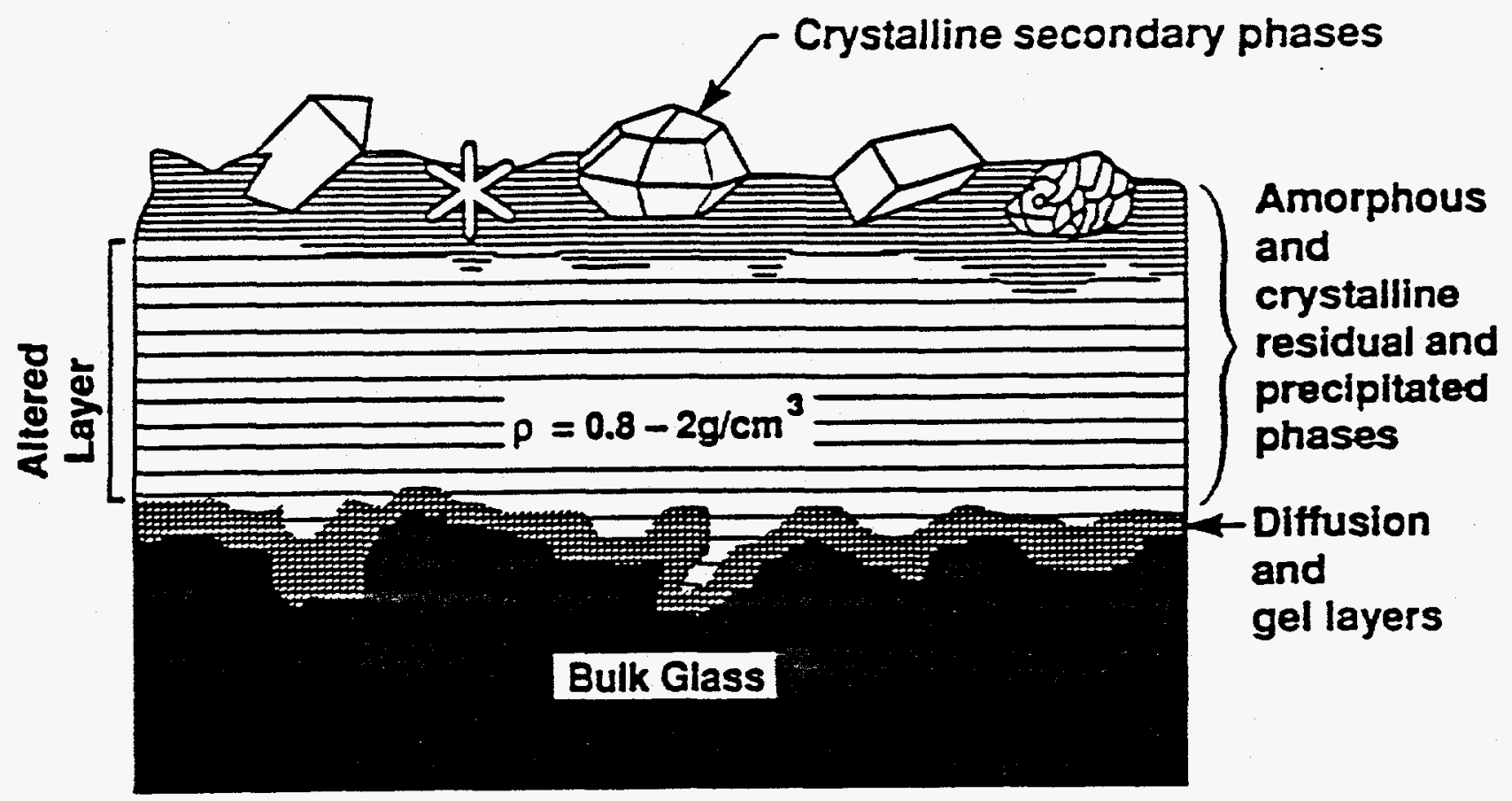


Figure 3-17... Size Spectrum of Waterborne Particles [38]

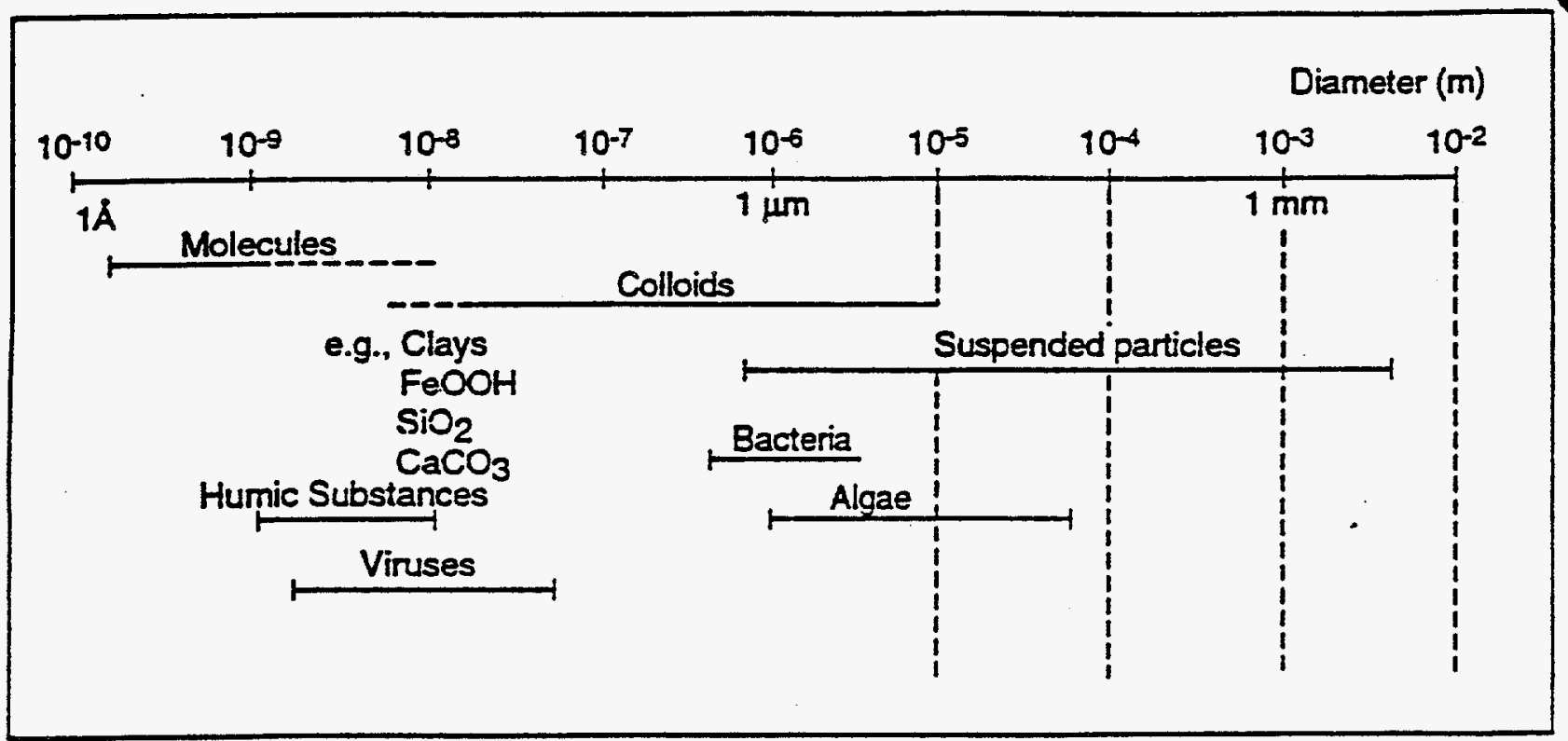

Figure 3-18. Continuum of Particles and Dissolved Organic Carbon in Natural Waters [41]

\section{Organic Carbon Continuum}

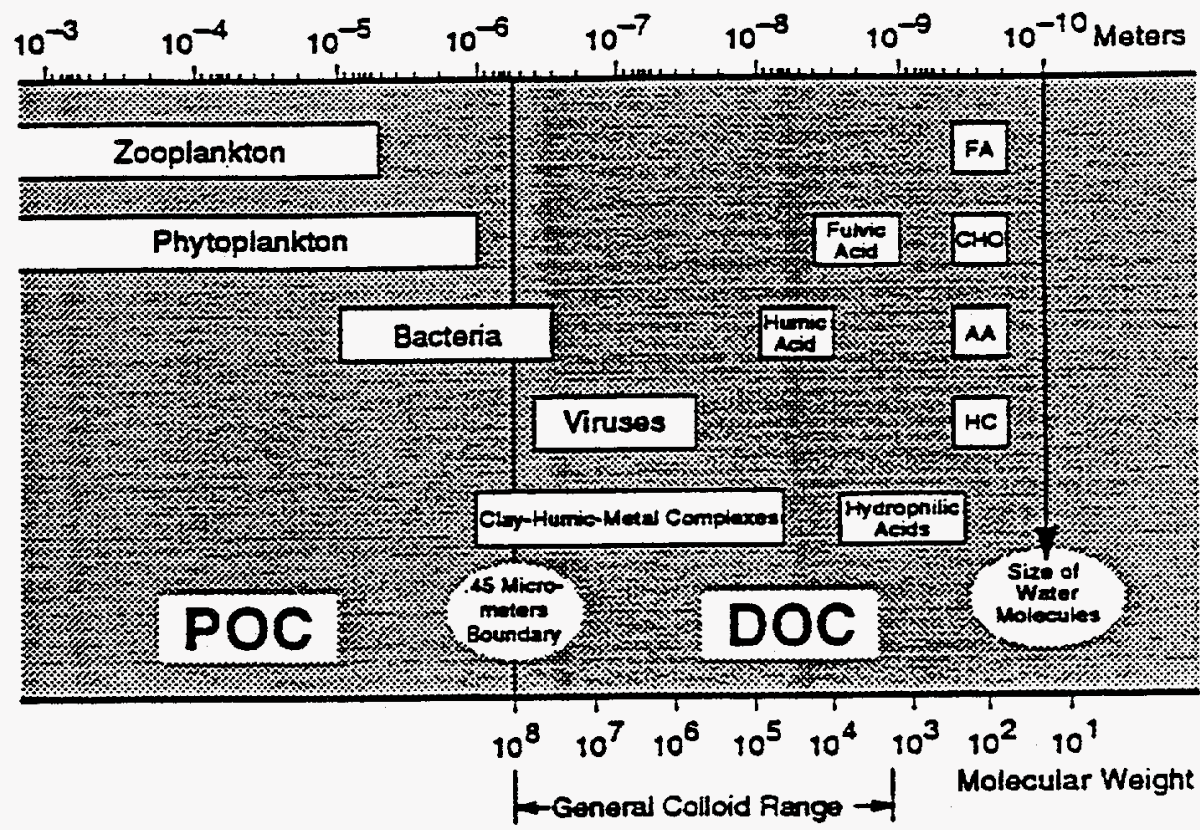

FA Fany Adds CHC Carbohydrates M Amino Acids HC Hydrocarbons 
Figure 3-19. Summary of Colloid Concentrations [45]

\begin{tabular}{|c|c|c|c|c|c|c|c|c|c|c|c|c|c|c|}
\hline \multirow{2}{*}{$\begin{array}{c}\text { Size } \\
\text { Range } \\
\text { (um) }\end{array}$} & \multicolumn{2}{|c|}{$\begin{array}{l}\text { Wells } \\
n=11\end{array}$} & \multicolumn{2}{|c|}{$\begin{array}{c}\text { Springs } \\
\mathbf{n}=9\end{array}$} & \multicolumn{2}{|c|}{$\begin{array}{l}\text { Volcanic } \\
n=10\end{array}$} & \multicolumn{2}{|c|}{$\begin{array}{c}\text { Carbonate } \\
n=7\end{array}$} & \multicolumn{2}{|c|}{$\begin{array}{l}\text { NTS } \\
\mathrm{n}=8\end{array}$} & \multicolumn{2}{|c|}{$\begin{array}{c}\text { Off-Site } \\
\mathbf{n}=12\end{array}$} & \multicolumn{2}{|c|}{$\begin{array}{c}\text { All Sites } \\
n=20\end{array}$} \\
\hline & $\bar{x}$ & $\sigma$ & $\bar{x}$ & $\sigma$ & $\overline{\mathbf{x}}$ & $\sigma$ & $\bar{x}$ & $\sigma$ & $\bar{x}$ & $\sigma$ & $\bar{x}$ & $\sigma$ & $\bar{x}$ & $\sigma$ \\
\hline$>1.0$ & 0.27 & 0.20 & 0.58 & 1.25 & 0.61 & 1.16 & 0.11 & 0.08 & 0.64 & 1.32 & 0.25 & 0.18 & 0.41 & 0.34 \\
\hline $1.0-0.4$ & 0.21 & 0.13 & 0.21 & 0.16 & 0.26 & 0.14 & 0.13 & 0.06 & 0.15 & 0.08 & 0.29 & 0.17 & 0.21 & 0.14 \\
\hline $0.4-0.1$ & 0.54 & 1.21 & 0.20 & 0.13 & 0.22 & 0.11 & 0.15 & 0.10 & 0.14 & 0.08 & 0.55 & 1.14 & 0.39 & 0.90 \\
\hline $0.1-0.03$ & 0.40 & 0.49 & 0.24 & 0.08 & 0.28 & 0.14 & 0.22 & 0.08 & 0.23 & 0.05 & 0.39 & 0.47 & 0.33 & 0.37 \\
\hline $1.0-0.03$ & 1.15 & 1.79 & 0.64 & 0.32 & 0.76 & 0.33 & 0.51 & 0.19 & 0.53 & 0.18 & 1.19 & 1.70 & 0.90 & 1.35 \\
\hline \multicolumn{15}{|c|}{$\begin{array}{l}\bar{x} \quad \equiv \text { mean colloid concentration in } \mathrm{mg} \cdot \mathrm{L}^{-1} \\
\sigma \quad \equiv \text { standard deviation } \\
\mathrm{n} \equiv \text { number of samples } \\
\text { Peavine Canyon, Campground Spring, Whiterock Spring, and Topopah Spring are omitted due to missing } \\
\text { data. }\end{array}$} \\
\hline
\end{tabular}


Final

Figure 3-20. Schematic Representation of Hydrologic Flow [47]

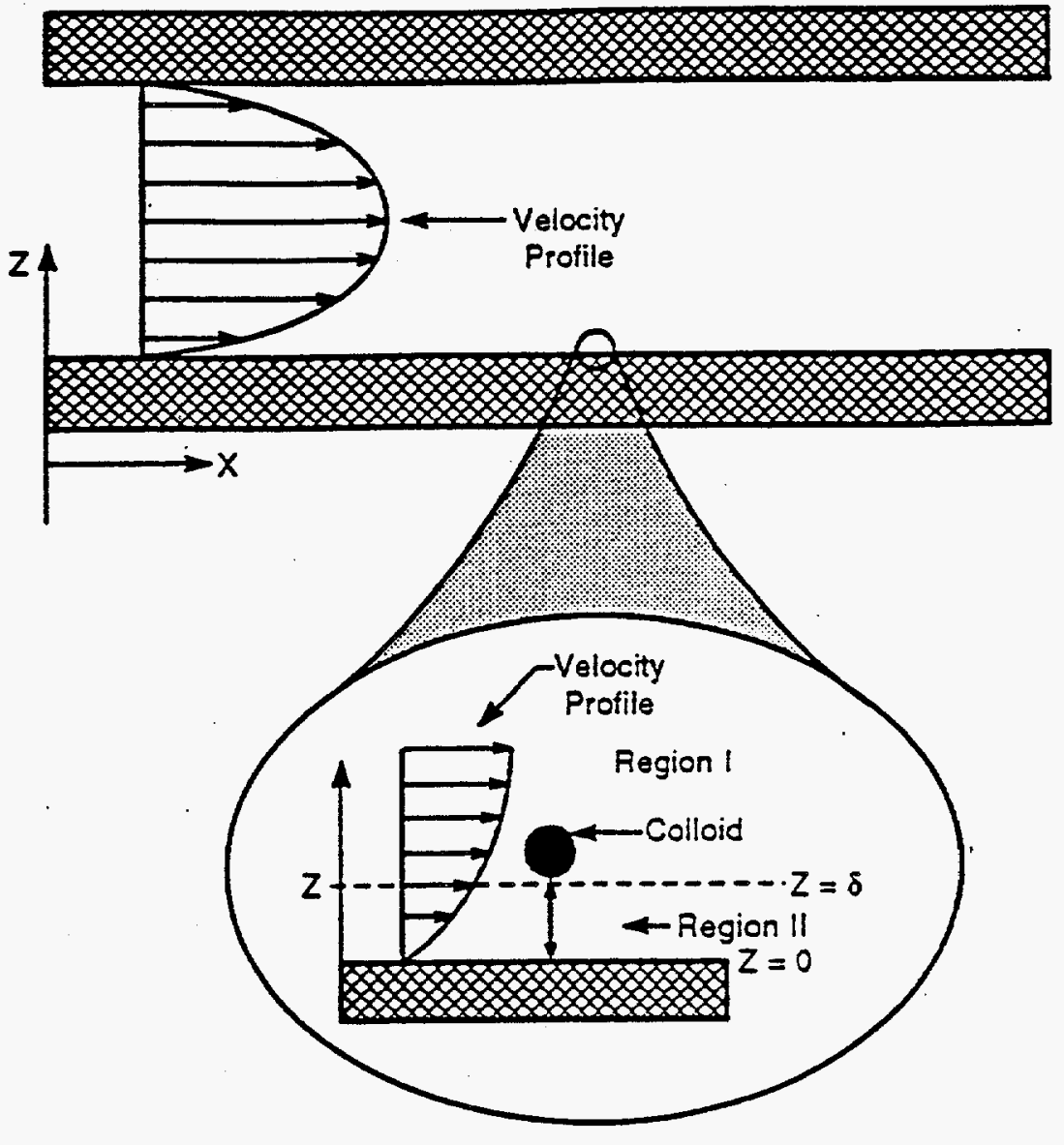


Figure 3-21. Drip Test Results of Simulated High-Level Waste Glass [48]

\begin{tabular}{||c|c|c|c|c||}
\hline \multirow{2}{*}{ Fraction } & \multicolumn{2}{|c|}{ Np } & \multicolumn{2}{c|}{ Pu + Am } \\
\cline { 2 - 5 } Initial & $\# 1$ & $\# 2$ & $\# 1$ & $\# 2$ \\
\hline \multirow{2yyyyy}{*}{ Delayed } & 17.4 & 6.0 & 108 & 1087 \\
\hline & 16.3 & - & 119 & - \\
\hline $1.0 \mu \mathrm{m}$ & 100 & 100 & 4 & 0.6 \\
\hline $0.40 \mu \mathrm{m}$ & 100 & 100 & 4 & 0.6 \\
\hline $0.10 \mu \mathrm{m}$ & 100 & 100 & 3 & 0.4 \\
\hline $0.05 \mu \mathrm{m}$ & 85 & 100 & 2 & 0.3 \\
\hline $0.015 \mu \mathrm{m}$ & 85 & 72 & 2 & 0.3 \\
\hline $0.003 \mu \mathrm{m}$ & 70 & 70 & 1 & 0.01 \\
\hline $0.001 \mu \mathrm{m}$ & 70 & 65 & 0.05 & 0.00 \\
\hline
\end{tabular}


Figure 22. Conceptual Engineered Barrier Options

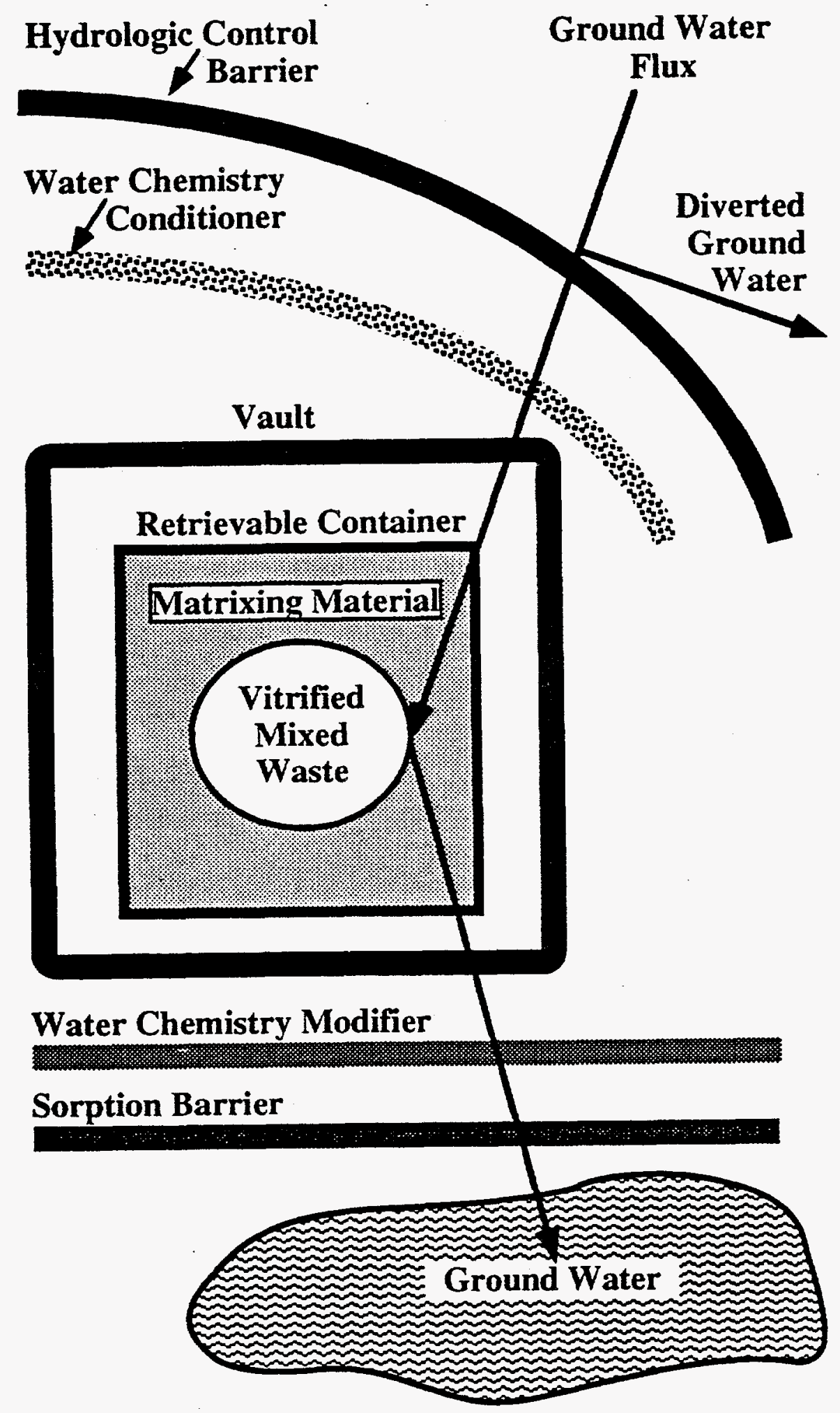




\section{REFERENCES}

10 CFR 60.102. Subpart E - Technical Criteria, Nuclear Regulatory Commission, Washington D. C.

Bates, J. K., J. P. Bradley, A. Teetsov, C. R. Bradley and M. B. Brink. 1992. Colloid Formation During Waste Form Reaction: Implications for Nuclear Waste Disposal. Science. 256:649-651.

Bock, W. D., H. Bruhl, C. Trapp and A. Winkler. 1989. Sorption Properties of Natural Sulfides With Respect to Technetium. in: W. Lutze and R. C. Ewing, eds. Scientific Basis for Nuclear Waste Management XII. Materials Research Society. Pittsburgh, Pennsylvania: $973-$ 977.

Boldt, A. L. 1994. Letter form Boldt to R. A. Karnesky entitled LLW Disposal Source Term. Westinghouse Hanford, Richland WA, January 13, 1994

Bourcier, W. L. 1991. Overview of Chemical Modeling of Nuclear Waste Glass Dissolution. Scientific Basis for Nuclear Waste Management XIV. T. Abrajano and L. H. Johnson, ed. ISBN 1-55899-104-2. Pittsburgh, Pennsylvania: Materials Research Society: 212:19-30.

Bourcier, W. L., S. A. Carroll, and B. L. Phillips. 1994. Constraints on the Affinity Term for Modeling Long-Term Glass Dissolution Rates. Mat. Res. Soc. Symp. Proc. Materials Research Society. Pittsburgh, Pennsylvania. 333:507-512.

Buddemeier, R.W. 1988. Transport of Colloidal Contaminants in Groundwater: Radionuclide Migration at the Nevada Test Site. Applied Geochemistry. 3:535-548

Choppin, G. R. and J. N. Mathur. 1991. Hydrolysis of Actinyl(VI) Cations. Radiochimica Acta 52/53:25-28.

Coles, D. G., and L. D. Ramspott. 1982. Migration of Ruthenium-106 in a Nevada Test Site Aquifer. Discrepancy Between Field and Laboratory Results. Science. 215:1235-1237.

Ebert, W. L., J. K. Bates, E. C. Buck and C. R. Bradley. 1993. Accelerated Glass Reaction Under PCT Conditions. Mat. Res. Soc. Symp. Proc. Materials Research Society. Pittsburgh, Pennsylvania. 294:569-577.

Feng, X., J. K. Bates, E. C. Buck, C. R. Bradley and M. Gong. 1993. Long-Term Comparison of Dissolution Behavior Between Fully Radioactive and Simulated Nuclear Waste Glasses. Nuclear Technology. 104(11):193-206.

Feng. X. and I. L. Pegg. (to be published). A Glass Dissolution Model for the Effects of S/V on Leachate $\mathrm{pH}$. Submitted to: J. Non-Crystalline Solids. Obtained through personal communication with the principle author.

Freeze, R. A. and Cherry, J. A. 1979. Groundwater and the Hydrologic Cycle. Chapter 6 in Groundwater; ISBN: 0-13-365312-9. Prentice-Hall, Inc. 
Freeze, R. A. and J. A. Cherry. 1979. Groundwater. Prentice-Hall, Inc. ISBN 0-13365312-9.

Glendon Glee, Personal Communications, Pacific Northwest Laboratories, Richland WA, August 1994

Hench, L. L., D. E. Clark, and A. B. Harker. 1986. Review: Nuclear Waste Solids. Journal of Materials Science 21:1457-1478.

Huang, C. P. and W. Stumm. 1972. The Specific Surface Area of $\gamma-\mathrm{Al}_{2} \mathrm{O}_{3}$. Surface Science. 32:287-296.

Jantzen, C. M. and M. J. Plodinec. 1984. Thermodynamic Model of Natural, Medieval and Nuclear Waste Glass. J. Non-Crystalline Solids 67:207-223.

Karnesky, Richard A. Personal Communications, Performance Assessment ' Team, Westinghouse Hanford Company, Richland WA, July 1994

Kent, D. B., V. S. Tripathi, N. B. Ball, J. O. Leckie, and M. D. Siegel. 1988. SurfaceComplexation Modeling of Radionuclide Adsorption in Subsurface Environments. Sandia National Laboratories, NURED/CR-4807, SAND86-7175. Washington D. C.

Kim, J. 1. 1993. The Chemical Behavior of Transuranic Elements and Barrier Functions in Natural Aquifer Systems. Materials Research Society Symposium. C. G. Interrante and R. T. Pabalan, eds. Boston, Ma: Materials Research Society: 294:3-21.

Kim, J. I. 1991. Actinide Colloid Generation in Groundwater. Radiochimica Acta. 52/53 $1: 71-81$

Kincaid, C. T., J. A. Voogd, J. W. Shade, J. H. Westsik, Jr, G. A. Whyatt, M. D. Freshley, M. G. Piepho, K. A. Blanchard, K. Rhoadsk and B. G. Lauzon. 1993. Performance Assessment of Grouted Double Shell Tank Waste Disposal at Hanford WHC-SD-WM-EE-004, REV. O. Westinghouse Hanford Company. Richland, Washington.

Kingston, W. L. and M. Whitbeck. 1991. Characterization of Colloids Found in Various Groundwater Environments in Central and Southern Nevada. DOE/NV/10384-36. Washington, DC: U.S. Department of Energy.

Knauss, K. G., W. L. Bourcier, K. D. McKeegan, C. L. Merzbacher, S. N. Nguyne, F. J. Ryerson, D. K. Smith, H. C. Weed, and L. Newton. 1990. Dissolution Kinetics of a Simple Analogue Nuclear Waste Glass as a Function of $\mathrm{pH}$, Time and Temperature. Scientific Basis for Nuclear Waste Management XIII. V. M. Oversby and P. W. Brown, ed. Materials Research Society. Pittsburgh, Pennsylvania.

Landes, K. K., 1981. Traps: Salt-Cored. Chapter 12 in Petroleum Geology. ISBN 0-88275226-X. John Wiley \& Sons, Inc. New York.

Lieser, K. H. and C. Bausher. 1988. Technetium in the Hydrosphere and in the Geosphere II. Influence of $\mathrm{pH}$, of Complexing Agents and of Some Minerals on the Sorption of Technetium. Radiochim. Acta. 44/45: 125-128. 
Maiti, T. C., M. R. Smith and J. C. Laul. 1989. Colloid Formation Study of U, Th, Ra, Pb, $\mathrm{Po}, \mathrm{Sr}, \mathrm{Rb}$, and $\mathrm{Cs}$ in Briny (high ionic strength) groundwaters: Analog Study for Waste Disposal. Nuclear Technology 84:82-87.

Malthotra, V.M., 1975. Development of Sulfur-Infiltrated High-Strength Concrete. ACl Journal. Title No. 72-32. 9:466-473.

Manaktala, H. K. 1992. An Assessment of Borosilicate Glass As A High-Level Waste Form. CNWRA 92-017. San Antonio, Texas: Center for Nuclear Waste Regulatory Analysis.

Manaktala, H., D. Turner, T. Ahn, V. Colten-Bradley, and E. Bonano. (to be issues). Potential Implications of Colloids on the Long-Term Performance of a High-Level Radioactive Waste Repository. San Antonio, Texas: Center for Nuclear Waste Regulatory Analysis.

Mann, Fredrick M. Personal Communications, Performance Assessment Team, Westinghouse Hanford Company, Richland WA, August 1994

Marshall, T. J. and J. W. Holmes. 1988. Soil Physics. Cambridge University Press. ISBN $0-521-35270-3$.

Marshall, T. J., and Hlomes, J. W., 1988. Interactions of Soil and Water. Chapter 2 in Soil Physics: Second Edition. ISBN: 0-521-35270-3, Cambridge University Press.

Mattus, C. H. and A. J. Mattus. 1994. Evaluation of Sulfur Polymer Cement as a Waste Form for the Immobilization of Low-Level Radioactive of Mixed Waste. Martin Marietta Energy System, Inc, Report ORNL/TM-12657. Oak Ridge, Tennessee.

Mayberry, J. L., L. M. DeWitt, R. Darnell, R. VanKonynenburg, W. Greenhalgh, D. Singh, R. Schumacher, P. Erickson, J. Davis, and R. Nakaoka. 1993. Technical Area Status Report for Low-Level Mixed Waste Final Waste Forms. U.S. DOE Report DOE MWIP-3. Science Application International Corporation, Idaho Falls, Idaho.

McBee, W. C., T. A. Sullivan, and B. W. Jong, 1983. Corrosion-Resistant Sulfur Concretes, Report of Investigations/United States Department of the Interior, Bureau of Mines: 8758 . U.S. Department of Interior, Washington, D.C.

McCarthy, J. F. and J. M. Zachara. 1989. Subsurface Transport of Contaminants. Environmental Science and Technology 23:496-502.

McElroy, J. L. and M. S. Hanson. 1986. High-Level Radioactive Waste. Chapter 17 in Radioactive Waste Technology. New York: The America Society of Mechanical Engineers: 649-705.

McVay. G. L. and C. Q. Buckwalter. 1981. Effect of iron on waste-glass leaching. Journal of the American Ceramic Society 66(3):170-174.

Mendel, J.E., ed. 1984. Defense High-Level Waste Leaching Mechanisms Program--Final Report. PNL-5157. Richland, Washington: Battelle Pacific Northwest Laboratories. 
Olofsson, U., B. Allard, B. Torstenfelt and K. Anderson. 1982. Properties and Mobilities of Actinide Colloids in Geologic Systems. Materials Research Society Symposium Proceedings, Scientific Basis for Radioactive Waste Management.-V. W. Lutze, ed. Pittsburgh, Pennsylvania: Materials Research Society: 11:755-764.

Olofsson, U., B. Allard, K. Anderson and B. Torstenfelt. 1982a. Formation and Properties of Americium Colloids in Aqueous Systems. Materials Research Society Symposium Proceedings, Scientific Basis for Nuclear Waste Management-IV. S. V. Topp, ed. Pittsburgh Pennsylvania: Materials Research Society: 6:191-198.

Penrose, W. R., W. L. Polzer, E. H. Essington, D. M: Nelson, and K. A. Orlandini, 1990. Mobility of Plutonium and Americium Through a Shallow Aquifer in a Semiarid Region. Enciron. Sci. Technol. 24:228-234.

Peterson, L. R., C. Q. Buckwalter, G. L. McVay, and B. L. Riddle. 1983. Glass Surface Area to Solution Volume Ratio and its Implications to Accelerated Leach Testing. Scientific Basis for Nuclear Waste Management VI. D. G. Brookins, ed. Amsterdam: North-Holland: 15:4754.

Serne, R. J., R. C. Arthur, and K. M. Krupka. 1990. Review of Geochemical Processes and Codes for Assessment of Radionuclide Migration Potential at Commercial LLW Sites. PNL, PNL-7285. Richland, Washington.

Siegel, M. D., J. O. Leckie, S. W. Park, S. L. Phillips, and T. Sewards. 1990. Studies of Radionuclides Sorption by Clays in the Culebra Dolomite at the Waste /solation Pilot Plant Site, Southeastern New Mexico, Sandia National Laboratories for United States Department of Energy, SAN89-2387, UC-721. Albuquerque, New Mexico.

Thurman, E. M. 1985. Organic Geochemistry of Natural Waters. Doedrecht, The Netherlands: Martinus Nijhoff/Dr. W. Junk Publishers.

Toste, A. P., L. J. Kirby, W. H. Rickard, and D. W. Robertson, 1984. Radionuclide Characterization, Migration, and Monitoring at a Commercial Low-Level Waste Disposal Site, Radioactive Waste Management, 5:213-226.

Turner, D. R. 1991. Sorption Modeling for Lign-Level Waste Performance Assessment: A Literature Review. CNWRA 91-011. San Antonio, Texas: Center for Nuclear Waste Regulatory Analysis.

Turner, D. R. 1991a. Mechanistic Approaches to Radionuclide Sorption Modeling. CNWRA 91-011. San Antonio, Texas: Center for Nuclear Waste Regulatory Analysis.

U.S. DOE. 1981. A State-of-the-Art Review of Materials Properties of Nuclear Waste Forms. PNL-3802. Richland, Washington: Battelle Pacific Northwest Laboratory.

U.S. DOE. 1988. Radioactive Waste Management. Chapter 3. DOE Order 5820.2A. U.S. Department of Energy. Washington D.C.

U.S. DOE. 1993. Technical Area Status Report for Low-Level Mixed Waste Final Waste Forms. DOE MWIP-3. Idaho Falls, Idaho: Science Applications International Corporation 
U.S. DOE Richland. 1993. Radioactive Waste Management. Chapter 3. RLID 5820.2A. U.S. DOE-RL, Richland, Washington.

U.S. Environmental Protection Agency. 1992. Code of Federal Regulations. Title 40. Office of the Federal Register National Archives and Records Administration. U.S. Government Printing Office. Washington D.C.

U.S. Nuclear Regulatory Commission. 1992. Code of Federal Regulations. Part 10. Office of the Federal Register National Archives and Records Administration. U.S. Government Printing Office. Washington D.C.

van der Lee, J., G. de Marsily and E. Ledoux. 1993. Are Colloids Important for Transport Rate Assessment of Radionuclides? A Microscopic Modeling Approach. Proceedings of the Fourth International High-Level Radioactive Waste Management Conference. La Grange Park, Illinois: American Nuclear Society: 1:646-652.

Washington State Department of Ecology. 1990. Washington State Administrative Code. WAC. Olympia, Washington.

Washington State Department of Ecology, United States Environmental Protection Agency, United States Department of Energy. 1994. Hanford Federal Facility Agreement and Consent Order, Fourth Amendment. January 1994. Available from any of the parties.

Weast, R. C. 1974. Half-lives of the Radioactive Isotopes. CRC Handbook of Chemistry and Physics. ISBN 087819-454-1. CRC Press; Cleveland, Ohio: B248

Windholz, M. S., Budavari, L. Y. Stroumtsos, and M. N. Fertig, 1976. Sulfur. The Merck Index. ISBN 911910-26-3. Merck \& Co., Inc.; Rahway, New Jersey. 


\subsection{TRANSPORTATION}

\subsection{INTRODUCTION}

Transportation of the vitrified LLW is discussed in this section. Transportation of the vitrified LLW waste includes movement from the LLW immobilization facility to the LLW disposal site, lag storage at the immobilization facility and the disposal site, and handling within the disposal site.

\subsection{REQUIREMENTS}

The requirements for the transportation system include the regulatory requirements of transportation and of interim storage, Hanford site requirements, and performance requirements.

\subsubsection{Regulatory Requirements}

4.2.1.1 10 CFR 71 - Transportation and Packaging of Radioactive Material. To meet the regulatory requirements for transportation in the public domain (off-site), the transportation package must be a NRC/DOE licensed package meeting the requirements of 10 CFR 71 .

4.2.1.2 49 CFR 173 - Shippers-General Requirements for Shipments and Packaging. Transportation and packaging made under the direction of the DOE may be evaluated, approved, and certified by the DOE against packaging standards equivalent to those specified in 10 CFR 71 (ref. 49 CFR 173.7(d)). Thus, if transportation will occur in a DOE controlled area (on-site), the package and transportation system is required to provide an "equivalent safety" to that of a licensed package by meeting the intent of 10 CFR 71.

4.2.1.3 49 CFR 174 - Carriage by Rail. Options that include transportation by rail shall meet the requirements of 49 CFR 174, as applicable to off-site or on-site shipments.

4.2.1.4 49 CFR 177 - Carriage by Public Highway. Options that include transportation over public roads shall meet the requirements of 49 CFR 177, as applicable to off-site or on-site shipments.

4.2.1.5 40 CFR 264 - Standards for Owners and Operators of Hazardous Waste Treatment, Storage, and Disposal Facilities and 40 CFR 265 - Interim Status Standards for Owners and Operators of Hazardous Waste Treatment, Storage, and Disposal Facilities. Interim/lag storage of containers shall meet the requirements of 40 CFR $264 \& 265$, Subpart I - Use and Management of Containers. Options that include pumping/piping of the vitrified waste from the vitrification facility to the disposal site shall meet the requirements of 40 CFR $264 \& 265$, Subpart J - Tank Systems. 


\subsubsection{Hanford Site Requirements}

4.2.2.1 DOE-RL-92-36 - Hanford Site Hoisting and Rigging Manual. Lifting operations shall be conducted in accordance with DOE-RL-92-36.

4.2.2.2 WHC-CM-2-14 - Hazardous Material Packages and Shipping Manual. All hazardous material shipments made under the direction of WHC shall be performed in accordance with WHC-CM-2-14.

\subsubsection{System-Wide Requirements}

For purposes of this study, the transportation system, operating 24 hours per day (if necessaryl, will be capable of accommodating a continuous throughput of 100 tonnes of vitrified LLW per day with a peak throughput of 200 tonnes of vitrified LLW per day. The distance from the LLW immobilization facility to the LLW disposal site is assumed to be one mile.

\subsection{OPTIONS}

\subsubsection{Transportation}

Three options for the transportation from the immobilization facility's staging area to the disposal site's staging area are to be considered: via a NRC/DOE licensed packaging; via a packaging/transportation system designed to provide an "equivalent safety" to that of a NRC/DOE licensed packaging; and via a pipeline.

4.3.1.1 NRC/DOE Licensed Package - This option includes, but does not specifically address, the following methods for shipment: shipment by truck, and shipment by rail.

Per 10 CFR 71, there are two types of licensed packages depending on the contents, Type $A$ and Type $B$, with Type $B$ having the more stringent performance standards. Given the volume of glass to be produced $\left(210,000 \mathrm{~m}^{3}\right.$ ), and the radionuclide content of the glass (Boldt 1994), a Type B packaging will be required (10 CFR 71 and 49 CFR 173). Strontium is the main contributor to this designation. Strontium provides for approximately $70 \mathrm{~A}_{2}$ (normal form) quantities and $2.85 \mathrm{~A}_{1}$ (special form) quantities in $1 \mathrm{~m}^{3}$ of waste. Strontium represents $88 \%$ for $A_{2}$ and $95 \%$ for $A_{1}$ of the total $A$ values in the waste. Type $B$ packaging is required when the $A$ value exceeds unity.

In order for a package to be licensed by the NRC/DOE, the package must be demonstrated to provide sufficient structural, containment, and shielding capabilities for the performance standards set forth in $10 \mathrm{CFR} 71$. The performance standards consist of a prescribed set of structural and thermal tests that the package must survive without loss of containment or shielding in excess of the limits specified by 10 CFR 71. Successfully demonstrating acceptance by these performance standards provides the necessary assurance that the package will perform safely when offered for public transportation. The NRC/DOE licensed package system inherently puts all the safety into the packaging. 
4.3.1.2 Equivalent Safety Transportation System - This option includes, but does not specifically address the following methods for on-site shipment: shipment by truck on a public access road; shipment by truck on a dedicated road; shipment by rail on a rail spur; and shipment by rail on a dedicated rail spur. These methods need to be considered along with various administrative controls including: limitations on public access; limitations on vehicle speed; limitations on package lift height; shipments contingent on weather conditions; and use of personnel trained specifically for completing these shipments.

In contrast to the NRC/DOE licensed package approach, the equivalent safety transportation system puts the safety in the entire transportation system, thereby meeting the intent of 10 CFR 71 by providing a degree of safety equivalent to a NRC/DOE licensed package. The equivalent safety transportation system includes the packaging, the carrier vehicle, and administrative controls. The equivalent safety approach is applicable to on-site shipments only, and is based on a risk and consequence analytical approach, employing statistical analyses.

As opposed to a NRC/DOE package being offered for public transport, an equivalent safety package is transported on-site where all aspects of the shipment, and thus the risk and/or consequence can be controlled to an acceptable level by the use of administrative controls. The following are examples of such administrative controls: use of personnel trained specifically for the shipment; limiting the lift height of the package; limiting the speed of the carrier vehicle; limiting the route of the carrier vehicle; limiting access to the transportation route; limiting the amount of fuel in the carrier vehicle to preclude a sustained, substantial fire in the event of an accident; and limiting shipments to days on which the weather is favorable. The use of administrative controls can appreciably affect the risk and/or consequence of the various accident scenarios.

4.3.1.3 Pumping/Piping. Per 40 CFR parts 264 and 265, a pipeline is required to provide double containment with a leak detection system. Also, a shielded pipeline will be required to meet radiation protection limits. The transportation of cullet through a pipeline may result in the production of fines that may adversely affect the performance assessment. Also, erosion of the pipeline due to the abrasiveness of the glass must be considered.

If cullet in a hot-pour matrix is to be transported through the pipeline, the pipeline must be heated. Parameters that must be considered include the following: the variation in temperature that can be tolerated by the hot-pour matrix; the recovery scenario for a plugged or partially plugged line; containment of off-gases and fines; the recovery scenario for a pumping station failure; adequate level of redundancy; and the level of control required for discharging into the disposal vault.

\subsubsection{Lag Storage}

Temporary storage of the waste at the vitrification facility and at the disposal site will be required to facilitate transportation and handling operations.

4.3.2.1 Lag Storage at Vitrification Plant - The requirements for interim storage at the immobilization facility will depend on the form of the vitrified LLW. 
Containerized Monoliths (including cullet in hot-pour matrix): Monoliths will require a staging area where they will be allowed to sufficiently cool (by controlled or natural means) prior to decontamination inspections and preparation for shipping. Also, an area is required for the accumulation of the containers waiting in queue to be transported.

Containerized Non-Monoliths (i.e., cullet, sheet): Non-monolithic waste forms will be cool prior to containerization, and therefore, a staging area for cooling will not be required. An area is required for accumulation of the containers waiting in a queue to be transported.

Bulk (with or without matrix): Hoppers or other storage bins (heated if necessary) will be required while waiting to be loaded-out to a transportation package or pumped/piped out directly to the disposal site. The bins may be required to provide containment of off-gases and fines.

4.3.2.2 Lag Storage at Disposal Site - The requirements for interim storage at the disposal site will depend on the form of the vitrified LLW.

Containerized: An area is required for accumulation of the containers after unloading from transport and waiting in a queue to be placed in the disposal site.

Bulk (with or without matrix): If a controlled discharge is required (i.e., laying and compacting as is done for asphaltic pavement), hoppers or other storage bins (heated if necessary) may be required to accumulate the waste. Containment of off-gases and fines must be considered.

\subsubsection{Handling}

Transportation/handling within the disposal site depends on the final form of the waste.

Containerized: The distribution and placement of the waste containers could be achieved by several means, depending on such factors as: size and configuration of container; size and configuration of disposal site, levels of radiation from the container; and levels of radiation in the disposal site.

Bulk (with or without matrix): The distribution and placement of the bulk waste depends on several factors including: final waste form; requirements for temperature control during set-up of the hot-pour matrix, requirements for limiting temperature gradients and heat buildup; and radiation levels.

\subsection{SELECTION METHODOLOGY}

The preferred option for transportation, lag storage, and handling are determined by rating each option's performance to the weighted evaluation criteria. The options are given a rating of 1 to 3 for each of the evaluation criterion, with a rating of 3 indicating the most desirable performance. The evaluation criteria are assigned a weight factor from 1 to 3 , with a factor of 3 indicating the highest priority. 


\subsubsection{Evaluation Criteria}

Each of the transportation, lag storage, and handling options are evaluated according to the general criteria. In addition, the options are evaluated to the applicable specific criteria for transportation, lag storage, and handling.

4.4.1.1 General Criteria - Each of the options are evaluated based on the following considerations: affect on performance assessment; ALARA, cost effectiveness; safety and environmental concerns; maintainability; and ability to meet the performance goals.

Effect on Performance Assessment: Any adverse affect on the performance assessment due to the method of transportation is evaluated.

ALARA: Worker's radiological and hazardous exposures are to be maintained as low as reasonably achievable. Each option is evaluated for its ability to meet the ALARA goal during operation and normal maintenance.

Cost Effectiveness: The costs for engineering, licensing and permitting, procurement, fabrication/construction, installation, operation and maintenance are evaluated for each option.

Safety and Environmental Concerns: Options are evaluated for the level of risk to personnel safety and the consequences to public health and the environment as a result of probable failures and accidents.

Performance Goals: Each system is evaluated for its ability to provide a peak throughput capacity of 200 tonnes per day with a continuous throughput of 100 tonnes per day based on a transportation distance of one mile from the vitrification facility to the disposal site.

4.4.1.2 Transportation Specific Criteria - In addition to the general criteria, the transportation options will be evaluated for adherence to regulatory requirements and reliability.

Regulatory Requirements: All viable options must satisfy the applicable regulatory requirements. Therefore, this criterion is only used to eliminate non-viable options.

Reliability: The reliability of each option is evaluated. Reliability includes frequency of replacement, system redundancy, and recovery after a failure.

4.4.1.3 Lag Storage Specific Criteria - In addition to the general criteria, the options for lag/interim storage are evaluated for adherence to the regulatory requirements and ability to be monitored.

Regulatory Requirements: All viable options must satisfy the applicable regulatory requirements. Therefore, this criterion is only used to eliminate non-viable options.

Monitoring: The lag/interim storage options are evaluated for their ability to provide an accessible means for containment and temperature monitoring of the vitrified waste. 
4.4.1.4 Handling Specific Criteria - In addition to the general criteria, the options for handling the waste within the disposal site are evaluated for the reliability of the handling system.

Reliability: The reliability of each option is evaluated. Reliability includes frequency of replacement, system redundancy, and recovery after a failure.

\subsubsection{Weight Factors}

Weight factors are assigned to the evaluation criteria to account for the priority and relative importance of each evaluation criterion. The basis for selection of the weight factor is presented in the following paragraphs.

4.4.2.1 Effect on Performance Assessment - Obtaining a disposal system that attains a good performance assessment is the paramount objective, and therefore, a weight factor of 3 is assigned to performance assessment.

4.4.2.2 ALARA - Minimizing personnel exposure to radiological and chemical hazards is an important concern in all operations and is assigned a weight factor of 2.

4.4.2.3 Cost Effectiveness - Minimization of costs needs to be considered for all options, but not to the exclusion of other design considerations. Therefore, cost effectiveness is assigned a weight factor of 2 .

4.4.2.4 Safety and Environmental Concerns - Public health and safety and environmental protection is a primary concern and is assigned a weight factor of 3 .

4.4.2.5 Performance Goals - The ability of the disposal system to meet the performance goals is important in meeting schedular constraints. However, other design considerations such as safety and ALARA need to take precedence. Therefore, meeting performance goals is assigned a weight factor of 1 .

4.4.2.6 Reliability - The reliability of the transportation and handling systems is very important in supporting continuous operation of the vitrification facility, maintaining cost effectiveness, meeting ALARA goals, and addressing safety \& environmental concerns. Therefore, reliability is assigned a weight factor of 3 .

4.4.2.7 Monitoring - The ability of the vitrified waste to be monitored during lag storage at the vitrification and disposal facilities is a valid consideration, but is not a driving factor. Therefore, monitoring is assigned a weight factor of 1 .

4.4.2.8 Regulatory Requirements - All options for transportation and handling must fully satisfy the applicable regulatory requirements. This criterion is only used for eliminating unsuitable options. Therefore, the regulatory requirements criterion is not used in ranking the options and is not assigned a weight factor. 


\subsection{OPTION EVALUATIONS}

Evaluation of the options and subsequent rating of the option's performance to each of the evaluation criterion is somewhat subjective. A discussion of how the rating of each evaluation criterion was determined is provided in the following subsections.

\subsubsection{Transportation}

A summary of the transportation option evaluation is presented in Table 4-1. The option with the highest score, the equivalent safety transportation option, is the preferred option. A detailed discussion of the option ratings is provided in the following paragraphs.

4.5.1.1 Effect on Performance Assessment - Either of the two transportation methods using packaging will have no detrimental affect on the condition of the glass form and thus the performance assessment. Therefore, packaging is rated 3 for effect on performance assessment. Pumping/piping the cullet form of glass is expected to result in the production of fines due to degradation of the cullet as it travels through the pipeline. Therefore, pumping/piping is rated 2 for effect on performance.

4.5.1.2 ALARA - Personnel exposure during operation, maintenance, and decommissioning are considered in the overall rating for ALARA.

Operation - Personnel exposure during the operation of a pipeline should be minimal except for discharge into a container at the disposal site or discharge directly into the disposal site. Therefore this option is rated 2 for ALARA during operation. Either of the packaging methods present a potential for personnel exposure, especially during loading and unloading. However, additional precautions can be taken to limit the possibility of exposure, and therefore, packaging methods are rated 2 for ALARA during operation.

Maintenance - Any required maintenance on the packaging can be performed when the packaging is empty and decontaminated. Therefore, packaging methods are rated for ALARA during maintenance. Maintenance on the pumps and pipelines may need to be performed during operation of the system or at least on an empty but not decontaminated pipeline. Therefore, the pumping/piping option is rated 2 for ALARA during maintenance.

Decommissioning - Exposure during decommissioning of the packaging systems will be minimal because the systems will be empty and decontaminated, and thus these options are rated 1 for decommissioning. Decommissioning of the piping system presents a much larger potential for personnel exposure. The pipelines may be empty but not contaminated; or may contain radioactive waste due to a blocked or partially blocked line. Therefore the pumping/piping option is rated 3 for ALARA during decommissioning.

4.5.1.3 Cost Effectiveness - The overall rating for cost effectiveness is determined by evaluating the costs associated with engineering, licensing/permitting, fabrication/construction, operation, maintenance, and decommissioning. 
Engineering - The engineering costs for a packaging system that provides an equivalent safety to that of a NRC/DOE licensed package are expected to be relatively high because in addition to the package performance evaluations, risk assessments and dose/consequence evaluations must be performed. Therefore, the equivalent safety packaging system option is rated 1 for engineering costs. The engineering costs for a NRC/DOE licensed packaging system can be expected to be significant, but not as costly as for an equivalent safety packaging system, and therefore, the licensed packaging system is rated 2 for engineering costs. The engineering costs for a pumping/piping system are also expected to be significant because of double containment, monitoring, and seismic concerns. Also, if a hot pour matrix is used, the complexity of the pipeline increases due to concerns of thermal expansion and maintaining proper temperature for the hot pour matrix. Therefore, the pumping/piping option is rated 2 for engineering costs.

Licensing/Permitting - The packaging system meeting the requirements of 10 CFR 71 is required to be licensed by the NRC or DOE licensing agency, and the application for license must demonstrate compliance with the regulatory requirements to the satisfaction of the licensing board. The licensing process generally involves a significant commitment of time and money, and therefore, the cost for licensing/permitting a NRC/DOE licensed package is rated 1. The pumping/piping system will require permitting to place a pipeline transmitting hazardous waste, and therefore, this option is rated 2 . The equivalent safety packaging system does not require licensing, but, as with the other options, will require documentation to demonstrate compliance to the appropriate regulations. Therefore, the equivalent safety packaging option is rated 3 for licensing/permitting costs.

Fabrication/Construction - Assuming a dedicated road or rail is required for the equivalent safety approach, the fabrication/construction costs for the three options are approximated to be roughly equivalent. Therefore, each option is rated 2 for the costs of fabrication/construction.

Operation - Operation of either of the packaging options will require the dedicated involvement of several personnel. The simpler operation of an equivalent safety packaging system versus a NRC/DOE licensed packaging may be offset by the additional personnel required to implement the administrative controls associated with the equivalent safety packaging system option. Therefore, the operation costs for either of the packaging options is assumed to be equivalent, and the operation cost is rated 2 for both of the packaging options. Most of the personnel operation costs for the pumping/piping option would be due to the operations required at the pipeline discharge at the disposal site. The discharge operations would include containment, monitoring, containerization (if required), and final placement in the disposal site. The operation costs for pumping/piping is rated 2 .

Maintenance - The cost of maintenance on the two packaging options can be expected to be minimal because maintenance can be performed on empty packages in a noncontaminated environment. Therefore, both of the packaging options are rated 3 for maintenance costs. Maintenance on the pumping/piping system may need to be performed in a radiation environment or after relatively complex decontamination operations and may require that connections be broken to perform maintenance. Therefore, the pumping/piping system is rated 2 for maintenance costs. 
Decommissioning - The cost of decommissioning either of the packaging system options will be minor, because the packaging systems will have little or no contamination, and components of the packaging system can be possibly used for other tasks. Therefore, both of the packaging options are rated 3 for decommissioning costs. Decommissioning of a pumping/piping system will be comparatively complex and costly due the probable levels of contamination, the possibility of blocked or partially blocked pipe, and the probability that the components of the pumping/piping system will not be useable in other tasks. Therefore, the pumping/piping system is rated 1 for the costs of decommissioning.

4.5.1.4 Safety and Environmental Concerns - The overall rating for safety and environmental concerns considers the level of personnel safety associated with operations and the level of safety and potential harm to the environment due to a failure in the transportation system.

Operation - A pipeline should require little or no day to day contact to provide continuous operation, and therefore the pumping/piping option is rated 3 for operation. Operation of either of the packaging options will involve several handling operations that may involve heavy lifting equipment and contact with the shielded container which presents the possibility of handling mishaps that could result in personnel injury. Therefore, both packaging options are rated 1 in operation.

Failures - Failure for either of the packaging options is defined to be a breach of containment. If the packaging was to lose containment, it is unlikely that the packaging would break wide open and disperse all of its contents, it is more likely that a small amount of contents would be dispersed. Furthermore, a monolithic glass waste form and a cullet waste form in a binding matrix are indispersible and a cullet glass waste form without a binding matrix would be dispersed onto the ground, but would not be absorbed into the ground or dispersed to the air. Therefore, both packaging options are rated 3 for possible safety and environmental concerns due to failure. Failure of a pipeline carrying a cullet glass waste form with a matrix could result in the cullet and matrix being dispersed over the ground, and depending on the matrix material, the matrix material could be dispersed to the air and absorbed into the ground. Therefore, the pumping/pipeline option is rated 1 for possible safety and environmental concerns due to failure of the pipeline.

4.5.1.5 Performance Goals - Each of the options are capable of supporting a throughput of 100 tonnes per day, so the rating will be based on the capability to support a peak throughput of 200 tonnes per day. Either of the packaging options could support the peak throughput by either increasing the number of shipments per transportation vehicle, or by using a spare vehicle and package during peak throughput operation. Therefore, the packaging options are rated 3 for performance goals. In order for the pipeline to accommodate the peak throughput, either a redundant system would be required or a single over-sized system with over-sized heating capacity (as applicable) would be required, and therefore, the pipeline option is rated 2 for meeting the performance goals.

4.5.1.6 Reliability - The overall rating for the reliability of the transportation options is based on the frequency of repair, the level of system redundancy, and the capability to recover and continue to support operations following a failure. 
Frequency of Repair - The packaging options should require minor repairs due to normal wear during usage over their intended lifetime, and therefore, both packaging options are rated 3 for frequency of repairs. The pumps for the pumping/piping option will likely require replacement or repair within the intended lifetime of the pipeline, and therefore the pipeline option is rated 2 for frequency of repair.

System Redundancy - For the packaging options, redundancy can be achieved by maintaining a spare packaging and/or transportation vehicle which can also be used to support peak throughput. Therefore the packaging options are rated 3 for system redundancy. Should the pipeline become plugged, or a pump fail, or the heating system (if applicable) fail, the only method to assure redundancy is to provide a complete secondary pumping/piping system. Therefore, the pumping/piping option is rated 1 for system redundancy.

Recovery after Failure - If a packaging system were to fail, throughput can be maintained by employing a spare system, and clean-up of any spilled material would be réadily achieved because the vitrified waste is a non-dispersible form. Therefore, packaging options are rated 3 for recovery after failure. Maintaining throughput after a piping system failure can only be accomplished via a redundant pipeline. Clean-up of the cullet and matrix after a pipeline failure will be relatively complex due to hazardous properties of the matrix and the possibility of fines created from the degradation of the glass during pumping/piping. Therefore, the pumping/piping option is rated 1 for recovery after failure.

\subsubsection{Lag Storage}

Based on the results of the transportation evaluation, a containerized waste form is assumed for the evaluation of lag storage options. Containerized monoliths and containerized non-monoliths are considered, and considerations for individually shielded versus non-shielded containers are evaluated. Handling of the containers within the lag storage area is a separate consideration not evaluated.

A summary of the lag storage option evaluation is presented in Table 4-2. The option with the highest score, non-monolithic waste form in non-shielded containers, is the preferred options. A detailed discussion of the option ratings is provided in the following paragraphs.

4.5.2.1 Effect on Performance Assessment - Lag storage will not cause degradation of the vitrified waste form, and thus has no affect on the performance assessment. Therefore the options are not rated for performance assessment.

4.5.2.2 ALARA - Personnel exposure during operation and maintenance are considered in the overall rating for ALARA. The form of glass in the container has no effect on ALARA during lag storage.

Operation - Individually shielded containers are necessary if the containers are to be contact handled. However, considering that the containers will be remotely handled during containerization, cooling (as applicable), and decontamination, remote handling of the containers in the lag storage area is likely. Therefore, the shielded container option is rated 2 and the non-shielded container option is rated 3. 
Maintenance - Using individually shielded containers allows personnel close access to the stored containers to perform required maintenance. However, for the non-shielded container option, a maintenance bay can be established to perform the required maintenance. Because there is no evident ALARA advantage to individually shielding the containers, both options are rated 2.

4.5.2.3 Cost Effectiveness - The overall rating for cost effectiveness is determined by evaluating the costs associated with engineering, fabrication/construction, operation, and maintenance. Other costs such as licensing/permitting and decommissioning are unaffected by the options considered here, and therefore, are not specifically evaluated for lag storage.

Engineering - For a monolithic waste form, the lag storage area may be required to provide additional heat removal capability or even controlled heat removal capability while the glass cools and solidifies. The containerized monolith option is rated 1 and the containerized non-monolith option is rated 3 for lag storage engineering costs. The engineering costs to accommodate remote handled non-shielded containers are expected to be greater than those for contact handled shielded containers and therefore, the non-shielded option is rated 2 and the shielded option is rated 3.

Fabrication/Construction - Because of the cooling requirements for monoliths, fabrication costs for this option will be greater than those for the non-monoliths. Therefore, the non-monolith option is rated 3 for construction costs, and the monolith option is rated 1. Fabrication costs for individual shields for each canister is assumed to offset the higher costs for constructing remote handling capability, and therefore, both options are rated 2 .

Operation - Operating costs for the monolith option will be greater due to the need for cooling. The monolith option is rated 2 and the non-monolith option is rated 3 for operating costs. Shielded versus non-shielded containers does not affect the operating costs of the lag storage facility.

Maintenance - Because of the cooling requirements, the monolith option will be more costly to maintain, and therefore the monolithic option is rated 2 for maintenance and the non-monolithic option is rated 3 .

4.5.2.4 Safety and Environmental Concerns - Other than the considerations already considered for ALARA, there are no safety and environmental concerns affected by the options being evaluated.

4.5.2.5 Performance Goals - The lag storage area must provide extra storage capability to account for variations in the throughput as well as for variations in the cooling time. However, if this is properly considered in the design of the facility, the performance goals will not be compromised, and the lag storage has no affect on the performance goals.

4.5.2.6 Reliability - The only factor that could affect reliability of the lag storage area is the reliability of the cooling system required for the containerized monolith option. Therefore, the monolith option is rated 1 and the non-monolith option is rated 3 . Options concerning shielding have no affect on reliability of lag storage. 
4.5.2.7 Monitoring - The monolith option will require additional monitoring requirements to determine the temperature of the container. The monolith option is rated 2 and the non-monolith container is rated 3 . Individual shields around the containers may inhibit monitorability, and therefore the shielded option is rated 1 and the non-shielded option is rated 3 .

\subsubsection{Handling}

Based on the results of the transportation evaluation, a containerized waste form is assumed for the evaluation of the disposal site handling options. Also, The disposal site is assumed to be an open pit or trench per Section 5 . Considerations for individually shielded, contact handled containers versus non-shielded, remotely handled containers will be evaluated.

A summary of the handling option evaluation is presented in Table 4-3. The option with the highest score, contact handled, is the preferred option. The remote handling and contact handling options scored approximately the same, and both options should be considered in a more detailed evaluation upon further determination of the parameters affecting handling. A detailed discussion of the option ratings is provided in the following paragraphs.

4.5.3.1 Effect on Performance Assessment - Neither the remotely handled nor the contact handled options will affect the performance assessment of the disposal system, and therefore, the options are not rated.

4.5.3.2 ALARA - Handling of properly shielded containers should result in no more personnel exposure than handling by remote operation. Maintenance of handling equipment for either the remote handling option or the contact handled option can be performed in a clean area away from the waste, thereby eliminating personnel exposure during maintenance. Because neither option presents an advantage over the other, the options are not rated for ALARA considerations.

4.5.3.3 Cost Effectiveness - The overall rating for cost effectiveness is determined by evaluating the costs associated with engineering, fabrication/construction, operation, and maintenance.

Engineering - Engineering a remote handling system will cost more than simply connecting the container to a crane and placing it in the disposal site. Therefore, the remote handled option is rated 1 and the contact handled option is rated 3.

Fabrication/Construction - The fabrication costs for remotely handled equipment will be greater than for the simple equipment required for contact handling. Therefore, the remote handled option is rated 2 and the contact handled option is rated 3 or construction costs.

Operation - A remotely operated handling system will require fewer personnel than a contact handled system, and therefore, the remote handled option is rated 3 and the contact handled option is rated 2 for operational costs. 
Maintenance - Remote handling equipment will be more complex than the simple contact handling equipment and therefore, the cost of maintaining remote handling equipment can be expected to be greater than that of contact handling equipment. The remote handling option is rated 2 and the contact handled option is rated 3.

4.5.3.4 Safety and Environmental Concerns - The overall rating for safety and environmental concerns considers the level of personnel safety associated with operations and the level of safety and potential harm due to a failure in the handling system.

Operations - Contact handling of large, heavy objects presents a greater potential personnel hazard than does remote handling. Therefore, the contact handled option is rated 1 and the remote handled option is rated 3 .

Failure - Should the handling equipment fail, the contact handling option poses a greater potential hazard to the operating personnel from both the failed equipment and the potential failure of the container's shielding which could result in radiation exposure to personnel. Therefore, the contact handled option is rated 1 and the remote handled option is rated 3.

4.5.3.5 Performance Goals - Because both the remote and contact handling options will be capable of supporting the continuous and peak throughput requirements, the options are not rated for performance goals.

4.5.3.6 Reliability - The overall rating for the reliability of the handling options is based on the frequency of repair and the level of system redundancy.

Frequency of Repair - Assuming both the remote and contact handling options consist of properly rated lifting equipment, any required repairs can be performed according to the maintenance schedule which would be similar for similar rated equipment. However, the devices required to remotely attach to and detach from the containers can be expected to require additional or more complex repairs. Therefore, the remote handled option is rated 2 and the contact handled option is rated 3.

System Redundancy - The contact handled option, due to its use of common handling equipment affords better system redundancy because its components can easily be replaced or supplemented. Therefore, the remote handling option is rated 1 and the contact handled option is rated 3 .

\subsection{RECOMMENDED OPTIONS}

\subsubsection{Transportation}

The equivalent safety transportation system is the recommended option for transporting the low-level vitrified waste the one mile distance from the vitrification facility to the disposal facility. The recommended method of transportation (i.e., via truck on dedicated road, via truck on public access road, via railcar on dedicated tracks, or via railcar on rail spur) is a topic for further study that should be performed in a detailed evaluation of the selected disposal option. 


\subsubsection{Lag Storage}

Based on the evaluation performed in this study, the recommended lag storage facility would accommodate remotely handled, non-shielded containers, and for lag storage facility purposes, the waste would be a containerized non-monolithic waste form (i.e., sheets, cullet). However, considering the results of the evaluation done for containerization, the lag storage facility should provide for cooling of containerized monoliths and provide for remotely handled, non-shielded containers.

\subsubsection{Handling}

The evaluation of handling methods indicates that the preferred option is contact handling, but remote handling scored nearly equal to contact handling. Considering that the containers are likely to be remotely handled in the vitrification facility due to both temperature and radiation levels, remote handling of the waste containers at the disposal facility is the recommended option. 
Table 4-1. Transportation Option Evaluation.

\begin{tabular}{|c|c|c|c|c|}
\hline $\begin{array}{l}\text { Transportation Options: } \\
\text { Weighted Evaluation }\end{array}$ & $\begin{array}{l}\text { Weight } \\
\text { Factor }\end{array}$ & "Licensed" & $\begin{array}{l}\text { "Equivalent } \\
\text { Safety" }\end{array}$ & $\begin{array}{l}\text { Pumping/ } \\
\text { Piping }\end{array}$ \\
\hline Affect on PA & & 3 & 3 & 2 \\
\hline WEIGHTED EFFECT ON PA & 3 & 9 & 9 & 6 \\
\hline ALARA: operations & & 2 & 2 & 1 \\
\hline maintenance & & 3 & 3 & 2 \\
\hline decommission & & 3 & 3 & 3 \\
\hline ALARA TOTAL & & 8 & 8 & 6 \\
\hline WEIGHTED ALARA TOTAL & 2 & 16 & 16 & 12 \\
\hline Cost: engineering & & 1 & 2 & 2 \\
\hline licensing/permitting & & 1 & 3 & 2 \\
\hline fabrication/construction & & 2 & 2 & 2 \\
\hline operation & & 2 & 2 & 2 \\
\hline maintenance & & 3 & 3 & 2 \\
\hline decommission & & 3 & 3 & 1 \\
\hline COST TOTAL & & 12 & 15 & 11 \\
\hline WEIGHTED COST TOTAL & 2 & 24 & 30 & 22 \\
\hline Safety \& Environ: operations & & 1 & 1 & 3 \\
\hline failure & & 3 & 3 & 1 \\
\hline SAFETY \& ENVIRON. TOTAL & & 4 & 4 & 4 \\
\hline WEIGHTED SAFETY \& ENVIRON. TOTAL & 3 & 12 & 12 & 12 \\
\hline Performance Goals & & 3 & 3 & 2 \\
\hline WEIGHTED PERFORMANCE GOALS & 1 & 3 & 3 & 2 \\
\hline Reliability: frequency of repair & & 3 & 3 & 2 \\
\hline system redundancy & & 3 & 3 & 1 \\
\hline recovery after failure & & 3 & 3 & 1 \\
\hline RELIABILITY TOTAL: & & 9 & 9 & 4 \\
\hline WEIGHTED RELIABILITY TOTAL & 3 & 27 & 27 & 12 \\
\hline WEIGHTED TOTAL & & 91 & 97 & 66 \\
\hline Weight Factor: $3=$ More Important, $1=$ Less 1 & & \multicolumn{3}{|c|}{ ore Desirable, 1} \\
\hline
\end{tabular}


Final

Table 4-2. Lag Storage Option Evaluation.

\begin{tabular}{|c|c|c|c|c|c|}
\hline $\begin{array}{l}\text { Lag Storage Options: } \\
\text { Weighted Evaluation }\end{array}$ & $\begin{array}{l}\text { Weight } \\
\text { Factor }\end{array}$ & Monolith & $\begin{array}{l}\text { Non- } \\
\text { Monolith }\end{array}$ & Shielded & $\begin{array}{l}\text { Non- } \\
\text { Shielded }\end{array}$ \\
\hline ALARA: operations & & & & 2 & 1 \\
\hline maintenance & & & & 2 & 2 \\
\hline ALARA TOTAL & & & & 4 & 5 \\
\hline WEIGHTED ALARA TOTAL & 2 & & & 8 & 10 \\
\hline Cost: engineering & & 1 & 3 & 3 & 2 \\
\hline fabrication/construction & & 1 & 3 & 2 & 2 \\
\hline operation & & 2 & 3 & & \\
\hline maintenance & & 2 & 3 & & \\
\hline COST TOTAL & & 6 & 12 & 5 & 4 \\
\hline WEIGHTED COST TOTAL & 2 & 12 & 24 & 10 & 8 \\
\hline Reliability: & & 1 & 3 & & \\
\hline WEIGHTED RELIABILITY & 3 & 3 & 9 & & \\
\hline Monitoring & & 2 & 3 & 1 & 3 \\
\hline WEIGHTED MONITORING & 3 & 6 & 9 & 3 & 9 \\
\hline WEIGHTED TOTAL & & 21 & 42 & 21 & 27 \\
\hline
\end{tabular}


Final

Table 4-3. Handling Option Evaluation.

\begin{tabular}{|c|c|c|c|}
\hline $\begin{array}{l}\text { Handling Options: } \\
\text { Weighted Evaluation }\end{array}$ & $\begin{array}{l}\text { Weight } \\
\text { Factor }\end{array}$ & Remote & Contact \\
\hline Cost: engineering & & 1 & 3 \\
\hline fabrication/construction & & 2 & 3 \\
\hline operation & & 3 & 2 \\
\hline maintenance & & 2 & 3 \\
\hline COST TOTAL & & 8 & 11 \\
\hline L & 2 & 16 & 22 \\
\hline Safety \& Environ: operations & & 3 & 1 \\
\hline failure & & 3 & 1 \\
\hline SAFETY \& ENVIRON. TOTAL & & 6 & 2 \\
\hline WEIGHTED SAFETY \& ENVIRON. TOTAL & 3 & 18 & 6 \\
\hline Reliability: frequency of repair & & 2 & 3 \\
\hline system redundancy & & 1 & 3 \\
\hline RELIABILITY TOTAL: & & 3 & 6 \\
\hline WEIGHTED RELIABILITY TOTAL & 3 & 9 & 18 \\
\hline WEIGHTED TOTAL & & 43 & 46 \\
\hline Weight Factor: $3=$ More Important, $1=$ Less important & & \multicolumn{2}{|c|}{$\begin{aligned} \text { Rating: } 3 & =\text { More Desirable } \\
1 & =\text { Less Desirable }\end{aligned}$} \\
\hline
\end{tabular}




\section{REFERENCES}

10 CFR 71, Transportation and Packaging of Radioactive Material, Code of Federal Regulations, Title 10, Part 71, Nuclear Regulatory Commission, Washington, D.C.

40 CFR 264, Standards for Owners and Operators of Hazardous Waste Treatment, Storage, and Disposal Facilities, Code of Federal Regulations, Title 40, Part 264, Environmental Protection Agency, Washington, D.C.

40 CFR 265, Interim Status Standards for Owners and Operators of Hazardous Waste Treatment, Storage, and Disposal Facilities, Code of Federal Regulations, Title 40, Part 265, Environmental Protection Agency, Washington, D.C.

49 CFR 173, Shippers - General Requirements for Shipments and Packaging, Code of Federal Regulations, Title 49, Part 173, Department of Transportation, Washington, D.C.

49 CFR 174, Carriage by Rail, Code of Federal Regulations, Title 49, Part 174, Department of Transportation, Washington, D.C.

49 CFR 177, Carriage by Public Highway, Code of Federal Regulations, Title 49, Part 177. Department of Transportation, Washington, D.C.

Boldt, 1994, LLW Disposal Source Term, "Don't Say It" to Karnesky, January 13, 1994, Westinghouse Hanford Company, Richland, Washington.

DOE, 1993, Hanford Site Hoisting and Rigging Manual, DOE-RL-92-36, Rev. O, U.S. Department of Energy, Richland Field Office, Richland, Washington.

WHC, Hazardous Material Packages and Shipping Manual, Westinghouse Hanford Company, Richland, Washington. 


\subsection{DISPOSAL SYSTEM}

\subsection{DISPOSAL SYSTEM SITING}

\subsubsection{Constraints and Requirements}

The constraints and requirements imposed on a disposal system siting by Federal and State statutes are compiled in Table 5-1. Constraints $(C)$ are specifications that must be met. Requirements (R) are features that should be satisfied to the greatest extent possible.

The Washington State Administrative Code (WAC-173-303) for regulation of dangerous wastes and Title 40 - Environment (40CFR) Resource Conservation and Recovery Act (RCRA) regulations are directly applicable to radioactive waste disposal at Hanford. Although NRC regulations are not binding on non-commercial facilities, the guidance provided in Title 10 Energy, Parts 0-199 of the Code of Federal Regulations (10CFR) is incorporated in this evaluation as they are comprehensive and relevant to the siting of a disposal site. Of these, the 10CFR guidance is the most inclusive and specific to the issues under discussion and are featured when establishing constraints and requirements for low-level waste glass disposal.

\subsubsection{Methodology to Evaluate Options}

The goal of this evaluation and selection process is to identify economically achievable disposal site alternatives. The initial screening process involves (1) identifying the constraints and requirements to be satisfied by the alternatives, (2) identifying potential disposal alternatives, (3) eliminating alternatives that do not satisfy all design constraints.

After the available alternatives are initially screened, the remainder can be evaluated by (1) selecting critical design requirements and considerations for siting decision analysis, (2) assigning a weighting factor to siting requirement to signify its relative importance, (3) assigning value factors to describe the extent to which a particular alternative satisfies each requirement, and (4) constructing a decision matrix table to compare alternatives and facilitate the selection of the best alternatives.

\subsubsection{Characteristics Related to Disposal Site Selection}

Emplacement of waste below the earth's surface uses the surrounding rock or geologic material as a physical barrier to events and processes that could cause releases to the environment. The processes and events that could influence the rate of radionuclide release can be placed into three main groups:

- geologic and tectonic processes,

- climatic events,

- hydrogeological and geochemical processes, and

- human induced processes 
In general, the effectiveness of the isolation to human and biological intrusion increases with depth. However, the depth selected must be balanced against practical constraints related to engineering considerations, operational safety, long-term performance objectives, cost, waste-type, potential hazards, and waste volume.

5.1.3.1 Geologic and Tectonic Processes. Tectonic phenomena of particular importance to physical isolation for a near surface disposal facility are the spatial separation of the facility from active volcanic centers or major fault zones to minimize the potential for disruption by igneous activity or large scale faulting. Vibratory ground motion and surface fault movement have the greatest effect on disruption of engineered barriers. The effect on facility isolation due to tectonic activity is determined through specific performance assessment.

Mild tectonic movements and the resulting change in the resulting rates of erosion are also considerations in evaluating physical isolation characteristics. Regional uplift or subsidence is occurring for a variety of reasons. The effects of uplifting on the disposal system include an increase in the rates of erosion with a potential reduction in the thickness of the geologic strata overlying the disposal facility. In the case of subsidence, the effects could be favorable with a decrease in erosion rates or deposition of sediments overlying the facility, or unfavorable if subsidence caused groundwater levels to intrude into the disposal facility.

5.1.3.2 Climate. The timing and magnitude of climate-induced changes is an important factor in depth selection.

A return to glacial conditions cannot be discounted during the period of interest to isolation. Glacial erosion could remove large thicknesses of the overlying rocks and permafrost could extend to depths of several hundred meters if the glacial event is sufficiently extensive.

Climatic changes can also have major effects on the groundwater and surface water flow systems. Climatic changes can cause increases in precipitation and groundwater recharge, a rise in the elevation of the groundwater table, and variations in surface water flow patterns. For disposal facilities sited in the unsaturated zone, the timing and magnitude of climate induced changes in the groundwater table elevation is an important factor in depth selection.

5.1.3.3 Hydrogeological and Geochemical Processes. For most disposal concepts, the most likely mechanism for the release of radionuclides to the environment is transport in groundwater. The preferred hydrogeological environments for waste isolation are likely to be characterized by predictable and long groundwater flow paths. The key parameters that are required to characterize the hydrogeological system are hydraulic gradients, hydraulic conductivities, and porosities of the natural geological media surrounding the facility. The demonstration that geological environments will act as a sufficiently good barrier to radionuclide migration over an extended period requires site-specific data obtained during site characterization for use as input on performance assessments.

Variations in regional hydraulic gradients could lead to undesirable changes to existing surface water drainage systems. These changes could be caused by tectonic, climatic, or man-induced processes. Increases in the hydraulic base level (uplifting or reduction in sea level) could lead to increased incision of new of existing drainage systems. Decreases in the 
ydraulic base level (subsidence or sea level rise) may include the potential for flooding. Although changes in hydraulic base levels are primarily influenced by major natural events, man-induced changes to control on river systems could have similar effects.

The geochemical conditions and processes in the host geologic formation serve as a barrier by providing an environment that slows or prevents the degradation of engineered barriers and limits the rate of mobilization and transport of radionuclides when they are released. In general, the most favorable geochemical conditions include a high $\mathrm{pH}$, reducing environment, well buffered by mineral in the host medium, and low concentrations of complexing ligands. Of the complexing ligands that influence radionuclide transport, most uncertainty is probably associated with dissolved organic complexes. The potential impact of microbial activity on disposal facility stability is not thoroughly understood and has only recently started to be investigated as a potential issue.

5.1.3.4 Man-induced Processes. Although changes in hydraulic base levels are primarily influenced by major natural events, man-induced changes to control on river systems could have similar effects.

\subsubsection{Disposal Options}

Radioactive waste disposal facilities can be characterized into two groups: near surface disposal facilities and disposal facilities located at great depths within the earth. The minimum depth for disposal of high-level radioactive waste is 300 meters below the earth's surface (10 CFR Part 60.122.b.5). Other radioactive wastes may be disposed in near-surface facilities (10 CFR Part 61.7).

For this evaluation of disposal options, it has been assumed that initial pretreatment/vitrification will allow tank wastes to be delisted as high-level radioactive waste. Therefore, near-surface disposal, will be acceptable and a deep geological repository will not be required.

Near-surface disposal facilities include unlined trenches covered with earthen materials; earth-covered tumuli; above-ground vaults; below-ground vaults; some abandoned mines and rock cavities; modular concrete canisters; and augured borehole shafts. Within this category, the following options for underground disposal exist:

- emplacement of waste in unconsolidated geologic material with or without engineered barriers,

- emplacement of waste in crystalline basalt rocks,

- emplacement of waste in argillaceous geologic formations,

- emplacement of waste in man-made or natural rock cavities,

- injection of self-solidifying fluids containing wastes into induced fractures within impermeable strata or into porous and permeable strata 
5.1.4.1 Unconsolidated Geologic Materials. Shallow ground repositories in unconsolidated geologic materials have been used successfully for the disposal of low-level wastes, especially in arid areas where the facility is located in permeable ground and over a deep groundwater table. The performance of these systems can be improved by capping the disposal units with impermeable covers. Fluid accumulation and contaminant migration can be controlled by the construction of engineered barriers and drainage collection systems. Extensive areas of the 200 Plateau at the Hanford Site are available for use as a disposal facility under this option.

5.1.4.2 Crystalline Rocks. Crystalline rocks exhibit great structural strength, low intrinsic permeability, massive thickness, and high chemical stability. Crystalline rocks occur abundantly in the earth's crust. Near-surface platforms strata of crystalline basalt are located west of FFTF, west of Gable Mt. and northwest of Rattlesnake Mt. These near-surface basalt formations may prove to be unsuitable for waste emplacement because of secondary permeability created by fractures and fissures.

5.1.4.3 Argillaceous Geologic Formations. Argillaceous (clay-rich) formations can offer low permeability, high sorption capability for most radionuclides, and high plasticity, all of which are properties that contribute to reliable long-term isolation. When clay-rich argillaceous layers are sufficiently thick and homogeneous, they have been utilized for the disposal of radioactive waste (see Mol Site, Belgium, section X.X). No thick, homogeneous, and continuous argillaceous strata are located within or near the Hanford Site.

5.1.4.4 Man-made or Natural Rock Cavities. A great degree of isolation can be provided by emplacing radioactive waste in cavities mined in bedrock or in dry abandoned mines. No rock cavities nor mines are located within or near the Hanford Site. The exploration shaft from the Basalt Waste Isolation Pilot Plant has been totally backfilled, revegetated, and will not be considered further.

5.1.4.5 Fluid Injection. Fluids containing radioactive wastes and solidifying agents can be pumped directly into porous and permeable strata. The strata utilized in these programs are at great depth far below usable groundwater aquifer resource. As necessary, secondary permeability can be increased by inducing the creation of fractures within the disposal formation using high-pressure "hydrofrac" technology. This option features ease of handling and high isolation potential. Wastes injected into deep geologic formations cannot be easily retrieved if corrective action becomes necessary.

\subsubsection{Evaluation of Alternative Disposal Options}

The generic disposal options were evaluated using the methodology explained in section 5.2. The results of the evaluation are presented in Tables 5-2 and 5-3. In Table 5-2, the initial screening process determined if a disposal option would satisfy $(Y)$ or not satisfy $(N)$ the stated design constraints. Disposal options that passed the initial screening were carried to the next stage of evaluation.

In the more detailed alternatives analysis (Table 5-3), design requirements were assigned a weighting factor (10 through 1) to describe the importance of the specific requirement in siting decisions. In this system, a 10 signifies that the requirement is very important and a 1 signifies that the requirement has no importance. For example, the depth to groundwater is an important variable in the performance assessment as is assigned a weighting factor of 10 . In contrast, the importance of natural resources (e.g. proximity to irrigation water in the Yakima and Columbia Rivers) is given a weighting factor signifying lesser importance (3) because alternate sources of irrigation could be identified, if necessary. 
Alternatives for generic disposal options were developed and assigned a value from 5 to 1. Alternatives that exhibit certainty for satisfying a requirement were assigned a value of 5; alternatives that could satisfy a requirement at minimal degrees of certainty were assigned a lower value. Thus, alternatives that are currently serviced by existing roads and railways were assigned a 5 while alternatives that would require construction of new services received a lesser score.

The summation of incremental scores (value $X$ weighting factor) yields a composite score which appears in the last column of Table 5-3. Alternatives with the highest composite scores are the most attractive for implementation. The weighting factors and values assigned in the tables are purely subjective and could be modified as additional data are collected or policy changes.

5.1.5.1 Initial Screening. The disposal siting options eliminated from further study either did not incorporate the requirements for corrective measures (e.g. retrieval, in the event contaminant migration was detected), or could not be considered due to the lack of suitable geologic environments at the Hanford Site. A decision matrix (Table 5-2) summarizes the initial screening results.

The options that are eliminated from further evaluation are:

- emplacement of wastes in a facility especially designed and excavated for waste disposal in argillaceous rock formations

- emplacement of waste in natural or man-made rock cavities

- injection of self-solidifying fluids containing wastes into induced fractures within impermeable strata or into porous and permeable strata

5.1.5.2 Disposal Siting Options. The following options are retained for further evaluation after the initial screening was completed:

- emplacement of waste at shallow depth, with or without engineered barriers, including facilities that are built on the land surface but eventually covered with earthen materials

- emplacement of wastes in a facility especially designed and excavated for waste disposal in crystalline rock formations

Geological environments that are potentially suitable for near-surface disposal of Hanford vitrified low-level waste are those where the associated fluxes and velocities of groundwater in the vicinity of the facility are as low as possible and the depth to groundwater is the greatest. These environments are limited to the areas distal from the Columbia River. The following areas were carried forward for additional evaluation:

200 Area Plateau. The 200 Area Plateau is selected as the best option for a disposal facility sited in unconsolidated geologic material. The 200 Area is centrally located on the Hanford site and is the least attractive for future development. Portions of the 200 Plateau close to the site of the proposed vitrification plant are available for use as a disposal facility. The 200 Plateau is the highest geographic area within the alluvial plain between basalt highlands and offers the greatest distance from the groundwater table. 
West FFTF Plateau. The area west of the FFTF facility is underlain by a broad, flat, basalt platform which is within 100 feet of the land surface (Figure 5-1). Disadvantages of this location are (1) shallower groundwater table, (2) its proximity to a public road and irrigation water resources (Yakima River), and (3) possible attraction for future land development. In addition, less characterization studies have been completed for this location.

Northwest Rattlesnake Mountain. The area northwest of Rattlesnake Mt. is underlain by a broad, flat, basalt platform which is within 100 feet of the land surface (Figure 5-1). The area is extremely remote and is not accessible by the general populace. Disadvantages of this location are (1) less characterization studies have been completed for this location, (2) the designation of the area as part of the Hanford wildlife sanctuary may preclude its use for waste disposal activities, (3) access to the site for waste transport is primitive and no railroad access is currently available.

West Gable Mountain. The area west of Gable Mt. is underlain by a broad, flat, basalt platform which is within 100 feet of the land surface (Figure 5-1). Although this locale is not close to the proposed vitrification plant, the area is serviced by existing roads and railroads. Disadvantages of this location are (1) shallow groundwater table, (2) its proximity to irrigation water resources (Columbia River), and (3) possible attraction for future land development.

\subsubsection{Identification of Preferred Alternative}

The 200 Plateau is identified as the preferred disposal site primarily on the basis of its elevation above the groundwater table; proximity to existing transportation resources and vitrification plant; constructability; and future land use. The area west of the FFTF facility was the next best alternative because of its crystalline rock foundation, elevation above the groundwater table, and constructability.

The area northwest of Rattlesnake Mt. is attractive because of its remote location. The site did not score higher because of the difficulty perceived in delivering vitrified waste to the location and its probable withdrawal as a acceptable site because of the existence of its status as a wildlife refuge.

The area west of Gable Mt. is reasonably close to the proposed vitrification plant and has ample transportation capabilities already in place. The site did not score higher because of its proximity to groundwater and surface water resources and the limited amount of land available for use for disposal.

\subsection{DISPOSAL SYSTEM CONFIGURATION}

The purpose of this section is to develop conceptual descriptions of the feasible design options for the proposed vitrified low-level waste (VLLW) disposal facility system configurations and operation needs. The level of detail included in this section does not restrict the scope of technical decisions that can be proposed during more definitive design stages. 


\subsubsection{Project Requirements}

The proposed facility configuration satisfies the design requirements contained in current Federal and State statutes. Descriptions of these requirements are provided in the following subsections.

5.2.1.1 Performance Objectives for Land Disposal of Radioactive Waste (10 CFR 61). Concentrations of radioactive material which may be released to the general environment in ground water, surface water, air, soil, plants or animals must not result in an annual dose exceeding an equivalent of 25 mrem to the whole body, 75 mrem to the thyroid, and 25 mrem to any other organ of any member of the public. Reasonable efforts should be made to maintain releases of radioactivity in effluents to the general environment.

5.2.1.2 Requirements for Design, Operation, and Closure. Design, operation and closure of the land disposal facility must ensure protection of any individual inadvertently intruding into the disposal site or contacting the waste at any time after active institutional controls over the disposal site are removed ALARA (61.42).

\section{Disposal Site Design for Land Disposal}

Disposal site design requirements for near-surface disposal (i.e., within 30 meters of the earth's surface) are provided - 10 CFR Part 61, Section 51:

- Site design features must be directed toward long-term isolation and avoidance of the need for continuing maintenance after site closure.

- The disposal site design and operation must be compatible with the disposal site closure and stabilization plan and lead to disposal site closure that provides reasonable assurance that the performance objectives will be met.

- The disposal site must be designed to complement and improve, where appropriate, the ability of the disposal site's natural characteristics to assure that the performance objectives will be met.

- Covers must be designed to minimize to the extent practicable, water infiltration, to direct percolating or surface water away from the disposed waste, and to resist degradation by surface geologic processes or biotic activity.

- $\quad$ Surface features must direct surface water drainage away from disposal units velocities and gradients which will not result in erosion that will require ongoing active maintenance in the future.

- The disposal site must be designed to minimize to the extent practicable the contact of water with waste during storage, the contact of standing water with waste during disposal, and the contact of percolating water with wastes after disposal. 


\section{Land Disposal Facility Operation and Disposal Site Closure}

Near-surface disposal facility operation and disposal site closure requirements are developed in 10 CFR Part 61, Section 52:

- Wastes must be disposed so that the top of the waste is a minimum of 5 meters below the top surface of the cover or must be disposed with intruder barriers that are designed to protect against an inadvertent intrusion for at least 500 years.

- Wastes must be emplaced in a manner that maintains the package integrity during emplacement, minimizes the void spaces between packages, and permits the void spaces to be filled.

- Void spaces between waste packages must be filled with earth or material to reduce future subsidence within the fill.

- Waste must be placed and covered in a manner that limits the radiation dose rate at the surface of the cover to levels that at a minimum will permit compliance with performance objectives.

- A buffer zone of land must be maintained between any buried waste and the disposal site boundary and beneath the disposed waste. The buffer zone shall be of adequate dimensions to carry out environmental monitoring activities specified in $\$ 61.53(d)$ and take mitigative measures if needed.

- Closure and stabilization measures as set forth in the approved site closure plan must be carried out as each disposal unit (e.g., trench) is filled and covered.

- Active waste disposal operations must not have an adverse effect on completed closure and stabilization measures.

- Only wastes containing or contaminated with radioactive materials shall be disposed of at the disposal site.

\section{Radioactive Waste Management}

Pertinent requirements for new Radioactive Waste Management (RWM) facilities are included in DOE Order 5820.A, Radioactive Waste Management:

- New RWM facilities shall incorporate environmental protection, safety, and health protection standards of DOE 5480.4 and RL $5480.4 B$.

- Designs for new RWM facilities shall incorporate features to facilitate retrieval capability.

Specific requirements for management of solid low-level radioactive wastes at the Hanford Site are provided in Chapter III of RLID Order 5820.2A, Radioactive Waste Management: 
- LLW at the Hanford Site shall be managed in compliance with applicable radiation protection standards and environmental regulations.

- Disposal systems for LLW disposed of on or after 09/26/88 shall be designed to meet the following objectives in accordance with schedule guidance in DOE 5820.2A, Chapter III, Paragraph 31.

(1) General Public Protection. Disposal systems shall be designed to ensure that exposure to any member of the public that results from disposal of solid LLW shall not exceed $25 \mathrm{mrem} / \mathrm{yr}$ Effective Dose Equivalent (EDE) through all exposure pathways for at least 1,000 years after disposal. The point of compliance shall be no further from the edge of the waste than the Hanford Site boundary during the period of active institutional control. After the active institutional control period (assumed to be not more than 100 years) the point of compliance shall be not more than 100 meters from the edge of the disposal site.

(2) Groundwater Protection. Disposal systems shall be designed to meet the Clean Water Act and the Safe Drinking Water Act as well as ensure that disposal of LLW after $09 / 26 / 88$ does not result in concentrations of radionuclides in groundwater exceeding those corresponding to an EDE of $4 \mathrm{mrem} / \mathrm{yr}$ to any person who might drink 2 liters per day of water from a well drilled into the aquifer, for at least 1,000 years after disposal. The point of compliance shall be no further than 100 meters from the edge of the waste.

(3) ALARA (Long-Term Protection). Reasonable effort shall be made to design disposal systems in such a way that potential exposures are ALARA for all times up to the year of maximum exposure. If the predicted population exposure is less than 500 person-rem/yr in the year of maximum exposure, the ALARA requirement is defined to have been complied with.

(4) Intruder Protection. Disposal closure systems shall be designed to ensure that exposure to individuals who inadvertently intrude the closed facility after the active institutional control period shall not exceed $100 \mathrm{mrem} / \mathrm{yr}$ for continuous exposure, or 500 mrem for a single acute exposure. For wastes that may remain hazardous to inadvertent intruders beyond 100 years, passive controls shall be incorporated to provide reasonable assurance that inadvertent intruders will be warned and deterred from disturbing the site for up to 500 years.

(5) Mixed-Waste Regulations. Disposal systems shall be designed to meet the applicable requirements of 40 CFR 264 and 265, and WAC 173-303 for the disposal of LLWMW.

- Solid LLW to be disposed of in burial grounds shall meet the guidelines and requirements of the current revision of the Hanford Site Solid Waste Acceptance Criteria, WHC-EP-0063.

- Solid LLW shall be disposed of at the Hanford Site by methods appropriate to achieve the Hanford Performance Objectives stated in Chapter III, section 3.a. above, consistent with the site-specific Radiological Performance Assessment prepared in compliance with Chapter III, Paragraph 3.b. above. 
- Wastes designated Greater-Than-Class $C$ shall be stored until disposal systems are developed to meet the requirements of DOE 5820.2A, Chapter III, Paragraph 3.i.(4).

- Disposal sites for solid LLW-MW (non-PCB) shall be located and designed in compliance with the applicable requirements in WAC 173-303, 40 CFR 264, 265 and 268, and the RCRA Dangerous Waste Permit.

\section{Landfill Operation Requirements}

Design and operating requirements for landfills in the United States are contained in 40 CFR Part 265, Subpart N, section 301:

- The owner or operator of each new landfill must install two or more liners and a leachate collection and removal system above and between such liners, and operate the leachate collection and removal systems, in accordance with \$264.301 paragraphs (d), (e), and (f).

- The owner or operator must design, construct, operate and maintain a run-on control system capable of preventing flow onto the active portion of the landfill during peak discharge from at least a 25 year storm.

- the owner or operator must design, construct, operate and maintain a run-off management system to correct and control at least the water volume resulting from a 24 hour, 25 year storm.

Additional requirements for land treatment operations within the State of Washington are provided in WAC 173-303-665:

- A landfill must have a liner to prevent any migration of wastes out of the landfill at any time during the active life (including the closure period) of the landfill.

- a leachate collection and removal system immediately above the liner that is to ensure that the leachate depth over the liner does not exceed $30 \mathrm{~cm}$.

[The owner or operator will be exempted from these requirements subsection, if the department finds, based on a demonstration by the owner or operator, that alternative design and operating practices, together with location characteristics, will prevent the migration of any dangerous constituents into the ground water or surface water at any future time.]

- The owner or operator must design, construct, operate, and maintain a run-on control system capable of preventing flow onto the active portion of the landfill during peak discharge from at least a twenty-five year storm.

- The owner or operator must design, construct, operate, and maintain a run-off management system to collect and control at least the water volume resulting from a twenty-four-hour, twenty-five year storm.

The owner or operator of a double-lined landfill may be subject to less stringents regulations if the following conditions are met: 
- The landfill be located entirely above the seasonal water tables.

- A leak detection system is designed, constructed, maintained, and operated between the liners to detect any migration of liquid into the space between the liners;

- The landfill has a leachate collection and removal system above the top liner that is designed, constructed, maintained, and operated in accordance with regulations on releases from solid waste management units in WAC 173-303645

Closure and Post-Closure Care (265.310)

Under 40 CFR, Part 265, subpart N, section 310, at final closure of the landfill or upon closure of any cell, the owner or operator must cover the landfill or cell with a final cover designed and constructed to:

(1) Provide long-term minimization of migration of liquids through the landfill;

(2) Function with minimum maintenance;

(3) Promote drainage and minimize erosion or abrasion of the cover;

(4) Accommodate settling and subsidence so that the cover's integrity is maintained, and

(5) Have a permeability less than or equal to the permeability of the bottom liner system or natural subsoils present.

Additional specifications for closure and postclosure care for landfills within the State of Washington are provided in WAC 173-303-610. At final closure of the landfill or upon closure of any cell, the owner or operator must cover the landfill or cell with a final cover designed and constructed to:

(1) Provide long-term minimization of migration of liquids through the closed landfill;

(2) Function with minimum maintenance;

(3) Promote drainage and minimize erosion or abrasion of the cover;

(4) Accommodate settling and subsidence so that the cover's integrity is maintained; and

(5) Have a permeability less than or equal to the permeability of any bottom liner system or natural subsoils present.

After final closure, the owner or operator must comply with all postclosure requirements contained in WAC 173-303-610 including maintenance and monitoring throughout the postclosure care period.

\subsubsection{Land Disposal Options}

5.2.2.1 Waste Isolation Depth. The disposal facility is most likely to be a near-surface facility. Above-grade and deep repositories are eliminated from further consideration in this evaluation due to the following reasons. 
- In the Low Level Waste Act of 1982, the United States Congress has stipulated that low-level waste disposal facilities may not be above-grade vaults. This stance was adopted to preclude long-term storage vaults from being considered as disposal facilities.

- Deep repository facilities for the low-level waste glass are not economically attractive. Federal requirements of 10 CFR Part 61 do not stipulate nor prohibit the use of deep repositories for disposal of low-level waste. At this time, nearsurface disposal appears to be technically acceptable and is the most costeffective option. However, subsequent performance assessment studies may demonstrate that near-surface facility configurations cannot satisfy the project performance objectives.

5.2.2.2 Waste Handling. Waste glass could be transferred indirectly or directly from the transport vehicle to the burial facility. Indirect transfer employs manned or robotic vehicles and direct transfer employs gantry or climbing cranes (see Figure 5-2). Rails or motorized tractors may have to be provided to allow the cranes or hoists to access the active portion of the disposal facility.

The use of cranes and hoists satisfies ALARA concerns better than powered transfer vehicles. The operators of the lifting devices are placed at a great distance from sources of radioactive contaminants and can manipulate the machinery remotely with great precision. The potential for direct contact with ionizing radiation and related decontamination concerns make the use of powered transfer vehicles less attractive as a waste handling alternative.

Direct Transfer using Cranes and Hoists. Gantry cranes offer the advantage to accurately position waste containers within the burial facility. The span over which they can be constructed would limit the width of the disposal cell.

Climbing cranes can span greater distances than gantry cranes but offer less reliable positioning capability and may require a man in the trench to direct the placement. The use of a climbing crane allows for more flexibility in facility dimensions.

Decontamination requirements for the cranes are not as extensive as those for the direct transfer vehicles. The only elements of the crane in intimate contact with the waste containers are the lifting slings which can be easily monitored and decontaminated.

Indirect Transfer Using Powered Vehicles. Vitrified waste could be removed from transport vehicles and transferred to the active portions of the disposal facility using a forklift or other powered vehicle. The use of these vehicles eliminates the need for transport networks to be extended towards active portions of the disposal facility as filling continues. In addition, vehicular transfer of waste containers offers the capability for accurate placement of waste containers in the burial facility.

Transfer vehicles can be directed by human operators or remotely controlled. Human operation would mandate the use of shielded vehicles to provide protection against ionizing radiation. Remotely controlled vehicles are more difficult to maneuver but reduce the potential for exposure to radiation. Because of regular and intimate contact with waste containers by the vehicles, frequent decontamination of the transfer vehicles and monitoring of vehicle operators will be required. 
5.2.2.3 Waste Emplacement. Waste containers can be emplaced in single or multiple layers within the burial facility. Single layer configurations and loose packing arrangements simplify waste handling concerns and minimize the dose consequences due to intrusion and contaminant migration scenarios. The single layer configuration results in the greatest degree of total land use and surface area disturbance.

Multiple layered arrangements in tightly packed configurations will minimize surface impact. The number of layers incorporated in the design will be determined by factors such as (1) geology of the disposal site, (2) the maximum allowable weight a container can support, (3) distance to the water table, (4) the thicknesses of sub-facility barriers, and (5) expected cyclical variations in groundwater elevation beneath the disposal site.

Multiple layered configurations may require stabilization using engineered backfill material. This material could be preformed blocks that have been molded with cavities into which waste containers can be lowered. Options for the backfill include sulfur-polymer cement or other low-permeable matrix material. The type of material used as backfill will determine the type of subfloor that is incorporated in the final design.

An alternative that has been rejected is waste emplacement in discrete boreholes drilled into the earth at the disposal site. The borehole emplacement option was rejected because of (1) the inability to install continuous barriers beneath the boreholes, (2) the inefficient use of land relative to the single or multiple layer options (boreholes could not be contiguous), and (3) the relative expense of installing liners in each separate borehole to meet RCRA requirements.

5.2.2.4 Disposal Units. The burial facility may be composed of a single unit or multiple units. At present, there is no requirement to construct multiple burial units. The use of multiple units may be desirable to satisfy deficiencies revealed during performance assessment activities.

5.2.2.5 Design Specifications. After incorporating the appropriate engineering controls, the waste burial facility must satisfy the following criteria:

- $\quad$ provide capacity for $210,000 \mathrm{~m}^{3}$ of vitrified radioactive waste, approximately $210,000 \mathrm{~m}^{3}$ of engineered matrix/containers, and approximately $105,000 \mathrm{~m}^{3}$ of vault and barrier elements;

- meet performance objectives for radionuclide releases to the environment and public;

- minimize leaching production and provide contingency to detect and collect leachate;

- $\quad$ provide groundwater protection prior to and after the installation of the final closure cover; and

- minimize the land area required and the impact on the environment. 


\subsubsection{Methodology to Evaluate Options}

The goal of this evaluation and selection process is to identify constructable disposal system alternatives. The initial screening process involves $(1)$ identifying the constraints and requirements to be satisfied by the alternatives, $(2)$ identifying potential alternatives for system configurations, and (3) eliminating alternatives that do not satisfy the design requirements.

The identification of a preferred alternative will not be attempted. Critical factors on which the final selection will be based can only be determined through performance assessment activities which are beyond the scope of this project. Instead, a description of one alternative that combines the majority the positive attributes of a potentially attractive configuration is provided in the final section. This configuration provides a conceptual framework on which more definitive design can be based.

5.2.3.1 Disposal Facility Considerations. The principal criteria and feasible options for the proposed disposal facility are contained in the following sections. This conceptual description can be refined through the completion of additional conceptual and definitive design reports and performance assessments.

General Layout. A single burial facility will be constructed entirely below the ground surface. The geometry and orientation of the burial facility will be determined by performance assessment activities.

Excavated soil may be used to construct earthen berms to minimize wind erosion and divert surface water run-on. Some excess soil will be reserved to provide material for construction of temporary and final covers. Temporary soil stockpiles can be established at the toe of the proposed burial facility. When sections of the burial facility have been filled with waste, soil stockpiles may be placed over closed portions of the burial facility to minimize land area disturbance.

The walls and floor of the burial facility will provide structural strength and distribute stresses away from the waste glass. Walls that are built in unconsolidated alluvium must exhibit sufficient strength to prevent slump or other failure while the trench is empty.

Walls and floors will be composed of a cementitous product. A sulfur-polymer based cement appears to be the best alternative for construction of these structures. The use of a gabian-wall structure should also be studied for possible application at the burial facility.

\subsubsection{Liner System}

The waste disposal facility will employ a double liner system which satisfies the requirements of RCRA. Liner systems have been approved for other RCRA compliant landfills at the Hanford site. The testing results for the effects of leachate and radiation on geosynthetic and natural soil liner components should be used in finalizing the specifications for construction of the proposed liner system. From the bottom up, the liner system components will consist of:

- compacted subgrade; 
- a low-permeability bentonite-crushed basalt mixture which will act both as a radionuclide sorber and fluid barrier;

- a layer of sulfur-based natural mineral to precipitate radionuclides that may potentially escape from the disposal trench;

- trench floor;

- a geomembrane (secondary liner) chosen for its high resistance to chemical deterioration;

- a gravel-bed leak detection layer;

- a primary HDPE geomembrane similar to the secondary liner discussed above;

- a gravel layer to optimize leachate collection;

- an operations layer (subfloor) to prevent mechanical damage to the liner system as waste containers are placed in the vault;

The geotextile materials will be extended up the walls from the floor to fully line the trench. Geocomposite drainage fabrics will be sandwiched between the wall-liners and against the wall to promote drainage of fluids to the leak collection and detection systems.

5.2.4.1 Leachate Management. The selection of a waste form and design of the facility are intended to minimize the generation of leachate. Leachate collected from the lined portion of the trench will be treated in a separate treatment facility. Precipitation into the unlined portion of the burial facility will be allowed to drain into the subgrade. Filled portions of the burial facility will be protected by temporary covers pending final closure. Surface water that collects in exposed portions of the finished burial facility will be recovered to minimize infiltration into the waste.

The trench floor will be divided into discrete units by use of internal wall structures to facilitate waste package stabilization and leachate management. The size of the units should be based on waste emplacement schedules, the anticipated frequency of precipitation events, and construction schedules.

The liner system in each leachate collection area will be sloped towards the walls of the burial facility. A sump at the primary gravel level will be used to collect leachate. A second sump will collect drainage from the secondary gravel to provide leak detection capability. These sump systems will be separate and distinct functional elements.

Riser pipes will lead from each sump up the outside of the burial facility. The riser pipes will be located and designed so that leachate pumping can be continued after the final closure cover has been installed. Submersible pumps can be lowered into position through these pipes to recover leachate fluids, if present. Instrumentation will be included to automatically monitor leachate levels and control the pumping cycles. The collected leachate will be piped to a storage facility by gravity flow. The collected leachate will be sampled and eventually returned to the wastewater treatment facility for treatment. 
5.2.4.2 Land Utilization. The land utilized for the disposal facility must be sufficient to provide a minimum of $525,000 \mathrm{~m}^{3}$ of capacity for the disposal facility. Approximately $210,000 \mathrm{~m}^{3}$ will be vitrified waste. An estimate that $210,000 \mathrm{~m}^{3}$ of matrix material will be incorporated in the waste container is considered conservative. This study proposes that a minimum of $105,000 \mathrm{~m}^{3}$ of additional disposal volume be included in the capacity requirements to accommodate structural elements and backfill of the final disposal facility.

Sufficient area must be provided to accommodate administrative buildings and related support facilities. The disposal facility area should also provide flexibility for expanded waste disposal activities, if necessary, without sacrificing the requirement to provide sufficient buffer areas around the facility. Waste filling activities and general land use should be phased so that the surrounding area is disturbed as little as possible to minimize the impact on existing vegetation and wildlife.

Site Preparation. The existing landscape and terrain will be prepared and utilities will be installed for the construction of the proposed disposal burial facility. Cut and fill excavation, grading, and embankments will be performed to provide the elevations and grades required for constructing the trench system and for building foundations. The trench site may be over-excavated to depths sufficient for construction of subsurface barriers, if used.

Drainage. The proposed sites are on unimproved semi-arid landscapes. All sites are near the top of natural plateaus and are not located in river or stream flood plains. The natural slope may be sufficient to provide adequate drainage. If insufficient, the natural slope may have to be graded to keep off-site stormwater and snow melt from running onto the site. Roads, rail tracks, parking areas, and building facilities will be oriented to allow for proper drainage.

Railroads and Access Roads. Rail and road improvements are anticipated to include construction of lead tracks/roads connecting the disposal facility to the existing Hanford transportation system. Improvements may also include looped transportation routes within the facility; sidings for container off-loading and on-loading; sidings for material storage while awaiting return to the vitrification plant; and upgrade of existing transportation routes, as necessary to accommodate relevant transportation regulations.

Other Site Improvements. Site improvements will be required to support additional roads, parking areas, walkways, fences, gate control points, security, fuel storage, and fluid storage areas.

\subsubsection{Buildings}

Buildings will be required to house support operations for the proposed disposal facility. The following sections describe the types of buildings that will be constructed to support waste disposal activities.

5.2.5.1 Operations Buildings. Operations buildings will include but not be limited to personnel decontamination rooms, lunch rooms, maintenance shops, offices, and communications centers. Operations buildings will be required for administrative support, maintenance, storage, utilities, and emergency services. 
5.2.5.2 Decontamination Facility. Transport packages, containers, vehicles, lifting equipment, and other support equipment may become contaminated during the operation of the disposal facility. The decontamination facility will use high-pressure wash and rinse units to decontaminate the exterior of exposed equipment. The decontamination system should incorporate a treatment system so that water can be recycled. Because the system will use recycled water, some build-up of radioactivity in the wash water is expected to occur over time. This build-up of radioactivity is expected to be slight because the proposed operations are relatively free of contaminated dust.

5.2.5.3 Wastewater Treatment Facility. A wastewater treatment facility will be provided to treat the combined leachate and decontamination facility wastewater. Because the volumes of contaminated water are expected to be minor, the treatment system can be a pre-packaged system incorporating sand trap, cyclone separation, settling, filtration, and storage processes. Provisions can be included for the addition of reverse osmosis or ion exchange treatment if polishing is desired.

5.2.5.4 Burial Facility Construction. The burial facility will be constructed using conventional equipment and techniques that have been proven in similar excavation applications. Physical barriers will be temporarily installed at the boundaries of the construction areas to prevent inadvertent entry into the waste placement areas. Preformed sections of concrete will be used to form the walls and floor of the trench.

During burial facility construction, the liner system will extend beyond the divisions between adjacent cells. This will prevent fluids from unlined areas of the burial facility from entering either the leachate collection or detection systems. The liner will be temporarily terminated by extending the geotextiles in the liner system to cover other more vulnerable layers. The exposed edge of the liner can be covered with a protective layer of soil. During subsequent phases of construction, the existing liner will be exposed and joined to new material.

\subsubsection{Cover Technology}

5.2.6.1 Daily Operational Cover. The upper surface of emplaced waste will be covered by a moveable cover that will protect the trench and waste containers from vectors and precipitation. The daily operational cover will limit leachate production and intrusion until the interim cover is installed.

5.2.6.2 Interim Cover. The interim cover will include a low-permeability layer to limit leachate production in completed portions of the burial facility. Materials such as geomembranes or bentonite-basalt mixture has been assumed to be satisfactory as an interim cover. Installation of portions of the final cover may also be cost-effective. The interim cover will be installed annually or at a greater frequency depending on waste emplacement schedules.

5.2.6.3 Closure Cover. The trench will be closed with a RCRA compliant cover composed of multiple layers of natural materials. The upper layers of the cover will be predominantly silt to provide high storage capacity and evapotranspiration. A capillary break will be provided by underlying sand layers. A thick layer of crushed basalt fragments will be provided to discourage intrusion from humans and burrowing animals. The base of the closure cover will be formed by the material introduced as the interim cover. 
The final cover will be constructed to minimize vertical loading which may cause unacceptable settlement. The waste glass and surrounding matrix represent the primary defence against waste deterioration and contaminant migration; therefore the closure cover may be a modified version of the Hanford Barrier. 
Figure 5-1. Elevation Contours on the Top of Geoelectric Layer 2 (Basalt) Using Magnatotelluric Data.

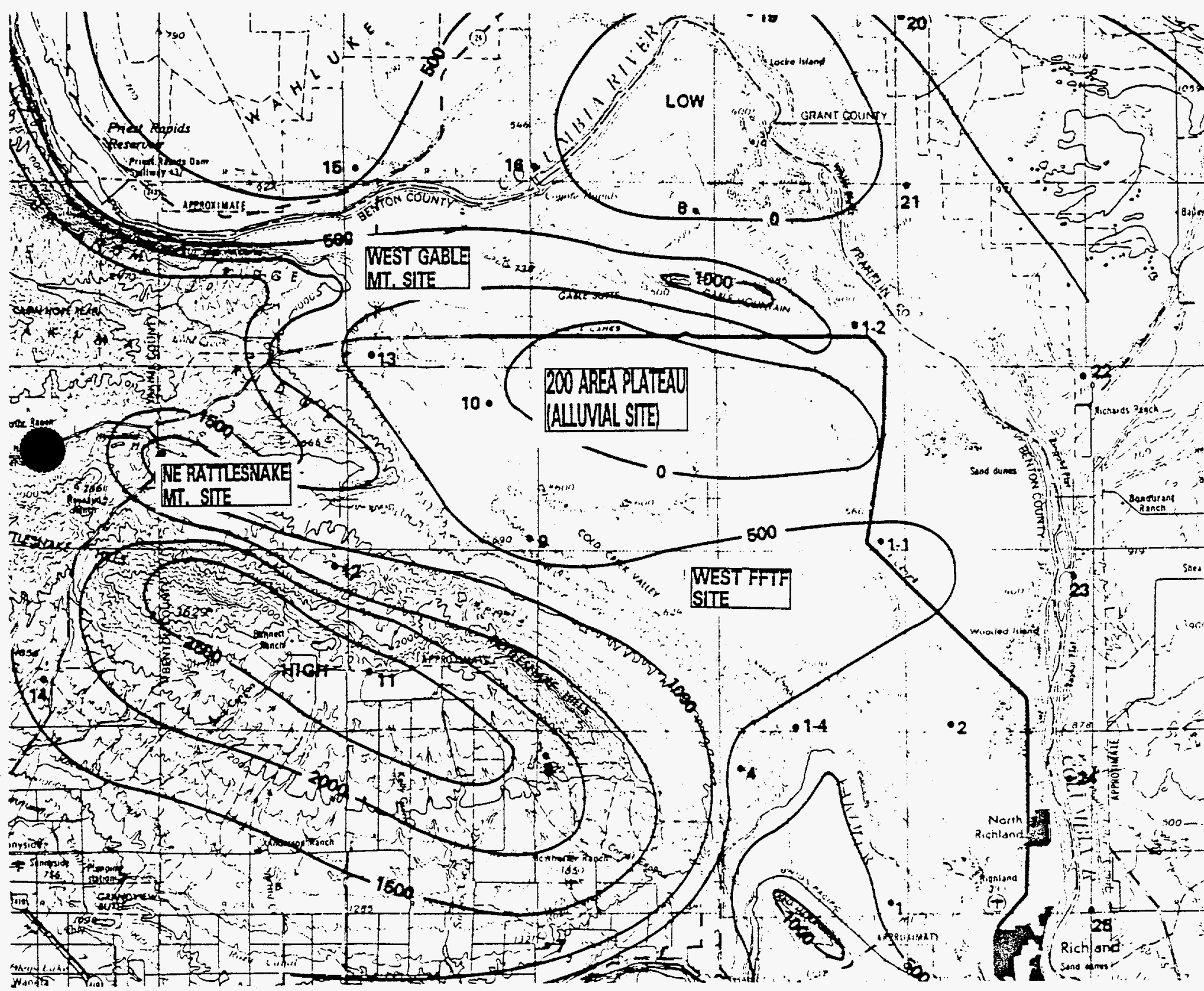


Figure 5-2. Examples of Cranes.
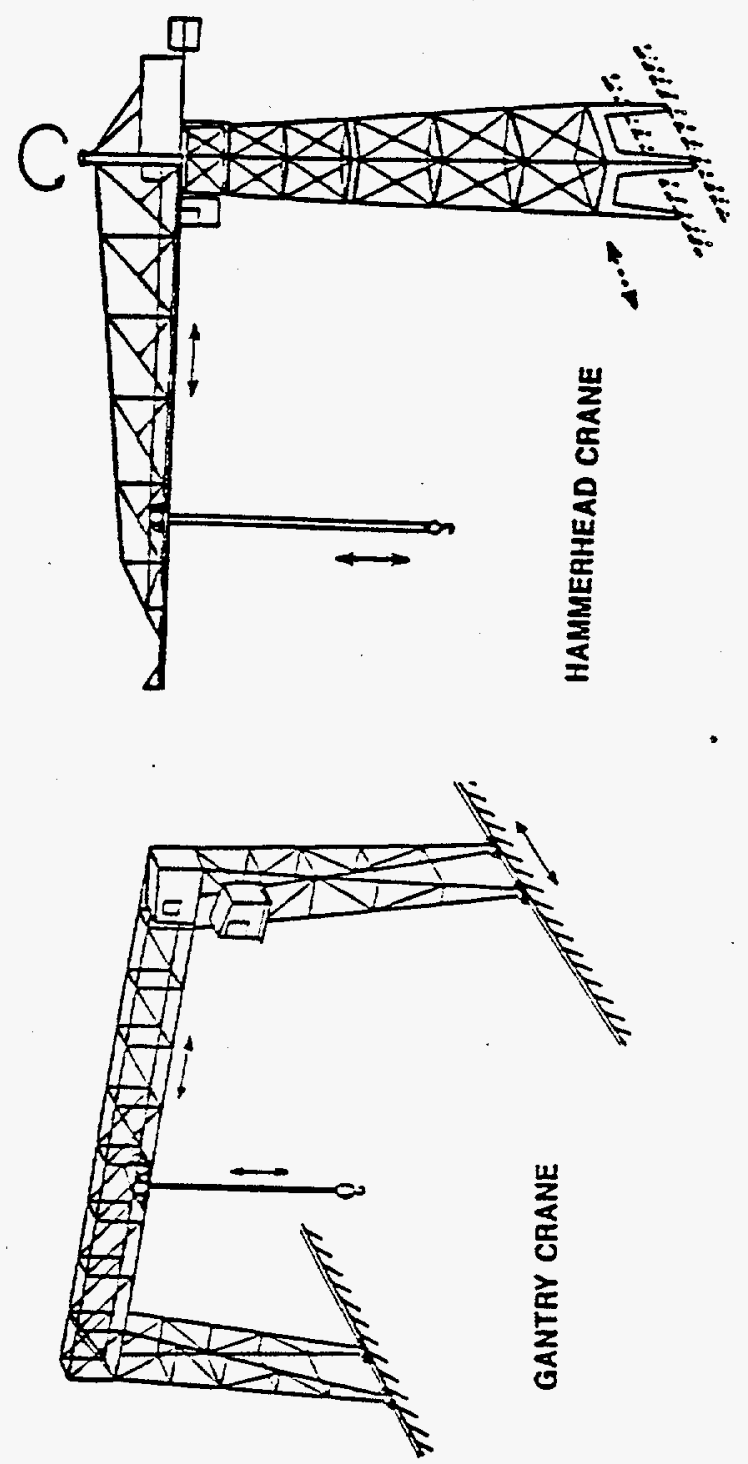

岁
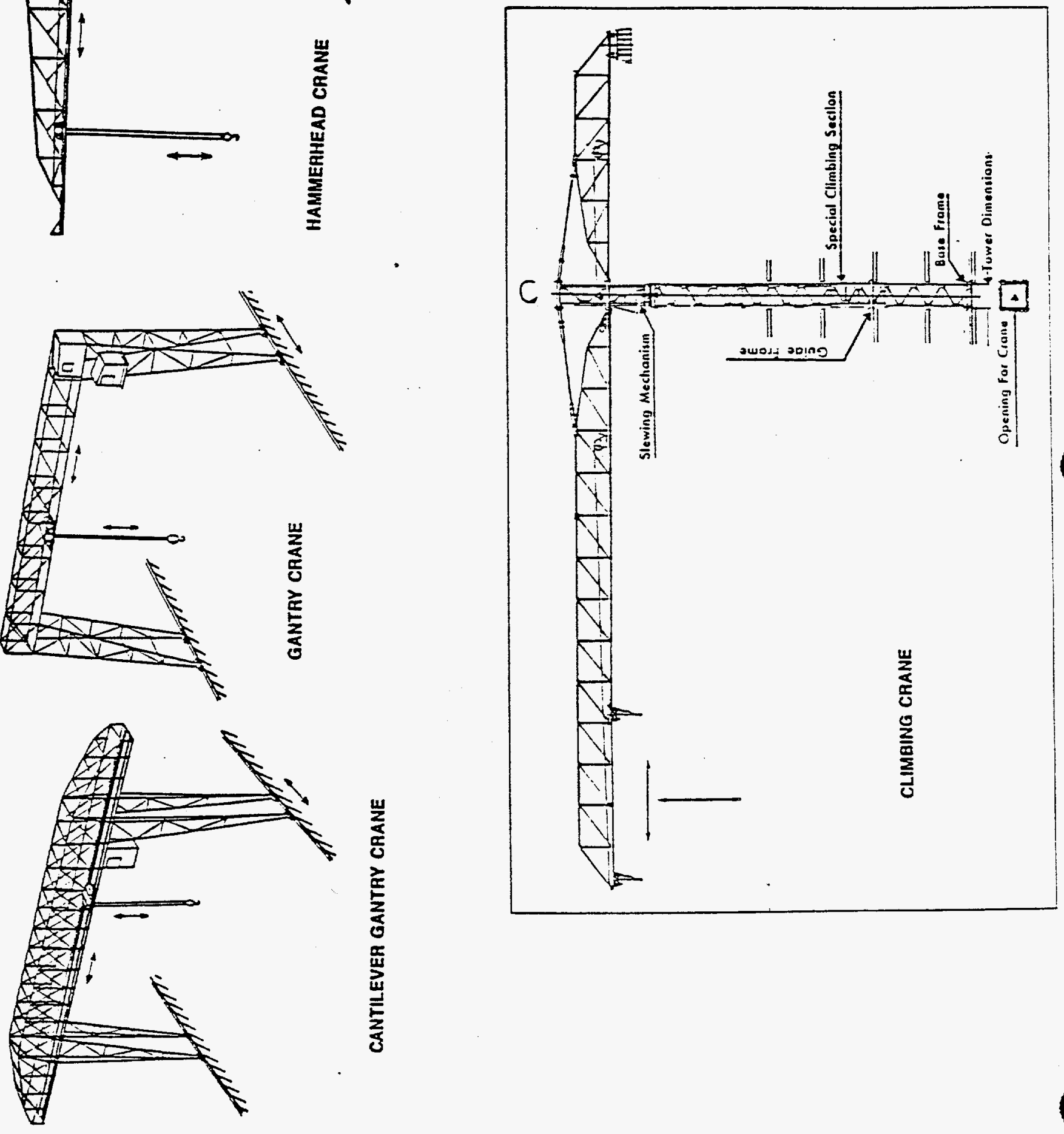
Table 5-1. Constraints and Requirements Imposed on a Disposal System by Federal and State Statutes. (5 pages)

\begin{tabular}{|c|c|c|}
\hline $\begin{array}{c}\text { Applicable Constraints/ } \\
\text { Requirements }\end{array}$ & Description & Source \\
\hline \multicolumn{3}{|c|}{ Constraints $(\mathrm{C})$} \\
\hline Design Life (C1) & $\begin{array}{l}\text { In choosing a disposal site, site characteristics should be } \\
\text { considered in terms of the indefinite future and evaluated for at } \\
\text { least a } 500 \text {-year time frame. }\end{array}$ & 10 CFR 6161.40 \\
\hline Surface Water (C2) & $\begin{array}{l}\text { Waste disposal shall not take place in a } 100 \text {-year flood plain, } \\
\text { coastal high hazard area, or wetland. }\end{array}$ & 10 CFR 6161.50 (a) (5) \\
\hline & $\begin{array}{l}\text { No dangerous waste management facility shall be located within } \\
\text { the one hundred-year flood plain as indicated in the most current } \\
\text { Federal Emergency Management Agency maps. } \\
\text { Land-based facilities shall be located such that the dangerous } \\
\text { waste management unit boundary is at least one-quarter mile } \\
\text { from a perennial surface water body. } \\
\text { No dangerous waste management facility shall be located in a } \\
\text { watershed identified in the report submitted to, and approved } \\
\text { by, the Department of Health under the authority of WAC 248- } \\
54-225(3), \text { Watershed control. } \\
\text { Land-based facilities shall be located such that the dangerous } \\
\text { waste management unit boundary is at least one-quarter mile } \\
\text { from the nearest surface water intake for domestic water. }\end{array}$ & WAC-173-303-282 (6)(c)(i) \\
\hline
\end{tabular}


Table 5-1. Constraints and Requirements Imposed on a Disposal System by Federal and State Statutes. (5 pages)

\begin{tabular}{|c|c|c|}
\hline $\begin{array}{c}\text { Applicable Constraints/ } \\
\text { Requirements }\end{array}$ & Description & Source \\
\hline & $\begin{array}{l}\text { Land-based facilities shall be located such that the dangerous } \\
\text { waste management unit boundary is at least one-quarter mile } \\
\text { from the following areas. } \\
\text { (A) Wetlands; } \\
\text { (B) Designated critical habitat, for federally listed threatened } \\
\text { or endangered species, as defined by the Endangered } \\
\text { Species Act of } 1973 \text { (P.L. } 93-205) \text {; } \\
\text { (C) Habitat designated by the Washington Department of } \\
\text { Wildlife as habitat essential to the maintenance or } \\
\text { recovery of any state listed threatened or endangered } \\
\text { wildlife species; } \\
\text { (D) Natural areas which are acquired or voluntarily registered } \\
\text { or dedicated by the owner under chapter 79-70 RCW, } \\
\text { Natural area preserves; and } \\
\text { (E) State of federally designated wildlife refuge, preserve, or } \\
\text { bald eagle protection area. }\end{array}$ & WAC-173-303-282 (6)(d)(ii) \\
\hline $\begin{array}{l}\text { Surface Water (C2) } \\
\text { (continued) }\end{array}$ & $\begin{array}{l}\text { Land-based facilities shall not be located in areas having a mean } \\
\text { annual precipitation level of greater than one hundred inches. } \\
\text { The mean annual precipitation map in the U.S. Geological } \\
\text { Survey Water-Resources Investigations Report } 84-4279 \text { shall be } \\
\text { used to determine whether a land-based facility is proposed to } \\
\text { be located in such an area. }\end{array}$ & WAC-173-303-202 (6)(e) \\
\hline Groundwater (C3) & $\begin{array}{l}\text { In no case is waste disposal permitted in the zone of fluctuation } \\
\text { of the water table. }\end{array}$ & 10 CFR 6161.50 (a) (7) \\
\hline
\end{tabular}


Table 5-1. Constraints and Requirements Imposed on a Disposal System by Federal and State Statutes. (5 pages)

\begin{tabular}{|c|c|c|}
\hline $\begin{array}{c}\text { Applicable Constraints } \\
\text { Requirements }\end{array}$ & Description & Source \\
\hline \multicolumn{3}{|c|}{ Constraints (C) (continued) } \\
\hline \multirow[t]{2}{*}{$\begin{array}{l}\text { Groundwater (C3) } \\
\text { (continued) }\end{array}$} & $\begin{array}{l}\text { The hydrogeologic unit used for disposal shall not discharge } \\
\text { groundwater to the surface within the disposal site. }\end{array}$ & 10 CFR 6161.50 (a) (8) \\
\hline & $\begin{array}{l}\text { Land-based facilities shall not be located in areas where there is } \\
\text { less than fifty feet vertical separation between the lowest point } \\
\text { of the dangerous waste management unit and the seasonal } \\
\text { highwater level of the uppermost aquifer of beneficial use. } \\
\text { Land-based facilities shall be located such that the dangerous } \\
\text { waste management unit boundary is at least one-quarter mile } \\
\text { from the nearest ground water intake for domestic water. }\end{array}$ & WAC-173-303-282 (6)(a)(ii) \\
\hline \multirow[t]{3}{*}{ Nearby Facilities (C4) } & $\begin{array}{l}\text { The disposal site must not be located where nearby facilities or } \\
\text { activities could adversely impact the ability of the site to meet } \\
\text { the performance objectives or significantly mask the } \\
\text { environmental monitoring program. }\end{array}$ & 10 CFR 6161.50 (a) $(11)$ \\
\hline & $\begin{array}{l}\text { Dangerous waste management facilities shall not be located } \\
\text { within the viewshed of users on wild and scenic rivers } \\
\text { designated by the state of federal government. } \\
\text { Land-based facilities shall be located such that the dangerous } \\
\text { waste management unit boundary is at least one-quarter mile } \\
\text { from the following land use areas: } \\
\text { (A) State or federally designated park, recreation area, or } \\
\text { (B) Wilderness area as defined by the Wilderness Act of } \\
\text { (C) Land identified as prime farmland at the time a notice of } \\
\text { intent is submitted to the department. }\end{array}$ & WAC-173-303-282 (7)(b)(ii) \\
\hline & $\begin{array}{l}\text { Land-based facilities shall be located such that the dangerous } \\
\text { waste management unit boundary is at least one-quarter mile } \\
\text { from residences or public gathering places. }\end{array}$ & WAC-173-303-282 (7)(b)(iii) \\
\hline Depth (C5) & $\begin{array}{l}\text { Near-surface disposal facilities will be within } 30 \text { meters of the } \\
\text { earth's surface. }\end{array}$ & 10 CFR 6161.51 (a) \\
\hline
\end{tabular}


Table 5-1. Constraints and Requirements Imposed on a Disposal System by Federal and State Statutes. (5 pages)

\begin{tabular}{|c|c|c|}
\hline $\begin{array}{c}\text { Applicable Constraints/ } \\
\text { Requirements }\end{array}$ & Description & Source \\
\hline \multicolumn{3}{|c|}{ Constraints (C) (continued) } \\
\hline Land Ownership (C6) & $\begin{array}{l}\text { Disposal of radioactive waste received from other persons may } \\
\text { be permitted only on land owned in fee by the Federal or a state } \\
\text { government. }\end{array}$ & 10 CFR 6161.59 (a) \\
\hline $\begin{array}{l}\text { Seismicity/Geomorphology } \\
\text { (C7) }\end{array}$ & $\begin{array}{l}\text { All dangerous waste management facilities shall be located such } \\
\text { that the dangerous waste management unit boundary is located } \\
\text { at least five hundred feet from a fault which has had } \\
\text { displacement in Holocene times. }\end{array}$ & WAC-173-303-282 (b)(a)(i) \\
\hline \multicolumn{3}{|c|}{\begin{tabular}{|l} 
Requirements \\
\end{tabular}} \\
\hline Long-term Stability (R1) & $\begin{array}{l}\text { The disposal site must be sited, designed, used, operated and } \\
\text { closed to achieve long-term stability of the disposal site and to } \\
\text { eliminate to the extent practicable the need for ongoing active } \\
\text { maintenance of the disposal site following closure so that only } \\
\text { surveillance, monitoring, or minor-custodial care are required. }\end{array}$ & 10 CFR 6161.44 \\
\hline Corrective Measures (R2) & $\begin{array}{l}\text { The licensee must have plans for taking corrective measures if } \\
\text { migration of radionuclide would indicate that performance } \\
\text { objectives may not be met. }\end{array}$ & 10 CFR 51.53 (b) \\
\hline Characterization (R3) & $\begin{array}{l}\text { The disposal site shall be capable of being characterized, } \\
\text { modeled, analyzed and monitored. }\end{array}$ & 10 CFR 6161.50 (a) (2) \\
\hline \multirow[t]{2}{*}{ Land Use (R4) } & $\begin{array}{l}\text { Within the region or state where the facility is to be located, a } \\
\text { disposal site should be selected so that the projected population } \\
\text { growth and future developments are not likely to affect the } \\
\text { ability of the disposal facility to meet performance objectives. }\end{array}$ & 10 CFR 6161.50 (a) (3) \\
\hline & $\begin{array}{l}\text { No dangerous waste management facility shall be located in an } \\
\text { archeological site or historic site designated by the state or } \\
\text { federal government. }\end{array}$ & WAC-173-303-282 (7)(e) \\
\hline Natural Resources (R5) & $\begin{array}{l}\text { Areas must be avoided having known natural resources, which, } \\
\text { if exploited, would result in failure to meet performance } \\
\text { objectives. }\end{array}$ & 10 CFR 6161.50 (a) (4) \\
\hline
\end{tabular}


Table 5-1. Constraints and Requirements Imposed on a Disposal System by Federal and State Statutes. (5 pages)

\begin{tabular}{|c|c|c|}
\hline $\begin{array}{c}\text { Applicable Constraints/ } \\
\text { Requirements }\end{array}$ & Description & Source \\
\hline \multicolumn{3}{|c|}{ Requirements (continued) } \\
\hline Groundwater (R6) & $\begin{array}{l}\text { The disposal site must provide sufficient depth to the water } \\
\text { table that ground water intrusion, perennial or otherwise, into } \\
\text { the waste will not occur. }\end{array}$ & 10 CFR 6161.50 (a) (7) \\
\hline & $\begin{array}{l}\text { To the extent feasible, proponents of land-based facilities should } \\
\text { seek sites with natural site characteristics which are capable of } \\
\text { providing protection of ground water resources. Natural } \\
\text { features such as low permeability soils and substrata, relatively } \\
\text { simple geologic formations, and high rates of evapotransporation } \\
\text { (evapotranspiration) in relation to the seasonal occurrence of } \\
\text { precipitation are preferable for the locations of land-based } \\
\text { facilities. Proposed land-based facilities shall comply with the } \\
\text { contingent ground water protection program, WAC 173-303- } \\
806 \text { (4)(a)(xxi), during the permitting process. } \\
\text { Non land-based facilities shall be located over an area } \\
\text { designated as a sole source aquifer under section 1424(e) of the } \\
\text { Federal Safe Drinking Water Act (P.L. 93-523). } \\
\text { Owners/operators of facilities shall identify whether the } \\
\text { proposed facility location is within a ground water management } \\
\text { area, as proposed or certified pursuant to RCW 90.44-130. In } \\
\text { order to maintain consistency with the purpose and substantive } \\
\text { requirements of certified ground water management area plans, } \\
\text { the department may require additional protective measures or } \\
\text { reject inconsistent projects. } \\
\text { Land-based facilities shall not be located within ground water } \\
\text { special protection areas designated by ecology under the } \\
\text { authority of chapter } 90.48 \text { RCW. }\end{array}$ & WAC-173-303-282 (6)(c)(ii) \\
\hline
\end{tabular}


Table 5-1. Constraints and Requirements Imposed on a Disposal System by Federal and State Statutes. (5 pages)

\begin{tabular}{|c|c|c|}
\hline $\begin{array}{l}\text { Applicable Constraints/ } \\
\text { Requirements }\end{array}$ & Description & Source \\
\hline Seismicity/tectonism (R7) & $\begin{array}{l}\text { Areas must be avoided where tectonic processes such as } \\
\text { faulting, folding seismic activity, or vulcanism may occur with } \\
\text { such frequency and extent to significantly affect the ability of } \\
\text { the disposal site to meet performance objectives or may } \\
\text { preclude defensible modeling and prediction of long-term } \\
\text { impacts. }\end{array}$ & 10 CFR 6161.50 (a) (9) \\
\hline \multirow[t]{3}{*}{ Geomorphology (R8) } & $\begin{array}{l}\text { Areas must be avoided where surface geologic processes such } \\
\text { as mass settling, wasting, erosion, slumping, landsliding, or } \\
\text { weathering occur with such frequency and extent to } \\
\text { significantly affect the ability of the disposal site to meet } \\
\text { performance objectives or may preclude defensible modeling and } \\
\text { prediction of long-term impacts. }\end{array}$ & 10 CFR 6161.50 (a) (10) \\
\hline & $\begin{array}{l}\text { No dangerous waste management facility shall be located such } \\
\text { that the dangerous waste management unit is within an area of } \\
\text { subsidence. }\end{array}$ & WAC $173-303-282$ (6)(a)(ii) \\
\hline & $\begin{array}{l}\text { No dangerous waste management facility shall be located such } \\
\text { that the dangerous waste management unit is within an area of } \\
\text { slope or soil instability, nor in the areas affected by unstable } \\
\text { slope or soil condition. }\end{array}$ & WAC $173-303-282(6)(a)(i i i)$ \\
\hline Drainage (R9) & $\begin{array}{l}\text { The disposal site must be generally well-drained and free of } \\
\text { areas of flooding or frequent ponding. }\end{array}$ & 10 CFR 6161.50 (a) (5) \\
\hline Surface Water (R10) & $\begin{array}{l}\text { Upstream drainage areas must be minimized to decrease the } \\
\text { amount of run-off which could erode or inundate waste disposal } \\
\text { units. }\end{array}$ & 10 CFR 6161.50 (a) (6) \\
\hline Retrieval Capability (R11) & $\begin{array}{l}\text { Designs for new RWM facilities shall incorporate features to } \\
\text { facilitate retrieval capability. }\end{array}$ & RLID 5820.2A $7.0(10)$ \\
\hline
\end{tabular}


Table 5-2. Initial Screening of Alternatives.

\begin{tabular}{|c|c|c|c|c|c|c|c|c|}
\hline $\begin{array}{l}\text { Constraints } \\
\text { Alternatives }\end{array}$ & $\begin{array}{l}\text { Design } \\
\text { Life } \\
\text { (C1) }\end{array}$ & $\begin{array}{l}\text { Surface } \\
\text { Water } \\
\text { (C2) }\end{array}$ & $\begin{array}{l}\text { Ground } \\
\text { water } \\
\text { (C3) }\end{array}$ & $\begin{array}{l}\text { Nearby } \\
\text { Facilities } \\
\text { (C4) }\end{array}$ & $\begin{array}{l}\text { Depth } \\
\text { (C5) }\end{array}$ & $\begin{array}{l}\text { Land } \\
\text { Ownership } \\
\text { (C6) }\end{array}$ & $\begin{array}{l}\text { Seismicityl } \\
\text { Geomorphology } \\
\text { (C8) }\end{array}$ & Remarks \\
\hline $\begin{array}{l}\text { Unconsolidated } \\
\text { Geologic } \\
\text { Materials }\end{array}$ & $Y$ & $\mathrm{Y}$ & $Y$ & $Y$ & $Y$ & $\mathrm{Y}$ & $Y$ & $\begin{array}{l}\text { The only alternative that } \\
\text { can meet all design } \\
\text { constraints. }\end{array}$ \\
\hline $\begin{array}{l}\text { Crystalline } \\
\text { Basalt Rock }\end{array}$ & $Y$ & $Y$ & $\mathrm{Y}$ & $Y$ & $Y$ & $Y$ & $Y$ & $\begin{array}{l}\text { Near-surface basalt } \\
\text { formations are located } \\
\text { west of FFTF, west of } \\
\text { Gable Mt., and northwest } \\
\text { of Rattlesnake Mt. }\end{array}$ \\
\hline $\begin{array}{l}\text { Argillaceous } \\
\text { Formation }\end{array}$ & NA & NA & NA & NA & NA & NA & NA & $\begin{array}{l}\text { Near-surface geologic } \\
\text { strata are not available. }\end{array}$ \\
\hline $\begin{array}{l}\text { Man-Made or } \\
\text { Natural Rock } \\
\text { Cavities }\end{array}$ & NA & NA & NA & NA & NA & NA & NA & $\begin{array}{l}\text { Mines/caverns do not } \\
\text { exist within the Hanford } \\
\text { Site. }\end{array}$ \\
\hline Fluid Injection & NA & NA & NA & NA & NA & NA & NA & $\begin{array}{l}\text { Near-surface geologic } \\
\text { strata are not available. }\end{array}$ \\
\hline
\end{tabular}

Table 5-3. Final Screening of Alternatives.

\begin{tabular}{|l|c|c|c|c|c|c|c|c|}
\hline \multicolumn{1}{|c|}{ Requirements } & $\begin{array}{c}\text { Long-term } \\
\text { Stability) } \\
\text { Geomorph. } \\
\text { (R1 \& R7) }\end{array}$ & $\begin{array}{c}\text { Ground- } \\
\text { water } \\
\text { (C5) }\end{array}$ & $\begin{array}{c}\text { Construct } \\
\text {-ability } \\
(10)\end{array}$ & $\begin{array}{c}\text { Land } \\
\text { Use } \\
\text { (R3) }\end{array}$ & $\begin{array}{c}\text { Seismicity } \\
\text { Tectonism } \\
\text { (R6) }\end{array}$ & $\begin{array}{c}\text { Drainage/ } \\
\text { Surface } \\
\text { Water } \\
\text { (R8 \&R9) }\end{array}$ & $\begin{array}{c}\text { Natural } \\
\text { Resources } \\
\text { (R4) }\end{array}$ & $\begin{array}{c}\text { Weighted } \\
\text { Score } \\
\text { Totals }\end{array}$ \\
\hline 200 Plateau Alluvium & 4 & 5 & 5 & 5 & 4 & 5 & 5 \\
\hline West FFTF Basalt & 5 & 3 & 4 & 3 & 5 & 5 & 225 \\
\hline $\begin{array}{l}\text { Northwest Rattlesnake Mt. } \\
\text { Basalt }\end{array}$ & 4 & 5 & 1 & 4 & 5 & 3 & 4 \\
\hline West Gable Mt. Basalt & 4 & 2 & 4 & 4 & 5 & 5 & 172 \\
\hline
\end{tabular}




\subsection{MONITORING}

\subsection{INTRODUCTION}

\subsubsection{Background}

The scenarios for successful vitrification and long-term safe storage of low-level waste (LLW) will require the use of nondestructive evaluation (NDE) technology for process control and nonintrusive monitoring of the glass forms, vault and engineering barriers. In addition, intrusive monitoring techniques will also be needed for periodic sampling for water and radionuclides around and under the disposal site. Monitoring and inspection technology will be needed for:

(1) Controlling the process of forming the vitrified waste by detecting and minimizing the formation of defects in the final product,

(2) Evaluating the final product or waste form to determine the defect (void, porosity, and crack) content and verify that the defect content is at or below acceptable levels,

(3) Monitoring the stored waste and closed vault structures to detect glass corrosion products as a function of time, and

(4) Long term monitoring for the migration of water and leached radionuclides through the disposal site (vault and engineering barriers) and surrounding environment.

Also, before the disposal site is sealed, test coupons of vitrified waste (similar to the stored vitrified waste form) and vault material will be appropriately placed in and around the site for periodic removal and testing throughout the active lifetime of the facility. The conduits or mechanisms for retrieval of these coupons will be developed in the near future. In addition, samples obtained from test wells or test conduits around and below the site will be periodically evaluated.

\subsubsection{Literature Review}

As part of this study, a review of literature was conducted to ascertain the state of the art in the nondestructive evaluation and monitoring technology. In addition, information on intrusive sampling was also obtained. The basis for the literature search was sensor technology and nondestructive evaluation of glass, concrete, barriers, and water tables. This resulted in identification of over 150 titles of which approximately 70 articles were received and reviewed. The articles covered topics such as ultrasonics, ground-penetrating radar, neutron scattering and absorption, positron annihilation lifetime spectroscopy, laser-induced fluorescence, beta-ray absorption, $x$-ray scattering and absorption, and optical scattering. These techniques will be addressed as they pertain to various aspects of the total LLW vitrification approach. Approximately 20 articles were obtained on water sampling and test coupon evaluation. 


\subsubsection{General Discussion of Waste Vitrification and Disposal Chronology}

The first step in the vitrification process is to monitor the waste and glass former streams. Then the waste stream is mixed with the glass formers, vitrified, poured into some form and allowed to solidify into the vitrified waste product. Once the vitrified product has been formed as glass blocks or plates in containers or cullet or marbles, it may be surrounded by (or mixed with) a matrix material such as sulfur cement. Simultaneously, the vault depository where the vitrified waste will be stored will also be constructed. Once the storage vault has been completed the vitrified waste must be transported to and received at this depository within the Hanford site. After all the waste has been placed into the vault, the waste will be covered with a minimum of a Resource Conservation and Recovery Act (RCRA) cover to control migration of water into the disposal site.

\subsubsection{General Discussion of Application of Monitoring Technology}

Inspection and monitoring techniques will be needed in various steps associated with the complete process from vitrifying the waste to the final storage and monitoring in a barriered vault. The approach taken was to consider inspection and monitoring at each step of the process, reviewing various techniques, and determining how they might be applied. The steps identified include monitoring of the waste/glass former streams, glass form, glass/matrix form, vault, and engineered sorption barrier(s).

Several major aspects related to the physical application of monitoring and evaluation technology include the development of procedures specific to the evaluation or monitoring requirement, the potential need for remote applications, and the physical instrumentation and wiring of the sensors. In the following paragraphs, the development of specific procedures is alluded to as a requirement, and the potential for remote application is described. However, the entire issue of instrumentation and physical wiring of the sensor technology, especially for long-term monitoring, has not been discussed. A significant amount of research and development has been conducted on fiber-optic transmission of electrical signals and data. Fiber optics are much more resistant to environmental problems than conventional wiring. However, the entire issue of instrumentation and wiring needs to be carefully addressed in the next few years. Often, the fiber-optic sensors can be chemically inert, can consume little power, are not affected by high-temperature or corrosive environments, have electrically low noise, and can handle numerous signals.

\subsection{REQUIREMENTS}

Three sources for determining requirements for monitoring and inspection of waste storage sites were reviewed: DOE 5280.2A; the Environmental Protection Agency (EPA) 40 CFR Chapter 1 Part 191 (7-1-92 Edition); and the Washington Administrative Code (WAC) Chapter 173-303-665 (which covers landfills for dangerous waste).

The Department of Energy (DOE) Order 5820.2A states it is necessary to "assure that external exposure to the waste and concentrations of radioactive material which may be released into the surface water, ground water, soil, plants, and animals results in effective dose equivalent that does not exceed $25 \mathrm{mrem} / \mathrm{yr}$ to any member of the public." Although this does not specifically say that the low level waste disposal site must be monitored, the only way to meet this above stated requirements is to monitor the disposal site. 
EPA 40 CFR Chapter 1 Part 191 (7-1-92 Edition) states that "disposal systems shall be monitored after disposal to detect substantial and detrimental deviations from expected performance. This monitoring shall be done with techniques that do not jeopardize the isolation of the wastes and shall be conducted until there are no significant concerns to be addressed by further monitoring." The cumulative release limits for a number of isotopes that could be contained in the vitrified waste are given in Table 1 on page 13 of EPA 40 CFR Chapter 1 Part 191 (7-1-92 Edition). This cumulative release rate covers a time frame of 10,000 years. In essence, the potential release rates would require detection of pico-curie levels.

WAC 173-303-665 states that a leak detection system must be designed, constructed, maintained, and operated between the waste/vault interface and the environment to detect any migration of liquid into the interface region.

This document also discusses the requirement for inspection during construction and operation. During the construction phase, the liners (or vaults) and covers must be inspected for uniformity, damage, and imperfections such as holes, cracks, thin spots, or foreign material. Immediately after construction, any synthetic liners or covers must be inspected to ensure tight seams and joints and the absence of tears, punctures, or blisters, and any soilbased and admixed liners or covers must be inspected for imperfections including lenses, cracks, channels, root holes, or other nonuniformities that may cause an increase in the permeability of the liner (vault) or cover. While the storage vault is in operation, it must be inspected periodically (for landfills, weekly is recommended; however, for the LLW storage, the period is yet to be determined) to detect evidence of (1) deterioration, malfunction, or improper operation of run-on and run-off control systems, (2) presence of liquids in leak detection systems, and (3) presence of leachate in and proper functioning of leachate collection and removal systems (if they exist). Also, after final closure of the vault, monitoring must continue to (1) verify that the leak detection system continues to operate properly throughout the expected storage life and (2) verify that the ground water monitoring system continues to operate properly.

\subsection{OPTIONS}

The literature review and experience with nondestructive sensor and measurement technology used for evaluation and monitoring provided a number of means to both evaluate the vitrified waste and to monitor for degradation of the vitrified waste and the associated barriers. The evaluation and monitoring technologies were studied with respect to three aspects: (1) for use in process control, inspection of the vitrified glass/waste product, and inspection of the disposal structures which require use of conventional sensor technology that can have minimum lifetime and can be maintained; (2) for use as monitors permanently placed in vaults or other structures which are not retrievable and must function for decades or longer; and (3) for use as monitors which are located outside the vaults within instrumented wells or similar conduits and which are accessible to maintenance as needed. This discussion is given in the following sections. 


\subsubsection{Inspection and Evaluation Technology for Glass and Disposal Site Structures}

The monitoring technology needed for evaluating the glass and the disposal site structures can utilize sensors and instrumentation that are much more accessible to human intervention, can be replaced, repaired, and maintained, and may need to work for approximately 20 years. The sections below discuss a number of sensors and sensor technologies which can be used during the process of making the glass as well as for evaluating the site structure prior to disposal of the vitrified waste.

6.3.1.1 Evaluating the Process Of Vitrification. Making good glass that will be durable and resistant to leaching will require the use of process control sensors and technologies. No matter which glass form is selected, it will be important to maintain uniform density and material properties (such as thermal expansion, heat conductivity, and tension strength) in the glass to minimize and mitigate the formation of cracks and voids. The process of vitrification will involve making quality glass, characterizing the waste stream that will be mixed with the glass, and characterizing the glass/waste mixture. Since the waste material will contain a large amount of sodium and radionuclides such as ${ }^{90} \mathrm{Sr},{ }^{137} \mathrm{Cs}$, and ${ }^{99} \mathrm{Tc}$, it will be necessary to monitor the glass chemistry and the parameters of the glass making process.

In addition, the disposal site structures, which will be constructed so that it is ready to receive the vitrified glass, must also be inspected (as required by WAC 173-303-665) prior to actual storage of the glass forms.

Potential techniques for process control and inspection of the glass product and preservice inspection of the disposal site structures are discussed below.

6.3.1.1.1 Optical Techniques For Process Control. Optical technology can be used in a number of ways to monitor and provide feedback control of the vitrification process. For example, the temperature of the molten glass can be monitored using optical pyrometers or other optically interfaced infrared technology. The output of the optical pyrometer can be used to control the furnace temperature. Optical pyrometry is illustrated in Figure 6-1.

Optical spectroscopy might be used to monitor the chemical composition of the waste stream by evaluating the optical spectral lines reflected or transmitted from the heated waste stream. This can be accomplished using recently developed technology which utilizes a pulsed laser to rapidly heat a small region of the material under evaluation. This produces a very localized plasma which emits optical radiation that contains spectral lines characteristic of the material. This approach is illustrated in Figure 6-2. Similar work discussed by Studt (1993) for evaluation of steel has resulted in a much more cost-effective way of analyzing the chemistry of molten steel than other techniques.

After the waste is mixed with the glass, the final product is usually transparent and has a specific color based upon the chemistry of the waste. The intensity of the light transmitted through the product could be monitored in various spectral bands to characterize and verify the uniformity of the glass composition (see Figure 6-3). It is anticipated that variation in properties of the glass or waste fill streams would cause changes in light transmission (either intensity and/or frequency). Since the light would penetrate a free standing glass form and no direct contact with the glass block is required, optical transmission 
could be used anytime during or after the glass is solid. The monitoring scenario might consist of inspecting a bare glass form as it passes by a laser or focused light/detector system in a production line. Although the parameters of the application of this approach must be determined, this technology would provide a fast inspection capability.

6.3.1.1.2 Gamma-Ray and X-Ray Technologies for Process Control. Since a key feature of the waste stream and the vitrified waste is density, gamma-ray techniques can be used to monitor the vitrification process by monitoring in real time the uniformity of the vitrified product. Gamma rays are high-energy particles that pass through material and are absorbed by the mass density of the material (see Figure 6-4). Gamma-ray transmission or absorption can be used to monitor the consistency of both the waste stream and the vitrified product. As the density of the waste increases, the gamma-ray transmission decreases.

$X$-ray fluorescence can also be used to characterize the elemental composition of the waste before it is mixed with the glass. Each atomic element has a characteristic electron structure. When this electron structure is changed due to atomic excitation (caused by energy absorption such as from an absorbed $\mathrm{x}$-ray), an $\mathrm{x}$-ray with energy characteristic of the electron configuration (called a characteristic $x$-ray) is produced (see Figure 6-5).

6.3.1.1.3 Infrared Technology for Process Control. Infrared sensors monitor the long wavelength energy (usually in the range of 0.8 to 5 microns) associated with thermal energy. Infrared technology can be passive or active. Passive infrared evaluates the energy contained in the material. Active infrared requires the use of a thermal source to excite the material under inspection and then monitor the release or absorption of the exciting thermal energy (see Figure 6-6).

Since the glass and waste streams must be heated prior to mixing, a passive infrared approach can be used to monitor their consistency and the spectrum obtained can provide information about glass/waste composition. Infrared technology can also be applied to the vitrified product.

6.3.1.2. Inspection of the Glass Form. After the glass has been formed, whether in large blocks, marbles, cullet, or flat plate, it needs to be inspected to verify that the block is free of voids, pores, and volumetric cracks and surface craze cracks. In addition, it would be helpful to evaluate the level of residual stress in the glass so that glass with large residual stress, which might later crack, would not be placed in storage and could instead by annealed.

Potential techniques for meeting these requirements include ultrasonics, $\mathbf{x}$-ray radiography, acoustic emission, fiber optics and optical techniques, positron annihilation lifetime spectroscopy, neutron scattering, and weighing.

6.3.1.2.1 Ultrasonics for Inspection of Glass Form. Ultrasonics can be used to inspect the blocks, plate, and marble forms, but is less applicable to the cullet form. The ultrasonic technique is very sensitive to cracks, voids, and inclusions. As the ultrasonic wave is traveling in a material and encounters a change in density (such as voids, pores, inclusions, or cracks), the wave is scattered (see Figure 6-7).

The ultrasonic wave must be efficiently introduced into the material under inspection. This is usually accomplished using a liquid coupling material. However, to minimize production of contaminated liquid during the inspection process, coupling techniques which 
make use of soft plastics and urethanes can be used. These approaches are referred to as dry-coupling techniques. Using dry-coupled ultrasonic wheels, the glass form can be inspected using remote and robotic approaches. Stockman, Mathieu, and Nicholson (1987) demonstrated the ability to detect, size, and characterize microspherical oxide inclusions (smaller than 200 microns) in glass using ultrasonics. The length of time and the degree of difficulty involved in the performance of ultrasonic examinations of the glass form will be dependent upon several issues including the critical defect size. The smaller the critical defect size, the longer in general the inspection takes. Specific procedure and application technology must be developed, but the basic ultrasonic technology has been developed and utilized for many years in many industries. Experience indicates that frequencies between 1 and $5 \mathrm{MHz}$ should be useful.

A concept of "layered" techniques, procedures, and evaluation criteria may be most appropriate for inspection of the glass form. This would involve using different angles and wave modes for characterization. Ultrasonic techniques can also be used to determine the depth, location and, in some cases, the type of the defect in the volume. Ultrasonic depth location is illustrated in Figure 6-8.

- The glass form may be more tolerant of subsurface flaws than surface cracks. This means that very small flaws at the surface must be detected. Resch et al. (1985) have demonstrated a surface wave technique for detection of small or shallow cracks in the glass surface. This is illustrated in Figure 6-9.

Ultrasonics may also be useful to evaluate the residual stress in the glass form. The ultrasonic work conducted by Suaris (1987) on a system used to study the levels of stress in concrete should have application to glass and barrier materials. This would also measure stress distribution through the volume thickness. The instrumentation for this approach is portable and should be amenable to remote sensing and monitoring.

6.3.1.2.2 X-Ray Radiography. X-ray radiography uses high-energy $\mathrm{x}$-rays to pass through material under inspection. As the $x$-rays pass through the material, they are affected by the density of the material. Defects such as voids or pores absorb less $x$-ray radiation. When a film or imaging system is placed behind the material, changes in the material density can be observed (see Figure 6-10) so that defects produce blank spots. Thus, $x$-ray radiography is sensitive to the detection of voids and pores. If a crack is located in the material, the distance through which the $x$-ray travels along the crack determines whether or not the crack will be detected (see Figure 6-11). Since the orientation of the crack is critical and since most cracks are not parallel with the $\mathrm{x}$-ray beam axis, $\mathrm{x}$-ray radiography is usually considered not to be very sensitive to cracks.

Digital radiography (DR) techniques (in which the imaging system used produces electronic signals that are converted from analog information to digital intensities) lend themselves to remote and robotic application since no film is needed. The digital images obtained using DR can be analyzed using computer algorithms which could provide a method for the data analysis to be totally automated. It is expected that the radiation level of the waste itself should have little effect on the use of DR, although highly radioactive vitrified waste could affect the size of the smallest defect to be accurately detected, since there would be more background noise in the image. 
Since the $x$-rays penetrate the glass and require no direct contact with the glass block, DR could be used any time during the glass solidification process. The monitoring scenario might consist of inspecting the glass form as it passes by the DR system in a production line. The parameters of the application of DR must be determined. However, this technology provides a fast, full-field inspection capability. Also, this technique would be most useful for inspecting large blocks of glass and less useful for other forms such as plate or cullet.

6.3.1.2.3 Acoustic Emission. Acoustic emission sensors can be applied to the glass form (block and plate) during the cooling stage to listen for defect generation. The acoustic emission approach is illustrated in Figure 6-12. As the glass is solidifying, any impurities or inhomogenities in the glass will produce stress sites. As the solidifying and cooling continue, the differences in localized thermal expansion cause defects to be produced. The production of defects causes energy to be released in the form of ultrasonic waves (or noise). Since the melted glass will most likely be poured into a mold or container for cooling, the mold or container, itself, will generate noise during the cooldown process. The noise generated during cooling which occurs as a result of natural contraction must be differentiated from defect generation. Work will be required to characterize the acoustic emission from the glass. However, the instrumentation and basic application concepts are developed. The application procedure must be developed.

Acoustic emission in the form of the acousto-ultrasonic (AU) method described by Grosskopf and Duke (1982) may be used for inspection of the glass form for cracks or areas of strain. In $\mathrm{AU}$, an ultrasonic excitation pulse is used to stress the material under test under several load conditions while monitoring the transmitted ultrasonic signal (see Figure 6-13). Analysis of the changes in the received signal can then be related to the condition of the sample. This method has been used successfully to locate damaged areas in siliconcarbide fiber-reinforced borosilicate glass at an early stage, before macroscopic crack formation. Some work would be required to determine the proper parameters to use for waste glass and the sensitivity of these parameters to the waste content.

6.3.1.2.4 Fiber Optics and Optical Techniques. Fiber optics and optical techniques can be used to inspect free standing glass forms, which should be basically transparent and/or translucent. Therefore, monitoring the. light passing through the glass should provide information about the glass quality. Light scattering due to formation of pores and voids can be detected either as loss of transmission (white light, laser light, or certain spectral bands) or reflected or backscattered light (see Figure 6-14). These approaches can be used with conventional or fiber optics. One non-contact, remotely actuated approach for detecting defects would be accomplished by projecting a uniform, high-intensity structured light source on one side of non-containerized glass form and monitoring the pattern of light that exits from the other side with a high-resolution camera. Any defects that exist within the volume would diffract or scatter the light in such a way as to create a unique light intensity pattern. Coupled to a high-speed frame grabber and computer, the camera would capture and digitize the light patterns in real time, and by comparing with patterns from good blocks, a decision as to the quality of the block could be made. The residual stress in the block can be observed using polarization effects. In addition, the optical approach can be used to image the entire glass form to verify proper size, dimensions, and shape if it becomes necessary to control these parameters. The effect of the waste on transmission and color of the glass must be taken into account for these methods to work. If the block is opaque these approaches will not work. The radiation level should be low enough to minimize the darkening of the optics. 
6.3.1.2.5 Positron Annihilation. Positron annihilation lifetime spectroscopy (PALS) is a very near-surface technique that allows positively charged beta rays to be incident onto a surface. Positron annihilation is illustrated in Figure 6-15. The technique can be used to detect free volume and pore sizes in materials, such as protective coating, silica gels, zeolites, and biological macromolecules. Work by Grobstein et al. (1991), Gregory (1991), Hasan et al. (1993), Hill et al. (1990), and Heater and Jones (1991) has illustrated the potential for the PALS technique. The technique utilizes a radioactive isotopic source such as $\mathrm{Na} 22$ which emits characteristic gamma rays within a few picoseconds of the emission of a positron. Detection of the characteristic gamma ray is followed by the detection of the $0.511-\mathrm{keV}$ gamma ray from the positron annihilation. This provides evidence of the presence of the positron and also permits the measurement of the positron's lifetime. The lifetime is a function of the electronic density in the vicinity of the positron. When the positrons are incident on the subject under inspection with the same environment, the probability of positron annihilation is a simple exponential. However, when the material is not uniform, then the mean lifetime is determined by the electronic density in the region where it spends its life. The comparison of lifetimes and intensities at various stages in the progress of defect accumulation can be very useful in revealing changes in the size or concentration of specific types of defects.

6.3.1.2.6 Neutron Techniques. Neutrons are high-energetic, penetrating atomic particles with no charge. As they pass through materials, they are affected by interactions in much the same way as billiard balls interact. This is illustrated in Figure 6-16. The scattered neutron is most affected by interaction with a particle of similar mass such as a proton or another neutron. Therefore, neutron techniques are most useful for providing information about the presence of hydrogen or other light molecules such as moisture. Neutron scattering, absorption, and radiography are very sensitive to voids and pores, and especially to moisture content. A californium source can be used to allow neutrons to be incident on the glass form, and neutron detectors can be used in a backscattered or transmitted mode. In the backscattered mode, the neutrons backscattered should increase with the amount of porosity. In the transmission mode, that intensity of transmitted neutrons should decrease with the amount of porosity. In addition, if a realtime imaging system is employed, the amount of porosity should be easy to visualize.

6.3.1.2.7 Thermography. Applications of thermography for detecting defects in composite materials (Rajaiah et al., 1990; Scott and Scala, 1982; Laine, 1992; and Vikstom et al., 1989) may have application to the inspection of the glass form. These studies showed that thermography can be used to detect defects such as delaminations, cracks, voids, and pores. In addition, thermography can be used to monitor the cooling of the glass forms and may also be useful in evaluating or monitoring the residual stress of the glass form.

Work by Sanchez-Lavega et al. (1990) looked at using the photothermal deflection technique for detecting semi-infinite gas slabs buried under the surface and parallel to the surface by passing a laser beam parallel to the surface of the slab. When the slab is hit by a high-intensity laser beam, a thermal wave is passed into the slab. Any defects will reflect the thermal waves and reheat the surface. When the probe laser beam is passed across the surface, the beam heats the air above the surface and deflects the beam. This could be used to remotely monitor glass for defects; however, the technology will require further development. 
6.3.1.2.8 Weighing. Finally, once the block or glass form is made, it should be weighed to verify density and consistency of material. It is assumed that each glass shape (such as block or sheet) will be produced in a mold or container with the filling carefully controlled. Therefore, if the process is working properly, each shape should have a mass that will be within a few percent of a nominal value.

6.3.1.3 Evaluation of the Glass/Matrix. To improve the resistance to leachability of the glass, the glass may be placed in or mixed with a matrix which is highly impermeable to water. One such matrix is sulfur concrete. The sulfur glass/matrix will be formed into storable shapes. For the glass/matrix approach to provide maximum resistance to water migration and glass leachability, the matrix shapes must be inspected to verify that there are no volumetric cracks, voids, or pores. Potential inspection techniques include low-frequency ultrasonics, $x$-ray radiography, acoustic emission, fiber optics, and beta ray.

6.3.1.3.1 Low-Frequency Ultrasonics. Low-frequency ultrasonics can be used to detect voids in the matrix and cavitation between glass form and matrix. Ultrasonic examination of the matrix material and glass/matrix should be very similar to the inspection of concrete (with aggregate) or composite materials (matrix with filler in various forms). This is particularly true in the case of cullet or marble glass forms with a relatively uniform distribution of the glass form throughout the matrix. In the case of block or sheet forms, the matrix material will be distinct components, and the examination of each may be considered separately, with the exception of the matrix/glass interface which must be examined to assure no voids exist at the interface.

The ultrasonic properties of the chosen matrix such as acoustic impedance, velocity, and attenuation will force certain choices in the examination of the materials. However, it is anticipated that frequencies significantly below $5 \mathrm{MHz}$ will be needed, possibly in the range of $50 \mathrm{kHz}$ to $250 \mathrm{kHz}$.

To avoid the possibility of introduction moisture into the matrix, dry-coupled techniques should be used.

6.3.1.3.2 X-Ray Radiography. X-ray radiography in the form of realtime digital radiography (DR) can also be used to inspect the glass/matrix form for defects such as voids and pores in the matrix as well as voids and pores in the glass. It is assumed that the - inspection technique needs to be able to detect cavities between the glass and the matrix. If the ultimate form is a block, then $\mathrm{x}$-ray sources with potentials greater than $300 \mathrm{kV}$ will most likely be needed.

6.3.1.3.3 Acoustic Emission Technology. Acoustic emission can be used to monitor the glass/matrix storage blocks for cracking and cavitation while the matrix cures and during long term storage. Piezoelectric or PVDF sensors could be embedded in the matrix or taped on the surface (see Figure 6-17). Weng (1982) and Dunn (1984) have demonstrated two AE techniques for monitoring and characterizing the deterioration of reinforced concrete due to corrosion of the steel-reinforcing member. These techniques may apply also to the case of the "glass-reinforced" matrix. Additional study will be needed to verify this approach.

6.3.1.3.4 Visual Inspection Techniques. The matrix form can be inspected using visual approaches to look for surface defects. Visual inspection can be conducted using automated camera systems which are interfaced with computer vision so that remote inspection and analysis can be conducted. 
6.3.1.3.5 Photo-Thermal Deflection. Photo-thermal deflection is an active infrared inspection technology that can be remotely applied to evaluate the quality of material under inspection. The photo-thermal technique is illustrated in Figure 6-18. The work by SanchezLavega using the photothermal deflection technique for detecting semi-infinite gas slabs buried under the surface and parallel to the surface could also be used to inspect the glass/matrix. By having a high-intensity laser beam hit the glass form, a thermal wave is passed into the slab. Any defects will reflect the thermal waves and reheat the surface. When the probe laser beam is passed across the surface, the beam heats the air above the surface and is deflected. This technique could be used to remotely monitor the glass/matrix form for defects; however, the technology will require further development.

6.3.1.4 Inspection of the Vault for Defects Prior to Service. The vault is the second barrier to mitigating the leaching of the vitrified waste, and it is imperative that the vault prevent water from reaching the vitrified waste for as long as possible. Therefore, the vault (which will most likely be fabricated from some type of sulfur concrete or a combination of sulfur concrete/asphalt) must be free of voids and cracks which could permit water migration through the material. Thus, NDE inspection techniques should be used to inspect the vault after construction.

Concrete contains microdefects even before the application of any loads. The microdefects may be bond cracks at the mortar aggregate interface or voids in the mortar matrix. These defects are a result of shrinkage, creep, bleeding, settlement of coarse aggregate, etc. This also applies to sulfur concrete. NDE techniques such as ultrasonics, acoustic emission, infrared, $x$-ray radiography, and ground-penetrating radar can be used to detect and monitor the presence and growth of cracks.

6.3.1.4.1 Ultrasonic Inspection. Low-frequency ultrasonics have been used for over 50 years to evaluate the quality of concrete. Work by Suaris (1987) showed that the amplitude of the transmitted ultrasonic pulse is better than the determinations of pulse velocity change for monitoring stress in concrete. In essence, the transmitted amplitude decreases as the stress increases. The amplitude begins to decrease at approximately 40 percent of the peak stress and continues to decrease (as much as 70 percent) when the peak stress is reached. The technology is portable and could be used for remote sensing and monitoring.

The materials utilized in the construction of the vault will affect the specific ultrasonic inspection parameters. If a sulfur concrete is used, then it may or may not contain filler or reinforcing material. Current concrete and composite inspection technology will form the basis for the actual techniques used.

Ultrasonic approaches can be used for voids and cracks. When the walls of the vault have been poured and cured, the entire material can be inspected using ultrasonics. It is anticipated that these techniques will be sensitive to defect voids as small as 0.25 inch diameter. The techniques should also be sensitive to distributed porosity or honeycomb. However, the level of sensitivity is dependent upon the ultrasonic property of the actual vault material. Also, ultrasonics can be used to monitor the cure of the sulfur concrete. Frequency ranges between $50 \mathrm{kHz}$ and $500 \mathrm{kHz}$ would be most useful for this inspection.

Due to the large size of the vault, it would seem prudent to use robotic/portable automated scanning systems capable of performing the ultrasonic inspection in the least manhour intensive manner. Again, dry-coupling techniques as described earlier need to be used. 
6.3.1.4.2 X-Ray Radiography. Assuming that the walls of the vault are poured or put up so that they will be free standing, then a realtime $x$-ray system with an $x$-ray-sensitive camera can be used in a through-transmission mode to inspect for voids and porosity (or honeycomb).

6.3.1.4.3 Acoustic Emission. Long-term acoustic emission monitoring of the vault could detect and locate any cracking or spalling of the vault structure. This would be most important in the first few years after construction while the structure settles. Embedded sensors linked to instrumentation on the surface could be expected to survive for several years.

Work by Adams et al. (1991) showed that for certain types of glass-reinforced plastic (GRP), analysis of modal properties can be a cost-effective way of determining defects. Some of the methods used include (1) determination of global response from measurements and excitation at a single point, (2) multiple measurements of local response over the structure due to single-point excitation, (3) measurement of local responses at all points on the structure due to excitation at the same points, and (4) measurement of global response at a selection of points due to multipoint excitation as in modal survey.

\subsubsection{Retrievable Monitors for Water and Other Defects in Vault}

The main cause of leaching is the migration of water into and through the vault and glass/matrix form. Boreholes and other types of conduits can be placed around and below the storage vault to serve as regions where sensors can be placed to detect moisture and radioactivity.

A number of techniques have been developed to detect levels of moisture in the ground. These include electrical resistivity approaches and radio-frequency imaging. Work by LLNL has shown that small-diameter boreholes (approximately 1 -inch diameter) can be placed around the vault to detect the presence of as little as 10 gallons of water. This technique is called electrical resistivity tomography (ERT) and will require boreholes as deep as 30 to 50 feet below the bottom of the vault. In addition, some question exists in terms of how far apart the ERT sensors can be placed relative to each other to accurately detect small amounts of water. A similar electrical resistivity technique using surface probes only has been developed by WESTEC.

The radio-frequency-imaging method (RIM) uses antennae that go into boreholes around or under the vault and detect the presence of small amounts of water lapproximately 50 gallons). The boreholes need to be approximately 2 inches in diameter, and varying antennae must be used to cover the entire frequency range from $2 \mathrm{kHz}$ to $16 \mathrm{MHz}$.

In addition, small compartments with access doors can be placed near the vault. These compartments would contain test coupons of vitrified waste in the matrix form and surrounded by vault material. Periodically, the test coupons will be removed and tested to measure deterioration of the glass.

Upon completion of the vault, sensors need to be placed around the vault that will allow the capability to monitor for the presence of water. It is assumed that the giass/matrix forms will be placed in the vault and then surrounded either by additional sand or some other filler that will fill in the voids. Moisture sensors can be periodically placed in the filler. 
Other potential techniques include neutron absorption, gamma-ray absorption, fiber optics, thermography, microwave, and ground-penetrating radar.

Neutron absorption has been used to monitor the level of moisture in soil, as illustrated in Figure 6-19. The neutron source is placed across from a detector with an amount of soil between the detector and source. The moisture scatters the neutrons so that the intensity of the neutrons getting to the detector decreases as the moisture increases.

A slightly different NDE technique was developed to measure moisture (Lahmon, 1970). The technique consists of using a 4.5-mc radium-beryllium source which emits fast neutrons and high-energy gamma rays. The moisture channel uses two boron trifluoride tubes which are sensitive to neutrons but not gamma rays. The density channel uses two halogenquenched detectors which are sensitive to gamma rays but not neutrons. The moisture is monitored by measuring the neutrons scattered back to the detectors. The density is measured by measuring the gamma rays scattered back to the detectors. Tests on samples showed an increase in neutron scattering of a factor of almost 10 for wet materials over dry materials. The system was used to study concrete and should have potential application to glass and barrier materials. The technology is fairly portable and could be used on a robot or a small hand cart.

A neutron radiation testing technique called neutron hygrometry, developed by $\mathrm{G}$. Sh. Pekarskiifor et al. (1978) is used for measuring the level of moisture in asbestos-cementcoated pipes. The pipewall thickness was from 1 to $5 \mathrm{~cm}$. A californium 252 source was used. The neutron flux is measured for both transmitted and reflected neutrons. The technique can measure moisture with an accuracy of approximately $\pm 0.5 \%$. The time needed per measurement is approximately 1 to 2 minutes.

\section{Gamma-ray absorption can also be used to monitor the moisture.}

Fiber-optic techniques can be used to detect the presence of water inside the vault walls or on the surface of the vault walls. The fiber optic can be attached to the walls so there is intimate contact between the fiber and the wall. If moisture contacts the fiber at any place along the wall, then the approximate location along the length of the fiber can be detected. In addition, work reported in Photonics Spectra and Laser Focus World describe the fiber-optic sensors that have been embedded in concrete structures to monitor curing, temperature, and long-term strain.

Thermography can be used to detect moisture in the vault and surrounding barriers. A study by Koerner et al. (1979) showed that thermographic techniques can be used to detect ground water. Thermographic cameras have been used with satellites to monitor for surface conditions on the earth such as water and vegetation. Similar approaches can be used for the vaults. Thermography can be applied using robotics.

Work by Lyon et al. (1986) showed that radar can help locate and determine the extent of internal damage or cracking in structures. Radar data can be interpreted for damage such as broken rebar, cracks or delamination in concrete, and the presence and size of voids. Radar systems are also useful for locating of buried structures in soils and for accurate measurement of depth to sewers, tunnels, and plastic pipe. Analysis of literature and results of projects indicate radar can locate cracks and voids in materials above and below ground. Radar can be used to discriminate soil features such as clay and rocky layers, and to precisely measure depth to targets including air filled voids and steel pipe. 
The radar units are operated near or on the ground using short nanosecond pulses with frequencies between 10 and $1000 \mathrm{MHz}$. The radar return is altered by changes in material composition and produces a signal which can be interpreted for anomalous structure or damage. The location of defects can be determined within approximately $3 \mathrm{~cm}$. This can be practically used for monitoring the condition of barriers. The instrumentation is portable and should be adaptable to remote sensing and monitoring.

\subsubsection{Nonretrievable Monitors Placed in the Glass Forms and Vault}

Prior to the closure of the vault containing the vitrified waste, various types of sensors that can monitor the presence of water and effects of leaching of the glass can be placed inside the vault. These sensors will not be retrievable and must be capable of operating for a long period of time. By using fiber optics embedded in the vault for supplying light and power to these sensors, the monitoring techniques described below can be useful for a number of years.

A number of monitoring techniques have been investigated for verifying the integrity of the waste (form) after it is placed in the depository. If it can be assumed that leachability is directly related to the corrosion of glass and that the corrosion process for glass produces a gel layer on the surface, then near-surface monitoring techniques such as laser (light) scattering, laser-induced fluorescence (LIF), and positron annihilation lifetime spectroscopy (PALS) can be used to detect the glass corrosion process. For the PALS technique, the isotopic beta-ray source $\left({ }^{22} \mathrm{Na}\right)$ which has a half-life of 2.6 years can be used with detectors whose power can be transmitted via fiber optics embedded in the vault. The light-scattering and LIF techniques can use laser light transmitted via embedded fiber optics and detectors and data acquisition which use electronics powered via embedded fiber optics (see Figure 6-20). The gel layer has a high level of hydrogen (Doremus, 1979); glancing incident neutron scattering should provide a method to detect the buildup of hydrogen.

Sensors can be placed at the surfaces of the glass for groundwater filtration. Once moisture is detected on the surface of a glass block, it may be assumed that water has broken through the engineering barriers. These types of sensors must be long-lived with minimal maintenance requirements. Potential techniques include neutron absorption, gamma-ray absorption, fiber optics, beta ray, microwave, and ground-penetrating radar.

Neutron probes can be placed on the outside surface of the glass form to determine when water impinges on the glass surface. Ohnuki (1984) developed an approach which makes use of fast neutrons (2-MeV neutrons emitted by a californium 252 source) detected by an NE-213 organic detector. The equipment setup is simple and can be used in a remote sensing scenario. The data clearly show that the counting rate of transmitted neutrons decreases as the moisture increases, and the technique was shown to be useful for moisture levels of approximately 5 to 40 percent.

This approach should have application to glass and barrier materials and would be an excellent way to also measure moisture distribution through the volume thickness, i.e., is there more water on the outside of the glass block than on the inside. The instrumentation for this approach is portable and should be adaptable to remote sensing and monitoring. 
Similar work by Unruh (1990) on the vadose zone (unsaturated zone) was conducted by monitoring fast neutron thermalization (FNT). Unruh showed that this technique provides a means of determining, with an acceptable degree of confidence, the continued integrity of solid waste landfills. FNT is an NDE method for determining the in situ moisture content of subsurface soils. The method uses a radioactive source to emit fast neutrons into the zone of investigation. The emitted neutrons collide with particle matter within the zone of influence and are slowed down or thermalized to their natural state. The thermalized neutrons are detected at the receiver located above the source and are counted for a preset length of time. An increase in moisture ins indicated by an increase in the neutron count. The technique is calibrated by using samples with known water content, and a linear regression curve is obtained which serves as the calibration curve of the instrument. This technique should be very practical for monitoring the condition of glass. The instrumentation for this approach is portable and should be adaptable to remote sensing and monitoring.

Work by Singh et al. (1977) on gamma-ray absorption and transmission show that the gamma-ray transmission method for the determination of moisture can be very accurate because the source, detector, electronic equipment, and thickness of the sample can be fixed. Using the normal Biers Law, theoretical expressions are provided for the intensities of transmitted gamma rays as a function of moisture. The equipment is portable and can be used for monitoring and remote sensing.

Work by Ayorinde (1983) look at using dual-energy gamma rays produced by $\mathrm{Cs}-137$ and Am-241 to simultaneously monitor soil density and moisture content. This has potential for monitoring degradation effects as well as moisture migration.

Fiber-optic approaches can help detect the onset of glass corrosion. One approach might include using a laser-excited fiber-optic sensor bonded to the glass block at several points. If cladding is removed at the points of interest, when moisture or glass corrosion products come in contact with the fiber, the light-guiding characteristics of the fiber change, which allows light to scatter away from the fiber. If the intensity of light transmitted down the fiber is monitored, then as the glass comes in contact with moisture or begins to corrode, the transmitted intensity decreases. Using optical time-domain reflectometry, the position of the water can be determined. A similar approach using infrared-sensitive fibers can be used to detect the presence of water vapor as well as water and glass corrosion products.

Beta-ray-absorption techniques can be used to detect small amounts of moisture (Bunnenberg and Kuhn, 1977). The beta emitter TL-204 (at approximately $2 \mathrm{mCi}$ ) is placed on a disc and placed on the glass or vault wall. An Si-surface barrier detector is centered above the disc at a distance of approximately $70 \mathrm{~mm}$. Calibration curves were obtained by artificially wetting and drying different probe materials. Measurements were obtained with 99-percent accuracy. The equipment is portable and can be used for monitoring.

Hill (1990) and Hill et al. (1990 and 1993) conducted work using positron annihilation for detecting the embrittlement and aging damage of polycarbonate structures caused by electromagnetic radiation from the sun. Some question has been raised about the potential for devitrification. The positron annihilation lifetime spectroscopy (PALS) technique might have potential for monitoring for the devitrification process. 


\subsubsection{Nonretrievable Monitors for Presence of Radionuclides and Moisture in Sorption Barrier}

The final barrier to keeping the radionuclides from getting into the water table is the sorption barrier. It is hoped that certain nuclides will react with the sorption layer and produce color changes which can be monitored using fiber optics. If the sorption layer is periodically illuminated with a broadband light source, the reflected spectra (gathered with fiber-optic detectors) can be analyzed to determine whether leaks through the sorption layer have occurred. Work conducted by Koerner et al. (1979) compared conventional approaches of measuring moisture in subsurface regions (which often consist primarily of boring and collecting samples) to a new approach using tracer dyes. Dyes are visually observed while tracers must be detected.

$X$-ray fluorescence can be used to detect the presence of high atomic number elements in the sorption layer.

Also, Koerner suggested that infrared also had potential to locate ground water and locate moisture in regions similar to the sorption barrier. He further suggested that microwave reflection and acoustic emission techniques could be used.

\subsubsection{Conventional Monitoring Technologies}

The most conventional approach to determining whether or not radioactive and hazardous materials are leaching out of the waste into the water is to drill test wells and chemically analyze the water for the presence of the hazardous contaminants. A thorough discussion of water quality analytical techniques is included in the Chapter 6 of the book entitled Hazardous Waste Management Handbook, edited by Andrew Porteous.

The water is tested for turbidity, color, electrical conductivity, $\mathrm{pH}$, permanganate value, biochemical oxygen demand, total organic carbon, and chemical oxygen demand. Other tests conducted include an evaluation of the free ammonia, total oxidized nitrogen, chloride, total hardness, phosphate level, fluoride, sulfide content, and cyanide. Techniques used for analysis include atomic absorption spectrophotometry, gas chromatography, flame ionization, high-performance liquid chromatography, mass spectroscopy, and ion chromatography.

\subsection{SELECTION METHODOLOGY FOR EVALUATION AND MONITORING}

\subsubsection{Sensor Technologies Used for Process Control and Inspection}

Upon definition of the exact glass-making process, the form of the glass, the matrix, the containers, and the vault and barriers, optimum evaluation and monitoring technologies and sensors can be defined. Once the sensors have been selected associated instrumentation can also be identified. Work will be required to develop appropriate procedures and verify the sensitivities of the chosen methodologies. 


\subsubsection{Retrievable Coupons and Sensors}

Upon definition of vault design and construction, concepts for placing and retrieving test coupons of glass and vault material can be developed. These coupon samples can be evaluated in aboveground laboratories. In addition, conduits and boreholes can be placed adjacent to the vault for sensor access. These sensors will be used only periodically. The technologies to be employed will be determined following an evaluation of the methodologies to characterize measurement capabilities.

\subsubsection{Nonretrievable Sensors}

One of the most important aspects of the long-term monitoring of the vitrified waste and storage vault is the need for embedded sensors that can operate for periods of hundreds of years. If fiber optics are used and a nonleak approach for running fiber optics from the top surface into the vault can be developed, then only the detectors and some sources will be required to last for hundreds of years. This concept could be used for optical, neutron, gamma-ray, and beta-ray techniques. For example, laser scattering could be conducted on glass surfaces inside the vault by setting up a glass sample in relationship to a fiber-optic transmitter and receiver. A laser and optical detector could be used at the ground level. For neutron, $x$-ray, and beta-ray techniques, long-lived sources could be buried in the vault. A detector could be placed on the glass or vault sample which would be powered via fiber-optic technology. Again, since the source is long-lived, the only requirement for the effective use of these approaches is that the fiber optic could be embedded in the vault in such a way that no leak path would exist.

\subsubsection{Fiber Optics and Raman Spectroscopy}

A recent development in monitoring ground water contaminants involves the use of fiber optics and Raman spectroscopy. This approach, developed by Hirschfeld et al. (1983), provides a number of advantages over presently used technologies. First, the present technologies require boreholes on the order of 6 inches be drilled so that samples of water can be obtained through them. The fiber-optic approach would require much smaller holes that could be put in with penetrameter technology. Second, when the fiber optic is in place, the sample can be studied in situ versus the present technology of pulling samples through the borehole to the surface. This usually guarantees the contamination of the test sample. Third, fiber optics is a real time approach versus sending a sample to a lab for analysis. Fourth, fiber optics can be placed in the layers around the site. For example, fiber optics could be placed in the clay layers, zeolite layers, and in the vault walls. The fiber-optic probe works by illuminating the fiber and sending light through the fiber. The fiber can be unclad in several regions, which allows the light to scatter into the surrounding medium. The scattered light interacts with the contaminants in the surrounding medium and causes fluorescence, which can be detected with the remote Raman spectroscopy unit illustrated in Figure 6-21. This approach can be used to monitor nitrates, determine $\mathrm{pH}$, and detect organics. The fiber optics can be embedded in the material for decades. 


\subsection{OPTIMIZATION OF EVALUATION AND MONITORING TECHNOLOGIES}

The sensors and instrumentation needed to evaluate the vitrification process and to inspect the glass form for defects already exist and with limited engineering effort can be applied to this process. The technologies needed to evaluate the glass form/matrix most likely exist, but the glass form/matrix needs to be identified before the technologies can be optimized. The sensors and instrumentation needed to perform the long-term monitoring must be further characterized with respect to lifetime and how to ensure long life.

\subsection{RECOMMENDATIONS}

The recommendations for the monitoring and evaluation sensors must be made after a more thorough definition of the glass form, matrix, and vault material and the exact form of the vault. Based upon the requirements in the RCRA, 40 CFR, and WAC documents, it seems clear that the site where the vitrified waste is stored must be monitored for contamination migration. To effectively ensure that the vitrified waste does not get into the water table for the longest time, it is recommended that a number of steps be taken along the vitrification/disposal process.

First, once the actual vitrification process has been developed, process control sensors should be used to monitor the critical steps in the vitrification process to ensure that the waste is in the most stable and bound condition in the waste.

Second, the vitrified waste should be placed in a matrix that greatly retards the potential for migration of water into the matrix/vitrified waste. Once the matrix has been formed, it should be inspected to verify uniformity, i.e., minimal porosity and no cracks. This inspection should occur just prior to placing the vitrified waste into the disposal vault.

The vault that will serve for the final disposal site must be constructed properly and also contain fiber-optic and other embedded sensors that will ultimately be used to monitor the potential migration of water through the vault and vitrified waste. The vault must be inspected to ensure that it is free of major defects that would allow water to easily migrate through it.

Finally, the closure of the disposal site needs to be inspected and have fiber-optic monitors placed in the various layers to monitor the migration of water into and through the vault.

The sensors and procedures associated with the recommended monitoring approach need to be optimized for the vault. 
Figure 6-1. Illustration of Optical Pyrometer.

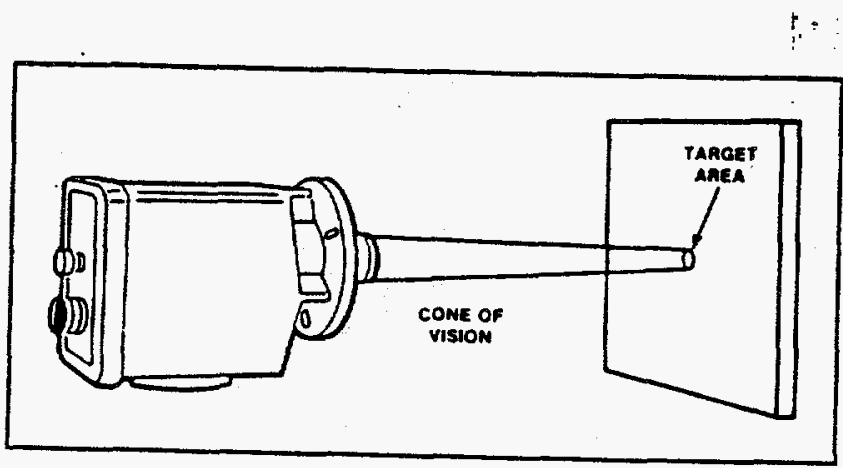

Figure 6-2. Illustration of the Optical Spectroscopy Technique Using Heating Laser to Form Plasma and Looking at the Plasma to Obtain Spectral Lines.
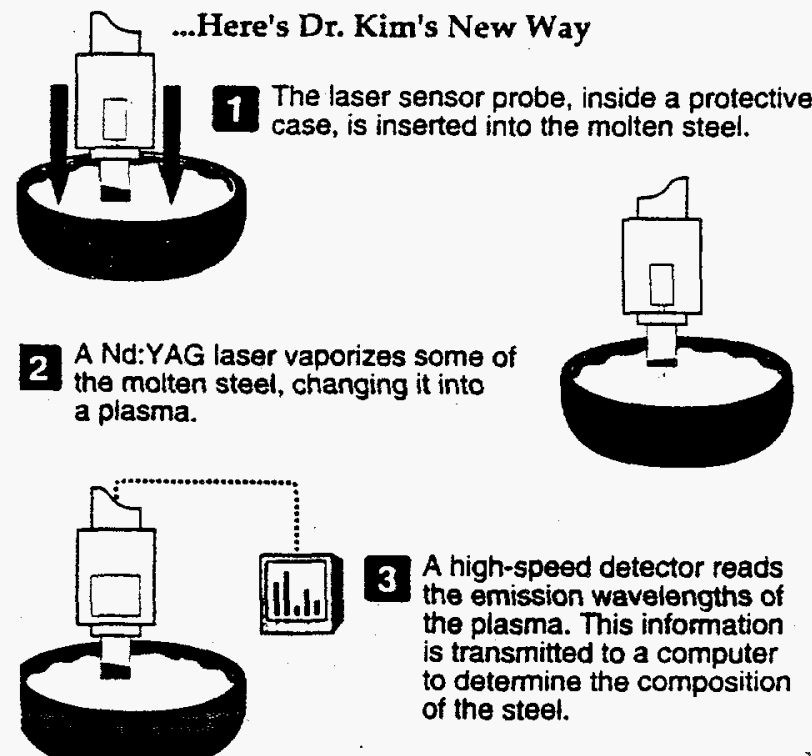

Time: Less than 1 minute 
Figure 6-3. Illustration of How Light Transmitter through Vitrified Glass Product Could be used to Monitor Consistency and Uniformity.

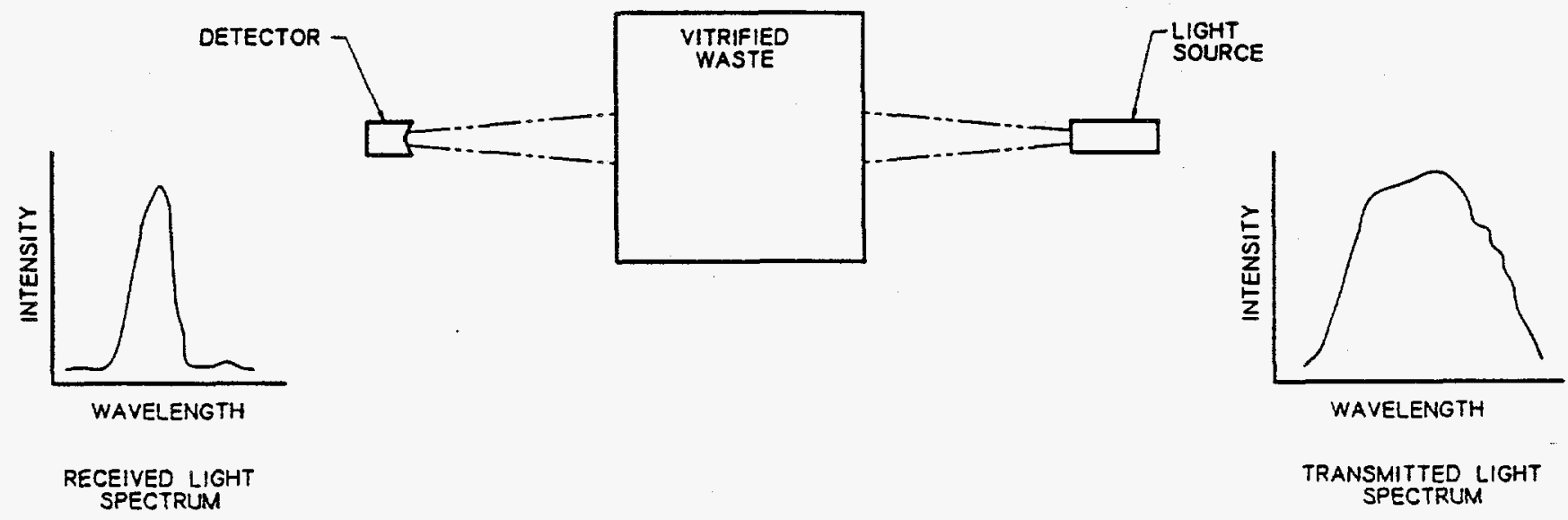

Figure 6-4. Illustration of Gamma Rays Penetrating a Material and Providing Information about Material Density.

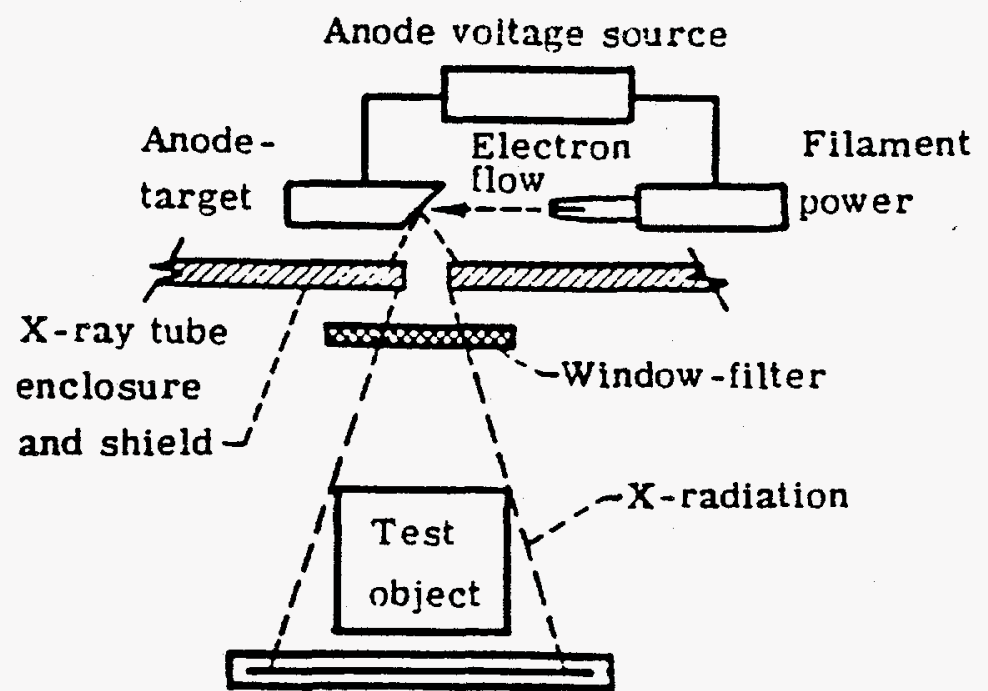

Film cassette 
Figure 6-5. Illustration of X-ray Fluorescence.

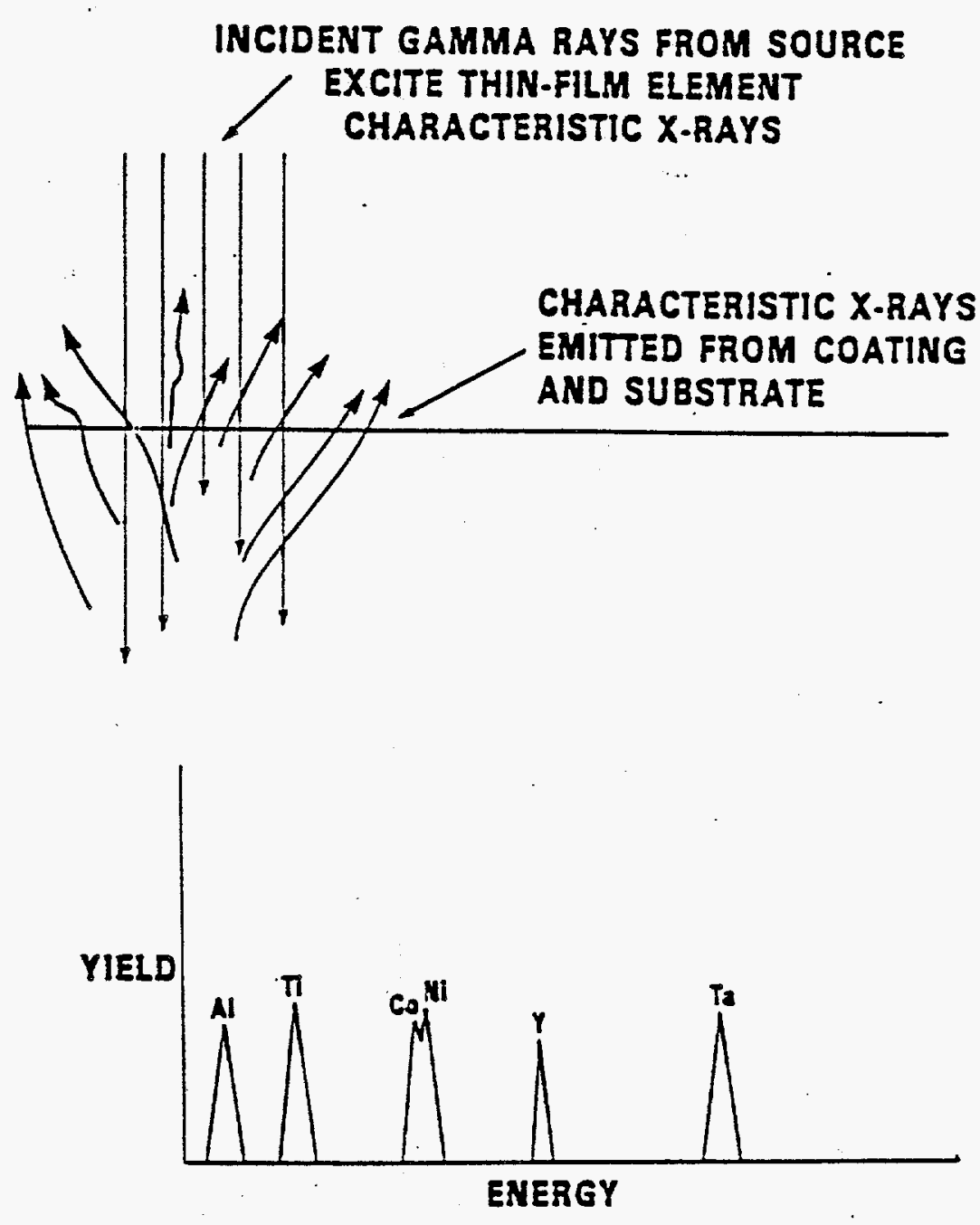

\section{CHARACTERISTIC X-RAY SPECTRUM OBTAINED FROM THE COATED SUBSTRATE}


Figure 6-6. Illustration of the Active and Passive Infrared Inspection Technique.

\section{Active}

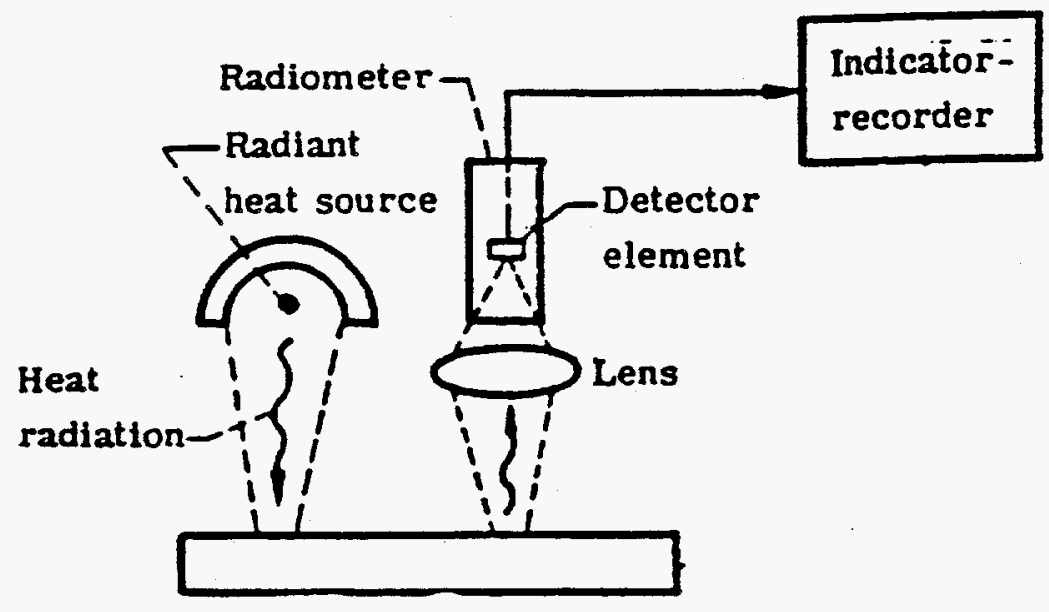

\section{Passive}

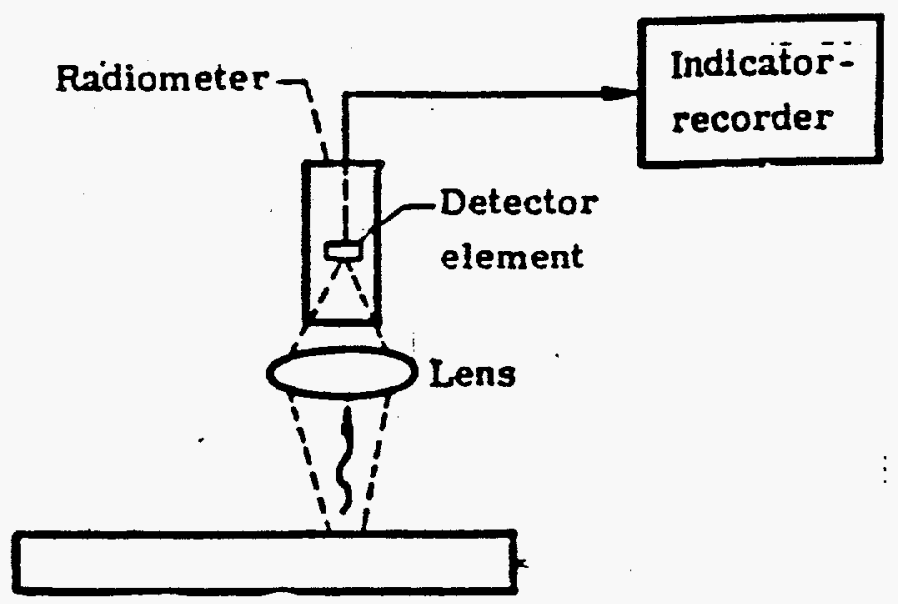


Figure 6-7. Illustration of Ultrasonic Inspection of Materia! (such as glass product form) for Defects.
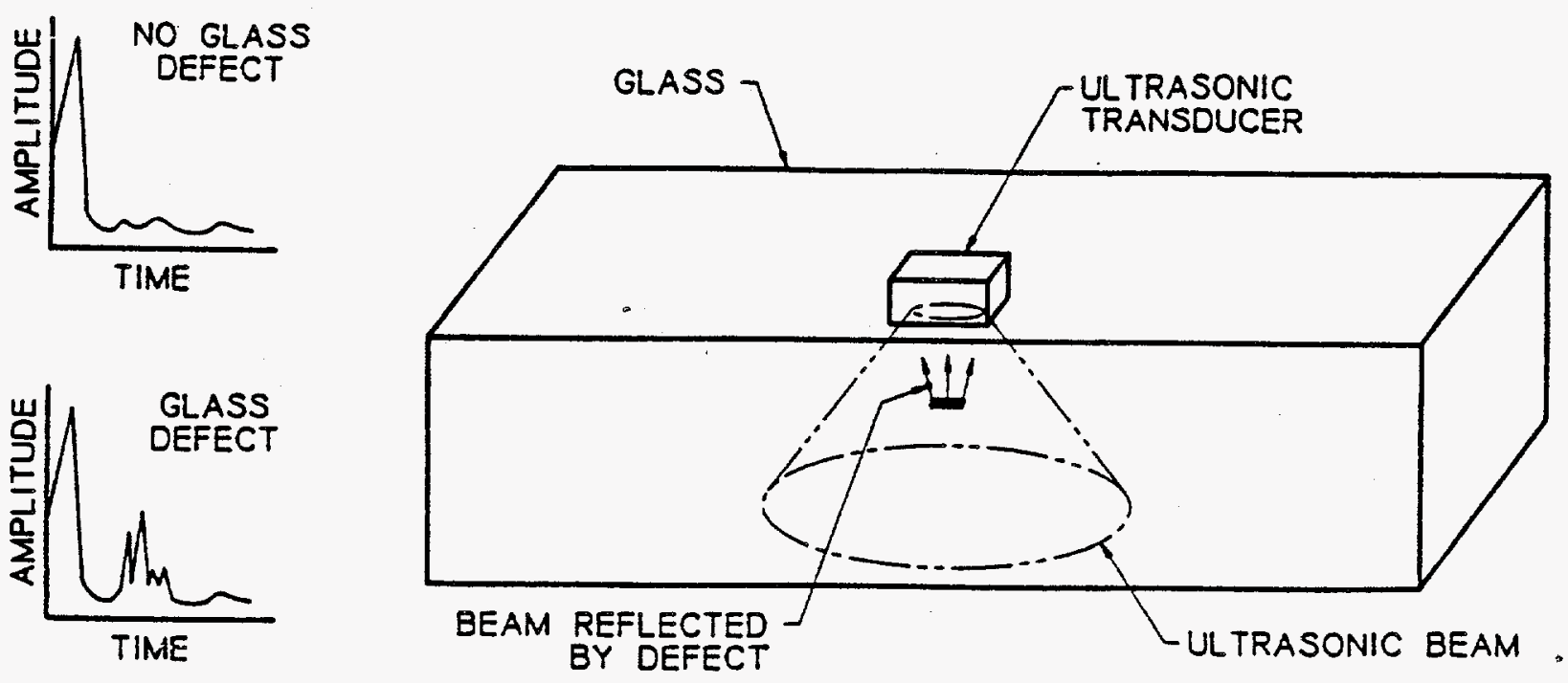

Figure 6-8. Illustration of Ultrasonic Beam Interacting with Material Defect.
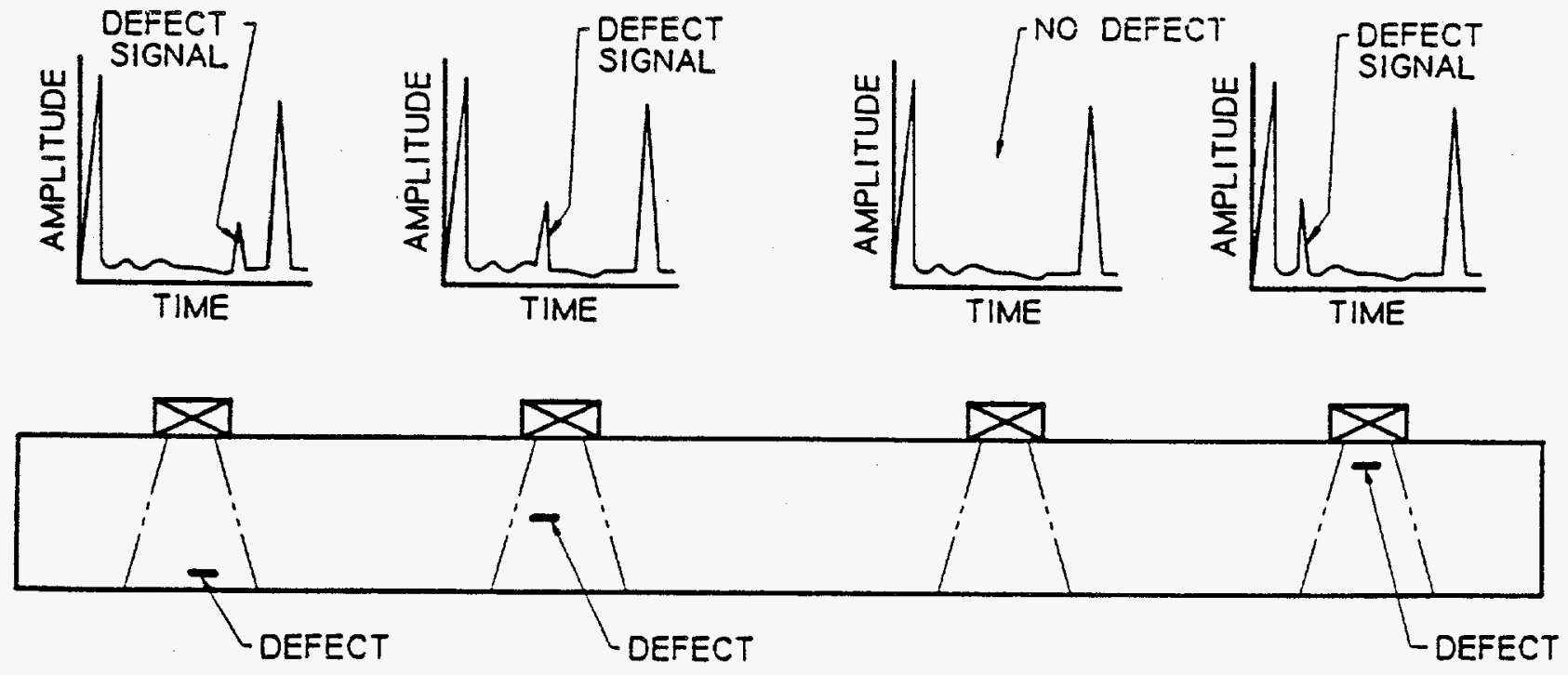
Figure 6-9. Illustration of Ultrasonic Surface Waves Used for Detecting Defects on the Surface of Material.

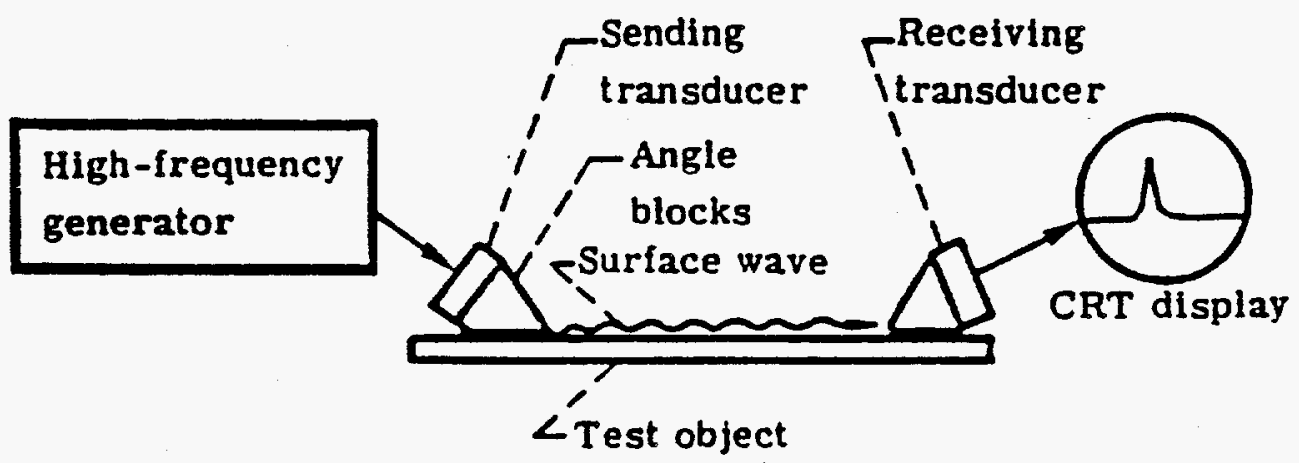

Figure 6-10. Illustration of X-ray Inspection Technique to Visualize Defects Buried in a Material.
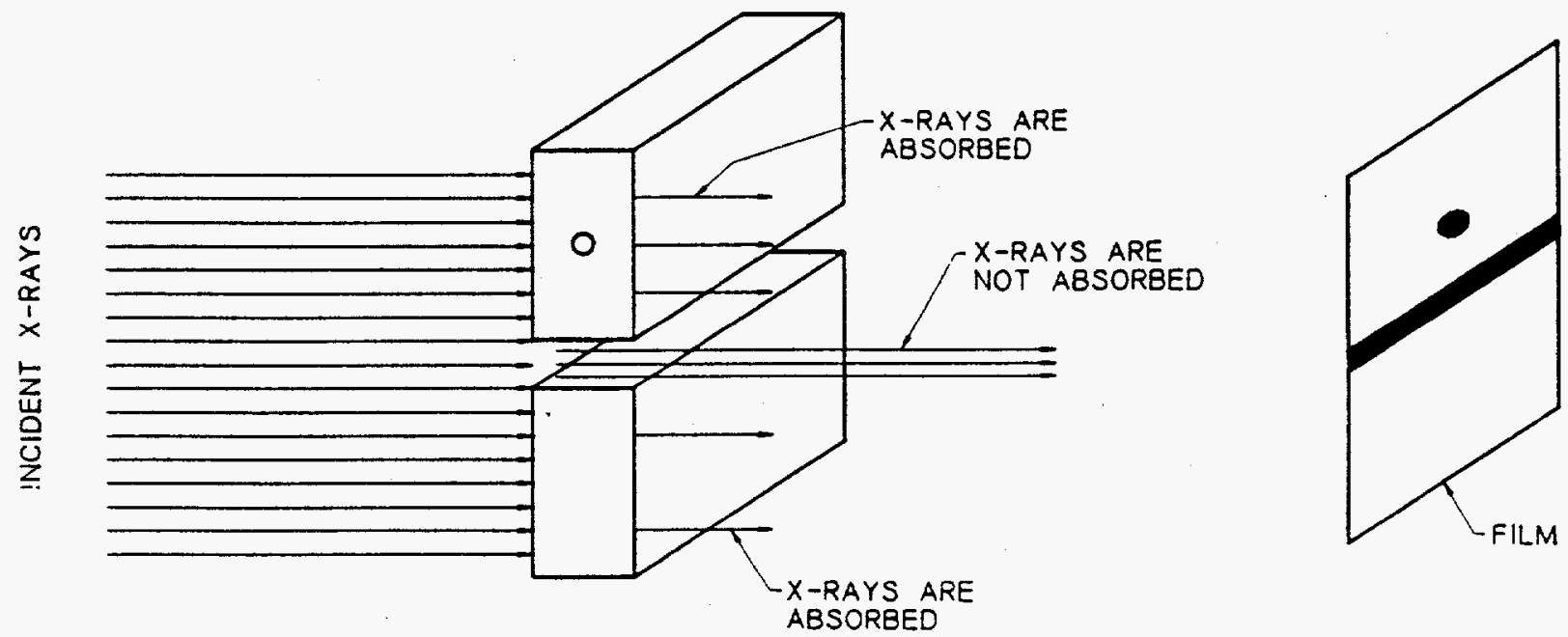
Figure 6-11. Illustration of X-ray Radiography Crack Detection Sensitivity as a Function of Crack Orientation.

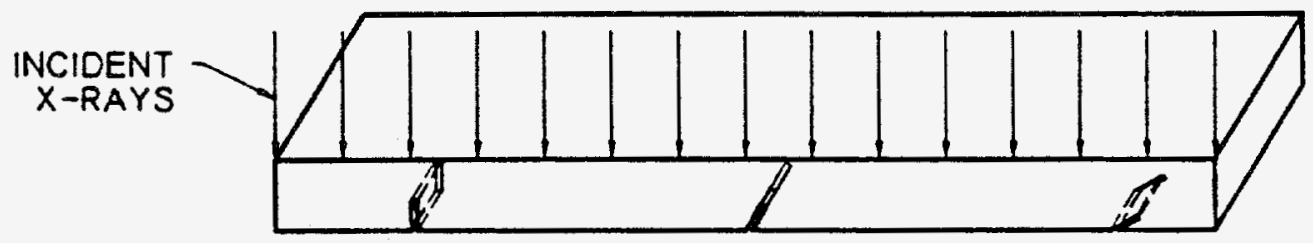

FILM

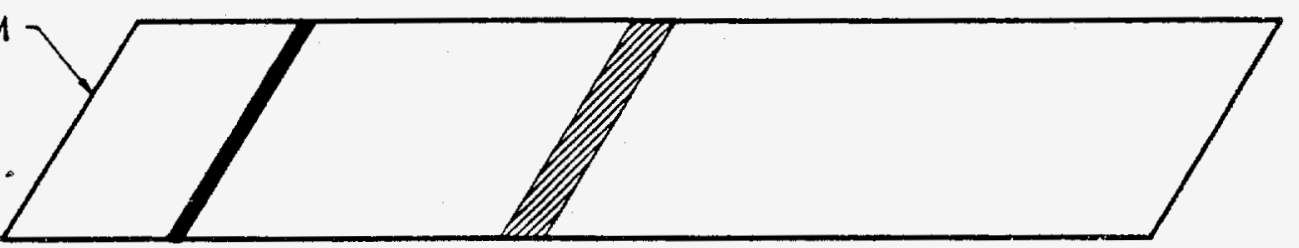

Figure 6-12. Illustration of Acoustic Emission Being Applied to Cooling Glass Forms.

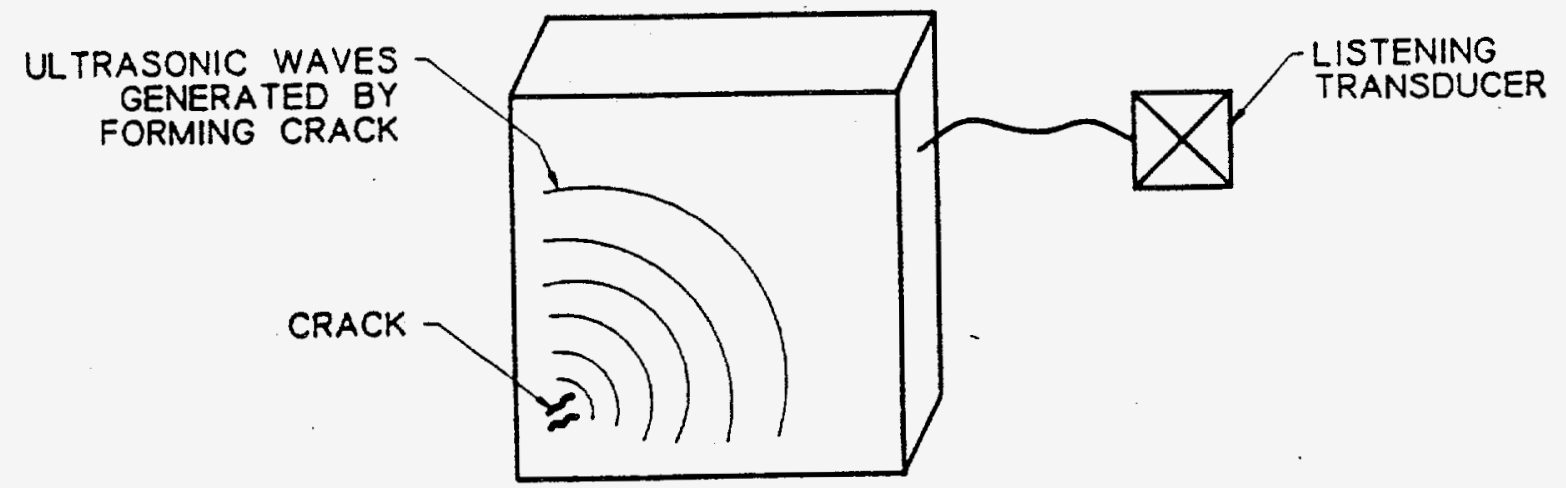


Figure 6-13. Illustration of Acousto-ultrasonics for Inspection of Glass Form.

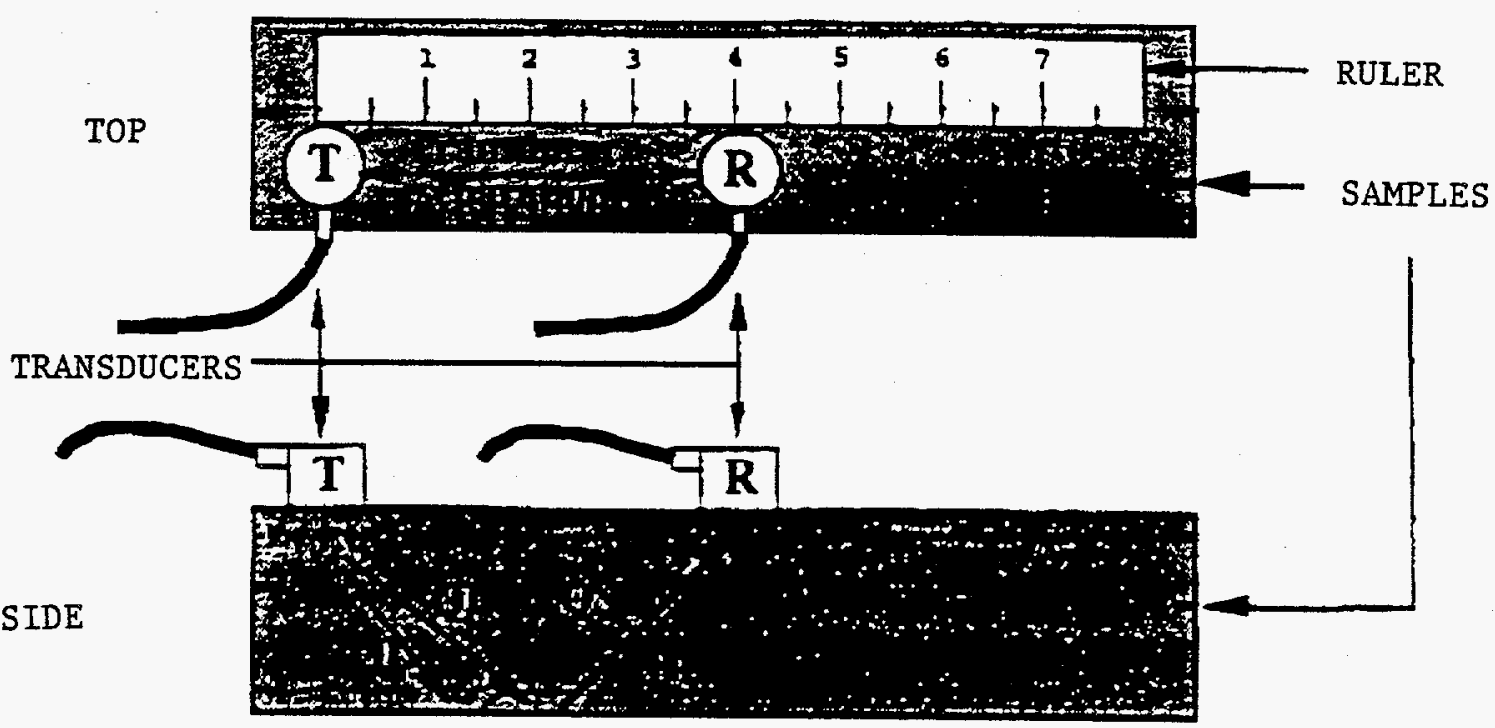

Figure 6-14. Illustration of Light Interaction with Glass to Inspect for Defects.

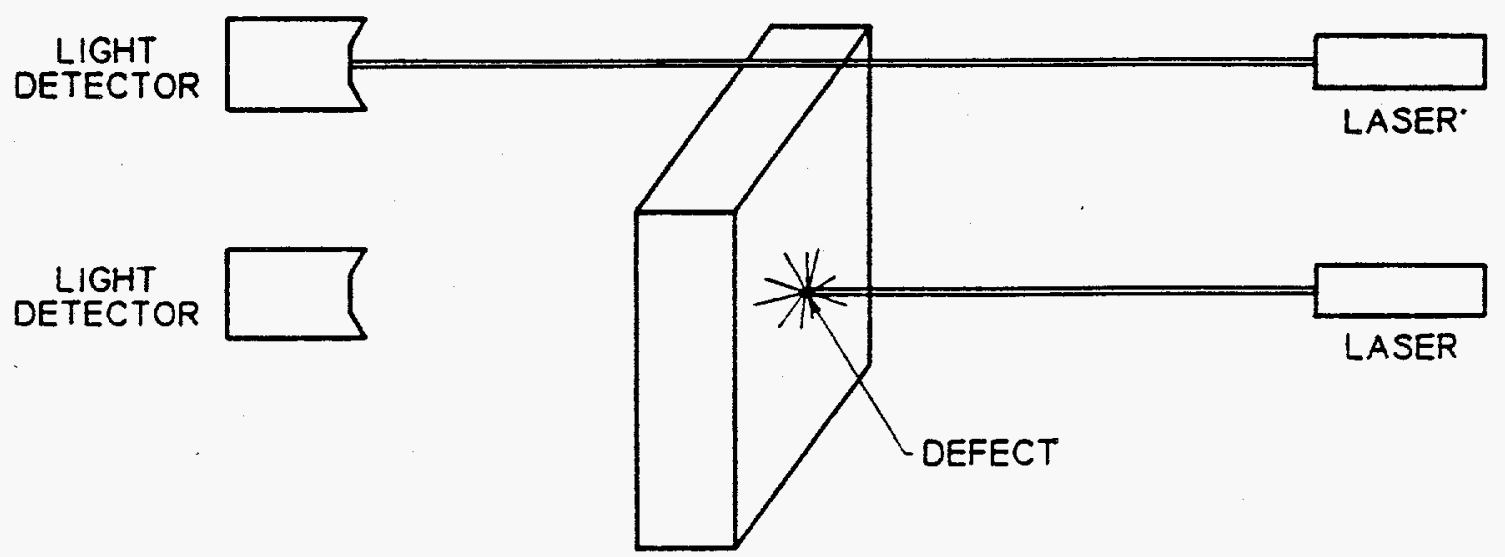


Final

Figure 6-15. Illustration of Positron Annihilation Lifetime Spectroscopy.

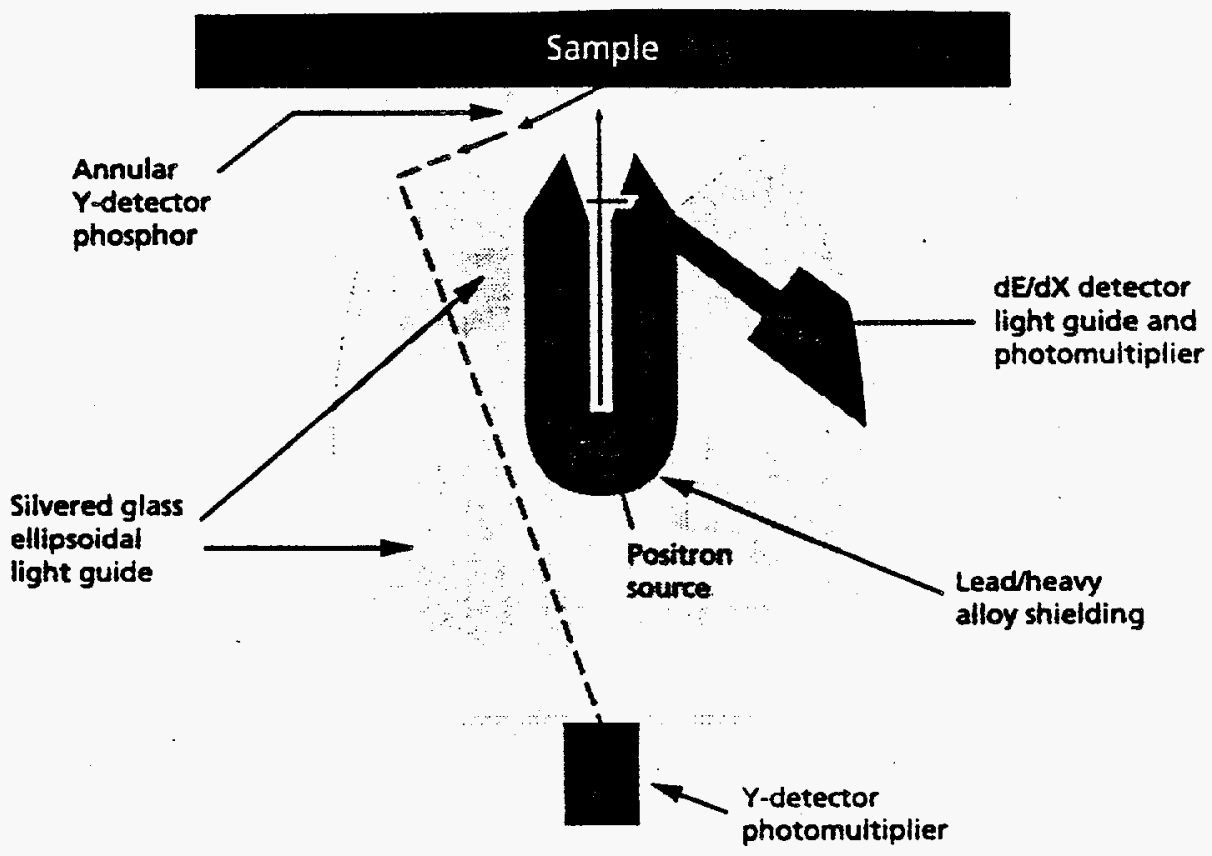

Figure 6-16. Illustration of Neutron Absorption for Detecting Defects in Glass Form.

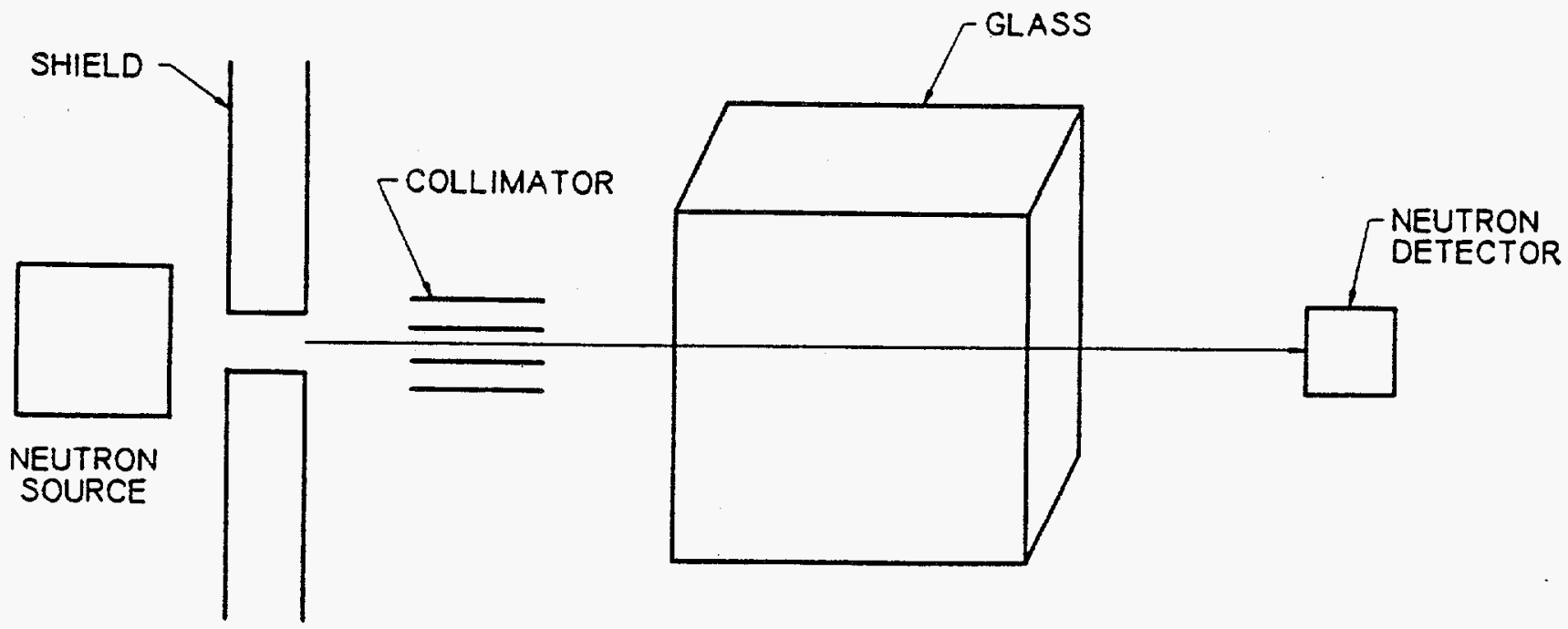


Figure 6-17. Illustration of Embedded Acoustic Emission Sensor to Detect Formation of Defects in the Matrix.

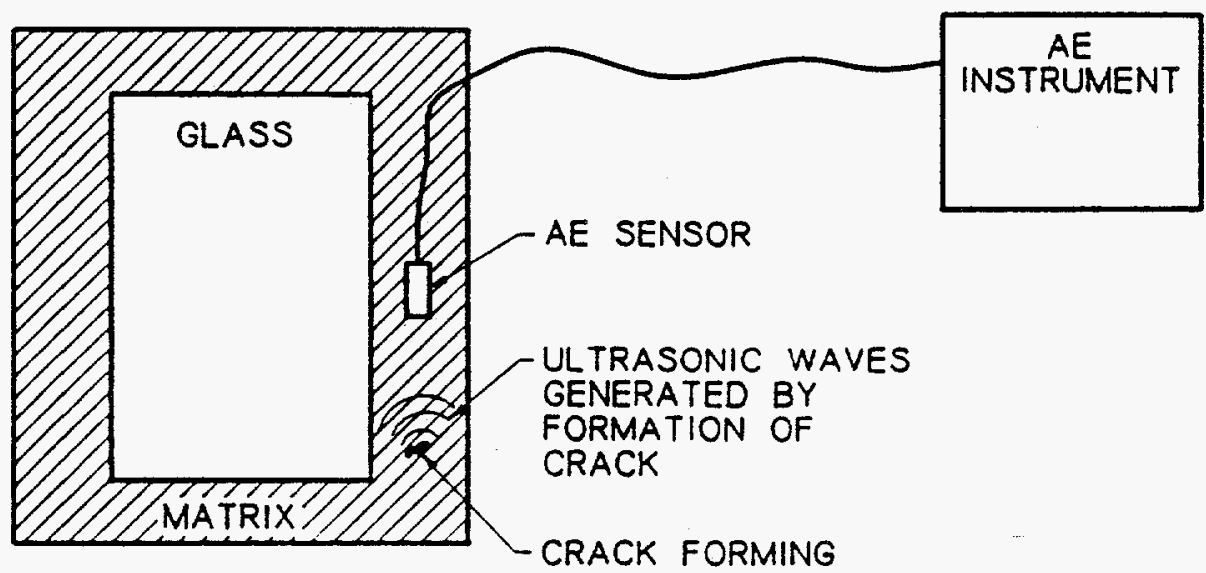

Figure 6-18. Illustration of the Photo-thermal Technique for Detecting Near-surface Defects using Scanning Laser Probe Beam.

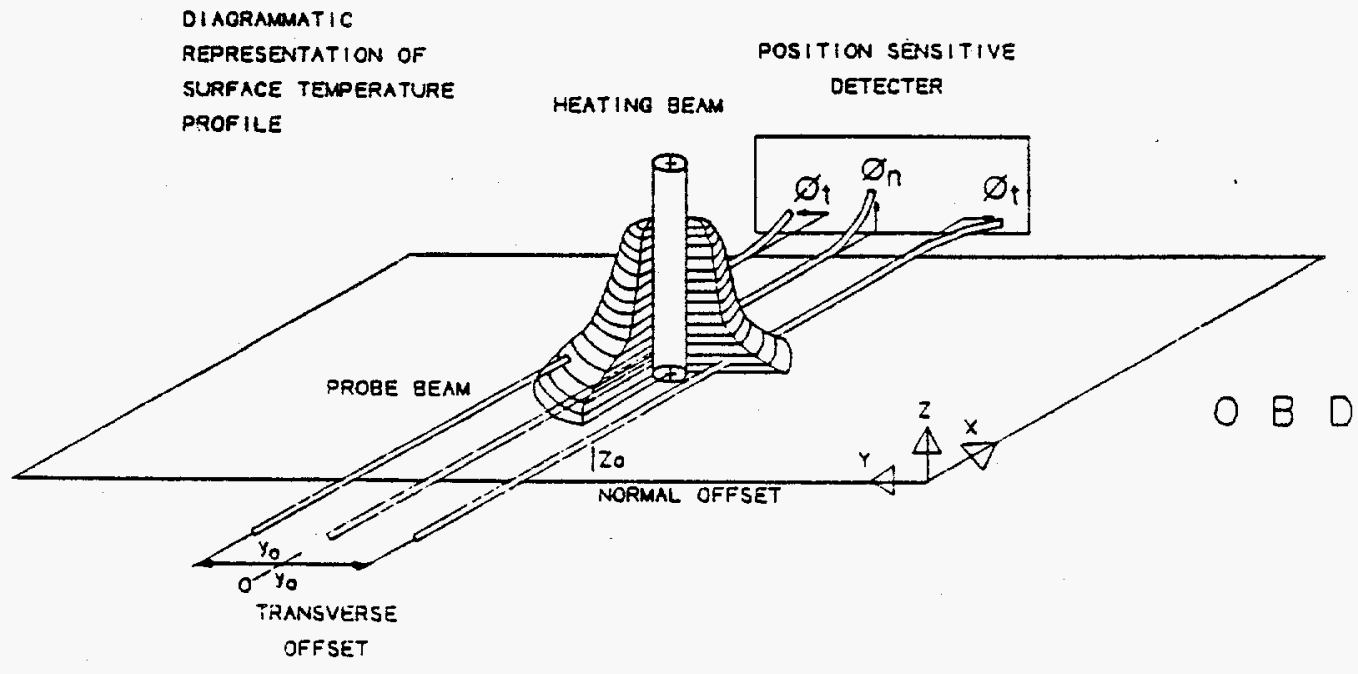


Figure 6-19. Illustration of Neutron Absorption Approach for Detecting Defects in Vitrified Waste or Monitoring the Amount of Moisture in the Sample of Soil.

CALIFORNIUM NEUTRON SOURCE
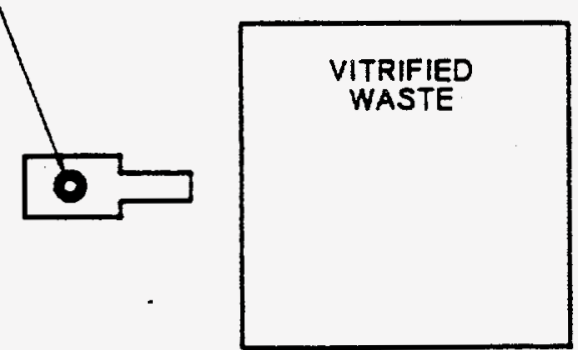

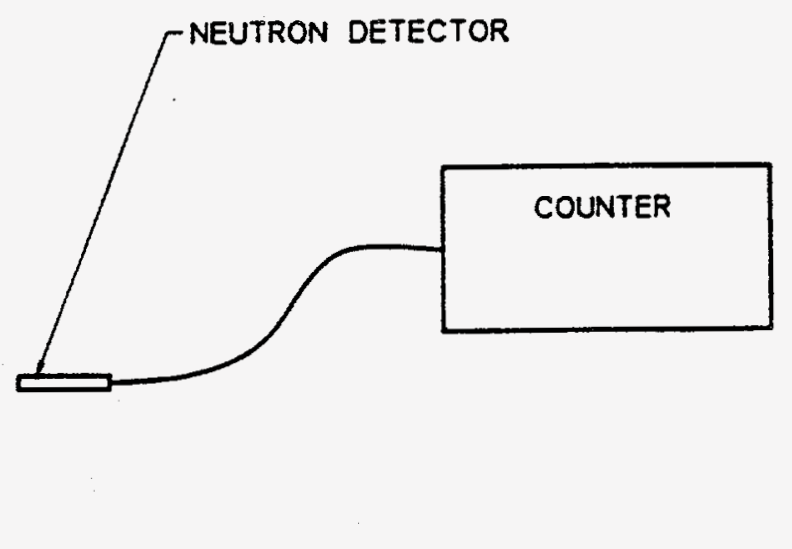


Final

Figure 6-20. Remote Raman Spectroscopy Unit.

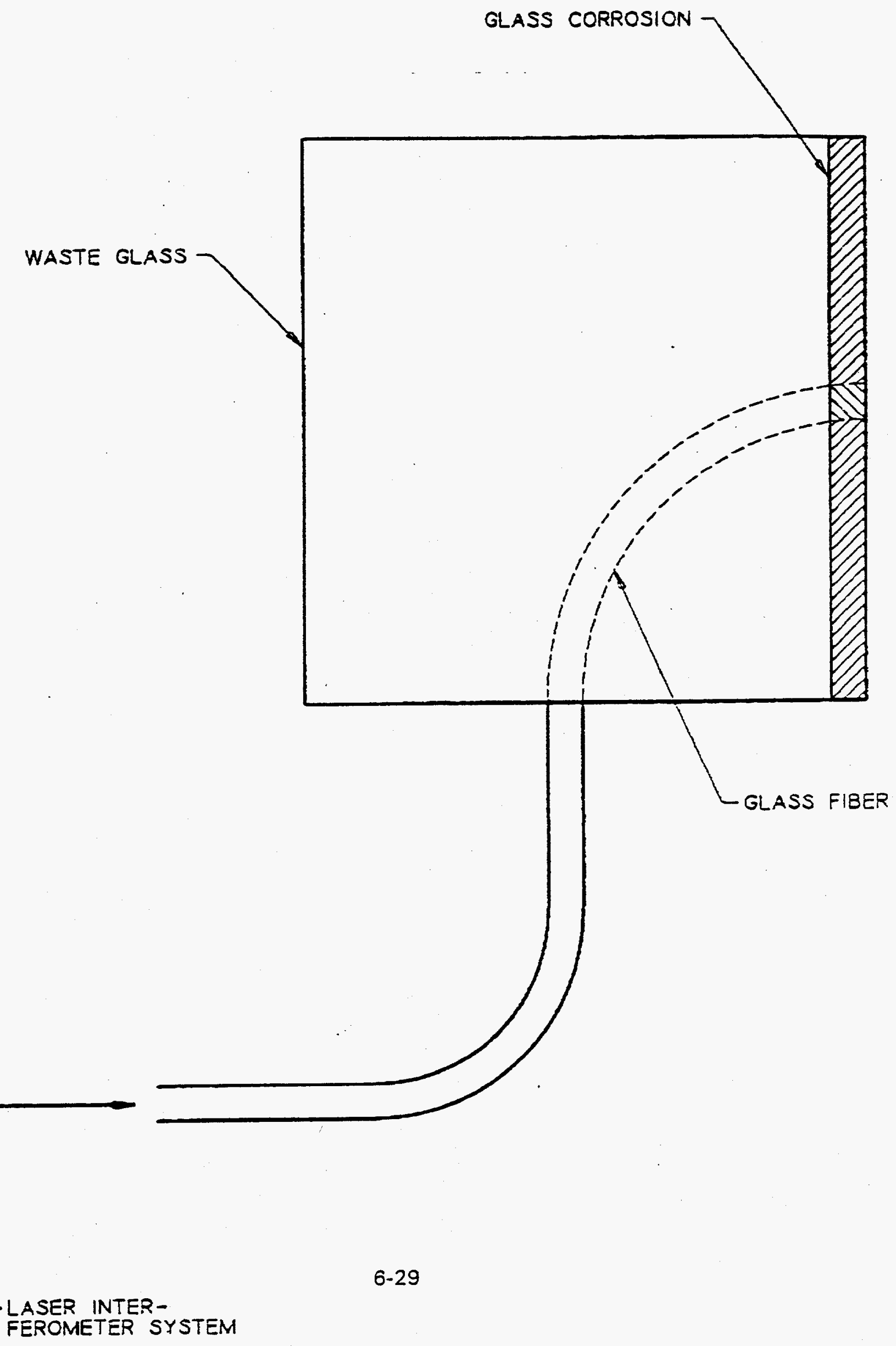


Figure 6-21. Illustration of Embedded Laser Sensor for Monitoring the Stored Waste Form over Extended Periods of Time.
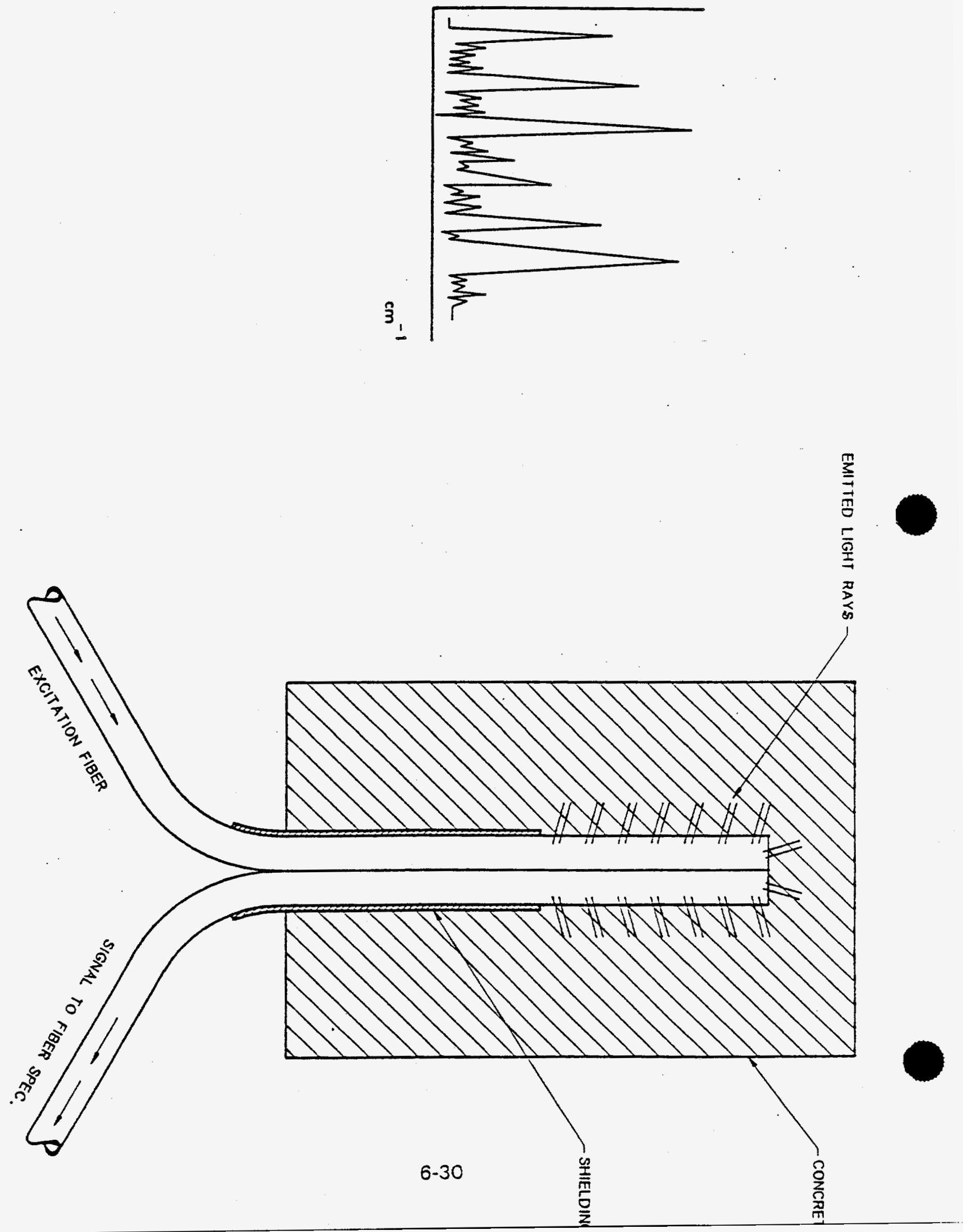


\section{REFERENCES}

Adams, R. D., J. M. W. Brownjohn, and P. Cawley, "The Detection of Defects in GRP Lattice Structures by Vibration Measurements," NDT\&E International, Volume 24, Number 3 , June 1991, pp. 123-131.

Ayorinde, O. A., "Application of Dual-Energy Gamma-Ray Technique for Nondestructive Soil Moisture and Density Measurement During Freezing," Journal of Energy Resources Technology, Vol. 105, March 1983, pp. 38-42.

Brose, R. J., and R. W. Shatz, "Neutron Monitoring in the Unsaturated Zone," Procedures of the First National Outdoor Action Conference of Water, Monitoring, and Geophysical Methods, Las Vegas, Nevada, 1987, pp. 455-467.

Bungey, J. H., "N.D.T. of Concrete - The Current Scene," Nondestructive Testing Evaluation, Vol. 5, pp. 277-300.

Bunnenberg, C., and W. Kuhn, "Application of the Beta Absorption Method to Measure Dew on Soil and Plant Surfaces," International Journal of Applied Radiation and /sotopes, 1977, Vol. 28, pp. 751-754, Pergamon Press, printed in Great Britain.

Caratin, H., M. K. C. Stelter, and J. C. Kuurstra (Ontario Hydro), "Upgrade Soniscope Concrete Testing Instrument," Ontario Hydro Report to Canadian Electrical Association, June 1989.

Doremus, R. H. "Chemical Durability of Glass", Treatise on Material Science and Technology, Chapter II, New York, NY, 1979.

Duke, Jr., J. C., and S. S. Russell, "The Investigation of Imperfections in Sheet Molding Compound," Materials Evaluation 40, April 1982.

Dunn, S. E., J. D. Young, W. H. Hartt, and R. P. Brown, "Acoustic Emission Characterization of Corrosion Induced Damage in Reinforced Concrete," Corrosion-NACE, Vol. 40, No. 7, 339-343, 1984.

Friebele, E. J., and A. D. Kersey, "Fiber Optic Sensors Measure Up for Smart Structures," Laser Focus World, May 1994, pp. 165-171.

Gammell, P. M., and M. A. Adams, "Detection of Strength Limiting Defects in Cellular Glasses by Dielectric Measurements," Journal of NDE, Vol. 2, No. 2, 1981.

Gregory, R. B. "Free-Volume and Pore Size Distribution Determined by Numerical Laplace Inversion of Positron Annihilation Lifetime Data," J. Appl. Phys. 70 (9), 1 November 1991, pp. 4665-4670.

Grobstein, T. L., S. Sivashankaran, and G. Welsch, "Fatigue Damage Accumulation in Nickel Prior to Crack Initiation," Materials Science and Engineering, A138 (1991) pp. 191203. 
Grosskopf, P. P., and J. C. Duke, Jr., "Nondestructive Evaluation of a Ceramic Matrix Composite Material," ASTM Publication Code Number 04-011570-30, Cyclic Deformation, Fracture, and Nondestructive Evaluation of Advanced Materials, 278$292,1982$.

Hady, G. J., T. W. Turner, and K. H. G. Ashbee, "Detection of Defects in Opaque Solids Using Visualized Ultrasound," Metal Science, September 1978, pp. 406-410.

Hasan, O. A., M. C. Boyce, X. S. Li, and S. Berko, "An Investigation of the Yield and Post Yield Behavior and Corresponding Structure of Poly (Methyl Methacrylate)," Journal of Polymer Science: Part B: Polymer Physics, Vol. 31, pp. 185-197 (1993).

Heater, K. J., and P. L. Jones, "On the Characterization of Glassy Polymers by Positron Annihilation Lifetime Spectroscopy," Nuclear Instruments and Methods in Physics Research, B56/57 (1991) pp. 610-614.

Hill, A. J. "The Physical Aging Mechanism in Glassy Polycarbonate Studied by Positron Annihilation Lifetime Spectroscopy," Materials Forum (1990) Vol. 14, pp. 174-182.

Hill, A. J., I. M. Katz, and P. L. Jones, "Isothermal Volume Relaxation in Aged Polycarbonate Measured by Positron Annihilation Lifetime Spectroscopy," Polymer Engineering and Science, Mid-July 1990, Vol. 30, No. 13, pp. 762-768.

Hill, A. J., D. R. Overberg, and B.W. Cherry, "Determination of Polycarbonate Embrittlement Using Nondestructive and Destructive Characterization Methods," PVP-Vol 257, Scientific and Engineering Aspects of Nondestructive Evaluation, ASME 1993, pp. 9394.

Hirschfeld, T., L. Deaton, F. Milanovich, and S. Klainer, "Feasibility of Using Fiber Optics for Monitoring Groundwater Contaminants," Optical Engineering, Vol. 22, No. 5, Sept/Oct 1983, pp. 527-531.

Kern, W., and R. B. Comizzoli, "New Methods for Detecting Structural Defects in Glass Passivation Films," J. Vac. Sci. Technol., Vol. 14, No. 1, Jan/Feb 1977.

Koerner, R. M., J. S. Reif, and M. J. Burlingame, "Detection Methods for Location of Subsurface Water and Seepage," Journal of the Geotechnical Engineering, Detection Methods, Vol. GT11, November 1979, pp. 1301-1317.

Lahmon, R., "A Method for the Nondestructive Detection of Moisture in Roof Sandwiches," Isotopes and Radiation Technology, Vol. 7, No. 3, Spring 1970.

Laine, A., "Detection of Failures in Plastic Composites Using Thermography," SPIE Vol. 1682, Thermosense XIV, pp. 207-212, 1992.

Liao, K., T. J. Dunyak, W. W. Stinchcomb, and K. L. Reifsnider, "Monitoring Fatigue Damage Development in Ceramic Matrix Composite Tubular Specimens by a Thermoelastic Technique," Composite Materials - Fatigue and Fracture, Vol. 4, ASTM 1993, pp. 620636. 
Luong, M. P., "Infrared Detection of Defects in Concrete and Rocks," Translations of the 10th International Conference of Structural Mechanics in Reactor Technology, Anaheim, CA, August 14-18, 1989, pp. 157-162.

Lyon, J. G., C. A. Mitchell, and T. M. Zobeck, "Ground Penetrating Radar for Evaluation of Internal Features of Structures and Soils," ASPRS-ACSM Fall Convention, Sept. 28Oct. 3, 1986.

Lytle, D., "Monitoring Wastes with Laser Microplasma," Emerging Technologies, Photonics Spectra, February 1994, pp. 46-47.

McCord, R. M., "Fiber Optic Probes Monitor Engine Condition," Mechanical Engineering, January 1981, pp. 37-40.

Melle, S. M. "Today's Sensors for Tomorrow's Structures," Photonics Spectra, April 1994, pp. 88-94.

Mudahar, G. S., G. Lal, and H. S. Sahota, "Soil Compaction Studies by Gamma Ray Transmission Method," J. Indian Soc. Soil Sci., Vol. 35, pp. 723-25, 1987.

NUMARC, "Class I Structures License Renewal Industry Report," NUMARC 90-06, June 1990.

NUMARC, "Management of Reinforced Concrete Structures for License Renewal of Nuclear Power Plants: Program for Nondestructive Testing."

Ohnuki, T., T. Yamamoto, and Y. Wadachi, "A Nondestructive Method for Determining the Distribution of Soil Water Content By Measuring Fast Neutron Transmission Using an NE-213 Organic Scintillator," Japanese Journal of Applied Physics, Vol. 23, No. 8, August, 1984, pp. 1124-1128.

Pekarskii, G. Sh., Yu. A. Volchenko, Yu. Ya. Katsman, and G. A. Kucher, "Nondestructive Neutron-Radiation Testing of Moisture Content in Newly Formed Asbestos-Cement Pipes," Translated from Izmeritel'naya Tekhnik.a, No. 5, pp. 80-81, May 1978.

Popovics, S., and J. S. Popovics, "A Critique of the Ultrasonic Pulse Velocity Method for Testing Concrete," Nondestructive Testing of Concrete Elements and Structures" Proceedings of Sessions sponsored by the Engineering Mechanics Organization of ASCE, San Antonio, TX, April 13-15, 1992

Power, J. F., and A. Mandelis, "Frequency-Modulated Impulse Response Photothermal Detection Through Optical Reflectance. 2: Experimental," Applied Optics, Vol. 27, No. 16. August 15, 1988, pp. 3408-3417.

Pye, D. J., and R. D. Adams, "Heat Emission from Damaged Composite Materials and Its Use in Nondestructive Testing," J. Physics D., Appl. Phys., 14 (1981) 927-41.

Raghunath, V. M., P. K. Bhatnagar, and W. Meenakshisundaram, "Non-Destructive Evaluation of the Water Content of Concretes by Low Energy Gamma Backscattering," Nuclear Instruments and Methods, 206 (1983), pp. 303-307. 
Rajaiah, K., and M. N. Raghavendra Rao, "Damage Assessment in Composites Through NDE: Some Recent Studies in India," Theoretical and Applied Fracture Mechanics 13 (1990) $125-135$.

Resch, M. T., D. V. Nelson, H. H. Yuce, and G. F. Ramusat, "A Surface Acoustic Wave Technique for Monitoring the Growth Behavior of Small Surface Fatigue Cracks," Jour. of NDE, Vol. 5, No. 1 (1985).

Rowe, R. G., and D. W. Skelly, "The Synthesis and Evaluation of Nb3Al-Nb Laminated Composites," Mat.Res. Soc. Symp. Proc., Vol. 273, pp. 411-416, 1985.

Saito, Y., T. Shoji, and H. Takahashi, "Non-destructive Diagnostics Technique by Means of Electrochemical Polarization Method for Materials Degradation of S/H Tubes of Fossil Boiler," pp. 367-374.

Sanchez-Lavega, A., A. Salazar, and J. Fernandez, "Nondestructive Evaluation of a SemiInfinite Buried Slab by Photothermal Deflection," Springer Series in Optical Sciences, Vol. 62, Photoacoustic and Photothermal Phenomena II, Heidelberg 1990.

Sattar, D., "Surveillance/Testing - License Renewal," LE-88-5

Scott, I. G., and C. M. Scala, "A Review of Non-destructive Testing of Composite Materials," NDT International, April 1982.

Shibata, T., M. Mimura, A. K. Shrivastava, and M. Nobuyama, "Moisture Measurement by Neutron Moisture Cone Penetrameter: Design and Application," Soils and Foundations, Vol. 32, No. 4, 58-67, Dec. 1992, Japanese Society of Soil Mechanics and Foundation Engineering.

Shull, P. J., J. C. Moulder, P. R. Heyliger, M. Gimple, and B. A. Auld, "Application of Capacitive Array Sensors to Nondestructive Evaluation," Review of Progress in QNDE, Vol. 7A, eds. D. O. Thompson and D. E. Chimenti, New York: Plenum, 1988, pp. $517-$ 523.

Singh, B. P., and S. Chandra, "Evaluation of the Optimal Thickness of Soil Between Source and Detector in the Gamma-Ray Transmission Method," Journal of Hydrology, 32 (1977) pp. 189-191.

Smith, H. E., "Evaluation of Nondestructive Assay System Performance on Z-9 Crib Soil Measurements: Phase 1," Report prepared for the U.S. Energy Research and Development Administration under Contract E (45-1) 2130, October 1976.

Srivastava V. K. and Prakash R, "Ultrasonic Detection of Cumulative Damage in Hybrid Glass Fibre/Zirconia/Epoxy Composite," Key Engineering Materia/s, Vol. 13-15, 1987, pp. 905-908.

Stockman, A., P. Mathieu, and P. S. Nicholson, "Ultrasonic Characterization of Model Defects in Ceramics (Part 2): Spherical Oxide Inclusions in Glass-Theory and Practice," Materials Evaluation 45, June 1987. 
Stockman, A,, P. Mathieu, and P. S. Nicholson, "Ultrasonic Detection and Characterization of Microspherical Defects in Model Ceramics," Review of Progress in ONDE, Vol. 5A, eds. D. O. Thompson and D. E. Chimenti, New York: Plenum, 1986, pp. 101-107.

Studt, T., "Collaborative R\&D Drives Changes in Steelmaking," R\&D Magazine, July 1993 , pp. 27-28.

Stupin, D., "Radiographic Detection of 100A Thickness Variations in 1-Micron Thick Coatings on Submillimeter-Diameter Laser Fusion Targets," Review of Progress in ONDE, Vol. 6B, eds. D. O. Thompson and D. E. Chimenti, New York: Plenum, 1987, pp. 14851494.

Suaris, W., and V. Fernando, "Detection of Crack Growth in Concrete from Ultrasonic Intensity Measurements," Materials and Structures, 1987, Vol. 20, pp. 214-220.

Sukekawa, M., M. Shiga, Y. Tobita, and S. Kirihara, "Fundamental Study on Nondestructive Detection for Creep Damage in Austenitic Stainless Steel," Proceedings of the Inter. Conference on Creep, April 14-18, 1986, Tokyo.

Svyat-skii, B. S., M. I. Apakhov, and L. A. Tryapkina, "Detectability of Defects in Inspection with Ultrasonic Inclined Transducers Made of Organic Glass and Caprolon," Defektoskopiya, No. 2, pp. 41-42, Feb. 1983.

Unruh, M. E., C. Corey, and J. M. Robertson, "Vadose Zone Monitoring by Fast Neutron Thermalization (Neutron Probe) - A 2-Year Study," Proc. Fourth National Outdoor Action Conference on Aquifer Restoration, Ground Water Monitoring and Geophysical Methods, May 1990, pp. 431-444.

Vikstom, M., J. Backlund, and K. A. Olsson, "Non-destructive Testing of Sandwich Constructions Using Thermography," Composite Structures 13 (1989) 49-65.

Weiss, V., Y. Oshida, and A. Wu, "Towards Practical Non-Destructive Fatigue Damage Indicators," Fatigue of Engineering Materials and Structures, Vol. 1, 1979, pp. 333341.

Went, M. S., S. E. Dunn, W. H. Hartt, and R. P. Brown, "Application of Acoustic Emission to Detection of Reinforcing Steel Corrosion in Concrete," Corrosion-NACE, Vol. 38, No. $1,9-14,1982$.

World News, Laser Focus World, Aug. 1992, p. 32.

Yaniv, G., B. Zimmermann, and K-A. Lou, "Development of an Optical Fiber Time Domain Sensor for Monitoring Static and Fatigue Strains in Composite Laminates," SPIE, Feb. 1993 Conference Proceedings.

Yeoman, D., "Water Quality Analytical Techniques," in Hazardous Waste Management Handbook, ed. by A. Porteous, London: Butterworths, Chap. 6, pp. 167-208.

Zeilinger, A., and R. Hubner, "Measurement of Moisture Motion Under a Temperature Gradient in a Concrete for SNR-300 Using Thermal Neutrons," 3rd International Conference on Structural Mechanics in Reactor Technology, Sept. 1975, Vol. 3, Part G-H. 


\subsection{INTERNATIONAL WASTE FORMS FOR HANFORD EQUIVALENT WASTES}

The purpose of this study is to perform a review of International Waste Forms for Waste Equivalent to the Hanford Tank Wastes to include:

(a) How the waste is pretreated, packaged, and disposed of

(b) What the performance criteria is for the waste form, the disposal system and the disposal site.

\section{Introduction}

An initial survey of the following countries was undertaken to determine which had waste similar to the Hanford Tank Waste. Countries surveyed included: Argentina, Belgium Brazil, Canada, China, Finland, France, Germany, Italy, Japan, Russia, Sweden, Switzerland, the United Kingdom and the United States of America. After the initial survey to identify types of waste, the following countries were selected for a more detailed review:

$\begin{array}{ll}7.1 & \text { China } \\ 7.2 & \text { France } \\ 7.3 & \text { Italy } \\ 7.4 & \text { Japan } \\ 7.5 & \text { Russia } \\ 7.6 & \text { United Kingdom } \\ 7.7 & \text { USA }\end{array}$

An additional Section 7.8 has been included to cover some typical examples of disposal methods of countries which have reprocessing of their waste carried out in another country Belgium, Germany, and Switzerland.

Nuclear power production and the use of radioactive materials for medical, defense and industrial uses, brings with it the question of waste management policy. Most countries using nuclear power have well developed strategies for radioactive wastes and there are many similarities between the programs of different countries. Radioactive waste consists of a variety of materials having different physical and chemical properties and containing different types of radioactivity. It is important to understand how waste is classified. There are no international standard definitions of waste categories, but broadly similar methods of classification are applied. Table 7.11 gives some indication of the different classifications of radioactive waste. For the purposes of this study, the following terminology is used.

\section{Low-Level Waste (LLW)}

Generally, this is accepted internationally as waste consisting of trash, debris from routine operations and decommissioning. It has primarily low concentrations of beta/gamma contaminated material, but may also include minor quantities of alpha contaminated material. LLW would be expected to have undergone some pretreatment such as volume reduction, and/or be placed in a binding matrix and sent for surface or near surface disposal. 


\section{Intermediate Level Waste (ILW)}

This waste contains higher concentrations of beta/gamma contamination. There is little or no heat output, but has long lived radionuclides. Internationally, this is the largest discrepancy of radioactive waste classification. The low level Hanford Tank Waste would be classified in this category; if generated in another country.

ILW would be expected to have undergone some pretreatment to convert it to a waste form which is stable for very long time periods. After treatment it would be placed in an inactive, low permeable geological formation.

\section{High Level Waste (HLW)}

HLW comprises either spent fuel, such as used fuel rods or assemblies, or highly active raffinates resulting from the first stage of fuel reprocessing. It contains high concentrations of long lived alpha emitting actinides and beta/gamma emitting fission products which can cause the waste form to have a temperature rise as a result of the radioactivity.

Internationally, the waste from reprocessing would be, or is proposed to be, encapsulated in a glass matrix and stored in a special vault at the treatment plant for some 50 years to allow the waste to cool to a level allowing permanent disposal in deep geologic formation. Both Canada and Sweden are proposing a direct disposal option for their fuel elements by placing them in a special container and depositing them in a geological formation.

\section{International Overview for Intermediate Level Waste}

Intermediate level waste treatment, packaging and disposal systems vary greatly internationally. Generally, designs/concepts are dependent on a particular country making the best possible use of the technology and geology available to them (i.e., Belgium Boom Clay and German Salt Domes).

The principle of deep geologic disposal for ILW has been accepted by many countries but it must be emphasized that most do not have the volume concerns of the Hanford waste although the U.K. NIREX deep repository will have a capacity of $650,000 \mathrm{~m}^{3}$. Many countries are involved in geological and hydrogeological investigations to gather knowledge of the performance of the repository. Deep disposal in the right environment ensures the waste form will remain isolated from the environment for a very long time.

It must be noted that some countries geology does not allow for safe, shallow burial of ILW and they are therefore forced into the use of deep geologic repositories. It can also be noted that public opinion and basic common sense has influenced the placement of repositories next to large radioactive reprocessing sites, providing the geology can be shown to be acceptable. 


\subsection{CHINA}

\subsubsection{Overview (see Figure 7-1)}

China has an expanding nuclear program which will total $6 \mathrm{GWe}$ by the year 2000 . The spent nuclear fuel will be reprocessed resulting in an overall increase of radioactive waste. The China National Nuclear Corporation (CNNC) has developed several methods for the treatment and storage of radioactive waste including solidification of LLW, hydrofracture disposal, (pumped, deep injection of grout) for ILW and vitrification for HLW. A research and development (R\&D) program for disposal of HLW has been in operation since 1985 .

\subsubsection{Inventory}

China has adapted a policy of separation for LLW, ILW, and HLW, but no details have been found in present investigations.

Activity

No details of activity have been found in present investigations.

\section{Volume}

No details on volume have been found in present investigations.

\subsubsection{Waste Form}

$\angle L W$

Conditioning of evaporator concentrates of LLW using bitumen has been developed and is to be put into operation on an industrial scale in the near future. The process has been pilot scale tested with simulated waste and further improvements on the process have been made in a cold trial using a full scale facility. The full scale facility has two independent process lines comprised of solidifying evaporators with rotary scrapers and auxiliary equipment. The throughput for LLW is 250 liters per hour for each line. The molten asphalt waste form is poured into 200 liter steel drums.

Solidification of LLW using cement has been specified for the first Chinese nuclear power plant - Qinshan Nuclear Power Plant. The facility has been built and will be put into operation in the near future with an operating throughput of $50 \mathrm{~m}^{3} /$ year.

$\| W$

For disposal of short lived ILW, the selected techniques are in-situ bulk grouting and underground hydrofracture using cement based grout.

In 1980, China initiated a program to study the feasibility of disposal of ILW in a deep shale formation using the hydrofracture process at the Sichuan Nuclear Fuel Plant at Yibin (see Figure 7-1). Studies on siting, geologic and hydrogeologic investigations, site characterization, cementitious slurry formulation as well as an underground injection test with radioactive tracers, have been completed. The conclusion drawn from the R\&D work was that the test 
area was suitable to the disposal of liquid radioactive waste using hydrofracture process and therefore, could be selected as a proposed site. Volumetric rates of around $40 \mathrm{~m}^{3} / \mathrm{hr}$ can be disposed of with each "well" handling up to $10,000 \mathrm{~m}^{3}$ at a depth of $1000 \mathrm{~m}$ below the ground's surface.

In-situ bulk grouting has been used where the disposal site for the shallow land burial is near the place of waste generation. Radioactive waste, cement and additive are fed into a mixer and continuously flow into the underground pools. Each pool has a vertical mixer equipped with a double propeller.

\section{$H L W$}

Liquid HLW has been stored safely in tanks at reprocessing plants. The vitrification technique has been chosen for conditioning of. HLW after several years of study. Before $1985, R \& D$ on vitrification was focused on the batch pot vitrification process, which was similar to the PIVER process. In 1986, due to the relatively limited throughput of the batch pot process, it was decided to cease R\&D on this process and replace it with the liquid-fed ceramic melter process, known as the PAMELA process.

A mock-up facility with a capacity of one cubic meter per day of simulated sulfatecontaining waste is being constructed. In principle, the mock-up facility will be designed and built relying mainly on Chinese efforts and importing some of the equipment and technology from Germany.

\subsubsection{Packaging}

For LLW, 200 liter steel drums are used for storage of bitumanized and cemented wastes.

\subsubsection{Transport}

No transport details have been found.

\subsubsection{Disposal Site}

A new site for in situ bulk grouting of LLW and ILW is being developed at Gebei, near the Lanzhou Plant. Several concrete pools $8 \mathrm{~m} \times 8 \mathrm{~m} \times 6 \mathrm{~m}$ deep are being built for the casting of cement grout. The aquifer is approximately $40 \mathrm{~m}$ below grade in this area. After the pool is full, a large quantity of clean grout is put on top of the vault as a cap. The final cover is $7 \mathrm{~m}$ of soil. There is no detail of any erosion protection for the cover.

\section{Hydrofracture}

Final studies at the Sichuan Nuclear fuel plant have been completed and the site is to be used for the disposal of ILW by direct injection of cementitious slurry $1000 \mathrm{~m}$ below ground surface into shale. 


\subsection{FRANCE}

\subsubsection{Overview (see Figure 7-2)}

The National Agency for Radioactive Waste Management (ANDRA), financed by French waste producers and fuel cycle firms, was established in 1979; in 1991 it adopted agency status. ANDRA is responsible for designing siting, constructing and operating long-term disposal facilities which include the specification of waste packaging and research into longterm safety.

About $70 \%$ of France's electricity is generated by nuclear power, mainly from PWR reactors. At the end of 1991, 56 units were in operation with a total capacity of 56,800 MWe. Another 5 units, accounting for about a further $7,000 \mathrm{MWe}$, are planned or under construction and will be commissioned progressively up to 1995.

The French nuclear industry covers all stages of the nuclear fuel cycle, from the mining of uranium, reprocessing of spent fuel, and final disposal of radioactive waste.

\subsubsection{Inventory}

French nuclear waste is segregated and treated to produce the two standard waste streams of HLW and ILW for disposal in deep underground vaults, and LLW for disposal in near-surface vaults. Table 7-1 gives an overall inventory of waste and Table 7-2 shows how the waste is conditioned at the La Hague reprocessing plant.

\subsubsection{Waste Form}

France has utilized a range of disposal methods for various waste forms.

HLW - Fission products are sent for vitrification

ILW - Hulls and end fittings from reprocessing are encapsulated in concrete

- Sludges from reprocessing/fuel storage are encapsulated in bitumen

- Technological Waste - encapsulated in grouted asbestos

LLW - Ion exchange resins - evaporator concentrates, clothing etc. - encapsulated grouted fiber and concrete overpack, after volume reduction by compression or incineration.

Pretreatment Method (only waste forms relating to Hanford Tank Waste are listed)

\section{Bituminizing of Effluent Treatment Sludges}

The process used in France was designed by the French Atomic Energy Commission (CEA). It has been operating industrially at Marcoule since 1966. 
It is based on the following principle: the settled sludges are introduced at the same time as bitumen and an emulsifier into an extruder heated by steam to around $120^{\circ} \mathrm{C}$. Four helicoidal screws simultaneously perform evaporation, mixing of the sludge with the bitumen, and advancing the bitumen/waste mix along the extruder tube.

The bitumen coated waste (BCW) is poured in two lifts into a 210 liter stainless steel drum. After the BCW is cooled and solidified, the drum is fitted with a crimped lid and transferred to an interim storage cell located near the bituminizing facility.

The evaporation products are sent to a condenser.

Two bituminizing facilities are currently in operation today at the Cogema sites:

- at Marcoule: a facility started in 1966 is equipped with a bituminization line with an interim storage capacity of 50,000 drums divided into thirteen cells,

- at La Hague: one facility started in 1989 (equipped with two bituminizing lines in parallel) is capable of producing 4000 drums/year and with an interim storage capacity of 20,000 drums.

Cement Embedding of Hulls and End Fittings of LWR Fuel Assemblies

When reprocessing began on LWR fuels at La Hague in 1976, France did not have an approved packaging process for hulls and end fittings. These wastes were accordingly stored temporarily in bulk under water in a concrete silo, and then in sealed drums stored in ponds.

The CEA developed a cement embedding process. Based on this process, Cogema built the first packaging facility in the UP3 plant and secured approval for the specifications of the corresponding containers.

The process operates according to the following principle.

In the shearing unit, the end fittings of spent fuel assemblies are first separated and then rinsed in two stages in a batch washer. Pieces of clad or hulls, after dissolution of the nuclear material, are washed in countercurrent flow in a continuous helicoidal washer.

The hulls and end fittings are then combined and introduced into a perforated basket placed in a 1600 liter stainless steel drum. The drum is then transferred to a fissile material counting instrument.

A cement grout of predetermined quality is then injected between the basket and the wall of the drum in order to embed all the materials. The system can perform the cement embedding of a drum in about 20 minutes.

After drying, the drum is fitted with a lid and transferred to a decontamination pit for transfer to interim storage on the site. 
An embedding installation of this type has been in industrial operation since August 1990, at the head end of the UP3 plant. The present interim storage capacity at La Hague is 2400 drums, divided into three modules.

\subsubsection{Packaging}

The French utilize various stainless steel drum sizes for all their ILW and LLW waste forms ranging from 100 liters to 1600 liters. Table 7-3 shows the packaged waste volumes.

\subsubsection{Transport}

Transport to the Centre de l'Aube can be via public road or rail.

\subsubsection{Disposal Site}

The French have adopted a policy of protection of radioactive waste from human intrusion for as long as necessary for the waste to decay to an acceptable level. The LLW for surface disposal can have only radionuclides with half lives less than 30 years which decay by a factor of 1000 after 10 periods or 300 years. The waste must therefore be monitored or kept under institutional control for 300 years, with a limit of $0.1 \mathrm{Ci} / \mathrm{t}\left(3.7 \times 10^{9} \mathrm{~Bq} / \mathrm{t}\right)$. ANDRA's facility at Centre de l'Aube has been designed for this purpose. HLW is treated as anything above LLW with activity of $10^{6} \mathrm{Ci} / \mathrm{m}^{3}$.

Since 1969, most French LLW and some ILW have been disposed of at the Centre de la Manche in northern France which is now full. ANDRA's new disposal facility 11.3 billion francs) at Centre de l'Aube, near Troyes in northern France will handle French LLWs into the 21 st century. (Attachment 7-1 gives a detailed description of the Centre de I'Aube facility).

\section{Closure}

Attachment 7-2 gives a detailed account of the final closure of the Centre de la Manche facility.

\subsection{ITALY}

\subsubsection{Overview}

The Italian Government announced a moratorium on Nuclear Power in 1987. This has meant closure of four nuclear stations, leaving three operational reactors; Latina, Caorso and Trino. Magnox reactor spent fuel from Latina has been sent to British Nuclear Fuels Ltd. for reprocessing. Currently the main storage sites for spent fuel are at Caorso and Trino power stations. 
Liquid waste was produced in the 1970's during a campaign of reprocessing of three reactor fuels:

Material Testing Reactor irradiated fuel (MTR)

Candu Reactor fuel

Elk River fuel

\subsubsection{Inventory}

The main elements of the MTR, Candu, and Elk River wastes are listed in Table 7-4.

Activity levels of the three wastes vary. The Elk River waste is mixed with the MTR waste and has a total activity of $59.6 \times 10^{3} \mathrm{GBq} / \mathrm{M}^{3}$, the main elements being $\mathrm{Cs}-137, \mathrm{Sr}-90$, and TRU. The Candu waste has a total activity of $120 \times 10^{3} \mathrm{GBq} / \mathrm{m}^{3}$, the main elements being Sr-90 and Uranium.

Volumes of the wastes are:

MTR $88 \mathrm{~m}^{3}$

Candu $24 \mathrm{~m}^{3}$

Elk River $3 \mathrm{~m}^{3}$

\subsubsection{Waste Form}

Waste from both MTR and Candu reprocessing are processed to remove the LLW which is sent for encapsulation in cement leaving the HLW to be sent for vitrification.

\section{Pretreatment Method}

MTR Fuel (see Figure 7-3)

For MTR, the pretreatment process includes the following steps.

1. Alkalinization, carried out with a concentrated solution of sodium hydroxide in order to allow:

- neutralization of the free acid

- a final $\mathrm{pH}, 13$ for the solubilization of Al as aluminate

- removal of $\mathrm{Sr}$ and Actinides by coprecipitation with ferric hydroxide

2. Cs removal by selective precipitation, using NaTPB (sodium-tetraphenyl-borate). This step is able to provide a high decontamination factor for cesium, thus allowing a full decontamination of the solution in a single batch precipitation. 
3. Double step solid-liquid separation by decantation, the first one in the same precipitation reactor, the second one into a decanter, where is possible to accumulate the slurry of several batches to improve the thickening. In addition the supernatant from the reactor and from the decanter can be centrifugated in order to increase the separation of the solid particles. Experimental tests have shown this operation is not so necessary in deed.

The main decontamination factors, DFs, achieved with this process are: Cs-DF, 1000, Sr-DF $=100$, TRU-DF (transuranium elements) 1000.

From the experimental results a production of $3-4.5 \mathrm{~m}^{3}$ of sludge is expected (dependant on the thickening); the average expected composition is shown in Table 7-5.

Figure 1 shows the envisaged process flow sheet for a batch of $0.5 \mathrm{~m}^{3}$ of HLLW-MTR. It is planned to carry out campaigns of 20 daily batches of $0.5 \mathrm{~m}^{3}$ of HLLW, followed by a slurry thickening stage.

\section{Candu Fuel (see Figure 7-4)}

The Candu process also achieves the coprecipitation of $\mathrm{Sr}$ and TRU elements with ferric hydroxide and Cs precipitation as CsTPB, but the alkaline agent is Sodium Carbonate, which allows $U$ to remain in solution as a complex. Laboratory tests have shown that coprecipitation of uranium would make the slurry quite bulky and not easily thickened and removed. In order to achieve a satisfactory DF for Pu, Am-241 and Cm-244, the precipitation has to be carried out in two steps by varying the $\mathrm{pH}$ conditions. Each step of the solid-liquid separation procedure is the same as for MTR process.

The main DFs achievable with this process are: Cs-DF- 1000 ; Sr-DF $=5-10$; TRUDF $=500-1000$.

A production of 1.5-2.4 $\mathrm{m}^{3}$ of sludge (depending on the achievable thickening during decantation) is estimated with the average composition indicated in Table 7-6.

The process flow sheet is shown in Figure 4 for a batch of $0.2 \mathrm{~m}^{3}$ of HLLW-CANDU. It is planned to carry out campaigns of 20 daily batches of $0.2 \mathrm{~m}^{3}$ of HLLW, followed by the thickening stage of the accumulated slurry.

After the pretreatment stage, both the MTR waste and the CANDU waste are treated in the same manner. Principally, the supernatant is sent for cementation while the sludge is sent for vitrification.

\section{Encapsulation}

Cementation Unit

The cementation unit, which will also treat the LLW presently stored at the EUREX site $\left(150 \mathrm{~m}^{3}\right)$, includes

- a feed tank for storing a weekly batch of supernatant

- a cementation unit 
- $\quad$ transfer and curing systems for cemented packages

- a station for quality control, grout sealing, and final measurements on cemented packages

- cemented packages interim storage

The expected throughput of the cementation section is 25 cemented packages (400 liter drums) a week (about $6 \mathrm{~m}^{3}$ of treated liquid waste). The produced packages will be suitable for surface disposal, according to the Italian policy.

The selected cementation process is the in-drum mixing type. The 400 liter drum, containing pre-weighed dry cement added by a screw feeder, is moved to the cementation station on a roller conveyor to allow the matrix setting and initial hardening.

To complete the conditioning process, the drum is capped with inactive grout, if the cement waste matrix has met specifications. Following one day setting time, the package is weighed, monitored for contamination and dose rate, and sent to the on-site interim storage.

The cementation of the about $160 \mathrm{~m}^{3}$ low level alkaline waste coming from the treatment of the HLLW-MTR will produce approximately $340 \mathrm{~m}^{3}$ of cement.

The cementation of the about $125 \mathrm{~m}^{3}$ low level alkaline waste coming from the treatment of the HLW-CANDU will produce approximately $240 \mathrm{~m}^{3}$ of cement.

\section{Vitrification Unit}

The vitrification unit, which will require a cell of $4 \mathrm{~m}$ length, $4 \mathrm{~m}$ depth, $5 \mathrm{~m}$ height (estimated size), includes 3 main units:

- Ceramic Melter

- Slurry and Frit Feeding System

- Off-gas System

The size and the features of the ceramic melter are presently under consideration.

The feeding system will consist of the following major components:

- feed tank for slurry

- pumping system for introducing feed rate-controlled slurry into the melter

- glass frit feeding system for introducing frit particles batchwise into the melter.

The off-gas system includes a jet-scrubber (for removing dust and condensating all steam in the off-gas), a NOx-column, a glass fibre filter, a HEPA filter and a blower.

The vitrification process is still under going study. Due to the limited quantity of highly active sludge, a very small unit, based on the ceramic melter technology, is under consideration. The preliminary design and construction estimate of the vitrification section has been completed. 
According to the presented data, the amount of the high-level waste slurry to be vitrified is:
- from HLLW-MTR:
$4.5 \mathrm{~m}^{3}$ maximum
- from HLLW-CANDU:
$2.4 \mathrm{~m}^{3}$ maximum

Direct feeding of the slurry to the ceramic melter is being considered.

\section{Vitrification of the Slurry from HLLW-MTR} $\mathrm{Na}_{2} \mathrm{O}$.

The major constituents of the HLLW-MTR waste residues (as oxides) are $\mathrm{Fe}_{2} \mathrm{O}_{3}, \mathrm{Al}_{2} \mathrm{O}_{3}$,

Based on a $10 \mathrm{wt} \%$ loading of the waste glass with waste calcines, a slurry feed rate of $4 \mathrm{l} / \mathrm{h}$ is assumed to keep the melter dimension as small as possible. The sélected process data are:

- Slurry feed rate to melter

- Glass production rate

- Glass frit rate to melter

- Specific radioactivity of the glass

- Time for production of 1 canister

- Total mass of glass

- Number of canisters $(400 \mathrm{kgl}$
$4 \mathrm{l} / \mathrm{h}$

$6 \mathrm{~kg} / \mathrm{h}$

$5.4 \mathrm{~kg} / \mathrm{h}$ $380 \mathrm{GBq} / \mathrm{kg}$

(Cs/Sr, average)

67 hours

(400 kg glass capacity of the can)

$6750 \mathrm{~kg}(\max )$

17

\section{Vitrification of the Slurry from HLLW-CANDU}

The major constituents of the HLLW-CANDU waste residues (as oxides) are $\mathrm{Fe}_{2} \mathrm{O}_{3}$, $\mathrm{NA}_{2} \mathrm{O}$ and some Uranium oxide. The radioactivity of the slurry is higher than the HLLW-MTR slurry, while the expected solid oxide residue is about half.

Based on a $10 \mathrm{wt} \%$ waste glass loading, the selected process data design are:

- Slurry feed rate to melter

- Glass production rate

- Glass frit rate to melter

- Specific radioactivity of the glass
$4 \mathrm{l} / \mathrm{h}$

$3.13 \mathrm{~kg} / \mathrm{h}$

$2.82 \mathrm{~kg} / \mathrm{h}$ $1500 \mathrm{GBq} / \mathrm{kg}$

(Cs/Sr, average)

\subsubsection{Packaging}

Italy's containers for LLW cementation packaging are 400 liter S.S. drums. The HLW is contained in $5-400 \mathrm{~kg} \mathrm{S.S.} \mathrm{canisters} \mathrm{similar} \mathrm{to} \mathrm{the} \mathrm{Standard} \mathrm{European} \mathrm{container} \mathrm{shown} \mathrm{in}$ Figure 7-32. 


\subsubsection{Transport}

All waste produced by reprocessing is stored at the reprocessing site. Hospital/engineering radioactive waste is transported by road to an industrial radwaste facility operated by Nucleco at a site near Rome.

\subsubsection{Disposal}

There are no present proposals for fuel storage in an engineered disposal facility in Italy. HLW and LLW has no identified disposal site and is currently stored.

\subsection{JAPAN}

\subsubsection{Overview (see Figure 7-5)}

About $30 \%$ of Japan's electricity comes from its 41 operating nuclear power stations. Plant operating waste, together with fuel fabrication and future reprocessing plants, accounts for the existing and projected waste volumes. As with other countries, additional radioactive waste comes from medical and industrial users. Low-level wastes are being disposed of at Japan's Nuclear Fuel Ltd's near-surface facilities at Rokkasho-mura site, in the northern peninsula of the main island of Honshu. This site opened in 1992, and is expected eventually to take up to $600,000 \mathrm{~m}^{3}$ of waste. This site also will host a uranium enrichment plant, a reprocessing facility and an HLW intermediate storage facility. Japan plans to build a rock laboratory for HLW disposal research at Horonobe, Hokkaido, though this will not be the final repository location. HLW disposal is planned to commence next century. Japan has reprocessing agreements with both the UK and France, who will return HLW to Japan for disposal.

\subsubsection{Inventory}

Japan has a variety of nuclear facilities which generate radioactive wastes in various forms, and the radioactivity contained in each type of waste varies significantly.

These wastes are generally classified into:

- $\quad$ high level waste from reprocessing operations

- beta-gamma waste from reactor sites/reprocessing facilities

- low level waste from medical/industrial users/reprocessing facilities

Activity

Wastes exceeding $1.11 \times 10^{4} \mathrm{~Bq} / \mathrm{m}^{3}$ will be disposed of in a deep underground facility vet to be designed. 
Figure 6).

Wastes lower than the above will be sent for shallow land burial at Rokkasho-mura (see

\section{Volume}

Currently, Japan has a TRU-bearing waste inventory which is equivalent to forty thousand, 200-liter drums. The second half of the 1990's will see a considerable increase in the amount of Japanese waste. The cumulative volume is forecast to reach the equivalent of approximately three hundred thousand 200-liter drums by the year 2010. Additional radioactive wastes containing TRU nuclides also are expected to be produced by the future decommissioning of nuclear-fuel facilities. This equates to $600 \times 10^{3} \mathrm{~m}^{3}$ by 2010. In 1990 , the volume of high level liquid waste stored at Tokai Reprocessing Plant was $365 \mathrm{~m}^{3}$.

\subsubsection{Waste Form .}

Japan has a carefully controlled segregation policy to divide waste into different streams for ultimate disposal; hulls and end pieces, concentrated liquid waste, spent solvent, sludge and miscellaneous solid waste from reprocessing.

The miscellaneous solid wastes are further divided by radioactive concentration into low-level and very-low level, and by incineration capability into "combustible" and "noncombustible" categories. Also, miscellaneous solid waste from a MOX fuel fabrication facility is divided into "combustible" and "non-combustible" categories.

\section{Pretreatment}

The treatment methods currently utilized at the Tokai Reprocessing Plant are:

- volume reduction through the evaporation and concentration of liquid waste from reprocessing

- bituminization of the concentrated liquid waste, and

- $\quad$ plastic solidification of spent solvent

Methods used at the MOX fuel fabrication facility are:

- incineration of combustible miscellaneous solid waste

- microwave solidification by melting of ash from incineration

- solidification by melting of miscellaneous non-combustible waste, and

- Solidification and pelletization of alkali solutions using Colloidal Silica as a binder 


\section{Pretreatment Method}

Treatment methods for drying, pelletizing, incinerating and solidifying using cement glass can be found in Attachments 7-3 and 7-4.

\subsubsection{Packaging}

Japan utilizes 200-liter steel drums for the encapsulation of LLW and ILW. The ILW drums are stored on site for disposal in a deep repository yet to be constructed, with the LLW drums being sent to the Rokkasho-mura repository.

\subsubsection{Transport}

Method

Japan operates road, rail, and sea transport policies for its LLW nuclear waste.

\section{Outline of $L L W$ Transport System}

The LLW transportation system includes marine transportation from the nuclear power plants to the Matsu Ogawara Port, located in Rokkasho Mura and the subsequent land transportation from the port to the final repository.

A special type of container vessel is used exclusively for the marine transportation of LLW and conventional type trucks are used for land transportation. The time for one journey along the Japanese Islands sea coast is 2 to 4 days, depending on the location of the nuclear power plant.

As for land transportation, there is a $9 \mathrm{~km}$ road from the port to the repository, where the major part of the transport route is inside the premises of the nuclear fuel cycle facilities except the public port and its adjacent area.

According to the repository program, 25,000 drums are to be packaged and disposed of every year. NFT estimates that at least 10 trips will be necessary per year assuming that 2,500 drums are stowed each time in the vessel. (Maximum stow capacity of the vessel is 3,072 drums in seven holds). Figure 7-7 shows the outline of the LLW transport system.

\section{LLW Transport Package}

Considering safety and convenience of LLW handling, a special transport package has been developed by Nuclear Fuel Transport Ltd (NFT). It is a specially designed closed type container which can hold 8 drums. This is the most adequate size as far as handling in the warehouse at each nuclear power plant is concerned. The package has been designed so as to meet the requirement of IP-2 as specified in IAEA Standard. 
The package lid with 4 fastening bolts can be opened and closed by a remote control tool. Each package identification number can be read automatically by means of a radio frequency identification instrument attached to each package. NFT has ordered 3,000 packages for use at Rokkasho-mura.

\subsubsection{Disposal Site}

\section{Location}

Japan's first facility for shallow land burial of LLW is at Rakish-Rokkasho-mura which is in Aomori Prefecture, $700 \mathrm{~km}$ north of Tokyo. It came into operation in 1992. The current plan is for 200,000 drum storage with the potential for 1 million drums.

\section{Geology}

The land disposal facility is constructed in the base rock after excavating the surface soil. The upper and side faces of the land disposal facility are filled with soil mixed with bentonite. The soil/bentonite mix is to prevent ground water from flowing in and dispersing through the land disposal facility.

The water table at the site is not deep enough, so the wastes will be buried below the water table. A facility strong enough to resist the flow of ground water has been designed and safety assessment of the ground water contamination scenarios have been calculated. The ground water volume is very small and very low velocity since it is brought about only by precipitation.

\section{Configuration}

The land disposal facility $(24 \mathrm{~m} \times 24 \mathrm{~m} \times 6 \mathrm{~m}$ high) is divided by bulkheads into 16 cells. The waste packages are placed in each cell and then the cells are filled with cement mortar such that no gap is left between waste packages. The spaces between the cell walls and waste packages are also filled with cement mortar.

The space between the cement mortar and the outer bulkhead and cover of the drain facility is provided with a porous layer having appropriate water-collecting functions. Any water that penetrates can be drained out. In addition, inspection routes are provided on the periphery of the land disposal facility in order to monitor and inspect the draining performance.

In placing waste packages, care is exercised to prevent uneven distribution of radioactive concentration and waste types within the disposal facility. Integrity

The exposure dose limits used in the safety evaluation are $1 \mathrm{mSv} / \mathrm{yr}$ for the institutional control period ( 300 years), which is the same limit as for other nuclear facilities in Japan, and $10 \mu \mathrm{Sv} / \mathrm{yr}$ for the post institutional control period. This is $1 / 10$ of the exemption level for the individual dose specified by the ICRP as $100 \mu \mathrm{Sv} / \mathrm{yr}$. 
The basic concept of safety assurance in Japan's shallow land disposal is isolation through the used of engineered and natural barriers until the radioactivity has decayed to a level which is not hazardous in terms of radiological safety. As the radioactivity of the waste decreases, control can be stepwisely reduced while maintaining safety. Specifically, the following three-step-control approach is adopted at the Rokkasho waste disposal site, where modular-type disposal facilities are to be constructed and progressively filled with waste packages.

At the 1st stage, the radioactivity must be confined within the engineered barriers such as concrete pits, and the confinement is supported with monitoring and leak detection in order to ensure that no leakage or release occurs. At the Rokkasho site, the 1 st stage lasts for 10 15 years.

At the 2nd stage, a system combining engineered and natural barriers provides a sufficient retardation effect against transfer of the radioactivity to the groundwater. Some monitoring and measurements are provided to ensure the safety of the public. The 2 nd stage will last for thirty years after the end of the 1 st stage at the Rokkasho site.

At the 3rd stage, the general public can have access to the burial site. Some specific acts such as digging up the soil or dwelling there are prohibited. The disposal company, the JNFI, has a plan to stop the institutional control of the Rokkasho site after 300 years.

\section{Closure}

The closure proposals for the Rokkasho waste disposal site are presently under investigation to determine the most suitable materials for the varying weather conditions of the area. It is expected to be similar to French and American designs for prevention of water ingress.

\subsection{RUSSIA}

\subsubsection{Overview}

Prior to 1993, the Soviet government had developed a large and complex system for the management of spent fuel and reprocessing wastes. The information is somewhat limited in content but gives a brief report on how Russian waste is being treated.

Today, the Russian program for disposing and managing high-level nuclear waste (HLW) and spent fuel consists of several areas:

- reprocessing reactor fuel

- solidification of liquid high-level wastes

- temporary storage, and

- permanent disposal

There are three main methods for solidifying liquid HLW calcining, vitrification, and ceramics. A flow chart for their process is given as Figure 7-8. Starting at the far left side of the flow chart, certain wastes (evaporated and non-evaporated) are fed through a ceramic 
melter to produce borosilicate glass and "vitro-melt." Evaporated or calcined waste can be sent through an induction melter to produce "vitro similar rock." Alternatively, calcined waste can be sent through a microwave heater and formed into ceramic blocks. These so-called one and two-state processes of glass and vitreous materials production have reached industrial scale. Five hundred liters per hour has routinely been cited as the production rate. The ceramics method is currently being applied only at the laboratory scale, but it is successful.

The Russians are also looking at vitrimetallic methods that are similar to the methods used by the Germans. The Russians are separating out cesium, strontium, transuranics, and transplutonium fractions. The transuranics and transplutonium fractions are put into glasses or ceramics. The cesium is solidified in green aluminum phosphate glass and the strontium in borosilicate glass. Due to volatility problems they think it is better to dispose of the cesium in green aluminum phosphate glass rather than in borosilicate glass. Apparently, lower temperatures can be used in the phosphate glass process, which helps lower volume requirements of the gas purification system. The final stability of the waste form is similar to that of borosilicate glass.

Borosilicate glass is the preferred waste form for strontium since there are no volatility problems and the glass (according to the Russians) can contain up to $50 \%$ of strontium oxides. These high percentage waste type glasses are being considered for use as radiation or heat sources. If there is no necessity for such products, strontium concentrations can be lowered to levels acceptable for disposal.

TRU concentrates are considered to be most safe when incorporated into a ceramic matrix based on clay, which after firing gives a mechanically and chemically stable material. Alternatively, ceramic oxide materials from super power frequency heat sources, e.g. microwave, would be acceptable.

These differing fractions, once solidified and formed into small beads, are then mixed in different proportions and combined into a vitro-metallic matrix for disposal. The mixture can be adjusted for different purposes. For example, to keep the percentage of strontium and cesium down (to lower the heat loading), the percentage placed in the matrix is reduced (Figure 7-9).

Development of a geologic disposal program for spent fuel and high level radioactive waste is now underway in Russia. The program is officially headed by the Russian Institute of Geology of Ore Deposits, Petrography, Mineralogy, and Geochemistry (IGEM). The geologic disposal program has two main directives. The first directive involves a country-wide screening for favorable areas. Favorability will be determined by criteria such as rock composition, tectonics, neotectonics, and hydrogeology. The second directive is to perform site specific investigations in certain areas where waste has been accumulating. These areas are Krasnoyarsk and Chelyabinsk, sites which were formerly utilized in weapons production or reprocessing. IGEM has focused its efforts on the Mayak Chemical Industrial Complex located in the Southern Uran Mountain region near Chelyabinsk. 


\subsection{UNITED KINGDOM}

\subsubsection{Overview}

The United Kingdom government's technologies for radioactive waste treatment and disposal are being undertaken by both BNFL who are providing the treatment and present LLW storage at Drigg and NIREX who are producing the new underground disposal facility for LLW and ILW.

ILW arising from the reprocessing of Magnox and Oxide fuels are being routed through dedicated conditioning and storage plants. The first encapsulation plant - for Magnox cladding wastes - was actively commissioned in 1990; encapsulation plants for THORP wastes and for flocs arising from liquid effluent treatment were completed in 1992.

It is intended that conditioned ILW and LLW will eventually be disposed of in a deep underground repository planned to be in operation by 2005. Geological investigation of potential sites at Sellafield is in progress and final proposals will be supported by extensive design and development programs currently underway. These programs include particular emphasis on the evaluation of waste form performance and on the subsequent migration of nuclides through the repository structure and the surrounding geology.

\subsubsection{Inventory}

\section{Type/Activity}

Although there is no unified categorization of radioactive wastes at the international level, there are similarities among the various national classifications. In the UK, it is common practice to allocate radioactive wastes into one of three categories:

HLW, or heat-generating wastes, are defined as those in which the temperature may rise significantly as a result of their radioactivity. The design of storage or disposal facilities for HLW must therefore take this factor into account.

LLW contains radioactive materials not acceptable for disposal as ordinary nonradioactive trash, but not exceeding $4 \mathrm{GBq} /$ te alpha and $12 \mathrm{GBq} /$ te beta/gamma.

ILWs are those containing radioactivity above the levels set for LLW, but which do not experience a significant temperature rise as a result of their radioactivity.

In practice, the HLW category is applied exclusively to the concentrated waste product from the primary separation stage of fuel reprocessing. Consequently in adopting this classification, certain wastes are categorized as ILW, although they may generate a modest amount of heat.

\section{Volume}

The current stored volume of ILW is $50,000 \mathrm{~m}^{3}$ however with the completion of BNFL's thermal oxide reprocessing plant the volume will be in the order of $400,000 \mathrm{~m}^{3}$ by 2010 . 


\subsubsection{Waste Type}

The U.K. operates a segregation policy for its waste types, similar to other large European waste producers. The waste is divided into three basic streams - LLW, ILW, and HLW. The greatest volume of waste occurs at the Sellafield Reprocessing Plant.

\section{Type $/ L W$}

A wide range of wastes fall into this category. ILW containing mainly short-lived activity arise mainly from nuclear power stations and research institutions. Examples are ion exchange resins and sludges from treating effluent streams and cooling pond water, fuel assembly debris and miscellaneous contaminated items.

Long-lived ILW from fuel reprocessing operations contain significant quantities of isotopes having half-lives of 30 years or more. Although a large number of ILW streams are generated at BNFL's Sellafield site, they may be grouped according to their origins or properties as follows:

- Fuel Element Cladding Wastes: comprising essentially solid wastes such as leached cladding and end assembly fittings from oxide fuel (known as hulls) and Magnox fuel element cladding (swarf).

- Miscellaneous Beta-Gamma Wastes: any waste which although contaminated has very little alpha emitting activity associated with it. This might typically be maintenance scrap and certain spent fuel storage equipment.

- Slurries: a broad range including ion exchange materials, flocs from liquid effluent treatment and sludges from the corrosion of Magnox swarf in water.

- $\quad$ Plutonium Contaminated Material (PCM): drummed packages of small scale wastes and large items of equipment such as excess gloveboxes.

\section{Pretreatment Method}

The encapsulation of ILW at Sellafield is currently being undertaken in three processing plants:

Encapsulation Plant 1 (EP1) opened in 1990 for cementation of Magnox swarf from the Magnox reprocessing plants.

Encapsulation Plant 2 (EP2) opened in 1992 and will cement encapsulate hulls and slurries from oxide fuel reprocessing.

Waste Packaging and Encapsulation Plant WPEP will encapsulate flocs, also using cement. 


\subsubsection{Packaging (see Figure 7-10)}

The ILW waste is containerized in a 500-liter single shell drum. A limited number of drum shapes have been adopted due to the process of immobilization of the waste form. However, the drums are all in the order of $0.8 \mathrm{~m}$ diameter $\times 1.2 \mathrm{~m}$ high.

\subsubsection{Transport (Figure 7-11)}

NIREX policy is that rail transport shall be used wherever practical to convey waste to the repository, although it is not possible to utilize rail transport for all waste. The company is therefore assessing both rail and road transport. (Sea transport could be used for part of the journey from some sites but it is not currently favored.)

Radioactive waste could be transported from the waste-producing sites to the repository in one of the following three ways:

- by rail, from a siding located within the site boundary;

- by road, to an off-site railhead and thence by rail; and

- by road, direct to the repository.

The capacity of most existing on-site sidings or off-site railheads serving wasteproducing sites is limited, so it may be appropriate to assemble the railcars into longer trains at various marshalling points before their onward journey to the repository. Extended or new sidings/railhead facilities may be required for some sites.

Within the NIREX transport system, movement of abnormal loads on the public highways is likely to be limited mainly to journeys to off-site railheads. At most of the sites involved, this would be a continuation of well-established transport practices for fuel casks. For assessment purposes, two particular scenarios have been considered:

- Maximum rail - the maximum possible number of packages are to be transported by rail.

- Maximum road - those packages which can be transported on conventional HGVs are to proceed by road, and all other packages (or where road transport is inappropriate) are to be transported by rail.

\subsubsection{Disposal Site}

\section{Location (Figure 7-12)}

United Kingdom NIREX Ltd. has the responsibility to provide and manage the ILW and LLW radioactive waste disposal facility. The proposed location of the deep repository is to be on a site adjacent to the BNFL Sellafield site in Cumbria, which is on the northwest coast of England. 


\section{Geology}

There is presently a continuing geological investigation program to satisfy safety and design concept requirements. The facility will be situated about $800 \mathrm{~m}$ below ground in the low permeable volcanic rock of the Barrowdale Volcanic Group. Studies presently are being concentrated on the hydrogeology of the area to obtain better understanding of water flow patterns. A typical cross section of the repository location within surrounding rock formation can be seen in Figures 7-13 and 7-14.

\section{Configuration}

Conceptual design work for the repository was started in the late 1980 s and, in July 1992, NIREX announced that it planned to construct a rock characterization facility as a stand alone project to develop a better understanding of the geological, hydrogeological, and drilling conditions at the proposed depth of about $650 \mathrm{~m}$. All aspects of the design and layout are being continuously updated however, the basic design concept is shown in Figures 7-15 and 7-16.

The total initial capacity of the repository is $650,000 \mathrm{~m}^{3}$, made up of $600,000 \mathrm{~m}^{3}$ of ILW and $50,000 \mathrm{~m}^{3}$ of LLW with a capacity to extend to a 2 million $\mathrm{m}^{3}$ final capacity made up of $800,000 \mathrm{~m}^{3} \mathrm{LLW}$ and 1.2 million $\mathrm{m}^{3} \mathrm{LLW}$.

\section{Integrity}

The target applicable to the repository at any time is set by the Uk Government at a risk to an individual in a year equivalent to that associated with a dose of $0.1 \mathrm{~m} \mathrm{sv} \mathrm{year}^{-1}$. However, it has been recognized by some government departments that a risk target of $10^{-6}$ would be more applicable. The National Radiological Protection Board (NRPB) treats this risk as covering both risk of fatal cancer and serious hereditary disorders and has adopted a risk factor of $0.06 \mathrm{sv}$ year. ${ }^{-1}$ NIREX's approach is one of continual development in proposing a satisfactory design to meet the above requirements.

\section{Closure}

Closure of the repository would be on a continuing cement backfill basis, with each cell or tunnel being back filled around the waste container - the object being to fill outwards each tunnel until the level of the repository was full.

\subsection{UNITED STATES OF AMERICA}

\subsubsection{Overview}

The U.S. Department of Energy (DOE) has generated and continues to generate large volumes of mixed LLW at many different sites across the USA. These wastes are generally going into interim storage and require treatment prior to final disposal. Some sites are already actively involved in waste treatment. The DOE has collected and analyzed data on mixed LLW for its Mixed Waste Treatment Project. The following information has been extracted to match as close as can be identified, the Hanford equivalent waste, although the actual inventory is somewhat different. 


\subsubsection{Inventory}

7-17).

The sites with the most significant inventory and generation are listed below (Figure

Hanford*
INEL

Oak Ridge

K-2S site

$\mathrm{Y}-12$

Oak Ridge Labs

Rocky Flats

Savannah River
$122,000 \mathrm{~m}^{3}$
$30,000 \mathrm{~m}^{3}$

$28,000 \mathrm{~m}^{3}$

$12,000 \mathrm{~m}^{3}$

$1,270 \mathrm{~m}^{3}$

* Before treatment $-210,000 m^{3}$ disposal volume
Mixed waste

Aqueous mixed waste

Inorganic solids Inorganic solids Aqueous mixed waste

Inorganic solids

Tritium aqueous waste

The following sites have been selected to give a brief overview of typical waste treatment systems in the USA.

\subsubsection{Savannah River}

The Savannah River Site (SRS) has been storing and disposing of solid radioactive waste since 1953. The disposal site known as the Solid Waste Disposal Facility (SWDF) is centrally located in the 300 square mile site and has disposed of $570,000 \mathrm{M}^{3}$ of waste. being LLW.

The gross volume of solid waste generated in a year is $40,000 \mathrm{M}^{3}$ with $34,000 \mathrm{M}^{3} \mathrm{ft}$

\section{Waste Classification}

The classification system at SRS categorizes waste according to type and activity level shown in Table 7-7. The disposal unit designs are based on the method of handling.

\section{Disposal Unit Design}

For this project, there are three separate disposal units and one storage unit designed to correspond with the classification system. Those waste forms containing long-lived radionuclides are not suitable for disposal at the SRS. These waste forms are stored for later disposal.

Specific design requirements for the concrete used for the structural components of the disposal units were to maximize durability and to minimize uncontrolled cracking. To meet this requirement, the units were designed with a specially formulated concrete mix with a unique blend of cement, blast furnace slag and pozzolan. This mix was selected from a series of mixes tested in a full-scale demonstration of workability, constructability, and early crack resistance. Descriptions of the individual units are as follows: 
Intermediate Level Nontritium Unit (ILNT) - Figure 7-19

The ILNT disposal unit is a below-grade concrete vault with dimensions: $57.6 \mathrm{~m}$ long by $14.8 \mathrm{~m}$ wide by $8.9 \mathrm{~m}$ high. The vault is divided into seven cells $7.6 \mathrm{~m}$ by $13.6 \mathrm{~m}$ separated by $0.5 \mathrm{~m}$ thick walls. Each cell is covered with steel raincovers to prevent the infiltration of rainwater. These units are designed with $0.5 \mathrm{~m}$ thick concrete tees (temporary roof shielding beams) for shielding during operations. The exterior end walls are $0.7 \mathrm{~m}$ thick with side walls $0.6 \mathrm{~m}$ thick. Total volume of the vault is approximately $5662 \mathrm{~m}^{3}$ providing two years disposal capacity. This unit is top loaded using a gantry crane. There are fabric nets on the interior walls of each cell to 'wick' in any filtrating water towards a conductive gravel layer under to waste packages. This gravel layer drains the leachate collection system that will be monitored during operation and after closure. The unit is to be closed with a $1.2 \mathrm{~m}$ thick concrete cap for overburden support and intruder protection.

\section{Intermediate Level Tritium Unit (ILT) - Figure 7-19}

The design is very similar to the design of the ILNT vault with like raincovers, shielding tees, and leachate collection. The below-grade vault has dimensions $17.2 \mathrm{~m}$ long by $14.8 \mathrm{~m}$ wide by $8.9 \mathrm{~m}$ high. The vault is divided into two cells. One cell is grouted full with cylindrical silo-type void spaces for the disposal of tritium crucibles; the other cell is open. There is an upper layer of shielding concrete with cylindrical plugs for closure after the crucible emplacement. The ILT disposal vault is constructed in close proximity to the ILNT vault to facilitate the use of the same gantry. The total volume of the open cell is approximately $990.8 \mathrm{~m}^{3}$; the waste packages are various sized steel boxes. The silo cell is designed to accommodate a fixed number of crucibles. The unit is to be closed with a $1.2 \mathrm{~m}$ thick concrete cap for overburden support and intruder protection.

\section{Low Activity Waste Unit (LAW) - Figure 7-18}

The LAW disposal unit is operated as a partially subgrade vault that is side-loaded using forklift trucks. The unit is constructed in three modules of four cells each. The overall structure is $196 \mathrm{~m}$ wide by $44.1 \mathrm{~m}$ long. There is approximately $7.6 \mathrm{~m}$ clear stacking height. Each cell is approximately $16.1 \mathrm{~m}$ clear span, supported by prestressed AASHTO highway bridge beams. The floor of each cell is sloped to a drainage trench that leads to a collection sump. There is one collection sump per two cells that will be monitored and sampled during operation and after closure. Expected general-use containers for this facility are: $2.5 \mathrm{~m}^{3}$ and $1.3 \mathrm{~m}^{3}$ steel boxes, and 208 liter drums. Each cell is equipped with ventilation fans and overhead lighting that will be removed at closure. It has been concluded that the inclusion of fire suppression equipment is in direct conflict with the intent of these facilities - preventing the contact of waste and water. There has been no official DOE concurrence with this conclusion.

All units have an exterior surrounding 'conductive' layer (Figure 7-21) of drainage gravel to 'wick' perched water to a non-monitored collection sump. All units are designed as 'strong' vaults, that is, the vault structure itself must provide the capability of supporting the overburden cover. This decision was made to provide long-term assurance of subsidence control. Subsidence has been found to increase the failure potential of conventional cover systems used in typical shallow land burial facilities without waste form stabilization. 
Tables 7-8 and 7-9 give the disposal limits for the Savannah River vaults. Table 7-10 gives performance objectives of the system.

\section{Closure}

The proposed cover system (Figure 7-20) has been designed to accommodate a significant amount of post-closure settlement while maintaining a permeability of $1 \times 10^{-7} \mathrm{~cm} / \mathrm{s}$ or less throughout its 30-year, regulatory lifetime. A composite cover consisting of a geomembrane underlain by a geosynthetic clay liner was selected because of its extremely low permeability, ability to elongate without tearing, and capacity to "self-heal" if punctured. These characteristics will enable the cover system to accommodate differential settlement without cracking or tearing, thus providing long-term protection with minimal maintenance. Also, to improve the ability of the cover system to span voids that may develop in the underlying waste, a geogrid has been included in the foundation layer. A gas vent layer has been included to allow for the safe collection and venting of landfill gases.

The LAW vaults were considered to remain intact and retain all radionuclides for 100 years, while the ILT vaults were assumed to retain all radionuclides for 300 years as a result of their more substantial design.

In addition to the 100 year active institutional control period mandated by DOE Order $5820.2 \mathrm{~A}$, the LAW vaults were assumed to provide an additional 200 years of passive control, by virtue of their more massive construction, to deter intrusion into the waste. The Nuclear Regulatory Commission allows up to 500 years of passive control for stabilized waste forms such as the LAW vaults.

\subsubsection{Oak Ridge}

The DOE operates three facilities at the Oak Ridge Reservation (ORR):

- the Oak Ridge National Laboratory (ORNL),

- the Y-12 Plant - weapons component fabrication plant, and

- the K-25 Site - gaseous diffusion plant (stopped production in 1985).

Waste Classification

The vast majority of waste at ORR is of solid material from mechanical operations. However, there are some quite large quantities of slurries and organic and aqueous liquids designated as type ' $B$ ' waste. DOE operations generate approximately $4,500 \mathrm{~m}^{3} /$ year of LLW mainly from ORNL and $6,000,000 \mathrm{Kg} /$ year of solid mixed waste mainly from $\mathrm{Y}-12$ and $\mathrm{K}-25$.

Wastes are presently matched for 4 existing treatment systems.

- Neutralization

- Stabilization

- De-activation

- Incineration 
Stabilization is currently limited to the Melton Valley Storage tank supernent which was planned for solidification during 1993. Studies are presently being undertaken on how to dispose of liquid slurries and waste for which there are no treatment facilities.

\subsubsection{Rocky Flats}

The Rocky Flats Plant near Denver, Colorado, generates various waste forms including TRU, low-level (LL), hazardous and sanitary waste. When hazardous waste is mixed with either TRU or LL waste, the resulting waste form is referred to as "mixed waste." Residues comprise a category of materials with sufficiently high concentrations of plutonium that the recovery of that plutonium for the purpose of providing raw material for weapons production was at one time considered to be economically more favorable than the production of new plutonium in a reactor facility. The Rocky Flats residues have been accumulating in anticipation of the construction of a full-scale, operational plutonium recovery facility. With the change in mission for Rocky Flats from weapons production to environmental restoration and waste management, plutonium recovery operations will not be required for the foreseeable future. The problem remains, however, as to the ultimate disposition of the residue backlog.

\section{Waste Classification}

The Rocky Flats Plant generates both liquid and solid waste through limited production operations, maintenance and environmental management and restoration activities. The treatment and storage processes for these operations are described in more detail below.

\section{Waste Volume}

$$
\begin{gathered}
1000 \mathrm{~m}^{3} \text { plutonium bearing residues in } \\
\sim 3700-55 \text { gallon drums } \\
\sim 3500-\text { small containers }
\end{gathered}
$$

\section{Liquid Waste Storage and Treatment}

Liquid process waste is generated throughout the plant site via utilities operations, laboratory analyses, environmental restoration, laundry, and limited production operations. Much of this waste is considered either hazardous or mixed waste, however, at this time all aqueous process waste is treated in a single facility (Figure 22). Following generation, radioactive aqueous liquid waste is stored in holding tanks pending fingerprint analysis for treatment in onsite facilities to remove radioactive contamination and convert the solids to an immobilized waste form for interim storage and eventual offsite storage or disposal. The liquid effluent is re-used onsite in plant utilities operations such as the steam plant and cooling towers. Because hazardous and mixed waste is treated in the liquid waste treatment facility, the resulting solids generated by this facility are considered hazardous or mixed waste.

Non-aqueous liquid waste (i.e., oils and spent solvents) are either immobilized in a separate onsite treatment facility in anticipation of future offsite disposal or are stored awaiting shipment to offsite facilities for treatment, disposal or reclamation. 


\section{Packaging}

There has been some considerable discussion on the packaging limitations to be applied to the Rocky Flats containers, mainly dealing with acceptable surface radiation levels and Waste Isolation Pilot Plant (WIPP) waste acceptance criteria.

\section{WIPP acceptance criteria:}

200 fissile gram equivalent/drum

$200 \mathrm{mrem} / \mathrm{hr}$ surface dose rate

This gives the problem that only 100 grams of bulk salt (which would contain significant high activity fissile material) from the treatment plant could be placed in a 55-gallon drum resulting in large voidage within the drum. This would require a very large number of waste drums - approximately 72,000

Present discussions between Rocky Flats/WIPP Project Integration Office are pursuing possible changes to the WIPP acceptance criteria to reduce the total number of containers.

In October 1991, Rocky Flats was issued with a RCRA Part B permit allowing for the storage of LL mixed waste which would allow mixing of solid TRU material with the solidified bulk salt.

Disposal

Present considerations are to transport the waste to the WIPP repository - see attachment 7-5 for details.

\subsubsection{West Valley and Los Alamos Disposal Facilities}

The disposal facilities for LLW at West Valley, New York, and Los Alamos National Laboratory, New Mexico, have been included in Attachments 7-6 and 7-7, to show typical examples of LLW disposal facilities used by other states in the USA.

\subsection{BELGIUM, GERMANY, AND SWITZERLAND DISPOSAL SYSTEMS}

The above countries have been included to show typical disposal facilities being utilized by countries whose nuclear waste is processed in another country. These three countries have been chosen to show the different techniques adopted to make use of the most suitable geology for the disposal site.

\subsubsection{Belgium}

Belgium has a significant nuclear power program (7 reactors) based on PWRs, and about $65 \%$ of its electrical energy demands are met by nuclear power. Current plans are to reprocess all reactor fuel in France or Great Britain, with HLW and TRU waste being returned 
to Belgium for disposal. The proposed site is at Mol, Belgium, with repository operation expected to start in 2030. The repository is designed to handle the wastes from $5600 \mathrm{MW}(\mathrm{e})$ of electric generating capacity over 30 years.

The proposed repository will be located in Boom clay. An underground tunnel and borehole designs are shown in Figure 7-23, with the HLW canisters placed in lined holes with a 45 degree angle from vertical. This particular clay has some unusual characteristics. In terms of waste isolation, it has the desirable properties of extremely low permeability to water flow, chemical conditions that result in low solubility of radionuclides, and very high retardation of migration of radionuclides. It also has one unusual engineering characteristic the clay is very plastic and tends to rapidly seal shut tunnels and holes. This characteristic requires fully lined emplacement tunnels and boreholes to maintain openings long enough for waste placement, and it is the only repository design to date in which all tunnels and boreholes will be lined.

\subsubsection{Germany (Figure 7-24)}

Germany currently has stopped reprocessing of spent fuel, but had contracts with both Cogema (France) and BNFL U.K. for reprocessing. The solid and HLW will be returned to Germany after reprocessing for eventual disposal in a deep repository at Gorleben. Germany is also investigating direct disposal designs for spent fuel elements after an initial cooling period. Only the waste from reprocessing is covered in this study.

\section{Waste Form}

Solid and HLW formations from the U.K. and France are covered under each respective country. Volumes processed is equivalent to $500 \mathrm{t}$ of spent fuel.

\section{Packaging}

Containerization details are covered under U.K. and France packaging systems. However, it is proposed that on return, the waste will eventually be disposed of by placing it in a further "Pollux" container to be placed in the salt dome repository at Gorleben.

A typical cask for LWR spent fuel is shown in Figure 7-25. It is expected that the HLW will be placed in containers similar to them.

\section{Disposal Site}

Germany is presently investigating a salt dome formation at Gorleben, northwest of Berlin as its preferred location for a radioactive waste repository.

The underground layout (Figure 7-26 and Figure 7-27) consists of a series of parallel tunnels. The proposed waste package is a self shielded container that allows manual handling. Disposal involves placing the container in a position within a tunnel in the repository and backfilling with salt. This is repeated until the tunnel is full.

The technical characteristic of a deep salt mine is that the salt slowly creeps over a period of years, eliminating any void within the repository. After a period of decades, former disposal tunnels will have no void spaces. 
Detailed investigations of salt formations for the disposal of nuclear waste have been undertaken in Germany, Russia and the USA. Rock salt formations vary in age. Typically, German salt domes are 3 to 40 million years old, but not all are suitable for waste disposal. Each site must be investigated to substantiate its use for a repository. Absence of ground water is a must. Stable temperatures ensure no changes occur in the salt structure. It has been shown that localized temperatures (i.e., around a container) up to $200^{\circ} \mathrm{C}$ in some salt formations will not effect the overall rock formation.

The closure of a rock salt repository represents an essential part of the multibarrier concept. Construction of a dam as a sealing system is under investigation at the Asse salt mine in Germany. The study will demonstrate the technical feasibility of tight sealing against elevated gas and fluid pressures.

The basic concept is shown in Figure 7-28, with the following conditions being presumed for the design.

In the operational phase:

- Limited brine inflow into the operating mine openings

- Limited inflow of solutions from the salt formations into backfilled and abandoned areas of the mine

- Gas generation due to radiolysis

- Natural gas inflow

In the post-operational phase:

- Water or brine inflow from the main anhydride layers

- Limited inflow of solutions from the salt formations

- Gas generation due to radiolysis

- Natural gas inflow

\subsubsection{Switzerland (Figure 7-29)}

Switzerland has a significant nuclear power program (five reactors) based on LWRs. Switzerland currently has contracts with France and Great Britain to reprocess all current spent fuel, but retains the option of direct disposal of spent fuel. The planning basis for the repository assumes initial operation in 2020, with the ultimate repository capacity of 7,999 tons $\left(1,200 \mathrm{~m}^{3}\right)$ equivalent of HLW (NAGRA 1985). The repository will also handle $53,000 \mathrm{~m}^{3}$ of TRU waste. This capacity corresponds to the waste from 10 reactors operating for 40 years or about twice the current Swiss nuclear program. Switzerland has stated its preference to using an international repository outside Switzerland if available. 
The proposed repository is to be located $-1200 \mathrm{~m}$ underground in crystalline rock or $-850 \mathrm{~m}$ underground in sedimentary rock. Selection of geology is to be made by 2000 . Access would be by shaft, and the repository in either geology would consist of a series of parallel tunnels mined using continuous rock-boring machines. The mining equipment and tunnel sizes would be similar to current practice followed in Switzerland for hydroelectric, rail, and ventilation tunnels. Current investigations are being carried out at Grimsel, beneath Jucklistock Massif.

The Swiss self-shielded waste package is a large, heavy, thick-walled, steel container containing HLW (Figure 7-30). Package placement in repository disposal drifts is accomplished by placing the first waste package at the end of the drift and working back out of the dead-end tunnel.

The steps in waste package placement are:

- large premolded clay blocks are placed on the floor of the tunnel;

- the waste package is placed on top of clay blocks;

- clay blocks fill the space between the package and ceiling, and

- added clay blocks fill the tunnel for the short distance separating each waste package (Figure 7-31)

The planned waste form for the Swiss repository is borosilicate glass HLW in steel containers. The steel container to be used (Figure 7-32) is a standard disposal container with standard dimensions that most countries in Europe have agreed to use.

\section{Concluding Observation}

The disposal of radioactive waste is of international concern to many groups of people. Political, conservation, national and international regulatory groups are all actively involved in disposal proposals for this controversial waste product.

International treatment disposal policies do differ but broadly have the same goal, safe immobilization of radioactive waste for thousands of years.

This study has attempted to show international policies for waste disposal in relationship to the Hanford Waste Form, with the main observations highlighted below:

- No information could be found to show that any other country is vitrifying Hanford equivalent waste. Most countries are encapsulating this type of waste in cement or bitumen.

- Waste volumes to be treated are very much larger than most other countries although information on China and Russia is limited.

- The LLW tank waste at Hanford would be classified as ILW in many countries, because of the long-lived nuclides. 
- The international consensus is deep disposal of ILW, providing the geology and the hydrogeology can be shown to be adequate.

- There are many long-term studies to determine the stability of geological rock formations and the movement of underground water. These studies will obtain practical scientific evidence of how the repository should perform over a long time period.

- Some countries are making the best use of available geological formations to isolate the waste. Belgium, for instance, has decided that Boom clay is very suitable for long-term disposal of nuclear waste. 
Figure 7-1. Locations of Chinese Nuclear Facilities.

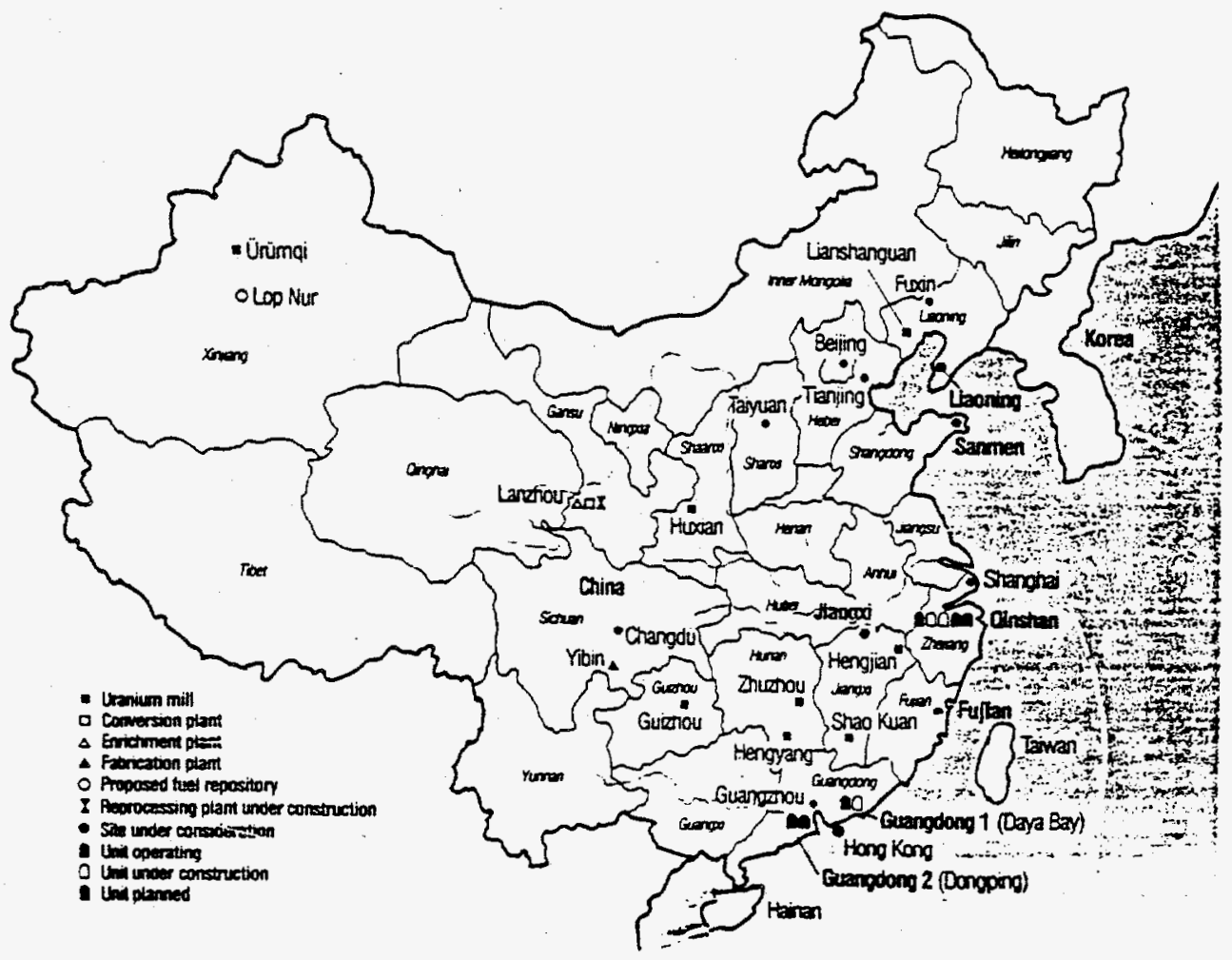

Figure 7-2. Locations of French Nuclear Facilities.

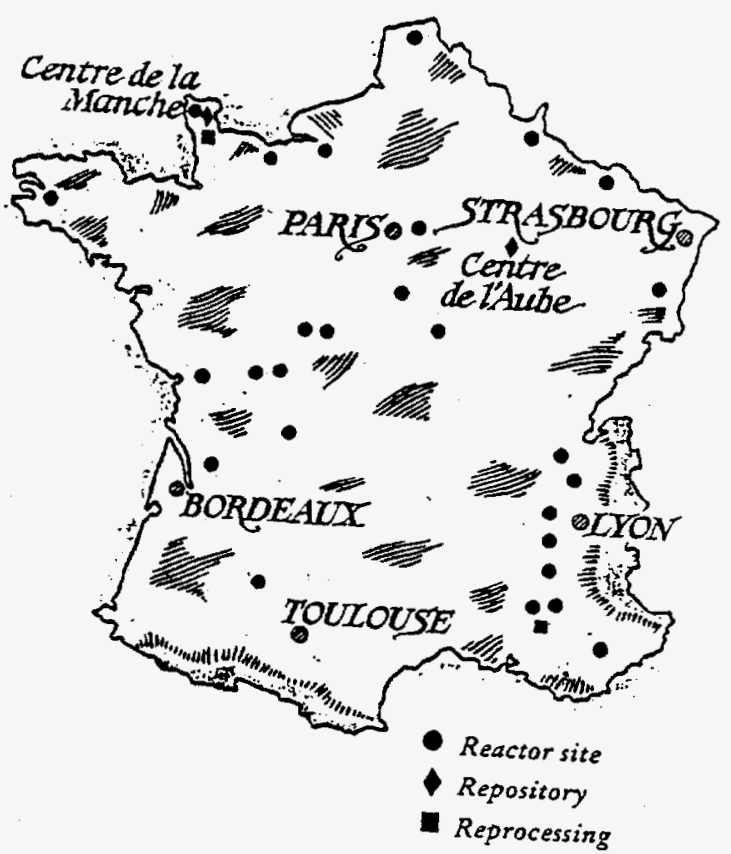


Final

Figure 7-3. Flow-sheet for Treatment of HLW-MTR.

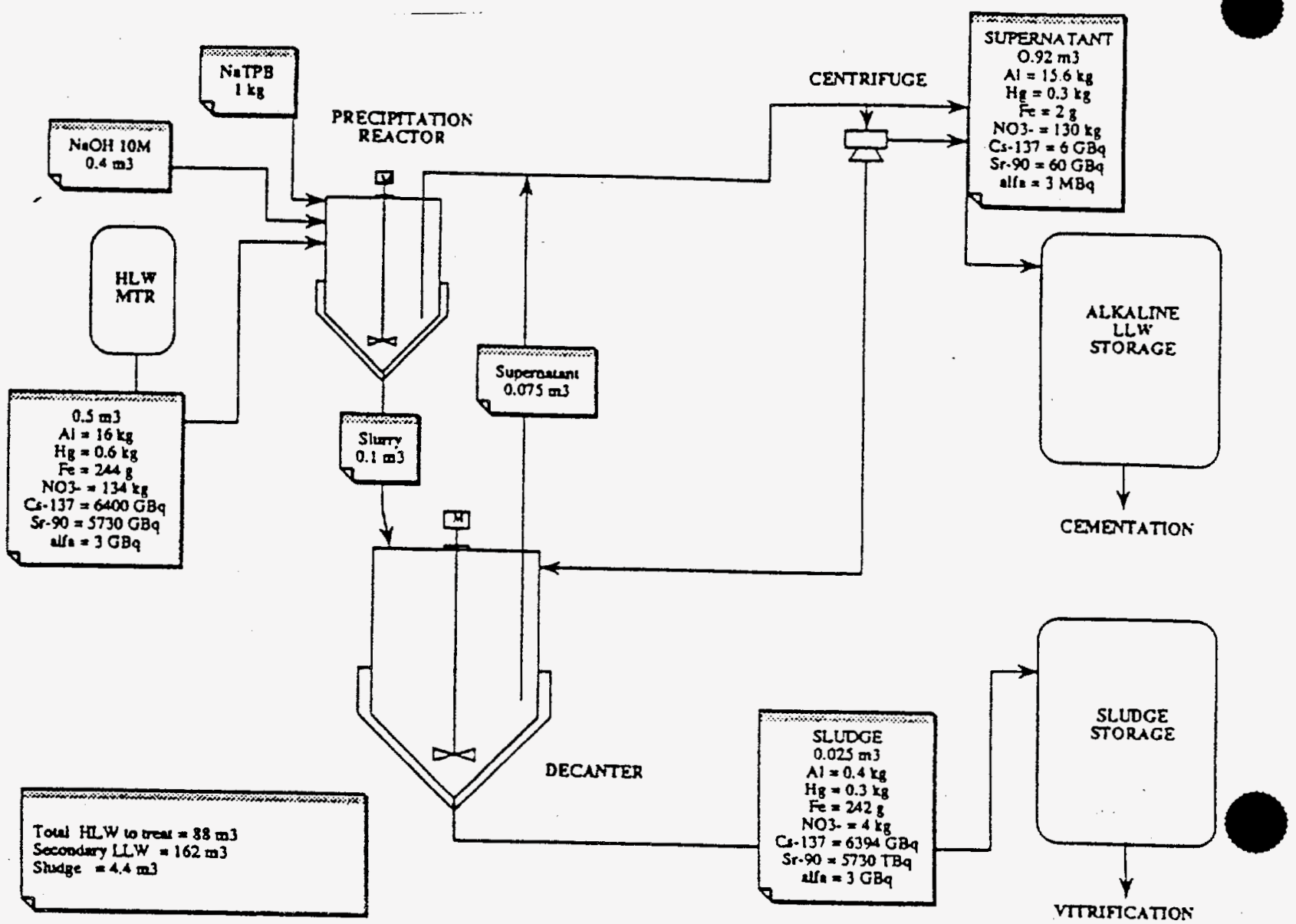


Figure 7-4. Process Flow-sheet for Treatment of HLW-CANDU.

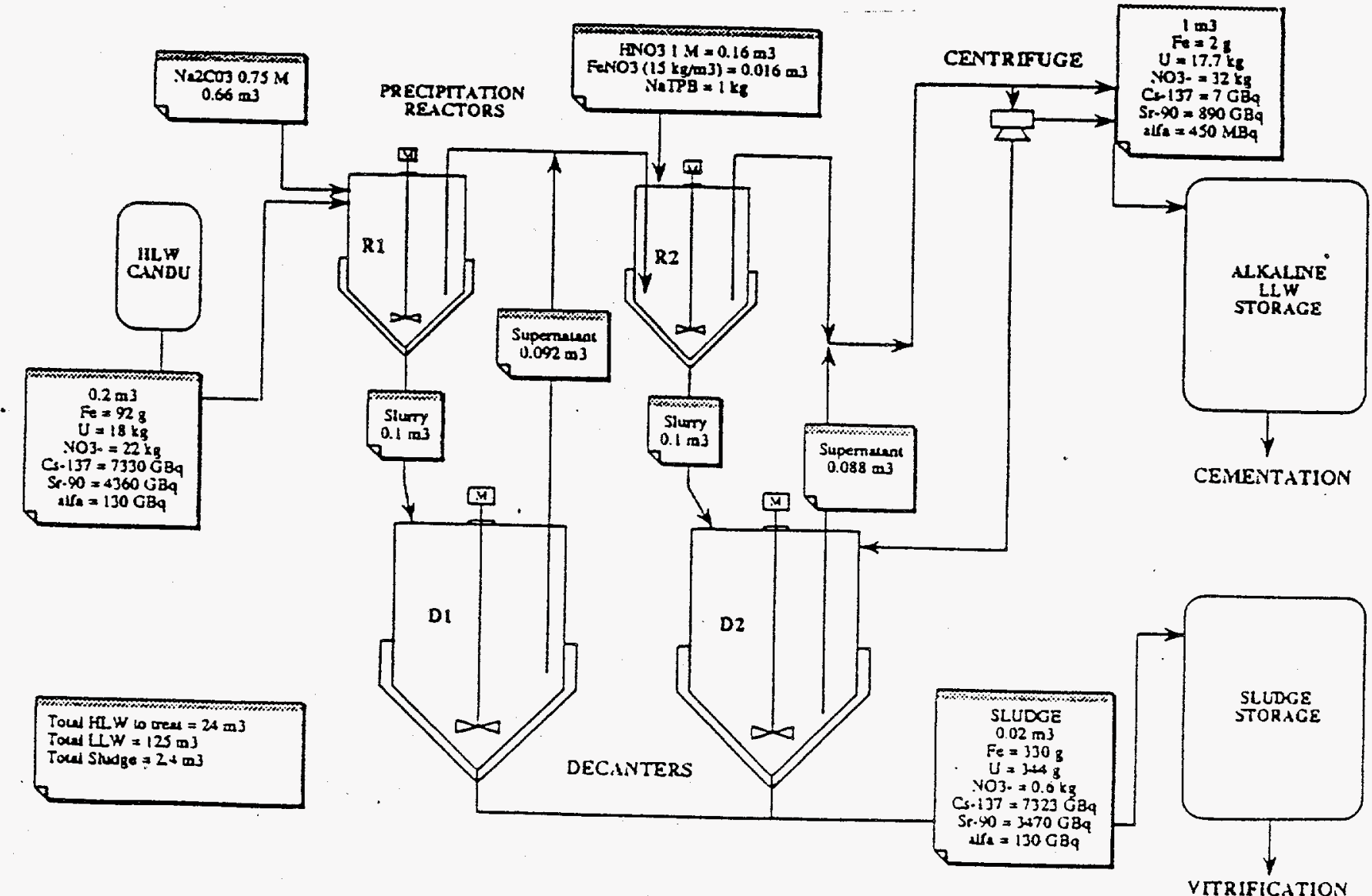

Figure 7-5. Locations of Power Plants and Rokkasho Fuel Cycle Facilities.

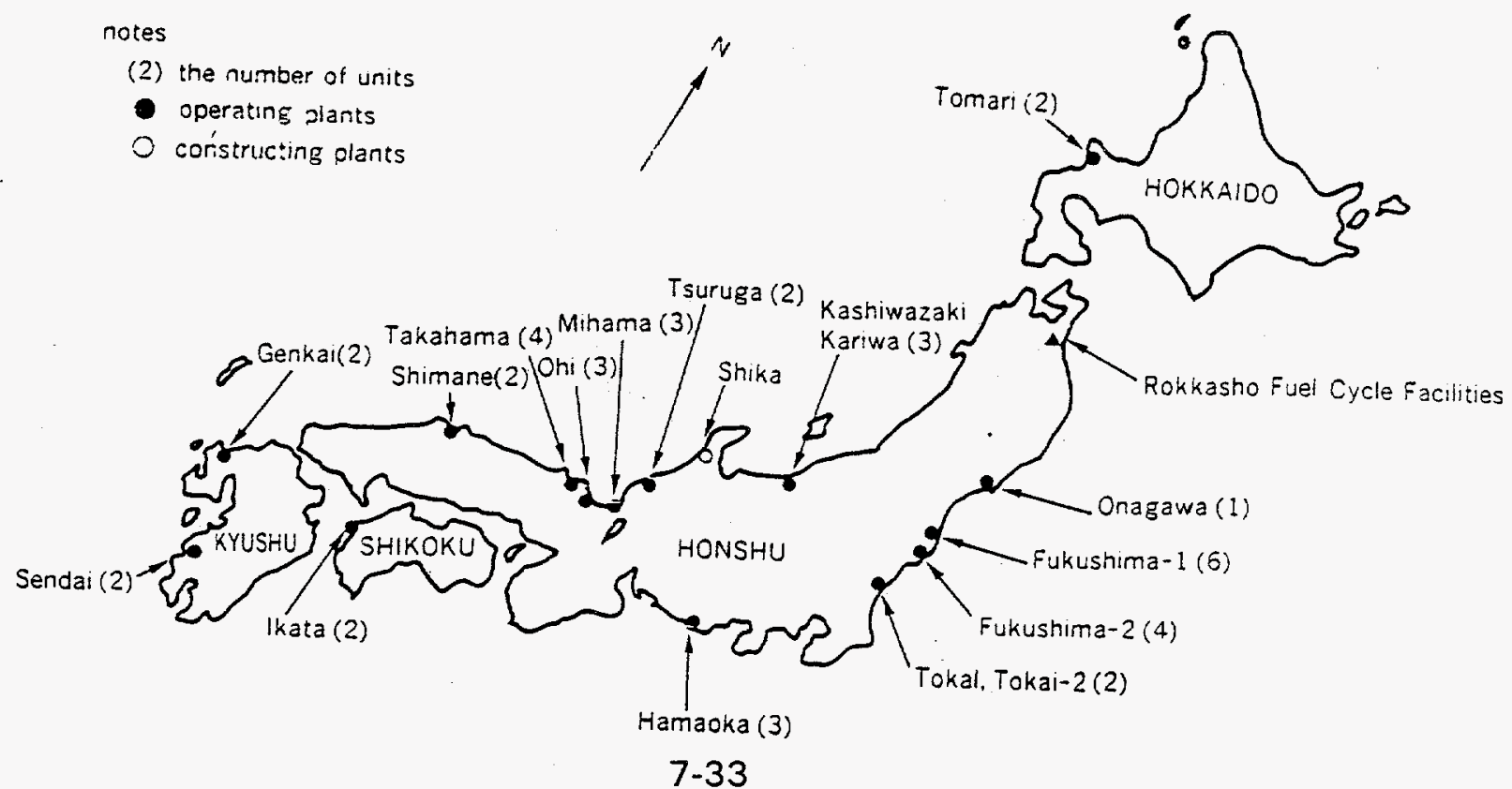


Final

Figure 7-6. Disposal of LLW Drum at LLW Storage Center.

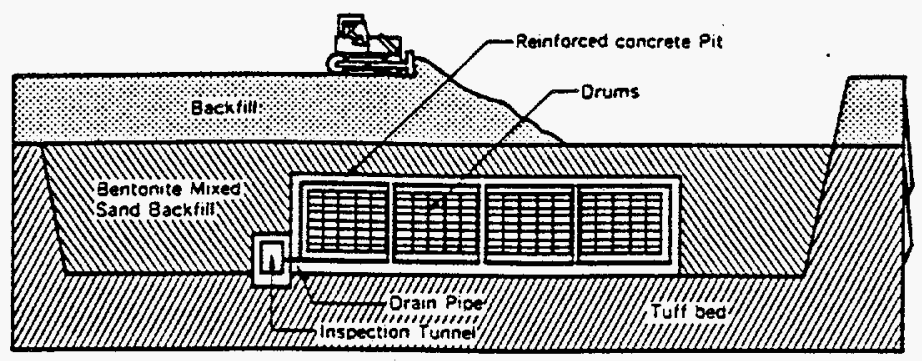

Figure 7-7. Outline of LLW Transport System.

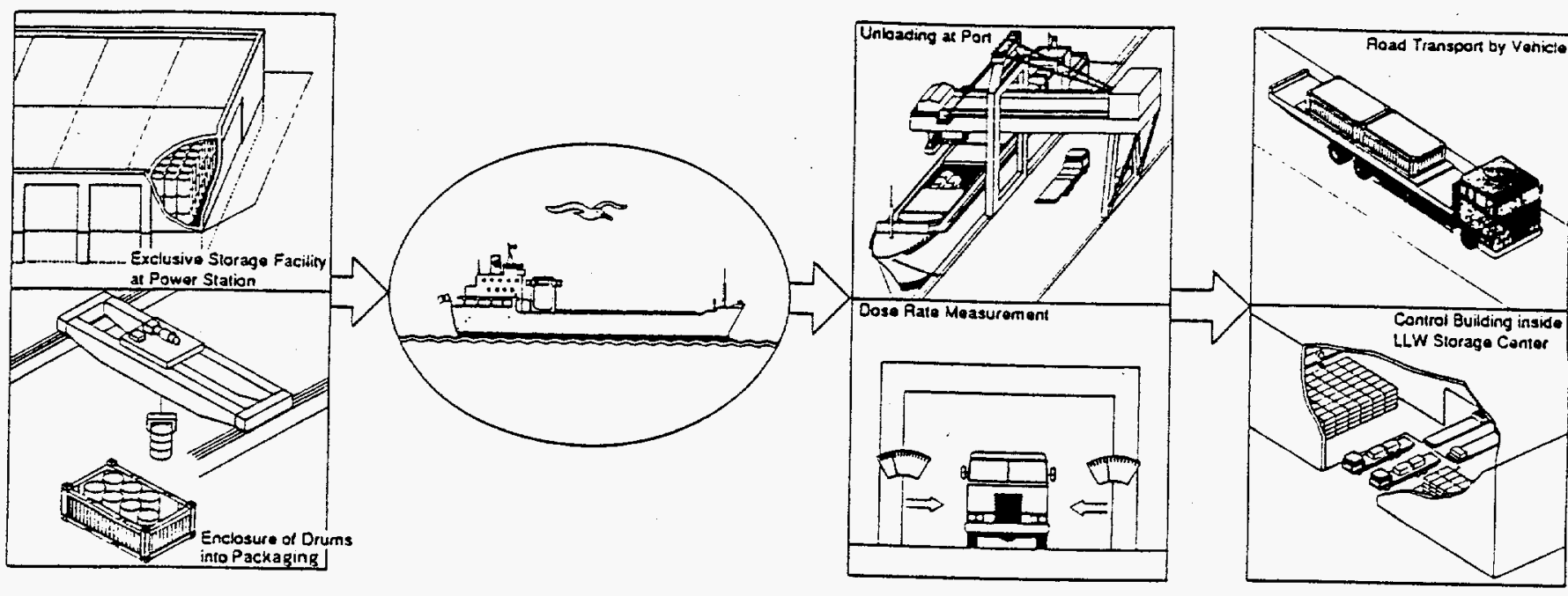


Final

Figure 7-8. Solidification Methods.

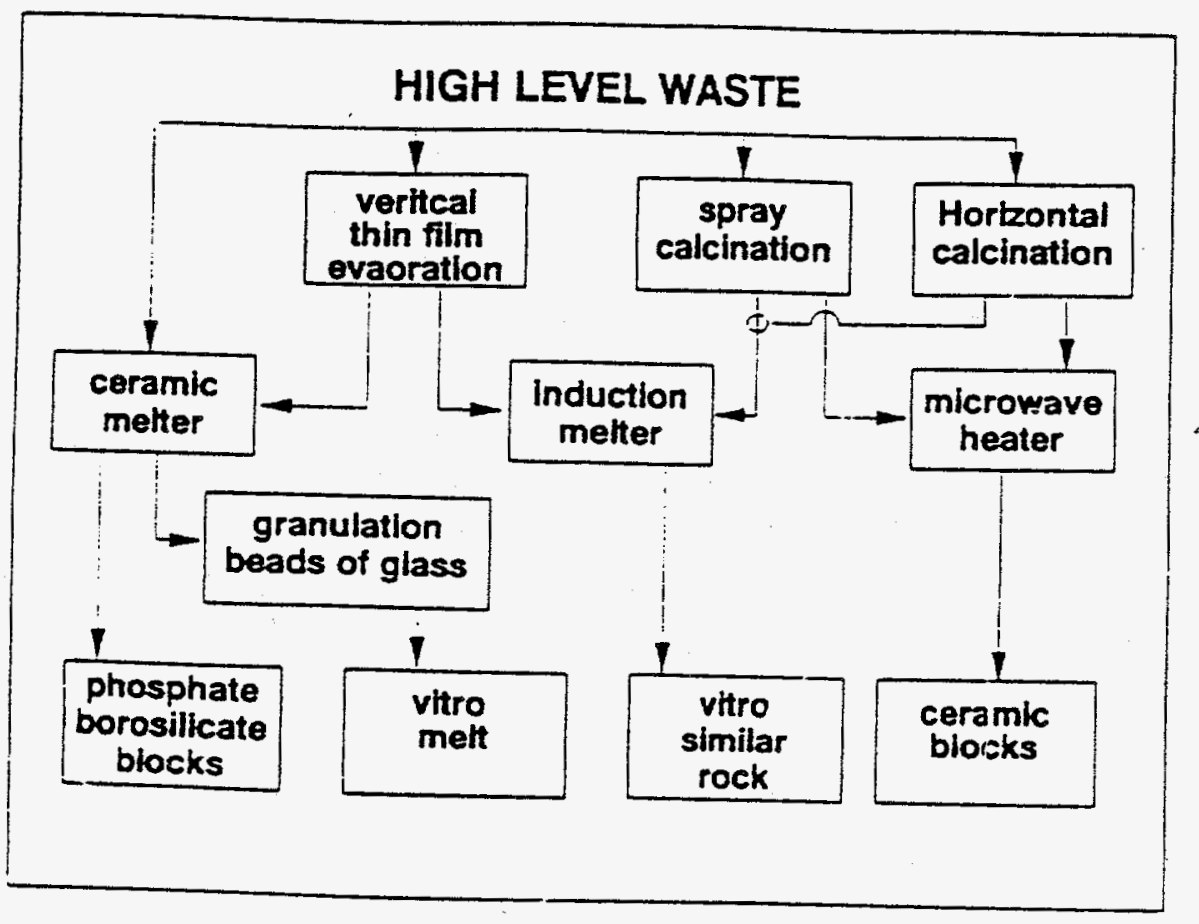

Figure 7-9.

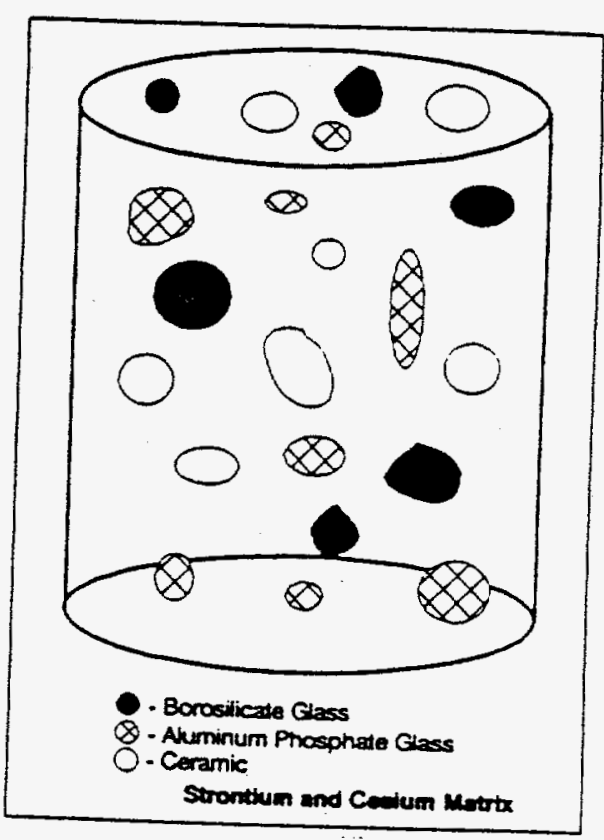


Figure 7-10.

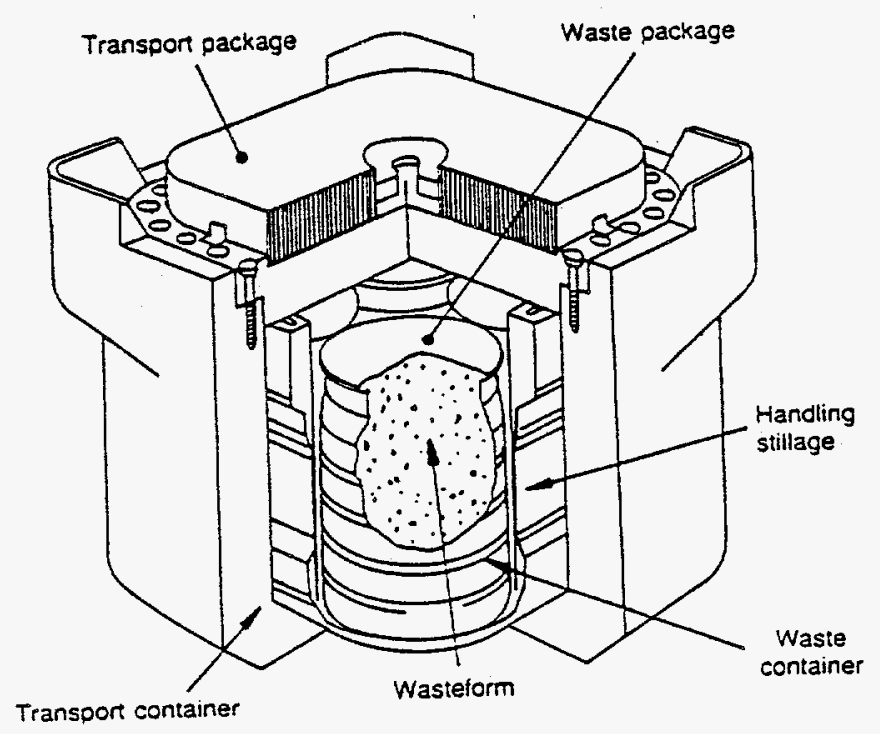

500 litre drum in a reusable transport container 
Figure 7-11.

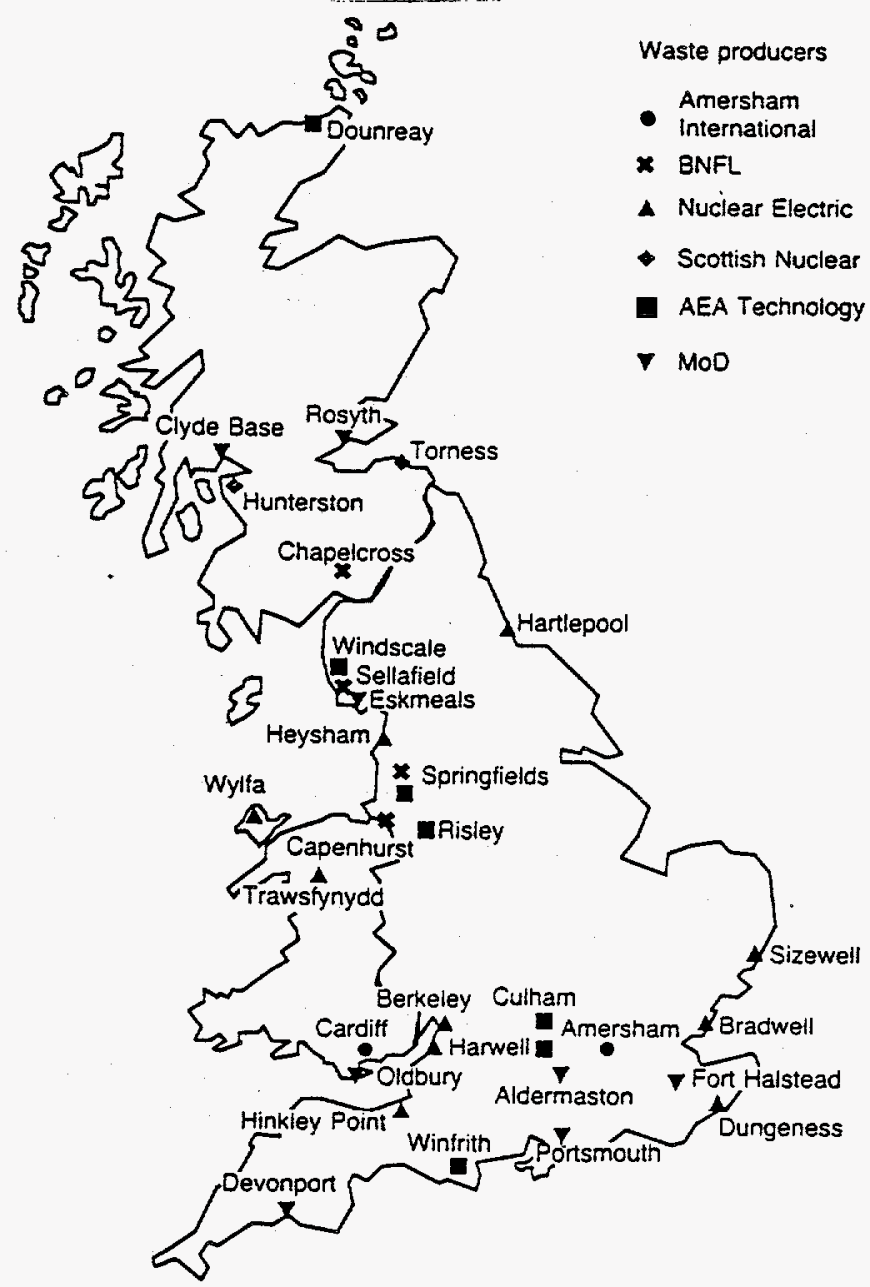

Major waste-producing sites in the UK 
Figure 7-12.

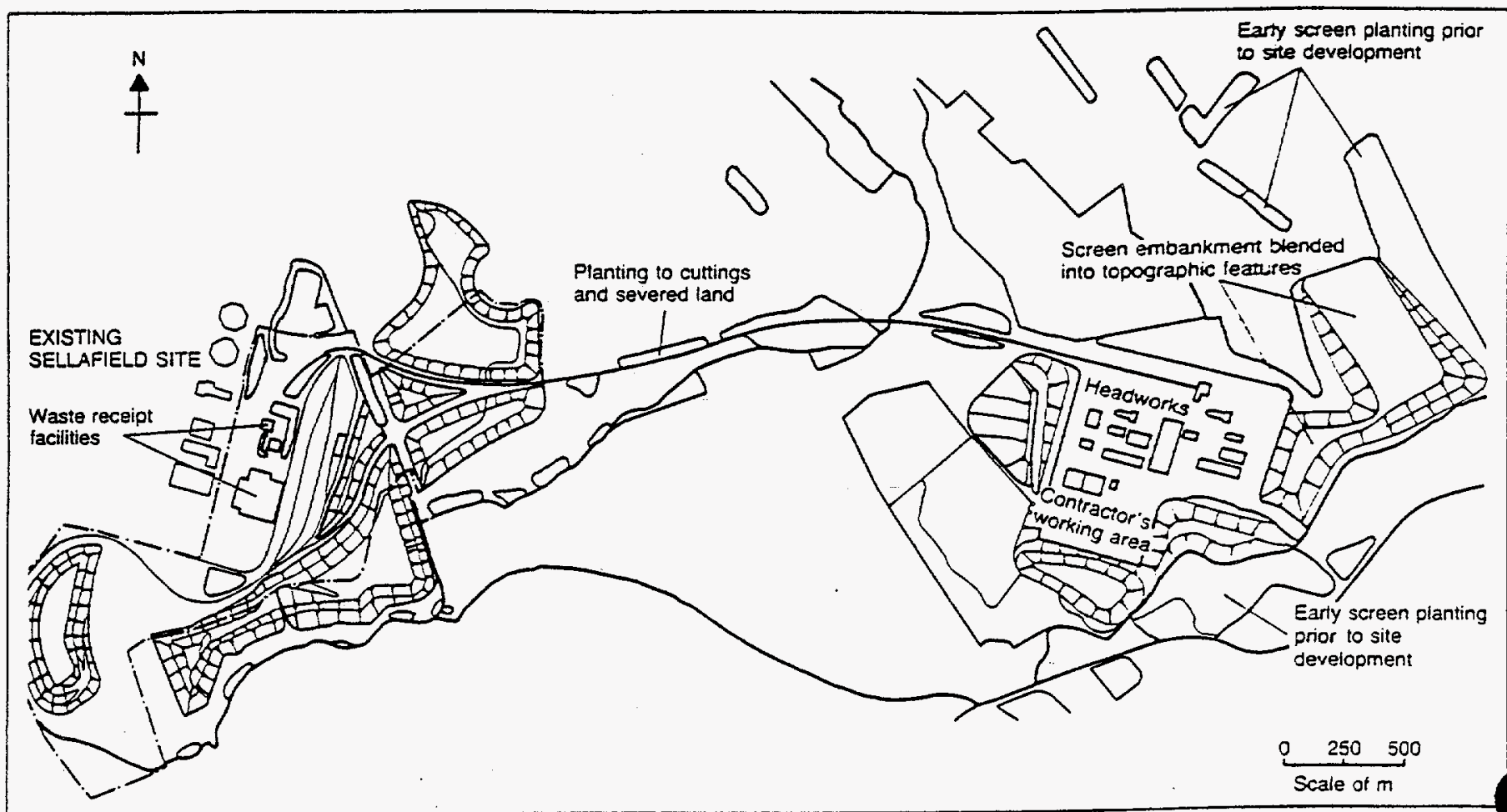

Initial site-specific design for Sellafield 
Final

Figure 7-13.

NW
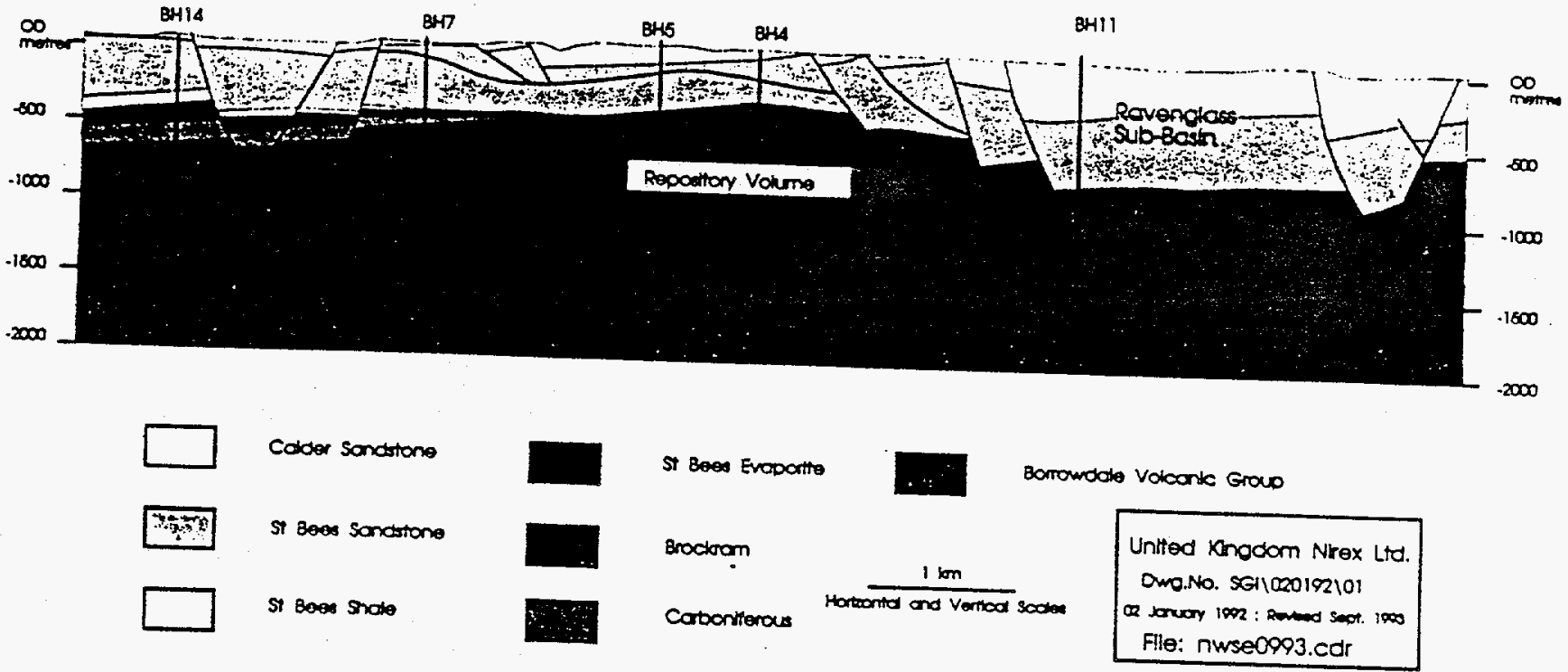

Schematic NW-SE geological cross-section through the Sellafield site area

Figure 7-14.

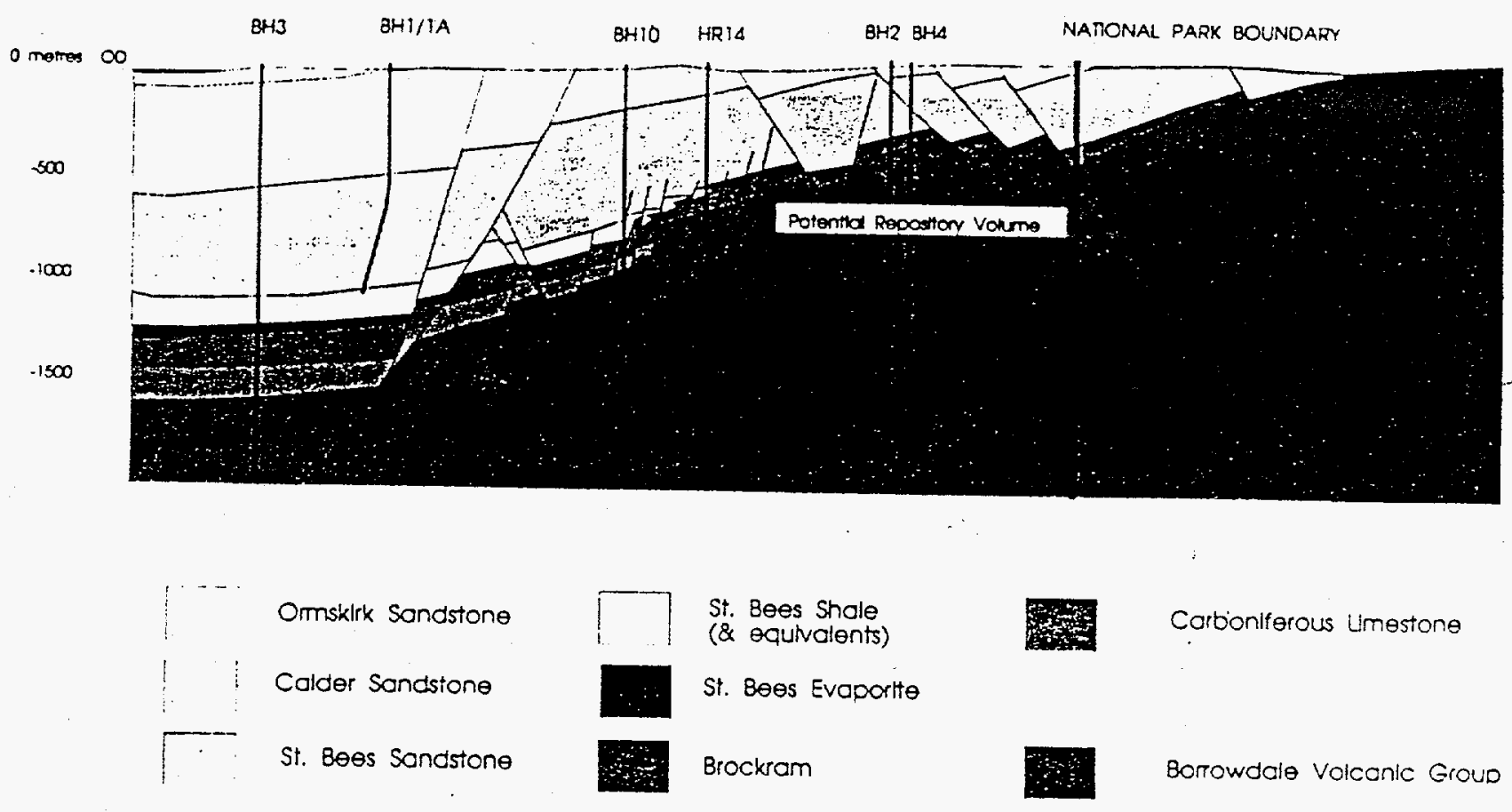

Schematic WSW-ENE geological cross-section through the Sellafield site area (horicontal = vertical scale) 
Figure 7-15. ILW and HLW Disposal Facility Design Concept.

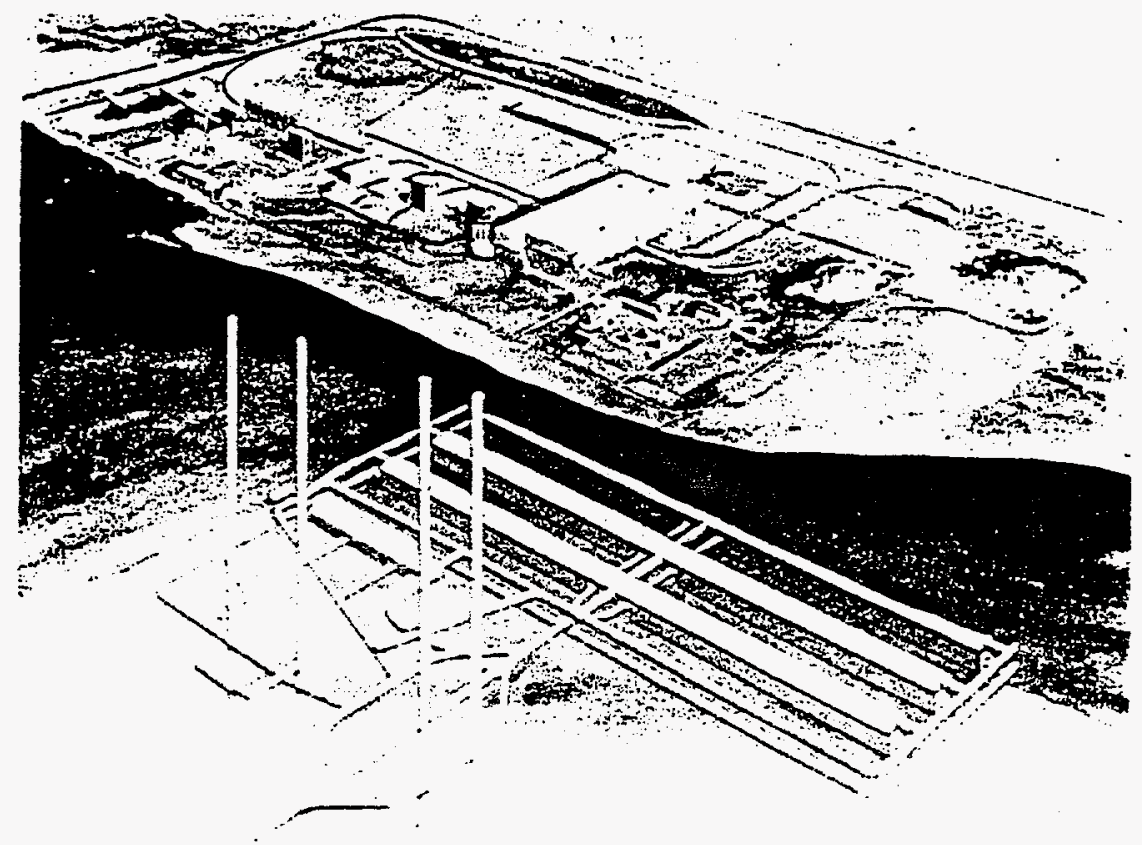

Artist's impression of the deep waste repository

Figure 7-16.

Waste drift derails: (a) construccion dritt with $6 \mathrm{~m}$ wide roachay and conveyor tunnel: (b) waste dritt (6-a m dia.) with win rail tracks for indridual packages
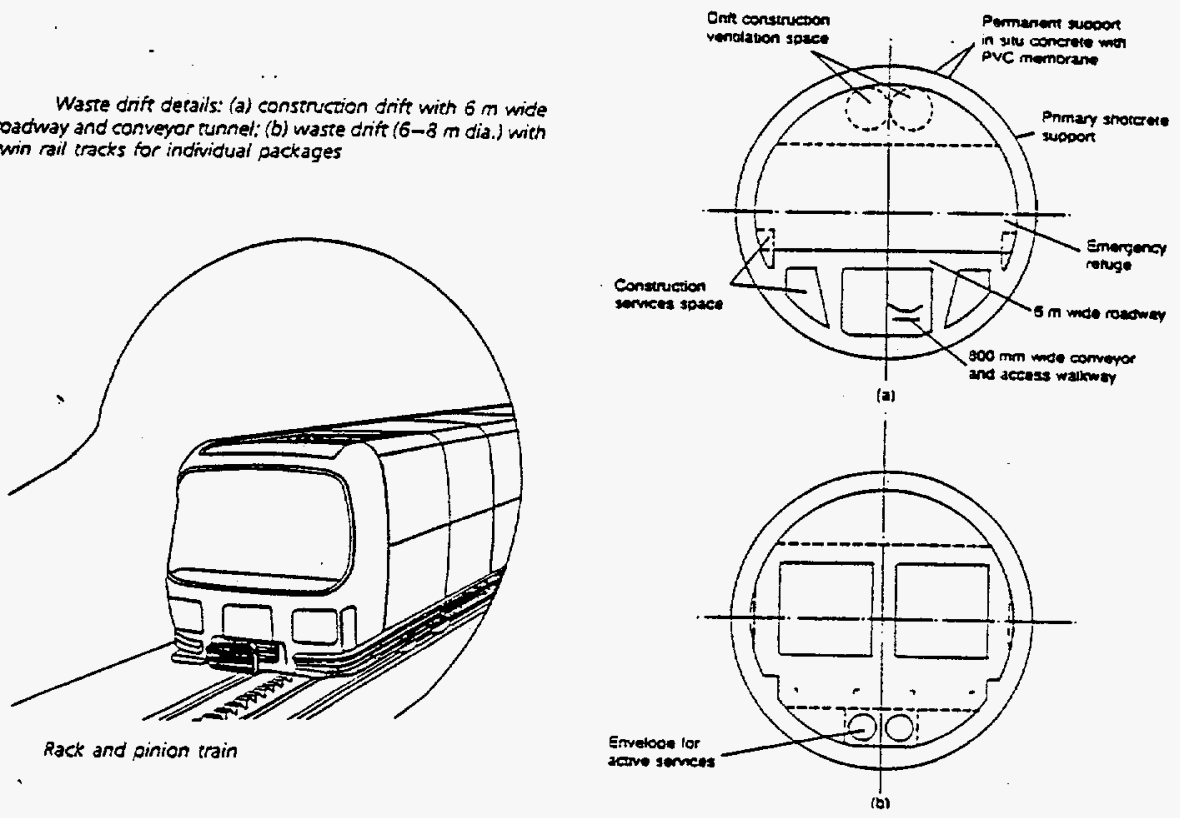

REPOSITORY DESIGN CONCEPTS 


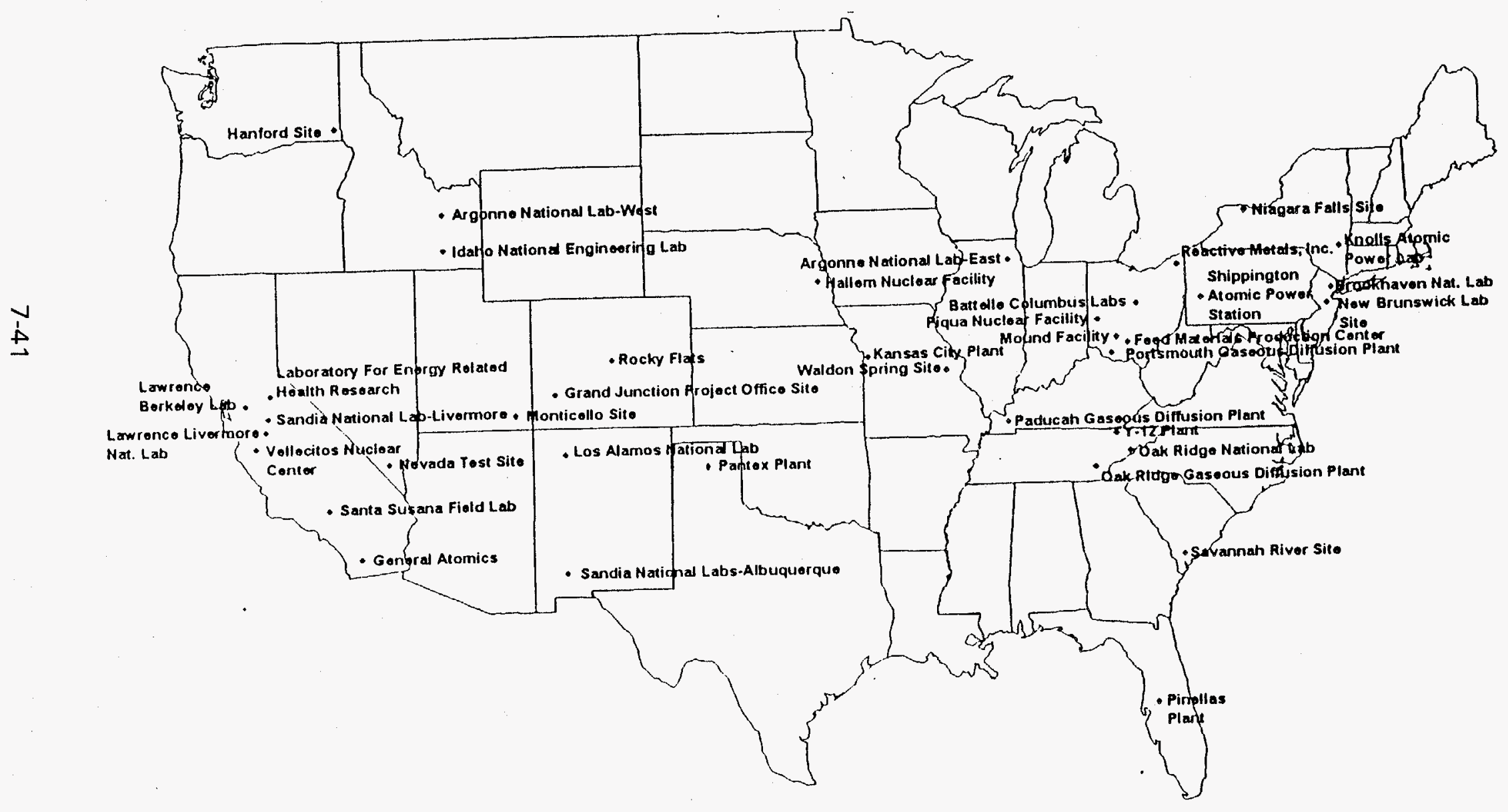


Final

Figure 7-18. Low Activity Vault Cross Section.

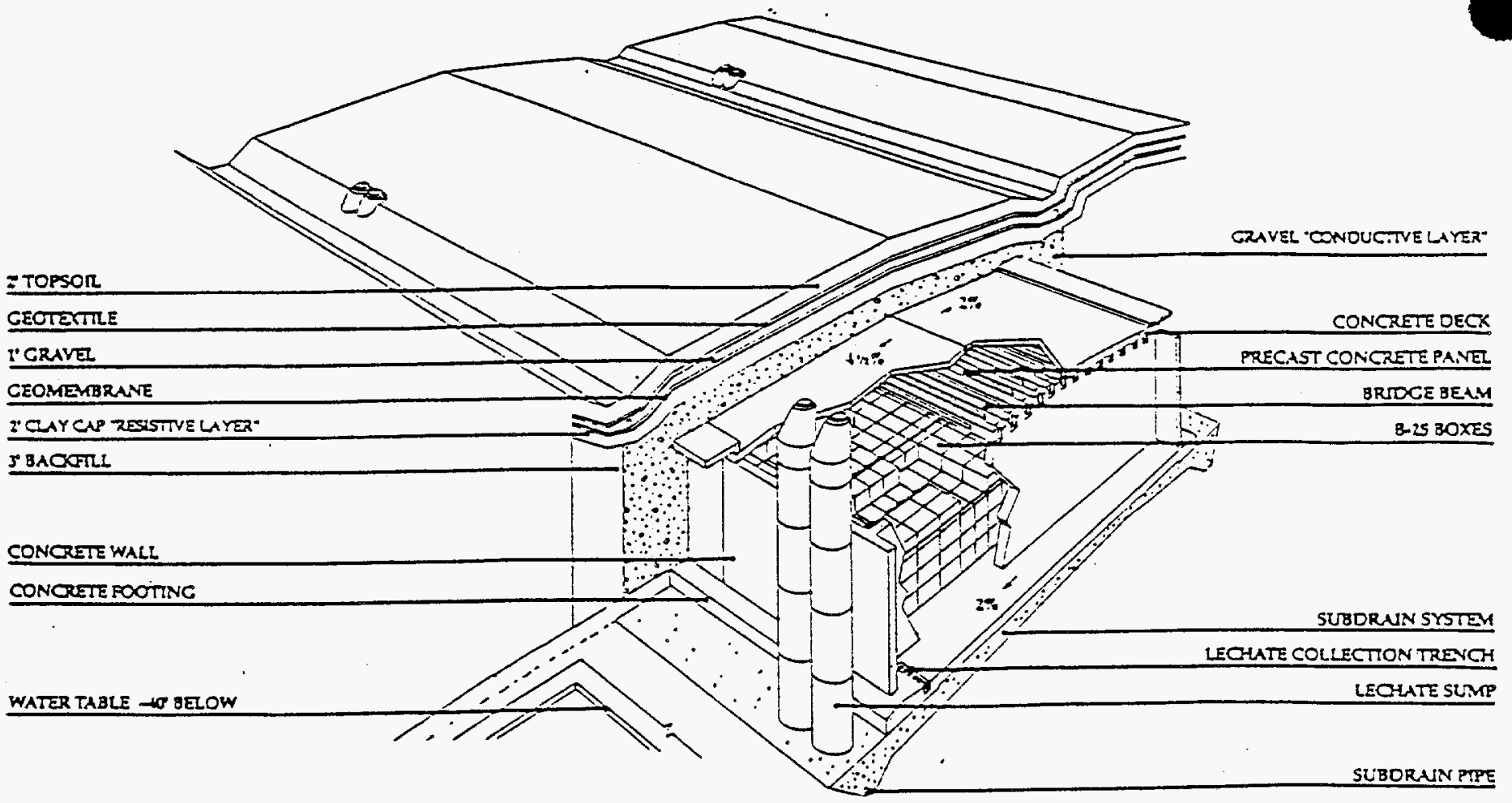

Figure 7-19: Intermediate Activity Vault.

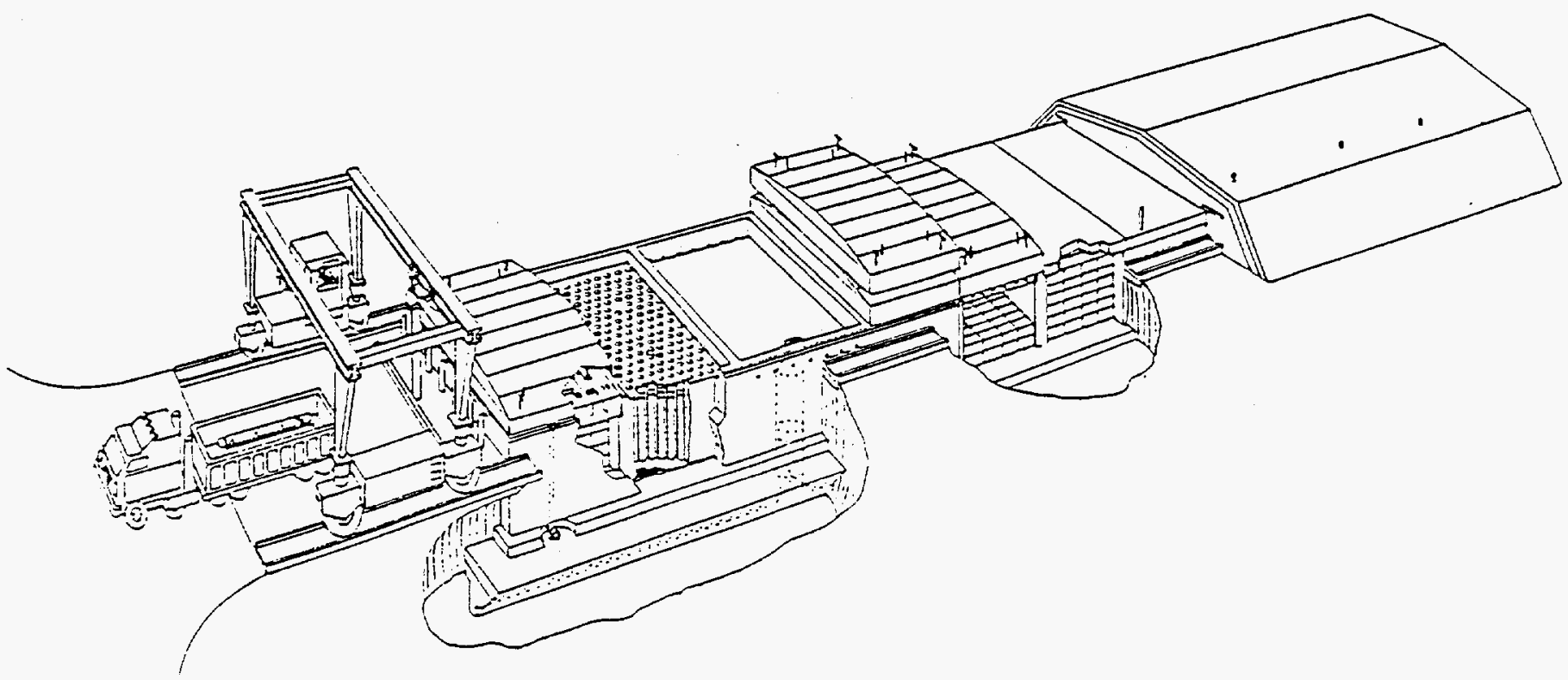


Figure 7-20.

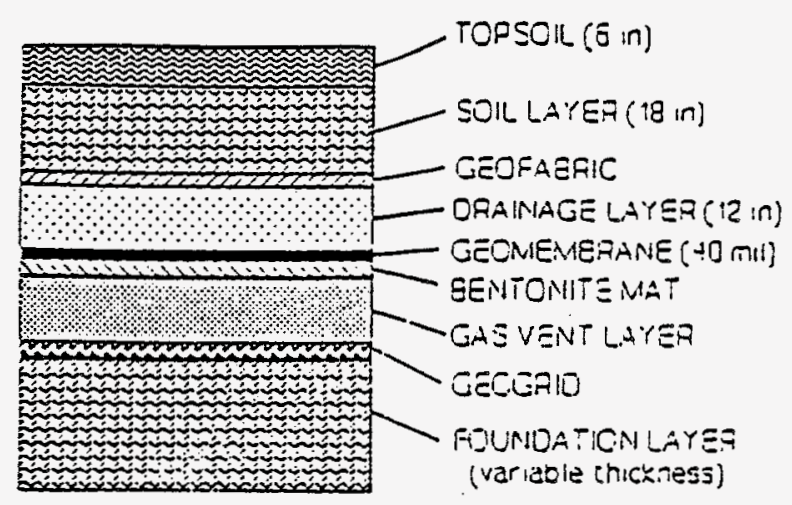

Conceptual design of cover system for the sanicary landfill.

Figure 7-21.

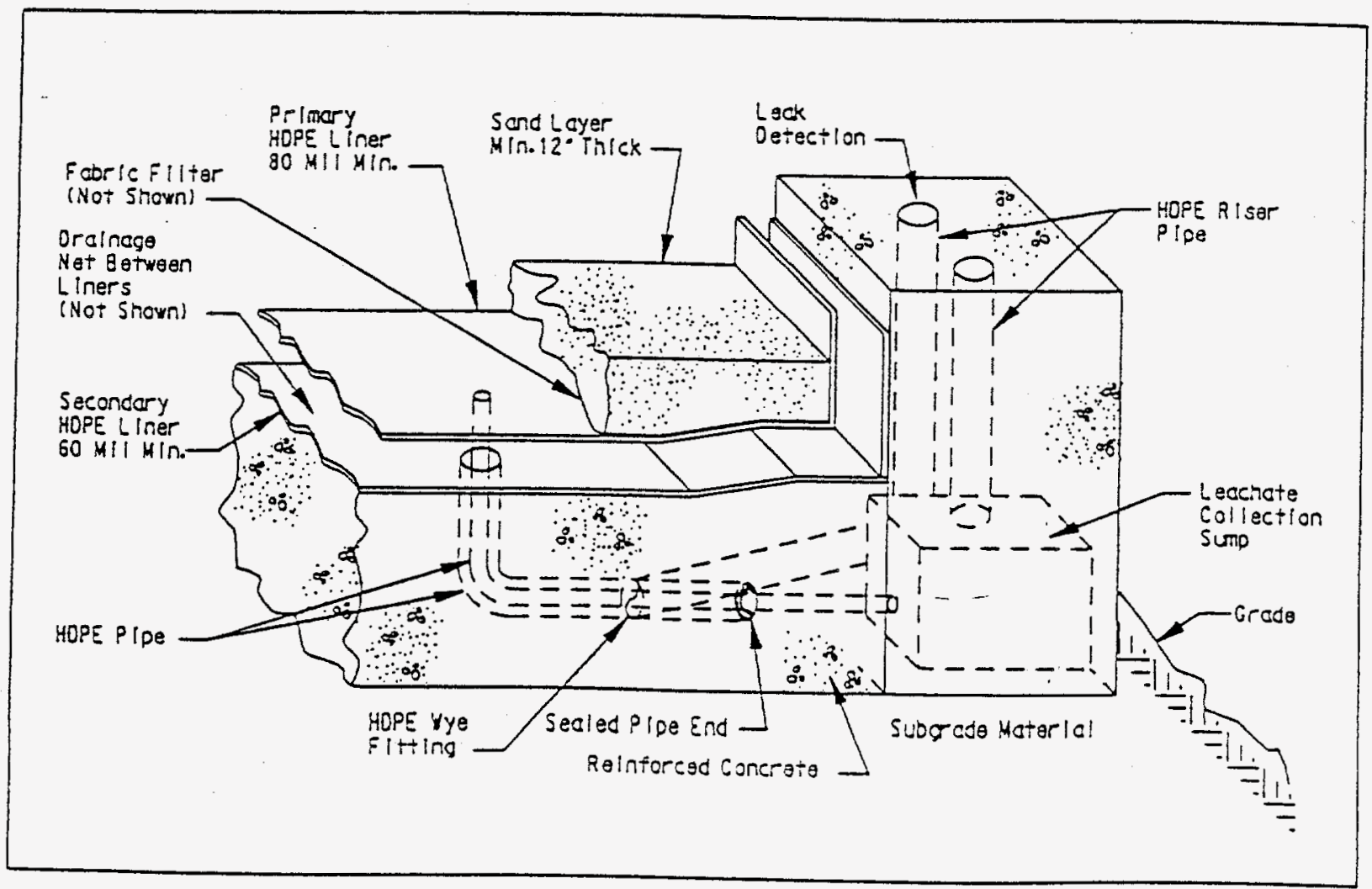

Leachate detectioa/collection system. 


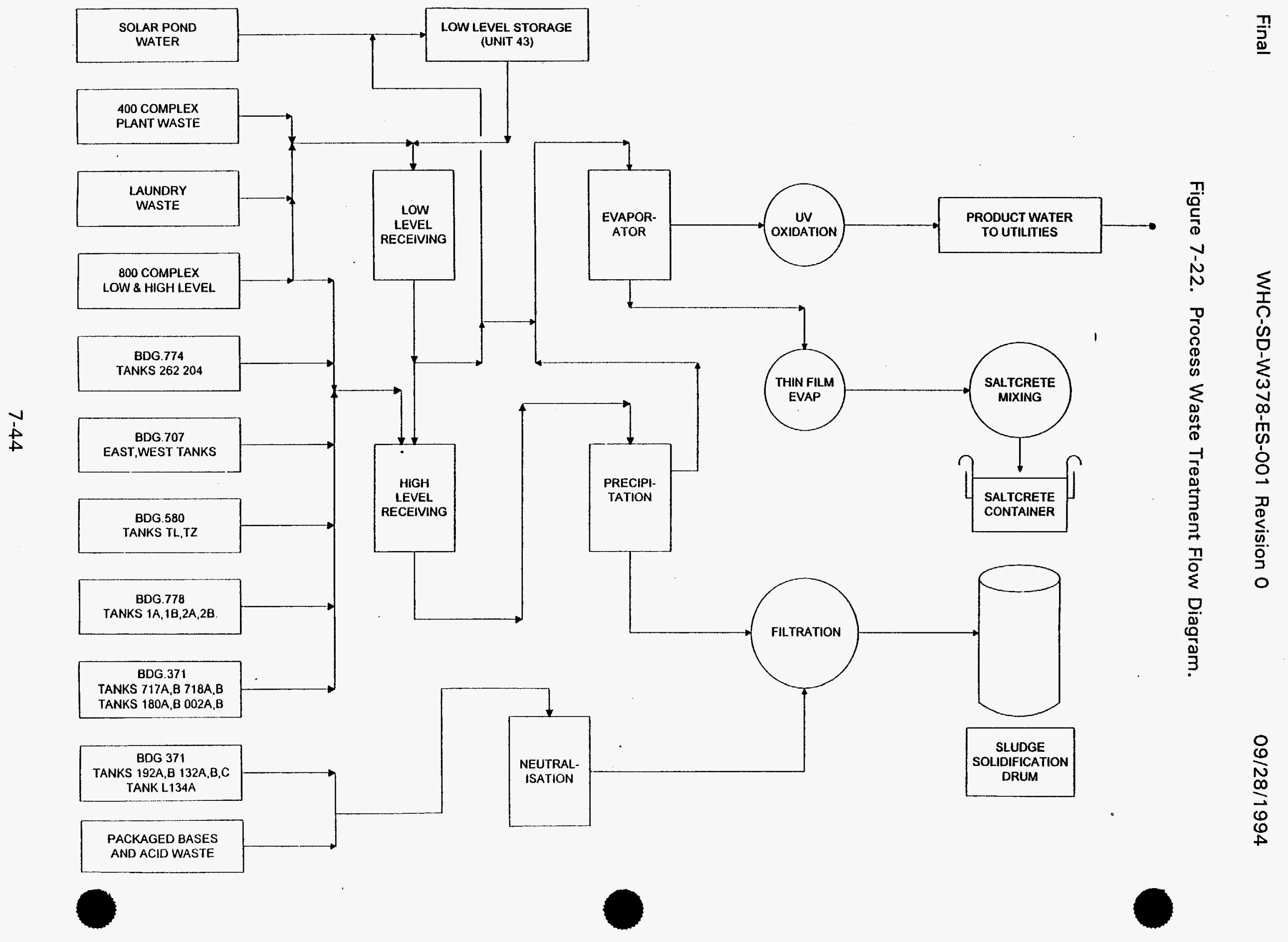


Figure 7-23. Repository Concept at Mol, Belgium.
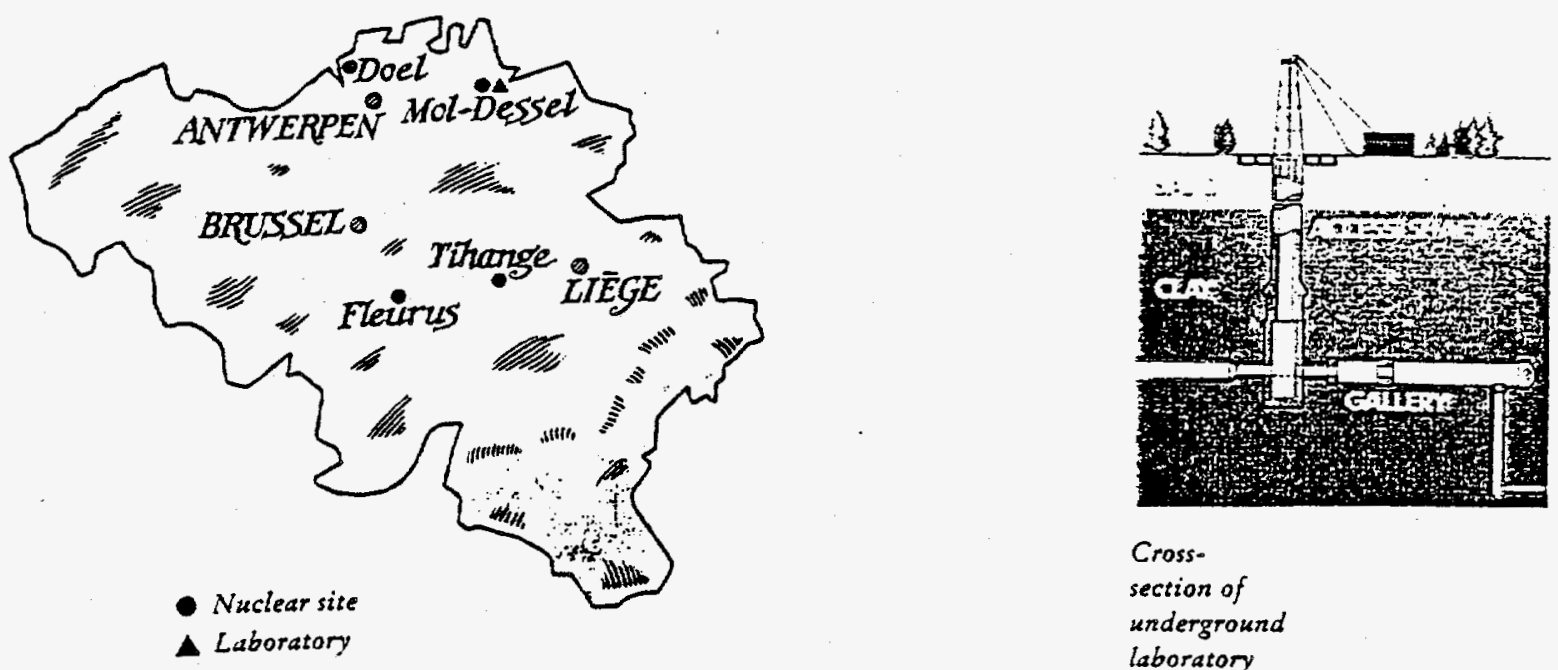

Cross-

section of

underground

- Laboratory

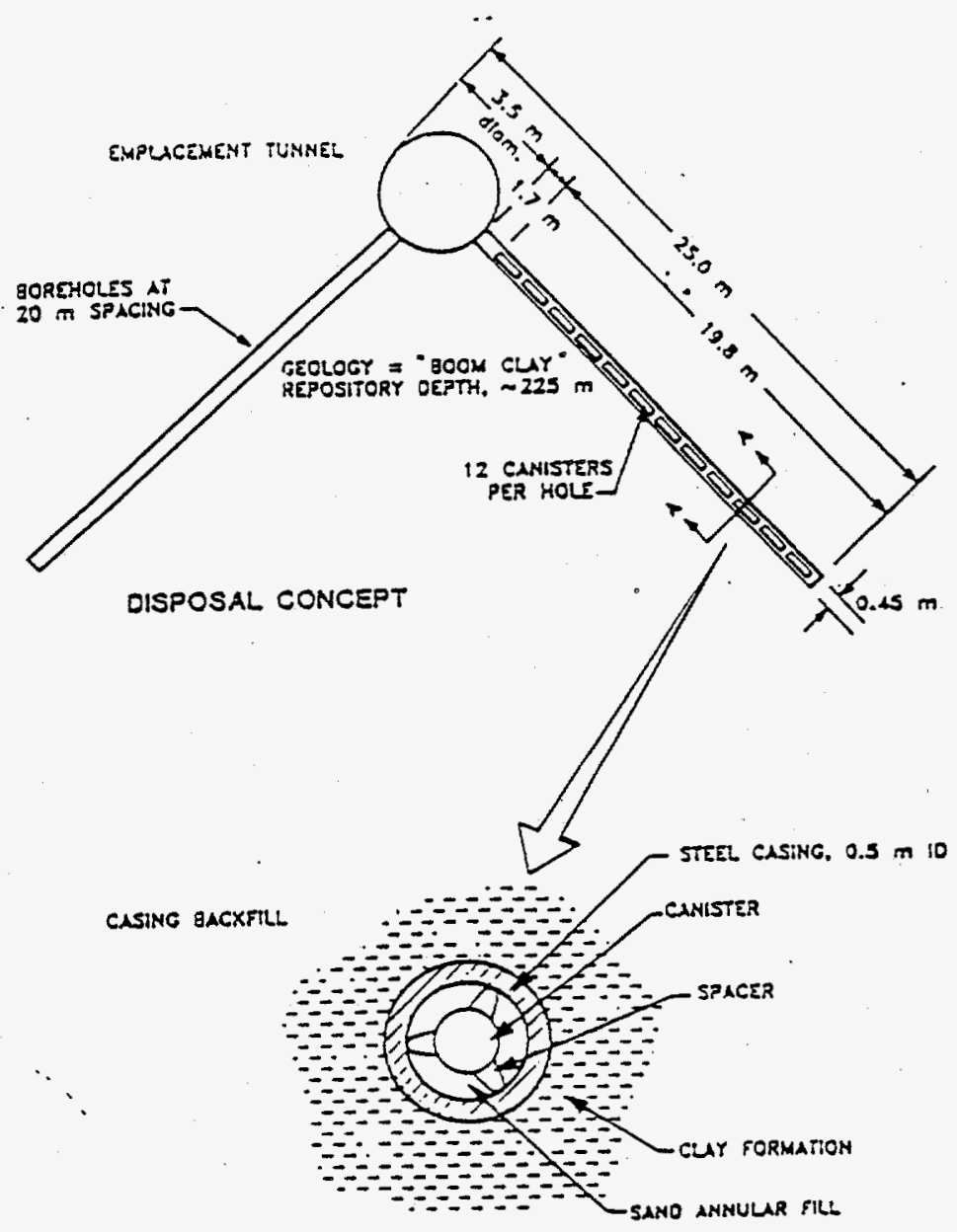

SECTION THAOUGH DISPOSAL BOREHOLE 
Figure 7-24. German Facilities and Deep Repository.
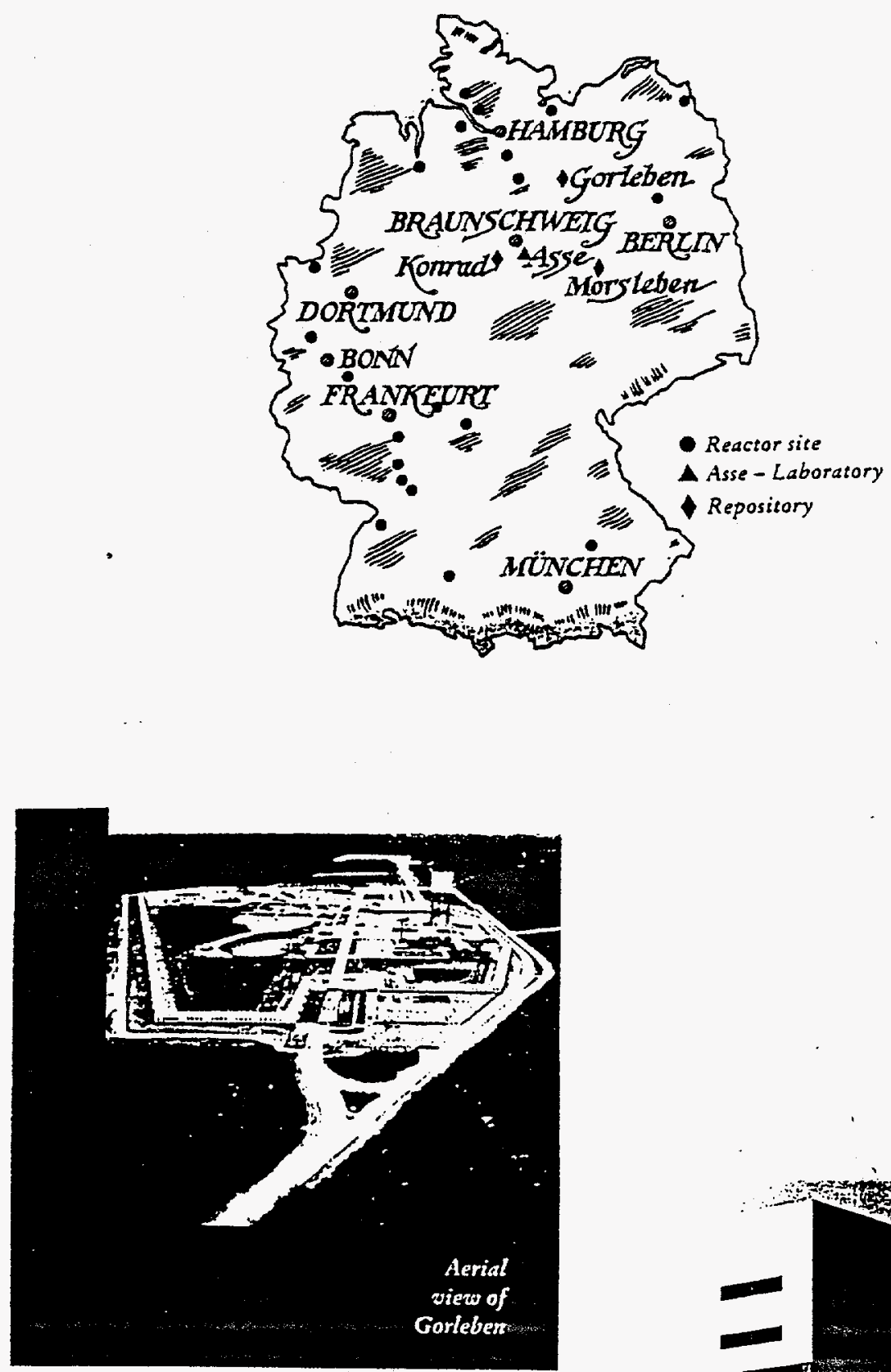

Gorleben

shaft

tower

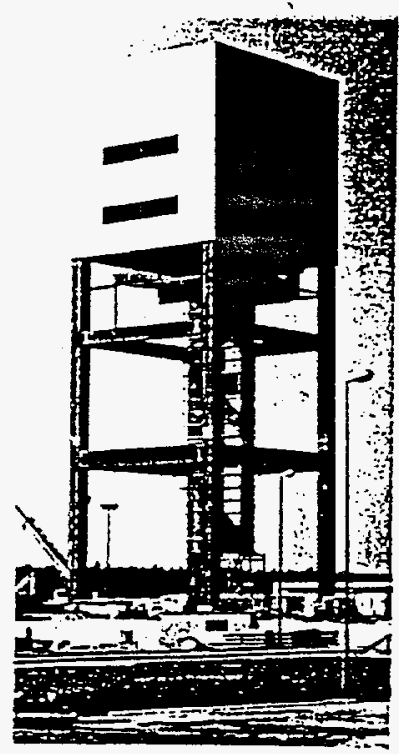


Figure 7-25. German Pollux Cask/Canisters for Consolidated LWR Spent Fuel.

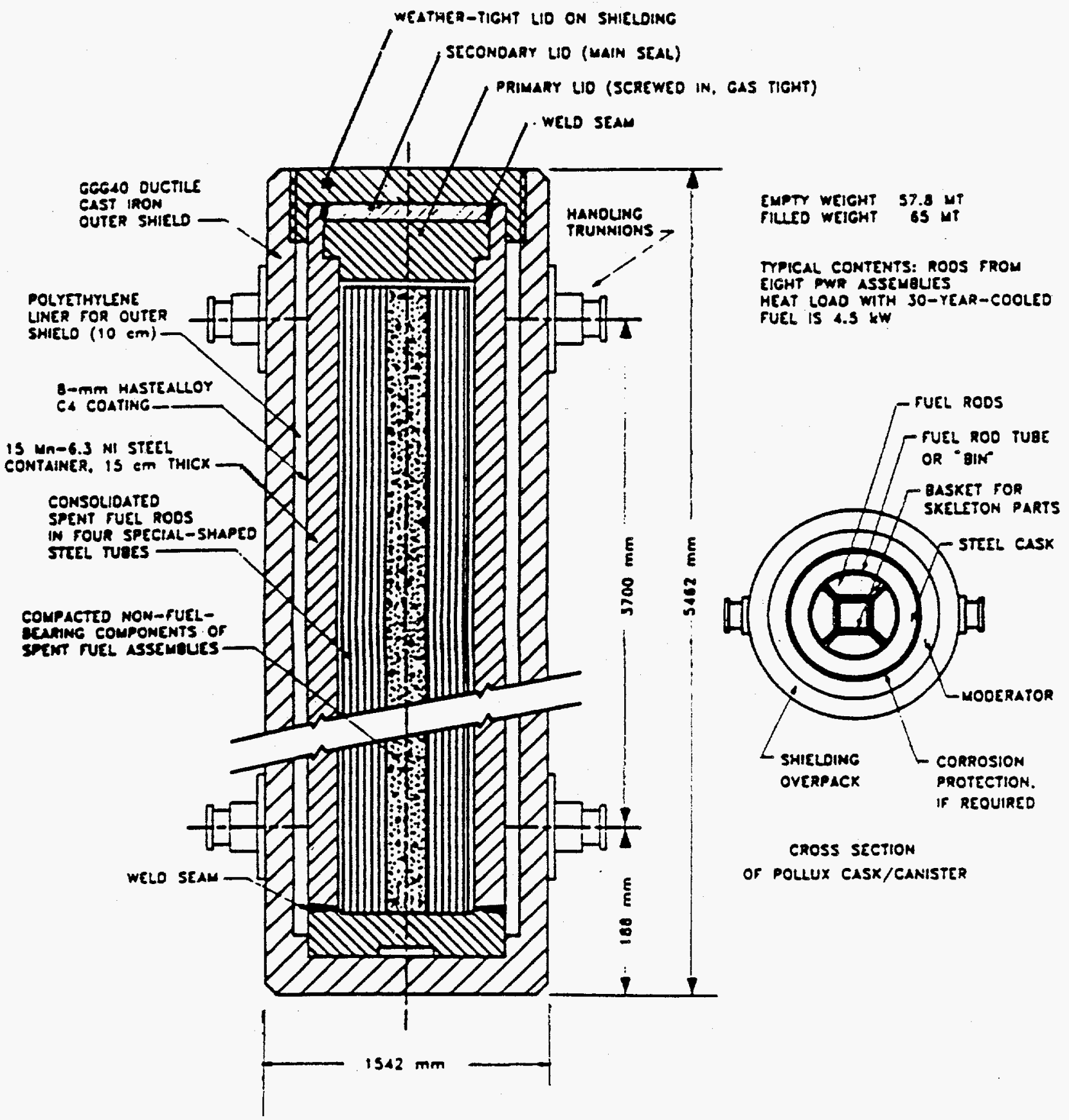

German Pollux cask/canisters for consolidated LWR spent fuel 
Figure 7-26. German Concept for Disposal of Spent Fuel in Salt.

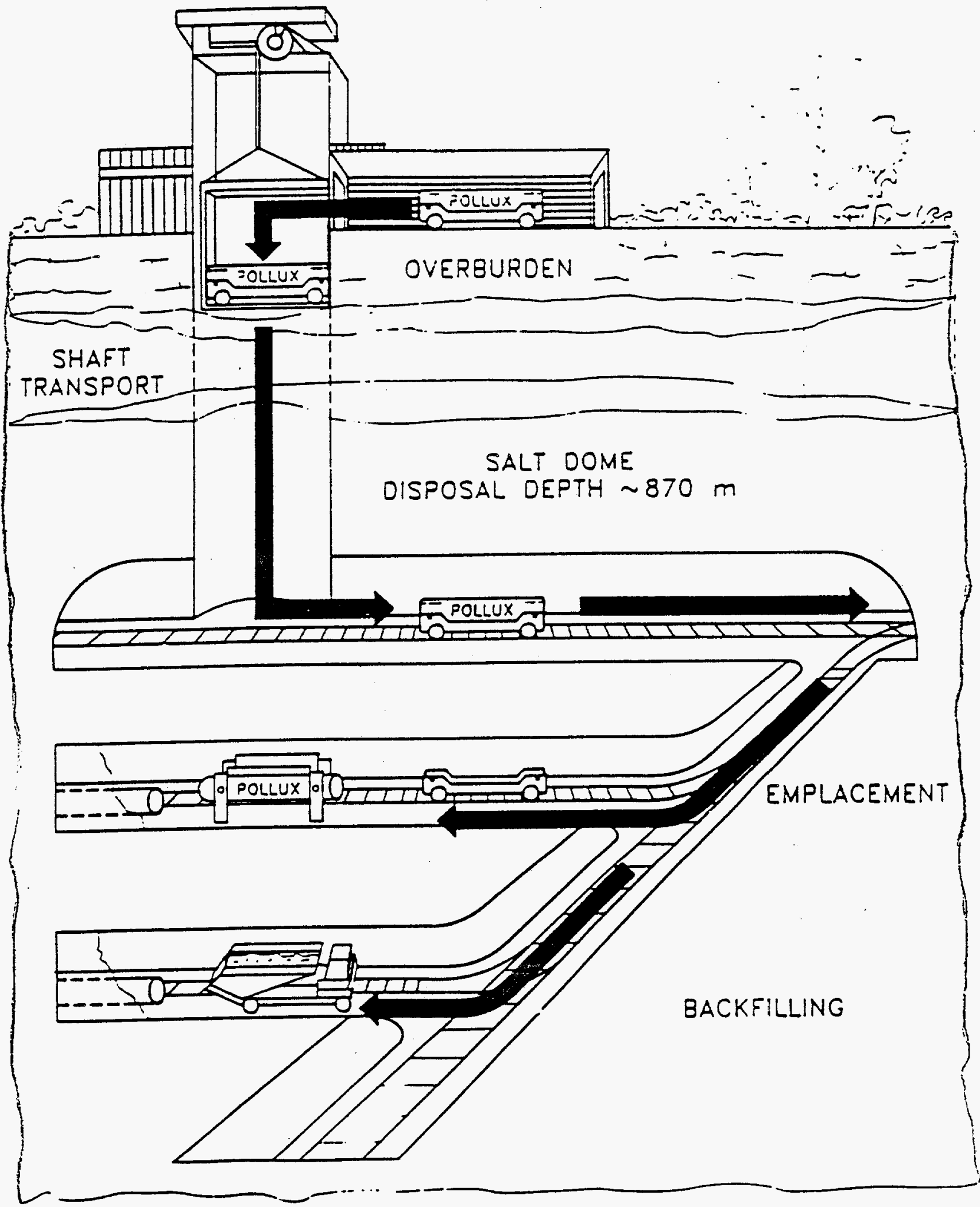

German concept for disposal of speat fuel in salt 
Figure 7-27. Engineered Multibarrier System.

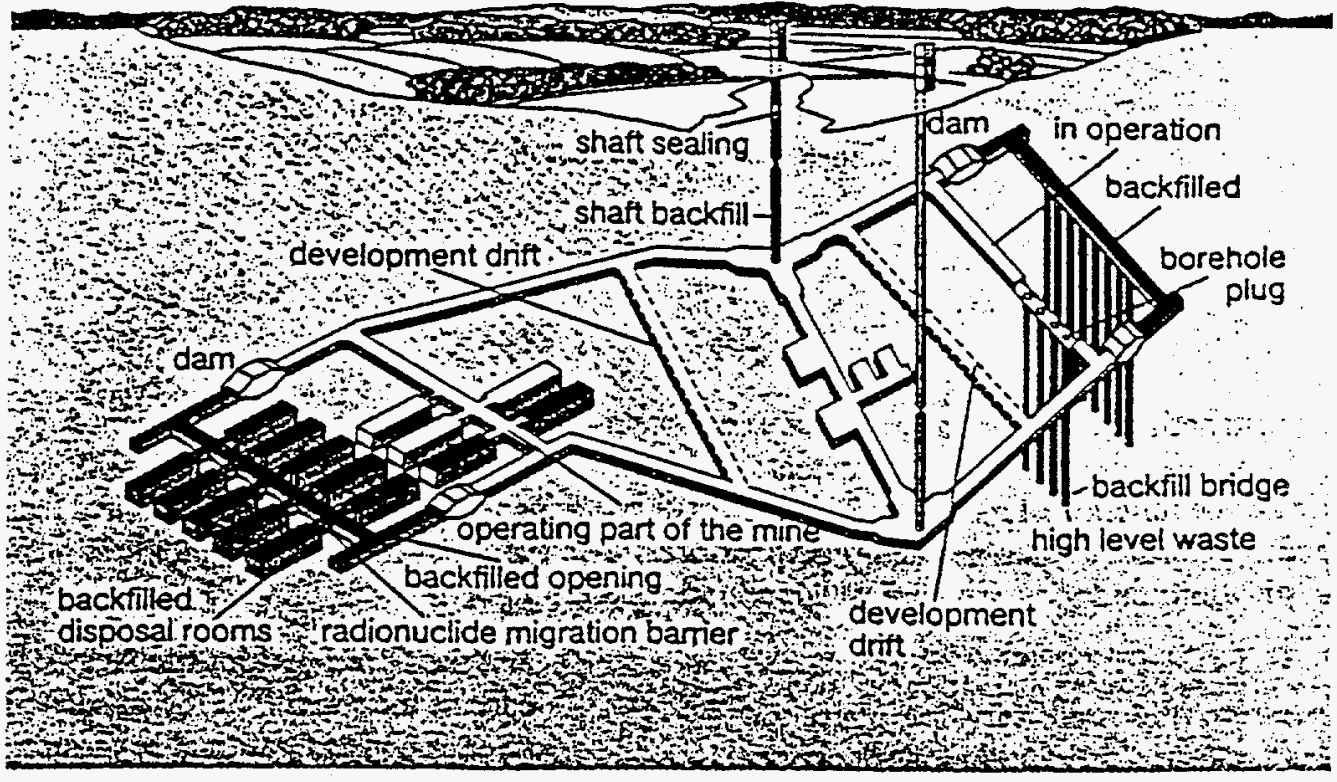

. Engineered Multibarrier Svstem.

Figure 7-28. Diagrammatic Sketch of Dam Construction (Vertical Section).

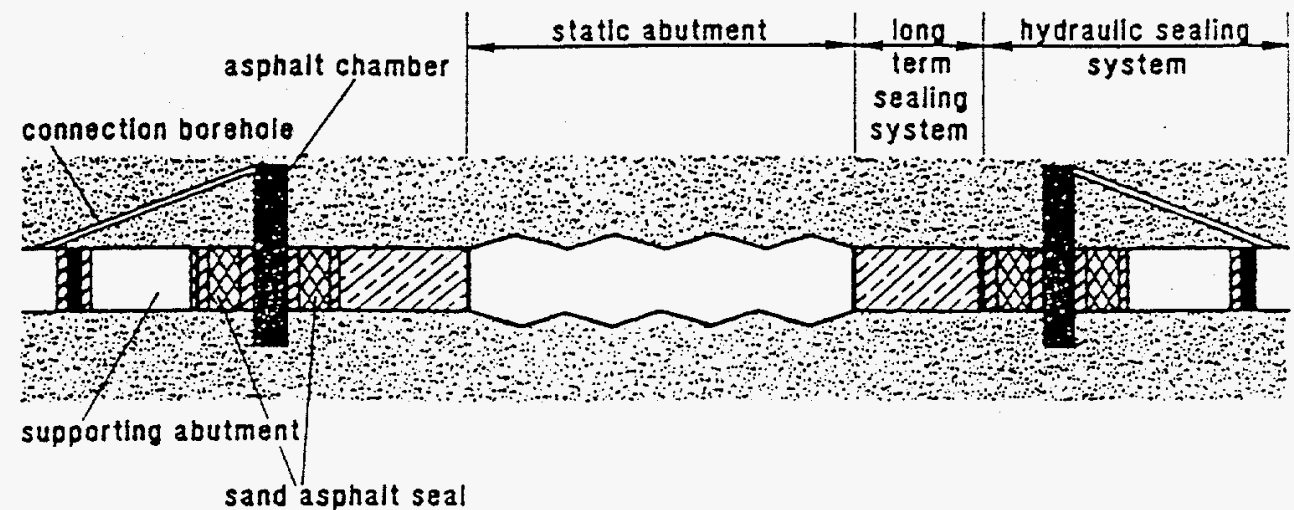

Diagrammatic Sketch of Dam Construction (Vertical Section). 
Figure 7-29. Swiss Nuclear Facilities and Repository Concept.
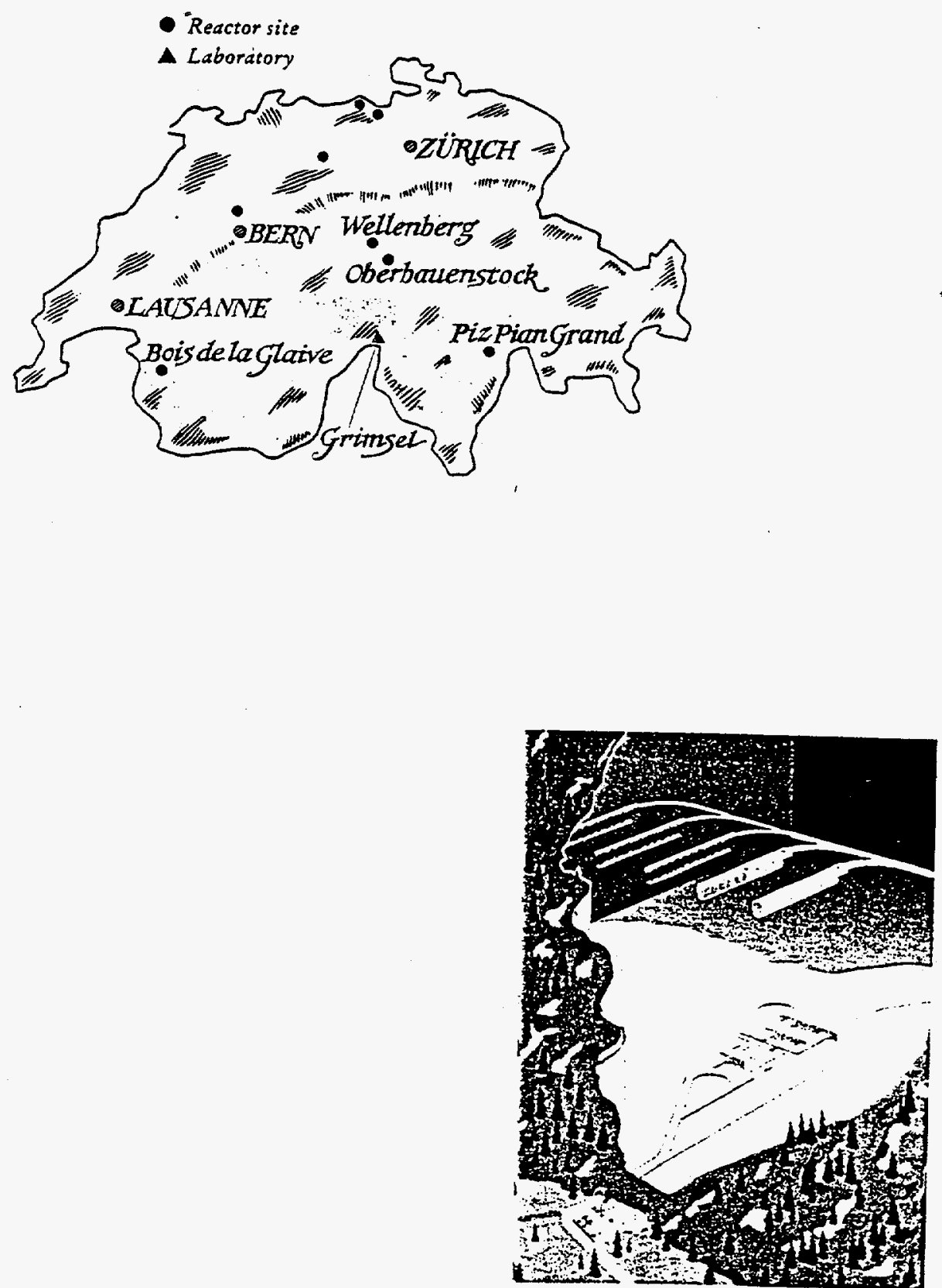

$$
\begin{aligned}
& \text { Concepts } \\
& \text { for } \\
& \text { borizontal } \\
& \text { access } \\
& \text { disposal }
\end{aligned}
$$


Figure 7-30. Disposal Container.

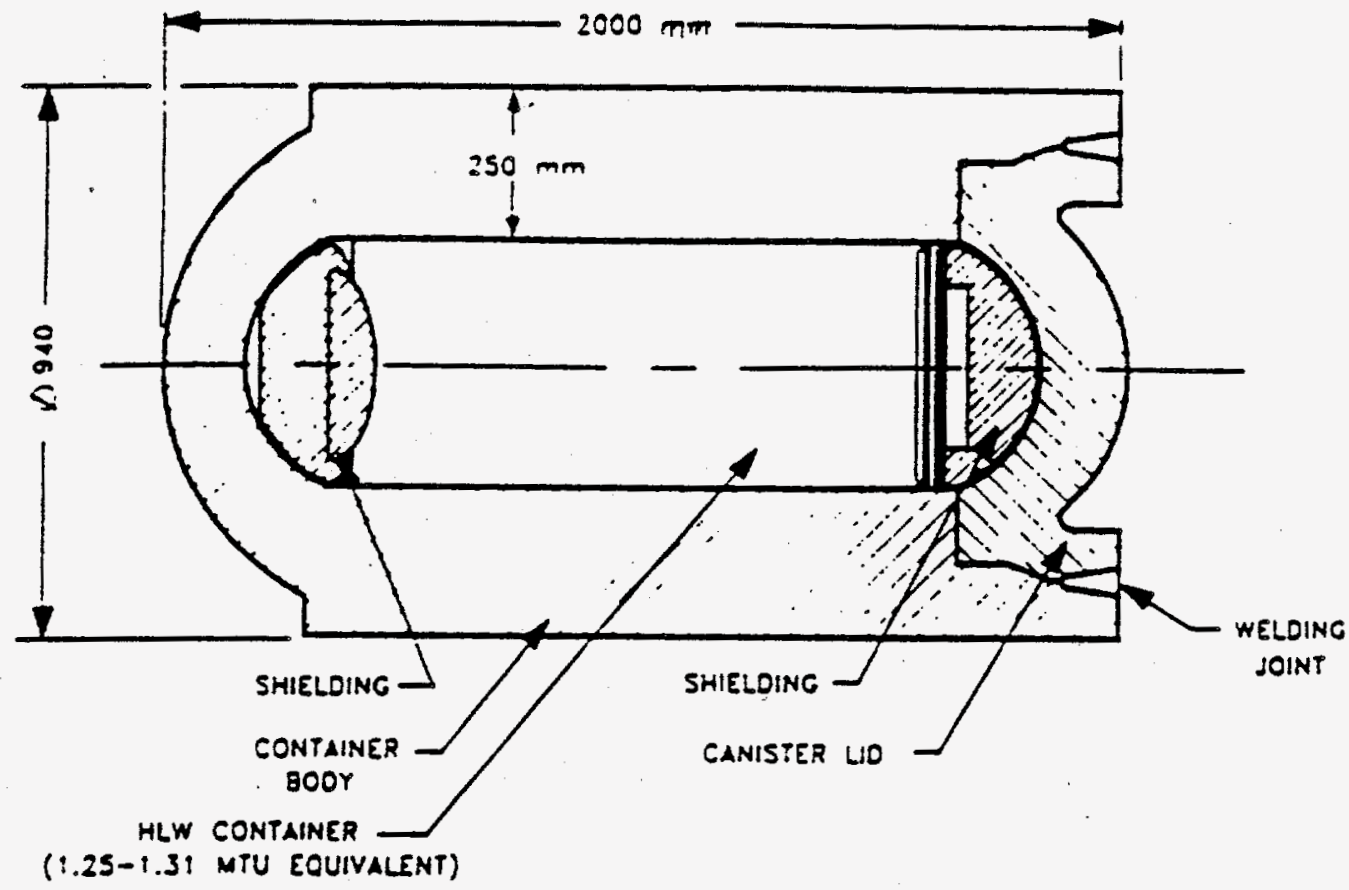

Figure 7-31. Emplacement Concept in Drifts.

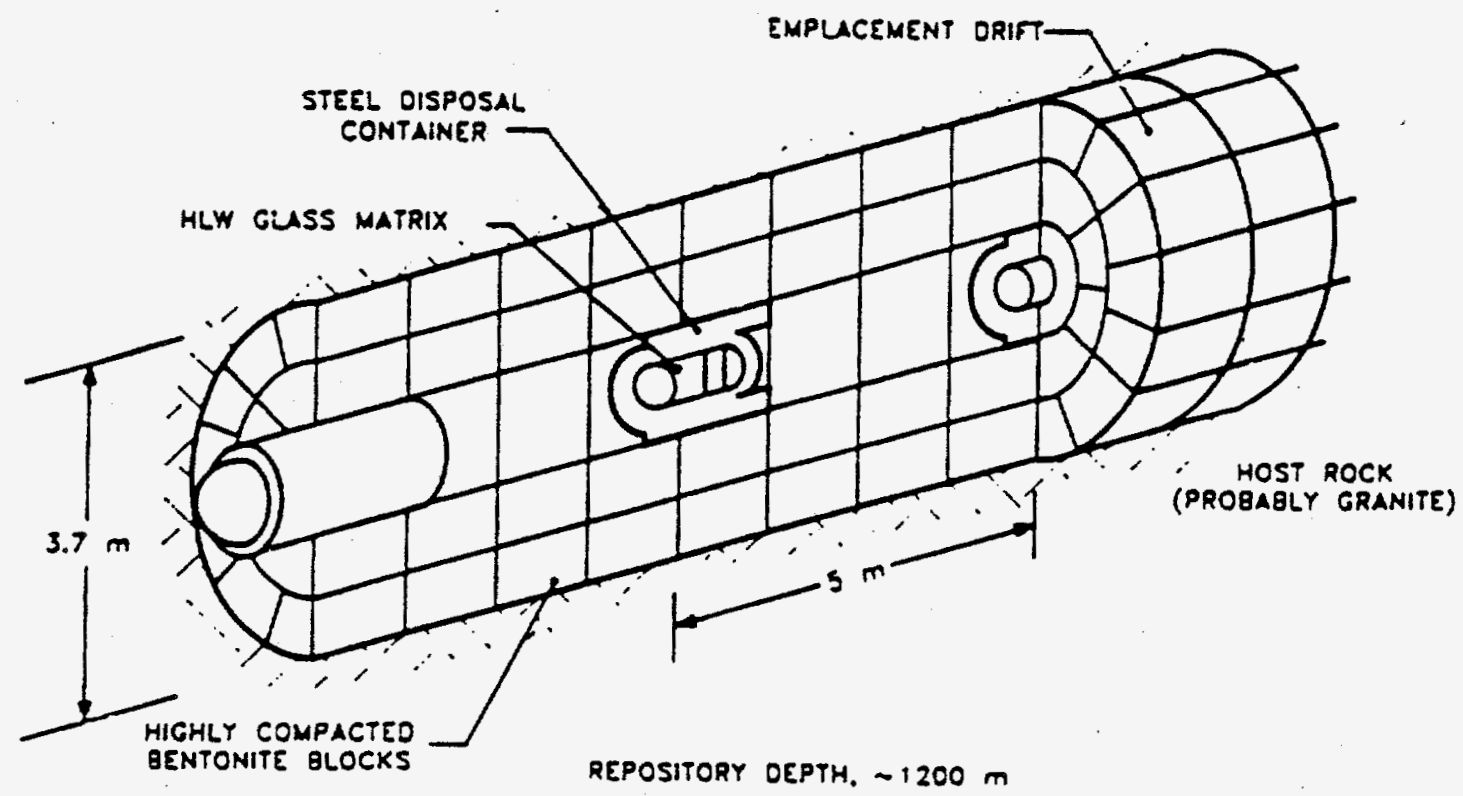

EMPLACEMENT CONCEPT IN DRIFTS

Swiss concept for waste pacbages and placement of pachages in drifts in granite 
Final

Figure 7-32. French, German, Swiss, and U.K. Canister for Vitrified HLW.

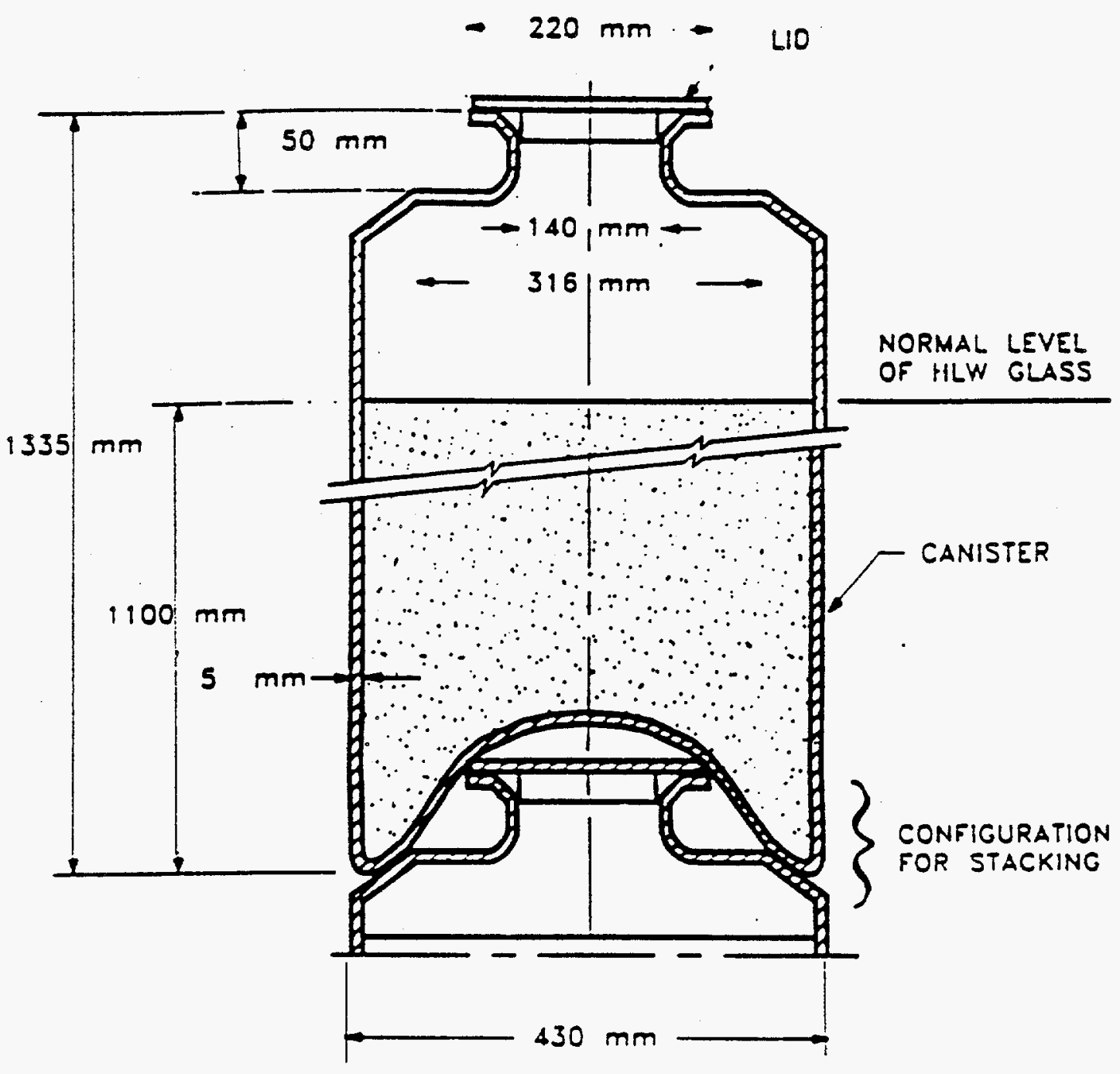

EMPTY WEIGHT: $75 \mathrm{~kg}$ FILLED WEIGHT: $473 \mathrm{~kg}$ GROSS VOLUME: $180 \mathrm{~L}$ GLASS VOLUME: $150 \mathrm{~L}$

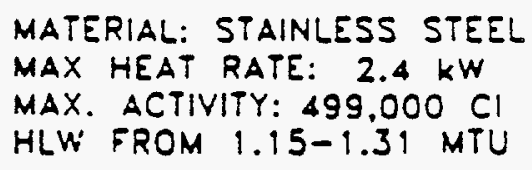

French, German, Belgian, Swiss, and U.K. canister for vitrified HLW 


\begin{tabular}{|c|c|c|c|c|}
\hline \multicolumn{5}{|c|}{$\begin{array}{l}\text { Volume of French Conditioned Waste Per Unit of Reprocessed Fuel } \\
\text { (for a nominal production of } 800 \mathrm{t} \text { Ulyear) }\end{array}$} \\
\hline \multicolumn{2}{|c|}{ Category of Waste } & Specifications & Cond'd waste & $\begin{array}{l}\text { Cond'd } \\
\text { method }\end{array}$ \\
\hline $\begin{array}{l}\text { Deep } \\
\text { underground } \\
\text { disposal }\end{array}$ & $\begin{array}{l}\text { Fission products } \\
\text { Hulls \& Ends } \\
\text { fittings } \\
\text { Sludges } \\
\text { Technological } \\
\text { wastes }\end{array}$ & $\begin{array}{r}130 \mathrm{l} / \mathrm{t} \mathrm{U} \\
600 \mathrm{l} / \mathrm{t} \mathrm{U} \\
630 \mathrm{l} / \mathrm{t} \mathrm{U} \\
1700 \mathrm{l} / \mathrm{t} \mathrm{U}\end{array}$ & $\begin{array}{l}115 \mathrm{l} / \mathrm{t} \mathrm{U} \\
600 \mathrm{l} / \mathrm{t} \mathrm{U} \\
450 \mathrm{l} / \mathrm{t} \mathrm{U} \\
200 \mathrm{l} / \mathrm{t} \mathrm{U}\end{array}$ & $\begin{array}{l}\text { Glass matrix } \\
\text { Concrete } \\
\text { Bitumen } \\
\text { Grouted } \\
\text { asbestos }\end{array}$ \\
\hline $\begin{array}{l}\text { Surface } \\
\text { disposal }\end{array}$ & $\begin{array}{l}\text { LL technological } \\
\text { waste }\end{array}$ & $3000 \mathrm{l} / \mathrm{t} \mathrm{U}$ & $1400 \mathrm{l} / \mathrm{t} \mathrm{U}$ & $\begin{array}{l}\text { Grouted fiber } \\
\text { concrete } \\
\text { overpack }\end{array}$ \\
\hline
\end{tabular}




\begin{tabular}{|c|c|c|c|c|c|c|c|c|c|}
\hline \multicolumn{10}{|c|}{$\begin{array}{c}\text { TABLE 7-2 } \\
\text { Conditioned Wastes (La Hague Plant) }\end{array}$} \\
\hline \multicolumn{2}{|l|}{ WASTE } & \multirow{2}{*}{ MATRIX } & \multicolumn{2}{|c|}{ PACKAGE } & \multicolumn{2}{|c|}{$\begin{array}{l}\text { CONDITIONED } \\
\text { RESIDUE }\end{array}$} & \multicolumn{2}{|c|}{$\begin{array}{l}\text { MAXIMUM ACTIVITY } \\
\text { (Ci) }\end{array}$} & \multirow{2}{*}{$\begin{array}{l}\text { MAXIMUM } \\
\text { THERMAL } \\
\text { RELEASE }\end{array}$} \\
\hline NATURE & $\begin{array}{l}\text { TYP } \\
\mathbf{E}\end{array}$ & & TYPE & $\begin{array}{l}\text { CAPAC- } \\
\text { ITY }\end{array}$ & $\begin{array}{l}\text { PAYLOA } \\
\text { D } \\
\quad(k g)\end{array}$ & $\begin{array}{l}\text { TOTAL } \\
\text { WEIGHT } \\
(\mathrm{kg})\end{array}$ & ALPHA & BETA & \\
\hline $\begin{array}{l}\text { FISSION } \\
\text { (1) } \\
\text { PRODUCTS } \\
\text { CONCENTRATES }\end{array}$ & $\begin{array}{l}\mathrm{HL} \\
\mathrm{W}\end{array}$ & GLASS & $\begin{array}{l}\text { stainles } \\
\text { s steel } \\
\text { contain } \\
\text { er } \\
(0,75)\end{array}$ & 150 & 400 & 480 & 3800 & $\begin{array}{c}800000 \\
\text { (FP) }\end{array}$ & $2980 W$ \\
\hline $\begin{array}{l}\text { SLUDGES } \\
\text { (2) }\end{array}$ & ILW & BITUMEN & $\begin{array}{l}\text { stainles } \\
\text { s steel } \\
\text { drum } \\
(2.5)\end{array}$ & 200 & 280 & 300 & 4 & $\begin{array}{l}500 \\
\text { (FP) }\end{array}$ & $2 w$ \\
\hline $\begin{array}{l}\text { HULLS AND } \\
\text { (3) } \\
\text { END FITTINGS }\end{array}$ & ILW & & $\begin{array}{l}\text { stainles } \\
\text { s steel } \\
\text { contain } \\
\text { er } \\
(0,5)\end{array}$ & 1300 & 3600 & 4000 & 5 & $\begin{array}{r}3000 \\
(F P) \\
12000 \\
\text { (AP) }\end{array}$ & $130 \mathrm{w}$ \\
\hline $\begin{array}{l}\text { (4) } \\
\text { TECHNOLOGICAL } \\
\text { WASTES } \\
\text { ZONE } 4\end{array}$ & ILW & CEMENT & $\begin{array}{l}\text { CBFC } 2 \text {. } \\
\text { (1) }\end{array}$ & 1200 & 2400 & 3500 & 10 & 50 & \\
\hline $\begin{array}{l}\text { (5) } \\
\text { TECHNOLOGICAL } \\
\text { WASTES } \\
\text { ZONES } 2 \text { AND } 3\end{array}$ & LLW & & $\begin{array}{l}\text { CBFC } 1 \\
(5,2)\end{array}$ & 650 & 1100 & 1800 & 0,1 & .20 & \\
\hline
\end{tabular}




\begin{tabular}{|c|c|c|c|}
\hline \multicolumn{4}{|c|}{$\begin{array}{c}\text { TABLE 7-3 } \\
\text { French Packaged Waste Volumes }\end{array}$} \\
\hline $\begin{array}{l}\text { Process } \\
\text { Vitrification }\end{array}$ & Unit & Marcoule & La Hague \\
\hline FP concentrate volume & $m^{3}$ & 1,435 & 518 \\
\hline activity & $10^{6} \mathrm{Ci}$ & 291 & 177 \\
\hline glass canisters & qty & 1,830 & 520 \\
\hline glass weight & $t$ & 640 & 260 \\
\hline Bitumen coating & & & \\
\hline bitumen drums & qty & 59,865 & 2096 \\
\hline Cement coating & & & \\
\hline $\begin{array}{l}\text { hulls and fittings, drums } \\
100 \text { liter compacted drum }\end{array}$ & qty & 720000 & $\begin{array}{r}45 \\
7900\end{array}$ \\
\hline 200 liter cemented drums & qty & 150000 & 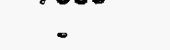 \\
\hline fiber concrete containers & qty & - & 1364 \\
\hline asbestos-cement containers & qty & - & 22 \\
\hline
\end{tabular}

Table 7-4

Main Components of ENEA's HLLW

\begin{tabular}{|c|c|c|c|c|}
\hline HLLW & & MTR & CANDU & Elk River \\
\hline density & $\left(\mathrm{kg} / \mathrm{m}^{3}\right)$ & 1200 & 1150 & 1100 \\
\hline $\mathrm{H}+$ & $(\mathrm{M})$ & 1.2 & 1.2 & 1.8 \\
\hline $\mathrm{Fe}$ & $\left(\mathrm{kg} / \mathrm{m}^{3}\right)$ & 0.49 & 0.46 & 2.1 \\
\hline $\mathrm{Hg}$ & $\left(\mathrm{kg} / \mathrm{m}^{3}\right)$ & 1.18 & - & - \\
\hline Al & $\left(\mathrm{kg} / \mathrm{m}^{3}\right)$ & 32 & - & - \\
\hline SO4 & $(\mathrm{M})$ & 0.015 & 0.01 & - \\
\hline NO3- & $(\mathrm{M})$ & 4.33 & 1.8 & 1.8 \\
\hline$U$ & $\left(\mathrm{~kg} / \mathrm{m}^{3}\right)$ & $5 \mathrm{E}-3$ & 90 & 0.01 \\
\hline Th & $\left(\mathrm{kg} / \mathrm{m}^{3}\right)$ & - & - & 0.8 \\
\hline Pu-241 & $\left(\mathrm{GBq} / \mathrm{m}^{3}\right)$ & 15 & 570 & 0.03 \\
\hline Pu-alfa & $\left(\mathrm{GBq} / \mathrm{m}^{3}\right)$ & 6 & 23 & - \\
\hline Am-241 & $\left(\mathrm{GBq} / \mathrm{m}^{3}\right)$ & 0.15 & 570 & - \\
\hline Cm-244 & $\left(\mathrm{GBq} / \mathrm{m}^{3}\right)$ & $3.7 \mathrm{E}-5$ & 44 & - \\
\hline Sr-90 & $\left(\mathrm{GBq} / \mathrm{m}^{3}\right)$ & $1.14 \mathrm{E}+4$ & $2.18 \mathrm{E}+4$ & $1.0 \mathrm{E}+5$ \\
\hline Cs-137 & $\left(\mathrm{GBq} / \mathrm{m}^{3}\right)$ & $1.28 \mathrm{E}+4$ & $3.66 \mathrm{E}+4$ & $1.0 \mathrm{E}+5$ \\
\hline Total alfa & $\left(\mathrm{GBq} / \mathrm{m}^{3}\right)$ & 6.15 & 640 & 1.9 \\
\hline Total activity & $\left(\mathrm{GBq} / \mathrm{m}^{3}\right)$ & $4.8 \mathrm{E}+4$ & $1.2 \mathrm{E}+5$ & $4.0 \mathrm{E}+5$ \\
\hline & & & & \\
\hline
\end{tabular}


Table 7-5: Main Components of the HLLW-MTR Sludge

\begin{tabular}{|l|c|l|}
\hline Density & $1200-1300$ & $\mathrm{~kg} / \mathrm{m}^{3}$ \\
\hline Fe & $10-15$ & $\mathrm{~kg} / \mathrm{m}^{3}$ \\
\hline $\mathrm{Al}$ & $10-12$ & $\mathrm{~kg} / \mathrm{m}^{3}$ \\
\hline $\mathrm{Na}$ & $60-70$ & $\mathrm{~kg} / \mathrm{m}^{3}$ \\
\hline $\mathrm{Hg}$ & $5-15$ & $\mathrm{~kg} / \mathrm{m}^{3}$ \\
\hline SO4= & $0.2-0.3$ & $\mathrm{~kg} / \mathrm{m}^{3}$ \\
\hline $\mathrm{NO3}-$ & $80-100$ & $\mathrm{~kg} / \mathrm{m}^{3}$ \\
\hline -TPB & $5-10$ & $\mathrm{~kg} / \mathrm{m}^{3}$ \\
\hline Cs 137 & $200-350$ & $\mathrm{TBq} / \mathrm{m}^{3}$ \\
\hline Sr 90 & $200-300$ & $\mathrm{TBq} / \mathrm{m}^{3}$ \\
\hline Pu 241 & $300-450$ & $\mathrm{GBq} / \mathrm{m}^{3}$ \\
\hline Total Alfa & $100-200$ & $\mathrm{GBq} / \mathrm{m}^{3}$ \\
\hline Total Activity & $800-1300$ & $\mathrm{TBq} / \mathrm{m}^{3}$ \\
\hline
\end{tabular}

Table 7-6: Main components of the HLLW-CANDU sludge

\begin{tabular}{|l|c|l|}
\hline Density & $1200-1300$ & $\mathrm{~kg} / \mathrm{m}^{3}$ \\
\hline $\mathrm{Fe}$ & $20-30$ & $\mathrm{~kg} / \mathrm{m}^{3}$ \\
\hline $\mathrm{Na}$ & $20-30$ & $\mathrm{~kg} / \mathrm{m}^{3}$ \\
\hline $\mathrm{U}$ & $15-20$ & $\mathrm{~kg} / \mathrm{m}^{3}$ \\
\hline SO4= & $0.2-0.3$ & $\mathrm{~kg} / \mathrm{m}^{3}$ \\
\hline NO3- & $30-50$ & $\mathrm{~kg} / \mathrm{m}^{3}$ \\
\hline -TPB & $10-20$ & $\mathrm{~kg} / \mathrm{m}^{3}$ \\
\hline Cs 137 & $400-700$ & $\mathrm{TBq} / \mathrm{m}^{3}$ \\
\hline Sr 90 & $200-300$ & $\mathrm{TBq} / \mathrm{m}^{3}$ \\
\hline Pu-241 & $6-9$ & $\mathrm{TBq} / \mathrm{m}^{3}$ \\
\hline Total alfa & $7-11$ & $\mathrm{TBq} / \mathrm{m}^{3}$ \\
\hline
\end{tabular}


Table 7-7

Savannah River Waste Classification

\begin{tabular}{||l|l|l||}
\hline \multicolumn{1}{|c|}{ Waste Class } & \multicolumn{1}{|c|}{$\begin{array}{c}\text { Dose } \\
\text { Rate/Activity }\end{array}$} & \multicolumn{1}{|c|}{$\begin{array}{c}\text { Handling } \\
\text { Method }\end{array}$} \\
\hline $\begin{array}{l}\text { Intermediate Activity } \\
\text { (Tritium and Non) }\end{array}$ & $\begin{array}{l}>200 \mathrm{mrem} / \mathrm{hr} \\
10-100 \mathrm{nCi} / \mathrm{gr} \alpha \\
\text { Low Activity }\end{array}$ & $\begin{array}{l}\text { Remote } \\
200 \mathrm{mrem} / \mathrm{hr} \\
10 \mathrm{nCi} / \mathrm{gr} \alpha \\
\text { Half life } 30 \mathrm{yrs} \\
1100 \mathrm{nCi} / \mathrm{gr} \alpha\end{array}$ \\
Long-lived & Remotact \\
\hline
\end{tabular}

TABLE 7-8

Disposal Limits for E Area Vaults Intermediate Activity Waste Vaults

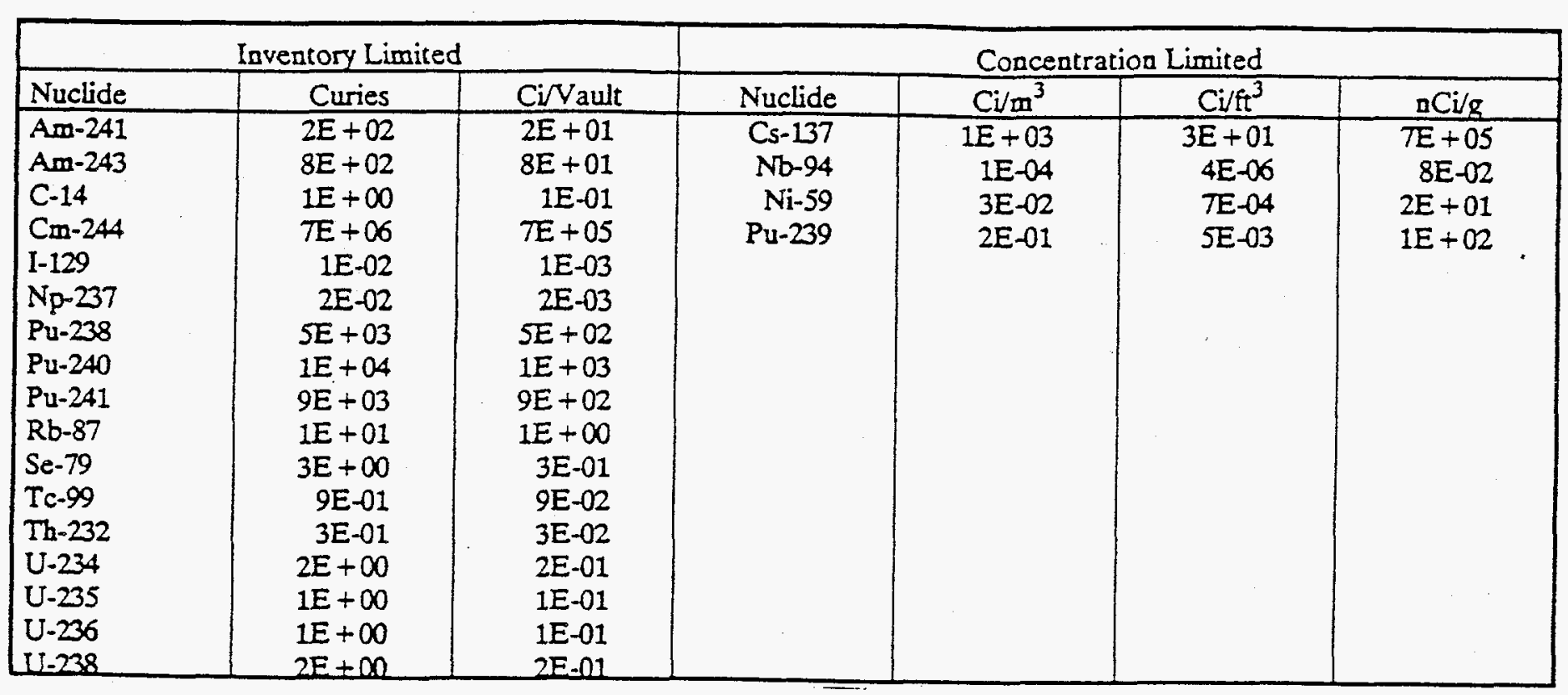


Final

TABLE 7-9

Low Activity Waste Vaults

\begin{tabular}{|c|c|c|c|c|c|c|}
\hline \multicolumn{3}{|c|}{ Inventory Limited } & \multicolumn{4}{|c|}{ Concentration Limit } \\
\hline Nuclide & Curies & CiNault & Nuclide & $\mathrm{Ci} / \mathrm{m}^{3}$ & $\mathrm{Ci} / \mathrm{ft}^{3}$ & $\mathrm{nCi} / \mathrm{g}$ \\
\hline $\begin{array}{l}\text { Am-241 } \\
\text { C-14 } \\
\text { I-129 } \\
\text { Np-237 } \\
\text { Pu-238 } \\
\text { Pu-241 } \\
\text { Rb-87 } \\
\text { Se-79 } \\
\text { Tc-99 } \\
\text { Th-232 } \\
\text { U-234 } \\
\text { U-235 } \\
\text { U-236 } \\
\text { U-238 }\end{array}$ & $\begin{array}{r}3 E+03 \\
2 E+01 \\
2 E-01 \\
4 E-01 \\
8 E+04 \\
1 E+05 \\
2 E+02 \\
5 E+01 \\
1 E+01 \\
5 E+00 \\
3 E+01 \\
2 E+01 \\
2 E+01 \\
3 E+01\end{array}$ & $\begin{array}{r}1 E+02 \\
9 E-01 \\
8 E-03 \\
2 E-02 \\
4 E+03 \\
7 E+03 \\
8 E+00 \\
2 E+\infty \\
7 E-01 \\
3 E-01 \\
1 E+\infty \\
1 E+\infty \\
1 E+\infty \\
1 E+\infty\end{array}$ & $\begin{array}{r}\text { Am-243 } \\
\text { Cs-137 } \\
\text { Nb-94 } \\
\text { Ni-59 } \\
\text { Pu-239 } \\
\text { Pu-240 } \\
\text { Pu-242 } \\
\text { Sr-90 }\end{array}$ & $\begin{array}{r}1 E-03 \\
1 E+01 \\
2 E-05 \\
1 E-02 \\
4 E-02 \\
1 E-01 \\
4 E-03 \\
2 E+02\end{array}$ & $\begin{array}{r}4 E-05 \\
3 E-01 \\
6 E-07 \\
3 E-04 \\
1 E-03 \\
4 E-03 \\
1 E-04 \\
7 E+\infty\end{array}$ & $\begin{array}{r}9 E-01 \\
7 E+03 \\
1 E-02 \\
7 E+\infty \\
2 E+01 \\
9 E+01 \\
3 E+\infty \\
1 E+05\end{array}$ \\
\hline
\end{tabular}

TABLE 7- 10

Locations, Times, and Dose Limits Used

\begin{tabular}{|l|r|c|c|c|}
\hline \multirow{2}{*}{ Performance Objective } & \multicolumn{2}{|c|}{ Point and Time of Compliance } \\
\cline { 2 - 5 } & & Waste Site & Waste Site Boundary & SRS Boundary \\
\hline & $500 \mathrm{mrem} / \mathrm{yr}(\mathrm{a})$ & $0-100$ years & NA & NA \\
Worker & $4 \mathrm{mrem} / \mathrm{yr}(\mathrm{b})$ & NA & All time & NA \\
Groundwater Protection & $25 \mathrm{mrem} / \mathrm{yr}(\mathrm{c})$ & $\mathrm{NA}$ & $>100$ years & $0-100$ years \\
General Population & $100 \mathrm{mrem} / \mathrm{yr}(\mathrm{c})$ & $>100$ years LAW & NA & NA \\
Intruder & & $>300$ years LAW & & \\
& & & \\
& & &
\end{tabular}

a. DOE limit is $\$ 000 \mathrm{mrem} / \mathrm{yr}$, SRS limit is $3000 \mathrm{mrem} / \mathrm{yr}, \mathrm{E}$-Area Vaults limit is $1500 \mathrm{mrem} / \mathrm{yr}$. This limit is one-third the E-Area limit.

b. Proposed EPA limit (17).

c. From DOE Order 5820.2A (1). 
TABLE 7-11

International Classification of Radioactive Wastes

\begin{tabular}{|c|c|c|c|c|}
\hline CATEGORY & FRANCE & JAPAN & U.K. & U.S.A. \\
\hline $\begin{array}{l}\text { High Level } \\
\text { Waste }\end{array}$ & $\begin{array}{l}\text { Vitrified fission } \\
\text { products with } \\
\text { heat } \\
\text { generation }\end{array}$ & $\begin{array}{l}\text { Primary } \\
\text { extracted } \\
\text { liquid } \\
\text { containing } \\
\text { fission } \\
\text { products and } \\
\text { its vitrified } \\
\text { product. } \\
\text { all waste } \\
\text { exceeding } \\
1.11 \mathrm{Gbq} / \mathrm{t}\end{array}$ & $\begin{array}{l}\text { All heat } \\
\text { generating } \\
\text { waste }\end{array}$ & $\begin{array}{l}\text { All waste } \\
\text { above low } \\
\text { level class C }\end{array}$ \\
\hline $\begin{array}{l}\text { Intermediate } \\
\text { Level Waste }\end{array}$ & $\begin{array}{l}>3.7 \mathrm{GBq} / \mathrm{t} \\
\text { half life }>30 \mathrm{yr} \text {. } \\
\text { mainly alpa } \\
\text { emmiters no } \\
\text { appreciable } \\
\text { heat } \\
\text { generation }\end{array}$ & $\begin{array}{l}\text { No } \\
\text { classification } \\
\text { but proposals } \\
\text { for TRU- } \\
\text { bearing waste } \\
\text { under } \\
\text { consideration }\end{array}$ & $\begin{array}{l}\text { Above low } \\
\text { level but no } \\
\text { heat } \\
\text { generation. }\end{array}$ & $\begin{array}{l}\text { No } \\
\text { classification }\end{array}$ \\
\hline $\begin{array}{l}\text { Low Level } \\
\text { Waste }\end{array}$ & $\begin{array}{l}\text { alpha } \\
<3.7 \mathrm{GBq} / \mathrm{t} \\
\text { half life<30yr. }\end{array}$ & $\begin{array}{l}\text { alpha } \\
<1.11 \mathrm{Gbq} / \mathrm{t}\end{array}$ & $\begin{array}{l}\text { alpha } \\
<4 G \text { bq/t } \\
\text { beta/gamma } \\
12 \mathrm{Gbq} / \mathrm{t}\end{array}$ & $\begin{array}{l}\text { alpha } \\
<3.7 \mathrm{Gbq} / \mathrm{t} \\
\text { half life<5yr. } \\
\mathrm{Cm-242} \\
<130 \mathrm{Gbq} / \mathrm{t} \\
\mathrm{Pu}-241 \\
<740 \mathrm{Gbq} / \mathrm{t} \\
\text { sub. divided } \\
\text { into classes } \\
\text { A,B\&C for } \\
\text { concentration/ } \\
\text { m }{ }^{3} \text { for } \\
\text { disposal } \\
\text { requirements }\end{array}$ \\
\hline
\end{tabular}




\section{ATTACHMENTS}

Attachment 1. - The Centre De L'Aube Low-Level Waste Disposal Facility

Attachment 2 - Final closure of the Centre de la Manche Radioactive Waste Disposal Facility

Attachment 3 - Pelletizing method for concentrated wastes generated from fuel reprocessing plants

Attachment 4 - Advanced volume reduction system for PWR plant

Attachment 5 - Waste Isolation Pilot Plant (WIPP)

Attachment 6 - Current status of the West Valley state licensed low level radioactive waste disposal areas

Attachment 7 - Liner and final cover optimization of mixed waste storage/disposal facility at Los Alamos National Laboratory

\section{REFERENCES}

Waste Management 90

- Symposium on Waste Management at Tucson, Arizona

Waste Management 92

- Symposium on Waste Management at Tucson, Arizona

High Level Radioactive Waste Management 1992

- Proceedings of the Third Annual International Conference

High Level Radioactive Waste Management 1993

- Proceedings of the Fourth Annual International Conference

Going Underground

- United Kingdom Nirex Ltd.

Managing Radioactive Waste in the European Community

- Commission of European Communities

Marine Transportation for Low Level Waste

- "Koki Tanaka" Nuclear Fuel Transport Company, Japan

Radioactive Waste Disposal in UK

- W. Heafield, H. G. Lewis, BNFL;

- P. T. Mclnerney, UK Nirex

Forecasting the Space Time Stability of Radioactive Waste Isolation in Salt Formations

- V. G. Khlopin, Radium Institute, Shvernick 
Final

The Nirex Repository

- Journal of the British Nuclear Energy Society; February 1994 - Volume 33, \#1

Locations, Volumes and Characteristics of DOE's Mixed Low Level Waste

- Ross, Elmore, Warner, Watehter, Carlson \& Devries - Waste Management 92

Nuclear Engineering International - June 1993

- Developing Techniques for Waste Disposal in China; Xiaoli Wang

Nuclear Plant Journal - July/August 1993

- Russian High Level Nuclear Waste Disposal Program; Linda L. Lehman 


\title{
THE CENTRE DE L'AUBE LOW-LEVEL WASTE DISPOSAL FACILITY
}

\author{
Gilles Chevrier and Michel Dutzer \\ ANDRA \\ B.P. 38 \\ 92266 Fontenay-aux-Roses Cedex \\ France
}

\begin{abstract}
Short-lived, low- and medium-level radioactive waste bas been disposed of since 1969 at the Centre de la Manche Disposal Facility in Normandy, not far from Cherbourg and adjacent to the La Hague reprocessing plant operated by COGEMA. The facility's capacity of $535,000 \mathrm{~m}^{3}$ on a site of 12 hectares will be exhausted in the 19941995 time frame. The Centre de la Manche currently receives $30,000 \mathrm{~m}^{3}$ of waste per year. The experience from over 20 years of operations at the Centre de la Manche has been particularly useful in defining the strategy for radioactive waste management in France.

The Centre de la Manche facility will be replaced by the Centre de l'A ube Disposal Facility, which began receiving waste in early 1992 . The Centre de l'Aube has a total capacity of $1,000,000 \mathrm{~m}^{3}$ and a total surface area of 30 bectares, and will be operated for 30 years.

This paper will first present the radioactive waste management program in France, including the types and quantities of waste generated, and will then provide a detailed description of the design concept of the Centre de l'Aube.
\end{abstract}

\section{LEGAL ASPECTS OF RADIOACTIVE WASTE MANAGEMENT IN FRANCE}

ANDRA, the national waste management agency of France (Agence aationale pour la gestion des dechets radioactifs), is, as its name implies, responsible for long-term radioactive waste management in France. The agency was created in 1979 and charged with the following specific responsibilities:

- development of technical requirements for the protection of public health and safery and of the environment, and to comply with regulations issued by the Government, including the Ministry of Research and Industry, the Ministry of Health, and the Ministry of the Environment;

- submission of the technical requirements to the Goverament for approval; and

- enforcement of the technical requirements.

ANDRA establishes technical specifications that comply with the safery requirements and performance objectives applicable to radioactive waste transportation and disposal, and is responsible for their application by the waste generators, including EDF, COSEMA, CEA, defense contractors, hospitals, industry and the research sector. ANDRA is responsible for site characterization and selection for both near-surface and deep waste disposal sites, and is in charge of disposal facility construction and operation. ANDRA also plays an active role in research on waste treatment and solidification methods.

ANDRA activities are financed by the waste generators. The generators are members of ANDRA's Steering Committee [Comite de Gestion], which is similar to a Buard of Directors, although ANDRA is, by law, a non-prefit organization. ANDRA's charter will be changed to that of a Public Industrial and Commercial Establishment [Etablissement Public Industriel et Commercial], most likely in 1992, pursuant to the law passed in late 1991 relative to research on bigh-level radioactive waste management.

\section{DESCRIPTION OF RADIOACTIVE WASTE IN FRANICE}

\section{Classification Criteria}

Unlike most industrial waste, radioactive waste gradually and inevitably loses its radioactivity over time. Radioactive decay is characterized by the "half life" of the radionuclides. The radioactivity of a given radionuclide decreases:

- by a factor of 2 during one half life;

- by a factor of 1000 during 10 half lives; and

- by a factor of more than 106 during 20 half lives.

Waste loses its radioactivity as a function of the radionuclides it contains. The decay period is therefore the primary criterion in classifying waste, and determines bow the waste will be managed.

Another criterion of importance is the initial radioactivity of the waste, which helps to determine how long it will take for the radioactivity to completely disappear. In the nuclear field, the convention is that:

- "low or medium level activity" is equal to $1 \mathrm{Ci} / \mathrm{m}^{3}$, or $3.7 \times 1010$ Becquerels, i.e., disintegrations per second; and

- "high level activity" is equal to $10^{6} \mathrm{Ci} / \mathrm{m}^{3}$.

These two criteria--half life and activity-are used to divide waste into two main classes:

- short-lived waste with low-and medium-level activities, and

- long-lived waste.

\section{Long-Lived Waste}

Long-lived waste is discussed in other papers at this conference, and will therefore be addressed here only briefly. Long-lived waste is divided into two categories:

- "alpha" waste, or transuranic waste, called Category $B$ waste in France, which is generally produced in fuel fabrication and reprocessing facilities; 
- vitrified waste, called Cacegory $C$ waste in France, which is generated by spent fuel reprocessing activities.

\section{Sbort-Lived. Low-and Medium-Level Waste}

By definition, the main radionuclides contained in shortlived, low- and medium-level waste, called Category $A$ waste in France, bave half lives that are equal to or less than 30 years. After 10 balf lives, or approximately 300 years, the betagamma activity of such waste is 1000 times lower and essentially negligible. The 300 years corresponds to the maximum length of the institutional control period specified in the regulations.

Category A waste is generated primarily in nuclear power plants and spent fuel reprocessing facilities, with smaller quantities coming from the operation and maintenance of facilities in the front end of the fuel cycle, from nuclear research centers, or from small generators such as uriversities or hospitals. Category A waste includes contaminated clothing, pieces of metal, tools, plastic sheets, failed equipment, ion exchange resins, and evaporator concentrates.

To be accepted for disposal in a near-surface disposal facility, Category A waste must be is solid form; must have good chemical, thermal and mechanical stability; must have good immobilization properties; wust bave a low leach rate; and may not contain toxic chemicals or flammable materials. The waste container must be grouted inside steel or concrete drams or boxes that can be handled and transported without risk to workers or the public.

\section{Waste Inveatory}

The majority of radioactive waste is generated by the nuclear power industry. It is interesting to analyze waste generation statistics based on industrial versus domestic consumption. Per capita waste generation in France is $10,000 \mathrm{Kg}$ of waste of all types, of which $1 \mathrm{Kg}$ is radioactive waste. Incluced in this kilogram of radioactive waste is the waste itself, the solidification or grout material, and the container. The vast majority, or about $950 \mathrm{~g}$ of this kilogram of waste, is short- lived waste.

$\begin{array}{lll}\text { Waste } & \begin{array}{l}\text { Annual } \\ \text { Volume } \\ \text { (cubic meters) }\end{array} & \begin{array}{l}\text { Cumulative } \\ \text { Volume In } \\ \text { Year 2000 } \\ \text { (cubic meters) } \\ \text { Type } \\ \text { Category A }\end{array} \\ \begin{array}{l}\text { Short-Lived Waste } \\ \text { Category B }\end{array} & 30,000 & 800,000 \\ \text { Alpha Waste } & 3,000 & 88,000 \\ \text { Category C } & & \\ \text { Vitrified Waste } & 100 & 2,090\end{array}$

Waile short-lived waste represents $90 \%$ of the total volune of radioactive waste generated in France, they contain only $1 \%$ of the total radioactivity. It should be noted that generators are making a substantial effort to reduce waste volumes.

It is interesting to examine the sources of Category A waste in France. In 1990 , some $32,584 \mathrm{~m}^{3}$ of waste were disposed of at the Centre de la Manche.
- $38.5 \%$ came from spent fuel reprocessing activities;

- 36.1\% came from suclear power plants;

- $13.6 \%$ came from large researcb centers;

- 5\% cane from non-nuclear industries;

- $4.8 \%$ came from facilities in the front end of the fuel cycle; and

- $1.9 \%$ came from small gezerators, such as bospitals and universities.

Approximately 100,000 waste containers are delivered to the Centre de la Manche annually, broken down as follows:

- metal drums represeas $47 \%$ of the volume but $90 \%$ of the number of containers;

- metal boxes represent $27 \%$ of the volume and $15 \%$ of the number of containers; and

- concrete overpacks represent 25\% of the volume and 5\% of the number of containers.

\section{DESIGN CONCEPT OF THE DISPOSAL FACILITY}

\section{General Requirements}

The principal performance criterion for the design of the disposal facility is to protect the waste from buman intrusion and from water infiltration until the radioactivity has decayed to an acceprable level.

The criterion is the same for botb short-lived waste disposal and long-lived waste disposal. However, the French design concept for short-lived waste, chosen for the technical and economic advantages it offers, is defensible from a safery point of view only if the disposal period is short exough to be realistic on a human scale, yet long enough to provide security against human intrusion. The cut-off for radionuclide half lives of 30 years is intended to meet this requirement, because the radioactivity will have practically disappeared within 300 years, which is considered to be a reasonable period of time for institutional control. Radionuclides with longer half-lives may be excepted in very limited quantities based on site-specific safety requirements to be described later. Thus, there are three distinct periods in the life of a near-surface disposal facility:

- the operating period, during which waste is received and disposed of at the facility, and cumulative activity increases until it reaches its authorized ceiling at the end of the period;

- the institutional control or moditoring period set at 300 years in France, during which the activity decays naturally, the integrity of the waste isolation system is monitored and the site is protected from buman intrusion; and

- the free access period, when all restrictions concerning the use of the site are raised.

\section{Multiple Barrier Disposal Concept}

The multiple barriet disposal concept for radioactive waste was fashioned after the engineered barriers in auclear power plants. There are three main barriers in the disposai system:

- the waste form, whose long-term integriry must be provided by appropriate mechanical (stability, compressive strength) and physico-chemical properties; 
- the eagineered disposal structures, designed to protect the waste from water; and

- the disposal site.

The multiple barrier design concept is the basis of the French regulation Regle Fondameatale de Surete, or Fundamental Safery Rule 1.2, which sets forth the performance criteria and the design bases of the disposal system, and which specifies that the safery of the facility in normal operations must rely on the first two barriers alone, with the site acting as a barrier only in the event of an accident causing the failure of the first two barriers.

\section{The Waste Form}

The waste form is the primary barrier in the multipie barrier disposal system. The use of the waste form as a barrie: is another way of saying that waste management at the disposal facility begins with the waste generator, well in advance of any waste deliveries to the site.

Waste immobilization has a dual purpose: 1) to confine the radioactivity in the waste and 2) to give the waste the required mecbanical stability for the engineered disposal system. The safery requiremeats relative to waste immobilization are translated by ANDRA into technical specifications for different waste forms that must be complied with by the waste generators.

Waste acceptance is based on a thorough review of the tecinnical documeatation prepared by the generator on the following:

- a detailed description of the waste and of the waste immobilization process;

- a complete test report on the waste characterization test program;

- a Quality Assurance Program relative to each waste immobilization process; and

- a description of the quality control program, including waste sampling and analysis.

The technical documentation is presented to ANDRA as a Waste Acceptance File for review and approval. ANDRA's Quality Control Division performs both scheduled and unscheduled inspections and audits to ensure that the immobilization process is implemented according to plan, and reports on inspection and audit results to the French nuclear safety authorities.

The technical specifications for the waste include activity ceilings for the various radionuclides. There is an overall limit for alpha-emitter activicy of $0.1 \mathrm{Ci}$, or 3,700 mega Becquerels, per metric ton for individual waste packages, and $0.01 \mathrm{Ci}$, or 370 mega Becquereis, per metric ton for the site as a whole.

In addition to the waste acceptance process, ANDRA developed a computerized waste tracking system that follows the waste from the moment it is generated to its final resting place in the disposal facility. The system links the waste generator, ANDRA headquarters in the Paris area, and the disposal facilities. The tracking system data base includes the identification number of the waste package, and all of the information needed to describe the package, including the type of waste, the type and activity of radionuclides contained in the waste, the type of container, etc. The information provided on the waste through the tracking systern is com- pared to the Waste Acceptance File pertaining to that waste. In this maseer, each container of waste is verified for compliance to specifications before the generator is allowed to ship it to the disposal facility.

The tracking system's data base is a useful tool in scheduling and tracking waste shipments, with the memorized location of the waste package being contiouously updated from the time it leaves the generator's site to the time it reaches the disposal facility. The data base is also used to maintain a detailed and constartly updated invertory of radionuclides disposed of at the site.

\section{The Engineered Disposal Structures}

The secondary barrier in the multiple barrier disposal system is constituted by the engineered disposal sonctures. The disposal structures are designed to allow the integrity of the waste isolation sysiem to be periodically verified. There are three main componeats to the disposal structures:

- the disposal nodule which recaives the waste;

- the disposal cap which provides long-term protection to the module against rainwater infiltration; and

- the collecion system for potential infiltration water.

The disposal system is protected from ground wate: infiltration by its placement in an unsarurated zone well above the bighest hisioric level of the water table. The base of the disposal module consists of an impermeable concrete pad with an integral drain for any infilitrated water. Water is directed by gravity to the separative wate: collection system, which can be monitored for the presence and activity of water during the operating and institutional control periods.

The disposal cap will undergo several transformations before reaching its final form after the closure of the disposal facility. During the operating period, temporary mobile sinelters, or moveable buildings, will be used to protect open disposal modules during loading operations. Once the modules are full, they will be backfilled, covered and coated with waterproof material that will serve as a temporary cove: until the final cap is consiructed.

The Innal cap will be designed to lasi for the duration of the institutiocal control period. The cap will be constructed of alternating layers of permeable and impermeable materials designed to limit water infiltration to no more than a few liters per square meter pe: year. Portions of the cap will be insirumented to periodically monitor its performance during the institutional control period. A full-scale instrumented section of the final disposal cap is already in place at the Centre de l'Aube disposal faciiity, and is being monitored to determine the efficac: of the cap design.

\section{The Disposal Site}

The tertiary barrier of the multiple barrier disposal system is the disposal site itself, which fulfills its role as a barrier only in the eveat of an accident that damages the first two barriers--the waste form and the engineered disposal structures-- during the operating and institutional control periods.

The site's true importance comes into play during the unrestricted site access period, when it is called upon to retain the remaining radionuelides at the site, or to slow their offsite migration. The site must therefore have the appropriate 
bydrogeological and materials retention characteristics enabling it to fulfill this role.

With respect to bydrogeology, the preferred site is one that is easily modelled, meaning, for example, one with a permeable upper formation overiying an impermeable lower formation, and with easily identified and monitored water outlet. A site with these characteristics makes it easy to model water pathways and therefore to assess the potential environmental impacts of the disposal site using different scenarios.

Relatively stable sites, from a geotectanical point of view, and with historically low seismic activity are sought to guarantee the long-term stability of the disposal facility.

\section{THE CENTRE DE L'AUBE DISPOSAL FACILITY}

\section{Description of the Facility}

Site screening activities were conducted in 1984 and 1985 in the administrative departments of Aube, Indre and Vienne, as well as near the town of Cholet in the Maine and Loire Departmeat. The region near the town of Soulaines, in the Aube Departmeat, was extensively characterized, both geologically and bydrologically. For example, aearly 500 relatively deep core drillings were taken to characterize the region.

The site chosen for the Centre de l'Aube disposal facility is on a low bill of sandy clay overlying a thick clay formation and bordered by the Noues d'Amance creek on one side, which corresponds precisely to the bydro-geological model described previously. The Soulaines site bad all of the waste isolation qualities sought by ANDRA, especially with respect to site hydrology.

The Centre de l'Aube disposal facility occupies a 95 hectare site about 40 kilometers east of the city of Troyes and about 200 kilometers east of Paris. To compensate for the timber that had to be felled at the site for construction of the disposal facility, ANDRA purchased a 96 hectare portion of land and planted it with trees. The site is connected to the national highway system by a 4 kilometer road, covering approximately 17 bectares. Waste is delivered by rail to a special rail terminal at the Brienne-le-Chateau train station, approximately 15 kilometers from the site.

The Centre de l'Aube is divided into two zones: 1) the disposal area, covering 30 hectares, where 24 disposal modvies are in operation and a total of 420 will have been constructed by the end of the operating period; and 2) the administrative area. A portion of the administrative area is inside the fence, in the controlled zone, and a portion is outside the controlled zone.

\section{Controlled Zone}

- the Waste Treatmeat Bullding, where boxed waste is grouted and drums are compacted and grouted in. side overpacks;

- the Mechanical Building, which controls access to the controlled zone;

- the Auxiliary Services Building, including change rooms, environmental monitoring laboratory and infirmary;

- the Buffer Storage Building;

- the Administration Building;

- the Storm Basin;
- the Guard Post; and

- the Weather Station.

\section{Uncontrolled Zone}

The Public Information Building, where visitors can ge: information on auclear waste management in gezeral and on the Centre de l'Aube site in particular. The site itself may be visited by the public upon reques:.

\section{Project Milestones}

Numerous technical, adminisirative and licensing activities occurred between the time the decision was made, in Iune 1984, to construct a new near-su-face disposal facility to the delivery of the first container of waste to the Centre de l'Aube at the beginning of 1992. The principal milestones are given below:

- October 1984 to June 1985 : site screeaing and field investigations;

- July 1985 to July 1986: characterization and selection of the Aube site;

- February 1987: approval of the Preliminary Safery Analysis Report for the Aube site by the auclear regulatory authorities;

- July 1987: following public bearings, signature of the Declaration of Public Utility by the Governmeat, paving the way for acquisition of the site by ANDRA;

- August 1987: issuance of a site clearing permit by the Ministry of Agriculture, and ANDRA purcinase of 96 bectares of land to plant trees equivalent to those felled at the site;

- October 1988: issuance of the construction permit for the disposal facility;

- January 1989: issuance of the construction permit for the rail terminal 15 kilometers from the site;

- September 1989: issuance of the Authorization for Creation of a Basic Nuclear Facility;

- July 1991: approval of the Interim Safery Analysis Report by the ouciear regulatory authorities;

- October 1991: approval to operate the facility by the Ministry of Industry and the Ministry of the Environment;

- December 24, 1991: issuance of the operating permit;

- January 13, 1992: first waste package is delivered to the Centre de l'Aube.

\section{Description of Centre de l'Aube Operations}

The operations conducted at the Centre de l'Aube relate primarily to either waste disposal or waste treatment. Both activities are described in the following sections.

\section{WASTE DISPOSAI}

The Centre de l'A ube disposal faciity must perform three basic functions: 1) waste isolation, 2) verify waste acceptability, and 3) protect operating personnel from radiation exposure.

\section{Waste Isolation}

The design of the disposal facility must isolate the waste from the environment and maintain the integrity 
of the waste package by protecting the latter from water, winich could drmage the package and cause radionuclide migration. To this end, the first precaution to take is to construct the facility above the highest historic level of the water table. Protection from surface water is provided during the operating period by a moveable building that covers disposal vaults when they are being loaded with waste, and by a conerete roof impregnated with impermeable polyurethane after the vault is filled and the moveable building is removed. Ultimately, the disposal wits are protected by a multiple layer disposal cap.

\section{Waste Acceptabilicy}

Waste is tracked from the moment it is generated and throughout the waste management cycle. Waste solidiffeation operations are largely automated and incorporate scanning of waste packages and transmission of relevant data to ANDRA's centralized computer tracking system. The computer accepts or rejects waste packages based on their conformance to pre- determined waste acceptance criteria before the waste even leaves the production site. The computerized waste tracking system is integrated into automated waste handling operations at the disposal site, and can interrupt bandling operations of a specific package if it does not comply with the waste acceptance criteria.

\section{Personnel Protection}

The design basis dose rate for the Centre de l'Aube is one tenth of the dose rate authorized for personnel is nuclear faciilities by French regulations, i.e., $5 \mathrm{mSv}$ per year, which is the dose rate allowed by regulations for members of the public.

\section{Engineered Disposal Structures}

The disposal structures at the Centre de l'Aube consist of a concrete vault measuring 8 meters bigh and approximately 20 by 20 meters on each side. Overpacked waste packages may be piled on top of each other inside the vault, in which case the vault is backfilled with gravel. When waste is not overpacked, it is placed in the vault a layer at a time and stabilized by a concrete pour, which serves as the pad for the next layer of waste packages. Once the vault has been completely filled, it is sealed with a concrete slab and sprayed with polyurethane to waterproof the top and sides of the vault. The slab and polyurethane coating constirute a temporary cover for the disposal vault.

Handling operations are performed inside a 16 meter high moveable metal building which covers one and a half disposal vaults at a time: the disposal vault receiving waste is completely covered, and half of the next vault is covered to sheiter waste delivery and unloading operations. The move. able building shelters waste from rain during handling operations, but also, and more importantly, prevents rainwater from entering the disposal structures.

The waste bandling erane moves along rails that are integral to the moveable building. The cab for the operator is stationary at the top of the building when large quantities or bigher activiry waste are bandied. The operator is protected from the radiation emanating from the disposed waste by the concrete walls of the disposal vaults, and by shielding windows in the cab.

Waste bandling operations at the Centre de l'Aube are largely automated to better manage their traesfer into their proper place in the disposal system. The identification codes of individual waste packages, and relevant data on each waste package, are entered into ANDRA's computerized tracking system prior to disposal. The packages are categorized according to waste form and the disposal method that corresponds to that waste form. When the waste is delivered to the disposal vault, the operator bas only to lif the waste package up to a robotic device, which takes control of the remaining bandling operations. The robot rotates the waste package in from of a bar code scanner, which transmits the data to the computerized tracking system. The computer compares the data from the waste package to the acceptance criteria for that particular package, and authorizes the robot to proceed with bandling operations if the waste is in compliance. The waste package is automatically placed in its pre-determined location inside the disposal vault by the robot, which records the location in the central computer system.

\section{Layout and Operation of the Disposal Facility}

The decision to bandle waste packages inside moveable buiddings led to a grid-type site layout in which there are parallel rows of disposal vaults about 25 meters apart. The Centre de l'Aube can have as many as 420 disposal vaults with a combined capacity of one million cubic meters of waste packages.

Operations are conducted row by row, with waste filling operations beginning with the farthest disposal vault, and gradually working towards the end of the row closest to the central service corridor. One side of the disposal vaults is therefore left unfinished to allow passage of waste delivery trucks to the disposal vault in operation.

Once a row of vaults is full, the 270 metric ton moveable building is moved onto the central service corridor in order to change rows. This is accomplished by the adjustable wheel assemblies at the foot of the building.

Berween 8 and 12 disposal vaults will be filled anoually, which means that the Centre de l'Aube will always have disposal vaults under construction during the operating period.

Once an entire disposal area has been filled, construction will begin on the final disposal cap. The design of the disposal cap for the Centre de l'Aube will probably be similar to the one for the Centre de la Manche.

\section{WASTE IMMOBILIZATION}

The Centre de l'Aube has two waste solidification units in the Waste Treatment Building, a grout injection unit for waste arriving in metal boxes, and a compaction and grouting unit for drummed waste. The facility will replace similar units at the Centre de la Manche. The purpose of the solidification units is to reduce waste transportation costs, and to offer a service to waste generators not wishing to invest in the construction of similar units at their own production sites. 


\section{Box Grouting Unit}

The grout injection station receives 5 and $10 \mathrm{~m}^{3}$ metal boxes which contain large-size or odd-size waste, and injects. them with grout. The unit includes:

- an unloading bay and drying station with a $350 \mathrm{kN}$ handling crane;

- a cart to transfer the boxes into the grouting cell through a gate; and

- grour injection equipment.

\section{Drum Compaction Unit}

Metal drums with $200 \mathrm{~L}$ capacity are compacted, and the pucks are placed inside $400 \mathrm{~L}$ drums. The compaction unit consists of:

- two truck unloading bays with bandling cranes;

- soller conveyors that transfer the drums to a 450 drum storage magazine, where drums are automatically stored;

- a 1000 ton compactor for $200 \mathrm{~L}$ drums;

- grout injection equipmeat for the $400 \mathrm{~L}$ drum overpacks; and

- a curing station with a bandling crane.

\section{CENTRE DE L'AUBE PROJECT COSTS}

\section{Capital Costs}

The total cost of the Centre de l'Aube project is 1.3 billion French francs, or approximately $\$ 550$ million. This figure includes all project-related expenses from the beginning of the site selection program in 1983 to the start-up of the disposal vaults in January 1992, the start-up of the box grouting unit in mid 1992, and the start-up of the drum compaction unit in late 1992. These costs are broken down as follows:

- 8\%: site sereening, field investigations and characterization;

- 20\%: project maragement, engineering and design studies;

- 43\%: construction of the site, access road, and rail terminal;

- 13\%: construction of the Waste Treatment Building, and

- 16\%: licensing, including safery analysis reports; ANDRA overhead; public information; and taxes.

The facility was financed by the waste generators. Each generator's share of the financing was based on forecasts of waste volumes to be delivered to the site from its start-up to the end of the operating period.

\section{Operating Costs}

Based on annual waste deliveries of $30,000 \mathrm{~m}^{3}$, operating costs of the Centre de l'Aube are estimated at approximately 200 million French francs, or $\$ 35$ million per year.

If vault construction costs, operating costs and disposal cap construction costs were to be lumped together, the average disposal cost would be approximately 8,000 French francs per $\mathrm{m}^{3}$ for a facility with a capaciry of one million $\mathrm{m}^{3}$.

\section{ENVIRONMENTAL MONITORING}

The fundamental principle behind near-surface disposal is to protect the environment from radionuclice migration. The environmental monitoring program, iocluding the taking of samples on and around the disposal site, designed to verify the integrity of the waste isolation system, is an important part of ANDRA's responsibilicies. The site monitoring program is itself monitored by the Central Departmeat of Radiation Protection (Service Central de Protection contre les Rayonnements lonisants- .SCPRI), which also performs its own monitoring activities on and near the site.

Initial site conditions were first measured to establish the reference sile parameters. The reference site parameters and the results of sampling and analysis campaigns are available to the public and to the Local Information Commission.

The disposal facility is inspected throughout the operating and institutional control period by government inspectors from the Departmeat of Nuclear Facility Safety, the Regional Departments of Industry, Research and the Environmeat, and the Central Department of Raciation Protecion to verify compliance with safety regulations. Information is provided to the public concerning inspection activities and results.

Environmental monitoring is the mosi effective means of verifying that the facility is pe-forming according to design. Samples of air, wate:, rive: sedimest, vegetation, milk, etc., are taken at regular intervals--daily, weekly, montbly, quarterly or sezi- annually-and analyzed as part of the ezvironmental monitoring program. Some 1,500 samples were analyzed to establish the reference site parameters prior to the start-up of the Centre de l'Aube facility.

\section{PUBLIC INFORMATION.}

Nuclear facility siting, especially a facility designed to dispose of radioactive waste, with all the negative connotations that it carries with it, isn't exactly received with enthusiasm by the public. Early on, a major public information program on radioactive waste aimed not only at the public, but at politicians, civil seriants and professional associations was initiated early on and pursued during all phases of the creation of the Centre de l'Aube disposal facility. A policy of openness was adopted from the very beginning by ANDRA.

A Local Information Commission, made up of politicians, including Pariiamentary representatives, mayors, and county administrators, of the media and of professional associations was established in July 1985. A.NDRA's headquarters and regional staffs participated in over 200 public information meetings to open up the channels of communication and to respond to the concerns of the inhabitants of the entire region.

Radioactive waste management is a long-term commitment, and the Centre de l'Aube project was conducted in that vein. For example, instead of simply compensating local communities financially for the loss of forest land ANDR $t$ purchased land equivaient in surface area to the site and planted it with trees.

The Centre de l'Aube has become a veritable local antraction, with more than 6,000 visitors per year.

\section{CONCLUSION}

The first containers of low-level, short-lived waste were delivered to the Centre de l'Aube on January 13, 1992. This 
event was, for ANDRA, the crowning achievement of seven years of hard work and constant communication with the licensing authorities and with the public, from site characterization through facility construction; seven years of getting to know and working with the local communities. It is a commit- ment that binds ANDRA to the community and to the environment for many years to come. For, above all, radioactive waste management is a commitment to protecting the environment and preserving it for posterity, and we have given our best to the Centre de l'Aube to make that a reality. 


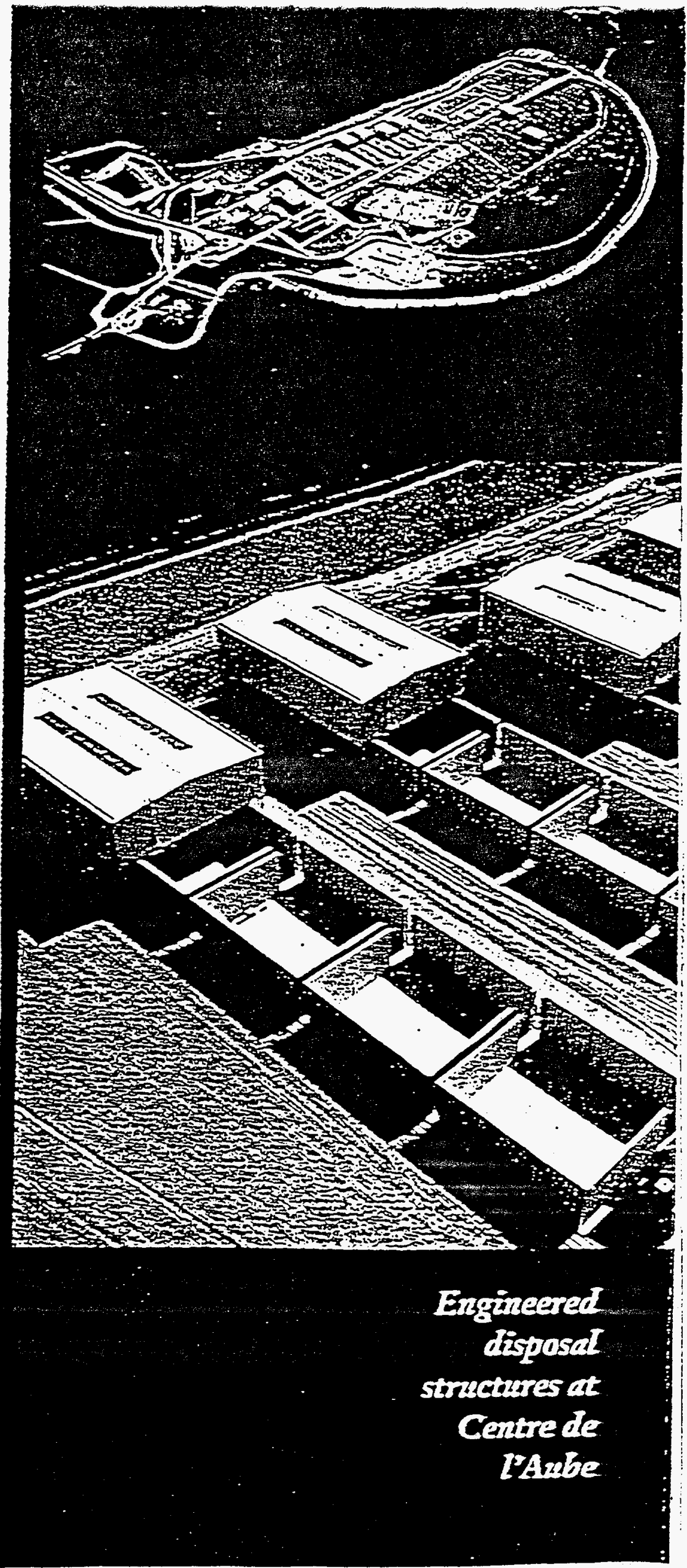

Revision 0 


\title{
FINAI CLOSURE OF THE CENTRE DE LA MANCHE \\ RADIOACTIVE WASTE DISPOSAL FACILITY
}

\author{
Philippe Convert \\ ANDRA \\ BP38 \\ 92266 Fontenay-aux-Roses Cedex \\ France
}

\begin{abstract}
Closure of a near-surface disposal facility, constituting the transition from the operating period to the institutional control period, involves the placement of a cap over the entire disposal area at the end of the operating period.

Three basic design criteria where adopted for the disposal cap. Impermeability, reliability, and protection. To meet these criteria, the design concept calls for the use of multiple layers totalling approximately 4 meters. The disposal facility will be monitored throughout the institutional control period. The long term monitoring program will be based on the existing program for the operating facility and will include special provisions for the cap itself.
\end{abstract}

\section{INTRODUCTION}

The primary performance objective of the radioactive waste disposal facility is to protect the public as well as the environment from potential releases of radioactive materials. To meet this objective, the disposal facility design must effectively isolate the waste. For near-surface disposal facilities, the final cap placed over the disposal units is an important part of the waste isolation system.

The Agence Nationale pour la Gestion des Dechets Radioactifs (ANDRA) has operated the Centre de La Manche Low-Level Radioactive Waste Disposal Facility since 1979. The facility is located near Cherbourg in northwestern France, next to the La Hague reprocessing plant operated by Cogema. The facility receives only short-lived, low- and medium-level radioactive waste. The Centre de la Manche is full, and a new waste disposal facility is under construction in the Aube department, with operations scheduled to begin in early 1992. In addition to this major new project, Andra is arranging for final closure of the Centre de la Manche facility.

Closure of a near-surface disposal facility, constituting the transition from the operating period to the institutional control period, involves the placement of a cap over the entire disposal area at the end of the operating period. Closure activities at the Centre de la Manche disposal facility will be conducted from 1990 to 1995 , with the end of the operating period scheduled for 1994. The duration of the institutional control period is presently set at 300 years.

At the Ceatre de la Manche disposal facility, the waste packages are placed inside engineered structures called "monoliths" or "tumuli". Collection systems for infiltrated water are located at the base of each disposal unit; the systems are connected to an underground network of galleries which drain into a sampling station to the northwest of the site. After sampling and analysis, the water is sent to Cogema's effluent treatment station for processing. The water collection systems are not a part of the disposal cap project and are not discussed in this paper.

\section{DESIGN CRITERIA FOR THE FINAL DISPOSAI CAP}

Requiremeats for radioactive waste isolacion imply three main design criteria for the disposal facility's final cap.

\section{Impermeability Criterion}

The amount of rainwater penetrating the cap and coming into contact with waste must be extremely low to prevent radionuclide leaching and subsequent migration.

\section{Reliability Criterion}

The cap must be impermeable for the duration of the institutional control period. The materials of construction must be selected for their contribution to long-term reliability.

\section{Protection Criterion}

In addition to resisting water infiltration, the cap must resist external forces suct as erosion, freeze-thaw cycles, water chemistry and living organisms. The disposal cap must be sufficiently thick and made of appropriate materials to protect the disposal units from such external forces.

\section{DESCRIPTION OF THE FINAL DISPOSAL CAP}

The final disposal cap at the Centre de la Manche will be constructed in two phases. Phase 1 will be completed in three successive operations seheduled for the 1991 to 1995 time frame. Phase 2 will involve placement of an impermeable laye: made up of natural materials over the preliminary disposal cap. Phase 2 will begin only after any settling of the Phase 1 cap bas ceased, which may take several decades. In the interim, observation of the Phase I cap may lead to changes in the Phase 2 cap design.

Externally, the disposal cap will look like a roof rade of sloped panels. The largest panel will measure $140 \times 25$ meters. The distance between both lower edges of the roof will be 50 meters. The panels on the outer edge of the disposal unit will be at the same elevation as the top of the waste packages. From the disposal units to the site boundaries, the cap will slope af a 2.3-to-1 incline until it reaches the perimeter road, and at a 1.5-to-1 incline below the road. 
Multiple-Layer Design Concept

The multiple layers of the disposal cap (Fig. 1), starting from the base of the cap, will be as follows:

- a bottom layer of schist will create the basic slope of the disposal cap, and provide a thick barrier between the waste and the cap;

- a drainage layer made of fine-grain sand will derect the presence of water beseath the bituminous geomembrane;

- a bituminous geomembrane made of a bitumen-saiurated geotexile;

- a drainage layer made of fine-grain sand will de:eet the presence of water beneath the impermeable layer of natural materials (Phase 2 only);

- an impermeable layer made of natural materials (Pbase 2 only);

- a drainage laye: made of fine-grain sand and local gravel will collect water that penetrates the schist of the biological barrier;

- a semi-impermeabie layer of schist will minimize the amount of water that reaches the geomembrane and constitute a biological barrier for the membrane against root sysiems and burrowing animals; and

- a layer of topsoil to promote grass growth.

The multiple-barrier system will extend to the perimeter road on all sides of the site.

\section{Water Collection System for the Covered Zone}

General: Water recovered from the cap will be collected in networks surrounding the site. Surface water will be separated from infiltration water by:

- a system of large pipes for surface water located immediately below the perimeter road; and

- a system of smaller pipes for infiltration water drained from the cap.

Surface Water: Surface water will be collected at the bottom of each curved roof panel. At the end of each double roof panel, the water will be drained off in rainwater changels located at the edge of the disposal cap where it meets the road. The channels will draw off surface water both from the roof and from the slope above the road by a gutter that runs the length of the perimeter road into a $1000 \mathrm{~mm}$ drain pipe which receives all surface water.

Infiltration Water: Two drainage systems above and beneath the bituminous geomembrane will collect all infilutution water.

\section{- Upper Drainage System}

The upper drainage system will consist of a layer of sand and local gravel in which a drain is placed.

\section{- Lower Drainage Syster}

The lower drainage system will consist of a layer of sand and two drains. This system will allow each half-pane! section of the cap to be isolated, which belps to locate the source of a failure of the impermeable layer signaled by abnormally high levels of drainage water. An identical drainage system will be installed between the clay layer and the bituminous geomembrane during Phase 2 operations.
Basic Design Phase I

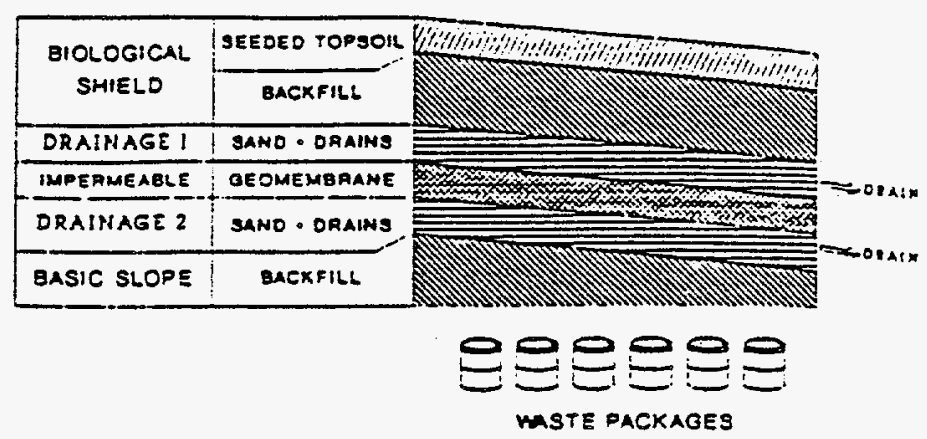

Basic Desigo Pase II

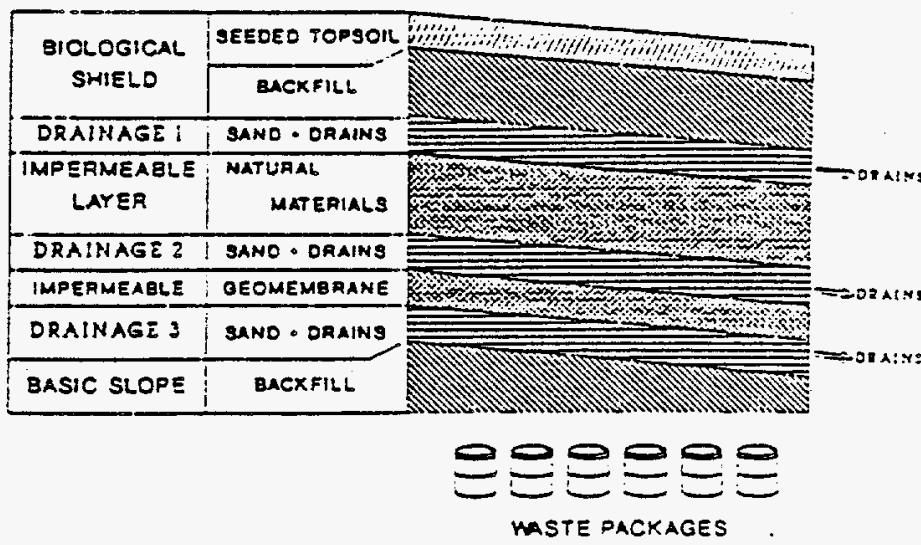

Fig. 1. The Ceatre de la Manche disposal facility final cap.

- Drainage Surrounding the Covered Zone

The bituminous membrane will be curved upwards at the perimeter of the covered zone to form a watertight gutter; a drain pipe will be placed in the gutter and the gutter will be filled with gravel. A secondary bituminous memorane located underneath the gutter will collect water from the lower sand layer.

At each of the roof's gutters, the drains will be connected to monitoring stations located along the side of the perimeter road. All monitoring stations will be connecred by one main drain pipe.

Monitoring Stations: The two surface water collection systems, one on the east side of the final disposal cap and one on the west side, drain nortbwest into the main monitoring station where there are low-meters, a collecting basin, radioactivity monitoring equipment, and $\mathrm{pH}$ measurement equipment. The monitoring station is connected to a storm basin that regulates the flow of water downstream to the Ste. Héléne stream.

The two drainage water collection systems, also to the east and west of the final disposal cap, will drain northwest into the drainage monitoring station equipped with a flowmeter and connected to the main monitoring station.

Rainwate: from the southern part of the site, where administrative services and the public information building are located, and from the road that parallels the Cogema fence, drains into a gutter connected to a monitoring station for site operations equipped with a flow-meter. This monitoring station will be connected to the main monitoring station at the end of the operating period. 
The flowrate of rainwater from the firal disposal cap will be determined by taking the difference between the flowrates measured in the main monitoring station and the sum of the flowrates from the drainage and operations monitoring stalions.

\section{Miscellaneous}

A four-meter-wide road around the perimeter of the site will be constructed to facilitate site monitoring and maintenance.

The eatire cap will be covered with a layer of topsoil and seeded, and shrubs will be planted on the lower slopes just below the site boundary to minimize maintenance of that area. These measures will enhance the environment while providing maximum security for the site.

\section{Civil Engineering}

Retaining Walls: Because the site bas a very small surface area, retaining walls with a maximum beight of 5.5 meters on the north side and 3.5 meters on the east will be needed. The retaining walls will be beavy, reinforced-concrete structures with shallow foundations built in weathered sandstone. The walls will be relatively thick and therefore will have a minimum amount of rebar.

For esthetic reasons, the lower part of the walls will be covered by a band of masonry. The masonry will extend over a low wall between the north and east walls; an identical wall is planned for the south end of the east wall.

Basin Reinforcement: In the final phase, the reinforcedconcrete basins of the underground collection system in the nortbwest part of the site will be covered by the final disposal cap. The present structure will be covered by a reinforcedconcrete support structure designed to withstand the vertical load of the backfill. The reinforced structure will consist of a reinforced-concrete slab supported by reinforced-concrete pillars and walls.

The cleared area above the existing roof of the basins will permit access to the basins and to the galleries of the north and west underground water collection systems for future maintenance operations.

\section{PLACEMENT OF THE DISPOSAL CAP}

Because of the stringent requirements for long-term reliabiiity, the bighest level of quality must be sought, both for the materials of construction, and for their emplacement. A quality assurance program has been established for the entire project to ensure that the required level of quaiity is achieved and maintained at all times.

\section{Materials Preparation}

Construction materials for which standards exist must conform to those standards. In the absence of specific standards, detailed technical specifications will be developed. All materials must undergo both suitabiity tests before use and quality control checks during use.

The schist in the backfill will be made up from stockpiles at the site or in its vicinity, and will be sorted to eliminate over-sized pieces. Other materials and prefabricated concrete components will come directly from the quarry or from prequalified mills and plants.
Materials bandling during delivery and storage must ensure that the quality of the materials is maintained from fabrication through utilization.

\section{Civil Engineering}

Construction of the retaining walls on the east and north of the site will involve site grading, rebar mat placement concrete formworks, and concrete pouring. After the forms bave been removed from the retaining walls, site drainage systems will be constructed and filled with gravel.

The protective support structure over the basins will be built in the same way as the retaining walls, although prefabricated concrete will be used to work around the existing basins. After the concrete foundation and the main walls bave been poured, prefabricated pillars and beams will be erected. A reinforced-concrete slab will be poured on top of the beams to stabilize the entire unit, and a waterproof covering will be placed over the slab.

The water collection and monitoring systems (checipoints and monitoring stations) will be constructed with prefabricated concrete as much as possible, while the foundations and larger pieces will be poured directly in place.

\section{Grading}

Several operations will be involved in site grading

Preparation of Graded Base and Bottom Laver

The central part of the tumulus will be graded to within a specified layer of schist from the existing temporary cover. A 2-to-1 slope will be graded at the perimeter of the disposal units, with the minimum distance of 0.50 meters to the waste packages being maintained at all times.

After grading has been completed, and the base compacted if necessary, the perimeter road will be constructed. The road bed will act as a boundary for the base layer embankment. As the embankment is built up, the base layer for the roof can be prepared with layers of compacted schist. The materials will be regularly analyzed to determine their in situ characteristics.

Sand. Gravel. and Drainage Pipes

After completion of the base layer, which will be leveled off at right angles to each trough at the top of the dam between gutters, the following activities will be conducted:

- the gutters will be dug;

- the reinforcing membrane and its geotextile covering will be laid;

- the lower drains will be laid;

- the lower layer of sand will be put in place and compacted;

- the geomembrane and its reinforcerent will be put in piace;

- the upper layer of sand will be put in place and compacted;

- the drainage ditch will be dug;

- the upper drainage layer will be put in place;

- the gravel layer will be put in place and compacted; and

- the geotextile will be put in place at the bottom. 
Quality control will focus primarily on size grading of the sand and gravel.

\section{The Bituminous Geomembrape}

The geomembrane for the gutters will be positioned the length of the gutters, running east-west or west-east.

The principal geomembrane of the cap will be positioned north- to-south in line with the steepest incline of the slopes. The geomembrane's reinforcement will be placed in the same direction as the geomembrane below the gutters.

The slope's geomembranes will be put in place first, and will be left unattacbed at the top of the siope. The roof geomembranes will be laid over the slope geomembranes, and will not be joined until the embankments around the perimeter of the site are finished.

Quality control will be performed on membrane placement operations, including checks of the condition of the geomembrane or the overlap of the edges. Joints will be inspected by ultrasound or by a vacuum box for individual spots.

\section{Drainage Pipes}

Drainage pipes will be inspected for conformance at the plant, especially for the size of drain slits. On-site leak tests of the joints are not planned, as the pipes in question are drairage pipes.

\section{Schist in the Biological Barrier}

Except for the first layer of schist in contact with the drainage layers, no particular specifications for schist grade size exist for the biological barrier. Large chunks of schist may actually discourage burrowing animals.

The schist will be laid and compacted in layers. Sand will be added to the top layer to promote evapo-transpiration. All but the top layer will be compacted in the same manner as the base layers of schist; the top layer will be packed more lightly to facilitate root growtb of surface vegetation.

Quality control of the schist layer will be identical to quality control of the base layer.

\section{Topsoil}

The only special instruction for placement of topsoil is that it need not be packed down. To limit erosion during the first planting montbs, a mixture of rapid-growth and slow-growth seeds is recommended.

\section{Markings for Photogrammetry}

Markings will be laid so that surface movements of the cap, such as subsidence, can be detected by aerial pbotogrammetry.

\section{CAP MONITORING INSTRUMENTATION}

The final disposal cap will be instrumented to monitor overall cap performance, to detect leaks or potential leaks, and to acquire data useful in constructing furure cap sections.

\section{Topographical Monitoring}

Ground movements caused by subsidence of waste packages are anticipated in the older, northern part of the site. The type and magnitude of ground movements could lead to deterioration of the cap's impermeability and should therefore be constantly monitored.

Markings will be placed on the cap in a grid formation so that ground movements can be detected by aerial photogram. metry. Aerial photographs will be taken frequently enough and filed so as to constitute a chronological record of groued movements. On-site topographical measurements and visual inspections of the surface condition of the cap will also be performed. The topographical data car be anajyzed to detect any high-risk areas.

\section{Hydraulic Monitoring}

The monitoring stations will be equipped with flowrate meters for surface water and infiltration water, both above and below the geomembrane.

The data acquired from the flowmeters will provide an indication of the performance of the upper layers with respect to run-off water, infiltration water, and evapo-transpiration. The first cap section to be constructed in Phase 1 will be instrumented to monitor interstitial pressures to verify the site water flow model. The monitoring device below the geomembrane will serve as a "first alert" in the event of cap failure.

\section{Drainage Beneath the Disposal Units}

The water collected in the underground water collection system will be monitored throughout the institutional control period. Flowrate and activity levels, as well as detaijed records on the waste disposal in the units, will provide a total picture of the performance of the cap in combination with the otber data acquired in the site monitoring program. 
WHC-SD-W378-ES-001

Revision 0
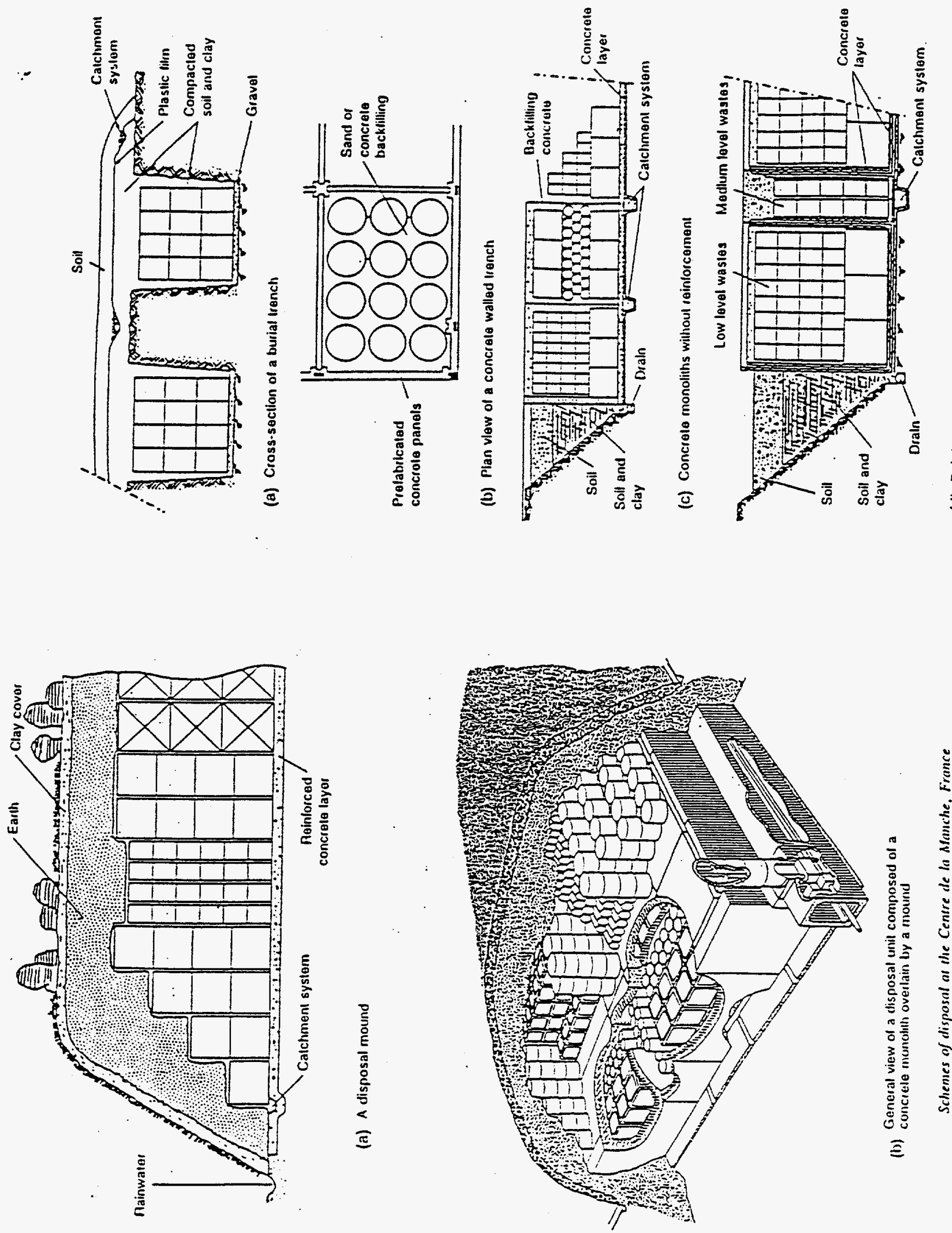

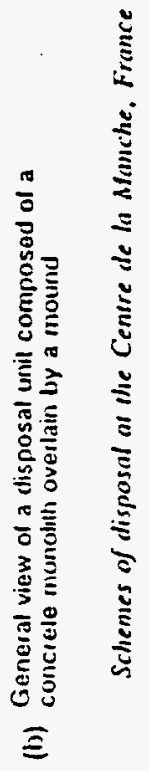




\title{
PELLETIZING MIETHOD FOR CONCENTRATED WASTES GENERATED FROM FUEL REPROCESSING PLANTS
}

\author{
Masumitsu Tovohara, Hiroyuki Matsuura, Yasuyuki Nakayama \\ Nippon Aromic Industry Group (NAIG) Co., Ltd. \\ 4-1, Ukistima-cyo, Kawasaki-ku, \\ Kawasaki-shi, 210 JAPAN \\ Mikio Wada \\ Toshiba Corporation \\ 8, Shinsugita-cyo, Isogo-ku, \\ Yokobama-shi, 235 JAPAN \\ Takao Sugino \\ Toshiba Ceramics Co., Lid. \\ 1, Ogakie-cyo, Kariya-shi, 448 JAPAN
}

\begin{abstract}
A pelletized form of the radioactive wastes is considered to be the most suitable for the interim storage of radioactive wastes in Japan. The simulated concentrated wastes from the reprocessing plant were dried and pelletized under uniaxial pressure using the binder of the inorganic constitueats which was prepared for this pelletizing treatmeat. The binder incorporated the dried powder of the concentrated wastes into a stable pellet block with the condensation polymerization of the colloidal-silica constituent and hydration of the cement constituent. The properties of the pellets were investigated from the viewpoint of the safety during the interim storage. The measurements of their mechanical and thermal properties, and the durability test under the gamma ray irradiation were carried out and the sufficient properties of pellets for the safe interim storage were confirmed.
\end{abstract}

\section{INTRODUCTION}

The low and intermediate level concentrated wastes erated from fuel reprocessing plants contain alpha, beta I gamma nuclides. The alpha nuciides are biologically ardous in comparison with the other nuclides. So the disal of these wastes should be strictly regulated.

In Japar, the regulations for disposal of these wastes e not been prepared. These contaminated wastes are, refore, to be stored at the storage facilities in the rocessing plants for the interim period until the regulais are prepared and the site of final disposal is estabıed. The most suitable form of these storage wastes is isidered to be pellets and the pelletizing system are nned to be developed.

The requirements for the pellets are as follows:

1. The small volume of radioactive waste.

2. No dispersion of radioactivities to the environment during the interim storage.

3. The flexibility of the various packaged forms satisfying the final disposal conditions.

We developed the inorganic binder for pelletizing these stes and made it possible to produce stable pellets. By : of a binder, pellets are expected to be improved on their perties such as the mechanical strength, the containment radioactivities and the durability under various condins. Pellets produced in this process are also expected to be packaged in a drum or a canister with such agents as cement grout for the finai cisposal.

The properties of the pellets obrained in this experiment are report here.

\section{INORGANIC BINDER}

The inorganic binder shown in Table I consists of solution and powder. The solution whose main component is colloidal silica makes the binder adhesive. The powder mainly consisting of cements initiates and promotes the reaction in the binder. The reaction begins by nixing both components of the solution and the powder. The reaction of this binder is schematically presented in Fig. 1. Colloidal silica is condensed to become an inorganic polymer. The particles of powdered wastes adhere with the polymer. The water, which is introduced with the solution of binder and formed in the condensation reaction of colloidal silica, is absorbed into cements in powder with the hydration reaction.

\section{EXPERIMENTAL}

The flow diagram of the drving and pelletizing process are shown in Fig. 2. The concentrated liquid wastes were dried into powder with the vertical wiped film dryer. The contents of the simulated concentrated wastes are shown in Table II. The concentrared liquid wastes mainly consist of $\mathrm{NaNO}_{3}$ and $\mathrm{Na}_{2} \mathrm{CO}_{3}$. $\mathrm{NaNO}$; comes from $\mathrm{HNO}_{3}$ neutraliz: ing with $\mathrm{NaOH}$ and $\mathrm{Na}_{2} \mathrm{CO}_{3}$ comes from the

solvent recovery process in reprocessing plants. Wie prepared five different samples of simulated concentrated 


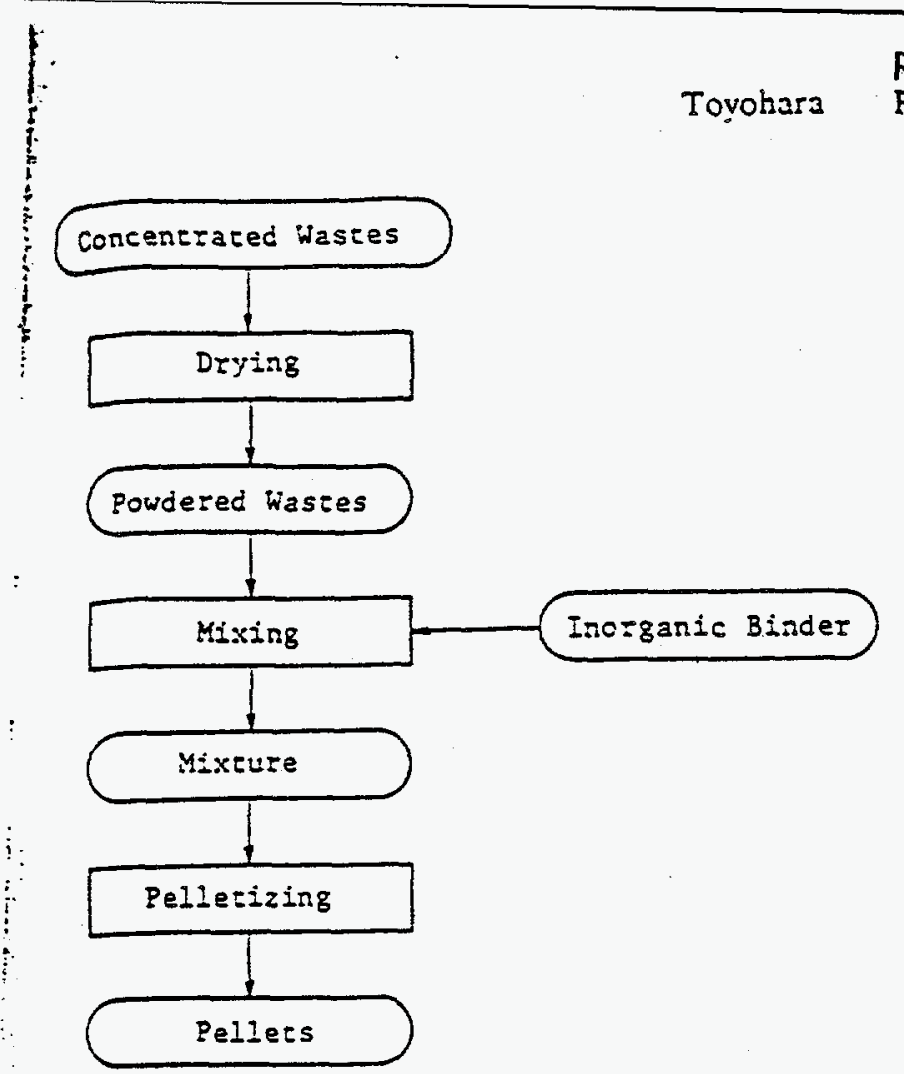

Fig. 2. Flow Diagram of Drying and Pelletizing Process.

cohesion. The binder began to polynerize with condensation and adbere to particies in the powder after pelletizing, but reacted relatively slow and it took some time to complete its reaction. This was the reason for the increase of the compressive strength of pellets after the pelletizing. It was found that the condensation reaction of this binder continued after 28 days and it took a long aging time just as it took a long aging time for cement to complete its aging.

The analysis of the pellet witb EPMLA (Electron Probe Micro Analysis) containing the same powdered wastes mentioned above (Run No. 1) is shown in Fig. 4. These photos in this figure were obserred at the same place in the pellet. The secondary electron inage of the pellet is shown in Fig. 4 (a). Characteristic $\mathrm{X}$-ray image of $\mathrm{Na}-\mathrm{K}_{\alpha}$ and $\mathrm{Si}$ $\mathrm{K}_{\alpha}$ are shown in Fig. 4 (b) and (c) respectively. The particles shown in Fig. 4 (a) are presumed to be powdered sodium nitrate, because characteristic $X$-ray of $\mathrm{Na}_{2} \mathrm{~K}_{\alpha}$ shown in Fig. 4 (b) comes from bulks of these particles. On the other hand, in that of $\mathrm{Si}-\mathrm{Kc}$. Si is a main component of binder, and comes from the boundaries of these particles as seen in Fig. 4 (c). From these observations, the binder exists berween the particles of powdered wastes and adheres to them.

The bulk densities and the compressive sirength of pellets are summarized in Table III. The density of the $\mathrm{NaNO}_{3}$ pellets was larger than those of $\mathrm{N}_{2} \mathrm{NO}_{3}-\mathrm{V}_{2} \mathrm{CO}$; pellets. And the densities of these pellets depended on their $\mathrm{Na}_{2} \mathrm{CO}_{3}$ concentration. These pellets were compressed to about $80 \%$ of theoretical density (about $2.4 \mathrm{~g}^{\prime} \mathrm{cm}^{3}$ ) of the mixure. The compressive strength of pe!lets obtained in this

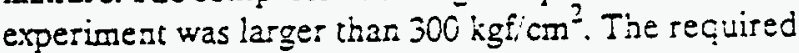
compressive strength of pellets is calculated to be about 0.5 $\mathrm{kgf} / \mathrm{cm}^{2}$ in case of storage in a 200-lite: drum and about 7 $\mathrm{kgf} / \mathrm{cm}^{2}$ in case of storage is the tank whose depth is $10 \mathrm{~m}$

\section{TABLE II}

\section{Contents of Simulated Concentrated Wastes and Properties of Powdered Wastes}

\begin{tabular}{|c|c|c|c|c|c|c|}
\hline & Run No. & 1 & 2 & 3 & 4 & 5 \\
\hline \multirow{3}{*}{$\begin{array}{l}\text { Contents oE } \\
\text { Concentrated } \\
\text { Wastes }\end{array}$} & $\mathrm{NaNO}_{3} \quad$ (wt. \%) & 30 & 29 & 28.5 & 27 & 24 \\
\hline & $\mathrm{Na}_{2} \mathrm{CO}_{3}$ (wt. \%) & - & I & 1.5 & 3 & 6 \\
\hline & Water (wt. \%) & 70 & 70 & 70 & 70 & 70 \\
\hline \multirow{4}{*}{$\begin{array}{l}\text { Properties of } \\
\text { Powiered } \\
\text { Wastes }\end{array}$} & $\begin{array}{l}\text { Appazent Density } \\
\left(g / \mathrm{cm}^{2}\right)\end{array}$ & 0.86 & 0.78 & 0.79 & 0.79 & 0.92 \\
\hline & $\begin{array}{l}\text { Average Size of Powder } \\
\quad(\mathrm{m})\end{array}$ & 35 & 84 & 40 & $4 i$ & $\therefore 0$ \\
\hline & $\begin{array}{l}\text { Angle of Repose } \\
\text { (cegree) }\end{array}$ & 48 & 48 & 45 & 45 & 48 \\
\hline & $\begin{array}{l}\text { Watez Contents } \\
\quad(w i . \%)\end{array}$ & $<0.5$ & $<0.5$ & $<0.5$ & $<0.5$ & $<0.5$ \\
\hline
\end{tabular}

* density; $1.2 \mathrm{~g} / \mathrm{cm}^{3}$ 


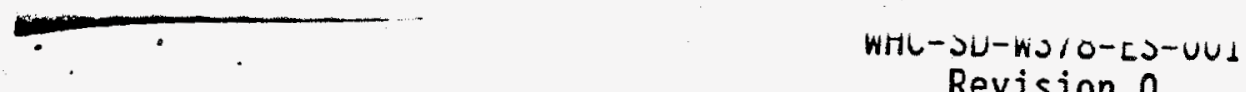

Toyohara

PELLETIZING METHOD FOR CONCENTRATED WASTE

TABLE I

Consitituent of Inorganic Binder and Its Reaction

\begin{tabular}{|l|c|c|c|}
\hline & Form & Main Component & Main Reaction \\
\hline Adhesive & Solution & Colloidal silica & Condensation \\
\hline Accelerator & Powcier & Cement & $\begin{array}{r}\text { Acceleration of Condensation } \\
\text { and } \\
\text { Water Absorption }\end{array}$ \\
\hline
\end{tabular}

wastes because the composition of the concentrated wastes depended on plant operation.

The powdered wastes and inorganic binder were mixed with Henshel's type mixer. The mixture containing $10 \%$ binder by weight was pelletized. The pellet was a cylindrical shape, $30 \mathrm{~mm}$ in diameter and $30 \mathrm{~mm}$ in length.

In order to evaluate the volume and properties of pellets, the bulk density and the compressive strength were measured under non-irradiation and irradiation by ${ }^{60} \mathrm{Co}$ gamma ray and the differentia! thermal analysis (DTA) was also carried out.

\section{RESULTS AVD DISCUSSION}

The relationship between the compressive strength of pellets and the curing time is shown in Fig. 3 . The pellets consisted of inorganic binder and powdered wastes. The composition of the wastes is shown in Table II as Run $\mathrm{N}_{0}$. 1. The compressive strength of pellets increased with curing time until $2 S$ davs and was considered to continue the gradual increase after 28 days. The strength of the peller is considered to come from the cohesion of the powder of itself and the combining strength of the binder due to its adhesiveness. Just after the powder was pressed for pelletizing, the pelletized powder showed the strength due to its

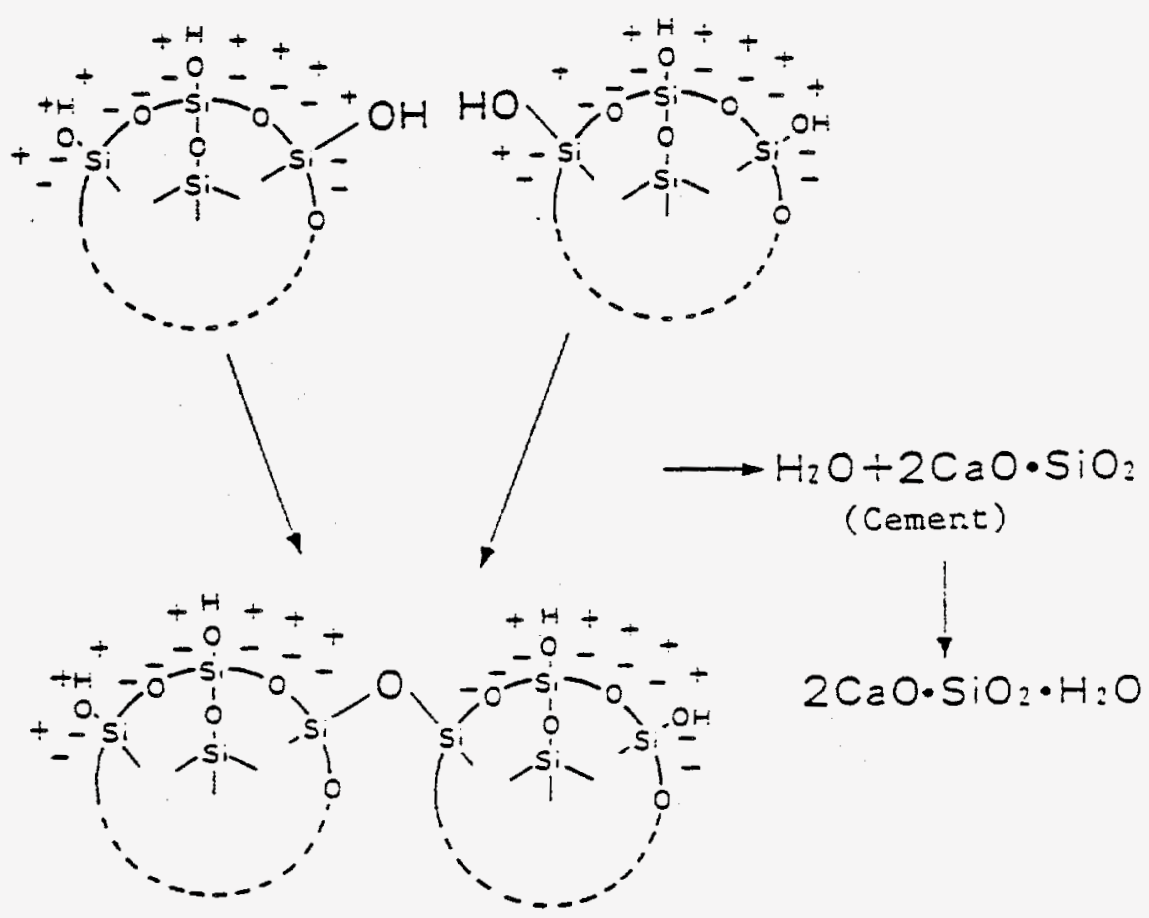

Fig. 1. Condensation Reaction in Inorganic Binder. 


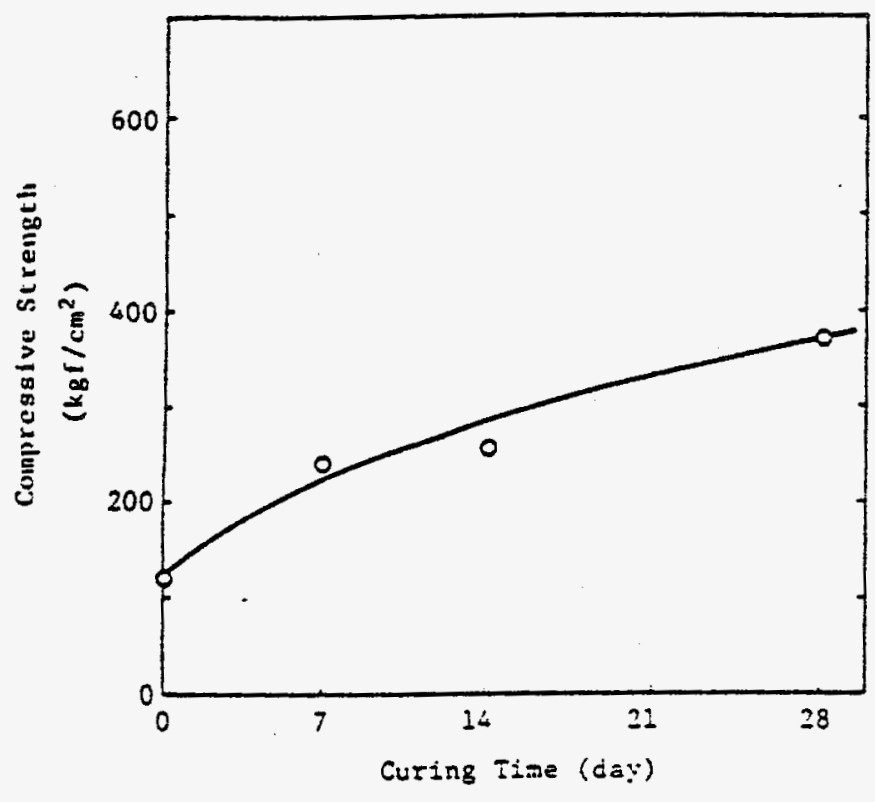

Fig. 3. Relationship Between Compressive Strength of Pellets and Curing Time. respectively. In consequence, these pellets have sufficient compressive strength during storage.

The effect of radiation exposure on the degradation of compressive strength of pellets is shown in Fig. 5 . The pellets from reprocessing plants include radioactivities and are subjected to radiation exposure during the storage period. The cumulative absorbed dose is estimated to be about $10^{\circ}$ sad. The compressive strength did not change as seen in Fig. 5 , even though the absorbed dose was increased up $1010^{3}$ rad. From the above results, we found that the pellets are stable during storage.

The results of DTA are shown in Fig. 6. The curve (A) represents the thermal reaction of pellets including inorganic binder and curve (B) represents that of pure sodium nitrate reagent which is a main component of concentrated wastes. Both curves agree with each other very well. Thus, it was proved that the reaction between inorganic bincer and $\mathrm{NaNO}_{3}$ did not occur in peliet. The solution containing colloidal-silica and powder mainiy consisting of cemenis were therefore adopted as an excellent binder since the organic binder might be oxidized by $\mathrm{NaNO}_{3}$ resulting in combustion.

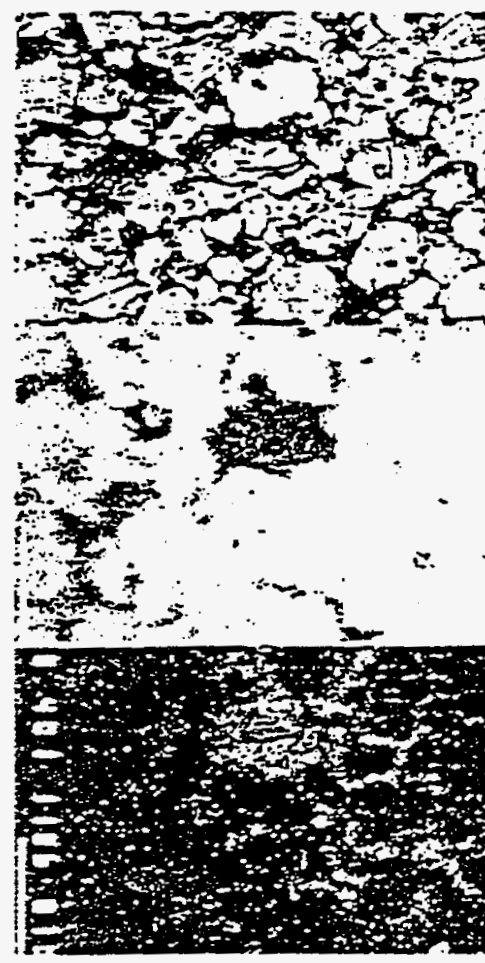

(a) Seconcazy Electron Iaage

100.

(b) Characteristic $x-$ Ray Image of $\mathrm{Na}-\mathrm{ic}$

$\Leftrightarrow$ Chacaczezistic X-Ray Image of 2 i $-\pi i=$

Fig. 4. Aralysis of Pellet with EPMA. 
TABLE III

Properties of Pellets

\begin{tabular}{|c|c|c|c|c|c|}
\hline Run ib. & \$! & 2 & 3 & 4 & 3 \\
\hline Bulk Density $\left(\mathrm{g} / \mathrm{Cm}^{3}\right)$ & 11.99 & 1.91 & 1.38 & 1.87 & 1.86 \\
\hline Combreasive Setergth" & 370 & 485 & 310 & 320 & 493 \\
\hline
\end{tabular}

- After 28 days

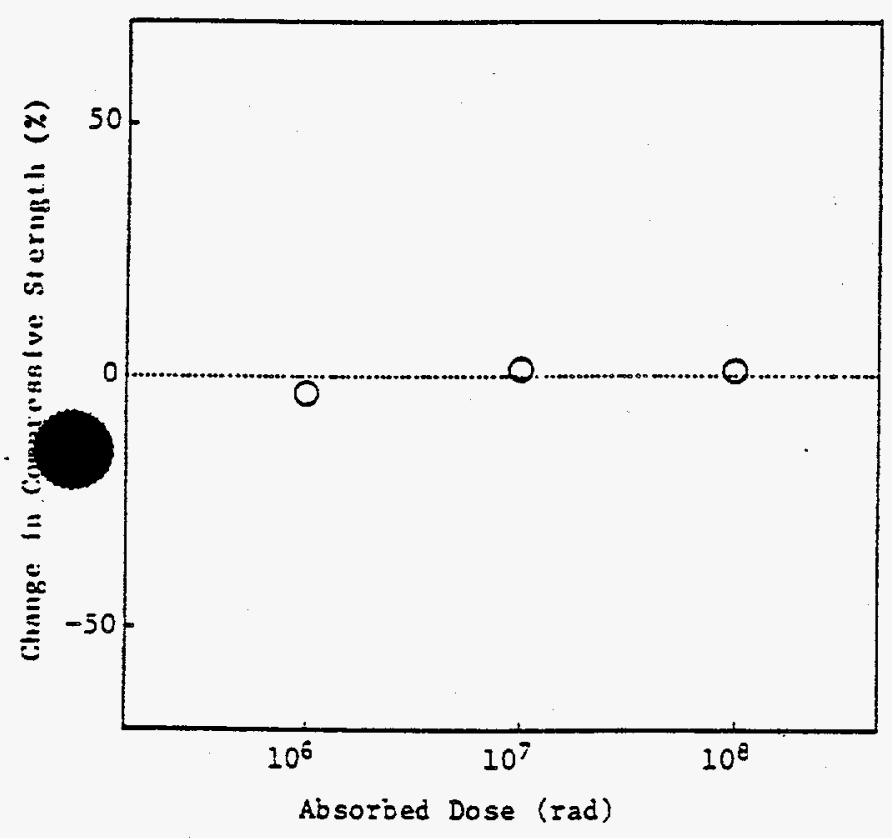

Fig. 5. Effect of Radiation Exposure on Degradation of Eompressive Strength of Pellets (Pellets are irradiated by ${ }^{\sigma}$ Co-gamma ray).

Calculation from density data in this experiment suggested that the large volume reduction of concentrated wastes was attainable by this pelletizing method and its reduction ratio was about one-third of the original.

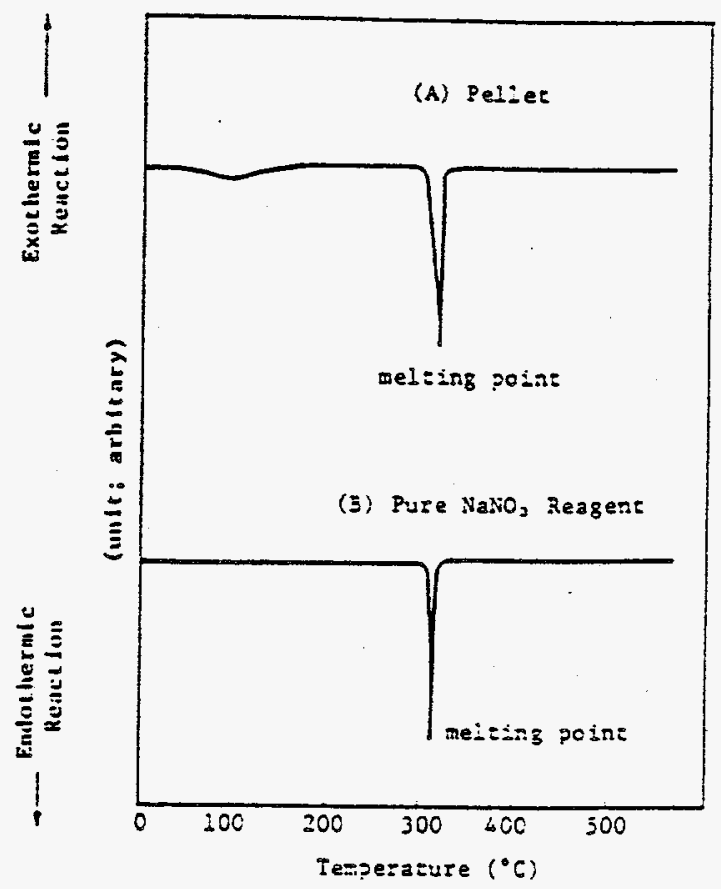

Fig. 6. DTA Curve of Pellet Produced in Run No. 1 and Pure $\mathrm{VaNO}_{3}$

These pellets were encapsulated with cement grout as the disposable homogeneous solid block and its compressive strength was about $80-120 \mathrm{kgf} / \mathrm{cm}^{2}$.

\section{CONCLLSION}

We developed the inorganic binder for pelletizing the concentrated wastes, aiming at the interim storage. This binder was mixed with the powdered wastes and the mixture was pelletized. The properties of these pellets such as the bulk density and the compressive strength under non-irradiation and irradiation by gamma ray were investigated. The differential thermal analysis was also done. From these results, the pellets produced in this experiment have sufficient properties for interim storage. And volume of pellets for storage are reduced about one-third in comparison with the original concentrated wastes. We are planning to develop the pelletizing system for the wastes from fuel reprocessing plants. 


\title{
ADVANCED VOLUME REDUCTION SYSTEM FOR PWR PLANT
}

\author{
Makoto Kikuchi, Koichi Chino, Hiroyuki Tuciaiya, and Takahiro Sanada \\ Hitachi Ltd. \\ Shoichi Sumitani \\ Kansai Electric Power Co.
}

\begin{abstract}
This advanced voiume reduction system provides high volume reduction and long term stability for final waste package, through the following techniques:

- drying and pelletizing conceatrated liquid waste, and incinerating combustible

waste for volume reduction; and

- solidifying with an inorganic agent (cemegt-giass) into an inorganic bigh integrity

for long term stability.
\end{abstract}

The system was installed in the Obi 3 and 4 PWR units of Kansai Electric Power Co.. Good performance has been obtained.

\section{INTRODUCTION}

The fundamental goals in developing radioactive treatmeat systems are:

1. reduction of radioactivity release into the environment;

2. reduction of waste generation;

3. reduction of generated waste volume;

4. stable packaging for final disposal;

5. radiation exposure reduction.

In the case of volume reduction, we developed a technique with regard to achieving a method of final disposal. That is, the developed technique can provide not only efficient, high volume reduction, but also long term stability for the final package of land disposal as outlined in Fig. 1.

- High volure reduction

- Volume reduction by drying and pelletizing waste.

- Decomposition of organic waste such as sludge and resins by incineration into inorganic waste (ash).

- Long term stability of final package

- Decomposition of organic waste by incineration

- Solidification by an inorganic agent (cemeatglass)

- Packaging waste into an inorganic, high integrity container

The drying and pelletizing system was adopted in the first commercial plant in June, 1984. Since then, our experience includes 3 plants in operation and 1 plant under construction. This paper describes the operating results when the advanced volume reduction system was appijed to a PWR plant.

\section{OUTLINE OF ADVANCED VOLUME REDUCTION SYSTEM}

The typical hlow of the advanced volume reduction system is shown in Fig. 2 It consists primarijy of three processes: a drying and pelletizing process $(1,2)$, an incineration process, and a cement-glass solidification process $(3,4)$.

Figure 3 illustrates the drying and pelletizing process. The concentrated liquid waste, whose major component is $\mathrm{Na}_{2} \mathrm{~B}_{4} \mathrm{O}_{7}$, is fed into the upper part of the thin film dryer. The liquid waste forms a thin film on the inner cylindrical surface which is beated by steam from the outside. The liquid film is concentrated as it falls and it is powdered by the rotating biades. The produced dry powder (particle diameter about 10 $\mu \mathrm{m})$ falls through the lower outlet and is stored in the hopper of a tabletting machine. The steam produced is led from the top of the dryer to the condenser and the condensed water is transferred to the concentrator.

This system has capability of inorganic ash generated from an incinerator. In this case, the ash is transferred to the boppe: by a conveyer. There the dried powder and ast are mixed by a screw feeder and pusied into a cylindrical die. The dry waste is compressed by a piston, and cylindrical pellets $(30 \% \times 30 \mathrm{bmm})$ are produced. These pellets are poured into a $200 \mathrm{~L}$ high integrity container. The container is made of polymer impregnated concrete whose mechanical strength has been reinforced by stee! fiber. (5)

Figure 4 illustrates the cement glass solidification system for the pellets. After the measured amount of cement-glass powder and water (water/cement-glass ratio $\fallingdotseq 0.3$ ) are combined in a mixer, the paste is simply poused into the drum containing the pellets. The viscosity of cement-glass paste is $1500 \mathrm{Cp}$ and that of regular cement is about $6000 \mathrm{Cp}$. Because of its low viscosity, cement-glass can fill the gaps between the pellets, and a voidless package is produced without a vibrating device. The mixer is treated as noncontaminated equipmenh, because mixing of radioactive waste pellets and cement-glass paste is unnecessary.

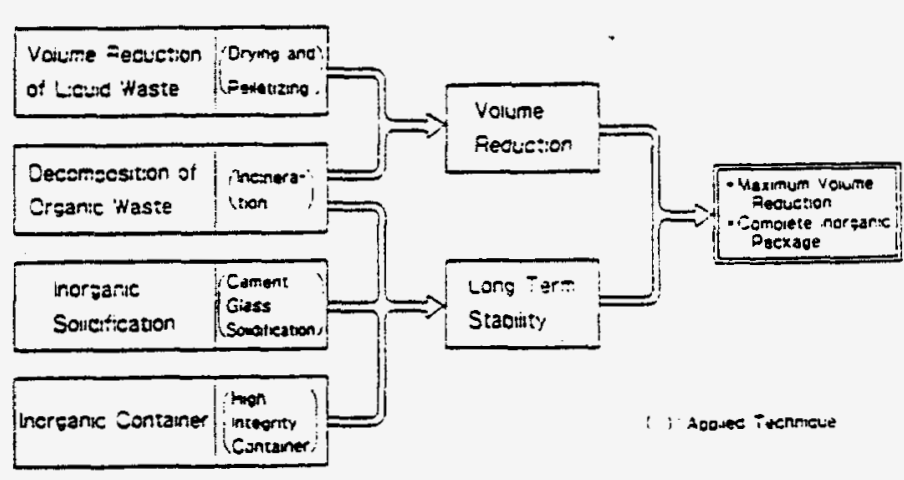

Fig. 1. Feature of advanced volume reduction system. 


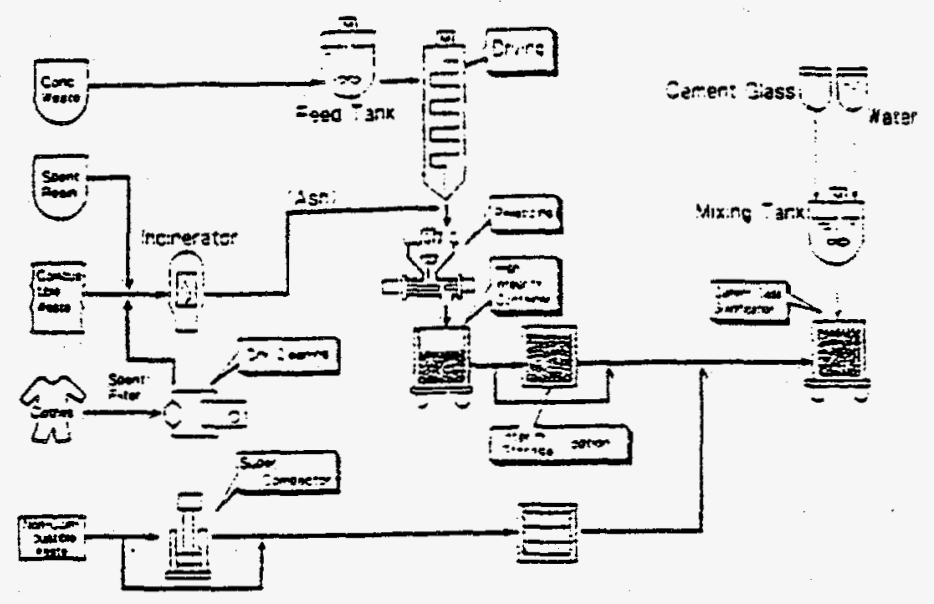

Fig. 2. Advanced radwaste volume reduction system.

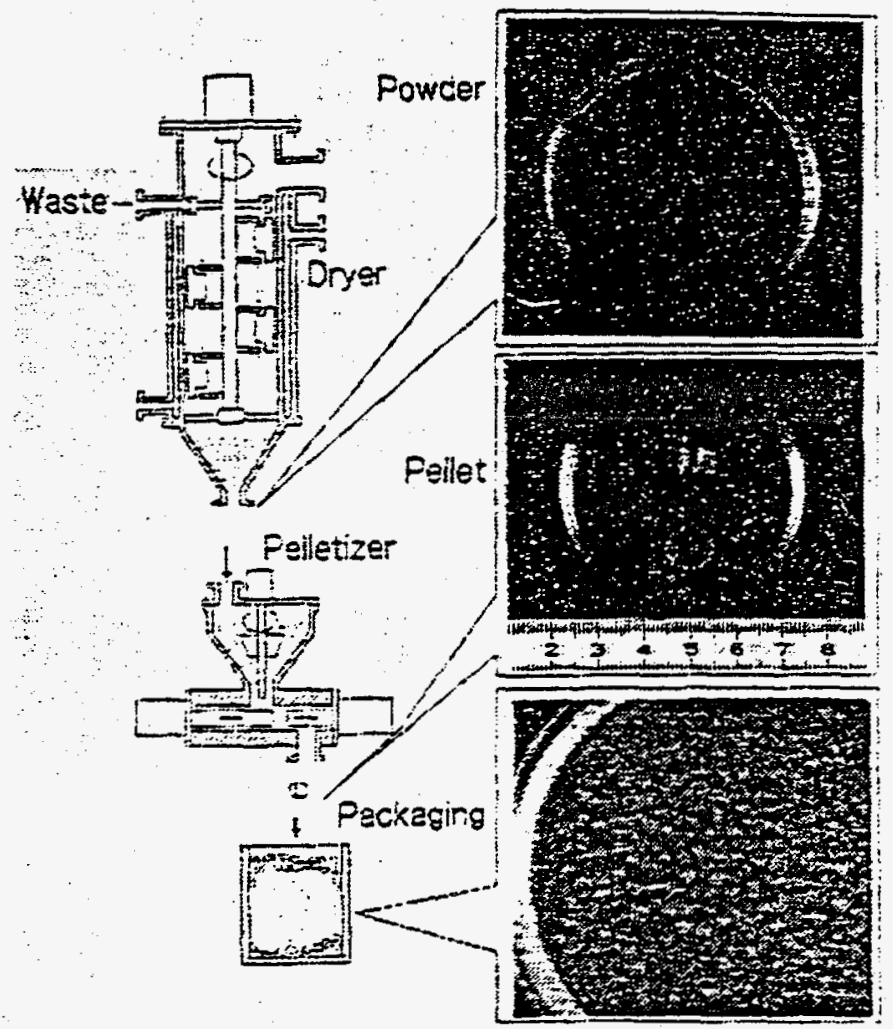

Fig. 3. Scheme of drying and pelletizing processes.

\section{PERFORMLYCE RESLLTS}

\section{Powdering Process}

The main component of BWR concentrated liquid waste is sodium sulfate, which exists only as Na_SO4. By contrast six chemical compounds are present in the complex sodium borate chemical reacion $\mathrm{Na}_{3} \mathrm{BO}_{3} . \mathrm{V}_{3} \mathrm{BO}_{2}, \mathrm{~V}_{2} \mathrm{~B}_{4} \mathrm{O}_{7}, \mathrm{~N}_{2} \mathrm{~B}_{3} \mathrm{O}_{5}$, $\mathrm{Na}_{2} \mathrm{~B}_{8} \mathrm{O}_{1 j}$, and $\mathrm{NaB}_{5} \mathrm{O}_{8}$. Experimental results using a pilor plant made clear that a vertical thin film dryer could produce only $\mathrm{Na}_{2} \mathrm{~B}+\mathrm{O}_{7}$ powder. If the ratio of $\mathrm{Nia} / \mathrm{B}$ differed from 0.5 , the viscosiry of sodium borate liọuid film on the heated surface increased too much. As a result, highly viscous liquid film stuck to the rotating blades and did not fall on the heated surface, hindering the powdering mechanism.

Powdering experiments witb different $\mathrm{Na} / \mathrm{B}$ ratios were conducted by a püot plant whose capaciry equaled to an actual plant. For a $0.5 \mathrm{Na} / \mathrm{B}$ ratio, the water content of the produced powder were aearly consiant throughout the experimeat. When the Na/B ratio was changed 100.47 or 0.56 , the water content gradually increased, but remained below 5 wr. Then, the amount of concentrated liquid waste was set to adjust the $\mathrm{Nia} / \mathrm{B}$ satio betwe 0.77 to 0.56 eatering before the thin film dryer.

The water content of sodium borate fowder produced by the thin film dryer was between 2 and 5 wt\%, which was considerably more than the 0 and 1 wT\% of water in sodiun sulfate powder. This difference was caused by water of crystallization in sodium borate. While sodium sulfate can exisi only a $\mathrm{Naz}_{2} \mathrm{SO}_{4}$ under the dryer operating conditions, $\mathrm{Na}_{2} \mathrm{~B}_{4} \mathrm{O}_{7}$ $\mathrm{can}_{2}$ exist as $\mathrm{N}_{2} \mathrm{~B}_{4} \mathrm{O}_{7} \cdot 5 \mathrm{H}_{2} \mathrm{O}, \quad \mathrm{Na}_{2} \mathrm{~B}_{4} \mathrm{O}_{7} \cdot 5 \mathrm{H}_{2} \mathrm{O}$, $\mathrm{Na}_{2} \mathrm{~B}_{4} \mathrm{O}_{7} \cdot 2 \mathrm{H}_{2} \mathrm{O}$, or $\mathrm{N}_{2} \mathrm{~B}_{4} \mathrm{O}_{7} \cdot \mathrm{H}_{2} \mathrm{O}$. Though sodium borate powde: contained about 3 wi $\%$ water, it seemed to be dry.

\section{Pelletizing Process}

While powders are compressed, they are gradually deformed plastically and the contact area berwesn them is increased. This plastic deformation is known to a key process for producing high density and strength of pellets. (6) If two contacting powders are the same chemical compound, they easily combined with each other. Since several chemical compounds are present in sodium borate powder, the mechanical strengti of their pellets is poor.

Then, about 4 w\% cellulose binder was added to the sodium borate powder and the minure was compressed into cylindrical pellers at a pressure of $0.15 \mathrm{GPa}$. The compressive sirength of the pellers was $1.6 \mathrm{MPa}$ which was enough to allow them to be thrown into the crum. The pellet densicy was 1.48

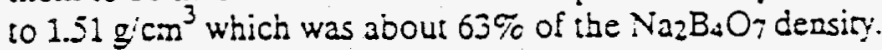

\section{Solidification Process}

The cement-glass solidification process is assumed as

$$
\text { c } \begin{aligned}
\left\{2 \mathrm{Si}(\mathrm{OH})_{4}+2 \mathrm{NaOH}+\mathrm{P}_{2} \mathrm{O}_{5} \cdot 2 \mathrm{SiO}_{2}\right\} \\
\rightarrow+\left(\mathrm{SiO}_{2}\right)_{\mathrm{I}}+2 \pi \mathrm{NaH}_{2} \mathrm{PO}_{4}-3 \mathrm{nH}_{2} \mathrm{O} .
\end{aligned}
$$

Since produced $\left(\mathrm{SiO}_{2}\right) \mathrm{n}$ forms a three-dimeasional structurs through the poinerization reaction, the compressive strength of solidiñed cement-glass exceeds $25 \mathrm{MPa}$. (6) Since X-ray diffraction analysis of the $\left(\mathrm{SiO}_{2}\right) \mathrm{n}$ did not show any crystal pattern, the structure was amorphous. (7)

Ordinary Portland cement is solidified according to the following reaction:

$3 \mathrm{C}_{2} \mathrm{O} \cdot 2 \mathrm{SiO}_{2}+3 \mathrm{H}_{2} \mathrm{O} \rightarrow 3 \mathrm{CaO} \cdot 2 \mathrm{SiO}_{2} \cdot 3 \mathrm{H}_{2} \mathrm{O} \cdot$ (Eq. 2)

This hydration reaction generates much beat and the temperature at the center of the cement package exceeds $100^{\circ} \mathrm{C}$. Since sodium silicate of cement-glass was fully bydrated initially, the heat generated was small and the mat. num temperature was below $50^{\circ} \mathrm{C}$.

Due to the mild solidification reaction, no shrinkage $\alpha$ curred during the solidification process. Therefore, no gaps formed between the container and solidified agent, and no cracks were observed in the package (Fig. 4).

\section{Waste Form Characteristics}

Table I summarizes the test results which show that the cemeat-glass package has bette: characteristics than previous waste packages using ordinary Portland cement.

The compressive strength of $200 \mathrm{~L}$ drum packages, which were produced by the pilot plant using simulated waste, 


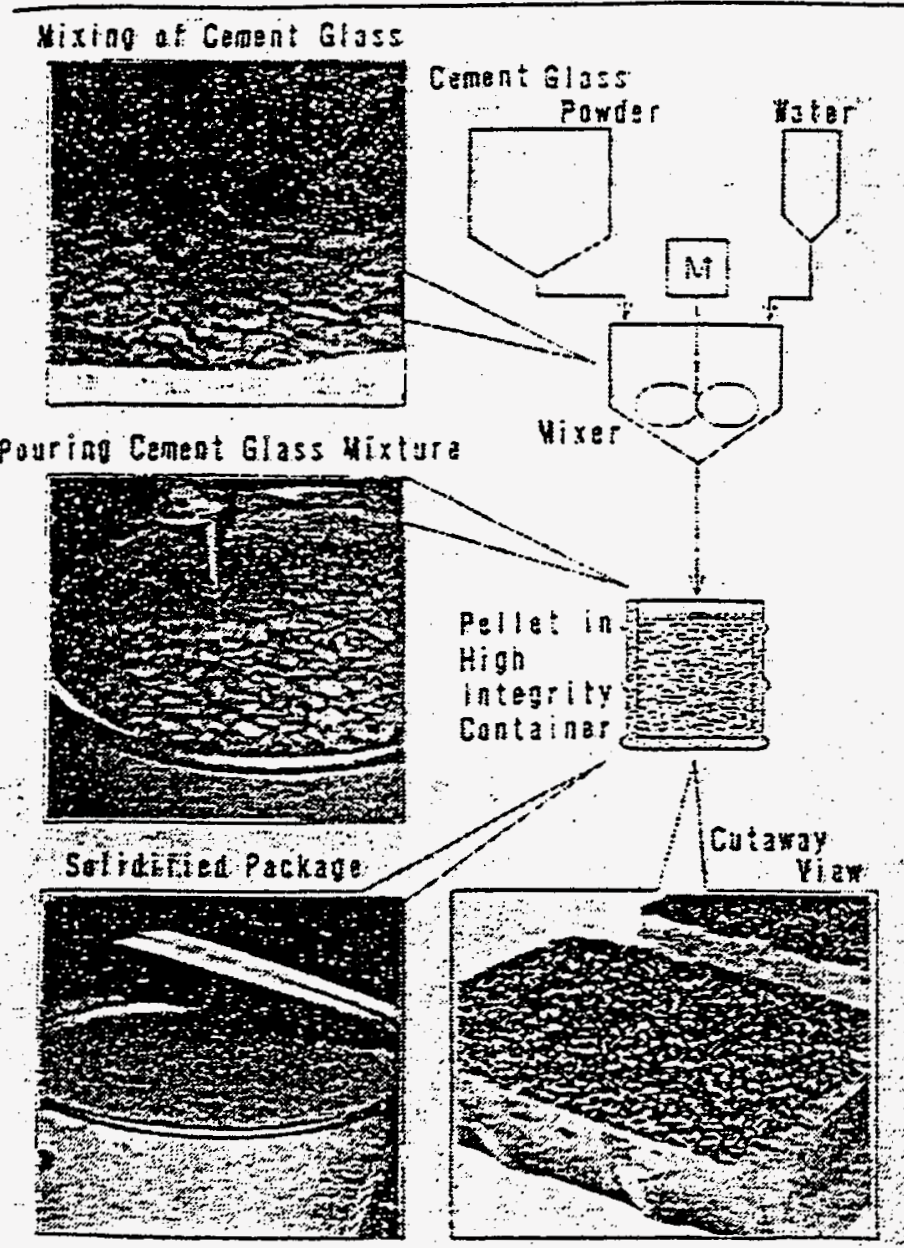

Fig. 4. Scheme of zement-glass solicinication process.

exceeds $17 \mathrm{MPa}$. Densities of the scdiur borate and ash packages are 1.6 and 1.3 respectively. Aiso drop and fire resistance tests were conducted using $200 \mathrm{I}$ drum packages as shown in Fig. 5. The package of sodium borate was dropped horizontally on the stee! plank from a $1.2 \mathrm{~m}$ beight. : Vo ciacks of the drum oceurred and no solidified material leaked from

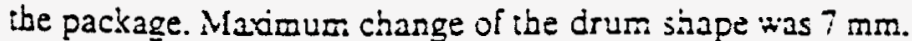
A $200 \mathrm{~L}$ drum was piaced in the cearer of a flame for 30 minutes. Weight loss was less tban 1.5 wr.c. because all of the radioactive material. the solidification agent, and the containe: were inorganic aaterial.

\section{OPERATING EXPERIENCE}

\section{BWR P!Lnt}

Two advanced volume reduction systerss which do not include a solidification process for pellets a-a used at Japantse BVR sites. The firsi system started comrercial operation in June $198-$ at the Canralized Racwaste Treatment Facility in the Fuxushima Daiicis Vuclear Powe: Siation of the Tokvo Electric Power Company. In this faciliry, concentaled liquid waste of the floor drain and regeneration waste from four reactor units are treated in one unit of the drying and pelletizing systen. A second commercial plant began its operation in Septemoer 1986 at the Tokai-2 Stalion of tise Japan Alomic Power Company.

The pellets were stored in a big cubic and in Fukushima site or a container in Tokai site, because the linal disposal method for low level radivactive waste has not been jetermined until the consitucion time.
Kikuchi VOLUMEREDLCTIONSYSTEM 1625

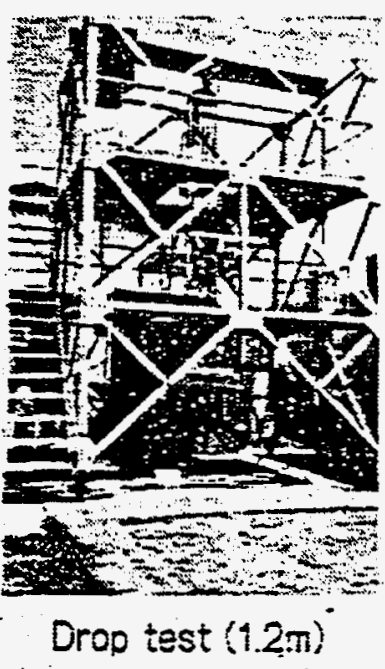

Fig. 5. Package pefformance tests.

\section{PWR PIant}

The final disposal progran for low leve! radioactive waste will be implemented in 1992 at a site in Aomori Prefecture located in the northern part of Japar. The technical standards of the pacikages for final disposal were published in January 1988 by the Science and Technology Ageacy. The pellet cement-glass package meers these stanciards.

Then, the first advanced volume :eduction system wiatic included a cement-glass solidificaticn process was installed For the Oti 3 and + units of Kansai Electric Powe: Co. in 1991. The capacity of drying concentrated iquid waste is $45 \mathrm{LB}$ and cylindrical pellets are prociuced at a rate of about $8 \mathrm{~kg} / \mathrm{h}$.

Because of the small volume of ite generated waste, the sysiem occupies a small space. Produced pellets are poured into $200 \mathrm{~L}$ drums that have an inser polymer impregnated concrete layer. Due to the high volume reduction ratio of the powdering and pelletizing processes, only one pellet package of a $200 \mathrm{~L}$ drum is solidified pe: week. Low viscous cemeatglass pasie is added for about 5 minutes, filling gaps between the pellets, and it is allowed to stanc for one day while solicifying. No shrinkage or cracks were observed.

\section{CONCLUSION}

In order to achieve maximum volume reduction and long te:m stasility, we have developed 30 inorganic packaging system. Its main features are drying and pelletizing processes for volume reduction, and cement-glass solidification for siability.

In order to apply it to a PWR plant, the following tectniques were developed. First the ciemical componeat of concentrated liquid waste was adjusied to improve drying ability of the thin film dryer. Secondly a tabletting machine was adopted instead of a briquetting machine because of the small volume of generated waste. The improved system was installed in the Ohi $j$ and + units and good operating experience has been obcained for actual waste.

\section{ACKYOWLEDGE.HEYTS}

Part of the cement-glass solidification tectraque was developed in a joint study with $10 \mathrm{~J}$ apanese power utilities and 
TABLE ?

Summary of Pellet Cexeat Glass Waste Form Characteristics

\begin{tabular}{|c|c|c|c|}
\hline Item & Size* & Test Method & Results \\
\hline $\begin{array}{l}\text { Specific gravity } \\
\text { Compressive strength } \\
\text { Heat cycle resistance } \\
\text { Fire resistance } \\
\text { Leachability } \\
\text { Drop test } \\
\text { Radiation resistance }\end{array}$ & $\begin{array}{l}* \\
* \\
* \\
* * \\
* * \\
*\end{array}$ & $\begin{array}{l}\text { Similar to JIS A1108 } \\
\text { Similar to ASTM C } 666-75 \\
-19^{\circ} \mathrm{C}-15^{\circ} \mathrm{C} 300 \text { cycle } \\
800^{\circ} \mathrm{C} 30 \mathrm{~min} \\
\text { Similar to LAEA } \\
1.2 \mathrm{~m} \\
10^{8} \mathrm{Rad}\end{array}$ & $\begin{array}{l}>1.3 \\
\geq 1.7 \times 10^{4} \mathrm{~Pa} \\
\bar{W} \text { eight cbanges } \leq 0.3 \% \\
\text { Size changes } \leqq 0 . \overline{1} \% \\
\text { Weight loss }<1.5 \mathrm{wt} \% \\
10 \cdot 100 \mu \mathrm{g} / \mathrm{m}^{2} \cdot \mathrm{d} \\
\text { No leakage } \\
\text { Strength change } \leqq 3 \% \\
\text { Weight change } 0\end{array}$ \\
\hline
\end{tabular}

wish to thank their personnel for valuable discussions and support. We also express our appreciation to Mizusawa Industrial Chemicals Lid., Chichibu Cement Co., Lid and Ozawa Concrete Co. Lid. for their cooperation.

\section{REFERENCES}

1. M. KIKUCHI, K CHINO, T. KOYAMA, I. ITO, $H$. YUSA, S. HORIUCHI, and M. HAYASHI, "Drying and Pelletizing of Nuclear Power Plant Radioactive Waste," Proc. Sump. Waste Management '82. Tucson Vol. 2601 (1982).

2. H. YUSA, M. KIKUCHI, S. HORIUCHI, and $M$. HAYASHI, "Volume Reduction System for Niuclear Power Plant Radioactive Waste," J. of Atomic Energy Sociery of Japan Vol. 24, No. 10, 770 (1982).
3. T. IZUMIDA, F. KAWAMURA, K CHINO, and $M$ KIKUCHI, "Stability of Cement Glass Packages Containing Sodium Borate Salt Generated Pressurized Wate: Reactor Power Plants," Nucl. Tec. Vol. 78, 158 (1987).

4. K. FUNABASHI, K. CHINO, M. KIKUCHI, S. HORIUCHI, and H. TUCHIYA, "Properties of A Radioactive Waste Pellet Package Using Cement-Glass," Nucl. Tec. (1991).

5. K CHINO, T.IZUMIDA, M. KIKUCHI, and Y. KIUCHI, "Properties of Pellet Cement Glass Package," Proc. Svmo. Waste Management '89, Tucson, Vol. 2,417 (1989).

6. P. J. JAMES, The Green Strength of Die-Pressed Zinc Powde:," Powder Metal., Vol. 20, 21 (1977).

7. S. HORIUCHI, M. KIKUCHI, K CHINO, T. BABA, H. YUSA, and H. NAITOH, "Solidification of CementGlass," J. of Nucl. Sci. and Tec., Vol. 26, No. 9, 887 (1989). 


\section{Waste Isolation Pilot Plant (WIPP)}

\section{The WIPP mission}

The U.S. Department of Energy's Waste Isolat ion Pilot Plant, or WIPP, is an important part of America's efforts to provide a practical, long-range solution to a complex question: how can we safely and permanently store materials contaminated with radioactivity during the production phases of

America's mational delense program?

Currently, such materials are stored using a variety of above-ground and shallow-land burial methods; allhough safe, these methods are not inlended as long-term solutions.

Instead, scient ists have long investigated the feasibility of storing radioactive waste material in deep geologic repositories.

$\stackrel{\infty}{p} \quad$ After reviewing the years of research into possible sites for permanent waste storage, Congress mandated, in the form of Public Law 96-164, the construction and development of WIPP as a research and development project, localed 26 miles cast of Carlsbad, New Mexico.

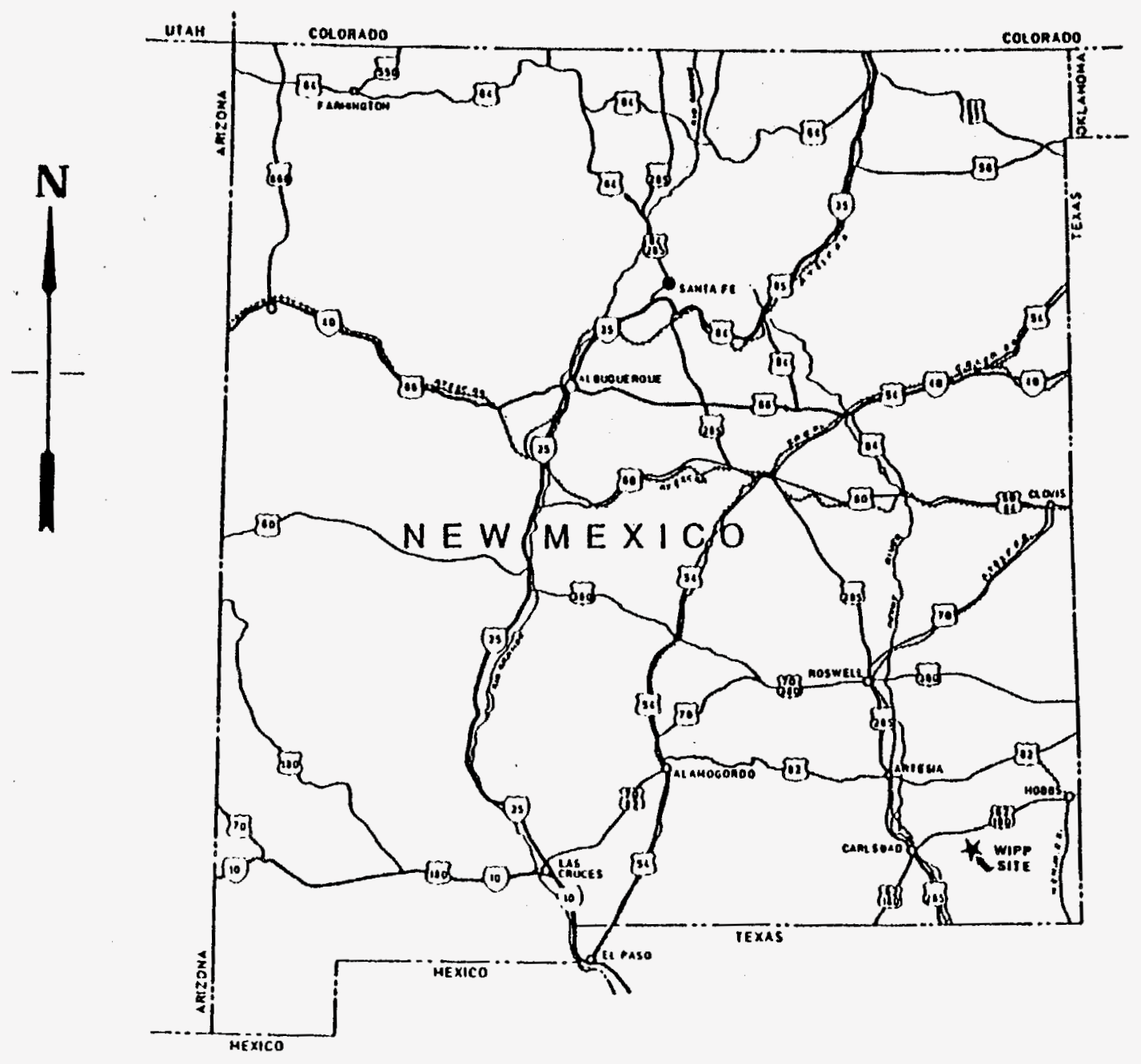



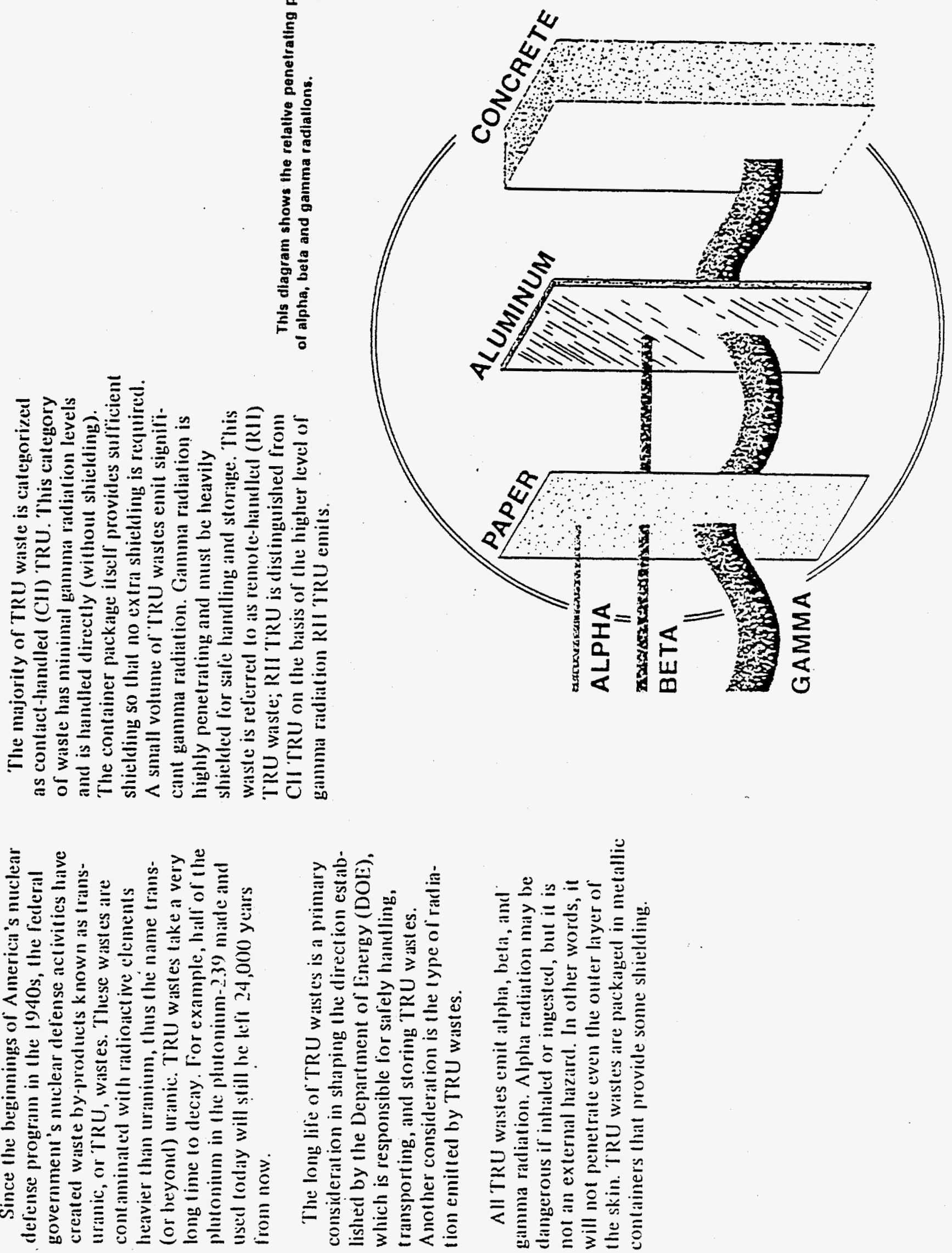


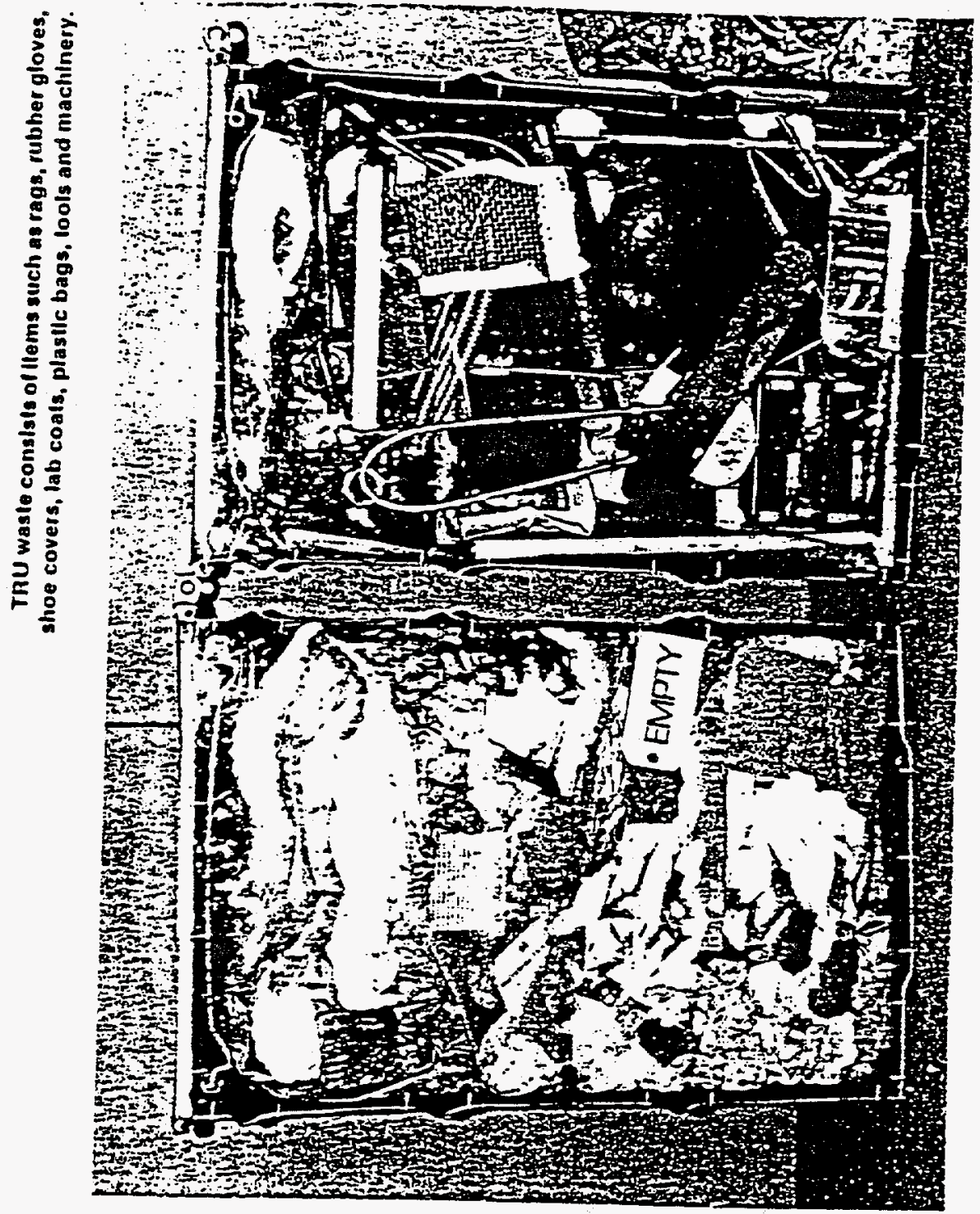

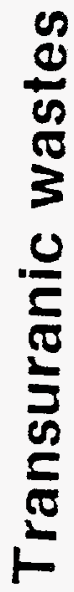
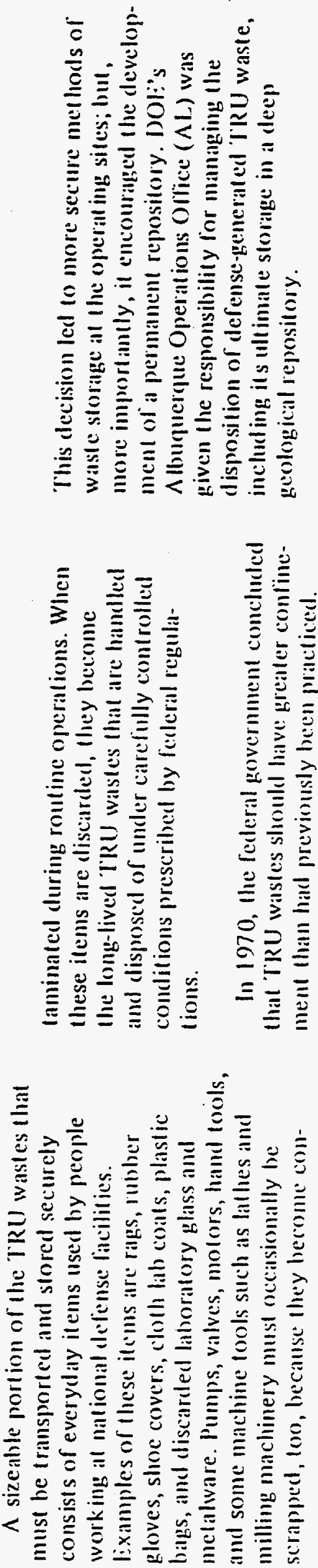


\section{Waste generator sites}

Numerous DOF facilities throughout the United Slates produce and store defensegeneraled TRU wastes.

The largest generator is DOE's Rocky Flats Plant out side Golden, Colorado. Rocky Flats workers pack the TRU wastes in met al drums or corrugated metal boxes, and then ship them to the Idalio National Engineering Labomtory. Here the drums or boxes are stacked on asphalt pads and covered with a removable layer of soil. This storage inethod allows the waste to be ensily retrieved for transport to the permanent storage site.

Once the Waste Isolation Pilot Plant is operational, all sites maly ship direclly to the WIP' facility.
Wasle contalners temporarlly slored in shallow-land trenches. As the trench IIIIs, II is covered wilh soll.
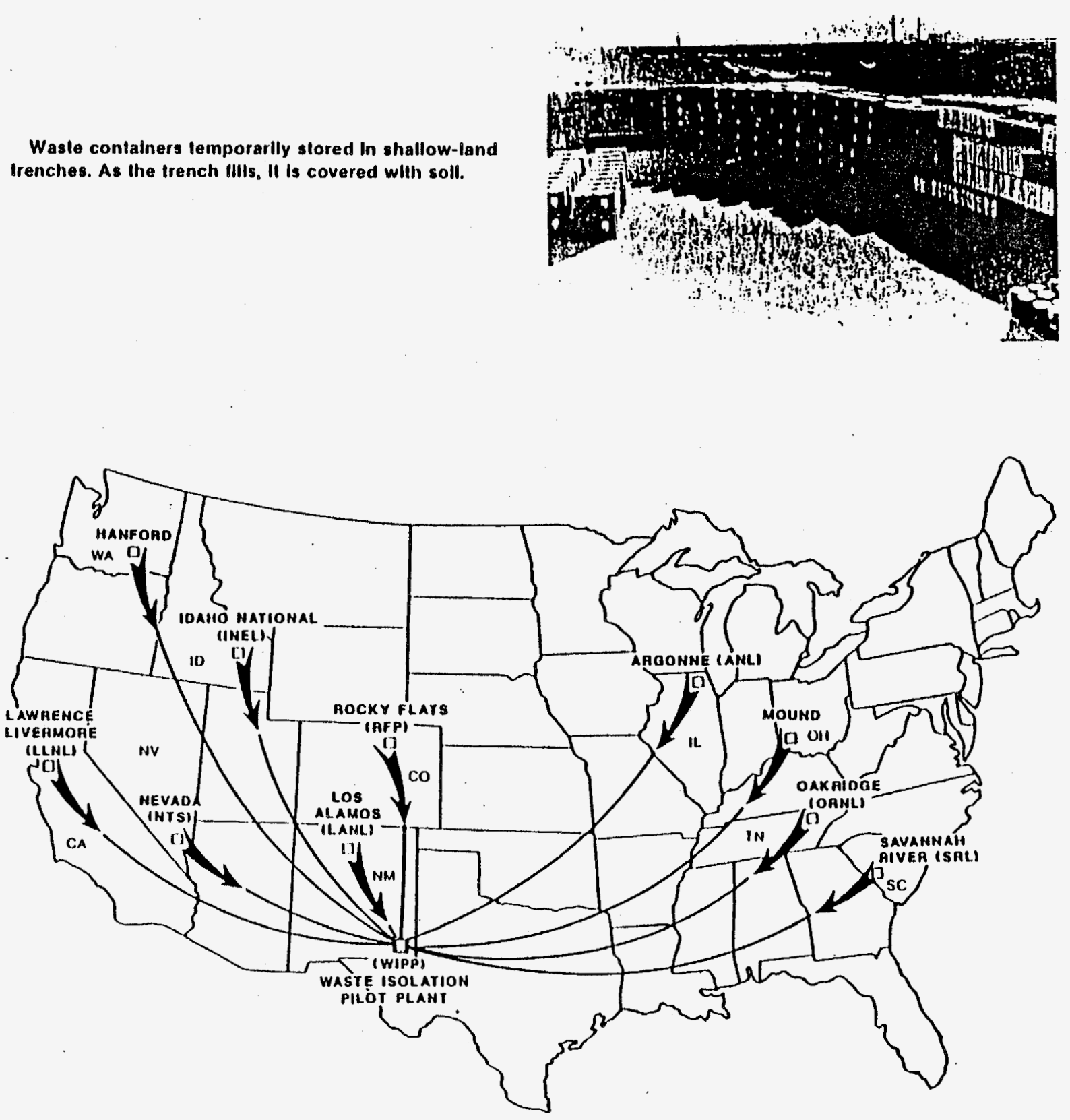


\section{Choosing the WIPP site}

\section{GEOLOGIC PROFILE}

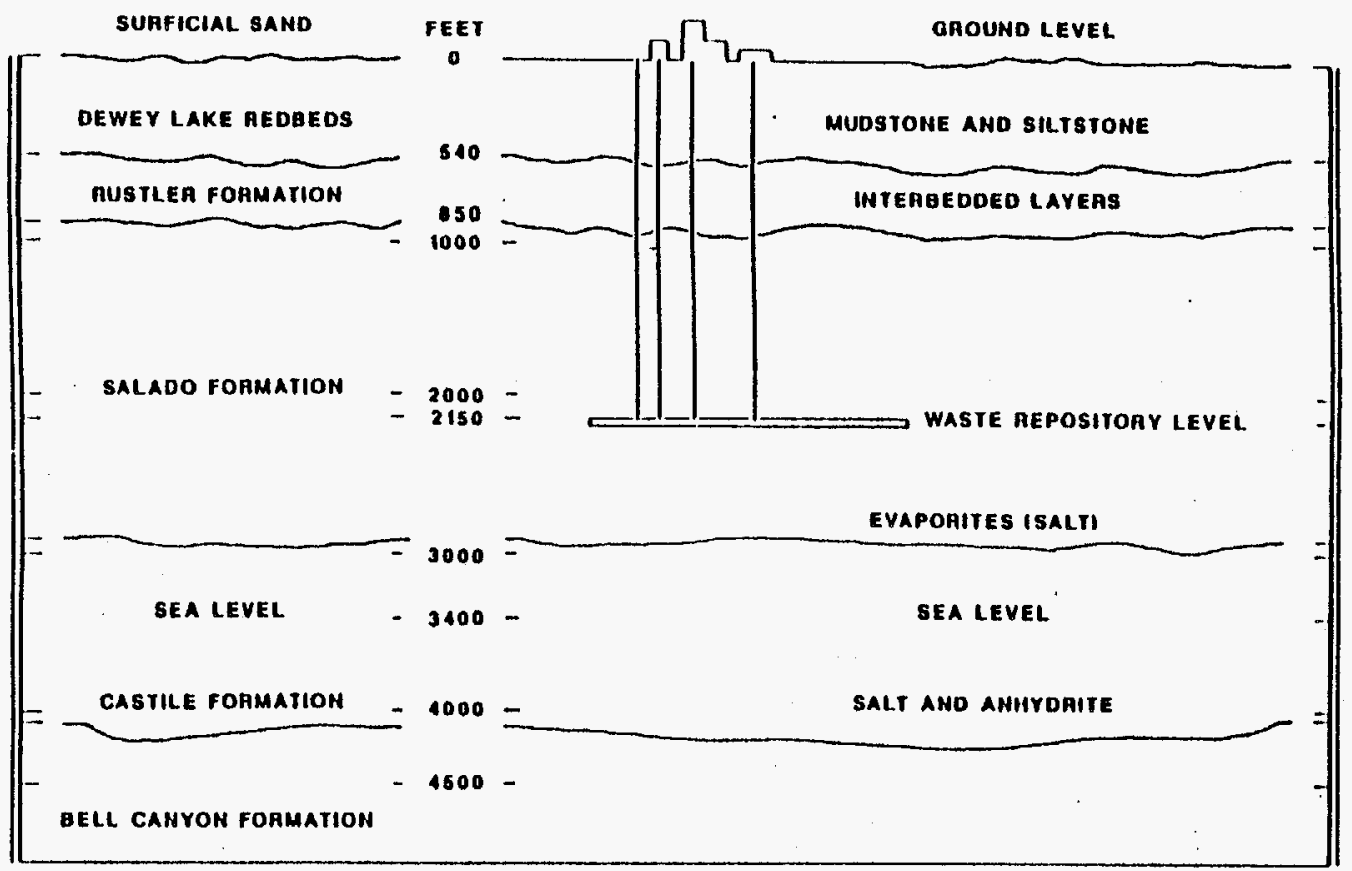

The WIPl sile, near Carlsbad, New Mexico, was chosen through a seleclion process that started in the mid-1950's, when the National Academy of Sciences recommended salt deposits as a promising medium for lle storage of ridlioactive wastes. Since that lime, bedeled sall has been one of the leadling rock candidates for the permanent storage of nuclear wasles. The principal advantages of sall include lloe liacts that (l) valst deposils of sill are found in stible peological areals will litlle earllucluake aclivity; (2) sall deposits demonstrate the absence of circulating ground water (for water would have eroded the salt beds, had it been present); (3) sall is relatively easy 10 mine; and (4) it has the ability to heal fractures because of its plastic quality (that is, sall will move in or "crecp" lo lill a void or to seal a wasle reposilory).

following years of slucly by the ()ak Ridge Nalional Liboralory and the U.S. Geological

Survey, a nalionwide search for a suilatble sile began in lhe early 1970's. The Permian Basin sall deposits, which underlie a large portion of eastern New Mexico, were idlentified as best salt islyeng early sile select ion crileria. Tlesese criterial were developed to ensure lhal any sile chosen wals geologically and envirommentally compatible will all the purposes of nuclear waste management, including permanent disposil.

The chanacteristics of the sall beds in the vicinity of WIPP have been extensively studied. The WIPl' sile contains salt beds that are nearly 3,000 feet thick, some of the thickest in the United States. The 225million-year-old salt rock has remained essentially stable and virtually uniflected by earlheyuake or linlle ing alctivily since being deposiled in its basin. The WIP'l' site contains no deep horeholes resulling from probes for oil or minerals; it is localed in a remole area, and is removed from any polentially disruplive geologgic feitures. These and olher characteristics, as confirmed by scientific data collecled from geologic informalion and fiekl tests, identified the present 10,240-acre site as the most favorable location for the Wasle Isolation Pilot Plant. 


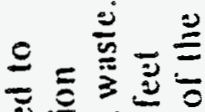

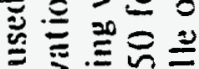

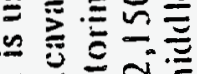

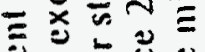

宔总总五

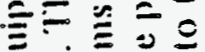

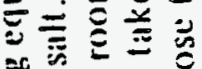

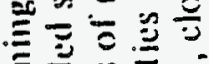

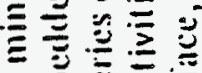

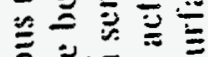

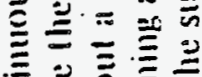

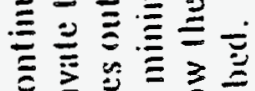

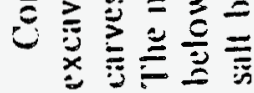

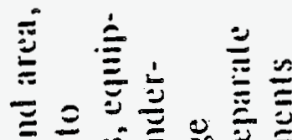

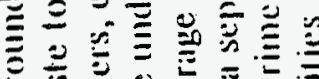

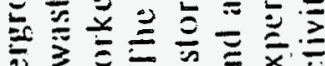

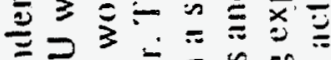

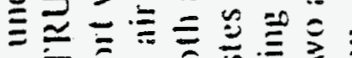

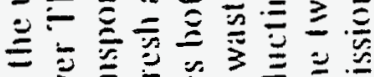

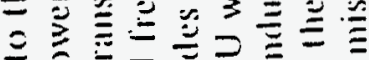

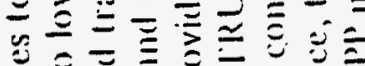

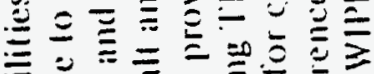

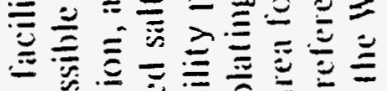

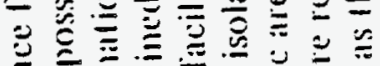

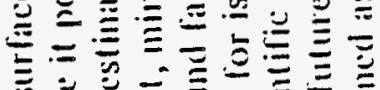

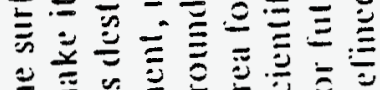

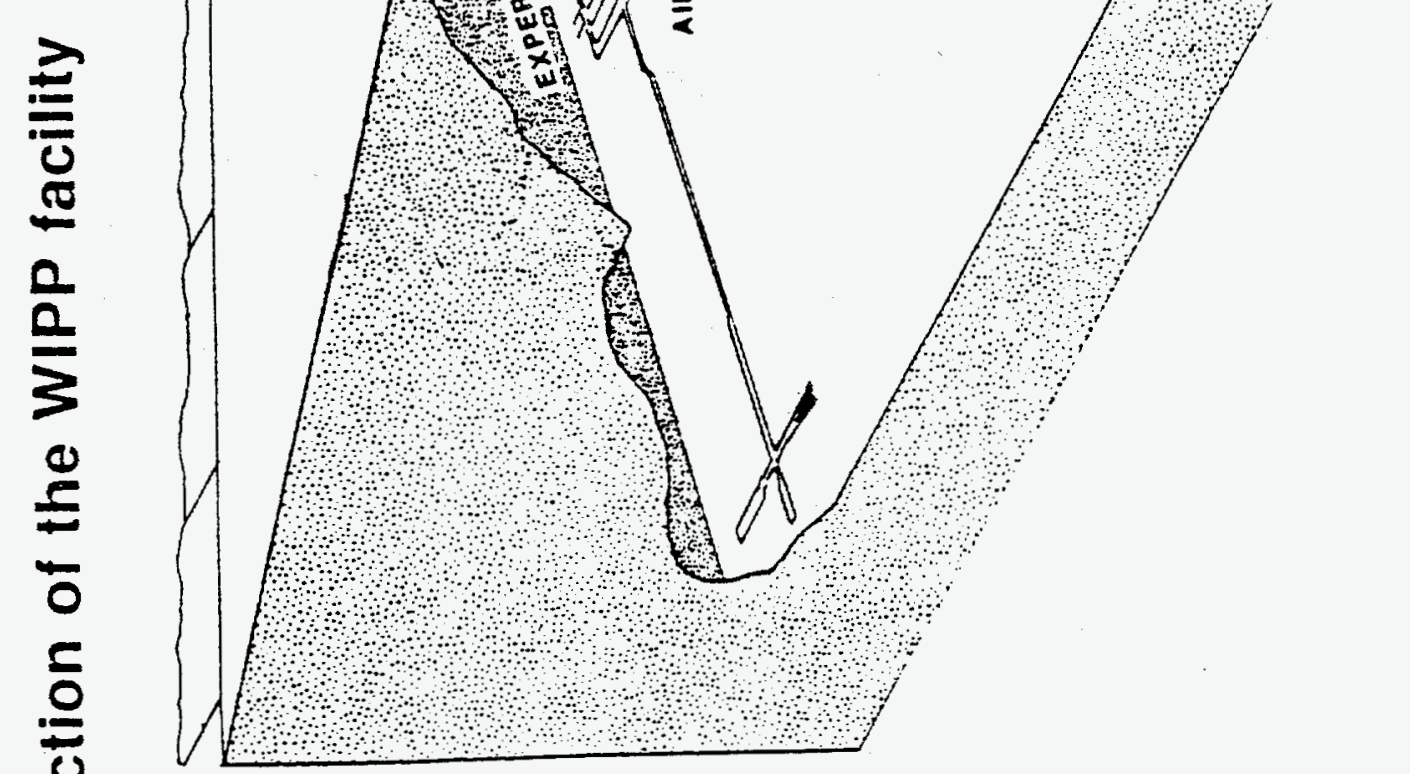

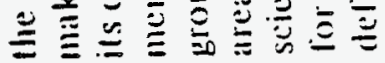

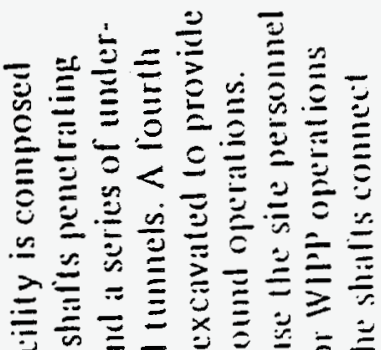

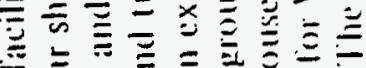

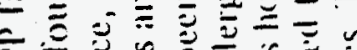

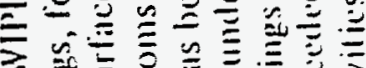

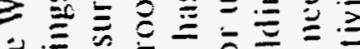

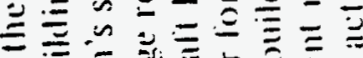

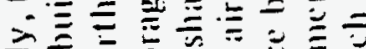

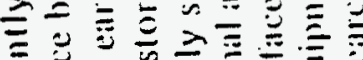

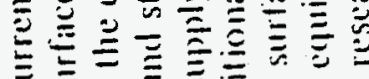

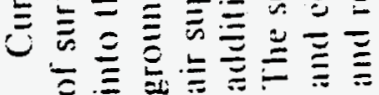




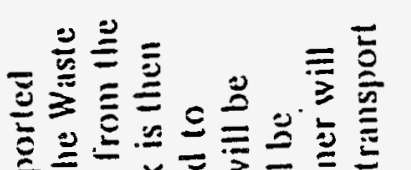

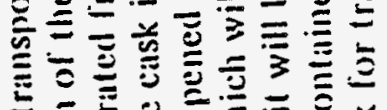

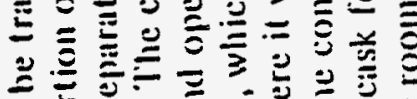

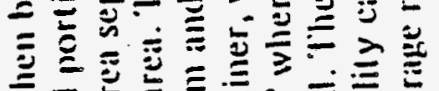

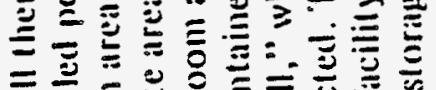

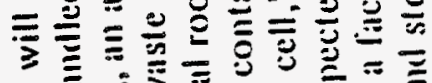

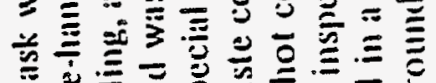

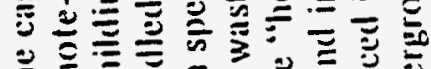

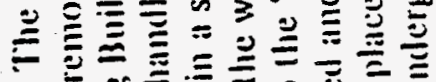

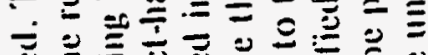

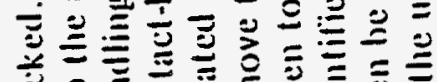

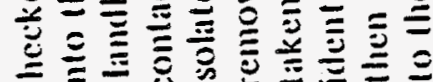

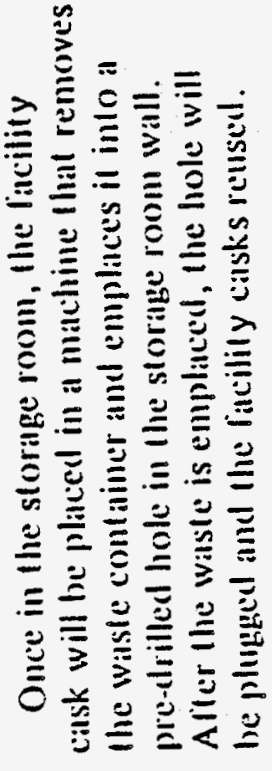

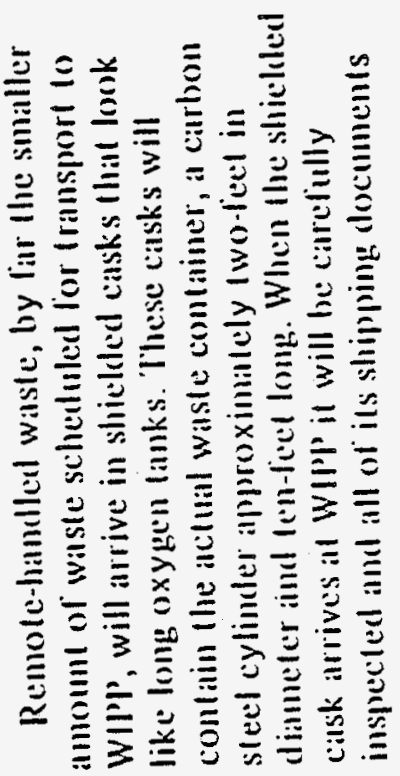

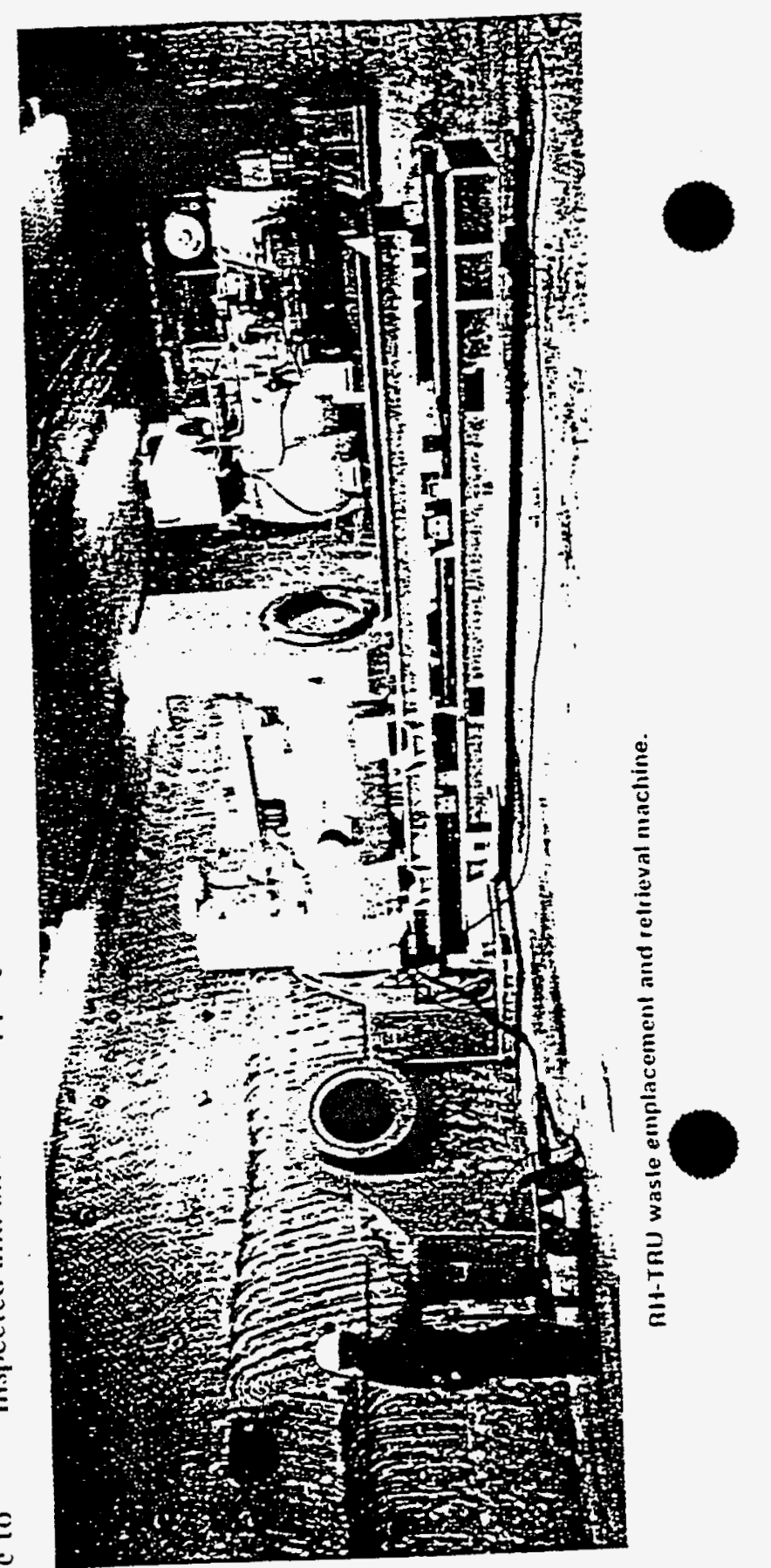

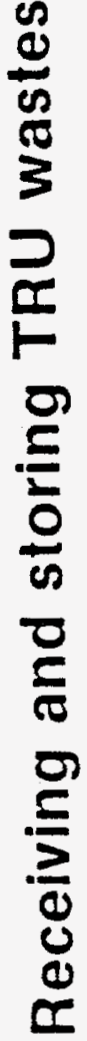

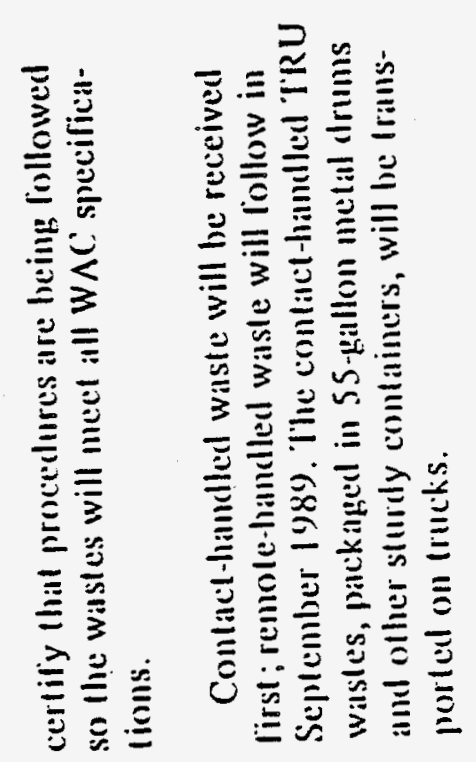

紊容

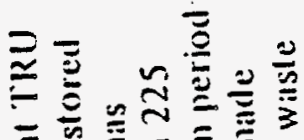

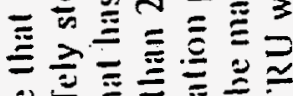

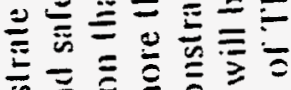

产言高产产亥

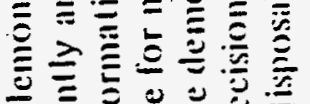

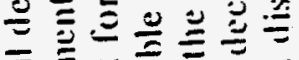

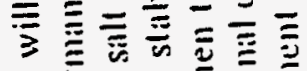

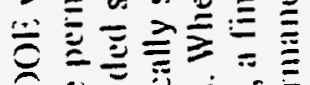

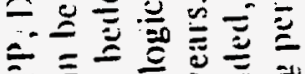

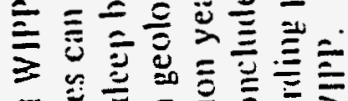

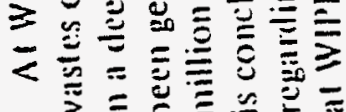

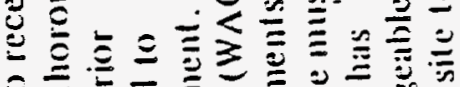

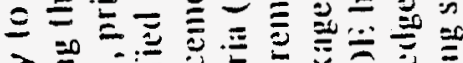

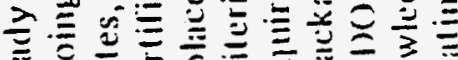

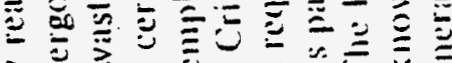

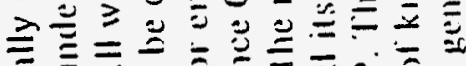

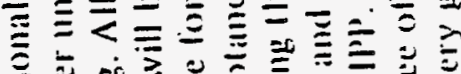

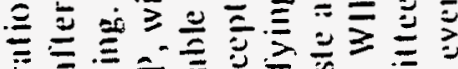

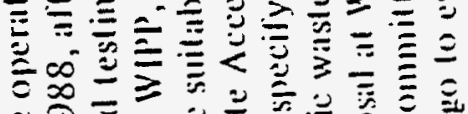

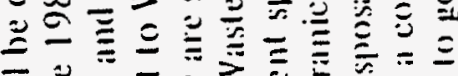

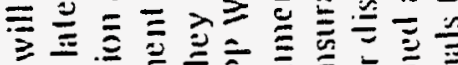

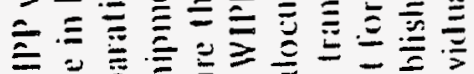

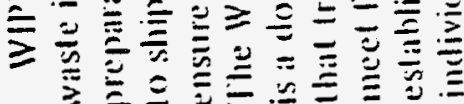




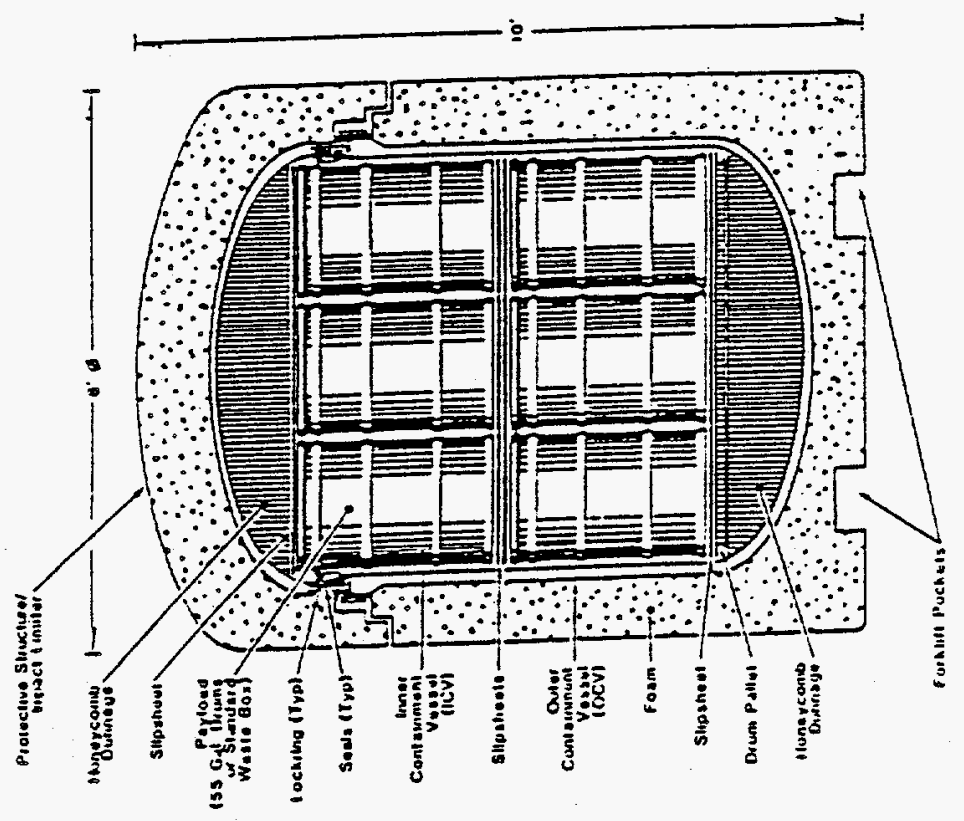

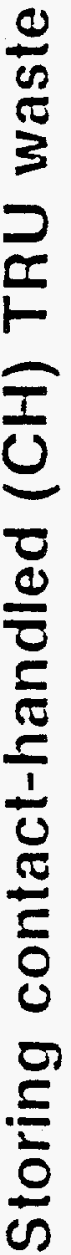

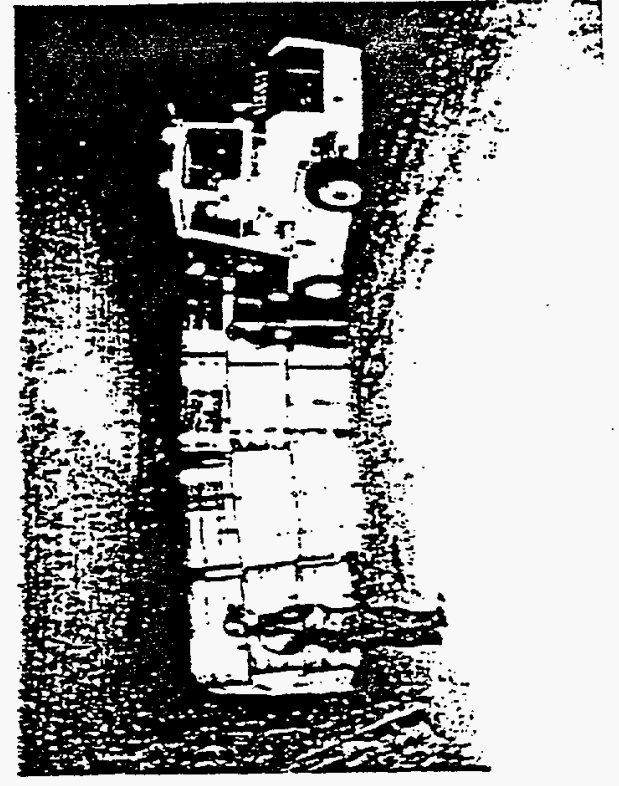

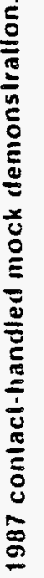

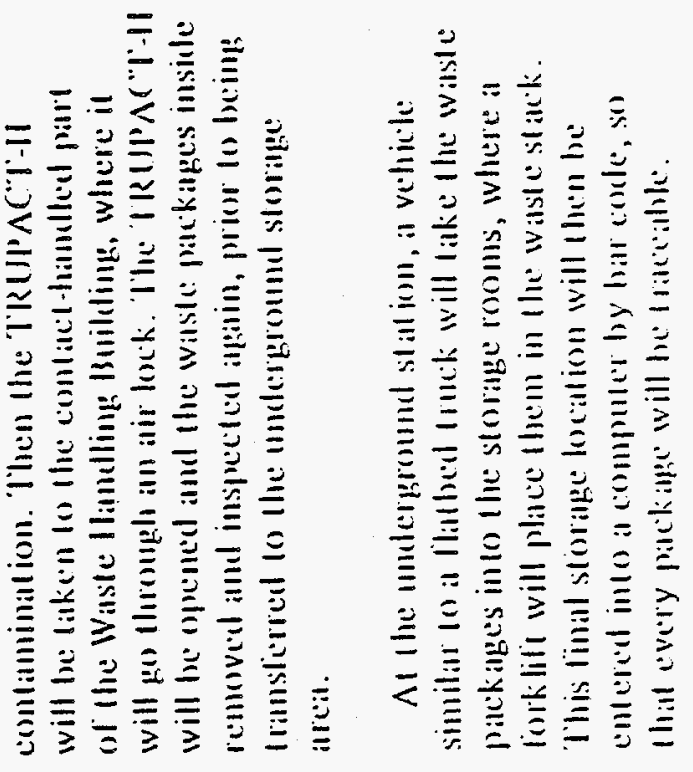

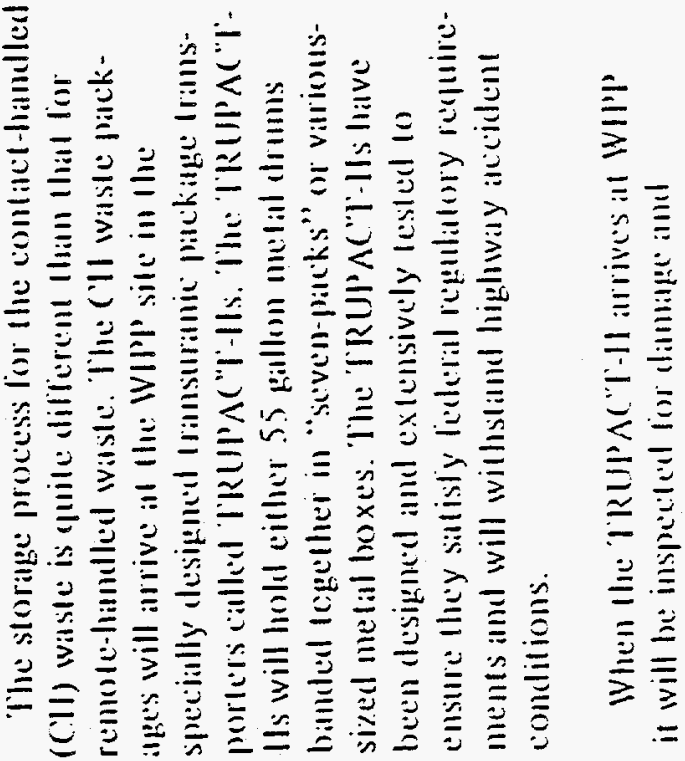




\title{
CURRENT STATUS OF THE WEST VALLEX STATE LICENSED LOW-LEVEL RADIOACTIVE WASTE DISPOSAL AREA
}

\author{
T. L. Sonotag \\ New York State Energy Research and Development Autbority
}

\begin{abstract}
The New York State Energy Research and Developmeat Authority (Energy Authority) retains management responsibility for the State-owned, closed, commercial low-level radioactive waste disposal area at the Western New York Nuclear Service Center in West Valley, New York. From 1963 to 1975, the facility was operated by Nuclear Fuel Services, Inc as a disposal site for low-level radioactive waste. Due to the characteristics of the soil and wet climate, water management problems were experienced from the very early years of operation. Water accumulation in several of the trenches eventually led to the cessation of burial operations. Redesigaing and reworking of the covers reduced, but did not completely eliminate, the problem of water accumulation in the treaches.

In 1983, the Energy Authority assumed management responsibility for the SDA from NFS. This paper summarizes the key projects and activities under way to maintain the faciliry in a safe condition and to support the goal of permasent stabilization and facility closure.
\end{abstract}

\section{SITE DESCRIPTION AND OVERTIEW}

\section{Westera New York Nuciear Service Center}

The Western New York Nuclear Service Center (Ceater) is locared 50 kilometers south of Buffalo, New York near the town of West Valley (Fig. 1). The 1,350-bectare Center is the site of the worid's first commercial nuclear fuel reprocessing plant. Facilities at the Center include the nuclear fuel reprocessing plant and its ancillary facilities consisting of a fuel receiving and storage pooL high-level liquid waste storage tanks, two solid waste disposal areas, and a low-level liquid waste treatment plant. One of the disposal areas is the Statelicensed commercial low-level radioactive disposal area (SDA). All major facilities are located on a 100-hectare plot near the center of the site (Fig. 2). Nuclear Fuels Services Co., Inc.(NFS) operated the site from 1963 to 1982 under a lease with the State of New York. The fuel reprocessing plant has not operated since 1972 and the SDA has been shut down since 1975. In February 1982 the U. S. Department of Energy (DOE) took possession of facilities at the Center (except for the SDA) for the purpose of carrying out the West Valley Demonstration Project (WVDP). The primary purpose of the WrDP, pursuant to the West Valley Demonstration Project Act (PL 96-368), is to solidify the high-level liquid wastes stored at the Center and to decontaminate and decommission the facilities used in the project. On March 30, 1983, responsibility for the SDA was officially transferred to the Energy Authority.

\section{State-Licensed Disposal Area}

The SDA occupies approximately 6 hectares of the WNYNSC and is located southeast of the reprocessing plant. The SDA consists of two distinct sets of parallel trenches, identified as north and south disposal areas (Fig. 3).

The north disposal area consists of five long trenches (1 through 5) and two "special" treaches ( 6 and 7 ). Treach 7 is a narrow, shallow concrete vault and Trezch 6 is actually a series of holes for the disposal of bigh-activity wastes that required immediate shielding.

The gorth area trenches are nominally 10 meters wide, 6 meters deep, and 180 meters long. The distance between these trenches is 15 to 2 meters. Iwo lagoons were excavated adjacent to the north trenches. The lagoons beld rainwater that was pumped out of the open trencies during disposal operations to provide reasonably dry working conditions. These two lagoons were closed by filling with soil in 1975 and 1977.

The south disposal area consists of seven trenches ( 8 through 14). This area was developed from 1969 to 1975, and incorporated a number of changes in construction practices based upon the experience gained from operating the north area: topsoil and coarse surface materials were removed; separation distance berween trenches was increased to $3 \mathrm{me}$ ters; treach floors were sloped away from previously disposed wastes; trenches were covered with individual caps; and cap thickness was increased to 2.4 meters (Fig. 4).

In 1975, a third lagoon was consiructed adjacent to the south trencies to hold water purned from the completed trenches, that were accumulating water. This lagoon was closed in 1991 by first installing a barrier membrane over the sedimests, then filling in with native soil and adding a clay cap.

The disposal trenches were excavated into the native Lavery till which because of its high clay conteat and bigh degree of over-consolidation, is highly impermeable at depth.

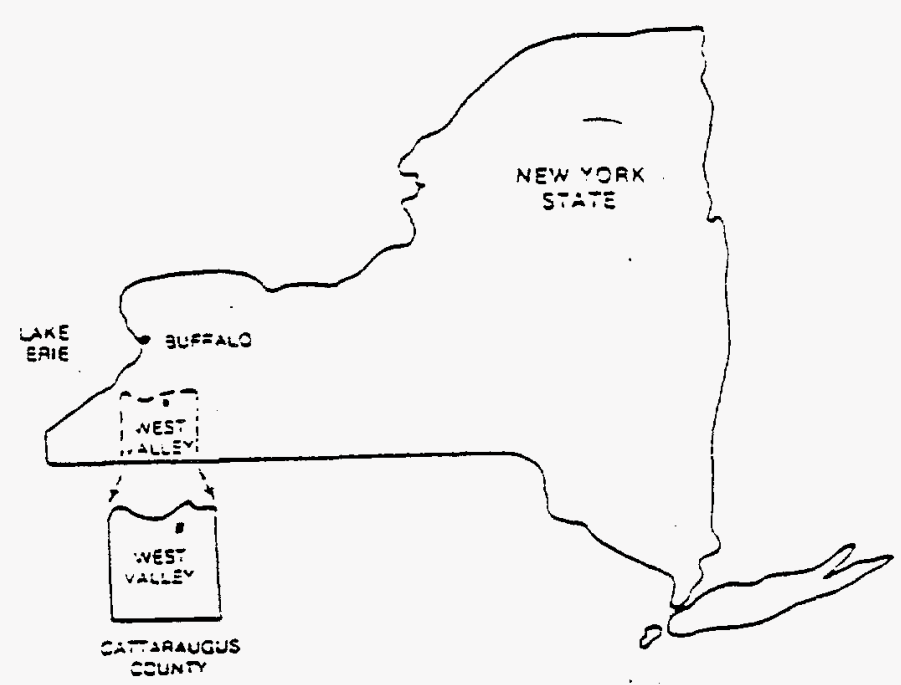

Fig. 1. Location of Western New York Nuclear Service Center. 


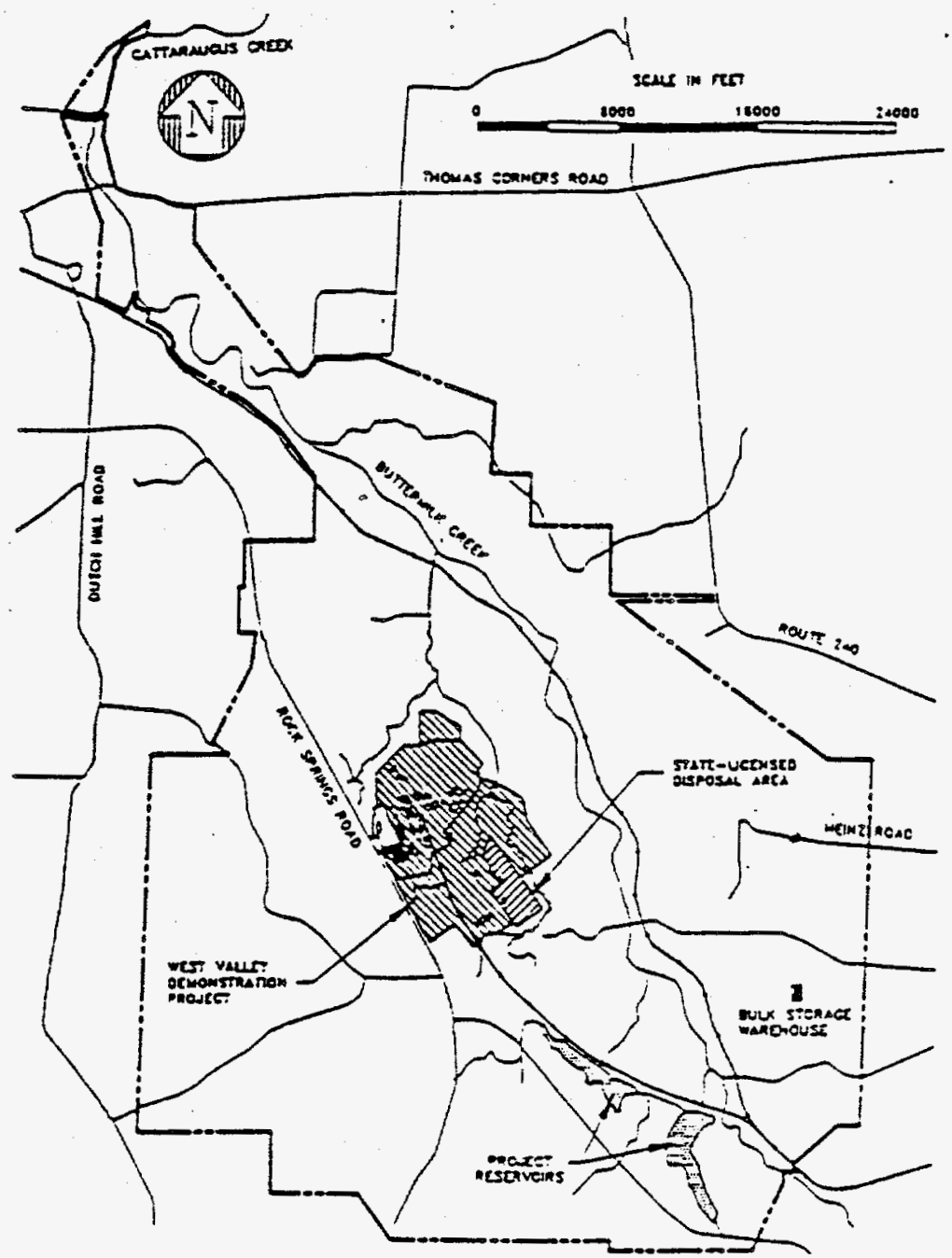

Fig. 2. Western New York Nuclear Service Center.

Samples taken from boreholes bave indicated, bowever, that the upper 3 meters of the till is weathered as a result of desiccation. The weathered ill is highly fractured and is generally more permeable than the unweathered till

\section{Disposal Operations}

From 1963 to 1975 , approximately 66,500 cubic meters of waste containing 736,000 curies were disposed in the SDA. The waste was received from instinutions, industries, government facilities, nuclear power plants, waste brokers, decontamination comparies, and NFS. Monitoring showed that 1.5-3 meters of water accumulated in the trenches during the first two to three years after each trench was covered and then began to level off, with the exception of Treaches 3,4 , and 5 . Following a brief period of apparent stability after individual cover mounds were established in 1969, the water in these trenches contioued to rise until March 1975, when the water seeped out laterally through the cover of Trenches 4 and 5 . NFS immediately halted disposal operations and no material has been disposed of in the SDA since.

\section{POST-CLOSURE SURVEMLANCE AND MAINTENANCE ACTIVITIES}

\section{NFS Activities}

Following the water seepage incident, NFS punped and treated water from the disposal treaches. From 1975 to 1977 , approximately 7.6 million liters were removed from the trenches, treated, and discharged. In an attempt to minimize water infiltration, an additional 12 meters of clay cap material was placed over the north trenches in 1978 to duplicate the construction of the south trencbes, which experienced much lower rates of water infiltration.

Beginaing in 1978 and continuing through 1979, sharp increases in water levels in Trenches 11 through 14 in the south disposal area were measured. These increases were attributed to an exrended dry summer period (which caused desiceation cracking in the cover) followed by a wet fall and winter. In the Fall of 1980, NFS improved the covers for Treaches 11 through 14 by stripping 15 centimeters of topsoil from the trench covers and 62 centimeters of clay cap material, placing and compacting 72 centimeters of compacted chay in layers, adding 31 centimeters of top soil, and performing final grading and seeding. Following completion of this work, NFS pumped down all of the trenches. The pumping campaign lasted from the Fall of 1980 to the spring of 1981 , removing an additional 3.02 million liters of water from the trenches, and was the last significant remedial activity performed by NFS.

\section{Site Management by the Energy Authority}

In accordance with an agreement between NFS and the Energy Authority the Energy Authority assumed possession 


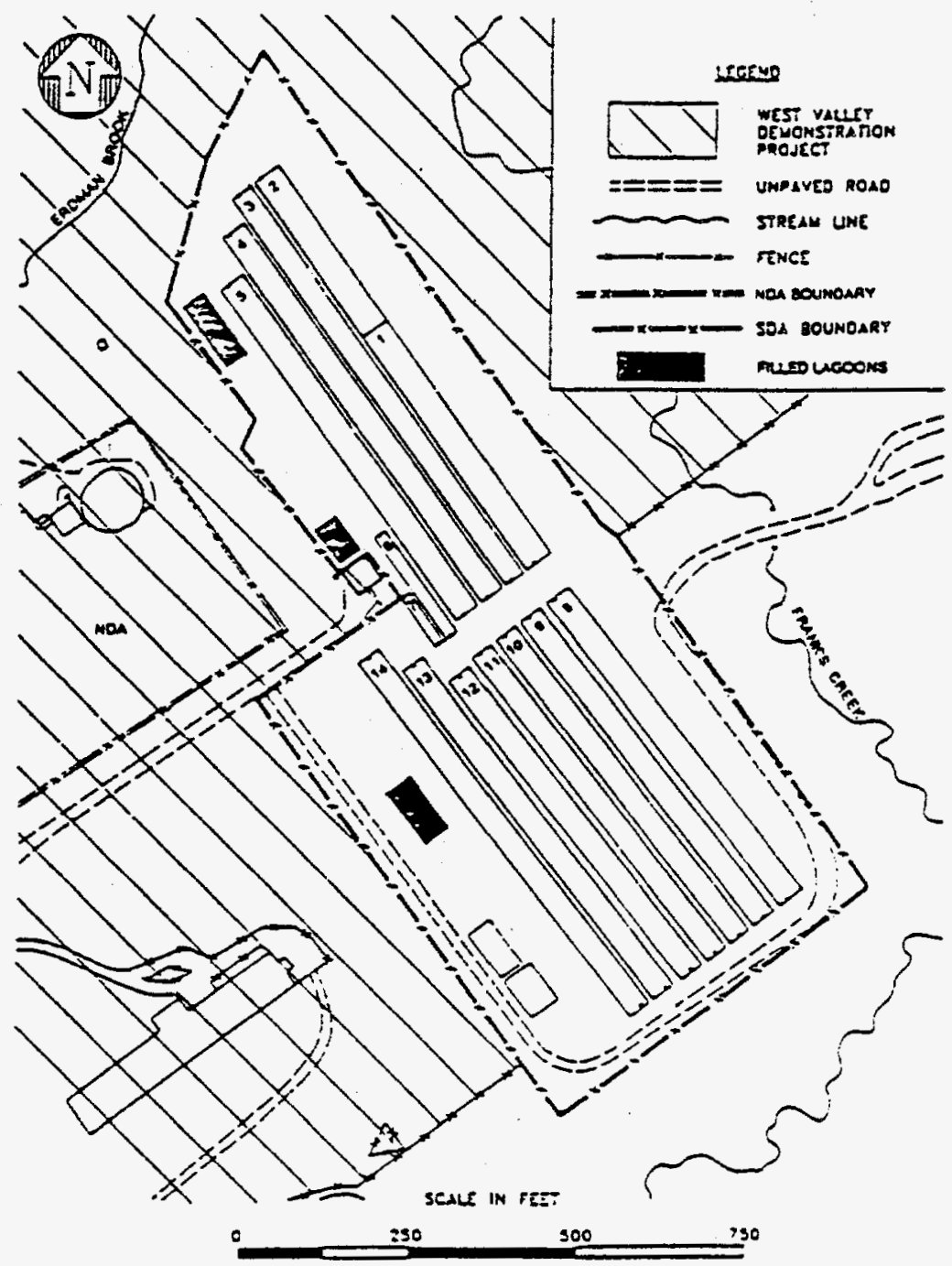

Fig. 3. State licensed disposal area (SDA).

of the SDA and heace responsibility for surveillance and maintenance in the spring of 1983.

Between 1983 and 1986, the Energy Authority and DOE sponsored a project to evaluate options for long-ierm management of the SDA. The study (1) called for the development of an interim pian to improve management practices pending development and implementation of a long term management strategy. In implementing this interim management plan, the Energy Authority bas focused its efforts on minimizing water infiltration through an active maintenance program, establishing a comprehensive eavironmental monitoring program, and collecting site specific data to allow for decisions to be made on ultimate stabilization and closure of the SDA.

TRENCM CRCSS SECTION AS EXCAVA:EO

IRENCW CROSS SEETION IS
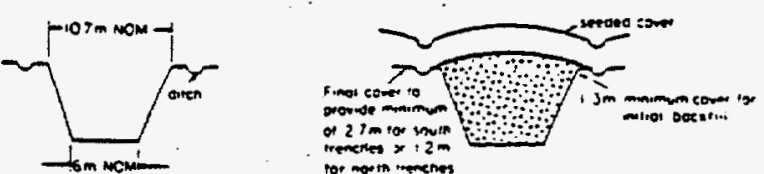

LONG̈ITUOINAL TRENCM SECTION

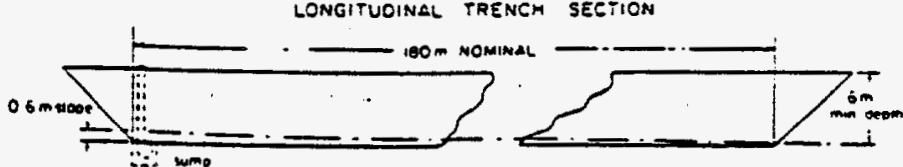

\section{TRENCH 14 INFILTRATION CONTROL EFFORTS}

\section{Sand and Gravel Body Removal Project}

Berween 1981 and 1986, Trench 14 water level increased at a rate of 2.5 to 5 centimeters per month; however, in June 1986, during a relatively rainy summer, a 20 centimeter increase was measured. This was followed by increases of 10 centimeters and 28 centimeters in July and August respectively (2).

Initially suspecting trench cover failure, the cover of Trench 14 and the drainage ditch berween Trenches 13 and 14 were inspected for defects (potholes, desiccation cracking, etc.). No visible defects were seen by Energy Authority staff. The Energy Autbority focused on the area west of Trench 14 as a potential source of water infiltration. Regrading of the area showed a dramatic reduction in water infiltration even though wet weather continued. Further investigation revealed the existence of a large sand and gravel body near the soutb end of Trench 14 that extended west to near the surface. Historic notes from burial operations indicate the sand and gravel body may extend through Trezches 13 and 14, encing in Trench 12. During the summer of 1987 , the sand and gravel body west of Trencb 14 was removed and replaced with compacted silty clay till.

Fig. 4. Disposal trenci construction details. 
As a result of the removal of the sand and gravel body, infiluation rates info Trench 14 were reduced to approximately 8 centimeters per year.

\section{Infiltration Controls Project}

In January 1991, during an unusual period of high rainfall and snow melh the water levels in Trench 14 increased by 18 centimeters and by 51 centimeters in adjacent Treach 13. The Trench 13 water increase was attributed to the water leve! in Trench 14 reaching the sand and gravel body between the treaches, and flow into Trench 13 was now possible. From previous pump down activities it was known that the void volume in Trench 13 was sigaificantly less than (approximately one-third) that in Treach 14. A detailed examination of the caps on Trenches 12, 13, and 14 showed no obvious or major deficiencies.

At this point, it was unclear what portion of the most recent source of water resulted from surface water infilerating through cracks in the cap as opposed to lateral ground water movement through fractures in the weathered till. Consequently, the Energy Authority focused its efforts on developing engineering solutions that would address botb potential pactways, while in parallel undertaking to evaluate the source of water accumulation. The case for lateral groundwater movement through the weathered till was supported by the observation of high water levels in many of the existing shallow ground water wells. Likewise the notion of vertical infiltration was supported by the periodic formation of sirktholes in the trench caps.(3)

To evaluate the shallow groundwater flow tegime and define subsurface litbologic conditions in the vicinity of Trenches 13 and 14,24 shallow piezometers were installed west and south of Trench 14 in April 1991. Because a single source for water infiltration was not ideatified, an engineering solution to address both borizontal and vertical water influx was developed. The infiltration controls consisted of a vertical barrier wall, or slurry wall to divert groundwate: flow in combination with a geomembrane cover to divert precipitation away from the trenches.

Slurry wall construction began in early September 1992 and was completed in three weeks. The excavated native soil was used in combination with bentonite clay and water to form a highly impermeable barrier to horizontal water flow. The objective for the project was to ensure that all cracks, fissures, and coarse deposits that could transmit water to the treach were cut off. The slurry wall was aligned to run along the west side of Treach 14 and deflect around both the north and south ends (Fig. 5). The 276-meter long slurry wall is approximately 0.9 -meters wide and extends 9-meters below exsting grade. While the primary intent of the slurry wall was isolate the trench from the adjacent weathered till, the underlying unweathered till was known to contain isolated sand and gravel deposits. Since it could not be determined for certain if these sand and gravel deposits intersected the trenches, it was decided to extend the wall to a level below the lowest trench elevation, thereby eliminating any possibility of a deeper ground water infiltration route.

The membrane cover, which is comprised of very lowdensity polyethylene (VLDPE), will extend from the center line of Trench 12 across Trenches 13 and 14 and end just west of the slurry wall. The membrane will be extended to Trench 12 since it is believed that Trencbes 12, 13, and 14 may be interconnected by a sand and gravel body. A drainage channe! will carry all diveried precipitation away from the trenches.

Following completion of the slurry wall, preparation of the surface of the treaches began for installation of the mem. braae cover. This work included stripping the grass cove: from the trench caps, regrading areas to accommodate membrane cover installation, and excavating the primary drainage channel for the membrane cover. Due to beavy rain and snow in November, installation of the membrane cover has been delayed until the Spring of 1993.

Afte: installation of the slurry wall Tresct 14 has showed a drop in inflitration rate from the previous two years (Fig. 6). Although the membrane cover bas not yet been installed, the grading work done as part of surface preparation is having a short-term positive effect by enhancing runoff. In the longe: tersa, however, an unprotected soil cover could entance in $[1$ tration due to effects of erosion and desiccation cracking. Therefore, the membrane will be installed as soon as weather permits.

\section{TRENCH 14 LEACHATE TREATMENT PROJECT}

Although the rate of water accumulation in Trench 14 tas been reduced by past remedial actions, water levels are near their historical high point. Consequently, the Energy Authority bas initiated plans to pump and treat the leachate.

\section{RCRA Compliance Issues}

The leachate in the SDA trenches results from the percolation of water through radioactive wastes itat were disposed of prior to passage of the Resource Conseriation and Recovery Act (RCRA) and its associated regulations. Wtile the leachate in Trench 14 contains both radionuclides and haz. ardous constituents, there is no specific information that details the sources of the bazardous constituents found in the leachate. Disposal records document only the radionuclides present in the disposal trenches. In the absence of this information; the Energy Autbority believes a listed bazardous waste designation is not warranted, but bas elected to protectively file a RCRA Part $A$ application to store and treat potentially mixed radioactive and bazardous wastes at the SDA. Discussions are currently under way with regulatory agencies regarding the RCRA status of the leachate. The Energy Authority will continue to manage the leachate as radioactive mixed waste until this issue is resolved.

\section{Status of the Leachate Treatment System Design}

A summary of the major constituents in Trench 14 leachate is included as Table I. Treatability studies have beea performed to investigate the applicability and effectiveness of a variety of technologies toward reducing the levels of hazardous and adioactive components in Trench 14 leachate. Car. bon acsorption, biological treatment, ultraviolet oxidation, evaporation, and ion exchange were tested. The treatabuity study concluded that the leachate treatmeat system sbould be based on a thres-stage treatment train cossisting of biological treatment in the form of a batch activated-studge reactor followed by filtration units, carbon polishing columns, and ion-exchange resin beds (Fig. 7). The batch biotreatment process is highly effective in reducing the organic content of the leachate. The carbon columns will remove trace organics not removed in the bioreactor. The ion exchange beds will remove radionuclides, except tritium, to below regulatory discharge limits. 


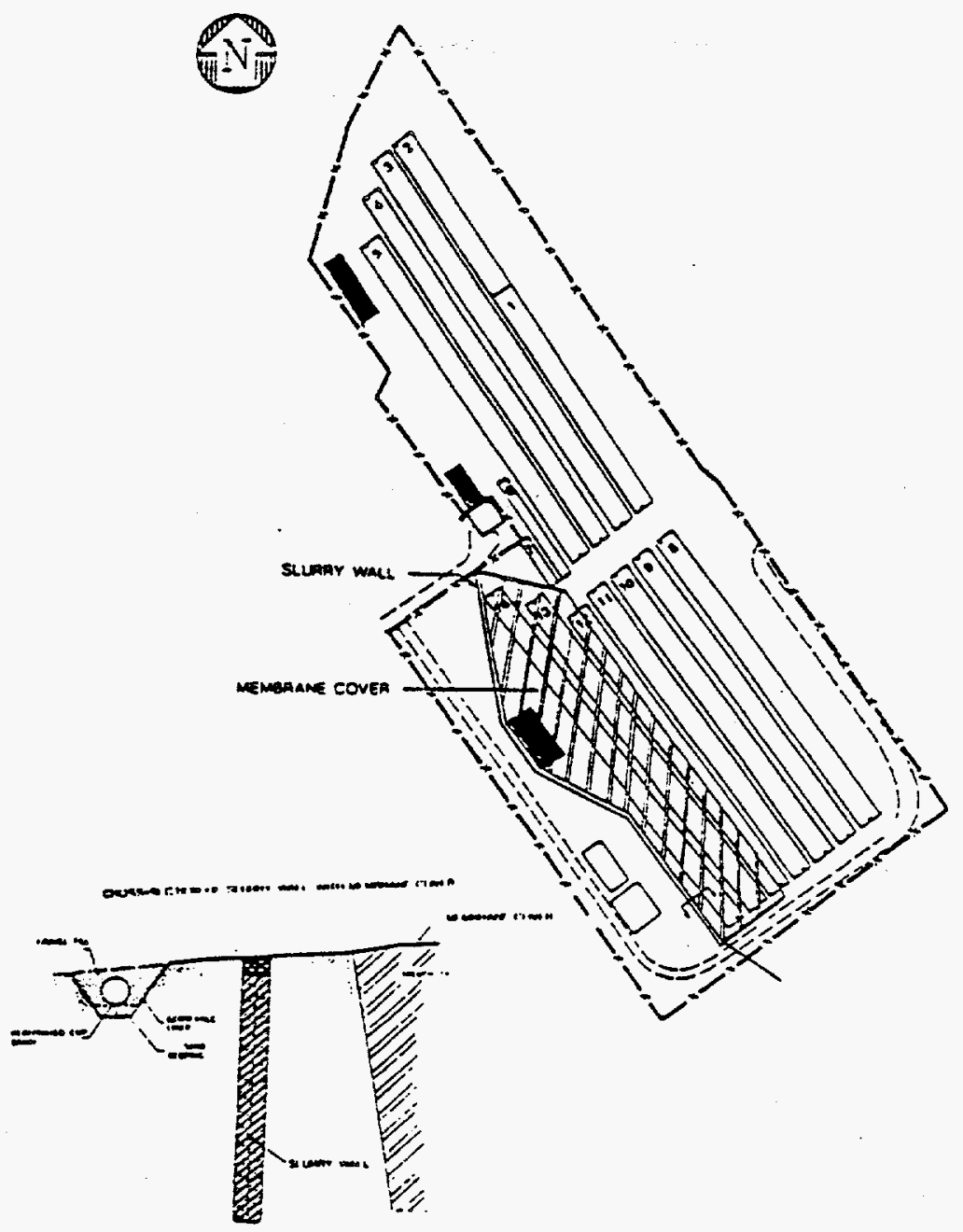

Fig. 5. Infiltration controls project.

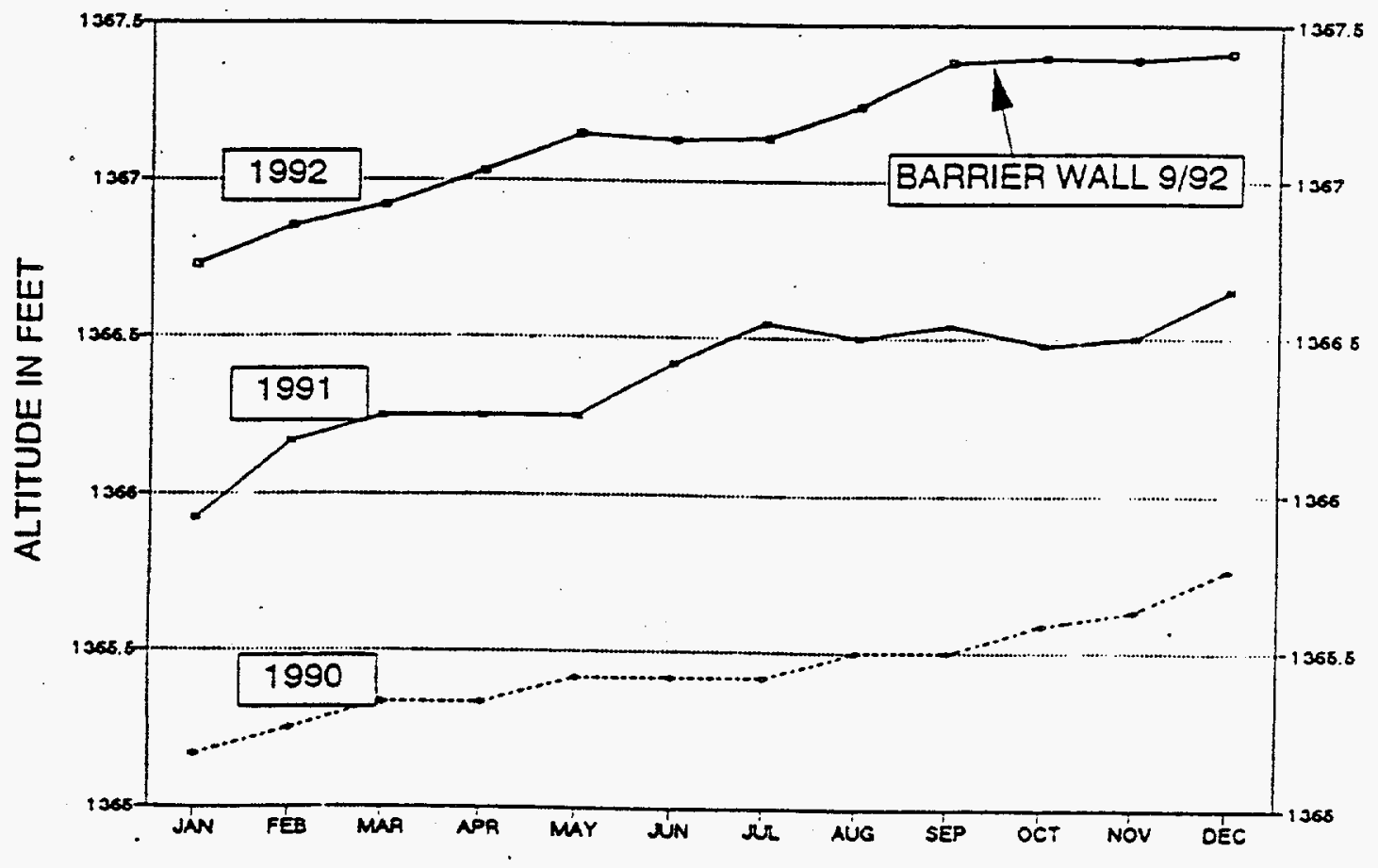

Fig.6. Trench 14 water levels 1990, 1991, \& 1992. 
During process development, the Energy Authority installed three storage tanks as a contingency to store untreated leachate is the event leachate leveis were to rise to the point of the weathered/unweathered till interface. One of these lanks was filled witt 28,350 liters of leachate in Marci 1991. The two remaining tanks have a capacity of 79,400 liters each and have not yet been used. Plans are to incorporate all three tanks into the treatmeat system. The smaller tank will be used as an initial feed tank to accept leachate from the Trench 14 sump pump. The remaining two larger tanks will be used to store and batch transfer treated leachate to the final disebarge poinc.

The Engineering Report containing the design basis for the treatment system was submitted to both EPA and DEC for approval in December 1992. The Energy Authority is curreatly in the process of soliciting bids for detailed design, construction, and operation of the treatment system, and anticipates having the system operational by spring 1994. Following an initial pilot phase operation, the system will be operated as needed to maintain water levels well below the weathered/unweathered till interface.

\section{SITE CHARACTERIZATION AND LONG TERM PLANNING}

\section{Environmental Impact Statement}

In 1989, the Energy Authority entered into an agreement with DOE to prepare a joint Environmental Impact Statement (EIS) for completion of the West Valley Demonstration Project and closure of facilities at the Ceater. The EIS will review closure altersatives ranging from the no action alternative to the "green field" alternative (complete exhumation and offsite disposal of all'contaminated materials) with several intermediate alternatives considered for each facility. A contractor was selected in late 1992 to prepare the EIS.

Environmental information for the EIS is now being collected. Data will include: water quality, air sampling, soils
TABLE I

Major Constituents In Trench 14 Leachate

\begin{tabular}{|l|c|}
\hline Concentration & $\begin{array}{c}\text { Constituent } \\
\text { in Leachate }(\mathrm{ppm})\end{array}$ \\
\hline BODs & 5,300 \\
Methylene Chloride & 78 \\
Benzene & 1.1 \\
Toluene & 34 \\
Xylenes (total) & 18 \\
Phenols & 7.4 \\
\hline & Concentration \\
Radionuclide & in Leachate $\left(\mu \mathrm{ci}^{\mathrm{m}} \mathrm{m}\right)$ \\
\hline Cs-137 & $2.24 \times 10^{-4}$ \\
Sr-90 & $1.84 \times 10^{-4}$ \\
H-3 & $4.98 \times 10^{-1}$ \\
I-129 & $2.90 \times 10^{-5}$ \\
C-14 & $1.19 \times 10^{-4}$ \\
\hline Note: Highest detected values are reported \\
\hline
\end{tabular}

sampling, :adiation surveys, source term evaluation, geology, seismology, ecology, pathway assessment, socio-economics, and cultural resources. SDA-specific information, collected as part of the Energy Authority's site maintenance and monitoring program, will be used to supplement the WVDP EIS data collection program.

\section{RCRA Facility Investigation (RFI)}

In March 1992, the Energy Authority signed a RCRA Section 3008(b) Administrative Order on Consent (the Consent Order) witb DOE, EPA, and the New York State

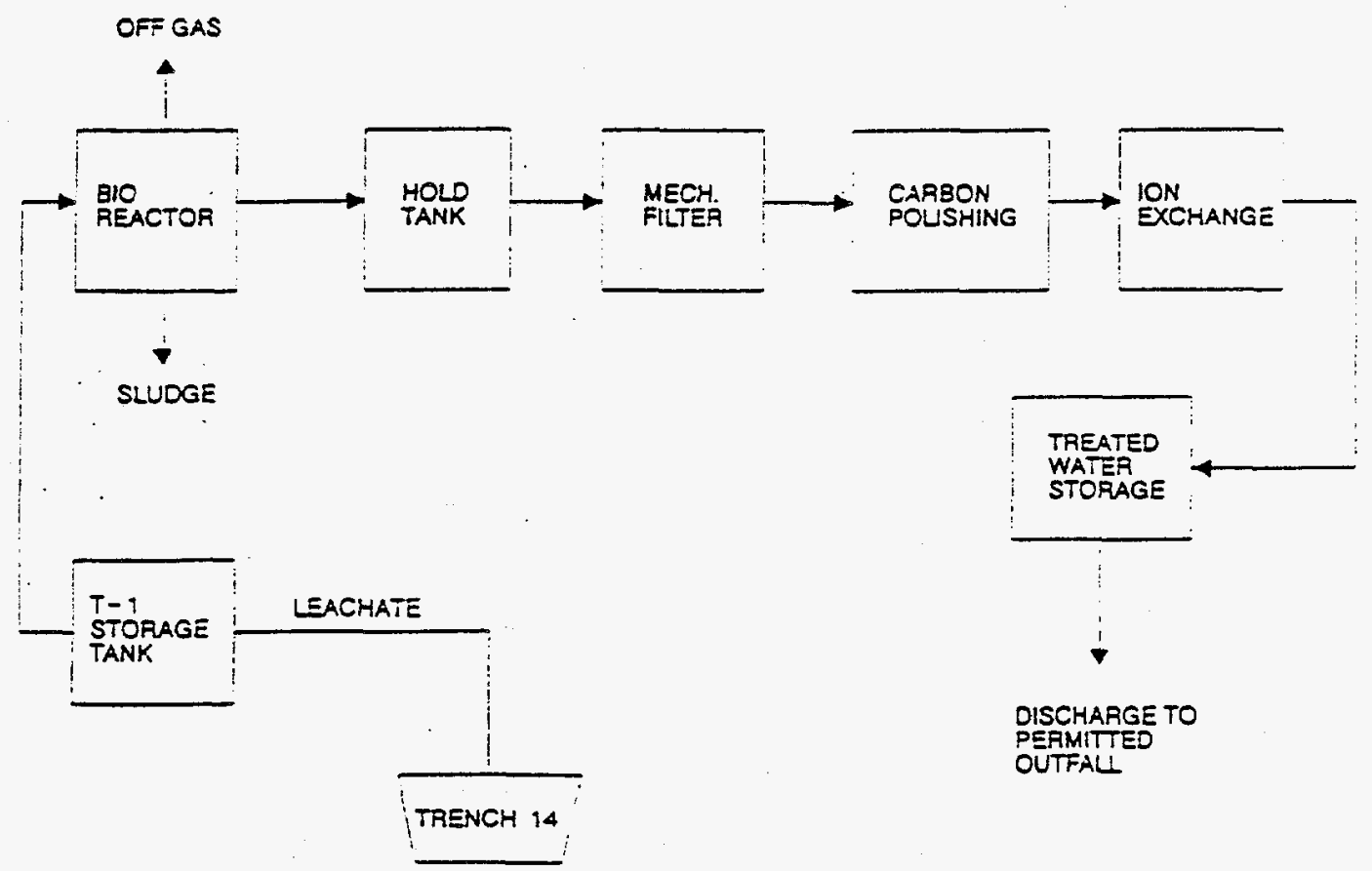

Fig. 7. Treoch 14 leachate Treatment System Process Flow Sheet. 
Department of Environmental Conservation (DEC). The Consent Order direets the Energy Authority and DOE to conduct investigations at the Center. The Energy Authority is conducting a RCRA Facility lovestigation (RFI) to determine if there have been any releases of $R C R A$ regulated hazardous wastes or hazardous constituents from SDA waste manage. ment units, and if releases are identified, to determine the nature and extent of contamination. The Consent Order also designated the Infiltration Controls Project and the Trench 14 Leachate Treatment Project as Interim Measures.

In June 1992, the Energy Authority submitted an RFI workplan to EPA and DEC. The scope of the RFI workplan includes a review of bistorical information, including data collected as part of the on-site environmental monitoring program and as part of EIS site characterization, and defines an investigative program for collection of additional data. To minimize duplication of effort, data collected for the RFI is being integrated with the data collection process for the EIS. The RFI workplao also includes a data management plan, a QAVQC plan, a bealth \& safery plan, and a community relations plan. The main area of focus for the Energy Authority will be the 14 disposal trenches and the three closed lagoons within the SDA.

The plas includes extensive soil sampling and installation of additional monitoring wells in selected locations. EPA and $D E C$ bave provided comments, and final approval of the RFI workplan is expected in February 1993. Field sampling is sebeduled to begin in May 1993. A final RFI report will evaluate data collected and address the seed for further corrective measures studies. The draft report is scheduled to be submitted to EPA and DEC by the end of 1994.

\section{CONCLUSIONS}

The Energy Authority is continuing to maintain the SDA in a condition that protects public health and safety and the environment. Ongoing environmental monitoring and characterization is being performed in support of facility closure. Although previous efforts bave reduced water infiltration, they bave not completely eliminated the problem. Efforts are continuing to further reduce water infiltration. A system for treatment of contaminated trench water is under design and expecied to be operational in the spring of 1994.

As ongoing effort to characterize the site for potential releases of hazardous constituents will be completed by the end of 1994. To evaluate alternatives for long-term management of the SDA, a joint (DOE/Energy Authority) EIS is being prepared.

\section{REFERENCES}

1. Envirosphere Company, "Executive Summary of the Site Stabilization Study for the LLRW Disposal Area at West Valley, New York," New York State Energy Research and Development Authority Report 87-14-e (1986).

2. ANDERSON, D.B.,"Surveillance and Maintenance of the West Valley State Licensed Low-Level Radioactive Waste Disposal Area 1983-198T, New York State Energy Research and Development Authority (1988).

3. BLICKWEDEHL R.R., "Evaluation of Alternate Infiltration Control Plans; State Licensed Disposal Area- Western New York Nuclear Service Center West Valley, New York" Dames \& Moore Report \# 10805-509-203 (1991). 


\title{
LINER AND FINAL COVER OPTIMIIZATION MIXED WASTE STORAGE/DISPOSAL FACILITY AT LOS ALAMOS NATIONAL LABORATORY
}

\author{
Alas MacGregor, P.E. \\ Principal Investigator \\ ERM Program Managemeat Company \\ Los Alamos, NM \\ Dean C. Nelson \\ Technical Team Leade: \\ Mixed Waste Storage/Disposal Facility \\ Los Alamos National Laboratory \\ Los Alamos, NM
}

\begin{abstract}
Los Alamos National Laboratory is planoing to construct a mixed waste landfill to serve the needs of the environmental restoration program. The landfill will consist of up to 19 steep-walled pits to safely dispose of mixed, low-level waste. The use of the steep-wall desigo required that the RCRA regulations for liner requirements be carefully review. Los Alamos is proposing to use geosynthetic clay liners (GCLs) on the pit side walls, which will be a unique appïcation of this product. Laboratory (and possibly field) geotechnical testing is planned to test the GCLs prior to finalization of design. The final cover design will make use of a naturah graded soil cover system that will include a capillary break, a bio-barrier zone including boulders and cobbles, and a composite impermeable layer to further limit inflitration.
\end{abstract}

\section{DESCRIPTION OF PROJECT}

The planned landfill disposal project will be one of the Eirst proposed mixed waste landfills to serve a Department of Energy facility. The landfill will be constructed below grade in volcanic ruff, which will enable the use of steep side walls. The facility will also be one of the first to seek a variance from the Jaruary 1992 EPA double liner requiremeats, taking into account facility design and location. Emissions from the facility will be controlled by constructing a temporary building over each waste pit so that all waste bandling and placement operation are conducted indoors. This will virtually eliminate liquid and airborne contaminants. The water-table is situated several hundred feet below the mesa top, so, coupled with an unsaturated zone monitoring system, this will preclude any contamination of ground water. After the building is removed, a multilevel, vegetative cover will be added that will take advantage of the local climate's favorability to high evapotranspiration to control seepage through the final cover. Wastes will either be treated prior to placement to meet land ban restrictions, or a variance will be obtained, and waste placement, including stabilization, will be managed to control settlement.

While remediation under the Los Alamos Environmental Restoration Program will not formally enter the remedial action phase until later this decade, voluntary interim measures can be implemented at any time during the investigation and evaluation process. The availability of the MWSDF will facilitate the timely remediation of contaminated sites and will allow site investigations to serve also as documentation that remediation has been successful. Figure 1 illustrates the design at this point in the planaing process.

\section{REQUIREMENTS FOR PIT LINER DESIGN}

The landfill will be excavated into the volcanic tuff formation found on the mesa tops at Los Alamos. Low-level radiological wastes have previously been placed in pits at Los Alamos in this manner. The pit dimensions for the mixed waste landfill will be limited so a temporary building can be built over the pit. This building will allow all waste placement operations to be accomplished indoors. The pit will be 45 fee: deep, and benches will be used as intermediate side-wall-liner anchor locations.

In compliance with EPA RCRA regulations and applicabie NRC/EPA guidance, the side and bottom of the disposal pits will be lined with a double-liner systern. Because of the steep pit side walls (four vertical to one horizontal), it will be necessary to find an alternative to the three feet of clay required by EPA as the outer componeat of the secondary composite liner. The innovative Geosynthetic Clay Liners (GCLs) offered by several manufacturers were selected as a possible clay replacement. These liners would also require a regulatory variance.

Specinic concerns that were addressed included past experiences with GCLs on steep slopes, approved regulatory variances from the specified liner thicknesses, ancioring approaches for the membranes, alternate cap designs, and chemical compatibility concerns.

\section{DETAILED INVESTIGATIONS}

Hydrologic water balance modeling was conducted to document the differences in seepage through the proposed cap system. With the use of the cap systems tested at Los Alamos, the bigh evapotranspiration design allows virtually no seepage through the top cover layers. The underlying geomembrane and clay (or GCL) layers will serve as back-ups and will divert infiltration during spring snow melt. Cover slopes were set fairly flat to blend with local grades and to minimize crosion.

No precedents were found for regulatory variances in similar situations. Many applicants are proposing to use $G C L$ as part of a composite in the primary liner system; capping systems are also being proposed in which GCLs would be used in areas or situations where clay would be unsuitable or economically unavailabie. One other steep-walled installation is being proposed for mixed waste, but the side wall liner is being eliminated. 


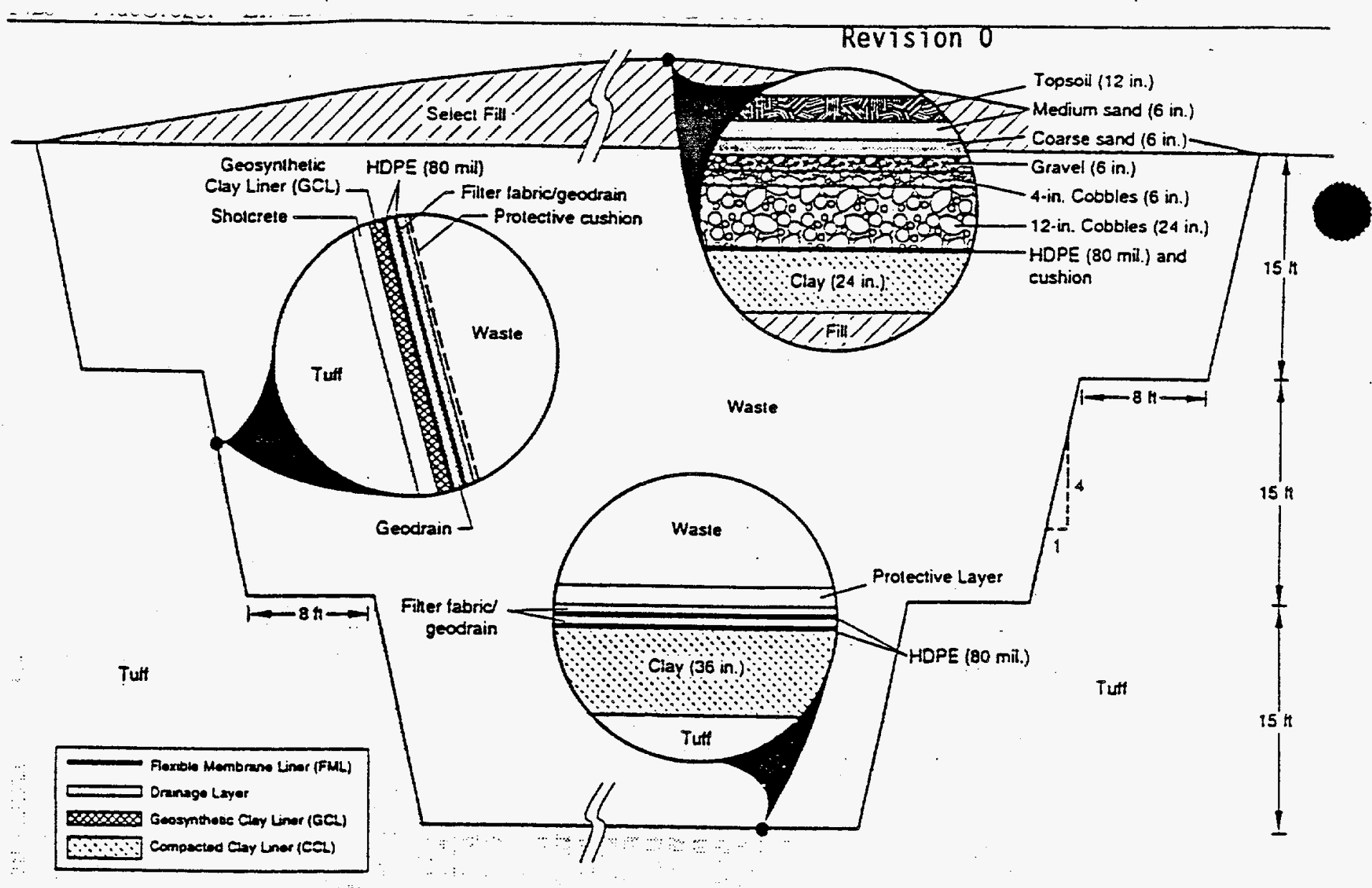

Fig 1. MWSDF recommended design schematic cross section.

It was determined that the pit walls must be prepared with shot-crete before any liner system can be placed. Studies are planned to determine the physical characteristics of the linit system in the proposed sequences and combinations. Comparative testing is planned for the three GCLs in combination with geomembranes, geonets, filter fabrics, and cusbions. The data obtained from the laboratory tes:s will allow the designer to select side-wall liner components and to accurately predict anchoring requirements.

\section{FINDLNGS AND RECOMMENDATIONS}

The vegetation layer is very effective in virtually eliminating seepage through the cap. Long-term performance will be improved by reliance on natural materials to maximize evapotranspiration. A flexible geomembrane will be included below the natural materials to control expected infiltration during spow melt.

A geosynthetic clay liner will be designed for the cap and will underlie the geomembrane. While more expensive than clay, the GCL will better withstand settlement, and its instal lation can be scheduled easier.

The use of a GCL on the side walls will limit the verical beight between benches to less than 15 feet. Because the complexity of the required anchoring systems and the small probability and minimal contribution of infiltration on the sides, elimination of the geosynthetic side-wall layer may be considered pending regulatory agreement.

The 3-foot clay layer will be retained as the lower component of the secondary liner, as per RCRA regulation. A GCL, as a lower component of a primary composite, is not necessary because the faciilty is located in a semi-arid climate.

If placed wastes are not stabilized or precompacted prior to placement, the voids berween containers, and any voids in and around bulk wastes, must be filled to prevent any unplanned (and unacceptable) settlement of the cap.

Future analysis will address specific physical parameters of standard and custom-designed geosynthetics, modeling of the liner systems for strength and performance, and support of permitting and performance assessment requirements. 


\subsection{OVERALL SYSTEM INTEGRATION}

The purpose of this section is to summarize the overall system requirements and to recommend a system of concepts which may be effective in meeting the performance assessment requirements for vitrified low level waste disposal. The options developed in other sections of the report have been combined and evaluated against the overall performance criteria to determine a preferred system.

As each of the preferred options has resulted from task specific requirements, details (such as package robustness and glass surface area to volume ratio) will not be considered again. Instead, the preferred system will be evaluated for adherence to the general system requirements.

\subsection{ASSUMPTIONS}

8.1.1 All regulatory requirements have been met in the individual report sections.

8.1.2 The overriding driving force is the ability of the system to meet the requirements of the performance assessment.

\subsection{SYSTEM REQUIREMENTS}

\subsubsection{Performance Assessment Requirements}

8.2.1.1 General Public Protection. The system shall be designed to ensure that exposure to any member of the public that results from disposal of solid LLW shall not exceed $25 \mathrm{mrem} / \mathrm{yr}$ Effective Dose Equivalent (EDE) through all exposure pathways for at least 1,000 years after disposal.

8.2.1.2 Groundwater Protection. Disposal systems shall be designed to meet the Clean Water and the Safe Drinking Water Act as well as to ensure that disposal of LLW after $09 / 26 / 88$ does not result in concentrations of radionuclides in groundwater exceeding those corresponding to an EDE of $4 \mathrm{mrem} / \mathrm{yr}$ to any person who might drink 2 liters per day of water from a well drilled into the aquifer, for at least 1,000 years after disposal.

\subsubsection{Other Requirements}

8.2.2.1 Retrievability. The LLW shall be retrievable for 50 years, starting from year 2028 . Although the retrievability simply has to be achievable, the ease at which retrievability can be carried out is a factor in choosing the final disposal system,

8.2.2.2 Optimum use of disposal volume. The system shall be designed to minimize land use and make maximum use of the disposal site. 
Final

8.2.2.3 Minimize dose uptake. The system shall be designed to minimize dose uptake to all operators of the vitrification facility, transport system, and disposal system.

\subsection{PREFERRED SYSTEMS}

Preferred systems have been developed from the preferred options of each of the individual sections. Where an alternative appeared to be in conflict with that of another section, the alternative was eliminated. The only option eliminated because of this conflict is the option of cullet in a container (i.e., cullet in a container was recommended as an alternative by the packaging section but cullet was not recommended as a glass geometry).

This process of elimination results in the following alternatives that can be combined to make the preferred systems.

\begin{tabular}{||l|l|l|l|l|l|l||}
\hline $\begin{array}{l}\text { Formulation } \\
\text { Packaging }\end{array}$ & $\begin{array}{c}\text { Geometry } \\
\text { and }\end{array}$ & Matrix & Transport & Barrier & $\begin{array}{c}\text { Disposal } \\
\text { Site }\end{array}$ & $\begin{array}{c}\text { Disposal } \\
\text { System } \\
\text { Config. }\end{array}$ \\
\hline $\begin{array}{l}\text { Soda Lime } \\
\text { Silicates }\end{array}$ & $\begin{array}{l}\text { Monolith in } \\
\text { Container }\end{array}$ & $\begin{array}{l}\text { Sulfur } \\
\text { Polymer } \\
\text { Cement }\end{array}$ & $\begin{array}{l}\text { Equivalent } \\
\text { Safety } \\
\text { Package }\end{array}$ & $\begin{array}{l}\text { RCRA, } \\
\text { hydrological, } \\
\text { conditioning, and } \\
\text { sorption barriers }\end{array}$ & 200 Plateau & $\begin{array}{l}\text { Burial } \\
\text { Trench }\end{array}$ \\
\hline $\begin{array}{l}\text { Alkali } \\
\text { Borosilicates }\end{array}$ & $\begin{array}{l}\text { Plate Glass } \\
\text { in Container }\end{array}$ & & & & & \\
\hline
\end{tabular}

From the above table, it can be concluded that the preferred alternatives from each section can be combined to form the preferred system. It is clear from the sections on glass formulation and glass geometry that the performance assessment requirements can be met by manipulation of these two factors alone. However the ALARA concept will require the use of barriers of matrix or both.

The use of a matrix tentatively identified as sulfur polymer cement, should significantly help in meeting long term performance assessment criteria. The long term behavior of sulfur polymer cement is not well known and requires more information. Process requirements such as temperature control, ensuring that the glass is completely "wet" by the SPC, and others need to be addressed.

\subsection{OBSERVATIONS, CONCLUSIONS, AND RECOMMENDATIONS}

The use of the following system for the manufacture and disposal of low level vitrified waste is recommended. A silica-based glass monolith into a SPC container, transported in an equivalent safety transport package to the disposal site where it will be disposed of using a multiple barrier system. Remote handling should be used in order to minimize dose uptake. Monitoring technologies should be applied for process control in making glass, inspection of the glass form, container, vault structures, and monitoring migration of water through the vault and corrosion of the glass. 